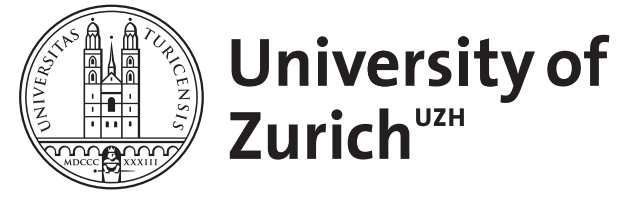

\title{
Re und Amun: Die Krise des polytheistischen Weltbilds im Ägypten der
} 18.-20. Dynastie

\author{
Assmann, Jan
}

Posted at the Zurich Open Repository and Archive, University of Zurich

ZORA URL: https://doi.org/10.5167/uzh-139531

Monograph

Published Version

Originally published at:

Assmann, Jan (1983). Re und Amun: Die Krise des polytheistischen Weltbilds im Ägypten der 18.-20. Dynastie. Freiburg, Switzerland / Göttingen, Germany: Universitätsverlag / Vandenhoeck Ruprecht. 
ASSMANN - RE UND AMUN 


\section{ORBIS BIBLICUS ET ORIENTALIS}

Im Auftrag des Biblischen Instituts der Universität

Freiburg Schweiz,

des Seminars für biblische Zeitgeschichte

der Universität Münster i. W.

und der Schweizerischen Gesellschaft

für orientalische Altertumswissenschaft

herausgegeben von

Othmar Keel,

unter Mitarbeit von Erich Zenger und Albert de Pury

\section{Zum Autor:}

Jan Assmann (1938) studierte Agyptologie, klassische Philologie und Archäologie in Heidelberg, Göttingen und Paris. Er ist Ordinarius für Ägyptologie in Heidelberg. Von seinen grösseren Veröffentlichungen seien genannt: Liturgische Lieder an den Sonnengott. Untersuchungen zur altägyptischen Hymnik I (Münchner ägyptologische Studien 19) Berlin 1969; Der König als Sonnenpriester. Ein kosmographischer Begleittext zur kultischen Sonnenhymnik in thebanischen Tempeln und Gräbern (Abhandlungen des Deutschen Archäologischen Instituts Kairo. (Agyptologische Reihe 7) Glückstadt 1970; Das Grab des Basa (Nr. 389) in der thebanischen Nekropole. Grabung im Asasif 1963-1970. Band 2 (Deutsches Archäologisches Institut. Abteilung Kairo. Archäologische Veröffentlichungen 6) Mainz 1973; Ägyptische Hymnen und Gebete (Die Bibliothek der Alten Welt. Reihe Der Alte Orient) Zürich / München 1975; Sonnenhymnen in thebanischen Gräbern (erscheint 1983).

In Vorbereitung: Ägyptische Religion (Kohlhammer, Urban Taschenbuch); Das Grab des Amenemope; Ägyptische Totenliturgien. 


\section{RE UND AMUN}

Die Krise des polytheistischen Weltbilds im Ägypten der 18.-20. Dynastie

UNIVERSITÄTSVERLAG FREIBURG SCHWEIZ VANDENHOECK \& RUPRECHT GÖTTINGEN 1983 
CIP-Kurztitelaufnabme der Deutschen Bibliothek

Assmann, Jan:

Re und Amun: Die Krise des polytheistischen Weltbilds im Ägypten der 18.-20. Dynastie / Jan Assmann. Freiburg (Schweiz): Universitätsverlag;

Göttingen: Vandenhoeck und Ruprecht, 1983.

(Orbis biblicus et orientalis; 51)

ISBN 3-7278-0278-2 (Universitätsverlag)

ISBN 3-525-53672-0 (Vandenhoeck und Ruprecht)

(c) 1983 by Universitätsverlag Freiburg Schweiz Paulusdruckerei Freiburg Schweiz

Digitalisat erstellt durch Flurin Baumgartner, Religionswissenschaftliches Seminar, Universität Zürich 
Für Erik Hornung 

I $\quad \mathrm{N}$ H

Vorwort

Einführung

Erster Teil: Re-Harachte

1.Kapitel: Die Mysterien des Sonnenkults

1. Vorüber legungen

2. Wissen

3. Handeln

2. Kapitel: Die Ikonographie des Sonnenlaufs 54

1. "Ikon" und "Konstellation" 54

2. Die Ikone des Sonnenlaufs im Spiegel des traditionellen Tageszeitenliedes $\quad 60$

2.1 Vorbemerkungen zum Typus des Tageszeitenliedes 60

2.2 Die Tageszeiten $\quad 62$

2.2.1 Der Morgen 64

2.2.2 Der Mittag 71

2.2.3 Abend und Nacht 83

3. Schlussbemerkung 94

3. Kapitel: Die Phänomenologie des Sonnenlaufs 96

1. Historische Aspekte 96

2. Theologische Aspekte 98

2.1 Einsamkeit und Einzigkeit 98

$\begin{array}{ll}2.2 \text { Ferne und Verborgenheit } & 101\end{array}$

$\begin{array}{ll}2.3 \text { Ferne und Nähe } & 104\end{array}$

2. 4 Allgegenwart des Lichts - Gotterfülltheit der $\begin{array}{ll}\text { Welt } & 108\end{array}$

2.5 Leben (creatio continua) 113

2.6 Das Mysterium der Teilhabe 124

3. Stilistische Aspekte 132

3.1 Der Morgen 133

$\begin{array}{ll}3.2 \text { Der Mittag } & 137\end{array}$

$\begin{array}{ll}3.3 \text { Die Nacht } & 141\end{array}$ 
Zweiter Teil: Amun-Re

4. Kapitel: Die Amun-Theologie der Frühzeit. Eulogien aus Gräbern von Hatschepsut bis Amenophis II

1. Eulogische Erweiterungen der Opferformel

1. 1 Typ A: Erweiterungen des Gottesnamens Amun-Re

1.2 Typ B: Erweiterungen des Gottesnamens

Re-Harachte

2. Hymnen

3. Der pKairo 58038 (Boulaq 17) = AHG Nr.87

4. Zusammenfassung

5.Kapitel: Die thebanische Amun-Theologie der Ramessidenzeit

1. Vorbemerkungen

2. Einzigkeit und Verborgenheit

2. 1 Einzigkeit

2.2 Verborgenheit

3. Transzendenz als verborgene Einheit

3. 1 Transzendenz und Verkörperung nach pLeiden

J 350 IV, 12-21

3.2 "Ba"

3.2.1 "Ba" und "Verkörperung" ( hprw )

3.2.2 "Ba" und "Verborgenheit", "Heiligkeit", "Grösse"

3.2.3 "Ba" und der in den Elementen verkörperte Lebensgott

3.2.4 "Ba" und der All-Eine

3.3 Einer und Alles

3.3.1 Ramessidische Belege

3.3.2 Spätzeit-Belege (in Auswahl)

3.3.3 Die Bedeutung der Formel

4. Schöpfung

4.1 Schöpfungslehren als "Naturlehren"

4.2 Die Transformationen des Urgottes: die "Reichstriade" als kosmogonische Stadien 
4.3 Narrative thebanische Schöpfungshymnen 226

4.3.1 Der Hymnus von Tura 226

4.3.2 Der Hymnus Hibis Tf.32 (ÄHG Nr.129) 229

4.4 Das Schöpfungsthema in ramessidischen Gräberhymnen 234

5. Leben 246

5.1 Der Begriff des Lebensgottes 246

5.2 Die Topik der lebenspendenden Elemente und die Entstehung der ramessidischen weltgott-Idee 250

5.2.1 Beispiele 250

5.2.2 Ursprung und Entwicklung 258

6. Der Gott des Einzelnen: Gott als "ethische Instanz" 264

6.1 Leben 264

6.2 Retter und Nothelfer 269

6.3 Richter 274

6.4 "Gewaltenteilung" und "Repräsentanz" 277

$\begin{array}{lr}\text { Literaturverzeichnis } & 287\end{array}$

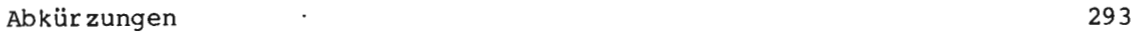

Register I: Sachen $\quad 294$

$\begin{array}{ll}\text { Register II: Stellen } & 300\end{array}$ 

Das vorliegende Buch möchte ein Stück ägyptischer Religionsgeschichte neu schreiben. Das neue dieses Versuchs liegt vor allem in der Beschränkung: in zeitlicher Hinsicht auf das Neue Reich, also die 2.Hälfte des 2.Jt.v.Chr., und in materialer Hinsicht auf die einzigartige Fülle von religiösen Texten aus diesem Zeitraum, d.h. den "theologischen Diskurs", der sich in ihnen entfaltet. Es geht also weniger um Religion, als um Theologie. Fragen des Gottesbegriffs waren aber in jenen Jahrhunderten zugleich Fragen des Weltbilds, die den umfassendsten Sinnhorizont menschlichen Erlebens und Handelns betrafen. Daher ist hier von einem polytheistischen "Weltbild" die Rede. Die Krise dieses Weltbilds, die im religiösen Umsturz von Amarna gipfelt, und die Ansätze zu ihrer. Uberwindung stehen auslösend hinter der einzigartigen Intensität des "theologischen Diskurses", der hier rekonstruiert werden soll.

Aber auch die Quellen, die uns diesen theologischen Diskurs als ein geschichtliches Phänomen erschliessen, sind zu einem grossen Teil neu. Sie wurden im Laufe der letzten 20 Jahre gesammelt, die meisten in thebanischen Beamtengräbern. Diese Texte erscheinen gleichzeitig in einer Edition unter dem Titel Sonnenhymnen in thebanischen Gräbern im Verlag Philipp v.zabern (Mainz). Die Sammlung und Auswertung dieser Quellen ermöglichten das Deutsche Archäologische Institut und die Deutsche Forschungsgemeinschaft. Die Niederschrift dieses Buches im Frühjahr 1981 erfolgte im Rahmen eines von der Deutschen Forschungsgemeinschaft finanzierten Forschungsfreijahrs.

Othmar Keel möchte ich dafür danken, dass er diese Arbeit in die Reihe Orbis Biblicus et Orientalis aufgenommen hat; vor allem aber gebührt mein Dank ihm und Frau Hildi Keel-Leu für die grosse Mühe, die sie mit der Betreuung der Herstellung auf sich genommen haben. Rolf Maienfisch danke ich für die sorgfältige Erstellung der offset-Vorlage. 

Die Blütezeit des ägyptischen Sonnenliedes, die drei Jahrhunderte von ca. 1500-1200 v. Chr., aus denen uns viele Hunderte von Sonnenhymnen überliefert sind, ist ein einzigartiges phänomen. Welche andere Epoche der ägyptischen Geschichte, ja: welche andere Kultur uberhaupt hätte im Laufe weniger Jahrhunderte eine derartige Fülle von Dichtungen zum Lobe der Gottheit hervorgebracht? Gewiss: diese Fülle hat einen äusseren Grund, der mit der Institution des ägyptischen Grabes zusammenhängt. Nachdem es einmal sitte geworden war, in seinem Grab Sonnenhymnen aufzuzeichnen, ist es nicht weiter verwunderlich, dass so viele derartige Inschriften auf uns gekommen sind. Anders als jene Inschriften, die man unter den Begriff "persönliche Frömmigkeit" zusammenfasst, und die ihre Aufzeichnung einer individuellen religiösen Erfahrung verdanken $^{1}$, ist die Aufzeichnung von Sonnenhymnen in Gräbern - so könnte man argumentieren - blosse Routine, Erflullung einer vorgegebenen Norm, die man ebensowenig als Ausdruck eines le-

1 Die "Personliche Frommigkeit" ist ein phanomen sui generis, das in diesem Buch nur insoweit behandelt wird, als es im Rahmen der Amun-Re-Theologie in Erscheinung tritt. Fur eine umfassendere wurdigung s. "Weisheit, Loyalismus und Frommigkeit", sowie meinen Aufsatz in $\operatorname{RdE~} 30$ (1978) 22-50. Ich darf bei dieser Gelegenheit den Leser auf eine Eigentumlichkeit der Zitierweise aufmerksam machen. Da dieses Buch die Summe von Forschungen zieht, die sich nun uber 20 Jahre erstrecken, und die sich bereits in zahlreichen sonstigen publikationen niedergeschlagen haben, kann es sich leider nicht umgehen lassen, den Leser fur Einzelheiten auf diese publikationen hinzuweisen, d.h. eine ungehorrige Menge von Selbstzitaten anzubringen. Ich habe in diesen Fallen den verfassernamen weggelassen. Was nun die "Personliche Frommigkeit" betrifft, so sind die o.g. Arbeiten naturlich nicht die einzigen Beitrage zum Thema. Die Literatur ist im Gegenteil fast unuberschaubar. Vor allem waren hier die fruheren Arbeiten von Erman und Gunn zu nennen, Brunners grundlegender Aufsatz uber die religiose Wertung der Armut im Alten Agypten, Fechts Monographie uber die Literarischen Zeugnisse der "personlichen Frommigkeit", poseners bahnbrechende Fruhdatierung des Phunomens (RdE 27) u.v.a.m. Der Leser findet diese ganze Literatur in den genannten Arbeiten. Das Selbstzitat dient nur als abgekurzter Wegweiser zur Literatur. Dieses verfahren, das in einer handbuchartigen, den Weg zur Literatur und zu den Einzeldarstellungen weisenden Behandlung denkbar unangebracht ware, ist in diesem Falle als skonomische Massnahme vielleicht legitim, wo es sich nicht um ein Handbuch handelt, sondern um einen Essay, der von dem eigenen verstehen der behandelten Zusammenhänge Rechenschaft ablegen will. 
bendigen, d.h. geschichtlich-zeitgenössischen theologischen Diskurses verstehen darf, wie es etwa angezeigt wäre, die noch weit zahlreicheren und über einen viel grösseren zeitraum verteilten biographischen Grabinschriften als Ausaruck eines lebendigen anthropologischen Diskurses, einer ständigen geistigen Auseinandersetzung mit den problemen von Ich und Gesellschaft, Mensch und Kosmos usw. usw. anzusehen, wo es hier doch "in wirklichkeit" um ein wesentlich weniger anspruchsvolles Verfügen über einen altüberlieferten Vorrat vorgeprägter Formeln und $\mathrm{Kl}$ ischees geht.

Wie immer es mit den biographischen Inschriften bestellt sein mag, die immer noch, von denen der spätzeit abgesehen, auf die Erschliessung ihrer geistesgeschichtlichen Dimension warten $^{2}$, so glaube ich doch, was die hymnischen Grabinschriften angeht, nach jahrzehntelanger Sammlung des einschlägigen epigraphischen Materials zu einem differenzierteren Urteil gelangt $z u$ sein. Gewiss ist vieles "Routine", Erfüllung einer vorgegebenen Norm, was an Sonnenhymnen in Gräbern des Neuen Reichs aufgezeichnet wird. Das sind die Fälle, in denen man auf einen Text jener kleinen Gruppe bewährter und z.T. ungeheuer oft reproduzierter 3 "Standard-Texte" zurückgreift, die ich in meinen Liturgischen Liedern an den Sonnengott behandelt habe. Auch nach Abzug dieser über 200 Bezeugungen einiger weniger Vorlagen 4 , die ihren "Sitz im Leben", wie sich in den meisten Fällen nachweisen 1 iess ${ }^{5}$, im kult haben, bleibt noch eine erstaunliche Fülle von Texten lubrig, die ein individuelles Gepräge haben und die, genau wie die inschrift- . lichen Zeugnisse der "Persönlichen Frömmigkeit", das "textliche Substrat" oder die Ausdrucksform einer geistig-religiösen Bewegung darstellen. Auch wenn sie nicht, wie jene, spontaner. Ausdruck einer individuellen religiösen Erfahrung oder Er-

2 E. Otto, Die biographischen Inschriften der ägyptischen Spätzeit (Probleme der Agyptologie 2, 1954). Hier vermisst man nun wiederum schmerzlich die Edition der Texte.

3 von dem Text LL III 1 sind derzeit uber 50 Bezeugungen bekannt.

4 Das Register A in LL, 373-377 verzeichnet 205 "Texte" auf 160 "Denkmälern", die als Bezeugungen der 17 in dieser untersuchung kommentierten Vorlagen zu verstehen sind.

$5 \mathrm{Vgl}$. Kap.1, n.2. 
schütterung sind (die sich freilich auch im Falle der "Persönlichen Frömmigkeit" der institutionalisierten Rahmenbedingungen für Formulierung und Aufzeichnung $\mathrm{zu}$ bedienen und einen entsprechenden "Formelschatz" zur Verfügung hat), sondern einer kollektiven Auseinandersetzung mit den Problemen und Phänomenen entspringen, mit denen es die ägyptische Sonnenreligion $z u$ tun hat, so sind sie darum doch nicht weniger geschichtlich, d.h. datierbare Zeugnisse eines ebenso datierbaren geistigen Prozesses. Was man im Hinblick auf die überlieferten Texte als ein literarisches phänomen die Blütezeit des ägyptischen Sonnenliedes nennen kann, wäre im Hinblick auf die dahinterstehende, in diesen Liedern zum Ausdruck kommende geistige Bewegung als das Ringen um die begriffliche Artikulation der Einheit des Göttlichen, d.h. den Einen Gott, zu bezeichnen.

Die Einzigkeit bzw. All-Einheit Gottes ist das zentrale theologische Problem des Neuen Reiches. Die Episode von Amar$\mathrm{na}$, wo in Form einer alle Lebensbereiche der ägyptischen Kul-tur umfassenden und verändernden Revolution von oben der versuch gemacht wurde, die Lehre des Einen Gottes mit Gewalt und unter einfacher Abschaffung der überlieferten polytheistischen Götterwelt durchzusetzen, stellt die geschichtliche Brisanz dieses problems höchst eindrucksvoll unter Beweis. Weniger bekannt ist, dass das problem mit dem Scheitern der Amarna-Religion keineswegs ad acta gelegt wurde. Was dem "Monotheismus" nicht gelang, weil er eine der Komplexität der ägyptischen wirklichkeitserfahrung in keiner weise gerecht werdende Reduktion des Weltbildes auf ein Gegenüber von "Oben" und "Unten", Gott und Welt, darstellte 6 , erscheint in der Folgezeit als die "pantheistische" Lösung einer theologisch reflektierten Vermittlung eines transzendenten Höchsten Gottes mit der kosmischen polytheistischen Götterwelt, in deren "farbigem Abglanz" seine - als solche verborgene - Einheit zur Erscheinung kommt. Dass ich Begriffe wie "Monotheismus" und "Pantheismus" nur zum zwecke einer bewusst überzeichnenden verdeut-

$6 \mathrm{Vg} 1 . \mathrm{Kap} .3 \$ 2 \cdot 2-2.4$ und 5 . 
lichung des problems und der Richtung, in denen Lösungen gesucht werden, verwende, versteht sich von selbst. Die Darstellung der Beflunde, wie sie in den folgenden Kapiteln unternommen wird, hält sich von derartigen Schlagworten bewusst fern. Das berechtigte Unbehagen, das der Agyptologe, vor allem nach der epochemachenden Destruktion solcher Modelle durch Erik Hornungs "Der Eine und die Vielen" (1971), derartigen Schlagworten gegenüber empfindet, sollte uns nicht den Blick verschliessen vor der vitalen Bedeutung, die die suche nach begrifflichen Artikulationen der Einheit Gottes und möglichen Vermittlungen dieser Konzeption (oder Erfahrung) mit der für den Agypter auf die Länge doch unaufgebbaren Wirklichkeit der polytheistischen Götterwelt in der ägyptischen Religion dieser Jahrhunderte besessen hat. Dieses Problem stellt sich nicht aus unserer eigenen "monotheistischen" Position, die uns das Verständnis eines polytheistischen Weltbildes zumindest erschwert, sondern es tritt uns aus den Texten selbst entgegen, unübersehbar, explizit, zentral. Es ist das beherrschende Thema des theologischen Diskurses, der mit der Wesensbestimmung des Göttlichen zugleich die Konturen des ägyptischen Weltbildes festlegte.

Die Texte, in denen sich dieser Diskurs manifestierte, sind Sonnenhymnen. Für die zwecke dieser Einleitung genügt es, die in den beiden Teilen dieses Buches als "Re-Harachte" und "Amun-Re" unterschiedenen und in ihrer relativen Eigenständigkeit dargestellten Aspekte des phänomens unter dem Oberbegriff "Sonnenreligion" zusammenzufassen. Im Horizont der Sonnenreligion hat sich die Frage nach dem Einen Gott ent$z$ ündet, in Sonnenhymnen findet sie ihren theologischen Ausdruck. Nicht alle von diesen Sonnenhymnen (im weiten, die Komplexe "Re-Harachte" und "Amun-Re" umfassenden Sinne) stehen in Gräbern; die längsten und bedeutendsten sind auf literarischen und liturgischen papyri sowie im Tempel Darius'I. in der Oase el-Hibe überliefert. Die "Gräberhymnen" dienen aber nicht nur dazu, das aus den anderen Quellen erschliessbare Bild abzurunden: sie geben ihm zuallererst seine historische Dimension. Erst dank der Fülle der Inschriften gelingt die 
zeitliche, lokale und wissenssoziologische Differenzierung der religiösen Uberlieferung. Nur in der Fülle der genau datierten Grabinschriften wird die Entwicklung der theologischen Konzeptionen sichtbar, lassen sich lokale Traditionen unterscheiden und lässt sich angeben, was zum exklusiven wissensvorrat einer höheren priesterschicht gehörte und was von diesen theologischen Konzeptionen Allgemeinbesitz einer breiteren Schicht war. Erst solche Differenzierung aber ermöglicht Verstehen, d.h. eine Rekonstruktion des Problemhorizontes dieser Texte, der Fragen, auf die sie eine Antwort geben. Die alles durcheinanderwürfelnde Mélange, in der die ägyptische Theologie uns normalerweise im religiösen Schrifttum überliefert ist, erzeugt einen Grad von Komplexität, der jedes umfassendere Verstehen ausschliesst. Die Sonnenhymnen der Grabinschriften, in denen sich der theologische Prozess der Sonnenreligion in der zeit, im Raum und in der sozialen Schichtung darstellt, eröffnen einen vielleicht einzigartigen, auf jeden Fall ersten zugang zum Verständnis einer Epoche und eines Aspektes der ägyptischen Religion.

Diesen Weg versucht das vorliegende Buch zu beschreiten. Es entstand unmittelbar nach dem Abschluss der kommentierten Edition aller mir in den Jahren 1963-1977 erreichbaren Sonnenhymnen der thebanischen Nekropole und zeichnet das Bild auf, das sich in mir während der jahrzehntelangen Beschäftigung mit diesen Texten von dem Gegenstand der Texte aufgebaut hat. Diese Edition, die unter dem Titel "Sonnenhymnen in thebanischen Gräbern" (STG) im Verlag Philipp v. Zabern (Mainz) erscheint, wird in der Hand des Lesers vorausgesetzt. Auf die dort edierten Texte wird hier als "Text Nr.X", auf den Kommentar mit den entsprechenden Chiffren, z.B. "Text Nr.149 (c)" verwiesen. Dort dargelegte Befunde und Sachverhalte werden hier nicht noch einmal referiert. Die hier gegebene Darstellung hat in Bezug auf die Edition einen supplementären Charakter: sie zieht die einzelnen, im Kommentar nur andeutbaren Linien aus zu einem geschlossenen Bild, das vor allem auch alle anderen verfügbaren Quellen: die Stelen, Statuen, Totenbücher, liturgischen und literarischen Handschriften, Tempelin- 
schriften usw. einbezieht. Was diese weiteren Materialien anbelangt, "so wird auch meine Ubersetzungssammlung Agyptische Hymnen und Gebete (AHG) in der Hand des Lesers vorausgesetzt. Hymnen, die dort enthalten sind, werden nur als "AHG Nr.X" zitiert, wo der Leser dann alle weiteren bibliographischen Angaben findet.

Man mag sich fragen, welchen wert eine derart weit vorangetriebene Exegese in einem Fach haben soll, dessen vornehmste Aufgaben immer noch in der primären Edition des Materials liegen. 7 Was für Theologie, klassische Philologie und neuere Literaturwissenschaften alltäglich ist, erscheint im Aufgabenhorizont der Ägyptologie als Luxus, wenn nicht gar als müssige spekulation. Wäre es nicht sinnvoller, neue Texte zu edieren, anstatt sich um ein Verstehen zu bemühen, das doch immer subjektiv bleiben muss? Sethe wäre z.B. wesentlich besser beraten gewesen, wenn er sich nach seiner meisterhaften Edition der Pyramidentexte an die ihm damals schon vorliegenden pyramidentexte auf Särgen des Mittleren Reiches gemacht hätte, anstatt der Versuchung nachzugeben, in Urgeschichte und älteste Religion "sein" Bild der Dinge aufzuzeichnen, wie es sich in ihm bei der Beschäftigung mit den Pyramidentexten aufgebaut hat. Die Chancen des Verstehens, die sich in den Sonnenhymnen des Neuen Reiches eröffnen, sind aber ungleich grösser als im Falle der Pyramidentexte. Die Texte sind so zahlreich und so differenziert, dass sie der Willkür und Subjektivität der Interpretation widerstand $\mathrm{zu}$ leisten vermögen und eine denkbar solide Basis darstellen für die Rekonstruktion ihrer Vorstellungswelt und ihres Anliegens. Was hier möglich erscheint, lässt sich nicht mit allen ägyptischen Texten anfangen. Daher darf man diese Chance nicht ungenutzt lassen. Wozu soll schliesslich, so liesse sich gegenfragen, das Edieren immer neuer ägyptischer Texte gut sein, wenn es nicht den weg zu einem besseren Verständnis der altägyptischen Kultur ebnen soll, der dann irgendwann auch einmal beschritten werden

7 Poseners Aufruf auf dem 1. Internationalen Agyptologen-Kongress in Kairo 1976 - tâche prioritaire, in: Acts 1st ICE, 519-522 - trifft die Sachlage genau. 
muss? Dass derartige Vorstösse schneller veralten als die Editionen, aus denen sie hervorgewachsen sind, versteht sich. "Verstehen" ist ein zeitgebundeneres Geschäft als "Edieren".

Worauf beruht denn nun aber diese vielbeschworene "Verständlichkeit" der ägyptischen Sonnenhymnen? Die blosse Menge tut es doch wohl nicht. Auch die Totenbucher sind uns zu vielen Hunderten überliefert. Auch sie verteilen sich auf verschiedene Epochen, verschiedene Orte und verschiedene soziale Schichten. Trotzdem gibt es kaum ein Kapitel in diesem Corpus - schon gar nicht das vielbehandelte siebzehnte ${ }^{8}$ - bei dem ich mich auf einem vergleichbar sicheren Boden des Verstehens fühle. Den entscheidenden Unterschied sehe ich in der Uberlieferungsform, die im Falle der Sonnenhymnik zeitweilig und weitgehend eine produktive, im Falle der Totenbücher eine rein reproduktive ist. Für die Sonnenhymnen stellt die produktivität ihrer Ubberlieferungsform ebenso die Bedingung der Möglichkeit eines (besonderen) Verstehens dar, wie bei den Totenbüchern die reproduktive Uberlieferungsform das verstehen erschwert bzw. vereitelt. Diese Unterscheidung sei im Folgenden etwas näher erläutert. ${ }^{9}$

Reproduktiv nenne ich eine Tradition, die sich im Kopieren immer derselben Texte erschöpft. Typische Beispiele hierfür sind in Agypten ausser dem Totenbuch etwa die literarischen "Klassiker". Wenn man die historische Dimension dieser Texte erschilessen will, muss man versuchen, die produktive Phase ihrer Uberlieferung zu rekonstruieren. Fur die Literatur stellt z.B. unsere Konzeption der "Herakleopolitenzeit" eine derartige, neuerdings stark umstrittene, Rekonstruktion dar. ${ }^{10}$ Auf dem Gebiet der Totenliteratur erscheinen die

8 Mit Bewunderung sei hier die Monographie von U. Rössler-Kठhler, Kapitel 17 des ăgyptischen Totenbuches (GOF IV.10, 1979) zitiert, die anstatt anspruchsvoller und vom Text her nicht substanziierbarer verstehensentwlirfe, fur die genug Beispiele zu zitieren wăren, die Komplexităt der Uberlieferung freilegt, die jedes vereinheitlichende verständ$\mathrm{n}$ is ausschliesst.

$9 \mathrm{Vgl}$. hierzu auch AHG, 91-94.

$10 \mathrm{Vgl}$. W. Schenkel, "Repères chronologiques de l'histoire redactionelle des Coffin Texts", in: W. Westendorf (Hrsg.), Gottinger Totenbuchstudi- 
Schwierigkeiten, eine produktive Phase zu rekonstruieren und damit die historische Dimension der Phänomene wiederzugewinnen, derzeit noch unuberwindbar. Sethes scharfsinniger versuch, die Komplexität der in den Pyramidentexten manifestierten Vorstellungswelten in Gestalt weit in die Vorgeschichte zurückführender "Reiche" zu entwirren, mutet heute fast abwegig an. 11

ReIigiöse Uberlieferung tendiert von der Natur der Sache her zur Reproduktivität, d.h. zu Kanonisierungsprozessen, die die "Heiligkeit" des Gegenstandes auf den im Umgang mit ihm erwachsenen Diskurs übertragen. Auch die Sonnenhymnen sind diesem Schicksal nicht entgangen. Die drei Aufzeichnungsformen, in deren institutionalisiertem Rahmen sich im Laufe des Neuen Reiches das eigentümliche Phänomen der funerären Sonnenhymnik zu seiner einzigartigen Blüte entfaltet:

1.) Die Hymnen am Grabeinaang, später auch an inneren Durchgängen und an der Grabfacade ${ }^{12}$;

2.) Die Hymnen auf im Grab aufgesteliten stelen und (stelophoren) statuetten ${ }^{13}$

en. Beiträge zum 17. Kapitel (GOF IV.3, 1975), bes. 29-31. Ich gebe Schenkel recht, dass es sich bei der "Herakleopolitenzeit" um eine "Fiktion" handelt, meine aber, dass derartige "Fiktionen" zum legitimen und unverzichtbaren, wenn auch standiger Korrektur bedurftigen Arsenal des Historikers gehoren. Wenn wir alle Fiktionen aus unseren Aussagen uber die altägyptische kultur verbannen wollten, wurde das wohl einem verstummen gleichkommen. Die Frage ist nur, ob es so etwas wie "illegitime" Fiktionen gibt. Eine Kriteriologie, die derartige Unterscheidungen exlauben warde, ist mir noch nicht gelăufig. Vgl. n.11.

$11 \mathrm{~K}$. Sethe, Urgeschichte und älteste Religion der Agypter, Beiheft ZDMG 1930. Nicht einmal hier darf man von einer "illegitimen" Fiktion reden. wie der die Gegenposition vertretende H. Kees in der schonen wurdigung, die er gleich im vorwort seines Werkes "Der Gotterglaube im alten Agypten" der setheschen These zuteil werden låsst, klar macht. Auch die Fiktion der vorgeschichtlichen "Reiche" hatte ihr Verdienst und ihre Leistung, insofern "mit der Sachlichkeit einer anatomischen Sektion oder einer geometrischen Losung alle Schichten abgehoben werden sodass die verschiedensten Einflussfelder klar erkennbar werden" (Kees, a.a.0., IV). Auch sethe ging es um Entwirrung von Komplexitat, nur dass er die zeitliche Dimension fur die einzig massgebliche hielt.

12 vgl. hierzu $5 T G$, Einfuhrung, $\$ 2$.

$13 \mathrm{Zu}$ den stelophoren statuetten s. die leider schwer zugängliche Monographie von Claire Lalouette. Fideles du soleil (Faculté des lettres et sciences humaines de Paris, Groupe d'études égyptologiques $I, 1963$ ) sowie H.M. Stewart, in: JEA 53 (1967) $37 f f$. 
3.) Die Hymnen, mit denen seit der Amarnazeit gern Totenbücher eröffinet werden ${ }^{14}$ :

diese drei Aufzeichnungsformen leben bis in die spätzeit fort. Die aufgezeichneten Texte aber erfahren einen Prozess der Erstarrung und Kanonisierung:

1.) Die Hymnen in den Gräbern der saitenzeit reproduzieren alte Vorlagen, wobei jetzt in grösserem Umfang Kulttexte aus dem im NR noch geheimen Bereich der "Mysterien" " $\mathrm{v}$.a. das stundenritual, herangezogen werden, die immer schon dem Bereich reproduktiver Uberlieferung angehörten;

2.) Die typischen Totenstelen der Spätzeit ${ }^{15}$ enthalten entweder einen Text aus Totb 15 (s.(3.)) oder das irrtümlicherweise als Totb 15 A 4/B 5 bezeichnete" mit dem Totenbuch jedoch nicht zusammenhängende Hymnenpaar an den auf- und untergehenden sonnengott;

3.) Den Totenbüchern werden die Sonnenhymnen nun nicht mehr in freier Auswahl vorangestellt, sondern in festgelegter Form als "Kapitel 15" integriert. 17 Dieses Kap. 15 ist seinerseits eine nachträglich kanonisierte zusammenstellung von Einzeltexten $(15 \mathrm{a}-\mathrm{h})$, die sämtlich eine bis in die 18.Dyn. zurückreichende Vorgeschichte aufweisen. 18

Die produktive Phase der in diesen Quellen reproduzierten Uberlieferung liegt, von den "Mysterien"-Texten, die z.T.äl-

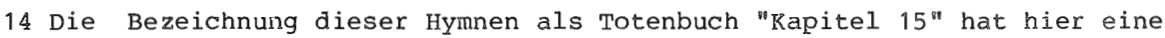
höchst unheilvolle verwirrung gestiftet. Bei diesen Hymnen handelt es sich um Texte ausserhalb des im NR noch sehr stark fluktuierenden korpus kanonisierter Sprüche, die diesem Korpus vorangestellt werden und in einer ganz ähnlichen Weise mit der Vorstellung des "Eingangs" oder vielmehr "Ausgangs" ( prt $m$ hrww) verbunden sind wie die Hymnen am Grab-Eingang (bzw. Ausgang). Erst im laufe eines später einsetzenden Kanonisierungsprozesses werden einige dieser Hymnen dann als "Kap.15" dem Spruchkorpus integriert.

15 P. Munro, Die spätägyptischen Totenstelen, æ̊gFo 25, 1973.

16 Th.G. Allen, "Some egyptian Sun Hymns", in:JNES 8 (1949) 349-356, vgl. LI $73 \mathrm{f} . \mathrm{n} .144$ und $291 \mathrm{n} .43$.

17 E. Lefébure, Traduction comparée des hymnes au soleil composant le XVe chapitre du Rituel funéraire égyptien (1868); T.G. Allen, The Egyptian Book of the Dead. Documents in the Oriental Institute Museum at the University of Chicago (1960).

$18 \mathrm{Vgl}$. H.M. Stewart, "Traditional Egyptian Sun Hymns of the New Kingdom" (Institute of Archaeology Bulletin No.6), London 1967, 42 m。n。96. 
ter sein werden, abgesehen, in der 18. und 19.Dyn. und braucht nicht rekonstruiert $z u$ werden, sondern ist in einer Fülle von Inschriften greifbar. Auch die 20. und 21. Dyn. sind, was die Sonnenhymnik angeht, noch produktiv ${ }^{19}$, werden aber von den späteren Epochen nicht reproduziert. Der "Archaismus" der Spätzeit ${ }^{20}$ greift nicht auf das ihm unmittelbar vorangegangene, sondern auf das von ihm als klassisch empfundene Alte zurück. Erst jetzt gewinnen die Sonnenhymnen in Gestalt des 15. Totenbuchkapitels den Charakter eines "Heiligen Textes", bei dem es auf den genauen Wortlaut ankommt.

"Heilige Texte" sind eo ipso an reproduktive Uberlieferung gebunden. Reproduktive uberlieferung erfordert ihrerseits eine Kultur der Auslegung, wenn der Sinn nicht im Laufe der Jahrhunderte verlorengehen soll. Denn im Gegensatz zu einer produktiven Uberlieferung, die das Thema in immer neuen Formulierungen der sich wandelnden geschichtlichen wirklichkeit akkomodiert, gerät der Text in der reproduktiven Uberlieferung über kurz oder lang in Abstand zur historischen wirklichkeit, einfach dadurch, dass sich die sprache wandelt, wörter und Formen obsolet werden oder andere Bedeutungen annehmen, neue Erfahrungs- und Verstehenshorizonte andere Bedeutungen und Bezugsrahmen konstituieren usw. usw. Diese Entwicklung ist nicht aufzuhalten, aber ihre Folgen lassen sich bis zu einem gewissen Grad kompensieren durch die Ausbildung einer philologischen und theologischen Hermeneutik, deren Aufgabe im Laufe der Zei.t nach Massgabe des unaufhaltsam wachsenden Abstandes zwischen "Text" und "Wirklichkeit" immer grösser und schwerer wird. So ruft der religiöse Diskurs (und mutatis mutandis auch der literarische) im Gefolge seiner Kanonisierung die Spezialisten auf den Plan, die mit der Tradierung nicht nur dieser Texte, sondern vor allem des fur diese Tradierung erforderlichen, immer grösser werdenden wissensvorrat befasst sind: die Brahmanen im Hinduismus, das Rabbinat

19 Zur 21.Dyn. s. Heerma van Voss, "Die Totenliteratur der 21.Dyn.", in: JEOL, $24(1975-76), 48 f$.

$20 \mathrm{H}$. Brunner, "Zum Verständnis der archaisierenden Tendenzen der ägyptischen Spătzeit", in: Saeculum 21 (1970) 151-161. 
im Judentum, die Schreiber und Vorlesepriester des Lebenshauses in Ågypten. Die Kanonisierung des religiösen Diskurses, die Etablierung eines exklusiven Priesterstandes und die Ausdifferenzierung eines religiösen Wissens aus dem Gesamtsystem der Kultur sind drei sich gegenseitig bedingende prozesse. Im Gegensatz zum Hinduismus und zum Judentum hat sich aber in Agypten das Kommentieren als notwendiges Korrelat zur Kanonisierung in engsten Grenzen gehalten. 21 Bei aller Bewunderung für die Leistung der ägyptischen Tradenten, die nur im Hinblick auf den beklagenswerten zustand der meisten Totenbücher (von den literarischen Hss. ganz zu schweigen!) etwas eingeschränkt wird, müssen wir uns doch eingestehen, dass wir mit den Texten allein gelassen sind, die schon im alten Ägypten selbst den Rang eines nur wenigen spezialisten zugänglichen, esoterischen wissens hatten.

In dem Masse, wie der religiöse Diskurs sich aus dem Gesamtsystem kultureller Kommunikation ausdifferenziert und zu einem von Spezialisten verwalteten Bereich kanonisierter Texte und esoterischen wissens wird, fallen priesterliche Kultreligion und Volksreligion auseinander. Die Fülle der in den Gräbern enthaltenen Inschriften gibt uns nun ausgezeichnete und einzigartige Möglichkeiten an die Hand, die Verbreitung religiösen wissens auch in nichtpriesterlichen, wenn auch in jedem Falle gebildeten und literaten Schichten des Volkes zu überprüfen. Denn hier befinden wir uns im Bereich einer produktiven Uberlieferung, wo innerhalb der institutionalisier-

21 Das bekannteste Beispiel einer kommentierenden Ubersetzung eines alten Textes in eine jüngere sprachform ist der Kommentar zum Nutbuch im pCarlsberg I, ed. H.O. Lange und O. Neugebauer, Papyrus Carlsberg Nr.1 (Det kg1. Danske Videnskabernes Selskab, Hist.fil. Skrifter I Nr.2, 1940). Vgl. auch S. Schott, Die Deutung der Geheimnisse des Rituals für die Abwehr des Bösen. Eine altägyptische Ubersetzung (AbhAWLMainz, 1954 Nr.5). Zum Problem der "Glossierung" von Totb 17 s. W. Schenke1, a.a.0. (n.10), 69 und U. Rössler-köhler, a.a.o. (n.8), 348-350. Das Problem dieser "Glossen" liegt darin, dass sie sich auf genau derselben Ebene bewegen wie der "Haupttext". Hier wird nichts "übertragen", in eine andere sprachebene oder Vorstellungswelt. Entsprechend wird auch nichts erklärt, es werden nur mögliche Bezüge hergestellt. Man könnte sich das Ganze auch als ein "Initiationsverhör" denken, das einen exklusiven Wissensvorrat nicht nur in der Form eines "Kompendiums" (U. Rössler-Köhler), sondern auch eines "Katechismus" zusammenfasst. 
ten Rahmenbedingungen von Gattungsstrukturen ${ }^{22}$ und Aufzeichnungsformen ${ }^{23}$ immer neue Texte hergestellt werden. Der Aufzeichnungssitte als einer Norm wäre ja genüge getan, wenn - wie es in den Königsgräbern mit der Sonnenlitanei der Fall ist - immer derselbe Text am Grabeingang angebracht würde. Die Tatsache, dass hier jedoch immer neue Texte aufgezeichnet werden, zeigt, dass nicht eine bestehende Aufzeichnungssitte zur Herstellung von Texten führte, sondern umgekehrt ein religiöser Prozess von ungeheurer "Popularität" sich seine Aufzeichnungsformen geschaffen hat. Am Kriterium der Produktivität der Gattung gemessen, war kein Bereich der ägyptischen Religion im Neuen Reich auch nur annähernd so "populär", d.h. in so vielen individuellen Texten in Gräbern verschiedener Nekropolen und von Angehörigen verschiedener sozialer Schichten verbreitet, wie die Sonnenreligion (im weiteren, auch Amun-Re umfassenden sinne). Erst in weitem Abstand folgt osiris, in dessen Verehrung die reproduktive Uberlieferung eine ungleich grössere Rolle spielt.

Was die Sonnenhymnen angeht, lassen sich nach dem Kriterium der Uberlieferungsform folgende drei Gruppen unterscheiden:

\section{1.) Texte eines esoterischen Wissensvorrats}

In der (reproduktiven) Uberlieferung dieser kanonisierten Texte spielen die Gräber der Saitenzeit eine tragende Rolle. Genau wie die Unterweltsbücher, im Neuen Reich streng gehüteter Schatz eines wissens, dessen Reproduktion auf Grabwänden königliches Privileg war, sind auch diese Hymnen erst jetzt den privaten Grabherren verfügbar geworden. Das kostbarste Dokument dieser Literatur ist ein Text, der, selber kein Hymnus, gelegentlich in verbindung mit Sonnenhymnen auftritt und die Bedingungen der Möglichkeit der kultischen Anbetung des Sonnengottes und damit das selbstverständnis dieser "esoterischen" Seite des Sonnenkults in einzigartiger Klarheit expliziert. 24 Dieser Text schlägt die Brücke zwischen den in die-

22 S. hierzu FHG, Einfuhrung.

23 S. hierzu Gs Otto, 59-65.

24 König als Sonnenpriester; vgl. Kap.1, $24 \mathrm{ff.}$ 
sem Kult verankerten "esoterischen wissenshymnen" auf der einen, und den "Unterweltsbüchern", d.h. der ebenfalls esoterischen kosmographischen wissensliteratur der Königsgräber, auf der andern seite und macht deutlich, dass beide Texte derselben Diskurswelt angehören. Wie das Amduat und das Stundenritual dürfte er einer vor das Neue Reich zurückreichenden Tradition angehören. 25

In den Königsgräbern hat man sich aber auf die Dauer nicht mit der reproduktiven Uberlieferung des Amduat begnügt. Nach der Amarnazeit treten Pfortenbuch, Höhlenbuch, das "Buch von der Erde" und andere Kompositionen hinzu. Nichts zeigt deutlicher die Intensität der Bewegung, in die die Sonnenreligion während der 18. und 19. Dyn. geraten war und die von der Sonnenreligion als dem Sinn-Zentrum des damaligen Weltbildes ausging, als diese Veränderungen, denen selbst der allen "populären" Strömungen entzogene Bereich unzugänglicher und esoterischer wissenstradition unterworfen war. So wird man auch damit rechnen dürfen, dass sich der kanonische Bestand der Sonnenhymnen, der in den Bereich dieses exklusiven priesterlich-königlichen wissens gehört, im Laufe des NR ebenfalls nicht unerheblich vermehrt hat. Auch hier ist man zweifellos nicht beim stundenritual stehen geblieben. Trotzdem ist die historische Einordnung dieser Texte unendlich viel schwieriger als im Bereich der produktiven uberlieferung diesseits jener unsichtbaren Deinarkationslinie, die das geheime wissen der "Mysterien" des Sonnenkults von der nach aussen gewandten und offenbar immer weitere Kreise umfassenden, immer mehr an

25 Zur Datierung des kulttheologischen Traktats uber den Konig als Sonnenpriester in das MR S. S.5 n.1 meiner Eđition. Die gleiche Datierung schlägt H. Altenmuller, in: JEOL 20,1968,27-42, auch fur das Amduat vor, das mit dem Traktat aufs engste zusammenhangt. Hornung halt an seinem Ansatz in die fruhe 18. Dyn. fest, wobei er sich vielleicht von seinem verstandnis des Werkes als eines "Jenseitsfuhrers", d.h. kgl. Totentexts leiten lasst. In der Tat ist der Abstanä zum Zweiwegebuch als dem vermeintlichen Vorganger in derselben Gattung so gross, dass man eine Epoche zwischen beide Texte legen mochte. Ich weise die beiden Texte verschiedenen Gattungen $z u$, halte das zweiwegebuch fur einen Totentext, das Amduat aber fur eine Kosmographie aus dem heliopolitanischen Sonnenkult. 
Boden und Bedeutung gewinnenden seite der Sonnenreligion trennte.

\section{2.) Standardtexte}

"Standardtexte" nenne ich die liturgischen Sonnenlieder, die denjenigen Grabherren als Vorlage gedient haben, die zur Herstellung neuer, eigener Texte nicht in der Lage waren. Diese Texte stammen aus dem kult, ohne darum geheim und esoterisch zu sein. Der Sonnenkult muss eine exoterische seite besessen haben, die auch dem Laien eine Art von Teilnahme ermöglichte. Von daher waren den Leuten bestimmte Texte im Ohr, deren Rezeptionsschicksal in den Gräbern eher auf mïndliche (d.h. Gedächtnis-) Uberlieferung weist als auf die Benutzung schriftlicher Vorlagen. 26 Der Begriff "Standardtext" deckt sich nicht mit dem, was H.M. Stewart als "traditional sun hymns" aus dem überlieferten Bestand ägyptischer Sonnenhymnen ausgesondert hat. Stewarts einziges Kriterium für die Einstufung eines Textes als "traditional" ist mehrfache Bezeugung. Nach diesem Kriterium sind dann selbst so ausgeprägt innovatorische Texte wie der Hymnus der Baumeister suti und Hor als "traditionell" einzustufen. 27 was ich einen standardtext nenne, ist nicht nur mehrfach, sondern auch vielfältig, d.h. in verschiedenen Uberlieferungsbereichen, bezeugt. ${ }^{28}$ Die Analyse dieser so ausgesonderten standardtexte erschliesst eine Vorstellungswelt, wie sie sich ganz entsprechend auch in einer Fülle anderer Zeugnisse des Sonnenkults, besonders in den zahlreichen Totenbuch-Vignetten und Sonnenlauf-Darstellungen in Gräbern manifestiert. Daher nenne ich "traditionell" alle Texte, die auf dieser vorstellungswelt beruhen, unbeschadet der Tatsache, dass sie ein-oder mehrfach bezeugt sind. Nach meiner Terminologie sind also alle standardtexte traditionell, aber nicht alle traditionellen Texte standardtexte.

3.) Individuelle Hymnen

"Individuell" nenne ich Hymnen, die in signifikantem Abstand

26 S. hierzu STG, Einfuhrung, $\$ 3$.

27 H.M. Stewart, a.a.o. (n.28), 53 f.

28 Zur Frage der Uberlieferungsgeschichte s. LL, $2 f . m . n .4$. 
zu dem stehen, was sich aus den ersten beiden Gruppen als die traditionelle Vorstellungswelt erschliessen lässt, d.h., positiv formuliert, in denen eine neue Vorstellungswelt zum Ausdruck kommt. Es gibt genug Texte, um nicht nur die Genese des Neuen in allen seinen Phasen, sondern auch innerhalb des Neuen verschiedene Traditionen unterscheiden zu können. So unterscheide ich eine "Neue Sonnen-Theologie", die sich in bewussten Gegensatz zur traditionellen Sonnenreligion stellt, auf der einen seite und zwei einander ablösende Ausprägungen der thebanischen Amun-Re-Theologie, die eine mit der Blüte zur zeit von Hatschepsut bis Amenophis II, die andere mit der Blüte im 13.Jh.v.Chr., auf der anderen seite.

Diese Hymnen markieren eine Position in dem grossen religionsgeschichtlichen prozess jener Jahrhunderte. Sie sind nicht nur als Inschriften, sondern auch als Texte datierbar, als Aussagen in einem Diskurs. Die Themen, um die es in diesem Diskurs geht, hat man als die zentralen Fragen der zeit zu betrachten. Die Fülle, die Vielfalt, der Umfang und das theologische Niveau dieser Texte zeugen von der Intensität der geistigen Auseinandersetzung mit diesen Fragen. Alles, womit der menschliche Geist sich über Jahrhunderte in einem kontinuierlichen gesellschaftlichen Diskurs intensiv beschäftigt, gerät in Bewegung und wandelt sich in einem geschichtlichen Prozess der Entfaltung, Ausarbeitung und Differenzierung. Uberlieferung, die aus einer derartigen Auseinandersetzung mit der wirklichkeit erwächst, ist immer produktiv.

Alle ägyptischen Texte wurzeln mit ihrer Erst-Formulierung in einer phase produktiver tberlieferung, innerhalb deren auch sie eine Position in einem Diskurs markieren. Die Formen und Zusammenhänge, in denen sie uns überliefert sind, sind aber in der Regel von dieser phase sehr weit entfernt und lassen nur selten eine Rekonstruktion der urspünglichen Sinn- und Funktionszusammenhänge zu. Hier muss sich der Philologe mit der Aufhellung von Einzelheiten begnügen, mit der Herstellung von oränung an einzelnen stellen eines Feldes, das er als Ganzes nicht überblickt. Die Sonnenhymnen des Neuen Reiches bieten eine günstigere Ausgangsposition. Sie stam- 
men aus der zeit ihrer Entstehung. Die historische Dimension des Diskurses, der sich in ihnen manifestiert, die Verteilung der Aussagen in den Sinn-Dimensionen der geschichtlichen wirklichkeit, nach zeit, ort und sozialer schichtung, ist nicht Sache mühseliger wo nicht gar müssiger Rekonstruktion, sondern an den Inschriften selbst unmittelbar ablesbar. Hier tut sich ein weg auf, der tiefer ins Innere ägyptischen Denkens zu führen verspricht als es uns normalerweise möglich ist. Nicht Einfühlung und anverwandelnde Wesensschau, die sich immer schon am ziel wähnen ohne die Notwendigkeit und vielleicht auch die Möglichkeit eines Weges zu Gesicht bekommen zu haben, sind hier gemeint, wenn von "Verstehen" die Rede ist, sondern ein ordnendes Trennen und Sortieren der Uberlieferungs-Komplexe, das durch Reduktion von Komplexität sinnhafte und als solche verstehbare zusammenhänge freilegt. Damit ist man noch lange nicht am "ziel", aber man hat einen weg beschritten, der uns weiter führt.

Der Uberlieferungskomplex, um dessen trennende Sortierung es in diesem Buche geht, ist die das halbe Tausend übersteigende Fülle der überlieferten Zeugnisse der Sonnen- und AmunTheologie des Neuen Reiches. Die Dimensionen dieser vorzunehmenden Aufgliederung sind, um es noch einmal zu sagen, zeit, Raum und soziale schichtung. Daraus ergeben sich die Kriterien der Differenzierung, die wir "dia-chronisch" (Zeit), "diatopisch" (Raum) und "dia-stratisch" (Sozialgefüge) nennen wollen. Die ersten beiden Kriterien verstehen sich von selbst. Die diachronische Differenzierung ergibt sich aus der Tatsache einer produktiven Uberlieferung, d.h. der Aufzeichnung immer neuer Texte, deren Aufzeichnungs- und Abfassungsdatum nicht weit auseinanderliegen kann. Die diatopische Differenzierung ergibt sich z.T. aus der Verteilung der Inschriften auf Fundorte, d.h. weitestgehend Theben und Saqqara. Dieses Kriterium reicht aber nicht hin. Bei reproduktiver uberlieferung, d.h. der genauen Kopie schriftlicher Vorlagen, muss man damit rechnen, dass diese vorlagen ihren eigentlichen ort ganz woanders haben als die Inschrift, die sie kopiert. Das Zentrum der ägyptischen Sonnenreligion ist Heliopolis. Man 
wird also damit rechnen dürfen, dass zumindest in der reproduktiven uberlieferung heliopolitanische Texte zur Aufzeichnung kommen. Dies Annahme wird vom inschriftlichen Befund voll bestätigt. Es lässt sich nämlich zeigen, dass alle auf reproduktiver Uberlieferung beruhenden Texte frei von Elementen thebanischer Amun-Theologie sind und auf der Vorstellungswelt der traditionellen Sonnenreligion beruhen. Daher lassen sich mit einigem Recht die beiden Textgruppen, die das überlieferungsgeschichtliche Kriterium der Reproduktivität und das inhaltliche Kriterium der reinen und traditionellen sonnen-Theologie gemein haben, die "Mysterien-" und die "Standard-Texte" in diatopischer Hinsicht Heliopolis zuweisen.

Auf diachroner Differenzierung beruht die Unterscheidung zwischen "traditioneller" und "Neuer Sonnen-Theologie". Die "Neue Sonnen-Theologie" scheint ein gemein-ägyptisches phänomen zu sein; sie lässt sich sowohl in thebanischen (Suti und Hor) als auch in memphitischen Texten ${ }^{29}$ greifen. Ihre frühesten Bezeugungen reichen aber nicht vor die Regierungszeit Amenophis III. zurück. ${ }^{30}$ wenn man früher solche Texte gern als Vorläufer der Amarna-Religion ansah und spätere (von denen wenig bekannt waren) als deren Nachklänge verstand, so ergibt sich jetzt aus dem neuen thebanischen Material mit aller Klarheit, dass wir es bei der "Neuen Sonnen-Theologie" mit einer von Amarna vollkommen unabhängigen Bewegung zu tun haben, die auch ohne den Einbruch der Umwälzung des Echnaton genau so verlaufen wäre, wie sie in den Texten greifbar wird. Die Texte der Nachamarna- und Ramessidenzeit setzen die in den Texten der Voramarnazeit entwickelte Position bruchlos fort. Das wäre nicht denkbar, wenn diese position als "Atonismus" verstanden und entsprechend diskreditiert worden wäre.

$29 \mathrm{Vg}$. MDIK 27.1 (1971) 1-20 sowie hier, Kap.3. Einer der wichtigsten Texte der "Neuen Sonnentheologie" steht im Grab des Ramesseum-Verwalters Haremhab, wo man ihn nicht vermuten wurde, denn er ist dort nur in geringen Fragmenten erhalten, die sich aber nach dem Berliner ptahhymnus pBerlin 3048 (AHG Nr.143) ergănzen lassen. S. Quibell, Exc.at Saqgara IV (1908-10) Tf.73.3; Kitchen, RI III, $188 f$.

30 S. MDIK 27.1, 1ff. In Theben: Text 76. 
Auf diachroner Differenzierung beruht auch die Unterscheidung einer "Frühphase" (Zeit: Hatschepsut bis Amenophis II) und einer "ramessidischen Phase" der thebanischen Amun-Theolo-

gie. Die Texte, in denen diese Phasen thebanischer Theologie zum Ausdruck kommen, sind sämtlich individuell, d.h. beruhen auf produktiver Uberlieferung und lassen sich ausserhalb Thebens nicht nachweisen. 31 Dazu kommt ein inhaltliches Kriterium: in ihnen kommt Amun nicht nur als gelegentliche Erweiterung des Gottesnamens Re-Harachte vor (was in thebanischen Inschriften überhaupt nichts besagen will ${ }^{32}$ ), sondern geht mit wesentlichen stücken seiner Theologie in diese Texte ein. Diese stücke sind

(a) die Urgott-Theologie

(b) ein personaler Gottesbegriff, damit verbunden

(c) eine ethische Dimension, wie sie der reinen SonnenTheologie fremd ist

(d) eine ausgeprägte Betonung der Einzigkeit Gottes, die sich in der Frühphase als "Primat", in der ramessidischen Form als "Transzendenz" darstellt.33

Anders als im Falle der Neuen Sonnen-Theologie, auf der die Amarna-Religion zwar $z u$ einem gewichtigen Teil basiert, auf die sie aber nicht verändernd zurückwirkt, bedeutet für die thebanische Amun-Theologie der Einbruch von Amarna einen gewichtigen Einschnitt. Das spezifisch "pantheistische" Gepräge der ramessidischen Amun-Theologie ist in deren Frühform nicht angelegt und ist nur als Antwort auf die Amarna-Religion verständlich: als der Versuch, die Idee des Einen Gottes mit der polytheistischen Vorstellung von der Göttlichkeit und Differenziertheit des Kosmos zu verbinden.

31 Abgesehen von der Parallele zu Text 68 im Grab des Paheri zu El-Kab (Urk.IV 111) und der im reinsten "thebanischen" Stil gehaltenen OnurisEulogie des Satepihu aus This (Urk IV 518). Auch der sog. Tura-Hymnus ist ein thebanischer Text, dessen seltsame Aufzeichnungsumstände wohl durch die Verfolgung der Amunreligion in der Amarnazeit zu erklären sind. Vgl. Kap.5, $\$ 4.3 .1$.

$32 \mathrm{Vgl}$. z.B. pBerlin $3050 \mathrm{I}$, ein reiner Sonnenhymnus, wie schon der Titel klar macht, in den sich aber dann in die Anrufung doch der Amunsname einfügt - für A. Barucq und F. Daumas Grund genug, diesen Text unter die "hymnes à Amon" einzuordnen (Hymnes et prières de l'Egypte ancienne, 1980, $\mathrm{Nr} .82$ ).

33 s. hierzu "Primat und Transzendenz", in: W. Westendorf (Hrsg.), Aspekte der spätägyptischen Religion (GOF IV.9, 1979), 7-42. 
Auf diastratischer Differenzierung schliesslich beruht die Aussonderung der "Mysterien". Hier handelt es sich um Texte aus einem Wissensvorrat, der nicht jedermann zugänglich war. Die Himmels- und Unterweltsbücher der königsgräber und des Osireions von Abydos gehören demselben wissensvorrat an. Man geht wohl nicht fehl, wenn man Heliopolis als seine eigentliche Heimat ansetzt. Der Kult von Heliopolis ist ein ritueller Mitvollzug des Sonnenlaufs in ober- und unterwelt ${ }^{34}$ und damit eine Begehung der zeit, die dadurch, als Kontinuität der Wirklichkeit, in Gang gehalten wird. Zugleich wird hier die zeit als Lebensvollzug des göttlichen Kosmos, als die zeit- = Lebens-Fülle des Kosmos verstanden, in die der Tote einzugehen hofft. Daher werden diese Texte als Totentexte für den König in seinem Grabe aufgezeichnet. Mit der diastratischen Dimension der "sozialen Schichtung" ist also eine wissens-soziologische Differenzierung gemeint, die auf dem Faktum der Zugänglichkeitsbeschränkungen beruht, mit denen bestimmte Texte, d.h. Wissensvorräte versehen sind. Diese Kategorie ist bisher, soweit ich sehe, vollkommen ausser acht gelassen worden. Man wird sich fragen müssen, inwieweit die von Alexandre Piankoff und jetzt vor allem von Erik Hornung in meisterhaften Editionen und Interpretationen erschlossene Vorstellungswelt der Himmels- und Unterweltsbücher wirklich "das" ägyptische Weltbild widerspiegeln und nicht vielmehr das Spezialwissen einer kleinen Gruppe von spezialisten, das mit den Fragen, die die hier behandelten Jahrhunderte der ägyptischen Geistesgeschichte bewegt und erschüttert haben, nur mehr oder weniger entfernt zusammenhing. 35 Manche der Kontroversen zwischen dem verehrten Freunde, dem dieses Buch gewidmet ist, und mir beruhen einfach darauf, dass unsere Materialien verschiedenen Wissensvorräten entstammen. Der eine, auch wenn er die Fülle der Privatinschriften überschaut,

34 Zur Krypta des heliopolitanischen Tempels als kultischer vergegenwärtigung der unterwelt $\mathrm{s}$. Text 158 (n) sowie Kap. 2 m.n.138.

$35 \mathrm{Vgl}$. aber E. Hornung, Agyptische Unterweltsbucher, 17ff. fúr eine die Wandlungen der ăgyptischen Sonnenreligion wiederspiegelnde Geschichte dieser Gattung. 
denkt von den königlichen unterweltsbüchern her, der andere, auch wenn er sich mit den Unterweltsbüchern intensiv beschäftigt hat, legt seinem Bild die Privatinschriften zugrunde. Die wissens-soziologische Differenzierung der ägyptischen Uberlieferung weist den Weg, aus der Kontroverse heraus und zu einem beiden Ansätzen gerecht werdenden und zugleich adäquateren Verständnis der geschichtlichen Wirklichkeit zu gelangen. 
$-21-$

Erster Teil

$$
\text { R E - H A R A C B T E }
$$


Erstes Kapitel

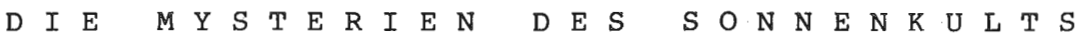

In dreifacher Gestalt tritt uns die ägyptische Sonnenreligion im Neuen Reich entgegen: 1.) als eine streng geheim gehaltene Kosmologie, die als "Unterweltsbücher" zum Gebrauch des Königs im Jenseits in den Königsgräbern aufgezeichnet wurde, deren Zusammenhang mit dem Sonnenkult, vor allem dem stundenritual aber durch den kulttheologischen Traktat über den König als Sonnenpriester klargestellt wird, 2.) als eine auf zahllosen privaten Denkmälern verbreitete Hymnik, die den Sonnenlauf in der polytheistischen Form als Zusammenwirken des Sonnengottes mit einer "Sphäre des seinigen" preist und zur Hauptsache auf einigen wenigen, immer wieder kopierten und variierten standardtexten beruht und 3.) als eine Art von Monotheismus, die in der Sonne sozusagen die natürliche Evidenz der Einzigkeit Gottes sieht und in Gestalt der Amarna-Religion sogar einen gewaltsamen Umsturz herbeiführt. Die ersten drei Kapitel widmen sich der Entzerrung dieses komplexen Befundes. Mit dem Bereich der "Mysterien" sei der Anfang gemacht. Dabei werden wir aber auf die Unterwelts- und Himmelsbücher nur am Rande eingehen und uns auf die liturgischen Texte sowie den zugehörigen Traktat beschränken, die auch in den privaten Grabinschriften - ausnahmsweise bereits im Neuen Reich, in grossem Umfang dann in den Gräbern der Saitenzeit eine Rolle gespielt haben.

\section{Vorüberlegungen}

Die einfachste Erklärung für das phänomen der "Standardtexte" im Sinne von Vorlagen von Bezeugungen in verschiedenen Anwendungsbereichen der ägyptischen Hymnik ist die Annahme, dass sie aus dem Tempelkult stammen. Diese zuerst von stewart vertretene These ${ }^{1}$, die auch meinen Liturgischen Liedern zugrun-

1 Stewart, in: JEA 46 (1960) 83. 
de liegt, hat sich nicht nur gattungsgeschichtlich wahrscheinlich machen, sondern in einer ausreichenden Menge von Fällen auch überlieferungsgeschichtlich nachweisen lassen ${ }^{2}$ und darf als gesicherte Grundlage weiterer Uberlegungen dienen. Sie impliziert aber eine Vorstellung des Sonnenkults, die mit dem, was wir sonst über Kult und Priestertum in Agypten wissen, nicht ganz übereinstimmt. Es gab in Agypten ja keine "Gemeinde", die solche Texte im Tempel gesungen hätte wie heutzutage die Lieder des Kirchengesangbuchs. Der Kult war Sache einer professionellen, strengen Reinheitsvorschriften unterworfenen Priesterschaft und vollzog sich, von Prozessionsfesten abgesehen, unter Ausschluss der Offentlichkeit im innersten Tempelbereich. Wie sollen nun aus diesem Kult heraus Lieder in weiten, nichtpriesterlichen Kreisen der Bevölkerung Verbreitung gefunden haben?

Dieser Widerspruch zwingt zu einer Differenzierung. Der ägyptische Sonnenkult, und wahrscheinlich nur er, hatte über die normale, allen kulten gemeinsame "Innenseite" hinaus allem Anschein nach auch noch eine "Aussenseite", an der weitere Kreise beteiligt waren und die wohl nicht einfach mit dem Festkult identisch war. zu dieser Annahme zwingt uns das Phänomen der "Standardtexte", deren Verbreitung in ägyptischen privatinschriften schlechterdings nicht in Einklang zu bringen ist mit unserem Bild eines normalen ägyptischen Kultvollzugs. Diese professionelle Normalform hat es aber im ägyptischen Sonnenkult auch gegeben, sie stellt seine "Innenseite" dar. Die hierher gehörenden Texte haben eine andere und sehr viel eingeschränktere Verbreitung als die "Standardtexte", die in jedem einzelnen Fall die starken zugänglichkeitsbeschränkungen deutlich macht, denen derartiges schrifttum unterworfen war.

Der ägyptische Ausdruck für den Begriff dessen, was die Innenseite des Kults bildet, ist sšt3w, wörtlich "das unzu-

2 So die Herkunft von LL I 2 aus dem Stundenritual, von II 1 aus dem AmunRitual, von II 2 aus dem Sonnenkult von Karnak und von II 3 aus dem Ritual fur Amenophis I. 
gänglich Gemachte" . Wenn wir diesen Begriff mit dem griechischen Ausdruck "Mysterien" wiedergeben, übernehmen wir nicht dessen ganze Bedeutungsfülle, sehen $z . B$. ab von solchen Aspekten wie Einweihung, Todesvorwegnahme und Gottwerdung des Mysten, und übernehmen nur die folgenden beiden Aspekte:

1.) das "Geheime", die strikten Zugänglichkeitsbeschränkungen, die mit den Mysterien wie mit den sక̌t3w verbunden sind

2.) die Gesamtheit von "Wissen", "Sprechen" und "Handeln", die mit dem Wort "Mysterium" bezeichnet ist.

Die "Innenseite" des ägyptischen Sonnenkults, seine Mysterien, wird konstituiert durch eine Tradition, die festlegt, was zu seinem Vollzug gewusst, gesagt und getan werden muss. Träger dieser Tradition ist ein kleiner Kreis professioneller Sonnenpriester und Schriftkundiger, der in keiner Weise identisch ist und verwechselt werden darf mit dem grossen Trägerkreis der Sonnenverehrung, die im Neuen Reich geradezu den Charakter einer "Bewegung" annahm. Nur in seltensten Ausnahmefällen gehört einmal einer der in dieser Arbeit behandelten Grabherren dazu.

\section{Wissen}

Das Glück hat uns einen kulttheologischen Traktat erhalten, der uns über Gegenstandsbereich und Bedeutung des Wissens im Sonnenkult in seltener Klarheit und Ausführlichkeit unterrichtet ${ }^{3}$. Dieser aller wahrscheinlichkeit aus dem MR stammende Text ist im NR zuerst im Tempel der Hatsepsut von Der el-Bahri, auf der Ostwand des Sonnenheiligtums, belegt und zwar in zeilengetreuer Reproduktion derselben Vorlage,

$3=$ Text Nr.37 in Grab 33 (Petamenophis), s. dort die Liste der inzwischen bekannten Varr. und Lit. Da auch J.C. Goyon in seiner Edition der Taharqa-Fassung wieder von einem "Hymnus" spricht und diesen auch noch als "complete version of chapter 15B of the Book of the Dead" identifiziert (Parker et alii, The Edifice of Taharqa, $38 \mathrm{m.n.15}$ ) sei hier noch einmal klargestellt, dass dieser Text vom Konig als Anbeter des Sonnengottes handelt, aber nicht selbst einen Hymnus darstellt. Die Tatsache, dass sich dieser Text auch einmal unter die Sonnenhymnen eines Totenbuchs verirrt hat, erkiärt sich daraus, dass dessen Inhaber Oberarchivar der königlichen Schriften war, macht ihn aber noch nicht zu einem Totenbuchtext. 
die auch im südichen Teil des Luxor-Tempels Amenophis' III. verwendet wurde ${ }^{4}$, dort aber, offenbar mit Rücksicht auf die besonderen Zugänglichkeitsbeschränkungen dieses Textes, die bei diesem Anbringungsort noch nicht hinreichend gewährleistet schienen, in einer zweifellos absichtlich verunklärten Form. 5 Der Text kommt auch später auf ähnlichen königlichen Denkmälern vor: im Sonnenheiligtum von Medinet $\mathrm{Habu}^{6}$ und im Gebäude des Taharqa in Karnak $^{7}$ sowie auf zwei Särgen der königlichen Familie der 25.Dyn. aus Nuri. ${ }^{8}$ In den Gräbern der Saitenzeit, die ja eine Vorliebe ihrer Grabherren für exklusive und altüberlieferte Texte an den Tag legen, ist der Text bislang dreimal bezeugt ${ }^{9}$, im NR kommt er dagegen nur in einem einzigen Grab und dazu in einer sehr verkürzten Fassung vor: im Grab des III.Amunspriester Tjanefer, das auch dadurch aus dem Rahmen fällt, als es einen Ausschnitt aus dem pfortenbuch enthält. ${ }^{10}$ Das einzige Totenbuch des NR, das den Text enthält, gehörte einem königlichen Oberarchivar. 11 Der exklusive bzw. esoterische charakter des Textes, d.h. seine zugehörigkeit zu einem Wissensvorrat, der ähnlichen zugänglichkeitsbeschränkungen unterlag wie die Unterweltsbücher der königsgräber, tritt in der uberlieferungsgeschichte deutiich zutage.

Der Text handelt über den König als Sonnenpriester, d.h. uber die Rolle 12 des Sonnenpriesters, wie sie zu den Funk-

4 Diese vermutung hat sich inzwischen durch die Rekonstruktionsarbeiten der polnischen Mission bestätigt, s. J. Karkowski, in: Etudes et Travaux XI (1979), 217-19.

5 H. Brunner, Die südichen Răume des Tempels von Luxor, AV 18(1977), Tf.65, S. 42 und $80-82$.

$6 \mathrm{MH} \mathrm{VI}, 424 \mathrm{C}$.

7 Parker et alii, The Edifice of Taharqa, Tf.18B und 31-33; S.38-40.

8 Auf diese ausgezeichnet erhaltenen varr. machte Goyon in seiner Edition der Taharqa-Version aufmerksam, s. ibd., Tf.31-33.

9 petamenophis:Text 37. Fur Grab 27 erwahnt von A. Roccati, in: Or Ant 15 (1976) 234 n.4. In Saqqara steht der Text auf zwei pfosten verteilt im Eingang des Grabes des P3-Srj-t3-jsw (E. Bresciani, in: Egitto e Vicino Or iente, 1 (1978) Tf.XVIII).

10 Seele, The Tomb of Tjanefer, Tf.32,35-37.

19 pBM 9953B, ed. Shorter, Catalogue, 3, 66-67.

12 Dass der Text uber eine allgemeine Rolle spricht und nicht uber eine aktuelle Anbetung, geht aus der verbform jw.f sdim.f hervor, die er verwendet. Zu ihrer Funktion als "Generalis" s. Schenkel, in: GM 40 $(1980) \quad 85-87$. 
tionen des ägyptischen Sakralkönigtums gehörte und von diesem dann wiederum an die lokalen priesterschaften des Sonnengottes delegiert wurde. Der Abschnitt, der vom Wissen des Sonnenpriesters handelt, bildet das Mittelstück und mit 20 Versen den längsten Abschnitt des dreiteiligen Textes. 13 In der Form einer Liste, in der das Wort rh "wissen" achtmal vorkommt, zählt der Text die Gegenstände dieses Wissens auf, die sich in seiner Darstellung folgendermassen gliedert:

1 Die Adoranten-Gemeinschaften der personalen "Eigensphäre" des Sonnengottes 14

1.1 Die "östlichen Ba's"

1.1.1 Worte und Handlungen der ö.B.

1.1.1.1 Die "Jubelmusik zum Sonnenaufgang"

1.1.1.2 Die offnung der Himmelstore

1.1.2 Das Wesen der ö.B.

1.1.2.1 Ihr bz (wahre Gestalt?) und ihre hprw (Erscheinungsform als paviane)

1.1.2.2 Ihre "Heimat" und ihre "Standorte" beim Sonnenlauf

1.2 Die "Schiffsmannschaften" der Sonnenfahrt: ihre worte

2 Die "arcana" des Sonnenlaufs

2. 1 Die morgendliche Entstehung des Sonnengottes

2.1 .1 als "Geburt"

2.1 .2 als "Spontan-Genese"

2.2 Das "geheime" Himmelstor

2.3 Die Sonnenboote

2.3.1 Die Bemannung der Tagesbarke

2.3.2 Die Nachtsonne als "Grosses Bild" in der Nachtbarke

2.4 Die "Landeplätze" und hpwt des Sonnengottes

Die aufgezählten Wissensgegenstände beziehen sich fast ausschliesslich auf die Morgenphase des Sonnenlaufs. Das hat seinen Grund darin, dass dieser Text nur einen Teil des gesamten kulttheologischen Traktats darstellt. Ihm korrespondierte ein zweiter Teil, der sich in genau entsprechender Weise auf die Abendphase des Sonnenlaufs und die Bedingungen der abendli-

13 Nach der Gliederung von G. Fecht. Zur inhaltlichen Interpretation des Textaufbaus s. Konig als Sonnenpriester $69 \mathrm{f}$.

14 Zum Begriff der "Sphäre des Seinigen" S. LL, 342-352. Zum Begriff der "Adorantengemeinde" ibd., $344 \mathrm{f}$. 
chen Anbetung des Sonnengottes bezog. Leider ist dieser Teil so schlecht überliefert und in den drei varr. so lückenhaft erhalten, dass sich bisher kein einheitlicher sinnzusammenhang erschliessen liess. 15 Er hatte vermutlich den gleichen Umfang, sodass sich der gesamte kulttheologische Traktat als eine Komposition von fast 90 versen darstellt, und sich auf die gesamten mit dem Sonnenlauf verbundenen wissensgegenstände bezog.

Eine besondere Rolle spielen bei diesen Wissensgegenständen die Worte, die von den Mitgliedern der göttlichen "Eigensphäre" des Sonnengottes ${ }^{16}$ bei verschiedenen Anlässen des Sonnenlaufs gesprochen werden. Das hat seinen Grund darin, dass sich der im Tempel vollzogene Kult als Abbild von Vorgängen versteht, die sich in der Götterwelt vollziehen ${ }^{17}$, im besonderen aber die dabei gesprochenen worte als in Götterrolle gesprochene Götterrede ${ }^{18}$ bzw. als die irdische wiederholung von worten verstanden werden, die in der Götterwelt gesprochen werden. Es gehört zu den eigentümlichsten Kennzeichen der ägyptischen Auffassung vom Kult, dass er als Kommunikation unter Göttern, nicht von Mensch und Gott, zelebriert wird. 19 So stimmt nach ihrem eigenen Verständnis die auf Erden vollzogene Anbetung des Sonnengottes nur ein in einen Lobgesang, der dem Gott in seiner eigenen Sphäre entgegengebracht wird, und legitimiert sich als zitat göttlicher Rede:

15 Varianten:

1.) Fragmente in Der el Bahri (unveröffentlicht, Hinweis J. Karkowski)

2.) Luxor, ed. H. Brunner, Die südlichen Räume, Tf.41

3.) Karnak, Gebäude des Taharqa, ed. J.C. Goyon, in: Parker et al., The Edifice, Tf.20, S. 42 .

Der Luxortext ist am besten erhalten, aber wiederum durch wiedergabe der Vorlage in Gegensinn ihrer Zeilengliederung verunklärt.

$16 \mathrm{zu}$ den "Konstellationen" des Sonnenlaufs s. Kap. 2.

$17 \mathrm{Vgl.} \mathrm{hierzu} \mathrm{F.} \mathrm{Junge,} \mathrm{"Wirklichkeit} \mathrm{und} \mathrm{Abbild",} \mathrm{in:} \mathrm{G.} \mathrm{Wiessner}$ (Hrsg.), Synkretismusforschung. Theorie und Praxis (GOF 1978), 102104. 108 .

18 S. hierzu GM 25(1977) 15ff. Vgl. den Text der Nedjemet, zit. auf S.52.

19 ÄHG $11 \mathrm{f} ., 85 ;$ GM 25, a.a.o. Vgl. speziell zur Sonnenhymnik LL 73, 174, $344 \mathrm{f}$. 
Sei gegrusst mit dem, was dir dein Auge sagt,

das dir den 'Weg der Ewigkeit' bahnt ${ }^{20}$ !

Sei gegrusst mit dem, was dir deine Sonnenscheibe sagt,

wenn sie $z$ u dir aufsteigen lăsst die, die in schrecken vor dir

sind!

Sei gegrusst mit dem, was die Msktt - Barke zu dir sagt,

wenn sie dahinfahrt | in gunstigem Segelwind|21!

Sei gegrusst mit dem, was ihre Gefahrtin, die $\mathbf{M}^{\mathbf{C}}$ ndt - Barke zu dir

wenn ihre Schwester anhalt! ${ }^{22}$

sagt,

Sei gegrusst mit dem, was dein Stab zu dir sagt,

wenn er sich ganz deiner Faust gesellt hat!

Sei gegrusst mit dem, was deine Mannschaft (zu dir) sagt,

wenn der Falke ihre Bilder hervorgebracht hat! 23

Sei gegrusst mit dem, was die Lichtlandbewohner zu dir sagen,

die wăchter der ufer des Himmels!

Sei gegrusst mit dem spruch der Treidler,

die das Ende des Zugseils ergreifen!

Sei gegrusst mit dem, was die unterweltsbewohner zu dir sagen,

wenn sie deine beiden Barken auf ihren vier wegen geleiten! 24

Dieser Hymnus zum Sonnenuntergang, der aus demselben Textzyklus wie der Traktat stammt, denn er kommt in Medinet Habu und im Gebäude des Taharqa mit ihm zusammen vor ${ }^{25}$, stimmt in die Rede ein, die dem Sonnengott von der "Sphäre der Seinigen" entgegengebracht wird und gibt dadurch eine sehr detaillierte und aufschlussreiche Beschreibung dieser spezifisch abendlichen Eigensphäre:

20 So nach Nedjemet, die aber sonst gegenuber MH den schlechteren Text hat. J.C. Goyon, Edifice, 44 ubersetzt nach MH "when thou darkenest the way of etexnity". Vgl. jedoch Totb $15 \mathrm{~A}$ IV $=$ AHG Nr.43,20.

21 Ergănzungsvorschlag von Goyon.

22 So nach $\mathrm{MH}$, vgl. Goyon $44 \mathrm{n} \cdot 39$

$23 \mathrm{~ms}$ bjk hmw.sn; Goyons Ubersetzung "Whose hawk makes the image" lässt sich mit dem Wortlaut schwer in Einklang bringen.

$24 \mathrm{MH}$ VI $422 \mathrm{~A}, 36 \mathrm{ff}$. Zu den vier Wegen s. Goyon, $44 \mathrm{n} .44$.

25 D.h. im Rahmen desselben Dekorationsprogramms, nicht jedoch in unmittelbarem kontext, denn der "Traktat", jedenfalls der uns verständiche Teil, bezieht sich ja auf die morgendliche, dieser Hymnus aber auf die abendliche Anbetung des Sonnengottes. 
1. Die innerste Konstellation: "dein Auge" 26

2. Die beiden Barken

3. Die Barken-Insassen: Konstellationen des Beistandes: "dein Stab" und "deine Mannschaft"

4. Die weiteste Konstellation: die Zeugen der Sonnenfahrt:

Lichtlandbewohner, Schakale (die als "westliche Ba's" den Pavianen als "östliche Ba's" entsprechen) und Unterwel tbewohner.

Der Hymnus setzt also das Wissen voraus und in die Tat um, das der zugehörige Traktat bestätigt: das Kennen der Worte, die dem Sonnengott von seiten seiner Eigensphäre gesagt werden. Das wissen, das der Traktat dem König von den "östlichen Ba's" zuschreibt, erstreckt sich aber nicht nur auf ihre worte, sondern auch auf ihre Lebensumstände, wobei auf dieselben Informationen angespielt wird, wie sie ein kryptographisch geschriebener Abschnitt des Buches vom Tage vermittelt. 27

Die "östlichen Ba's", die in dem Traktat zur morgendlichen Sonnenanbetung eine so dominierende Rolle spielen, sind die bekannten "Sonnenaffen". Sie sind deshalb so wichtig, weil sie die götterweltliche Adorantengemeinde des Sonnengottes darstellen, in die sich der Sonnenpriester mit seinem Hymnus reiht. Indem er die sonne anbetet, wird er zu einem von ihnen:

"Ich habe der Sonne Hymnen gesungen,

ich habe mich den Sonnenaffen zugesellt und bin einer von ihnen." 28

In Der el-Bahri, Luxor, Medinet Habu und Karnak (Taharqa) wird der Traktat auch von einer Darstellung der Paviane be-

26 Die Konstellation des Gottes mit dem Auge, das ihn "umgibt" und der Scheibe, "in der" er sich befindet, kennzeichnet den Sonnenuntergang, s. LL 39f., 49-52.

27 S. hierzu konig als Sonnenpriester, $50 \mathrm{ff}$.

$28 \mathrm{~Tb}$ 100. Zu einer eindrucksvollen bildlichen Gestaltung dieser vorstellung $s$. H. de Meulenaere, in: JEOL 20 (1968) 3 mit Tf.I: hier ist, auf einem Pyramidion der 26. Dyn. in Glasgow, der Beter mit einem gleichfalls anbetenden pavian auf der schulter dargestellt. 
gleitet. $29 \mathrm{Zu}$ dieser Darstellung gehört ein kosmographischer Text, der mit dem Traktat eng verbunden ist und auf dem Sarkophag des Aspelta mit ihm zusammen überliefert wird:

Die Paviane, die Re verkunden,

wenn dieser grosse Gott geboren wird

zur sechsten Stunde in der Unterwelt.

Sie erscheinen fur ihn erst ${ }^{30}$ nachdem sie ihre Gestalt angenommen haben ${ }^{31}$,

indem sie zu beiden Seiten dieses Gottes sind, und ihm erscheinen ${ }^{32}$ bis er sich im Himmel niederlasst, 33

indem sie fur inn tanzen und fur inn springen,

fur inn singen, fur inn musizieren und fur ihn "Freudenlärm" veranstalten,

Wenn dieser grosse Gott erscheint in den Augen der "Untertanen" und des "Himmelsvolkes" 34 ,

dann horen diese die Jubelworte von wetjenet ${ }^{35}$.

Sie sind es, die Re verkunden

im Himmel und auf Erden. 36

Dies ist das mythische, d.h. götterweltliche vor- und Urbild der irdisch-kultischen Sonnenanbetung. Nur wer die Paviane kennt, kann sich als Sonnenanbeter zu ihnen gesellen und einer von ihnen werden.

29 Der el Bahri, s. J. Karkowski, in: Etudes et Travaux, IX, 70f. fig.3.

30 Emphatische Form: "dass sie fur ihn erscheinen, ist ...".

31 So nach Taharqa und Aspelta; auch die Spuren in Der el Bahri lassen auf das Suffix.sn schliessen; MH: .f. hpr ist uberall geschrieben als hiesse es hprw "Verwandlungen"; gemeint ist die von den "Ostlichen Ba's" bei Sonnenaufgang angenommene Gestalt, die zu dem gehort, was der Sonnenpriester von ihnen weiss (Traktat, Vers 18).

32 So nach Karkowskis Rekonstruktion des Der el Bahri-Textes. Taharqa und Aspelta lassen das redundante $\mathbf{h}^{\mathbf{C}} \mathbf{j} . \mathbf{s n} \mathbf{n} . \mathbf{f}$ fort.

$33 \mathrm{zu}$ htp mit Bezug auf den Sonnenaufgang s. Konig als Sonnenpriester, 28.

$34 \mathrm{Vgl}$. Livre du jour, BE 13, 5: $\mathbf{h}^{\mathrm{C}} \mathrm{jt}$. $\mathrm{f} \mathrm{m}$ jrtj hnmmt "sein Erscheinen in den Augen der Menschheit", ahnlich Amduat I 196.6-7. Weitere Stellen s. LL, 41 .

35 Zu diesem "Punt-artigen" Land s. die Belegsammlung LL 209,96.

36 LL, 208f.; Konig als Sonnenpriester, 28f.; Karkowski, a.a.0., 70-72; J.C. Goyon, Edifice, 46f., Tf.38 (Parallel-Versionen von Medinet Habu, Taharqa, Aspelta). 
Der zweite Teil der königlich-priesterlichen Wissensgegenstände, wie sie in dem Traktat aufgezählt werden, betrifft den Sonnenlauf selbst, dem die "östlichen Ba's" und mit ihnen der Sonnenpriester beiwohnen: das "Geborenwerden" und "Entstehen" des Sonnengottes, wie es die ersten 10 verse des Traktats eingehend beschreiben, das "geheime Tor" und die "Landeplätze", zwischen denen, und die beiden Barken, in denen die Himmelsfahrt sich vollzieht. 37 Der stil dieser listenartigen Aufzählung ist andeutend, nicht ausbreitend: das wissen, um das es hier geht, wird konstatiert, aber nicht vermittelt. Diese Unterscheidung lässt sich am besten verdeutlichen anhand eines Vergleichs der ersten 10 Verse, die den Sonnenaufgang beschreiben, und des Verspaares 24-25, das die Kenntnis dieser Vorgänge konstatiert. Die ersten 10 Verse reden die sprache der "Kosmographie" und finden sich fast wörtlich in Unterweltsbüchern wieder, die sich auf den Sonnenaufgang beziehen. ${ }^{38}$ In den Unterweltsbüchern der königsgräber des NR haben wir einen Teil jener Texte vor uns, in denen der mit dem Sonnenkult - und zwar seiner "Innenseite" - verbundene Wissensvorrat überliefert wurde. Das geht aus dem Titel des Amduat in aller Deutlichkeit hervor, der sich in der gleichen katalogartigen Aufzählung von Wissensgegenständen wie der kulttheologische Traktat auf einen anderen Ausschnitt desselben Wissensvorrats bezieht, den auch der Traktat im Blick hat:

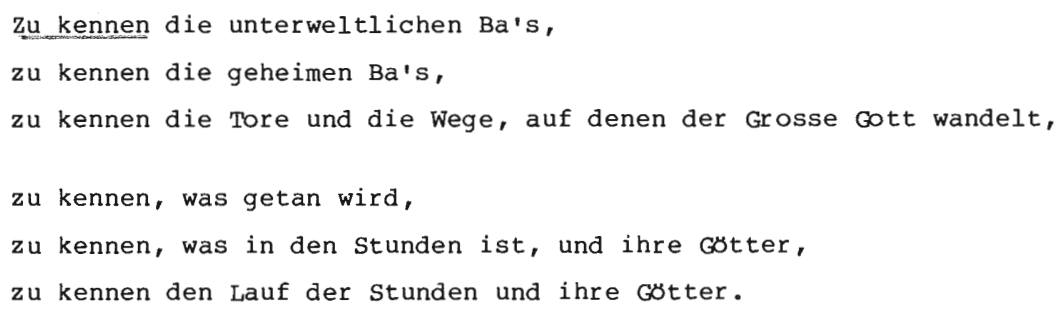

37 S. dazu Konig als Sonnenpriester, 53-55. J.C. Goyon ubersetzt hpwt nicht mit "Steuergerate", sondern als "runnings", was vielleicht besser ist. Zu hpt als Bezeichnung des Sonnenlaufs s. LL $218 \mathrm{n} \cdot 143$.

$38 \mathrm{Vgl}$. die ubersicht König als Sonnenpriester, 47. 
Zu kennen ihre verklärungen fur Re,

zu kennen, was er ihnen zuruft,

zu kennen die Gedeihenden und die Vernichteten. ${ }^{39}$

Dieser Katalog ordnet seine Wissensgegenstände nach denselben Kategorien wie der Traktat:

1. Die göttlichen Wesen der Eigensphäre des Sonnengottes, ihr Wesen, ihre Handlungen und Reden

2. Die Stationen des Sonnenlaufs ("Tor", "Wege")

Der kulttheologische Traktat legt fest, welches Wissen der morgendiche Sonnenkult zur Voraussetzung hat. Das Amduat. dient der Zusammenfassung und Vermittlung des entsprechenden Wissens, soweit es sich auf die Nachtphase des Sonnenlaufs bezieht. Wenn man bislang diese Unterweltsbücher für nichts anderes als königliche Totentexte, sozusagen die pyramidentexte des Neuen Reiches hielt, dann ist durch die Auffindung des Traktats der Sonnenkult bzw. die "Mysterien" des Sonnenlaufs als ihr eigentlicher und ursprünglicher "Sitz im Leben" erwiesen. Wir mussen also auch hier unterscheiden zwischen Aufzeichnungsform und (ursprünglicher) verwendungssituation ${ }^{40}$. Der könig nimmt sich diese Texte mit ins Grab (das er als Abbild des nächtlich-unterweltlichen Sonnenweges anlegt) ${ }^{41}$, um sich mit dem Sonnengott zu vereinen als "einer, der die Einweihung $(\mathbf{b z w})$ in die Mysterien der Unterwelt kennt, eingedrungen in die Heiligkeit der Mysterien". 42

Nun wird man nicht soweit gehen, anzunehmen, dass das Amduat bzw. seine heliopolitanische Vorlage im kult aufgeführt wurde; es gehört nicht zu dem, was gesagt und/oder getan, sondern - der Titel macht das ganz deutlich - was gewusst wird. Die Form, in der das für den Sonnenkult notwendige wissen festgehalten und überliefert wird, ist die Kosmographie. Uber

39 Ubersetzung nach Hornung, Unterweltsbucher, 59.

40 Diese Unterscheidung habe ich in Gs Otto, 59-65 anhand der Harfnerlieder eingefuhrt.

41 S. hierzu E. Hornung, Das Grab des Haremhab im Tal der Konige, 1971; Unterweltsblucher, $17 \mathrm{ff}$.

42 Sonnenlitanei, S. LL, 30. Dort weitere Belege fur ahniliche Wendungen. 
die Beziehung von Kosmographie (=dem, was gewusst wird) und Liturgie (= dem, was gesagt und getan wird) im sonnenkult sind wir ebenfalls erst neuerdings besser unterrichtet: seit der Auffindung des "Stundenrituals". 43 Die 12 Hymnen zu den 12 Tagesstunden bilden den "liturgischen" Teil dieses Rituals, dessen "kosmographischer", als "das Buch vom Tage" bekannter Teil die stationen des Sonnenlaufs und die Vorgänge in den Tagesstunden beschreibt. Bezeichnenderweise ist auch von diesem Ritual nur der kosmographische Teil in das Dekorationsprogramm der königsgräber übernommen worden. Dem König wird nur der "Wissensvorrat" des Sonnenkults ins Grab mitgegeben, während der Kult selbst im sonnenheiligtum seines Totentempels vollzogen wird. Daher gehört der kosmographische Teil der Sonnenmysterien ins Grab, der liturgische Teil in den Tempel.

Die 12 Hymnen des Stundenrituals ${ }^{44}$ vermitteln einen höchst anschaulichen Eindruck von dem, was man sich unter einem "geheimen" (esoterischen, exklusiven) Sonnenhymnus vorzustellen hat, im Gegensatz zu den "landläufigen" Kultliedern, wie sie die standardtexte repräsentieren. So äussert sich ein besonderes Wissen etwa in den häufigen Bezugnahmen auf Wesen der Umgebung des Sonnengottes, auf deren Kenntnis es ja der Kosmographie so ankommt:

\section{Anruf \\ 17 Uräen \\ 2}

3

44 Feuerschlangen

Vorhut und Gefolge 8
Erwähnung

Umringlerschlange, Auge, Uräen, Kronen

Bewohner der äussersten weltgegenden

Chonsu; Götter um die Kajüte

43 LL, 113-163; ÄHG Nr.1-12. Eine Edition aller derzeit bekannten Versionen ist durch $\mathrm{E}$. Graefe in Vorbereitung.

44 Die Rezitationen zu den Nachtstunden sind Ausschnitte aus Totenbuch-Kapiteln. 
Anruf

9

10 Uräusschl ange

11 Vorhut und Gefolge

12 Westliche Götter
Erwähnung

Türkisgötter; Bewohner der Westwüste

Götter des westens, Treidler

Charakteristisch erscheint ferner, dass eine Reihe von Hymnen (es sind die um die Mittagsstunde gruppierten) nicht mit einer Anrede, sondern mit den worten "Re erscheint..." in der Form einer "Vorgangsverkündigung" 45 anfangen:

5 "Re erscheint, das Gold der Götter"

6 "Re erscheint, er hat seinen Thron eingenommen"

7A "Re erscheint, die Macht des Himmels"

8 "Re erscheint, der stier der Maat"

Wir werden solche Merkmale bei anderen Hymnen wiederfinden, deren Herkunft aus dem gleichen kultischen Bereich, den heliopolitanischen "Mysterien", naheliegt.

Das Rezeptionsschicksal des Stundenrituals entspricht ziemlich genau dem des kulttheologischen Traktats: 46

1. Totentempel der 18.Dyn.: Hatschepsut, Thutmosis III.

2. (nur kosmographischer Teil): Königsgräber (Ramses VI).

3. Eine $\mathrm{KF}$ des liturgischen Teils (nur 1. und 12. Tagesstunde) in einem ramessidischen Beamtengrab: TT 183.

4. Zahlreiche Bezeugungen in Saitengräbern:

a) In-extenso-Fassung des liturg. Teils:

TT 27, 34, 37, 196, 279; Saqqara: Bakenrenef.

b) KF des liturg. Teils: TT 128; nur 1. und 12. Tagesstunde: Amenirdis.

c) Einzelne Hymnen: TT 27 (Nr.2), TT 33 (Nr.2 und 5), TT 34 ( Nr.7), TT $36(\mathrm{Nr} .1)$.

d) Eine KF des kosmographischen Teils: TT 132.47

TT 183 stellt also eine Ausnahme dar, genau wie TT 158 für den kulttheologischen Traktat. Auch bei TT 183 erklärt sich

$45 \mathrm{Vgl}$. LL, 122, Zusammenfassung und $261 \mathrm{f}$.

46 Fur genauere bibliographische Angaben S. LL, 15-17.

47 Piankoff, ASAE 41 (1942) 151ff., Hinweis von E. Graefe. 
die Kenntnis des geheimen Texts aus der beruflichen stellung des Grabherrn: Nebsumenu war jt-ntrr -Priester des Re-Atum im Lebenshaus. Der Kult im "Lebenshaus" diente bekanntlich der Kontinuität der Zeit und des Lebens ${ }^{48}$ und dem Schutz des Königs: das stundenritual, das in zahlreichen Fürbitten auf den Schutz des königs bezug nimmt ${ }^{49}$, kann sehr gut zu den dort durchgeführten Liturgien gehört haben. Das Grab des Nebsumenu enthält noch eine fragmentarische Var. des Spruchs zum Maatopfer, der ebenfalls aus dem inneren Bereich des Kults stammt. 50 Besonders aufschlussreich für die Quellen, aus denen dieser Grabherr seine Sonnenhymnen geschöpft hat, ist aber der Text, der zusammen mit dem Hymnus zur 1. Tagesstunde auf der südichen Eingangswandung steht (Nr.173). Hier ist nämlich ganz explizit von einem besonderen wissen um die Geheimnisse des Sonnenlaufs die Rede:

"Ich kenne die hprw des Re,

wenn er aufgeht...

Ich kenne die Fahrt |der Barke des| Chepre"

Im weiteren Verlauf des leider sehr zerstörten Textes, der übrigens wie die "Mittagshymnen" des stundenrituals mit einer Vorgangsverkündigung beginnt ("Re erglänzt im Osten des Himmels" - allerdings ist nicht ganz sicher, ob diese worte den Textanfang darstellen), ist dann sogar von dem höchsten arcanum die Rede, von dem die Mysterien des Sonnenlaufs wissen: von der nächtlichen Vereinigung von Re und Osiris. 51 Die hprw des Re zu kennen gehört ebenfalls zur (allerdings erst spät bezeugten) Thematik der kosmographischen Literatur. ${ }^{52}$

Darüberhinaus findet sich die erste Strophe des Hymnus zur ersten Tagesstunde auf einem Stelophor in Brooklyn, der aus der frühen 18. Dyn. und aus Theben stammt, während der Hym-

48 Vgl. Ph. Derchain, Le Pap.Salt 825 (B.M.10051), rituel pour la conservation de la vie en Egypte (1965), I, 13ff.i Ders., "le rôle du roi d'Egypte dans le maintien de l'ordre cosmique" (Le pouvoir et le sacré, 1962), 61-73. Vgl. auch Zeit und Ewigkeit, 28-30.

$495,18-19 ; 6,25-26 ; \quad 7 A, 18-19 ; 8,16-18 ; 9,15-19 ; \quad 10,15-21 ; 11,19-20$; $12,28-29$.

50 Text 175b, vgl. Text 62 und weitere Lit. z. St.

51 LL 101-105, s. a. Kap.2.

52 LL 43 n. 17; $160 f$. 
nus zur 12. Tagesstunde in einer erweiterten Fassung in einigen Totenbluchern der 18. Dyn. und später vorkommt und in einer auf dieser Fassung beruhenden KF sogar als Kap.15h in die kanonisierte spätzeit-Rezension aufgenommen wurde. ${ }^{53}$ Wir dürfen uns also die Abgeschirmtheit der geheimen Kultliteratur nicht $z u$ undurchlässig vorstellen. Aber auch das Totenbuch ist ja eine Geheimliteratur und als Grabbeigabe unzugänglich. Ausserdem wird gerade diesem Text im Unterschied zu allen anderen Sonnenhymnen des Totenbuchs ein Titel-Rubrum beigefügt, das ihn als "die Geheimnisse der Unterwelt, eine Einweihung in die Mysterien des Totenreichs" ausgibt. 54

Wenn sich die Herkunft einer Grabinschrift aus dem geheimen Wissensvorrat des Sonnenkults hat nachweisen lassen, dann liegt es nahe, dass der betreffende Grabherr auch andere Texte aus dieser Quelle geschöpft hat. So findet sich im Grab des Tjanefer z.B. sowohl der kulttheologische Traktat in einer $\mathrm{KF}$, als auch ein Auszug aus dem Pfortenbuch, und im Grab des Nebsumenu weisen wie oben dargelegt auch die anderen Sonnentexte die Merkmale des Kultischen und des Geheimen auf. Daher ist es methodisch geboten, sich die Gräber der Saitenzeit genau anzusehen, in denen das stundenritual und/oder der kulttheologische Traktat vorkommen. Hier bietet sich vor allem das Grab des Obersten Vorlesepriesters petamenophis an, der auf der ostwand der ersten pfeilerhalle zusammen mit dem Traktat eine ganze Sammlung von Sonnenhymnen anbringen liess:

Text Nr. Lokalisation Identifikation

$\begin{array}{lll}31 & \text { Eingang, links } & \text { Tb } 15 \mathrm{a}+\mathrm{b} \\ 32 & \text { Einhang, links } & \text { Tb }[\mathrm{c}]-\mathrm{e} \\ 33 & \begin{array}{l}\text { Eingang, innerer } \\ \text { Pfosten, links }\end{array} & \text { Stunderritual, 2.Std. } \\ 34 & \begin{array}{l}\text { Ostwand Nordteil } \\ \text { Z.1-16 }\end{array} & \frac{\text { Kulthymus, belegt in Medinet }}{\text { Habu }}\end{array}$

53 LL 21-23.

54 LL 19f., 28-36, spez. 29-31, 70-76. 


\begin{tabular}{|c|c|c|}
\hline Text Nr. & Lokalisation & Identifikation \\
\hline 35 & ibd., 17-18(?) & Stundenritual, 1.std. \\
\hline 36 & ibd., 19(?)ff. & Kulthymnus $=$ Text Nr.83 \\
\hline 37 & $\begin{array}{l}\text { Ostwand sudteil } \\
2.1-9\end{array}$ & Kult theologischer Traktat \\
\hline 38 & ibd., $10-17$ & $\begin{array}{l}\text { Hymnus im stil des Stunden- } \\
\text { rituals }\end{array}$ \\
\hline 39 & ibd., $18-21$ & Stundenritual, 5.Std. \\
\hline 40 & ibd., $22-25$ & Kulthymnus $=" \mathrm{~Tb} 15 \mathrm{~A} 4 "$ \\
\hline
\end{tabular}

Die "landläufigen" Sonnenhymnen des Tb 15 stehen aussen auf der Eingangswandung, die "geheimen" Kulthymnen innen. Fur vier von den 8 hier angebrachten Texten ist diese Herkunft bereits bekannt: die drei Hymnen aus dem Stundenritual und den Traktat. Für die restlichen vier wollen wir die wahrscheinlichkeit dieser Herkunft prüfen. Nr.34 ist inschriftlich im Sonnenheiligtum von Medinet Habu bezeugt, ausserdem im Totenbuch der Königin Nedjemet, dessen Hymnen sämtlich liturgischer Herkunft sind. ${ }^{55}$ Es gibt kaum einen anderen Sonnenhymnus, in dem die Proklamation eines spezifischen Wissens derart im Vordergrund steht wie in diesem. Text, in dem es um die Kenntnis der $7 \mathrm{Ba}$ 's und $14 \mathrm{Ka}$ 's des Sonnengottes geht. Ebenso spezifisch sind die Vorstellungen, die der Text auf dem Gebiet des Handelns an den Tag legt und die uns im dritten Teil dieses Kapitels noch beschäftigen werden. Nr.36 ist ein offenbar spätramessidischer Kulthymnus, dessen liturgische Herkunft nur luberlieferungsgeschichtlich nahegelegt ist. Da man nicht annehmen kann, dass Petamenophis den Text im Grab des Imiseba (Nr.65, Zeit Ramses IX) kopiert hat, muss man eine gemeinsame, beiden zugängliche Quelle postulieren, fur die eine Hs. des thebanischen Sonnenkults das Nächstliegende ist. Nr. 38 ist ein Hymnus, der alle Merkmale des stundenrituals aufweist:

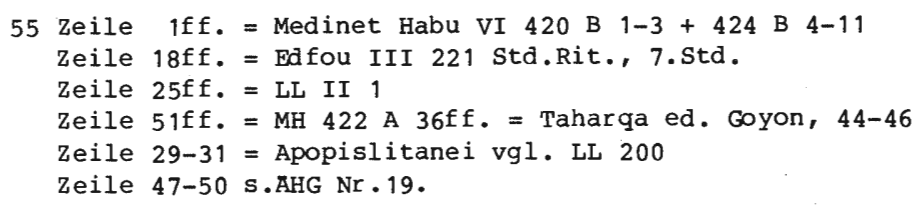


Vers

$\begin{array}{rl}5 & \mathrm{nb} \mathrm{h} \\ 6 & j \mathrm{c} w \\ 19 & \mathrm{mhn}(\mathrm{t}) . \mathrm{f}\end{array}$

19 Uräen

1.2 Auge vgl. Stundenritual

4,$6 ; 7 \mathrm{~A}, 3 ; 8,2 ; 9,4$.

2,$1 ; 3,3$.

$1,16-17 ; 2,13 ; 4,6.10-12.16 ; 5,3 ; 10,3-6$. $15 ; 12,4$.

2,$14 ; \quad 3,12 ; \quad 4,13 ; 5,8 ; 6,2 \cdot 17.19 ; 7 \mathrm{~A}, 15$; $7 \mathrm{~B}, 11 ; 12,5-9$.

Bezugnahme auf Umgebung: 16 "jene deine vier funkelnden Gesichter", vgl. die 4 Feuerschlangen in Text 4 des stundenrituals. Mit Versen 34-35:

"Er sagt dir das, was in der Nachtbarke ist,

er kundet dir, was in der Tagbarke ist."

vgl. "Traktat" (Text 37), 27-28:

"Er kennt den, der in der Tagbarke ist,

und das grosse Bild in der Nachtbarke".

Text 40 schliesslich ist eine Var. des als "Tb 15 A 4 " bekannten Textes. 56 Mit dem Totenbuch hat dieser Text allerdings nicht das geringste zu tun; er kommt nur auf spätzeit-stelen mit antithetischer Sonnenanbetung vor, wo er (rechts) als Aufgangs-Hymnus einem Abendhymnus (links: "Totb 15 B 5" ${ }^{57}$ ) gegenübersteht. Dieser Text erweist sich nicht durch Wissens-, sondern durch Handlungsbezlige als ein Kulttext, der aber wohl erst der spätzeit angehört.

Auch Grab 27, das den "Traktat" 58 und das stundenritual 59 aufweist, scheint seine Sonnenhymnen aus ähnlichen Quellen geschöpft zu haben. Auf Text $28 \mathrm{c}$ werden wir im zusammenhang der spezifisch kultischen Handlungsimplikationen einzugehen haben: Text 27 breitet über die gleichen Handlungsimplikationen hinaus auch ein spezifisches Wissen aus: er nennt die "Sieben Uräen" beim Namen, die auch im Stundenritual zur 1.Tagesstunde, wenn auch nicht namentlich, angerufen werden. Alle diese Hymnen gehören im weiteren Sinne zum Stundenritual

56 Th.G. Allen, in: JNES 8, 349-355; Barucq-Daumas, Hymnes et prières, $149 f$. Nr. 45 .

57 = Text 137 in TT 132; LL $291 \mathrm{n} .43$; AHG Nr.23.

58 Unveroffentlicht, $s$. Roccati, in OrAnt 15, $234 \mathrm{n} .4$.

59 Nach mundlicher Mitteilung von A. Roccati. 
dazu, bezeugen dieselbe Vorstellungswelt wie diese und stammen aus demselben inneren Bezirk des Sonnenkults, einem Wissensvorrat, der vor der Saitenzeit durch strenge Zugänglichkeitsbeschränkungen geschlutzt war.

\section{Handeln}

Uber das, was in den Sonnen-Mysterien gewusst werden muss, sind wir durch den kulttheologischen Traktat und das Licht, das er auf die ursprüngliche Bestimmung der königlichen Unterweltsbucher wirft, in einer sehr detaillierten weise unterrichtet; luber das, was dabei getan werden muss, sagt der Traktat nichts, denn die abschliessende strophe uber die Aufgabe des königs,

den Menschen Recht zu sprechen

die Gotter zufrieden zu stellen,

die Maat zu verwirklichen,

die Isfet zu vernichten,

den Gottern Opfer und den Verklärten Totenopfer darzubringen,

bezieht sich nicht speziell auf die Sonnen-Mysterien wie der Abschnitt luber das Wissen, sondern allgemein auf die kultische Rolle des königs. Dafur gibt es im Sonnenheiligtum von Medinet Habu eine Frieszeile, die die aktive seite der königlichen Sonnenpriesterschaft hervorhebt: 60

Es lebt der Prüsente Gott, klug ( jp ) wie Re, scharfsinnig ( $w h^{c}-j b$ ) wie der in Hermupolis, der erleuchtete Sohn ( sb3q), der aus Atum hervorging; der Beistand ( ndtj) des Harachte, der die (Sonnen-)Feinde niederwirft mit der "Strahlkraft" seines Ausspruchs der bewirkt, dass die Barke in Herzensweite dahingeleitet.

Die ersten drei Verse dieser Prädikation beziehen sich auf das Wissen, die letzten drei auf das Handeln des Königs als 
Sonnenpriester. Sie stellen dieses Handeln aber als Sprechen dar: nicht mit der kraft seines Armes, sondern mit der "Strahlkraft", der magischen Wirksamkeit seines Ausspruchs 61

wirft der König die Feinde des Sonnengottes nieder. Zwar wird man das "Dromenon" der Sonnenmysterien nicht ganz und gar im "Legomenon" aufgehen lassen: die ständige Bezugnahme auf "Feuer" und "Verbrennen" in den Hymnen des Stundenrituals und verwandten Texten ${ }^{62}$ weist deutlich genug auf begleitende Brandopfer hin und gelegentlich ist auch von einem Milchopfer die Rede $^{63}$; diese Handlungen haben aber nur begleitenden Charakter und die entscheidenden Wirkungen: die vernichtung der Feinde und die Bewirkung freier Fahrt für das Sonnenboot, werden durch das Rezitieren der Hymnen bewerkstelligt.

Wenn man von den Handlungsimplikationen der Sonnen-Mysterien ein ähnlich differenziertes Bild gewinnen will wie von ihren Wissensvoraussetzungen, dann muss man die Hymnen daraufhin betrachten, wie in ihnen die anspruchsvolle Vorstellung zum Ausdruck kommt, uber die blosse Anbetung des Sonnengottes hinaus mit ihrer Rezitation kosmische Wirkungen zu erzielen wie die Niederwerfung des Sonnenfeindes. Die Form, in der die Texte derartige Handlungsimplikationen explizit machen, ist der "Schlusstext", in dem ein sprecher am Schluss seines Hymnus, der strikt jeden Bezug auf Sprecher und Sprechsituation ausgeklammert hat ${ }^{64}$, nun in seiner kultischen Rolle hervortritt, den Gott auf sich und seine ihm dargebrachte sprachHandlung aufmerksam macht und ihn um gnädige Gegenleistungen bittet. 65 Abgesehen von dieser Bitte, die wieder einen neuen Sprechakt darstellt, ist der schlusstext das, was die (linguistische) Sprechakt-Theorie einen "metakommunikativen Hypersatz" nennt. Wie man einem versprechen den Satz voranstellt

61 Die Wiedergabe von 3hw als "Strahlkraft" auch in diesem Kontext, wo magische wirksamkeit gemeint ist, folgt einem vorschlag von $\mathrm{H}$. Brunner. Zur Wendung 3hw tpjw $r 3 \mathrm{~s}$. LL 210 und $365 \mathrm{n} .90$.

$622,13 \mathrm{f} . ; 4,4.6 \cdot 10-12$; Text 163, 20f \& 25f.; Text 27 passim.

63 Text $38,23-24$; vg1. Text $254,28-30$ ?

64 LL 360-63.368-71; AHG $85 \mathrm{f}$.

65 A. Barucq, L'expression de la louange divine, 26 und 364ff. ("présentation de soi"); LL $217 \mathrm{ff}$; fur ein besonders ausfuhrliches Beispiel s. AHG $\mathrm{Nr} \cdot 144 \mathrm{C}$, 105-158. 
"Hiermit verspreche ich dir...", so lässt man einem kultischen Sonnenhymus den Satz folgen "hiermit habe ich dir deinen Feind niedergeworfen". Genau wie ein Versprechen,ein Wunsch, ein Fluch, ein Urteil usw. wird durch einen solchen metakommunikativen Hypersatz auch der kultische Sonnenhymnus als ein "performativer" sprechakt ausgelegt, eine Form, "in Worten zu handeln"66, und die Art dieser Handlung spezifiziert. So sagt es der kürzeste aller mir bekannten Schlusstexte: 67

"... seitens des Oberhofmeisters Senenmut.

Hiermit habe ich deinen Feind niedergeworfen."

Der Hymnus, dem Senenmut diesen Satz folgen lässt, steht stilistisch den stundenritualhymnen nahe und scheint ebenfalls aus dem Bereich der "Mysterien" zu stammen. Senenmut hat ihn auch an unzugänglicher stelle aufgezeichnet.

Uberhaupt macht man, wenn man die Masse der überlieferten Sonnenhymnen auf solche Schlusstexte hin durchgeht, die Erfahrung, dass man auf dieselbe kleine Gruppe von Texten verwiesen wird, die wir schon unter dem Aspekt des "Wissens" als Hymnen der Sonnen-Mysterien erkannt haben. Der Schlusstext in Form eines "metakommunikativen Hypersatzes" ist eine ausgeprägt kultische Form, da er eine kultische Rolle und Bevollmächtigung voraussetzt. Der Situation des normalen "Toten" ist diese Konzeption ganz unangemessen, da er ja "in eigener Sache" und nicht in einer kultischen Rolle vor den Sonnengott tritt. So verweist er höchstens mit Worten auf sich wie

"Ich bin einer, der heil war auf Erden." 68

Schauen wir uns die für unsere Frage nach den Handlungsimplikationen der Kulthymnik aufschlussreichen Schlusstexte näher an:

66 J.L. Austin, How to do Things with Words (1962); LL 13,363-372; AHG 87-90.

67 Text 240 .

68 Z.B. Nr.52,65; AHG III $4=$ AHG Nr.27, 21. 


\begin{tabular}{|c|c|c|c|}
\hline Text & Verse & Inhalt & Handlungstyp \\
\hline \multirow[t]{2}{*}{$\begin{array}{l}\text { Std.Rit. } \\
1 . \text { Stunde }\end{array}$} & $13-15$ & $\begin{array}{l}\text { NN lasst die Maat aufsteigen } z u \text { Re, } \\
\text { lasst sie einsteigen in die Barke } \\
\text { des Re, sodass sie sich mit dem } \\
\text { sitz vereint }\end{array}$ & $\begin{array}{l}\text { Aufsteigenlassen } \\
\text { der Maat }\end{array}$ \\
\hline & $21-24$ & $\begin{array}{l}\text { NN offnet dir den weg des grunen } \\
\text { Reihers } \\
\text { leitet den Schutz auf dem sonnen- } \\
\text { weg }\end{array}$ & Weg-Of fnung \\
\hline 2. Stunde & $15-17$ & $\begin{array}{l}\text { NN vertreibt die Wolken auf dem } \\
\text { Sonnenweg } \\
\text { er gibt deinen Barken Hochkommen } \\
\text { und Auftrieb deinem Gefolge }\end{array}$ & Auftrieb \\
\hline 4. Stunde & $13-18$ & $\begin{array}{l}4 \text { verse: (NN huldigt Geleitgottern) } \\
\text { damit du Macht gewinnst uber deinen } \\
\text { Feind } \\
\text { sein Ba und sein Schatten vernich- } \\
\text { tet werden }\end{array}$ & $\begin{array}{l}\text { Feindesver- } \\
\text { nichtung }\end{array}$ \\
\hline 8. Stunde & $14-15$ & $\begin{array}{l}\text { NN hat dir deine Wege georfnet } \\
\text { er hat eingestimmt in den Jubel }\end{array}$ & $\begin{array}{c}\text { Weg-of fnung } \\
\vdots\end{array}$ \\
\hline 9. Stunde & $13-14$ & $\begin{array}{l}\text { NN fullt alle deine Feinde } \\
\text { er betet deine schonheit an, } \\
\text { straft deinen Feind }\end{array}$ & $\begin{array}{l}\text { Beistand } \\
\text { "Doppel-Inten- } \\
\text { tion" } 69\end{array}$ \\
\hline 10. Stunde & $13-14$ & (Anbetung und Besunftigung) & \\
\hline $\begin{array}{l}\text { 11. Stunde } \\
\text { 12. Stunde }\end{array}$ & $25 f f$ & $\begin{array}{l}\text { NN vereinigt sich mit Re in Leben } \\
\text { (Besănftigung) }\end{array}$ & Schutz? \\
\hline $\mathrm{Nr} \cdot 38$ & $19-29$ & $\begin{array}{l}\text { NN bringt dir die susse Milch } \\
\text { deiner Mutter Isis ... } \\
\text { NN hat dich geschutzt } \\
\text { er hat dir alle deine Feind ge- } \\
\text { fallt }\end{array}$ & $\begin{array}{l}\text { Milchopfer } \\
\text { Schutz } \\
\text { Beistand }\end{array}$ \\
\hline
\end{tabular}

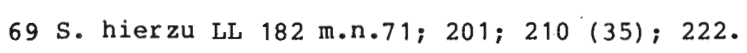




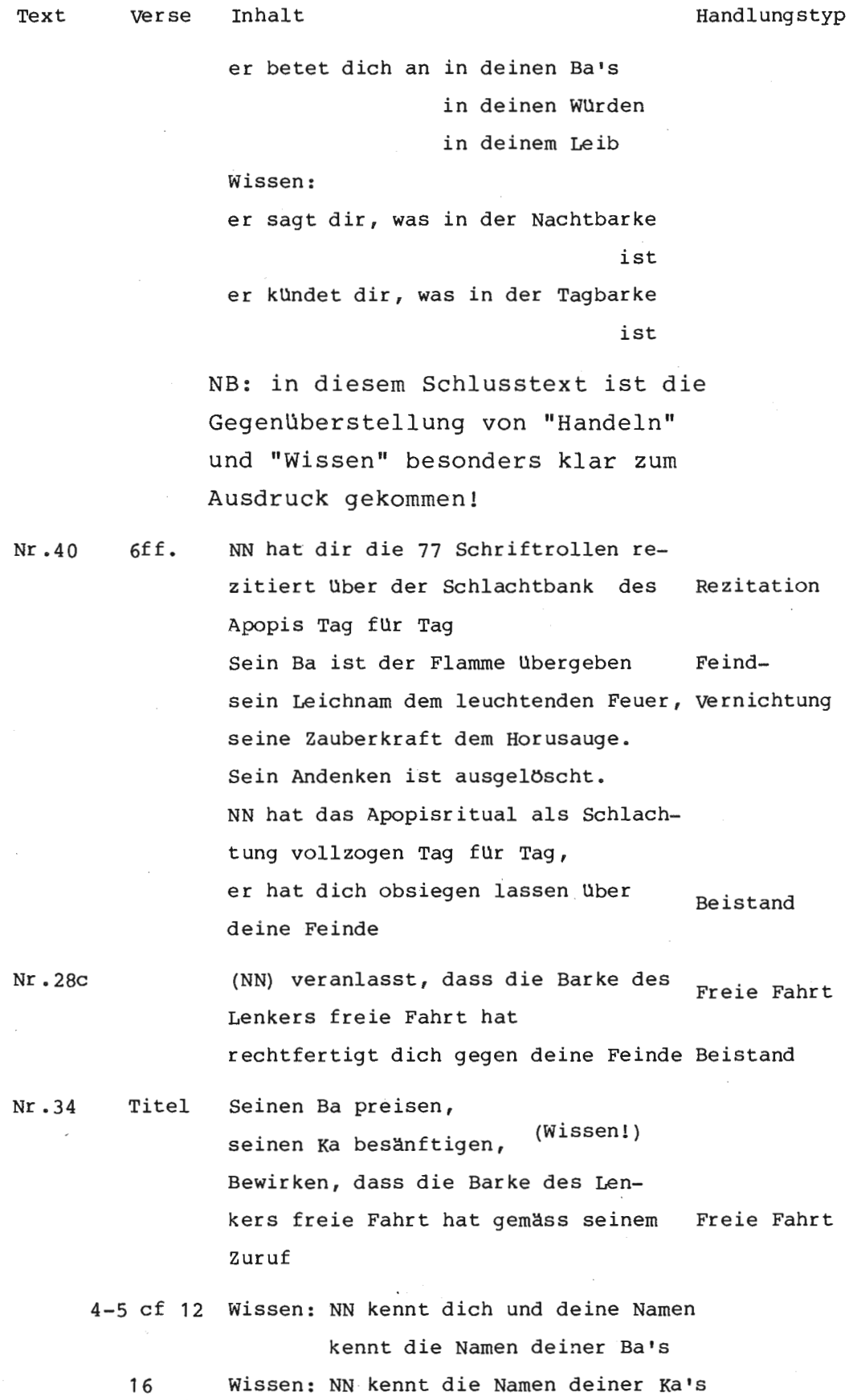


Text Verse Inhalt Handlungstyp

23-24 Wissen: NN hat dich besănfigt

mit jenen deinen schonen Namen, er hat deinen Ba besănfigt, er hat deinen ka besanftigt

41ff Kultische Gotterrollen:

er ist Isis, wenn sie deine Kronen

befestigt

er ist Huh, wenn er dich trăgt ${ }^{70}$ Auftrieb

$43 \mathrm{f}$ NN hat den "Reinen Kanal" betreten

damit er den Gott schaue im Urwasser Schau

und die Flut besănftige.

Er hat die Feinde niedergekumpft

fur $\operatorname{Re}$

Beistand

er hat seine Feinde vernichtet an

ihrer Richtstatte.

Nr.41 $13 f \mathrm{f}$ Aufsteigenlassen der "7 Ka's" durch

Maat (?) 71

Offnung der Wege in Himmel und Un-

terwelt

Weg-of fnung

Offnung von Augen und Ohren

"NN ist zu dir gekommen, um zu dir

zu sprechen: er ist es, der dich

liebt (Var.: den du liebst) unter

den Menschen"

Er hat fur dich Myrrhen gekaut am kultische

Ufer des Messersees

Reinheit

Er ist es, der die Maat dem Re sagt

Er ist es, der die Maat dem Atum

Aufsteigenlasklindet

sen der Maat

der mit ihr den Sonnengott preist

70 Anspielung auf das Bild des Sonnenkindes "auf den Armen von Huh und Hauhet", vgl. Text 233 (b) und konig als Sonnenpriester 42 n.2.

71 Nedjemet hat "deine Tochter", Montemhet "deine Mutter"; offenbar ist Maat gemeint. 


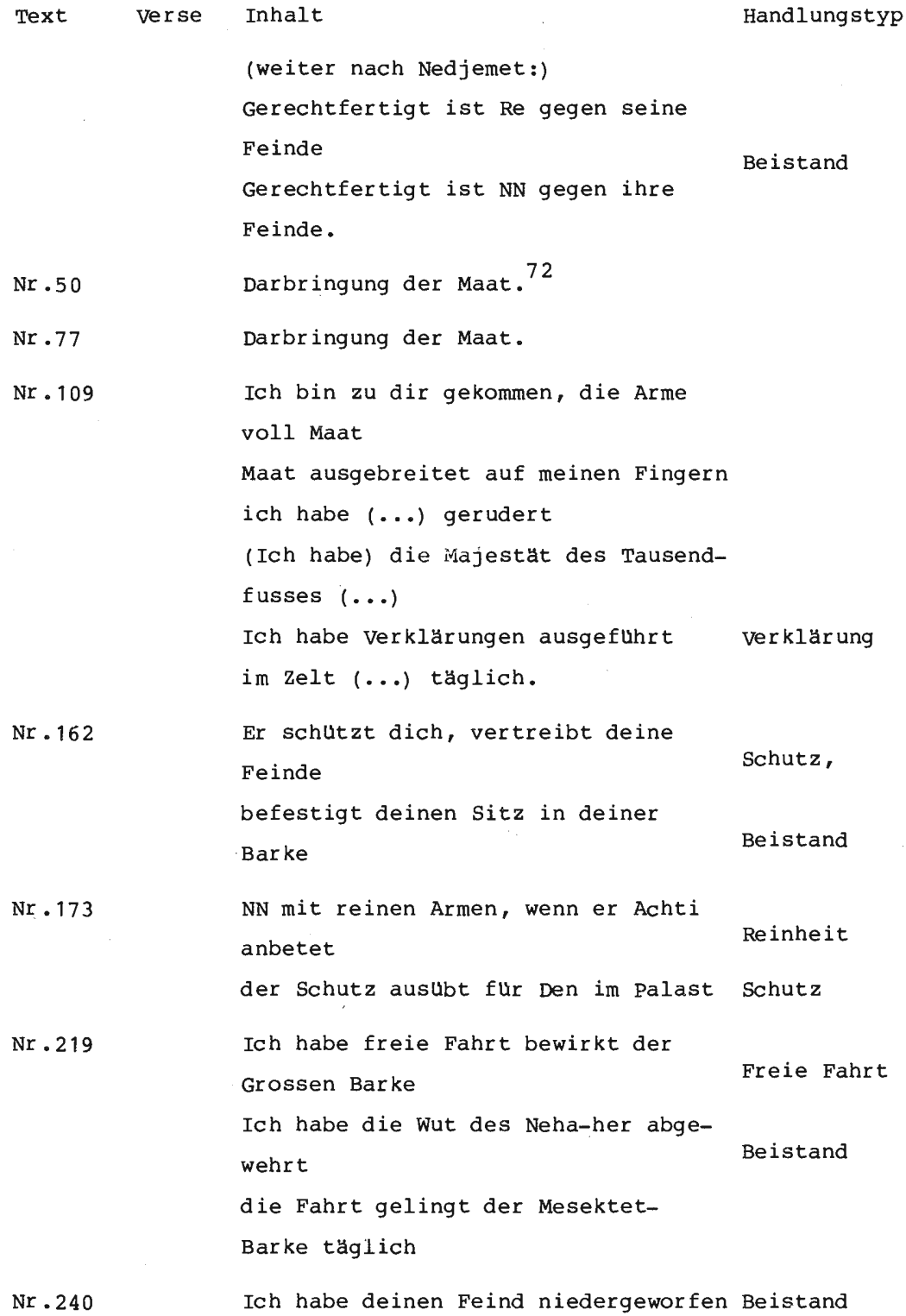
Ich habe deinen Feind niedergeworfen Beistand

72 s. hierzu die ausfuhriiche Zusammenstellung der Belege LL 154-157 vgl. auch $162 \mathrm{f}$. 


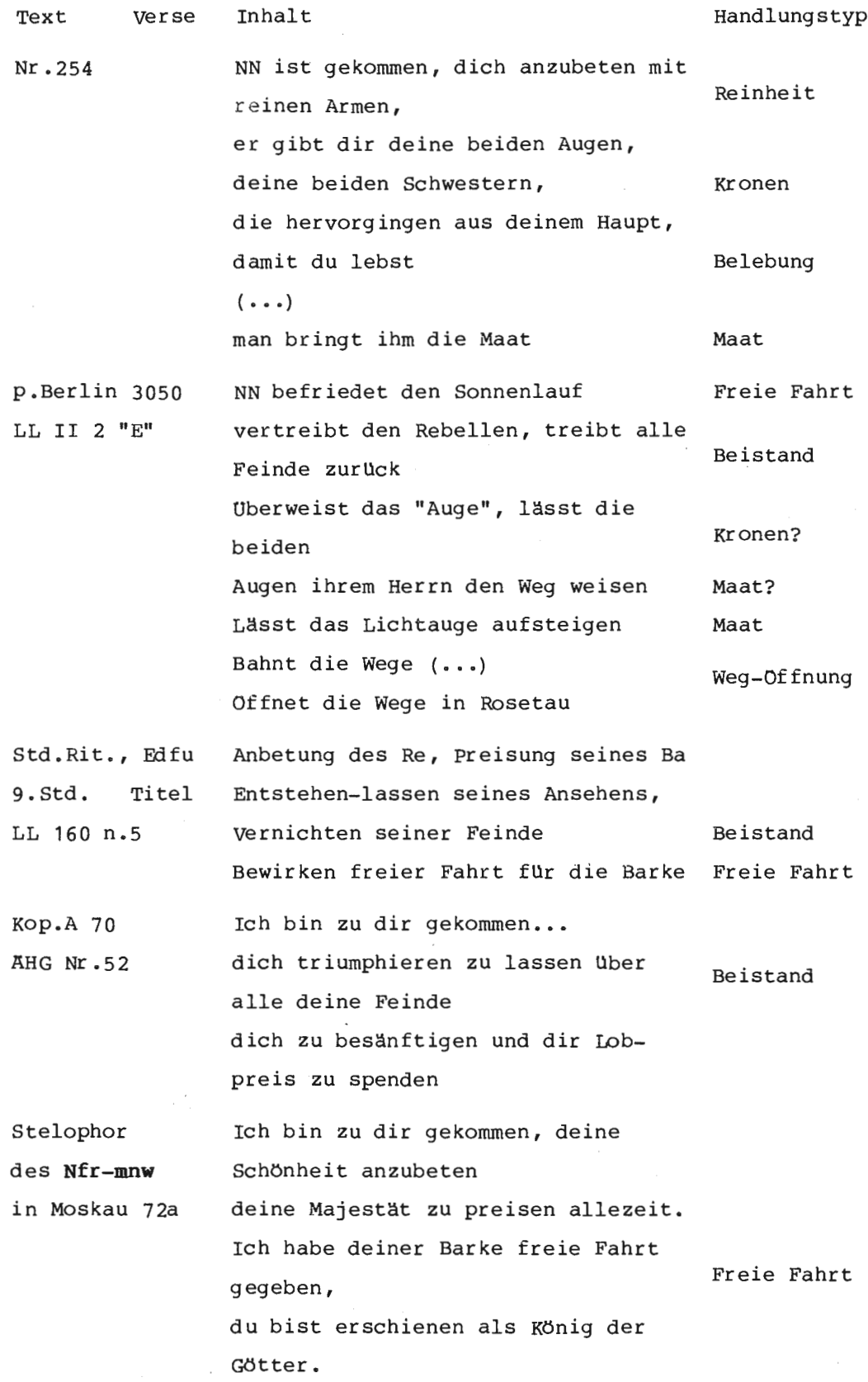


Text

Inhalt

Handlungstyp

Meine Arme tragen Maat, ich bringe

Maat

sie dar,

damit ich ihre Majestat sich mit der

Msktt - Barke vereinen lasse.

Re wahrt in glunstigem segelwind fort-

wahrend ( $\mathrm{m}-\mathrm{r} 3^{\mathrm{c}}$ ) taglich, Tag fur

Tag

Totb des

Ani

AHG Nr.30,

Urk VI, 97

Stele Ramses IV Abydos; BIFAO 45,159
Ich schlage den Esel, ich bestrafe

den Rebellen

ich habe Apopis vernichtet in seinem Angriff;

ich habe den Abdu-Fisch gesehen, als sein Fall eingetreten war, ich habe den Inet-Fisch gesehen in Schau seinen verwandlungen, als er das Boot fuhrte auf seinem Kanal. Ich habe Horus gesehen am steuerruder und Thot, die Maat auf seinen Armen. Ich habe das Vordertau ergriffen in der Nachtbarke und das Achtertau in der Tagbarke. Ich habe Apopis gehemmt in seinem Ansturm,

ich habe den Feind ausspeien Beistand

lassen, was er verschluckt hatte 73

Ich habe die Msktt - Barke in gunstigem wind vorbeigelenkt Freie Fahrt

an jener Sandbank des Zweimessersees. 74

Ich habe fur dich Apopis gefallt, Beistand ich habe bewirkt, dass deine Barke fahrt

ohne aufzulaufen auf der Sandbank des Apopis bei der grossen Fahrt.
Beistand 
Text

in diesem Tempel, wenn sie den Horizontischen in seinem Lichtland preisen: sie geben Lobpreis den (Gottern) im Himmel, Doppelum den Feind zu fallen auf seinem Intention! Wege

indem sie Chepre gunstigen wind zufuhren

indem sie seine Barke auf diesen

hnt's stellen

Auftrieb?

indem sie die Mannschaft in Jubel

versetzen

ihre Herzen begluckt mit Maat

Maat

Während das "Aufsteigenlassen der Maat" wohl eine eher allgemeine umschreibung für die dem Sonnenkult eigene Form der (vielleicht speziell morgendlichen?) Anbetung ist ${ }^{75}$, heben die Motive des Beistands (Feindvernichtung, Schutz) und der Bewirkung Freier Fahrt (Weg-Offnung, Sandbank) die spezifisch "apotropäischen" Funktionen hervor, die mit dem könig als Sonnenpriester und den Mysterien der Sonnenheiligtümer verbunden werden. Ich habe in meinen "Liturgischen Liedern" die "Doppelintention" dieses Sprechens, das zugleich "die Uräusschlange preist und auf Apopis spuckt" (Amenemope ${ }^{76}$ ), die stilistischen Eigentümlichkeiten der hierher gehörenden Texte (z.B. Imperative, sdm.f - Formen beim Feind-Thema, das sonst in stativ-Formen als "Behobene Krisis" dargestellt wird) als Hinweis auf ihren magischen Charakter, der die Nähe zu Texten wie dem Apopisbuch und schliesslich allgemein zu jener Literatur, die die Agypter als b3w $\mathbf{R}^{\mathbf{C}} \mathbf{w}$ "Machterweise des Re" be-

75 Die erste Tagesstunde "erhebt sich fur" Maat, im zugehørigen Hymnus spielt die Maat-Darbringung eine besondere Rolle. Vgl. ausfuhrlich LI (n. 72 ).

76 pBM 10474,x,19-20, vgl. LL 182 n.71. 
zeichnen, ausfuhrlich dargelegt. 77 Die inzwischen aufgefundenen Hymnen, vor allem die Hymnen zu den ersten stunden des Stundenrituals, haben diese Analyse voll bestätigt, sodass man jetzt etwas positiver, als ich es damals gewagt hatte, von solchen "apotropäischen" Sonnenhymnen als einer besonderen Unter-Gattung der ägyptischen Sonnenhymnik sprechen kann, deren "Sitz im Leben" die Mysterien des Sonnenkults sind, jener innerste und königliche Bereich des kults, mit dessen Vollzug sich die vorstellung kosmischer wirkungen, eines unmittelbar unterstützenden Eingreifens in die Vorgänge des Sonnenlaufs verbindet.

Der magische Charakter der Stundenritual-Hymnen zeigt sich z.B. an ihren zahlreichen Imperativen $(1,1 ; 2,4-9 ; 3,1 ; 5,6$. $18 ; 6,24 ; 7 \mathrm{~A}, 10.11 .13 ; 7 \mathrm{~B}, 1 ; 8,4-6 ; 9,1-3)$, ihr apotropäischer Charakter an der dominierenden Rolle, die die Uräusschlangen und Kronen mit ihren Flammen spielen (Uräen: 1,16$17 ; 2,13 ; 4,6.10-12.16 ; 5,3 ; 10,3-6.14 ; 12,4$. Augen: 2,14 ; 3,$12 ; 4,13 ; \quad 5,8 ; 6,2.17 .19 ; 7 \mathrm{~A}, 15 ; 7 \mathrm{~B}, 11 ; 12,5-9$. Krone $(\mathrm{n})$ : $2,8-9 ; \quad 3,7 ; 4,5 ; 6,2-3)$. Die gleichen Kriterien weisen auch die anderen Texte auf, die wir mit dem stundenritual zusammen dem "Mysterien"-Bereich des Sonnenkults zugewiesen haben: Nr. 27 (Uräen V.10-24); Nr.28C (Flamme V.5); Nr.38 (Umringlerschlange V.6 und 19; Uräen V.19; Flamme deines Auges V.12; Imp. V.15); Nr.163 (Re-Apopis- Kontrastierung V.8-9 ${ }^{78}$; unmittelbare Re-Apopis-Konfrontation V.7.20.25 ${ }^{79}$; Augen-Flamme V.20-21); Nr.240 (Unmittelbare Konfrontation V.11).

Weitere Beispiele apotropäischer Hymnen sind etwa Nedjemet $z$. 29-31 (Re-Apopis-Kontrastierung ${ }^{80}$ ) und ein Hymnus im Sonnenheiligtum von Medinet Habu, von dessen Titel noch erhalten ist

Bewirken, dass die Barke freie Fahrt hat ...

... Apopis ${ }^{81}$

77 LL 181f.,220-224. Zu den b3w R ${ }^{C}$ w s. 222 n. 171.

78 S. LL $200 f$.

79 S. LL $221 \mathrm{f}$.

80 tbersetzung: LL 200 . 
Der letzte Teil dieses Hymnus lautet in Ubersetzung:

(...) Re in seiner Barke,

wenn er den Himmel quert in der Tagesbarke,

die Flamme seines Augenpaares auf seinem Kopf.

o Grosse, Herrin der Flamme,

die in ihrem Korb ist, Erste der Neunheit,

$(\ldots)$

die den Rebellen abwehrt in seiner Stunde,

und die Feinde des Re verbrennt!

Mogt ihr Auftrieb geben der Barke,

mögt ihr freie Fahrt geben jener Barke des Re,

mögt ihr das Gemetzel veranstalten an Apopis,

mögt ihr ihn niederwerfen (...)

Mit solchen Hymnen greift der "König als Sonnenpriester" als "Beistand des Harachte", wie es die oben zit. Frieszeile ausdrückt, in den Sonnenlauf ein, indem er die Abwehrkräfte des Sonnengottes stärkt und die feindlichen Mächte lähmt. Ahnlich schildert auch das Amduat auf götterweltlicher Ebene die Begegnung von Re und Apopis: "Zu einem wirklichen Kampf kommt es gar nicht: vielmehr beginnen Isis und Seth unverzüglich mit der 'Bezauberung' ( hk3) des Feindes, an der sich auch Re selbst beteiligt. Die magische Kraft ihrer Zaubersprüche lähmt Apopis und beraubt ihn seiner 'Stärke' ( phtj) .."82

Die "performative" Funktion des Sonnenliedes, wie sie die Schlusstexte beschreiben und wie sie in stil und Thematik der Hymnen zum Ausdruck kommt: Auftrieb und Freie Fahrt der Barke, Beistand fur den Gott, Vernichtung des Feindes, hat sich nun wesentlich genauer, als mir das noch in den "Liturgischen Liedern" möglich war, eingrenzen lassen auf eine Konzeption, die auf jenen Bereich des Sonnenkults beschränkt ist, die ich hier die "Mysterien" des Sonnenkults genannt habe. Die Mysterien des Sonnenkults sind eng an die Rolle des königs als Sonnenpriester gebunden und finden in den Sonnenheiligtümern und

81 Medinet Habu VI 421B. Von Apopis ist nur das Schlangendeterminativ erhalten.

82 E. Hornung, Amduat II, $139 \mathrm{f}$. 
wahrscheinlich auch im Lebenshaus statt. Ihre Funktion ist es, den Sonnenlauf in Gang zu halten, was gleichbedeutend ist mit der kosmischen ordnung einerseits, und dem Leben von könig und menschlicher Gemeinschaft andererseits. Nur der könig ist zu ihrer Ausführung bevollmächtigt, auch wenn er in praxi diese vollmacht an die zuständige priesterschaft delegiert.

Wenn diese Konzeption des königtums auch wohl nicht ganz von ungefähr an afrikanische Regenmacher-Könige erinnert und zweifellos in prähistorische schichten der ägyptischen Kultur zurückreicht 83 , so darf man doch nicht übersehen, dass dem König in dem komplexen kosmischen Geschehen des "Sonnenlaufs" weniger die Rolle eines "Machers", als vielmehr eines Teilnehmers zufällt. Alle Handlungen, deren Ausführung dem Sonnenpriester-König obliegen: das Aufsteigenlassen der Maat, Auftrieb und freie Fahrt für die Barke, die Bekämpfung des Apopis, die offnung der Wege usw. usw., werden zugleich auch von Göttern wahrgenommen. Der Feind wird von Isis und Seth (zuweilen durch Thoth ersetzt ${ }^{84}$ ) abgewehrt, Götter haben die Aufgabe, der Barke "Auftrieb zu verschaffen" 85 , sie zu segeln, zu rudern und zu treideln. Die Aufgabe des Königs als des Herrn der Sonnenmysterien und der Sonnenheiligtümer bestand also nicht darin, den Sonnenlauf in Gang zu halten, sondern darin, die menschliche Gemeinschaft in den Sonnenlauf zu integrieren, dadurch, dass er an ihm teilnimmt, ihn bestärkend und bestätigend mit seinen Rezitationen begleitet. Was er in Gang hält, ist der Gesamtzusammenhang von Kosmos und Gesellschaft, jener Begriff von "Kontinuität", der für das ägyptische Zeitdenken so charakteristisch ist. ${ }^{86}$ zu dieser Teilhabe befähigt ihn sein Wissen. Diesen Zusammenhang von Wissen

83 Die Forschungen $w$. Westendorfs sind im Umkreis der mit der pantherkatze M3fdt verbundenen vorstellungen auf verschiedene Konzeptionen offenbar sehr hohen Alters gestossen, die alle um das problem der "SonnenKinetik" kreisen: Maat als "Lenkerin" ("Ursprung und Wesen der Maat", in: Fs Walter Will, 1966), Ka als Hebekraft (Fs Vicichl, Société Egyptol. Geneve, Bull. 4(1980) 99-102) und allg. Altägyptische Darstellungen des Sonnenlaufes auf der abschussigen Himmelsbahn, MAS 10.

84 LL $308 f$.

85 Livre du jour, ed. Piankoff, BE 13, 14 unten.

$86 \mathrm{~S}$. Zeit und Ewigkeit 28-30. 
und Teilhabe (vgl. hierzu auch König als Sonnenpriester, 57) formuliert sehr klar die Beischrift zu der vignette, die im Totenbuch der Königin Nedjemet das 15.Kap. begleitet (ed. Shorter, Catalogue, 77):

Osiris Nedjemet, gerechtfertigt, kennt

jene Worte, die die ostlichen Seelen sprechen;

osiris Nedjemet ist inmitten deines Kollegiums,

Osiris, und tritt ein in die Mannschaft des Re, Tag fur Tag.

Dieses Wissen wird aber gleichzeitig auch zu einer idealen Grabbeigabe, denn es garantiert ihm auch nach dem Tode die Teilhabe am Sonnenlauf. Die Art und Weise, wie seine anbetende Figur den kosmographischen Darstellungen des Sonnenlaufs eingeschrieben ist, macht diesen Wunsch sehr sinnfällig. ${ }^{87}$ Auch hier heisst es in der Beischrift:

Re anbeten, wenn er untergeht im Leben,

durch den Konig Ramses VI., er bewirkt,

dass die beiden Barken des Re in Frieden dahingleiten.

Im Jenseits gehört er selbst zu der göttlichen "Eigensphäre", die er im Diesseits in seiner kultischen Rolle nachgeahmt hat.

Die Mysterien des Sonnenkults haben zwar auf ihre Weise Anteil an der erstaunlichen Blute der Sonnenreligion in der 18. und 19. Dynastie, wie man an der Entwicklung der unterweltsbücher ablesen $\mathrm{kann}^{88}$, und die zahlreichen Sonnenlieder dieser Zeit stehen teilweise den Grundgedanken der Mysterien nicht ganz fern, wie man an der Bedeutung des Feind-Motivs sehen $k_{a n n}{ }^{89}$. Aber es erscheint mir doch sehr wichtig, diese beiden Phänomene sorgfältig zu unterscheiden. Die Mysterien sind zweifellos wesentlich älter als die Blütezeit des Sonnenliedes, und sie haben diese Blute auch um viele Jahrhunderte überdauert. Wie das stundenritual in Edfu schliessen lässt, wurden sie noch in den spätzeittempeln durchgeführt.

87 Z.B. Livre du jour, ed. Piankoff, Tf.IV, S.14.

88 Hornung, Unterweltsblucher 17-23.

89 s. Kap. 2. 
Dem "Zeitgeist" der 18. und 19. Dynastie standen sie vermutlich eher fern. So kommt zu dem wissens-soziologischen Grund dafür, dass sie praktisch erst in der saitenzeit in den privatgräbern auftauchen, noch ein anderer. Gewiss gehörten sie im NR zu einem geschützten Wissensvorrat, der einem kleinen Kreis Eingeweihter vorbehalten war. Darüberhinaus aber hatte man in der 18. und 19. Dynastie einfach eine Flulle von Texten zur Verfügung, die dem religiösen Bewusstsein der Epoche wesentlich besser entsprachen. In der Saitenzeit war diese Blüte des ägyptischen Sonnenliedes längst vorluber; daher lag es nahe, auf die altgeheiligten Kulttexte der Sonnenheiligtümer zurückzugreifen. 
Zweites Kapitel

D I E I K O N O G R A P H I E D E S S O N N E N -

L A U F S

\section{1. "Ikon" und "Ronstellation"}

Entgegen den Erwartungen, die der Titel dieses Kapitels im Leser weckt, soll es auch hier um sprachliche und nicht um bildliche Darstellungen des Sonnenlaufs gehen. 1 statt von "Ikonographie" hätte ich auch, weniger irreführend, von "Bildwelt" sprechen ko̊nnen. Ich benutze das Wort "Ikon" jedoch im technischen Sinn als eine medien-indifferente, d.h. sowohl bildlich als auch sprachlich realisierbare Formulierung bzw. Artikulation von Inhalt. Aufbauend auf Uberlegungen zur "Verborgenheit des Mythos in Agypten" ${ }^{2}$, die sich mit dem Phänomen beschäftigten, dass Mythos im strengen Sinne einer narrativen Form in ägyptischen religiösen Texten auffallend selten zur sprache kommt, versuche ich, mit dem von $\mathrm{H}$. Blumenberg ${ }^{3}$ entlehnten Begriff des "Ikons" die spezifisch nicht-narrative Form in den Blick zu bekommen, in der Mythos in den ägyptischen Texten in Erscheinung tritt. "Mit dem Ausdruck "Ikonographie" ist also genau das gemeint, was man in herkömmlicher

1 wobei ich mir bewusst bin, dass eine Einbeziehung des überreichen Bildmaterials die These, um die es mir in diesem Kapitel geht, sehr wesentlich unterstützen und veranschaulichen würde. Die ebenso notwendige wie reizvolle Untersuchung hätte nicht nur die bekannten "Vignetten" zu behandeln, die erst nach der Amarnazeit belegt sind (s. dazu H. Schäfer, Agyptische und heutige kunst und Weltgebäude der Alten Ägypter (1928); K. Sethe, Altägyptische Vorstellungen vom Lauf der Sonne, SPAW 1928; H. Schäfer, "Altägyptische Bilder der auf-und untergehenden Sonne", in: ZÄS 71(1935)), sondern liesse sich anhand etwa von Pektoralen und ähnlichen Werken der Kleinkunst bis ins MR zurückführen (Erika Feucht-Putz, Die Königlichen Pektorale, Motive, Sinngehalt und Zweck, Bamberg 1967). Erik Hornung bereitet eine Arbeit über Sonnenlauf-Darstellungen vor, vgl. einstweilen "Die Tragweite der Bilder", in: Eranos Jb. 1979 (1981), 183-237 und ders., in: MDIK 37(1981)217-26.

2 GM 25 (1977), 7-43.

3 Hans Blumenberg, Arbeit am Mythos (1979).

4 J. Assmann, "Die Zeugung des Sohnes", in: H. Stolz (Hrsg.), Mythos im Alten Orient - drei Beispiele (OBO, im Druck). 
Terminologie die "Mythologie" des Sonnenlaufs nennen würde" also jene sicht der kosmischen Vorgänge, in der sie als Handlungen in der Götterwelt erscheinen und wo von Barken und ihren Mannschaften, von den "Sonnenaffen" und den Schakalen, von Isis und Seth, Horus und Thoth und von Apopis, dem Sonnenfeind, die Rede ist.

Mythen nennt man Erzählungen von Handlungen, die in der Götterwelt spielen. 5 Auch der "Sonnenlauf"6 erscheint in der uns hier interessierenden Darstellungsform als eine Handlung bzw. ein Komplex von Handlungen in der Götterwelt. Sie werden aber nicht "erzählt", weil ihnen die spezifisch narrative Kohärenz einer Geschichte abgeht. Geschichten beziehen ihre spezifische Kohärenz und Dynamik aus der Uberwindung einer anfänglichen Mangelsituation. ${ }^{7}$ Die Geschichte von Osiris, die ja nicht etwa bei seinem (nirgends vor Plutarch zur Sprache kommenden) irdischen Königtum, sondern bei der "Mangelsituation" seiner Ermordung und Zerstückelung ihren Anfang nimmt, kann hier als paradigmatisch gelten. Dieser narrative Kern der uberwindung einer Mangelsituation entfaltet sich in der Geschichte in einer Kette von Episoden, die durch eine finalistische Logik miteinander verknüpft sind, im Hinblick auf das angstrebte ziel nämlich, auf das sie hinführen. ${ }^{8}$ Die letzte Episode, z.B. der "Triumph des Horus", überführt die Ereigniskette in die sphäre des Resultativen und beschreibt die Welt, wie sie nun ist und wie sie, kraft ritueller Vergegenwärtigung des Mythos, für immer zu bleiben hat. 9

5 Dies ist jedenfalls das in der Agyptologie geläufige Verständnis von Mythos, wie es besonders $S$. Schott, Mythen und Mythenbildung im alten Ägypten (UGAA 15, 1945) zugrundeliegt.

6 Mit "Sonnenlauf" ist immer der scheinbare Lauf der Sonne um die Erde, mit "Bewegung" immer die scheinbare Bewegung der Sonne gemeint. Nicht gemeint ist mit dem Ausdruck "Sonnenlauf" eine bestimmte ägyptische Vorstellung von dieser scheinbaren Bewegung, eben als "Lauf" ( hpt ). Der Ausdruck bezieht sich im Folgenden immer auf das kosmische Phänomen in seiner "natürlichen" Erscheinungsform, nicht auf eine bestimmte seiner "ikonischen" Veranschaulichungen.

$7 \mathrm{~s}$. hierzu W. Burkert, Structure and History in Greek Mythology and Ritual (Berkeley 1979), 14-18 und meinen in n.4 zit. Aufsatz.

$8 \mathrm{~J}$. Assmann, "Das ägyptische Zweibrüdermärchen", in: ZÄS 104(1977) 1-25.

9 Diese Beschreibung folgt der Skizze einer Analyse des Osiris-Mythos in

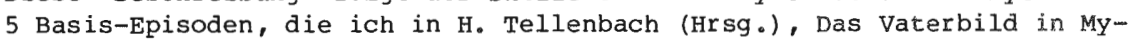
thos und Geschichte (1976),38-41 dargelegt habe. 
Die "Ikone", in die sich die ägyptische Vorstellung vom Sonnenlauf entfaltet, bilden einen zyklus, wo Anfang und Ende immer wieder ineinander übergehen. Hier tritt nie der ubergang ins Resultative ein. Der zyklus der Ikone gehört nicht der geschichtlichen zeit des menschlichen Erdendaseins an, in der die Geschichten spielen (auch wenn ihre Protagonisten Götter sind), sondern der in sich selbst kreisenden Zeit des kosmos, in der die Handlungen sich in ewiger wiederkehr, "Tag für Tag", wiederholen. So strukturieren, ja "ornamentalisieren" die Ikone die Zeit als ein Muster von Handlungsfiguren, das in unendlichem Rapport immer wiederkehrt. 10

Gleichwohl sind auch die Ikone des Sonnenlaufs in einer Art von Kohärenz miteinander verbunden, die nicht der Logik entbehrt. Es ist nicht die finalistische Logik, sondern die Logik der Analogie, die sie verknüpft. Nach dieser Logik werden in jener Konzeption des Sonnenlaufs, die wir hier näher untersuchen wollen, die kosmische und die anthropologische Ebene zueinander in Beziehung gesetzt. So entsteht die 4-"Phasen" Struktur des Sonnenlaufs:

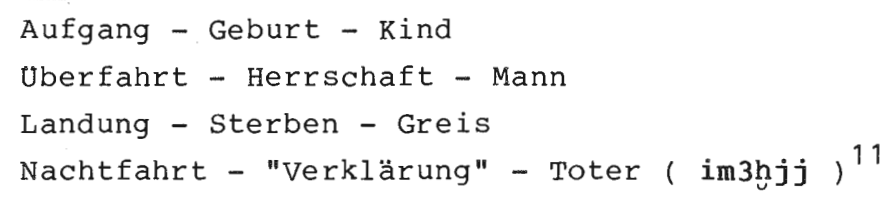

10 Zum Begriff der "Ornamentalisierung der Zeit" als dem Prinzip des Rituals s. GM 25, $27 \mathrm{f}$.

11 In der ikonischen struktur des "Tageszeitenliedes" (\$. $\$ 2,1$ ) werden die dritte und die vierte phase, Landung und Nachtfahrt, zu einem Bild. zusammengefasst. Auch die korrespondierende Lehre von den hprw des Re unterscheidet 3 hprw:

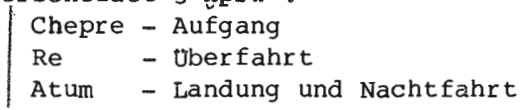

Man konnte also auch von einer 3-Phasen-struktur sprechen, wie ich das LL 333-339 und AHG 48 getan habe. Damit verschleiert man aber die bewusste verwischung einer Grenze und das bewusste In-Eins-Sehen zweier Seinsformen, nămlich Greisenalter und Gestorbensein. Auch andere Beobachtungen zwingen dazu, Landung und Nachtfahrt auseinanderzuhalten. Die Landung wird als Vereinigung mit der Muttergottheit ausgedeutet, die Nachtfahrt aber gipfelt in der Vereinigung mit dem vater (s. dazu $\$ 2 \cdot 2 \cdot 3)$. 
Das klingt in dieser Darstellung vielleicht künstlicher, als es dem Agypter erschienen ist, für den diese Dreiteilung des Tages und Vierteilung des Gesamtumlaufs eine unmittelbare, "natürliche" Evidenz besessen haben muss. ${ }^{12}$ Künstlich dagegen sind die 24 "Ikone", in die sich entsprechend der stundengliederung und der stündlichen Begehungen der zugehörigen Rituale der Sonnenlauf in den "Mysterien" des Sonnenkults entfaltet. Diese Ikone lassen sich nicht mit der Logik der Analogie zu irgendetwas in Beziehung setzen, das die natürliche Evidenz der Lebensalter besitzt, und stehen oft nur in komplementärer Beziehung zueinander, als gleichermassen "wahre" Bilder für denselben Grundgedanken. 13 Auf diese spezielle "Ikonographie" brauchen wir hier aber nicht einzugehen. Die "Ikone" gehören in den Zusammenhang eine weltbilds, das strikt polytheistisch ist. Damit soll gemeint sein, dass die Götter immer nur in Bezug und in Angewiesenheit aufeinander im Blick stehen und keiner ohne die anderen, d.h. ohne bestimmte Andere denkbar ist. Was bliebe etwa von Osiris übrig, wenn man versuchen wollte, von Isis und Horus, von Seth, Nephthys, Anubis und Geb abzusehen? Osiris träte dann etwa als der Tod in den Blick, dem

"alles gehört, was lebt auf Erden.

zu dir kommt alle welt in gleicher weise,

du bist der Herr, es gibt keinen ausser dir,

dies alles, dir gehört es." 14

In solchen Darstellungen (die übrigens zeigen, dass die Krise des polytheistischen Weltbildes in Ägypten nicht ausschliesslich Sache der Sonnenreligion war) bleibt die "mythische Dimension"15 seiner Wesensentfaltung ausgeklammert. In der mythischen Dimension entfaltet sich das Wesen eines Gottes in. Konstellationen, in denen er, handelnd und leidend, zu ande-

12 S. hierzu LL,333ff。; zur Beziehung der Sonnenphasen/Lebensalter auf das Sphinxrätsel s. W.B.Kristensen, The Meaning of Religion (1960) 68 .

13 Den komplementären Charakter der stunden-Ikone des Amduat, die oft nicht einen Teil, sondern einen Aspekt des Ganzen darstellen, hat Kristensen, Het Leven uit den Dood, $26 \mathrm{ff}$, betont, der aber wohl in seiner Deutung sämtlicher Stunden als komplementäre Aspekte der gesamten Nachtfahrt zu weit geht.

14 ÄHG $\mathrm{Nr} .219,36-39$. 
ren Gottheiten in Beziehung tritt. Diese Gottheiten gehören so in die Form seiner handelnden (und leidenden) Wesensentfaltung oder "Selbstverwirklichung" hinein, dass sie in der weise einer "Sphäre des Seinigen" einen geradezu unwegdenkbaren Aspekt seiner Person bilden. ${ }^{16}$ Hier ist nicht der Ort, den sich geradezu aufdrängenden Entsprechungen auf der Ebene des Menschenbildes nachzugehen. Der sogenannte "Familiensinn" des Agypters ist nichts anderes als eine der Ausdrucksformen eines Personbegriffs, der die person (a) als Vielheit integrierter Teile oder Aspekte wie Leib, Ba, Ka, Herz, Schatten ${ }^{17}$, (b) als Teil eines Ganzen versteht, das über die unmittelbare "Sphäre des Seinigen" hinaus die menschliche Gesellschaft und ihr Sinnzentrum, den König, umfasst. 18 Das polytheistische weltbild hat eine anthropologische Basis, die ihm für das ägyptische Denken eine Art von Notwendigkeit gibt. Sie bestimmt jenen Aspekt des ägyptischen Gottesbegriffs, den ich "die mythische Dimension der Götterwelt" nenne."

In der Theologie des Sonnenlaufs entfaltet sich die "mythische Dimension" nicht zu einer Mythologie von Geschichten, die man sich vom sonnengott erzählt ${ }^{20}$, sondern zu einer "Ikonographie" von Bildern, in denen die Handlungskonstellationen der jeweiligen phase des kosmischen Zyklus dargestellt

$15 \mathrm{Vgl}$. hierzu LÅ II, 769-771; Biblische Notizen 11(1980)55-58.

16 LL $339 f f$.

17 Vgl. JEA 65(1979) 70-72,75-77; E. Brunner-Traut, Gelebte Mythen (1981), 64-67; A. Rupp, Vergehen und Bleiben. Religionsgesch. Studien zum Personenverständnis in Ågypten und im Alten Testament (Saarbrücken 1976).

18 S. hierzu Vaterbild (n.9), 21-29, spez.27, sowie meinen Artikel "Persönlichkeitsbegriff und -Bewusstsein", in: LA IV.

19 Die anderen Dimensionen der Götterwelt bzw. des polytheistischen ägyptischen Gottesbegriffs nenne ich die "kosmische" und die "kultische" (oder: "lokale"). Im prinzip erscheint jeder wirkliche Gott in jeder der drei Dimensionen: er hat eine kosmische Erscheinungsform bzw. Wirkungsweise, einen Kultort, wo er als stadtgott verehrt wird (oder "zu Gast" ist) und eine sprachliche Artikulation seines Wesens, etwas, das man von ihm aussagen kann, einen Namen, eine Genealogie und in besonderen Fällen eine Mythologie.

20 Beispiele für Mythen, in denen der Sonnengott Protagonist ist, sind etwa das "Buch von der Himmelskuh" und der Heilungszauberspruch von der "List der Isis"; mit der "Ikonographie des Sonnenlaufs" haben diese Geschichten nichts zu tun. 
sind. Es sind "mythische Bilder", die sich jederzeit zu Geschichten entfalten können. 21 In ihrer Gesamtheit bilden sie in genau derselben weise die mythische Dimension der Sonnen-Theologie, wie sich die Fülle der Osiris-Isis-HorusSeth Geschichten zur mythischen Dimension des Gottes osiris zusammenschliesst. Theologisch gesehen haben die Ikone des Sonnenlaufs für den Sonnengott genau dieselbe Funktion, wie die Mythen für osiris: sie entfalten das wesen des Gottes in einer sphäre des seinigen. Deshalb erscheint es mir legitim, einen allgemeineren, nicht-narrativen Begriff von Mythos anzusetzen, der beides, die Ikone als "mythische Bilder" und die Geschichten als "mythische Episoden" umfasst. Die anthropologische Basis des Mythos macht ihn auf menschliches schicksal und Daseinsverständnis beziehbar; die menschlichen ordnungen finden im Mythos ihr Urbild und ihr Fundament. Daraus erklärt sich von einer grundsätzlicheren Uberlegung her das prinzip der Analogie, das den Ikonen des Sonnenlaufs, wie wir oben gesehen haben, ihre Kohärenz gibt.

In der mythischen Dimension erscheinen die Götter als "Personen", d.h. als Träger von Rollen in Handlungskonstellationen. Als "Handelnde" und "Leidende" ist Personalität ihr entscheidendes Merkmal. Naturphänomene und Numina handeln nicht. Dem Begriff der Handlung kommt demnach eine entscheidende theologische Bedeutung zu. Handlungen sind immer kommunikativ, d.h. sie haben einen Sinn, der sich nur in Bezug auf den bzw. die Teilnehmer an der Aktion realisiert. Mit dem Begriff der Handlung ist demnach der Begriff der Konstellation schon gegeben. Man kann Gott nicht als Handelnden denken, ohne ihn nicht in Beziehung zu setzen zu Wesen, die seinem Handeln Sinn und ziel geben. Wer die polytheistische Götterwelt leugnet und trotzdem. an dem Begriff Gottes als eines Handelnden festhält,

21 Das Apopisbuch (pBremner Rhind, 22.1-33.18 ed. Faulkner BÄ III) bietet einige Beispiele für Ansätze zu solcher narrativer Expandierung des FeindIkons, z.B. in dem Text AHG Nr.18, wo Vers $35 \mathrm{ff}$. auf die "Vorgeschichte" der Konfrontation zurückgegriffen wird: das "Komplott", das der Feind gegen den als Herrscher erschienenen Sonnengott geschmiedet hatte. Vgl. auch AHG S.49-54. 
bürdet der Menschheit die ganze Last des Konstellationspartners auf, wie der hebräische Monotheismus. ${ }^{22}$

Diese sehr allgemeinen und grundsätzlichen Uberlegungen sind in unserem Zusammenhang deshalb wichtig, weil sie die innere Zusammengehörigkeit von Phänomenen aufzeigen, an denen sich der tiefgreifende religionsgeschichtliche wandel in der 18. und 19.Dyn. manifestiert. Die "neue Sonnentheologie", deren Darstellung wir im 3. Kapitel unternehmen, destruiert die traditionellen "Ikone", d.h. Handlungskonstellationen, und versucht mit dieser "Entmythisierung" zu einem rein auf der Phänomenologie der kosmischen Vorgänge beruhenden Gottesbegriff zu gelangen. Die resultierende Einsamkeit des Sonnengottes auf seiner himmlischen Bahn hat den geschilderten Anthropozentrismus zur logischen Konsequenz.

2. Die Ikone des Sonnenlaufs im Spiegel des traditionellen "Tageszeitenliedes".

\subsection{Vorbemerkungen zum Typus des Tageszeitenliedes}

Als "Tageszeitenlied" bezeichne ich jenen Typus von Sonnenhymnen, deren Textplan sich an der Abfolge der "Tageszeiten" Morgen - Mittag - Abend - Nacht - Morgen orientiert, auch wenn er nur zwei oder drei der vier Phasen des Gesamtzyklus zur Darstellung bringt. Das Tageszeitenlied bezieht sich immer, auch in seiner "entmythisierten" Form, auf den Sonnenlauf und nicht auf den. Sonnengott. Daher ist ihm, als der Darstellung von Vorgängen und Handlungen, die "verbale" Form ebenso konstitutiv, wie der Eulogie als der Darstellung von Wesensbestimmungen die "nominale" Form (s. Kap.4). Das Tageszeitenlied bezieht sich in der Form der "Verklärung" oder sakramentalen Ausdeutung auf einen Vorgang, die Eulogie in der

$22 \mathrm{Vgl.hierzu}$ O. Keel, in: 0. Keel (Hrsg.), Monotheismus im Alten Israel und seiner Unwelt (Bibl.Beitr.14, 1980), 11-30. Zu dem hier gebrauchten Begriff von Handlung vgl. H.Arendt, in: H.Lenk (Eg.), Handlungstheorien interdisziplinăr, Bd. 2.1 (1978), 13-87. Spezifischer ist der Begriff des "Kommunikativen Handelns" bei J.Habermas, Theorie des kommunikativen Handelns, Frankfurt 1981. 
Form des "Namens" auf ein Wesen, eine Identität. 23 "Sakramentale Ausdeutung" nenne ich die In-Beziehung-Setzung von Sinn-Dimensionen, und zwar zunächst der Dimension des kultischen Handelns ("Realwelt") und der Dimension seiner "mythischen" Bedeutung ("Götterwelt"). Solche In-Bezug-Setzung und gegenseitige Transparent-Machung der einen sphäre auf die andere hin geschieht sprachlich in jenem sprechakt, den ich im Anschluss an S. Schott "Verklärung" nenne und der, wenn er vielleicht auch nicht genau dem ägyptischen Begriff s3hw "Verklärung" entspricht, jedenfalls sehr eng mit dem ägyptischen Begriff von der Kraft des Wortes als 3hw tpjw r3 zusammenhängt. 24 Die Sinn-Dimensionen, die das Tageszeitenlied in seiner ursprünglichen Funktion als "Verklärung" des Sonnenlaufs zueinander in Bezug setzt, sind - wenn es gestattet ist, die Ergebnisse langjähriger Untersuchungen nicht nur anhand von Sonnenhymnen, sondern auch von Totentexten in einem Satz zusammenzufassen - (a) die kosmische Ebene der in dem Begriff "Sonnenlauf" zusammengefassten Vorgänge, (b) die Ebene des Königtums und (c) die Ebene des Totenglaubens. Der Sinngehalt der Handlungen, als welcher der Sonnenlauf in der mythisch-ikonischen Denkform erscheint, erschliesst sich erst dann vollständig, wenn man sie auf diese drei Sinn-Dimensionen bezieht. Ich möchte das am Beispiel der Handlung "Uberwindung" illustrieren. Was sich auf der kosmischen Ebene als Uberwindung von widerständen darstellt, die sich im Sonnenfeind Apopis personifizieren - Stillstand, Wolken, Finsternis - , wird in der Sinn-Dimension des Königtums als uberwindung innerer und äusserer Feinde und Inbegriff der triumphierenden Herrschaft des Rechts gedeutet und in der Sinn-Dimension der menschlichen Existenz als Uberwindung des Todes bedeutungsvoll. Das Ikon sieht alle drei Sinn-Dimensionen in eins und bezieht sie aufeinander in der Form gegenseitiger Verweisung. Kosmos, Königtum und Totenglauben bilden in der

$23 \mathrm{Zu}$ "Nennen" und "Verluren" als Grundformen hymnischer Rede in Agypten s. AHG, 26-45. Zum "Verbalstil" des traditionellen Sonnenliedes im Unterschied zum "Nominalstil" der Eulogie s, ferner LL, 4ff. Sowie LA II 40-46 s.v. "Eulogie, Königs-" und III 106f. s.v. "Hymnus".

24 LL $364 \mathrm{ff} . \mathrm{m} \cdot \mathrm{n} .90$; GM 25, 15-23. 
Darstellung des hymnischen Tageszeitenliedes drei sich gegenseitig deutende und aufeinander verweisende Ebenen der Bedeutung. So erscheint der Sonnenlauf als Urbild der Herrschaft und des ewigen Lebens, und im täglich neuen Gelingen der uberwindung des Feindes und des Todes erlebt der Agypter die Garantie seines eigenen Fortbestands sowohl auf der Ebene der politischen als auch der persönlichen Identität.

\subsection{Die Tageszeiten}

Die weitaus überwiegende Mehrzahl der bildlichen Darstellungen des Sonnenlaufs in Gräbern, Totenbüchern und auf Särgen ist nach dem Schema B - A - B aufgebaut. ${ }^{25}$ In der zentralen Position A ist die Handlung des Sonnengottes - der Aufgang $^{26}$ - und die an dieser Handlung beteiligten Gottheiten, meist osiris als Djed-pfeiler und Nut als Himmel, dargestellt. 27 In der Position B sind die Adoranten dargestellt, die diesem Vorgang anbetend beiwohnen. Immer sind es die paviane, oft dazu noch andere göttliche Wesen sowie der Tote in Ba-Gestalt. Die Kosmographien der Kónigsgräber sind nach demselben, um $90^{\circ}$ in die Horizontale gekippten Schema aufgebaut: "jeder Nachtstundenbereich ist in drei Register eingeteilt im Mittelregister fährt die Sonnenbarke mit ihrer Begleitung dahin, in den beiden anderen Registern werden die wesen und Phänomene aufgezählt und beschrieben, denen der Sonnengott

$25 \mathrm{Da}$ " $\mathrm{A}$ ", die Handlung des Gottes, handlungstheoretisch den Vorrang hat vor "B", der Handlung der Gotter, die auf "A" reagieren, spreche ich im Folgenden vom B - A - B -Schema, womit ich aber naturlich dasselbe meine, was W. Westendorf S.V. A-B-A-Schema in seiner Bedeutung als Symbol des Sonnenzyklus erschlossen hat, $s$. Agyptische Darstellungen des Sonnenlaufs auf der abschússigen Himmelsbahn (MAS 10, 1966), Index S. $99 \mathrm{s.V}$. Schema, A-B-A.

26 In der Kontroverse zwischen H. Schäfer und K. Sethe uber die Bedeutung dieser Bilder wird man beiden Recht geben: H. Schäfer, der in ihnen eine Darstellung des gesamten zyklus sehen wollte, was die Gesamtbedeutung des Bildes angeht, K. Sethe, der sie ausschliesslich auf den Sonnenaufgang beziehen wollte, was den zentralen Teil, die Handlung des Sonnengottes angeht. Auch ich sehe darin eine Aufwärtsbewegung von der Unterwelt (=Osiris als Djed-Pfeiler) zum Himmel.

27 Belege s. König als Sonnenpriester, $45 \mathrm{n} .2$; ein besonders schönes Beispiel publiziert $E$. Feucht, Das Grab des Nefersecheru (TT 296), Szene 25 (im Druck). 
auf seiner Nachtfahrt begegnet."28 Nur herrscht hier nicht

die strenge symmetrie in der Besetzung der B-position, die die "Vignetten" kennzeichnet.

In genau entsprechender Weise zerlegt sich der Vorgang des Sonnenlaufs auch in der sprachlichen Darstellung der Hymnen in eine $A-$ und eine B-Komponente, die nun allerdings nicht zyklisch angeordnet, sondern, immer in der Abfolge A-B, einander gegenubergestellt werden. A stellt die Handlung(en) des Sonnengottes, B die Responsion der dieser Handlung beiwohnenden "Gemeinden" dar. Diese Struktur ist allen Tageszeiten gemeinsam.

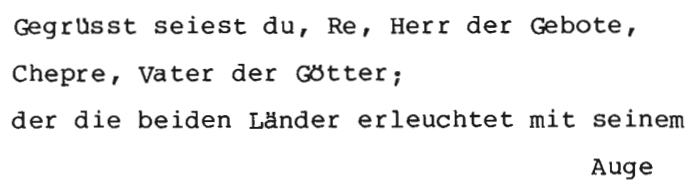

Morgen

bis zum Eintritt deines Untergangs In Leben

Die Sonnenaffen beten dich an,

B : Empfang Sie verkunden dich am Torweg des Horizonts, sie tanzen vor dir, sie singen vor dir.

Du nimmst den Sitz ein in der Tagesbarke, die bemannt ist mit den "unvergănglichen"; Handlung des du gehst daraus hervor weiten Herzens; A: Gottes: Uber- gefallt sind dir alle deine Feinde, fahrt, Sieg der Frevler ist gefallen vor deinem Messer, Mittag sein $(\ldots)$ ist abgeschnitten von ihm.

B: Respons der Die Mannschaft des Re ist in Jauchzen Begleiter und freut sich uber den zustand der Feinde ihres Herrn. 


\begin{abstract}
Re geht unter in der Nachtbarke,
Handlung des die bemannt ist mit den "Unermudlichen";

A: Gottes: Unter- die Schakale sind versammelt am Schlepptau,

gang, Nachtfahrt sie ziehen dich, und dein Herz ist weit, zu deinem untergang im Horizont des West-
\end{abstract}

bergs.

Abend

$\begin{array}{ll} & \text { Die verklärten und die "Westlichen Ba's" } \\ & \text { frohlocken beim Nahen deiner Majestat; } \\ \text { B : Empfang } & \text { sie sehen dich, wie du in Frieden gekommen } \\ \text { in deiner Wurde des "Ba" im Himmel. } & \text { bist }\end{array}$

\title{
2.2 .1 Der Morgen
}

A: die Handlung des Gottes

Als Handlung gesehen hat der Sonnenlauf drei Aspekte: einen passiven als Geboren-Werden des Sonnengottes durch die Himmelsgöttin, einen intransitiven als Erscheinen des Gottes und einen transitiven als Bestrahlung der Erde. Der passive Aspekt stellt als Wiedergeburt die Sinn-Dimension des Totenglaubens in den Vordergrund; deshalb ist er in Totentexten fast häufiger als in Sonnenhymnen 30 und spielt vor allem in den bildichen Realisierungen des Morgen-Ikons ${ }^{31}$ eine so grosse Rolle, die den Sonnenaufgang als Symbol der Wiederauferstehung aus dem Tode darstellten. ${ }^{32}$ Auch der kulttheologische Traktat widmet wie überhaupt die kosmographischen Beschreibungen des Sonnenaufgangs 33 dem passiven Aspekt des Sonnenauf-

29 Berlin $7306=$ AHG Nr.61.

30 Einige Belege, die sich leicht vermehren liessen: LL, 119.

31 Diese Bilder stellen zwar in der Regel nicht den Geburtsvorgang dar (das gehort mehr in den Bereich der "Mysterien", vgl. das Buch vom Tag BE 13 Tf.I und VIII), aber doch den Sonnengott in einer passiven Form, von den Armen seiner "Konstellationspartner" "emporgehoben" und "empfangen".

32 Das ist wohl der Grund dafur, warum die Morgenphase als dominierender Aspekt des Gesamtzyklus erscheint; der Bezug auf Auferstehungsvorstellungen ergibt sich durch das Auferstehungssymbol des Djed-Pfeilers mit dem Lebenszeichen.

33 S. dazu Konig als Sonnenpriester, 46f, mit der synoptischen Darstellung 5.47 unten. 
gangs genausoviel Raum wie dem intransitiven, während der transitive hier ganz fehlt:

...bei seinem Herauskommen, wenn er seine kugel off fnet

und zum Himmel auffliegt als Chepre,

intransitiv indem er eintritt zum Mund

( hpr ) und herauskommt zu den Schenkeln

bei seiner Geburt am Osten des Himmels.

Sein vater Osiris hat ihn emporgehoben,

passiv die Arme von Huh und Hahet haben ihn empfangen

( $m s j$ ) Er lässt sich nieder in der Morgenbarke.

Genauso wird der Geburtsvorgang auch in den Sonnenheiligtümern dargestellt. 34

In den Sonnenhymnen spielt der passive Aspekt des Sonnenaufgangs, das Geburtsmotiv, eine auffallend untergeordnete Rolle. 35 Dabei ist doch das Sonnenkind "auf den Armen von Isis und Nephthys" das typische Morgenikon, das z.B. in der ptolemäischen Epigraphik geradezu als schriftzeichen für dw3w "Morgen" vorkommt. ${ }^{36}$ Einige sprachliche Entsprechungen dieses Bildes habe ich LL 197f. und 202f. zusammengestellt; sie stammen meist aus Hymnen, die in den inneren Bereich der "Mysterien" gehören. 37 Ein besonderes Ikon der Morgensonne ist das Sonnenkind auf der Blüte, das, wie H. Schlögl nachweisen konnte, in der Amarna- oder Tutanchamun-Zeit aufkommt. 38 Der Hymnus aus dem Totenbuch des Nachtamun (pBerlin 3002) stammt aus der Nachamarnazeit: 39

34 Z.B. Medinet Habu VI Tf.420 B.

35 z.B. Totb Ani AHG Nr.38,3: ms tw mwt.k hr drt.s "Deine Mutter gebiert dich auf inrer Hand"; vgl. auch LL $120 \mathrm{f}$.

$36 \mathrm{~Wb} V 422$.

37 Das gilt sicher fur den pBerlin 3050 sowie fur die Hymnen des Totb der Konigin Nedjemet (Kap.3, n.55), weniger fur das Totb des Nacht, LL, 202 (28), zitat 2.

38 H.A. Schlögl, Der Sonnengott auf der Blute (AH 5, 1977).

39 AHG Nr.43; "Kind des Morgens" ( hjj $\mathbf{n}$ dw3t) wird der Sonnengott genannt auf dem Pyramidion eines Amenophis in Kairo (zit. nach photo Heidelberg 99a34) und pLouvre 3292=AHG Nr.48,5; "Kind im Osten" ( hjj jmj B3hw) Text 45 (TT 36),2; Ihii der Neunheit Text 129; "Kind ( hjj) der Flamme mit funkelnden Strahlen" ocairo 25206; "Ein Kind ( hjj) ist er, das sich verjungt zu seiner Zeit, gesăugt ( $3 t)$ von Nut 'zu 
Sei gegrusst, Knabe aus dem Scho|ss!,

Kind, das in der Lotosblume aufgeht,

schoner Jungling, der aus dem Lichtland komint

und |die beiden Länder| erhellt mit seinem Licht.

Zum passiven Aspekt des Sonnenaufgangs gehört neben der Geburt, die den Sonnengott zum Himmel als Mutter in die Beziehung einer Konstellation setzt, die Aufzucht durch die Mutter selbst (Text LL II 1) oder durch die Ammen, Isis und Nephthys (Text LL II 2) oder die beiden kronengöttinnen (Text LL III 4). Das Motiv von der Aufzucht des Kindes setzt den kosmischen Vorgang in eine besonders evidente Beziehung sowohl zum Totenglauben ${ }^{40}$, als auch und vor allem zum königtum, wo die "Aufzucht zum Königtum" ( rnn r njswt) durch die Kronengöttinnen und die "Bildung der schönheit" ( gm3 nfrw) durch die Muttergottheit zentrale Bedeutung haben.

Die typische Form, in der der Sonnenaufgang hymnisch dargestellt wird, ist jedoch die knappe, meist zweizeilige Gegenüberstellung seines intransitiven und seines transitiven Aspekts:

Er geht auf im Lichtland des Himmels

und hat die beiden Lander er leuchtet mit Gold. ${ }^{42}$

beiden Zeiten' ( $r$ trwj )" pBerlin 3056,8,7-8; "vollkommenes Kind ( sfj), das aus dem Urwasser kam" pBerlin $3055=$ AHG Nr.126, 11. Alle diese Texte sind ramessidisch und spater.

40 Als ein Beispiel fur viele CT VI 395:

Nut, die Grosse, erhebt dich in deiner schonheit, sie umfungt dich mit ihren Armen;

die beiden Herrinnen von Buto saugen ( $3 t$ ) dich, wie Horus, den Sohn der Isis.

$41 \mathrm{zu}$ rnn $r$ njswt $s$. Leclant, in: Mél.Mar.264n.3,275n.3; zu qm3 nfxw s. Maria Munster, Untersuchungen zur Gottin Isis, MAS 11(1978), $143 f$.

Wenn Leclant 3 Säugungen unterscheidet, eine nach der Geburt, eine bei der Krönung ( $\mathbf{r n n} \mathbf{r}$ njswt) und eine nach dem Tode, dann nimmt er die Sinn-Dimensionen wieder auseinander, die das komplexe Ikon der saugung in einem Bild zusammenfasst.

42 Theban Necropolis, Tf.VII. Dies und zahlreiche weitere Beispiele s.LL 293f. n.50. F. Junge erklärt diese Stilform grammatisch als "Wechselsatz": "Wenn du aufgehst, dann hast du erleuchtet...", s. Syntax der mittelagyptischen Literatursprache, (1978) 177ff. Diese Erklärung leuchtet fur das einzige Ein-Vers-Beispiel dieses Motivs ein, das ich vielleicht zu Unrecht zum Ausgangspunkt meines Exkurses uber Stilfor- 
Dieses Satzpaar bildet ein "thought couplet"43, das in seiner antithetischen Verknüpfung von Intransitivität und Transitivität eines Vorgangs der Stilform der Theophanie-Schilderung folgt. 44 Der Sinn dieser stilform basiert zu einem gewissen Teil auf den temporaldeiktischen Kategorien der beteiligten Verbformen, wie sie die folgende Ubersicht zusammenstellt:

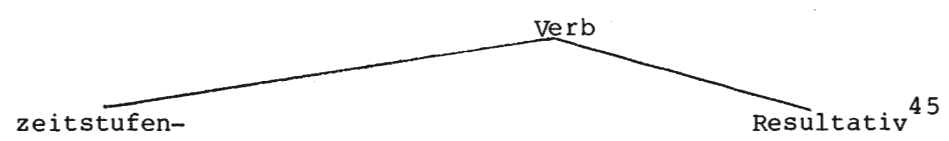

und aspekt-

neutral

"Vorgang an sich"

sdm.f u.a. Formen

$$
\text { wbn.k }
$$

nfr-wj tw

\begin{abstract}
intransitiv
\end{abstract}
zustand des

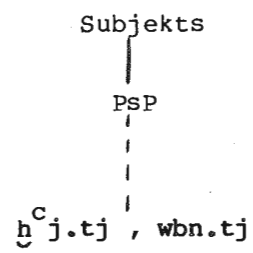

transitiv

zustand des

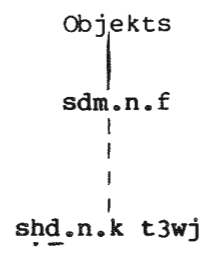

Die Stilform stellt also in einer konzisen und komplexen Antithese Vorgang und Handlung, Erscheinung des Gottes und Auswirkung der Erscheinung auf eine betroffene objekt-Sphäre gegenuber. Auf den Sonnenaufgang als Theophanie angewandt wird daraus die Gegenüberstellung von Himmel (als ort der Erschei-

men genommen habe, weil diese wahrscheinlich an die distichische Form des "thought couplet" gebunden ist: wbn.k shd.n.k t3wj - zumal hier einige varr. shd.k schreiben. Die Verwandtschaft mit manifesten Wechselsätzen wie wb̆n.k ${ }_{n h}$ rhjjt "wenn du aufgehst, lebt die Menschheit", ist evident. Die stilform selbst möchte ich aber nach wie vor als stilistische koordination (nicht grammatische Subordination) zweier sätze verstehen. Die Rolle der Stilistik bei der Textkonstitution geht, wie oft bemerkt, uber das hinaus, was eine ausgeprägte Satzgrammatik wie die von F. Junge zum Vorbild genommene generative Transformationsgrammatik beschreiben kann. Zur koordination von sdm.f und sdm.n.f vgl. jetzt Vernus, in: RdE 32 (1980) 117-121 und Zabkar, in: Zas 108 (1981) 145-165.

43 J.L. Foster, in: JNES 34 (1975) 1ff.; INES 39 (1980) 89-117; Ders., Thought Couplets and Clause Sequences in a literary Text: The Maxims of Ptah-hotep (1977); s.a. LA IV s.V. "Parallelismus membrorum".

44 LL $294 \mathrm{f}$.

$45 \mathrm{zu}$ dieser Kategorie s. GM 11 (1974),64 f.m.n.22. 
nung) und Erde (als Ort der Wirkung) und Gott und Welt (da die gesamte welt vom allgegenwärtigen Licht ${ }^{46}$ erfüllt ist).

B: die Begrússung des Sonnengottes

Auf der B-Seite der Morgenstrophen finden wir zunächst und vor allem die paviane $\left(j^{c} \mathbf{n w}\right.$ ) oder "Sonnenaffen" (jmjwhtt, wieder, die als "östliche Ba's" in der Kosmographie die Rolle der morgendichen Sonnen-Anbeter spielen. 47 Der oben zitierte Hymnus der Stele Berlin 7306 kann da als durchaus typisch gelten; weitere Beispiele sind etwa pBerlin $3050 \mathrm{C}$, 5-13 (LL II 2, S.189) und Leiden K 9 (LL, 209, dort 208-210 weitere Stellen). Oft ist auch von der "Neunheit" als den zeugen und Adoranten des Sonnenaufgangs die Rede: ${ }^{48}$

Die Neunheit gibt dir Lobpreis

dafur, dass sie leben von deinen Strahlen.

Sie beruhren die Erde bei deinem Nahen,

wenn sie die Kraft deiner Majestät erblicken als erlauchte,

grosse Macht.

Sie sagen zu dir, wenn du erscheinst,

ihre Arme gebeugt vor deiner Macht:

"Willkommen, Willkommen, o Herr der Gotter,

Atum Harachte!"

Dieses Thema ist den Hymnen ganz besonders wichtig, offenbar aus demselben Grund, weshalb auch die Darstellung der "östlichen Ba's" im Livre du jour und im kulttheologischen Traktat eine so grosse Rolle spielt: weil der Lobpreis der götterweltlichen "Gemeinden" das Urbild der Anbetung des Sonnengottes durch den Menschen darstellt und weil der Mensch sich mit seinem Lob in die Himmlischen einreiht, zu "einem von ihnen" wird: ${ }^{49}$

$46 \mathrm{Vgl}$. hierzu Kapitel $2 \$ 4$.

47 S. hierzu Kap.1, 29f; KÖnig als Sonnenpriester, 48-53; LL 207-214.

48 Bologna 1891 = AHG Nr.59; Kairo JE 13698; pLeiden J 344 vso I,9-10.

49 Totb 100, s.o., Kap.1 
Die Sonnenaffen beten dich an,

die Lichtland-Bewohner jubeln dir zu;

die Liegenden (Schlangen) erheben sich vor dir auf ihren

Schwănzen,

die Stehenden setzen sich nieder vor dir.

Die Turflugel des Lichtlands werden vor dir geoffnet,

der Weg des Nhh wird fur dich gefegt;

die im sudnimmel beten dich an,

die im Nordhimmel erheben dich,

die Neunheit kommt zu dir in verneigung,

sie kussen die Erde vor dir auf ihrem Bauch.

Sie sagen zu dir "Willkommen,

vater der Väter aller Götter!" 50

In thebanischen Gräbern und Totenbüchern der Nachamarnazeit gibt es eine ganze Reihe von Sonnenhymnen, deren Ausführung dieses Themas sich wie eine exakte Bildbeschreibung der entsprechenden bildlichen Darstellungen liest, deren Aufkommen in den Gräbern ja in dieselbe Zeit fällt: 51

Den die versammelte Neunheit preist,

ihre Arme in Lobgebărden,

dem die Ba's von Buto und Hierakonpolis zujubeln,

die Sonnenaffen beten dich an,

"Lob inm!" sagt alle Welt. 52

dich preist die versammelte Neunheit,

die beiden Herrinnen und die Merti ziehen ihn auf,

den schonen, geliebten Jungling;

wenn er aufgeht, lebt die Menschheit.

Die Ba's von Heliopolis jubeln ihm zu,

die Ba's von Buto und Hierakonpolis erheben ihn,

"Betet ihn an!" sagen die Sonnenaffen,

"Lob inm" sagt alles Getier allzumal. 53

50 Totb 15AIV pBerlin $3002=$ AHG Nr.43.

51 Die frluhesten Beispiele, TT 41 und pteiden T 2, stammen aus der Nachamarnazeit.

52 Text 59a (TT 49), 5-10.

53 Text LL III 4 (Standardtext E) in der Fassung von pLeiden T 2, S. LI 
Auch die Ausfuhrung des Themas in dem Hymnus, mit dem die unterweltichen Gottheiten den Sonnengott in der ersten stunde des Amduat begrussen, ist nichts anderes als eine zusammenfassende Bildbeschreibung: "sie beginnt mit den Paviangruppen des oberen und unteren Registers, bringt dann (immer nur mit dem Gruppentitel!) die preisenden Göttinnen des oberen und die leuchtenden Uräen des unteren Registers, danach die beiden übrigen Gruppen des oberen Registers (anbetende Götter und Stundengöttinnen). Anschliessend wendet sich die Aufzählung den Gottheiten des Mittelregisters $z u$, die aber nur in Auswahl genannt werden, um dann die beiden übrigen Gruppen des unteren Registers ... folgen zu lassen." 54 Eine echte Bildbeschreibung klingt dann auch genauso wie das Thema "Begrussung" in einem Sonnenhymnus:

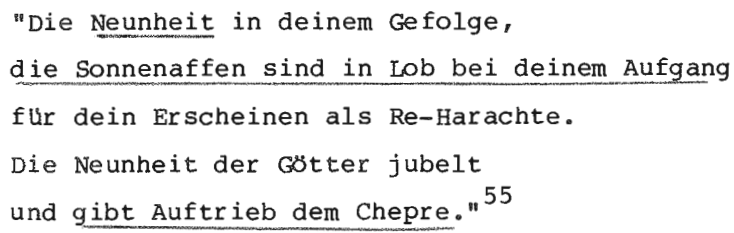

Zugleich macht dieser Text sehr schön deutlich, dass es auch bei dem morgendlichen Lobpreis nicht nur um eine Begrüssung des Gottes geht, sondern auch um eine Mitwirkung im Sonnen1auf. Die Hymnen geben dem morgendlichen Gott (Chepre) "Auftrieb" ( stzw: Aufrichtung, derselbe Ausdruck wird auch von der Wieder-Aufrichtung der "auf der Seite liegenden" Toten gebraucht und erscheint parallel zu s3hw "Verklärungen" als Bezeichnung fur Totensprüche). ${ }^{56}$ wir haben im 1.Kapitel die Argumente dafür beigebracht, dass auch der im Sonnenheiligtum

314f. 331-32. $331 \mathrm{n} .77$ einige Hinweise auf Parallelen in bildlichen Darstellungen des Sonnenaufgangs.

54 Hornung, Amduat Ir, $40 f$.

55 Urk IV 1673. Zum Thema "Auftrieb" s.Kapitel 1,

56 Wb IV 361, 6-7 vgl. 5; dort vielleicht zu blass als "Lobpreisung, Erhebung mit Worten" aufgefasst. Gemeint sind Spruche, die den Liegenden aufrichten wie die Litaneien, die mit wtz tw beginnen (LL 199f.): "Die Spruche der Vorfahren erzăhlen wahre Dinge; wer sie hört, erhebt sich auf seinem Platz" (Schott, Der Denkstein Sethos' I. in Abydos, $80)$. 
vollzogene kult sich als aktive Mitwirkung im Sonnenlauf versteht, eine Vorstellung, die zuweilen sogar von Gräber-Hymnen übernommen wird.

\subsubsection{Der Mittag}

A: Die Handlungen des Gottes

1. Die Uberfahrt

Die Mittagsstrophe des Tageszeitenliedes ist diejenige, die den Charakter des Sonnenlaufs als einer Barkenfahrt hervorhebt. Naturlich wird die gesamte Bewegung der Sonne als eine Fahrt zu Schiff vor- und in der Kosmographie auch dargestellt; in der hymnischen Darstellung des Sonnenlaufs tritt dieser Aspekt aber nur in der Mittagsstrophe hervor. 57

Die Vorstellung des Sonnenlaufs als einer Barkenfahrt ist zugleich die ältest belegbare ${ }^{58}$ und langlebigste Konzeption; noch in den griechisch-römischen Tempeln ist sie voll in Geltung. Im Bild der Barke wird die Bewegung der Sonne veranschaulicht und in den Barkenprozessionen der Tempelfeste auch von anderen Göttern nachvollzogen. Die Sonnenbarke ist aber nicht nur ein symbol für den Begriff der Bewegung, sondern auch und vor allem für den der königlichen Herrschaft und der damit verbundenen richterlichen Gewalt. Die beiden Barken des Sonnengottes - Msktt für die Nachtfahrt, $\mathbf{M}^{\mathbf{c}}$ ndt für die Tagfahrt - entsprechen den "beiden grossen Schiffen", in denen der König des Alten Reichs sein Reich durchzieht, um Recht zu sprechen und die steuern festzusetzen. 59 Die Himmelsuberfahrt hat den Charakter einer solchen Königsreise, und die Barken sind vielmehr ein Instrument der Herrschaftsausübung als der blossen Fortbewegung.

57 Der Barkenwechsel am Morgen - htp $m \mathbf{M}^{\mathbf{C}}$ nḍt "sich niederlassen in der Morgenbarke", s.dazu Kठnig als Sonnenpriester, 28 - wird in der oben zit. Stele Berlin 7306 sowie in LL III $4 \mathrm{~S} .326$ und std.Rit. 8. Std., ibd. 122f . erwahnt.

58 Elfenbeinkamm des Djet, Engelbach, in: ZAS 65(1930)115f .; Westendorf, Altagypt. Darst. des Sonnenlaufs (MAS 10), Tf.8 fig.14, S. 22-24.

59 o. Firchow, "KOnigsschiff und Sonnenbarke", in: WZKM 54 (1957) 34-42;

R. Anthes, "Sonnenboote in den Pyramidentexten", ZAS 82 (1957) 77-89. 
In der Ikonographie der Sonnenbarken versinnbildlicht das Richtgerät die richterliche Gewalt und die Falkenstandarten die Königsherrschaft. Durch diese beiden Symbole werden die beiden Barken, die sich voneinander nicht oder kaum unterscheiden ${ }^{60}$, im Sinne distinktiver Merkmale gegen andere Götterbarken abgehoben. Von den Kosmographien der königsgräber zeigen die Himmelsbilder an den Decken (das Buch vom Tage und der Nacht, und Verwandtes ${ }^{61}$, den differenzierten Typus, die Unterweltsbủcher an den wänden, Amduat und Pfortenbuch, jedoch eine vereinfachte Form ohne Richtgerät, Falkenstandarte, Matte bzw. "Treibtafel" am Bug ${ }^{62}$; auch die Kajüte wird oft duch die mhn -Schlange ersetzt, die sich schützend um den Sonnengott ringelt.

Die Zweizahl der Boote ergibt sich aus dem Gegensatz von Tag und Nacht, Ost und West, aus dem sich die Gesamtbewegung der Sonne zusammensetzt. Der Sonnengott fährt am Tage in der Ost-West-gerichteten $\mathbf{M}^{\mathbf{C}}$ ndt -Barke, bei Nacht in der WestOst-gerichteten Mskt -Barke. Der Barkenwechsel findet morgens und abends statt. ${ }^{63}$ Diese durchdetaillierte Barkenkon-

60 In den Darstellungen des NR und spater sitzt auf dem Bug der Nachtbarke oft ein Kind, auf dem der Tagbarke eine Schwalbe; vgl. z.B. Hornung, Unterweltsbucher, Abb.113. Zur graphischen Differenzierung der beiden Barken vgl. die Inschrift des Schatzhaus-Schreibers Ptahnefer,

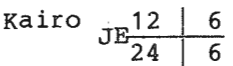

Wenn man verklärt wird, dafur dass man den Gott angebetet hat, dann werde ich Steuermann sein in der Barke der Millionen, und werde uberwiesen werden von der

\section{zu der 4 IIS}

im Gefolge des Sonnengottes, wenn er den Himmel quert.

61 Z.B. Assmann, Das Grab der Mutirdis, 91 Abb.41.

62 Nach der einleuchtenden Deutung von E. Dondelinger, Die Treibtafel des Herodot am Bug des ăgyptischen Nilschiffes, (1976); Steuerruder und gelegentlich - Treibtafel bilden die einzige im eigentlichen Sinne navigatorische Ausstattung eines Schiffes, das doch, wie es in den Texten heisst, gerudert und gesegelt wird. Eine Darstellung der Tagesbarke mit Mast und Segel ist mir nicht bekannt, vgl. aber die beiden Schiffe auf dem Bild des Sonnenuntergangs im Buch der Nacht, Hornung, Unterweltsblicher Abb.114.

63 E. Thomas, "Solar Barks from Prow to Prow", in: JEA 42 (1956) 65-79. Firchow leitet die Zweizahl der Sonnenboote aus der "Lehre von den bei- 
zeption der Sonnenbewegung spielt aber in den Hymnen keine Rolle. Die Zweizahl der Boote entspringt aber darüberhinaus auch einer Grundstruktur des ägyptischen Denkens in polaren Begriffs-Paaren oder "dualen Einheiten", die einen abstrakten und komplexen Oberbegriff als "Ver-einigung" zweier konkreter, sich er-gänzender Teilbegriffe ausdrückt. ${ }^{64}$ was in den beiden Barken und allen anderen auf den Tag-Nacht-zyklus bezüglichen Symbolpaaren zum Ausdruck gebracht wird, ist ein Begriff von Periodizität und Perpetuität, der den ägyptischen Begriff der kosmischen Zeit als einer ewigen in sich kreisenden Bewegung kennzeichnet. 65

Die Darstellung, die das Tageszeitenlied dem Sonnenlauf gibt, konzentriert alle mit der Barkenfahrt verbundenen vorstellungen auf die spezifisch mittägliche Manifestation des Sonnengottes als "Re". In dieser Gestalt erscheint der Sonnengott als Herrscher und Richter, der in der Barke als dem Instrument und dem Symbol seiner Herrschaftsausübung sein Reich durchzieht, um Recht und Ordnung - die Maat - darin durchzusetzen. Der Satz, mit dem die Mittags-Stophen in der Regel anheben und ihr Thema mit Hilfe eines "thematischen Stichworts" gleich zu Anfang ankündigen ${ }^{66}$, drückt diese spezifisch herrscherljche Manifestation des Sonnengottes so aus:

d3j.k pt (oder: nmj.k hrt m 3 wt-jb (oder: jb.k 3wjw)

"Du durchfuhrst den Himmel weiten Herzens"

den Lündern" (n.64) ab, fur Anthes ist sie ein "schwieriges problem"; beide ziehen die von $E$. Thomas vorgetragene und aufgrund ihrer selbstevidenz garnicht weiter diskutierte Losung uberhaupt nicht in Erwăgung.

$64 \mathrm{Vgl}$. E. Otto, "Die Lehre von den beiden Ländern in der agyptischen Religionsgeschichte" = StudAeg I (1938) 10f f。; A.Massart, in: Mélanges Bibliques (Fs. A. Robert) 1957) 38ff. Zum Begriff der "dualen Einheit" s. LL 380 s.v., $z u$ dem der vereinigung LL 307f. n.33. Vgl. auch E. Otto, LA I, 1148-1150 s.v. "Dualismus" und E. Hornung, Der Eine und die Vielen, $237 \mathrm{~m} . \mathrm{n} .72$.

65 zur Zyklus-Symbolik der beiden Barken s.LL 274 m.n.76; 288-89 (5); 28990 (7-8); 377 m.n.8a; J. Zandee, in: JEOL 18 (1964) 257; s.a. Ph. Derchain, "Perpetuum Mobile", in: Orientalia Lovanensia Period.6/7 (Fs Vergote 1975/76) 153ff. Zum Zeit- und kontinuitatsbegriff s. Zeit und Ewigkeit, 28-30.

66 S. hierzu LL $387 \mathrm{s.v}$. Struktur, thematisches Stichwort. 
Die "Herzensweite" ist ein spezifisch königlicher Affekt, das Gefül des Siegers beim Triumphzug. ${ }^{67}$ Die ubliche Ubersetzung "Freude" vermag dies Bedeutungsfulle nicht ganz wiederzugeben. Das Herz des Gottes weitet sich durch die Uberwindung des Feindes. Die entsprechende strophe eines in den Gräbern recht verbreiteten Hymnus sei hierfur als ein sehr typisches Beispiel angeführt: 68

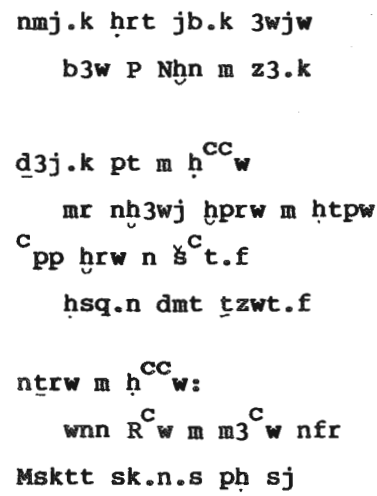

Du querst den Himmel weiten Herzens, die Ba's von Buto und Hierakonpolis in deinem schutz

du querst den Himmel in Frohlocken, der Messersee ist friedlich geworden;

Apopis ist gefallen vor seinem Gemetzel, das Messer hat seine Wirbel durchschnitten. Die Gotter sind in Frohlocken, Re wahrt in gutem Fahrwind; die Mesektet-Barke hat ihren Angreifer vernichtet, die $\mathrm{Me}^{\mathrm{C}}$ andet-Barke hat Freude ergriffen.

Die Barke der Millionen freut sich, die Mannschaft des $\operatorname{Re}$ ist im Fest, wenn sie sehen, dass der Rebel1 gefallt ist, dass die Flammende inn bezwungen hat.

Die Uberfahrt des Sonnengottes uber den Himmel bringt in den Mittagsstunden die Konfrontation mit dem Sonnenfeind Apopis. Diese Konfrontation wird aber nur in den Kosmographien als solche beschrieben. Das "Buch vom Tage" verlegt den Kampf mit Apopis in die 6.Tagesstunde, die "für seth aufsteht", und be-

67 Der Konig als nb 3wt jb "Herr der Herzensweite", und die Herzensweite als Gabe der Gotter an den Konig, sind so geluufige vorsteliungen, dass sich Belege erubrigen. Fur die Hymnen findet sich eine Belegsammlung in LL 277f. n.75. Die 7.Tagesstunde, die auf die Stunde des Himmelskampfes folgt, heisst s3wt-jb "die das Herz weit macht".

68 Text 20 u. Varr., s. STG oder AHG Nr.64 fur die ubersetzung. Fur annliche Darstellungen dieses Themas s. LL, $276 \mathrm{f} . \mathrm{n} .70$. 
zieht sich auch in den Beschreibungen der 7. und 8. Stunde noch auf den Himmelskampf. ${ }^{69}$ Auch die "apotropäischen" Hym-nen, die ebenso wie die Kosmographien ihren Sitz im Leben in den "Mysterien" des Sonnenkults haben, beziehen sich direkt auf den Kampf, als Handlung der beistehenden Götter, aber auch des Sonnengottes selbst. 70

Das Mittags-Thema des Tageszeitenliedes ist aber nicht der .Kampf, sondern der Triumphzug des Gottes, der den siegreich uberstandenen Kampf bereits zur Voraussetzung hat. Die konfrontation mit dem Feind kommt hier nur in der Form der "behobenen Krise" 71 zum Ausdruck, die sie in der Form des Resultativs darstellt:

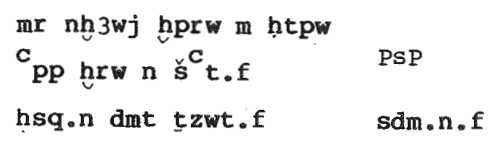

Nicht der Kampf wird dargestellt, sondern der zustand des besiegten Feindes und der wiederhergestellten Harmonie. So stellen auch die "Vignetten" die Mittagsphase dar: die Sonnenbarke über dem von Messern zerschnittenen Feind. 72

Die Konfrontation mit dem Feind bringt die beistehenden Götter ins Spiel. Es gehört zur Vorstellung der Barkenfahrt als einer Königsreise dazu, dass der Sonnengott von einem "Hofstaat" ( snjt ) 73 umgeben ist, wie ihn bestimmte Litaneien im Sonnenkult namentlich spezifizieren und anrufen: 74

$69 \mathrm{BE}$ 16-17, LL 297. In der 9.Std. heisst es dann: "Der Herr des Alls lebt nach der passage dieser ublen Sandbank".

$70 \mathrm{Vgl} . \mathrm{V} \cdot \mathrm{a}$. LL 221f. mit Hinweisen auf weitere Behandlungen des Themas.

71 S. LL $379 \mathrm{s.V}$. Behobene Krisis; zum Begriff der periodischen Krise s.a. Zeit und Ewigkeit, $28 \mathrm{f}$.

72 Sehr haufig auf Sargen, s., als ein Beispiel fur viele, A. de Buck, De Zegepraal van het Licht (1930) Afb. 18.

$73 \mathrm{snw/jjt} \mathrm{ḩ3t} \mathrm{k3r,} \mathrm{vgl.} \mathrm{z.B.} \mathrm{C'T} \mathrm{I} \mathrm{391,} \mathrm{390,} \mathrm{386,} \mathrm{VII} 458$.

74 Ritual fur Amenophis I, pChester Beatty IX rto 6,3-10 und pkairo+Tu$r$ in $C$ 8,7 - T 19,8; Gardiner, Hieratic Papyri in the BM, 3rd ser. I, 88f. (19) Tf.52-53; Nelson, in: JNES 8, 231 ep.33; LL 351 n.61. Dort Verweise auf Parallelen und verwandte Litaneien, s.a. LA III, 1064. 


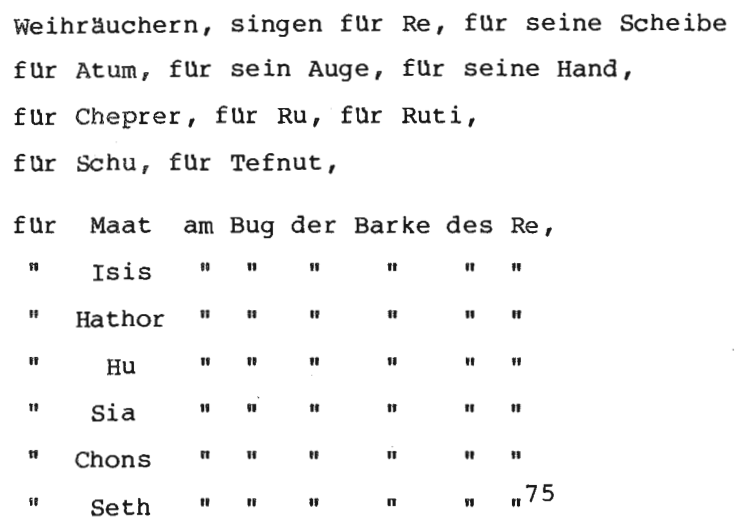

Nach der Beschreibung der 6. Stunde im Buch vom Tage spielen die entscheidende Rolle beim Kampf gegen Apopis Isis "mit ihrem Zauber" 76 und seth. 77 Obwohl auch seth sich nach Darstellung anderer Textsorten - z.B. CT II 350/51 - zuweilen magischer Mittel bedient, ist es doch vor allem sein speer, der den Gegner zu Fall bringt. ${ }^{78}$ Die Uräusschlange des Sonnengottes schleudert Feuer gegen den Feind ${ }^{79}$, worin man wohl eine "sakramentale Ausdeutung" begleitenden Brandopfers zu sehen hat ${ }^{80}$, Thoth, der zuweilen Seth am Bug der Barke ersetzt, zerschneidet ihn mit einem Messer. ${ }^{81}$ Der Sonnengott selbst in der Darstellung, die das Tageszeitenlied diesem Geschehen gibt, kämpft nicht: der Feind wird nicht von ihm, sondern "für ihn" erlegt. 82

75 In der var. pchester Beatty und Mundoffnung Sz.59: Thoth. Zu Thoth als Stellvertreter des Seth vgl. Otto, in: Or 7,69ff.

$76 \mathrm{BE} \mathrm{13,} \mathrm{16;} \mathrm{vgl.} \mathrm{Totb} \mathrm{100:} \mathrm{"Ich} \mathrm{machte} \mathrm{mich} \mathrm{zum} \mathrm{Genossen} \mathrm{der} \mathrm{Isis} \mathrm{und}$ stäkte ihre Zauberkraft".

77 Isis und Seth sind auch Gottheiten, die Apopis in der unterwelt bekămpfen, s. Hornung, Amduat II, $130 \mathrm{ff}$.

78 Zum "Dreissig-Ellen-Speer" s. Text 52, 25 und Pyr 1212a, vgl. Săve-soderbergh, On Egyptian Representations of Hippopotamus Hunting (1953)

33. Zu Seth in der Sonnenbarke s. BE 13, $16 \mathrm{n} .2 \mathrm{mit}$ Lit.

79 Belege: LL 275 n.64; $130 \mathrm{f}$. (4)

$80 \mathrm{Vgl}$. Apopisbuch AHG Nr.18, 41f.:

Apopis ist vor der Flamne gefallen, der Frevler ist im Brandopfer.

$81 \mathrm{Vgl}$. z.B. den Thoth-Hymnus Urk IV 2092f. AHg 222, 33-36 sowie AHg Nr. $43,37-38$.

82 LL 89 (13) U.ర. 
Der Sieg über Apopis ist weniger eine Manifestation der Kraft, als des Rechts und der Ordnung, der Maat, die als Folge und Ausdruck des Sieges "vor Re erscheint". ${ }^{3}$ Der Kampf hat den Charakter des vollstreckten Urteils, die Konfrontation des Sonnengottes mit dem Feind den eines Akts der Rechtsprechung. ${ }^{84}$ Re durchzieht den Himmel "gerechtfertigt". ${ }^{85}$ Apopis verkörpert daher nicht nur kosmische Gegenkräfte des Lichts und der Bewegung, sondern auch das Prinzip des "Bösen" ( dw qd).

Die Uberwindung des Feindes findet im Zenith der Sonnenbahn an einer Ortlichkeit statt, die als "Zweimessersee" 86 , "Sandbank des Zweimessersees" 87, "Sandbank des Apopis"88 oder nur "(jene) Sandbank" bezeichnet wird. 89 In der kosmographischen Beschreibung der Tagesstunden im Buch vom Tage ist in der 6. bis 8.Stunde von "dieser Sandbank" die Rede, die erst in der 9.Stunde überwunden ist:

"Der Himmel ist in Schönheit,

die Erde ist in Harmonie. ${ }^{90}$

Die Götter haben das Seilende ergriffen,

die um die Kajute, ihr Herz ist weit.

Der Herr des Alls lebt nach der Passage ( znt) dieser ublen

die Feinde des Re hat er gefällt. ${ }^{91}$

Sandbank,

83 LL 177-179.

84 Daher ist oft von "bestrafen" ( $\mathbf{s s w n )}$ ) die Rede, z.B. LL 301, 11; AHG $\mathrm{Nr} .87 \mathrm{G}, 182$; pGreenfield XXIX, III:

Apopis ist in der Flamme vergangen, sein Gemetzel ist vollzogen, du hast ihn bestraft,

die Flamme des Horusauges hat ihn verzehrt.

85 Z.B. Text 58, 16; Text 74, 6; Text 165, 9; Text 182, 17; AHG Nr.56, 4; LL $181 \mathrm{f}$.

86 LL 271f. Zur Lesung: Altenmuller, ZAS 92 (1966) 86-95.

87 Urk VI 123 .

88 BIFAO 45, 159 Z.25; Totb 7; Amduat 7.Std.; Vandier, Mo alla 220; Hornung, Amduat III, $65 \mathrm{zu}$ S.132.; pChester Beatty VII $r$ to $V, 4-5$.

89 Buch vom Tage: der Zusatz qsn "schlimm, unheilvoll, schwierig" auch Totb 7.

90 Zur stilform des Festlieds, die hier anklingt, s.LL 250 ff., sowie u., $80-82$.

$91 \mathrm{BE} \mathrm{13,18f.,} \mathrm{LL} 297$. 
Das ägyptische wort für "Mittag", $\mathrm{C}_{h} \mathrm{C}_{\mathrm{w}}$, heisst wörtlich "Stillstand". So hat man wohl tatsächlich die Mittagsstunde als stille stehende zeit empfunden, in der die sonne auf dem Zenith zwischen Aufstieg und Abstieg für eine Weile in ihrer Bewegung innehält. Einem veranschaulichenden Denken in Bildern wird daraus der Sonnenfeind, der in Gestalt einer Schlange oder Schildkröte 92 den Himmelsozean soweit aussäuft, dass die Sonnenbarke durch das resultierende Niedrigwasser auf der "Sandbank des Apopis" aufläuft und erst weiterfahren kann, wenn seth seinen speer in den Feind gestochen und ihn gezwungen hat, "wieder auszuspeien, was er verschluckt hat".93 Die sprichworthafte Verbreitung dieser Redensart spricht für die allgemeine Verbindlichkeit dieses "Ikons", zugleich aber auch für die Verschiedenheit der Sinn-Dimension, in denen es bedeutsam war. ${ }^{94}$ Dasselbe gilt auch für die Wendung von der "Sandbank des Apopis", die in Inschriften der 1.Zwischenzeit als Ausdruck für Dürre und Hungersnot vorkommt. 95

Es handelt sich also bei diesem mittäglichen stillstand der Sonnenbarke nicht um die vorstellung einer rein kosmischen Krise, an deren tägliche Uberwindung man sich mit der zeit wohl hätte gewöhnen müssen, sondern um die Uberwindung einer Gefahr, von der das gesamte Leben in allen seinen SinnDimensionen betroffen ist, und die sowohl jederzeit als auch in jeglicher Gestalt - als Hungersnot, Seuche, Krankheit, Schlangenbiss, Aufruhr, Krieg usw. - in das Leben sowohl der Gemeinschaft als auch des Einzelnen einbrechen und mit der Störung der ordnung in einer ihrer Sinn-Dimensionen den Sonnenlauf, die zeit, das Leben zum stillstand bringen kann. Die-

92 Zur Schildkrote als Gotterfeind s. van de Walle, in: La Nouvelle Clio 5, 180; T. Säve-soderbergh, in: MDIK 14, 175ff. J. Vandier, Le Pap. Jumilhac, 201f. (616); H.G. Fischer, Ancient Egyptian Representations of Turtles (1968).

93 LL $198 \mathrm{f}$.

$94 \mathrm{Vgl}$. Belege wie Israelstele und BM 566.

95 J. Vandier, La famine dans l'Egypte ancienne RAPH 7 (1936), 74ff.; W. Schenkel, Die Bewăsserungsrevolution im Alten Agypten (1978) 50f.; Vandier, Mo alla 220; zusammenfassend luber die Sinn-Dimensionen der "Sandbank" s. LL 295-298. 
ser "sympathetische" Zusammenhang von Kosmos und Gesellschaft, Sonnenlauf und menschlicher Ordnung, tritt besonders deutlich in späteren Quellen hervor. Die Heilungszaubersprüche der Metternichstele stellen einen Unglücksfall auf der privat-menschlichen Ebene, z.B. einen Skorpionstich, als störung der umfassenden ordnung dar, die den sofortigen stillstand der Sonnenbarke und damit des Lebens zur Folge hat, um die Götter zum Eingreifen zu bewegen. ${ }^{96}$ Die Sprüche gegen den Gott seth (Urk VI) malen die kosmische katastrophe aus, die der Einbruch des Götterfeindes in die Ordnung des Landes und die Schändung der Kultgeheimnisse heraufbeschwört.97 Auch hier heisst es an erster Stelle:

"damit die Sonne sich nicht verfinstert
auf der Sandbank des Zweimessersees". 98

Der pJumilhac stellt die Folgen einer allfälligen Vernachlässigung des Kultbetriebs in den Ausmassen einer solchen globalen Katastrophe dar. ${ }^{99}$ Das sind aber keine spezifisch spätzeitlichen Vorstellungen, sondern sehr alte und sehr reale Angste, die auf vielfältigen historischen und persönlichen Erfahrungen beruhen - Hungersnöte, Epidemien, Umsturz, Fremdherrschaften usw. - und deren obsedierender Charakter an der Persistenz dieser Topik in ganz verschiedenen Bereichen der ägyptischen Literatur deutlich wird. 100

Das Ikon vom Sonnengott in der Barke, der im "günstigen Wind" über den vernichteten Feind und seine Sandbank dahinfährt, gibt der Hoffnung oder vielmehr dem Vertrauen auf uberwindung der Krise und Abwendung der Katastrophe in allen ihren Erscheinungsformen Ausdruck und ist Symbol und Inbegriff

96 A. Klasens, A Magical Statue Base, 31-32, 96.

97 Urk VI 122-128.

98 Urk VI 123.

99 pJumilhac ed. Vandier, 129ff. \$ XXVI col.XVII,15-XVIII, 21.

100 S.Schott, "Altagyptische vorstellungen vom Weltende", in: Analecta Biblica 12, 1959, 319-330; P. Derchain, Le Pap.Salt 825, I, 24-28; Zeit und Ewigkeit, 26-30 sowie meinen Beitrag "konigsdogma und Heilserwartung" in: D. Hellholm (Hrsg.), Apocalypticism in the Mediterranean World and the Near East (im Druck). 
der "Wohl-Fahrt" im allgemeinsten Sinn. ${ }^{101}$ Am Beispiel dieses Ikons lässt sich am deutlichsten zeigen, worauf es diesem Denken in Bildern als einer Form der Konstitution von Wirklichkeit ankommt und worin der Wahrheitsgehalt dieser Ikone besteht, aus dem sich ihre unglaubliche Langlebigkeit erklärt. Ihre Funktion ist nicht Erklärung, sonder Sinngebung der kosmischen Phänomene. Das Ikon integriert sie in ein Weltbild, wo eine Sinn-Dimension auf die andere verweist.

B: Der Siegesjubel des Gefolges

Mit dem Sieg des Sonnengottes feiern die Hymnen die Uberwindung einer Krise, die alles Leben bedroht, und so allgemeiner Betroffenheit entspricht die Erleichterung, die im Jubel der Götter zum Ausdruck kommt. "Feiern" ist ein in vielfacher Hinsicht treffendes Wort sowohl für das Thema dieses Abschnitts der "Mittags-Strophe", als auch für die Form, in der sie es behandelt. Die Darstellungsform des Siegesjubels orientiert sich nämlich an der Form des kultischen Festlieds. Da ich diesen zusammenhang in den Liturgischen Liedern sehr ausführlich dargelegt habe ${ }^{102}$, möchte ich mich hier kurz fassen. Zu den charakteristischen Merkmalen einer Gattung chorisch gesungener Lieder, die das Erscheinen der Gottheit bei Prozessionsfesten feiern ${ }^{103}$, gehört

(a) die schilderung des allgemeinen Festjubels, immer mit Himmel und Erde beginnend, was die Sonnenhymnen im Hinblick auf die spezifischen "Gemeinden" des Sonnenlaufs abändern, und immer in den Verbformen und Satztypen der zuständlichkeit;

(b) die anschliessende Nennung der Erscheinung des Gottes als der ursache des Jubels, wofür es an der entsprechenden Stelle der Sonnenhymen z.B. heisst:

"Wenn sie sehen, dass der Rebell gefallt ist"; ${ }^{104}$

101 Vgl die Beziehung der Metapher vom "gunstigen Segelwind" auf die Wohlfahrt des Einzelnen, Bauer 55; Amenemope X,11; Urk IV 944,2.

102 LL 246-262, s.a. LA III, $853 f$.

103 LL 250-252.

104 LL 237-39. 
(c) die anrede-lose, nicht-dialogische Form, die die Wirkung des erschienenen Gottes beschreibt, ohne diesen selbst anzureden. Auch dieses Merkmal übernehmen die Sonnenhymnen, und da sie sonst fast in jedem Vers auf den Angeredeten Bezug nehmen, ist dieser Wechsel der Anredestruktur das untrúglichste Kennzeichen dafür, dass hier in einer anderen Form - in der Form des Festlieds - gesprochen wird.

Während das B-Thema der Morgenstrophen eine Handlung darstellt, nämlich die Begrüssung, die dem Sonengott von seinen "Gemeinden" entgegengebracht wird, stellt das B-Thema der Mittagsstrophe einen zustand dar, in den die "Gemeinden" versetzt werden. Diese Opposition tritt in der Verschiedenheit der Satzformen und der Anredestruktur in den beiden strophen sehr deutlich hervor, wofur wiederum Text 20 ein typisches Beispiel darstellt:

$\begin{array}{llllll}\text { Morgen } & \text { Verb- } & \text { An- } & \text { Verb- } & \text { An- } & \text { Mittag } \\ & \text { form } & \text { rede } & \text { form } & \text { rede } & \end{array}$

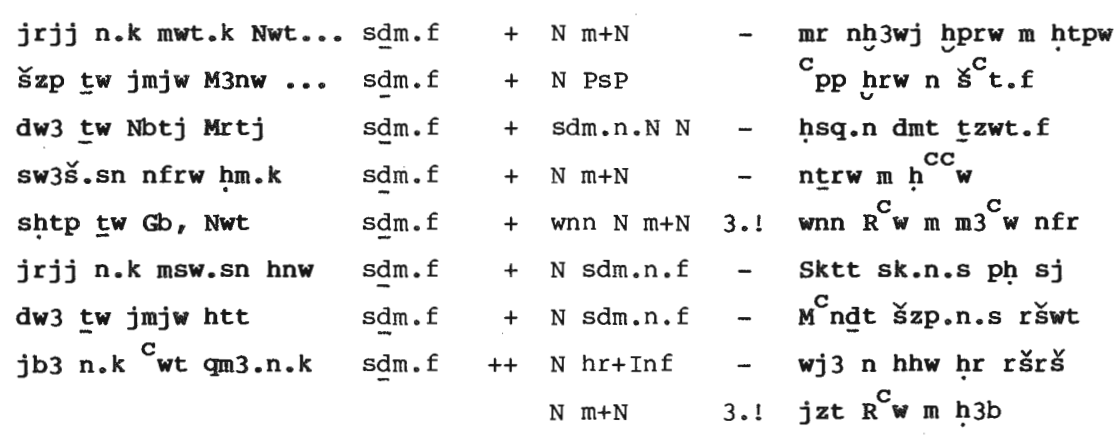

Die thematische Opposition scheint mir ausser Zweifel. Von daher fällt Licht auf die Bedeutung der verwendeten Verbformen und Satztypen. Die Sätze mit der Abfolge V-S stehen im Dienst der Handlungs-Darstellung, die Sätze mit der Abfolge S-V (wobei $V$ auch $=m+N$ ) beziehen sich auf zustände. Damit sind keine grammatischen Regeln aufgestellt, sondern die syntaktische Ausdrucksform einer thematischen Opposition in den Sonnenhymnen beschrieben. Trotzdem muss sich eine solche philologischstilistische Beobachtung natürlich mit dem Regelsystem der 
Grammatik vereinbaren lassen, was aber bei dem augenblicklichen stand der Diskussion nur unter grossen Schwierigkeiten möglich erscheint ${ }^{105}$ und auf jeden Fall über den Rahmen dieses Kapitels hinausfüht. Worauf es mir in diesem zusammenhang allein ankommt, ist der charakter des Festlichen, den das Tageszeitenlied der Himmelsüberfahrt verleiht. Im Totenbuch der Nedjemet beginnt ein Hymnus, der ausschliesslich dem Mittagsgeschehen gewidmet ist, sogar wie ein Festlied mit dem Wort für "Fest": hrww nfr "schöner Tag". Ich zitiere den Text in extenso wegen seines besonders ausgeprägten ikonischen Charakters:

De in Tag ist schön, du Barke des Re,

in dieser schönen Stunde des Tages!

Schön gehst du auf, Sonne! (Siebenmal).

Das Gesicht der Barke

ist nach westen gewendet auf der Sandbank.

Der Sohn der Nut hält seinen speer.

Er hat die Schildkröte geschlachtet, die Gazelle gefält,

den Feind zertreten.

Tilapia ist in Jubel,

der Abdu-Fisch im Fest,

die Götter des Himmels jauchzen und schlagen die Pauke.

Re ist in Freude,

der Erleuchter der beiden Länder ist in Frohlocken.

Die grosse Gelobte, Osiris Nedjemet, gerechtfertigt,

ist errettet vor jenem Feinde. ${ }^{106}$

In der Uberwindung der Sandbank hat sich auch die Errettung der Beterin ereignet.

$105 \mathrm{~F}$. Junge, Syntax der mittelägyptischen Literatursprache, W. Schenkel, in: GM 29 (1978) 105-117; Ders., in: GM 40 (1980) 81-96. Bevor die Diskussion der mittelägyptischen Syntax nicht auf grössere Texteinheiten oberhalb der Satzgrenze erweitert wird, werden sich stilistische Regelhaftigkeiten wie die hier beschriebene kaum grammatisch erfassen lassen. Die im Entstehen begriffene Diss. von R. Hannig uber Text und Tempus wird hier weiterfuhren.

106 AHG Nr . 19. 


\subsubsection{Abend und Nacht}

Abend und Nacht werden nicht ikonisch geschieden wie Morgen und Mittag, sondern in einem Bild zusammengeschaut. In dieser Phase erscheint der Sonnengott als Atum, der "Vollendete", der präexistente Gott des urbeginns, zu dem jeder zyklus zurückkehrt, um wahrhaft von Neuem anfangen zu können. 107

\section{A: Handlung des Gottes}

Die Handlung des Gottes hat einen doppelten Aspekt, einen manifesten und einen verborgenen, eine Aussen- und eine Innenseite: der Gott erscheint den Toten in der Unterwelt, und er durchläuft dabei selbst die Existenzform eines "verklärten Toten" (jm3hjj). Mit seinem descensus ad inferos erweckt er nicht nur die Toten aus dem Todesschlaf, sondern lebt ihnen die Uberwindung des Todes vor. Schon der älteste Text, der das Thema der Unterweltsfahrt der Sonne behandelt, spruch 1068 der Sargtexte, deutet diesen Doppelaspekt an:

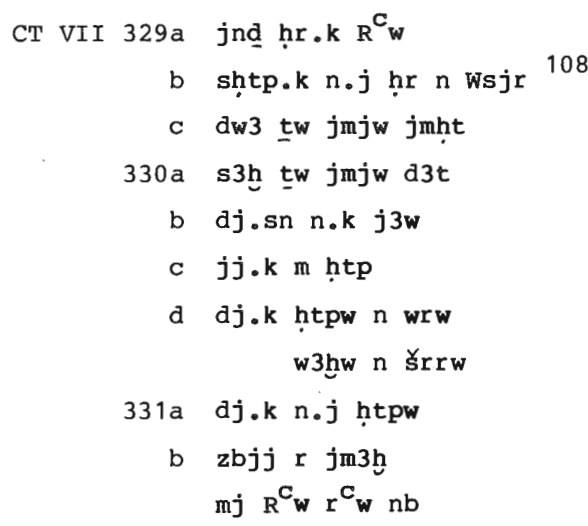

Sei gegrüsst, Re!

Mögest du mir das Angesicht des Osiris besänftigen.

Die Bewohner der Tiefe beten dich an,

die Bewohner der Unterwelt verklären dich,

107 zeit und Ewigkeit, 44 n.155, 47 m.n.161; König als Sonnenpriester, 44 m.n. 2 und 9 .

108 Var. shtp.k hr n Wsjr NN. 
sie geben dir Lobpreis,

wenn du in Frieden kommst,

um Opfergaben zu geben den Grossen

und Gedeihen den Kleinen

Mögest du mir opfergaben geben

und ein Gelangen zur Ehrwlurdigkeit

wie Re Tag fur Tag.

Von der "Ehrwürdigkeit" des Re, die sich in diesem Text der Tote wüscht, ist auch in den Sonnenliedern des Neuen Reichs nicht selten die Rede, vor allem in dem verbreiteten standardtext "D" (z.B. Text Nr.180b):

Willkommen in Frieden, du hast die Erde erreicht,

die Arme des Westbergs haben dich umfangen!

Deine Majestät hat die Ehrwurdigkeit angenommen,

indem du gelandet bist an deiner stelle von gestern.

Die Arme deiner Mutter sind als Schutz um dich,

Sjb fällt deine Feinde;

die Westlichen Ba's ziehen dich

auf dem Weg im Heiligen Land;

Du erleuchtest das Angesicht der Unterweltlichen,

du erhörst das Rufen dessen im Sarge.

In dieser Darstellung des Nacht-Ikons treten fünf typische Komponenten hervor:

(a) Die "Landung" ( $\mathbf{s} 3 \mathrm{~h} \mathbf{t} 3$ ) im Westen, als Eingehen in die "Arme" des Westbergs

(b) Die "Landung" ( $\mathrm{mnj}$ ) als Abschluss des Zyklus und Eingehen in die jenseitige Existenzform eines jm3hjj.

(c) Die Umarmung durch die Mutter

(d) Das Ziehen der Barke durch die "Westlichen Ba's"

(e) Die belebende Fürsorge für die Toten durch Licht und Zuspruch.

Wir wollen die Komponenten dieses Bildes der Reihe nach durchgehen.

(a) Der räumlich-kosmische Aspekt des Geschehens, das Eintreten der Sonne in das Westgebirge, wird in diesem Verspaar genau so beschrieben, wie es die bildlichen Darstellungen des 
Sonnenuntergangs gern zeigen, wo aus dem Westberg ein Armpaar herauskommt, das die untergehende Sonne umfängt. 109 Der Charakter des Vorgangs als einer Erscheinung des Gottes in der Unterwelt kommt in der Anrede "Willkommen" zum Ausdruck. Es ist die typische Anrede des Gottes am Abend, da der Sonnenuntergang im Gegensatz zum Sonnenaufgang als "Ankunft" gedeutet wird. 110 Den Oberweltlichen erscheint der Gott am Morgen nur, indem er sich zugleich von ihnen entfernt und den ganzen unermesslichen Abstand von Himmel und Erde zwischen sich und die Menschen legt ${ }^{111}$, zu den Unterweltlichen kommt er aber leibhaftig und spricht mit ihnen. Die Anrede "Willkommen" ist aus der Unterwelt heraus gesprochen zu denken. 112

(b) Der innere, personhafte Aspekt dieses Vorgangs ist die Wandlung des Gottes in die jenseitige Existenzform des Verstorbenen als jm3hjj, in der auch der Mensch das Leben zu "wiederholen" hofft. Der Sonnengott "empfängt" diese wlurde; dieser vorgang hat also etwas Passives. In der Darstellung des Textes LL I 2 heisst es: "Dir ist Ehrwürdigkeit gegeben bei Osiris". 113 Es ist die Passivität des Todes, die darin zum Ausdruck kommt. Der Ausdruck jm3h bezieht sich sowohl auf die Versorgung eines "Grabherrn" mit Grab, Kult und Riten, die sein Weiterleben gewährleisten, als auch auf seine wurdigkeit zu solcher Versorgung. Auch der Sonnengott erscheint so als ein "Versorgter", der den Ubergang ins Jenseits in der Einbezogenheit in schützende und belebende Konstellationen besteht:

\author{
Der Schutz des Re bewahrt dich, \\ der zauber des Thoth ist bei dir, \\ die Heilkraft der Isis durchdringt deine Glieder
}

Diese Sätze stammen nicht etwa aus einem Totentext, sondern aus einem Hymnus zum Sonnenuntergang. 114

$109 \mathrm{LL} 232 \mathrm{n} .9 \mathrm{vgl} .61 \mathrm{n} .97$.

110 LL 46-48; Text 17 (a); Text 52 (h), (m).

111 LL 302-306.

112 LL $46-48$.

$113 \mathrm{Vgl}$. LL 63f. fur weitere Belege (Amduat; LL I 3, 77, 8a) .

114 Florenz 1603, Schiaparelli, Cat.Gen....Firenze I, 337; W. Berend, Mu- 
(c) Inbegriff der belebenden und bewahrenden Konstellation, in deren "Einbezogenheit" sich der Tod als ubergang zu neuem Leben erweist, ist die Umarmung durch die Muttergottheit und Himmelsgöttin Nut. 115 Nach der Darstellung der Kosmographien geht der Sonnengott am Abend nicht in die Umarmung, sondern in den Mund der Himmelsgöttin ein, um am Morgen aus ihrer Scheide wieder auszutreten. ${ }^{116}$ Davon ist in Sonnenhymnen jedoch so gut wie nie die Rede. ${ }^{117}$ Die Ikone der Sonnenhymnik veranschaulichen die kosmischen Vorgänge so, dass sie auf andere Sinn-Dimensionen hin transparent werden. In diesem Fall ist dieses verfahren ganz besonders evident. Mit dem Bild der Umarmung der Sonne durch die Himmelsgöttin gibt das Tageszeitenlied dem Sonnenuntergang dieselbe sakramentale Ausdeutung, wie Totensprüche ("Verklärungen") der Beisetzung, und zwar in derart identischen Formulierungen, dass man bei isolierten zitaten nicht entscheiden könnte, wer gemeint ist: der Sonnengott oder der Tote. ${ }^{118}$ Der Sinn dieser Konstellation liegt in der vereinigung mit der Mutter, die den Tod als Heimkehr zum Ursprung ausdeutet. 119 Interessant ist jedoch, dass diese Vereinigung in dex ikonischen Veranschaulichung die Form der Umarmung annimmt und nicht die eines Wieder-Eintretens in den Mutterschoss. Die ikonische Formulierung folgt den Gesetzen der bildlichen Darstellbarkeit und rituellen Begehbarkeit. 120

sée Egyptien de Florence, 98-99; Barugc-Daumas, Hymnes et prières, $\mathrm{Nr} .43$ (dort anders aufgefasst). Vg1. Totb 181, s. LL $97 \mathrm{~m} . \mathrm{n}$. 23. Dieser Text ist dadurch interessant, als er osiris und den nachtlichen Sonnengott auf geheimnisvolle Weise gleichsetzt:

Die Herren der Unterwelt frohlocken,

sie beten dich an, wenn du zu ihnen gelangst

in jenem deinem Gesicht des Osiris

vgl. ahnlich Text $180 \mathrm{C}, 6-8$ und weitere stellen in $(\mathrm{n})$.

115 LL 146 n.34; LA IV 266-271.

$116 \mathrm{k} \not \mathrm{nig}$ als Sonnenpriester, 26f . $42 \mathrm{f}$.

$117 \mathrm{Vgl}$. Text 233; AHG Nr. 129, 110 (Hibis 32, 23).

118 Eine Sammlung einschlägiger Totentexte gibt A. Rusch, Die Entwicklung der Himmelsgottin Nut zu einer Totengotheit, MVAg 27, 1922. Vgl. auch $0 ., \mathrm{n} .40$.

119 LL $382 \mathrm{s.v}$. Heimkehr; LA IV, 267-269.

120 Bildlich wird diese Konstellation $z \cdot B$. realisiert durch die Nut-Darstellungen im Innern des Sarges, vgl. die Beschreibung dieses Bildes im Totenpapyrus I Rhind, XI,5, die ein besonders schones Beispiel fur den Zusammenhang von Bild und Sprache im ikonischen Denken darstellt: 
(d) Die "Westlichen Ba's" sind die Schakale, die zum Sonnenuntergang gehören wie die "Ostlichen Ba's", die paviane, zum Sonnenaufgang. 121 Ihre Aufgabe ist es, das Sonnenboot durch die Unterwelt $z u$ treideln. So stellen es das Buch der Nacht und Barkenszenen in Sonnenheiligtümern dar, 122 eigenartigerweise aber nicht die Unterweltsbücher. ${ }^{123}$ Das Ikon der durch die Unterwelt getreidelten Sonnenbarke erschliesst sich in seinem Bedeutungsgehalt ebenfalls vom Totenglauben her. Zu den zentralen wünschen des Toten gehört es nämlich, "das Vordertau der Nachtbarke zu ergreifen". ${ }^{124}$ Damit ist der Wunsch nach Identifikation mit jenen wesen gemeint, die als "Schakale", "Westliche Ba's", "Westliche Götter"125 oder "Unterweltliche Götter"126 bezeichnet werden, genauso, wie auch die Paviane des Sonnenaufgangs Identifikationsfiguren des Beters darstellen.

(e) Die belebende Fürsorge des Sonnengottes für die Unterweltlichen erfüllt sich in. "Leuchten" und "Anhören". Die von seinen Strahlen erweckten Toten tragen ihm ihre Bitten vor:

Sie sagen dir alle ihre Bitten, nachdem du fur sie erstrahlt bist ${ }^{127}$

Sie sagen dir, was sie auf dem Herzen haben, wenn du innen deinen Anblick wiederholt hast ${ }^{128}$

meine Arme sind ausgebreitet, deinen Gottesleib zu umfangen, damit ich deinen Leib beschirme, deine Mumie beschutze und deinen $\mathrm{Ba}$ belebe fur immer.

Auch der Abend-Teil des kulttheologischen Traktats erwähnt sie, cf. J.C. Goyon (n.122), Tf. 20A, 8 und S.42 m.n.15.

$121 \mathrm{Zu}$ den Schakalen s. Text 61 (a) mit weiterer Lit., sowie LL 54f., dort auch Hinweise zur Gleichsetzung der b3w jmntt mit den Schakalen.

122 Medinet Habu VI 422C usw., s. J.C. Goyon, in: Parker et al., The Edifice of Taharqa, $42 \mathrm{n} .17$.

123 Im pfortenbuch wird die Sonnenbarke auch getreidelt, aber durch die "Unterweltlichen Gotter", die nicht als Schakale, sondern menschengestaltig dargestellt werden (Hornung, Unterweltsbucher 204 oben, 212 usw.) Schakale erscheinen dort in anderer Funktion als wachter des "Sees des Lebens" (218f.).

124 Z.B. CT VI 3139; VII 14 o; Text 52, 71 usw. s.a. W. Barta, Aufbau und Bedeutung der altăgyptischen opferformel (1968), 159, 245. Auch in dem Hymnus AHG $\mathrm{Nr} .44,31$ treideln die Toten selbst das Sonnenschiff.

125 Z.B. Std.Rit., 12.Std., 10. 15; Medinet Habu VI $422 \mathrm{C}$.

126 So passim im Pfortenbuch.

127 Totb 15 B II AHG Nr.44, 23.

128 okairo $25106=$ AHG Nr.191, 27-28. 
Die lebenden $\mathrm{Ba}^{\prime}$ 's erwachen auf ihren Sitzen,

nachdem sie den Herrn der Götter erblickt haben. 129

Eigenartigerweise wird die sprachliche Kommunikation des Sonnengottes mit den Unterweltlichen, die als ein Akt der Belebung überall neben dem Schauen des Lichts genannt und offenbar für genauso wichtig erachtet wird, nicht nur als Hören und Erhören, sondern auch als Spenden von Atemluft ausgedrückt :

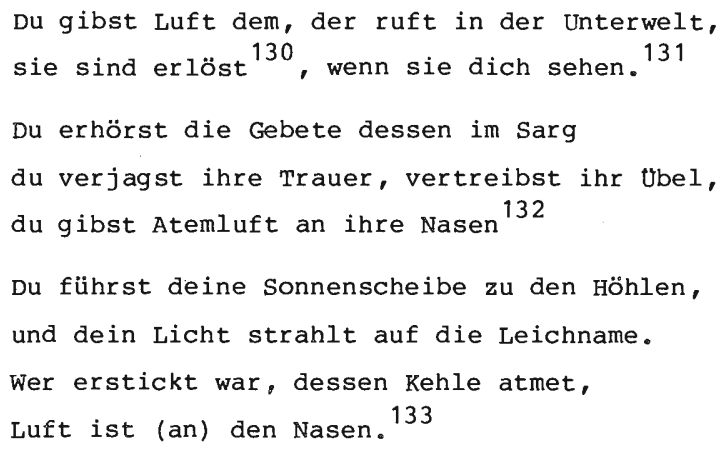

Dass mit diesem Luft-Spenden tatsächlich eine Art belebender Zuspruch des Gottes gemeint ist, geht aus der detaillierten Darstellung, die die unterweltsbücher diesen Vorgängen und Handlungen geben, hervor. Die Worte, mit denen der Sonnengott die Toten anredet, ihnen Recht spricht und ihren Lebensunterhalt zuweist ${ }^{134}$, sind der Hauch, von dem sie leben. "Sie atmen vom Hören seiner stimme". 135

Die Vereinigung mit der Mutter ist eine typisch "ikonische" Formulierung der Nachtphase, die in den Unterweltsbüchern keine Rolle spielt, da diese ja keine "sakramentale Aus-

129 Edfou $V$ 131-132.

130 wh cf. Mariette, Abydos I 52: "Du (Re) erlösest ihn (Osiris), du lässt seine Nase atmen."

131 pBerlin $3048,7,6=$ AHG $\mathrm{Nr} .143,141 \mathrm{f}$.

132 Totb 15 B II $=$ AHG $\mathrm{Nr} .44,28-30$.

133 owien 6155+oCG 25214, Vittmann, in: WZKM 72 (1980) 2 Tf.2-3.

$134 \mathrm{zu}$ Versorgung und Rechtsprechung als den dominierenden Aspekten der Totenfürsorge des Sonnengottes s. LL 145f. m.n.29-30.

$135 \mathrm{LL} 144 \mathrm{f}$. m.n.26. 
deutung", sondern eine kosmographische Beschreibung des sonnenlaufs geben. In ihnen tritt aber ein anderer Aspekt der Unterweltsfahrt. hervor, der ebenfalls auf einer anthropologischen Analogie beruht:

"Die ganze Nachtfahrt des Sonnengottes wird gelegentlich so dargestellt, als käme der Sonnengott in seiner Ba-Form vom Himmel herab in die Welttiefe 'wegen seines Leichnams'"136. Im Höhlenbuch wird die Analogie zum menschlichen Totenschicksal explizit ausgezogen:

"Ich lasse die Ba's auf ihren Leichnamen sich niederlassen, nachdem ich mich (selbst) auf meinem Leichnahm niedergelassen habe." ${ }^{137}$

Von diesem nächtlichen "Besuch" ( sjp) des Sonnengottes bei seinem unterweltlichen Leichnam wissen bereits die Sargtexte ${ }^{138}$, gleichzeitig bildet sich die entsprechende anthropologische Konzeption der nächtlichen Vereinigung von $\mathrm{Ba}$ und Leib heraus. 139 Auch in den Hymnen ist davon gelegentlich die Rede. 140 Man hat aber den Eindruck, dass diese Dinge bereits zu den "Mysterien" gehören.

Ganz entschieden zu den Mysterien des Sonnenlaufs gehört jene Deutung dieses Vorgangs, die darin die Vereiniqung von

136 Hornung, Unterweltsbücher 36 mit Bezug auf den Schlusstext zur 2.Std. des Amduat.

137 Hornung, Unterweltsbücher 317: Höhlenbuch I., 3.Reg.

138 S. Text $158(\mathrm{n})$. Nach diesen und vielen anderen Stellen ist Heliopolis der Ort, wo der unterweltliche Leichnam des Sonnengottes verborgen. ist:

CT VII $19 \mathrm{~h}$ Meine Glieder sind Re, wenn er nach Heliopolis hinabsteigt, um seinen Leichnam zu beweinen.

СT IV $64 \mathrm{c}$ Ich sehe meinen Vater, den Herrn des Abendrots, ich küsse meinen dt -Leib in Heliopolis.

CT I 184-85 Du fährst stromauf in der Msktt -Barke, du fährst stromab in der M nd -Barke, dein $\mathrm{Ba}$ ist dem oberen Himmel überwiesen, dein 'Fleisch' und dein Leichnam in Heliopolis.

139 Lebensmüder, vgl. W. Barta, Das Gespräch eines Mannes mit seinem Ba (MÄS 18, 1969).

140 Hymnus des Jpwj3 (Quibell-Hayter, Teti Pyramid, North Side, Tf.IX, S. $32-33) ; \mathrm{z} .3: \mathrm{b} 3 \mathrm{n} \mathrm{pt}, \mathrm{h} 3 \mathrm{t} \mathrm{n}$ d3t

"Der Ba zum Himmel, der Leichnam zur Erde" Die Sätze wirken im Kontext wie ein Fremdkörper; vgl. Amduat I 57: pt $\mathrm{n}$ b3.k, t3 n h3t.k; I, 59: b3.k n pt, Wsjr, h3t.k n t3, hntj-jgrt; vgl. auch $\mathrm{Pfb}^{-}$9.Std., Hornung, Unterweltsbücher 268 und sehr oft sonst (z.B. Sonneniitanei). 
Re und Osiris sieht:

"Wer das enthüllt, stirbt eines gewaltsamen Todes,

weil es ein grosses Mysterium ist:

Re ist das und Osiris." 141

Im Antagonismus von Re und osiris verkörpert sich auf allerhöchster Abstaktionsstufe jene "duale Einheit", als die der Agypter die Wirklichkeit insgesamt - alles seiende ( wnnt nbt ) - denkt: als nḥh und dt . 142 Aus der nächtlichen Vereinigung dieser komplementären Aspekte der Zeit entsteht die "Kontinuität der zeit", d.h. die Kontinuität des Lebens, das sich in der zeit verwirklicht. ${ }^{144}$ wichtig aber für das verständnis dieser Konstellation ist aber vor allem die Tatsache, dass sich in dieser Umarmung von Re und osiris (="Morgen und Gestern" "nḥh und d̂t ) nicht Ba und Leichnam, sondern Sohn (als das "Morgen") und Vater (als das "Gestern") vereinen. 145 Auch diese Konstellation erscheint dadurch als in verschiedenen Sinn-Dimensionen bedeutungsvoll: denn in der Umarmung von vater und Sohn überträgt sich, so meint man, der Ka. 146 zuweilen erscheint auch Tatenen in der Rolle des umarmenden Vaters ${ }^{147}$, genau wie Isis (anstatt Nut) in der Rolle der umarmenden Mutter auftreten kann. ${ }^{148}$ Entscheidend für den Bedeutungsgehalt der Konstellationen ist die Konstanz der Rolle, nicht ihre Besetzung.

B: Anbetung und Jubel der Unterweltsbewohner

Der Vergleich der Verbformen und Satztypen, in denen die BSeite des Geschehens am Morgen und am Mittag dargestellt

141 psalt $825,18,1-2$ vgl. Lanzone, Pap. du Lac Moeris, Tf.VI. S. hierzu ausführlich LL 101-105.

142 CT IV 198ff., vgl. Hornung, "Zum ägyptischen Ewigkeitsbegriff", in: FuF 39, 1965, 334-336; Der Eine und die Vielen, 178.

$143 \mathrm{~S}$. Zeit und Ewigkeit, 28-30 mit Hinweisen auf die grundlegende Interpretation des psalt 825 durch $\mathrm{Ph}$. Derchain.

144 LL 103-105.

145 LL, ibd.; König als Sonnenpriester, 43f. n.4.; Zeit und Ewigkeit, 44 $\mathrm{m} \cdot \mathrm{n} \cdot 155$.

146 Frankfort, Kingship and the Gods (1947), 32f., 66, 122, 132ff.; Kaplony, LA III, $275 \mathrm{~m} \cdot \mathrm{n} .3$.

147 LL 60-63.

148 LL 56-60. 
wird, hat uns die Möglichkeit einer klaren Unterscheidung an die Hand gegeben zwischen der Anbetung als Handlung und dem Jubel als zustand. So können wir auch im Hinblick auf die Nachtstrophen fragen, ob die Responsion der unterweltlichen auf die Handlung des Gottes als Anbetung oder als Jubel, als Handlung oder als Befindlichkeit ausgedrückt wird. Hier scheint sich nun ein stilistischer Wandel abzuzeichnen. In den älteren Hymnen und auch im Amduat wird die Responsion der Unterweltlichen regelmässig als Handlung dargestellt: als Begrüssung wie am Morgen in der Oberwelt. In ramessidischen Hymnen dagegen überwiegen durative und zustandsformen:

\begin{tabular}{|c|c|c|c|c|c|}
\hline & $\begin{array}{l}\text { An- } \\
\text { rede }\end{array}$ & $\begin{array}{l}\text { Verb- } \\
\text { form }\end{array}$ & $\begin{array}{l}\text { Verb- } \\
\text { form }\end{array}$ & $\begin{array}{l}\text { An- } \\
\text { rede }\end{array}$ & \\
\hline $\begin{array}{l}\text { eispied 1: } \\
\text { LL I } 2\end{array}$ & & & & & $\begin{array}{l}\text { Beispiel 3: } \\
\text { pLouvre } 3292 \text { "M" }\end{array}$ \\
\hline
\end{tabular}

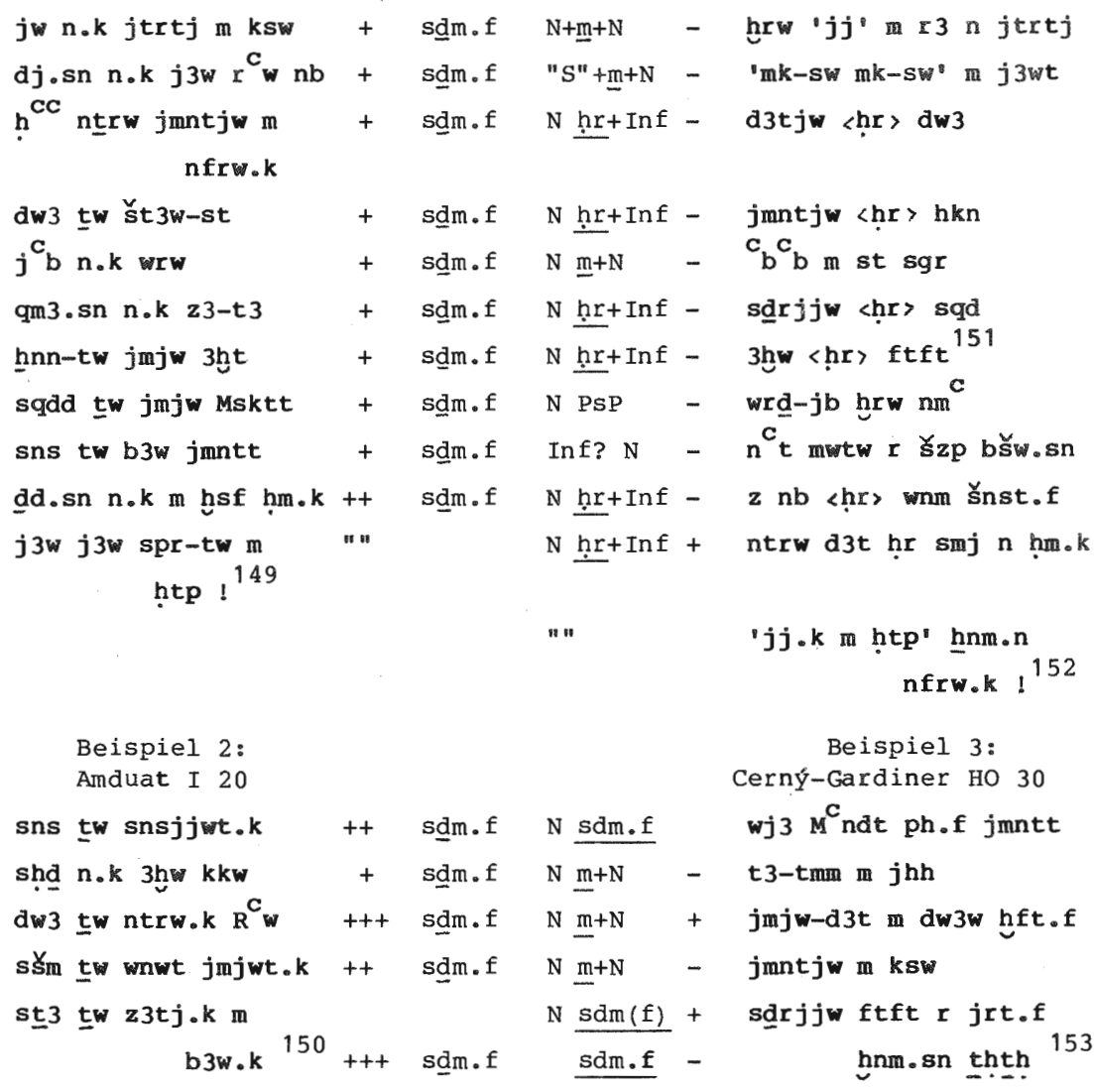


Beispiel 5:

An- Verb- Verb- An-

rede form form rede

THO 15 B II

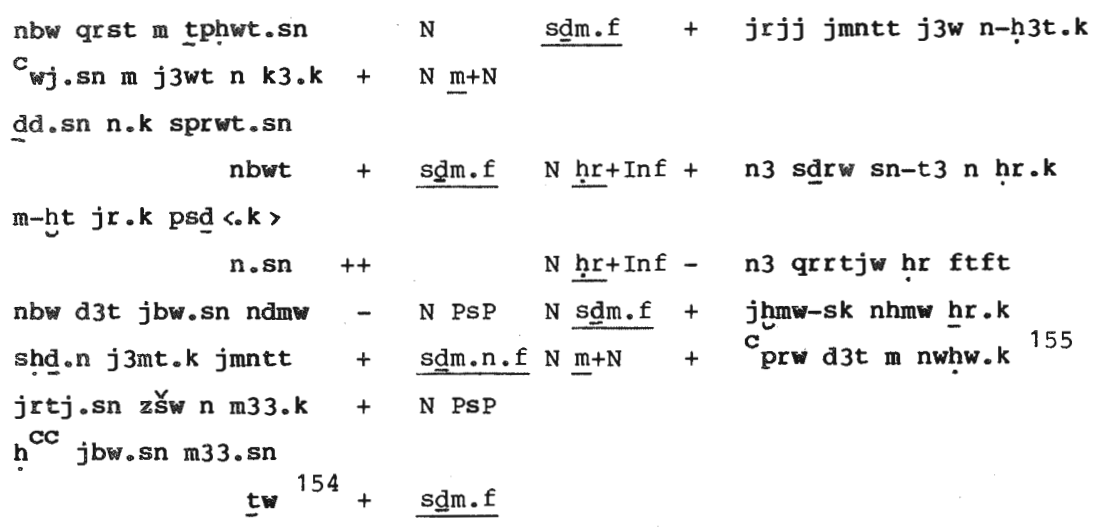

Beispiel 1 und 2 zeigen den Typus der Handlungsdarstellung in seiner reinen Form, Beispiel 3 und 4 den Typ der Situationsschilderung. Beide Male, besonders ausgeprägt in Beispiel 3, korrespondiert dem Wechsel der Satztypen auch ein Wechsel der Anrede-Stuktur: Handlungen sind als kommunikative Akte bezogen, Zustände nicht. Beispiel 5 und 6 illustrieren die Mischung beider Typen, die das häufigste ist.

Auch in der Schilderung des Empfangs, die dem Sonnengott in der. Unterwelt zuteil wird, spiegelt sich die Hoffnung des Toten auf ein gleiches Schicksal. Auch hierin lesen sich Totentexte wie Sonnenhymnen, und umgekehrt:

Jubelruf erschallt im Totenreich,

die Unterweltlichen rufen "Willkommen!",

so sagen sie zu diesem $N$.

Die in ihren Grabern, ihr Herz weitet sich wegen dieses $\mathrm{N}$ :

"Du bist der grosse Gott, der Himmlische unter den Gottern. 156

Die Arme deines Vaters Geb empfangen dich,

deine Mutter Nut umarmt dich;

die Gotter, die durch die unterwelt fuhren,

sie jubeln aus Liebe zu dir.

Sie empfangen dich in Frieden: 
149 Ubersetzung:

Die beiden Landeskapellen kommen zu dir in Verneigung, sie geben dir Lobpreis Tag fur Tag.

Die westlichen Gotter jubeln uber deine Schonheit, die mit geheimen Sitzen beten dich an;

Die Grossen gesellen sich zu dir, sie stimmen dir "Hute dich, Erde!" an.

Die Bewohner des Lichtlands rudern dich, die Insassen der Nachtbarke fahren dich.

Die Ba's des Westens preisen dich, sie sagen zu dir beim Nahen deiner Majestät:

Willkommen, willkommen, angelangt in Frieden!

150 Ubersetzung nach Hornung, Unterweltsblucher $67 f$. :

Es preisen dich deine preisenden,

es erleuchten dir deine Uraus-Schlangen die Finsternis.

Es beten dich deine Gotter an, Re!

Es geleitet dich die Stunde(ngottin), in der du bist,

es ziehen dich deine beiden Töchter in deiner Barke.

151 ftft, "hupfen" ist ein Wort, das gern fur die Reaktion der auflebenden Toten auf das Sonnenlicht verwendet wird, vgl. Beispiel 4 und 6 und LL $249 \mathrm{~m} \cdot \mathrm{n} \cdot 16-18$.

152 Ubersetzung $s$. AHG Nr.47:

Lobruf (erschallt) im Munde der beiden Landeskapellen,

"Da ist er, da ist er!" (rufen) die stätten,

die Unterweltlichen sind in Anbetung,

die Westlichen in Preisungen,

Frohlocken (ertönt) an der stätte des Schweigens.

Die Schlafenden kommen gefahren,

die Verklärten hupfen,

der 'Mudherzige' ist auf der Bahre niedergesunken.

Die Toten geleiten heran, um ihre Rationen zu empfangen,

jedermann isst seine speise.

Die Götter der Unterwelt erstatten deiner Majestăt Meldung:

"Willkommen in Frieden! Wir haben uns mit deiner Schonheit

153 Ubersetzung: vereinigt!"

Die Barke M ${ }^{C}$ ndt hat den Westen erreicht,

die Menschheit jauchzt.

Die Unterweltlichen sind in Anbetungen vor inm,

die Westlichen in verneigung.

Die Schlafenden hupfen vor seinem Auge, Jauchzen ergreift sie.

154 Ubersetzung S.AHG $\mathrm{Nr} .44$ :

Die Hohlenbesitzer in ihren Gruften,

inre Arme sind in Anbetungsgesten fur deinen Ka.

Sie sagen dir alle ihre Anliegen, nachdem du fur sie aufge-

die Herren der Unterwelt, inre Herzen sind froh: leuchtet bist;

dein Glanz hat den Westen erhellt.

Ihre Augen sind offen, um dich zu sehen,

ihre Herzen jubeln, wenn sie dich erblicken.

155 Ubersetzung s.STG, Text 244.

156 CT IV 97. 
"Willkommen, willkommen!" ${ }^{157}$ sagen sie zu dir, nachdem du in Frieden angekommen bist und dein Haus der Ewigkeit erreicht hast, dein Grab der Dauer. 158

\section{Schlussbemerkung}

Zwei Beobachtungen haben sich wie ein roter Faden durch alle Detailuntersuchungen dieses Kapitels hindurchgezogen und sollen abschliessend noch einmal hervorgehoben werden:

(1) Die Aquivalenz von Bild und Sprache, die prinzipielle Ausdrückbarkeit von "Gedanken" - d.h. Formulierungen von Inhalt im Sinne von "forme du contenu" (Hjelmslev) - im einen oder im anderen Medium.

(2) Die Komplexion mehrerer Sinn-Dimensionen in einem Ikon, das bewusste In-Eins-Sehen verschiedener Sphären und ihre Darstellung in der Form wechselseitiger verweisung. Dadurch eröffnet das Ikon dem Menschen die Möglichkeit der Teilhabe am götterweltlichen Geschehen. Er kann sich in das Ikon hineinversetzen, indem er z.B. morgens $\mathrm{zu}$ einem der Paviane wird, mittags Apopis erlegt (Totb

$39)$ und abends "das Vordertau der Nachtbarke ergreift".

Beide Punkte stehen und fallen mit dem polytheistischen Weltbild, das die Götterwelt in "Konstellationen" strukturiert. Die Konstellationen sind das Prinzip ihrer Bildlichkeit: ohne sie wäre die Götterwelt nicht "ikonisch" darstellbar, was die "Ikone" darstellen, sind Konstellationen. Sie sind ebenso aber auch das Prinzip der Identifikation, durch das der Mensch an dem götterweltlichen Geschehen teilhat, dadurch nämlich, dass er als Priester im Kult und als Toter im Jenseits eine Rolle in einer Konstellation spielen und so zur Gottheit in Beziehung treten und am göttlichen Leben teilhaben kann.

157 Eig. j3w j3w "Lob, Lob!". Zur Aquivalenz von jjwj jjwj und j3w j3w als Willkommensgruss $\mathrm{s}$. die Beispiele LL 46-48.

$158 \mathrm{CG} 29301$ ed. Maspero, Sarcophages de l'époque persane et ptolemaique, S. 45 . 
Die Amarna-Revolution kommt in dieser Hinsicht einem "Bildersturm" gleich. Darauf werden wir im folgenden Kapitel eingehen. Die Frage, die sich aber in unserem zusammenhang aufdrängt, ist Folgende: hat dieser Versuch einer radikalen Destruktion des ikonischen polytheismus etwa im Gegenzug die Flut der Verbilalichungen ausgelöst, die nun erst in breiter und zur 21. Dyn. hin stetig anwachsender Front die Totenbücher, Gräber und Särge erfüllen, bis schliesslich in der 21. Dynastie das Bild sich vollkommen verselbständigt und in den "mythological papyri" und den Bildfriesen der Särge zum alleinigen Ausdrucksträger des Inhalts wird? Dieser Frage kann hier natürlich nicht nachgegangen werden, aber der zusammenhang erscheint mir evident. 
Drittes Kapitel

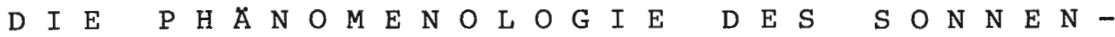
L A U F S

\section{Historische Aspekte}

Die vorangegangenen beiden Kapitel haben ein vollkommen ahistorisches Bild der ägyptischen Sonnenreligion gezeichnet und weder nach dem geschichtlichen ort seiner Entstehung gefragt, noch nach den wandlungen, denen es der Lauf der Jahrhunderte oder gar Jahrtausende unterworfen hat. Dieses Vorgehen erscheint mir dadurch gerechtfertigt, dass ich mich bewusst auf Grundstrukturen beschränkt habe, denen in der Tat eine gewisse Zeitlosigkeit innerhalb der ägyptischen Geschichte eignet. Sowohl was die Innenseite dieser Religion, die "Mysterien", als auch was ihre Aussenseite angeht, die "Ikone", liegt ihr Ursprung für uns im Dunkel und Wandlungen sind nicht erkennbar.

Diesen Grundstrukturen möchte ich nun in den folgenden Kapiteln zwei Konzeptionen gegenüberstellen, die demgegenüber sowohl hinsichtlich ihres Ursprungs als auch ihrer wandlungen einen sehr genau angebbaren ort in der geschichtlichen Entwicklung haben. Erst durch das chronologisch und sozialgeschichtlich determinierte Feld der thebanischen Gräberhymnik hat sich die Möglichkeit erschlossen, diese Konzeptionen als geschichtliche Phänomene zu begreifen. Die eine von ihnen, denen dieses Kapitel gewidmet ist, ist eine neue Sonnen-Theologie, die nicht einfach nur "anders" ist als alles Vorhergegangene, sondern die das genaue Gegenteil, die reinste Negation alles dessen darstellt, was ich in den vorangegangenen beiden Kapiteln dargestellt habe: die Verwischung der "Ikone", die Zerschlagung der "Konstellationen", die Negation einer Teilhabe durch wissen und Identifikation, die Ersetzung der "mythischen" durch die "kosmische Dimension". 
Damit ist nicht nur die Amarna-Religion gemeint, sondern eine neue Sonnen-Theologie, die vor Amarna einsetzt - ihre Anfänge lassen sich bis in die zeit Amenophis' III zurückverfolgen - und die sich nach Amarna bruchlos fortsetzt. Amarna basiert zwar auf dieser Theologie, ist aber keineswegs mit ihr identisch, sonst wäre sie mit Amarna untergegangen. Im Gegenteil stammen aber die bedeutendsten Hymnen dieser theologischen Richtung aus Gräbern der Nachamarna- und Ramessidenzeit. Auf keinen Fall wird man argumentieren dürfen, dass hier nach irgendeinem "Trägheitsgesetz" eine im Grunde diskreditierte Tradition noch ein mehr oder weniger kurzes "Nachleben" führt, oder gar von "Nachklängen" der Amarna-Religion reden. Zu den Grabherren, in deren Gräbern sich Hymnen dieser Richtung finden, gehören der Wesir und Hohepriester Paser und der Hohepriester Nebwenenef, die man zu den führenden Köpfen der geistig-religiösen Erneuerung nach Amarna zu rechnen hat. Die "neue Sonnentheologie" hat auch nach der katastrophalen Erfahrung von Amarna nichts von ihrer Aktualität eingebüsst und ist ganz offensichtlich nicht als Amarna-Religion empfunden worden.

Andererseits ist es nicht nur schwierig, sondern auch müssig, Unterschiede zwischen dieser neuen Sonnentheologie und der Sonnentheologie der Amarnatexte herausfinden zu wollen; es handelt sich wirklich um "Nuancen" ${ }^{1}$, und auf einige von ihnen werden wir zu sprechen kommen. Es kann aber nicht der geringste Zweifel daran bestehen, dass die Amarna-Religion aus dieser Bewegung hervorgewachsen ist und eine radikale variante dieser Religion darstellt. Die folgende Beschreibung des Phänomens wird daher die Amarnatexte miteinbeziehen. Es ist also offensichtlich nicht die Sonnentheologie selbst der

1 Vgl. hierzu die Beiträge von Piankoff und Aldred, zit. in Saeculum 23 (1972) 110,8-9. Die Unterschiede, die auf blosse "Nuancen" herauslaufen, betreffen wohlgemerkt nur die Sonnen-Theologie oder "Naturlehre" der Amarna-Religion auf der einen, und die "neue Sonnen- Theologie" auf der anderen Seite, also weder die Amarna-Religion als Ganzes, noch die Sonnenreligion insgesamt. Zur Amarna-Religion vgl. jetzt auch E.Hornung, in: O.Keel (Hrsg.), Monotheismus im alten Israel und seiner Umwelt (Bibl.Beitr. 14, 1980) $83-97$. 
Amarna-Religion, die als häretisch verketzert wurde, sondern vielmehr die Radikalität und Intoleranz ihrer Durchsetzung, vor allem muss aber der zweite Pfeiler, auf dem das theologische Gebäude der Amarnareligion steht: die Köniqstheologie, 2 als unerträglich empfunden worden sein.

Nachdem uns die neuen thebanischen Texte - es sind vor allem die Nrn. 76, 113, 151, 161, 253, 54 - gelehrt haben, diese Bewegung nicht einfach mit der Amarna-Religion gleichzusetzen, erweist sie sich als Ausdruck einer epochalen Krise des polytheistischen Weltbildes, die mit dem Ende der Amarna-Religion keineswegs ausgestanden war. Diese Texte erschliessen uns ein neues Bild der Epoche, die mit der Formel "Rückkehr zur Orthodoxie" nicht erfasst werden kann. ${ }^{3}$

\section{Theologische Aspekte}

\subsection{Einsamkeit und Einzigkeit}

Die Einsamkeit Gottes ist ein Begriff, der nicht im Gegensatz steht zu Polytheismus, sondern zu "Einbezogenheit", nämlich in eine Konstellation. Einsamkeit, ein Begriff, den die ägyptische Schrift durch das Determinativ des "schlechten Vogels" der Sphäre des Mangels zuweist", gilt im Horizont eines Personbegriffs, der das Ich als Teil eines Ganzen versteht, als summum malum, Inbegriff eines Mangelzustands, den es in der Götterwelt nur im Urzustand gab und der aufgrund seiner Unhaltbarkeit die Fülle der Schöpfung zur Folge hatte. Einsamkeit ist, wie E.Hornung sehr überzeugend dargestellt hat, eine Kategorie des Nichtseins und des Todes. Leben ist immer "einbezogen". Dies muss man berücksichtigen, um den ersten Lehrsatz der neuen Sonnentheologie in seinem ganzen Gegensatz zum traditionellen Weltbild verstehen zu können. Er

2 S. hierzu ausfuhrlicher meinen Aufsatz "Die loyalistische Lehre Echnatons", in: SAK 8 (1980), 1-32.

3 Vgl. dagegen AHG, 64-77; "Primat und Transzendenz", 26f.; LA I 528 m.n.

4 In der Formel $w^{\mathbf{C}} w^{\mathbf{c}}{ }^{32} w$ wird $w^{\mathbf{c}} j w$ in den $C T$ und im Kairener Amuns-Hymnus mit dem schlechten vogel determiniert; vgl. dazu Kap.5.

5 Der Eine und die vielen, 180-181, $171 \mathrm{f}$. 
lautet: die Sonne ist bei ihrem Umlauf allein. Das wird in den Texten zuweilen ausdrücklich gesagt ${ }^{6}$, bildet im übrigen aber die Grundvoraussetzung ihres Gottesbildes, denn nie ist von andern Göttern die Rede, die in irgendeiner Form am Sonnenlauf beteiligt sind.

Im Fokus der Monotheismus-Debatte bekommt man die Bedeutung dieser Aussage nicht in den Blick. Es kommt nämlich in erster Linie nicht darauf an, ob es ausser diesem einsamen Gott des Sonnenlaufs noch andere Götter gibt oder nicht, sondern darauf, dass er ohne Bezugnahme auf andere Götter gedacht und handelnd dargestellt werden kann. Dem polytheistischen Denken ist ja, wie wir gesehen haben, ein Gott als Handelnder nicht denkbar ohne bestimmte andere Götter, die mit inm eine Handlungskonstellation bilden. Dieser Gott aber ist in seinem Handeln, als welches nach wie vor der Sonnenlauf verstanden wird, allein. Gewiss macht es einen Unterschied, ob ein Gottesbegriff unabhängig von andern Göttern gedacht werden kann, oder ob er die Existenz anderer Götter geradezu ausschliesst. Dies ist der Unterschied, der die Amarna-Religion von ihrem Kontext abhebt. Er spielt aber mehr in der Praxis der Religion eine Rolle als etwa in den Texten, da von den andern Göttern nirgendwo in den neuen Sonnenhymnen die Rede ist, in Theben sowenig wie in Amarna; allenfalls als eine Gattung der Geschöpfe und Lebewesen erscheinen sie in diesen Texten neben Menschen und Tieren, aber nicht als Konstellationspartner des Gottes.

Die Einsamkeit des Sonnengottes ist die theologische Ausdeutung eines kosmischen Phänomens, nämlich die Einzigkeit der Sonne, die auch zuweilen ausdrücklich hervorgehoben wird: Text 253

\section{jtn.k w jw stwt.f m hr}

"Deine Sonnenscheibe ist allein, ihre Strahlen sind im Gesicht"

$6 \mathrm{Vgl}$. z.B. AHG Nr.90, 7:

"Du hast dich gezeigt am Himmel, indem du allein bist." 
Eine Ausdrucksweise wie "deine Sonnenscheibe" wäre in Amarna nicht denkbar; auch dies gehört zu den Differenzen zwischen der neuen Sonnen-Theologie und ihrer Amarna-Form. In Amarna ist der Gott die Sonne selbst, allenfalls ist sie seine "Verkörperung" ( hprw ). 7 In den anderen Texten ausserhalb Amarnas gilt sie als sein $h^{\mathbf{C}}{ }^{w}-$ Leib ${ }^{8}$ oder sein dt-Leib ${ }^{9}$. Auch dies bringt eine unendlich viel engere Relation zwischen Gott und Gestirn zum Ausdruck als in der traditionellen Konzeption, wo die Sonne als "Auge", Kopfschmuck, Uräus, Attribut des Gottes betrachtet wird. ${ }^{10}$ Der Gott der neuen SonnenTheologie ist im wahrsten Sinne des Wortes sonnen-gestaltig. Die Kräfte, die das polytheistische Denken in Gestalt einer Sphäre beistehender Gottheiten um ihn versammelte, werden nun in ihrem kosmischen Charakter als wirkungen der Sonne beschrieben. Das Feuer der Uräusschlange wird zur sengenden Glut, ${ }^{11}$ die kraft des seth zur alles "bezwingenden" ${ }^{12}$ Strahlung. Indem der Gott die "Sphäre des Seinigen" gleichsam absorbiert, in sich aufgenommen hat, ist er der einzig Handelnde. Sein Handeln aber ist strikt "heliomorph": nur das wird ihm als Handlung zugeschrieben, was sich der theologischen Ausdeutung der kosmischen Phänomene als Wirkung des Sonnenlichts erschliesst.

Die polytheistische Religion hatte den Sonnenlauf demgegenüber als ein komplexes Handlungsgefüge dargestellt, in dem der Sonnengott zwar Protagonist, aber durchaus nicht der ausschliesslich aktiv Handelnde war. Er wird geboren, gesäugt, aufgezogen, angebetet; der Feind wird fur ihn vernichtet; er wird in der Unterwelt von den Armen seiner Mutter umfangen -

7 Sandman, 76.5; 76.8-9; 95, cf. auch 91; MDIK 27.1, 17 n.40a.

8 Text $181 \mathrm{a} .50$.

9 Urk IV 2178 usw., s.MDIK $27.1,17 \mathrm{n} .40 \mathrm{a}$.

10 LL 114 (2).

$11 \mathrm{Vgl}$. Suti-Hor AHG Nr.89, 57: "Er macht die Hitze, wenn er will und die kuhle, wenn er will, er lasst die Leiber erschlaffen, wenn er sie umfängt"; Amarna Grosser Hymnus AHG Nr.92, 107-109 ("...die Hitze, damit sie digh sp(uren").

$12 \mathrm{Vgl}$. wf "niederbeugen, bezwingen" als Bezeichnung der Handlung des Sonnengottes in Bezug auf die von ihm bestrahlten Fremdländer: Amarna Grosser Hymnus, AHG Nr.92, 24 . 
um nur einige der spezifisch passiven Aspekte des Handlungskomplexes Sonnenlauf zu nennen. Alle Handlungen aber sind in irgendeiner Form auf ihn bezogen; dadurch wird die Beschreibung dieser Handlung $\mathrm{zu}$ einer hymnischen Charakteristik seines "Status"13. Die semantischen Kategorien dieser Handlungen, in denen die traditionellen "ikonischen" Darstellungen den Sonnenlauf beschreiben, habe ich zusammengefasst als

$$
\text { LICHT - BEWEGUNG - LEBEN - HERRSCHAFT. } 14
$$

Dies sind auch die semantischen Kategorien der theologischen Ausdeutung, die die kosmischen Phänomene des Sonnenlaufs als die eine Handlung des einen Gottes in der neuen Sonnentheologie erfahren. Im Sinne der Prävalenz des Kosmischen in der neuen Theologie dominieren Licht und Bewegung; Leben und Herrschaft werden ihnen untergeordnet. Im Licht und durch seine Bewegung belebt und beherrscht Gott die Welt. ${ }^{15}$ Dabei ist es höchst eindrucksvoll, was sich diesem neuen, auf die kosmischen Phänomene konzentrierten Blick alles als Wirkungen des Lichtes und der Sonnenbewegung erschliesst. Wir werden die Beispiele im Einzelnen noch betrachten. Man kann sich gut vorstellen, dass es nur noch eines schrittes bedurfte, um schlechthin alles auf diesen einen Handelnden zurückzuführen und seine Einsamkeit als Einzigkeit zu proklamieren.

\subsection{Ferne und Verborgenheit}

Er hat sich hoch entfernt, niemand kennt seine Gestalt ${ }^{16}$

Du hast dich befestigt sehr, sehr weit,

sehr, sehr fern;

du hast dich gezeigt im Himmel, indem du allein bist. ${ }^{17}$

Du machtest den Himmel fern um seinetwillen,

sehr, sehr weit,

sehr, sehr fern. 18

13 Zur (semantischen bzw. "inneren") Form des traditionellen Sonnenliedes als "Statuscharakteristik" s. AHG, 33-45.

$14 \mathrm{~S}$. dazu ausfuhrlicher AHG, 35-63.

15 Ausfuhrlicher: AHG, 54-63 vgl. auch Zeit unả Ewigkeit, 49-54.

16 BM 706, Kitchen, RI I, 330.

17 Leiden $\mathrm{V} 70=\mathrm{AHG} \mathrm{Nr} .90$; Leiden $\mathrm{K} 12=\mathrm{Kitchen,}$ RI III, 175, 3-4.

18 pBerlin $3048=$ AHG $\mathrm{Nr} \cdot 143,81-83$. 
Hoher, den man nicht erreichen kann,

(...) Herr des Thrones, der geheimhält, was er verborgen hat,

(...) Verborgener, dessen Aussehen man nicht kennt. ${ }^{19}$

Du Hoher, dessen Lauf man nicht kennt,

wie geheimnisvoll sind deine Erscheinungsformen!

Grosse Macht, Erster des Lichtlands,

Hoher, Hoher, den niemand erreichen kann! 20

Der du den Himmel schufest, um deine Erscheinungsform zu erhohen, um zu verhullen, worin du dich aufhältst,

du hast ihn fern gemacht, um ihm dein Abbild anzuvertrauen....21

Du hast dich entfernt als der 'Ferne' Uber ihnen. ${ }^{22}$

Wenn du im Himmel bist, erkennt dich deine Ungebung nicht,

dein Gefolge versteht nichts von dir,

die Neunheit dringt nicht an dich heran. 23

Er hat seinen Sitz umgeben mit Feuer,

und sich hoch entfernt uber jeden Gott,

sehr, sehr fern, zu geheim, um ihn zu erreichen,

seine Strahlen aber dringen in die Erde. ${ }^{24}$

Das Thema der Ferne und Verborgenheit des Sonnengottes, das die vorstehenden Beispiele illustrieren, ist der "neuen Sonnentheologie" eigentümlich. In den "ikonischen" Darstellungen des Sonnenlaufs ist davon nicht die Rede. Dieser Unterschied findet seine Erklärung darin, dass sich der Aspekt der Ferne und Verborgenheit des Sonnengottes nur aus der Perspektive des Menschen heraus erschliesst, dieser standpunkt aber aus der ikonischen Darstellung bewusst ausgeschlossen war. Man kann diesen Unterschied in Beziehung setzen zu dem, was Emma Brunner-Traut als den Gegensatz von "Aspektive" und "Perspektive" herausgearbeitet hat ${ }^{25}$, wenn man sich nur darüber im

19 Ibd., 206-214 unter Weglassung des Refrains.

20 oC $25207=$ AHG Nr $192,5-8$.

21 Texte $161=253$.

22 pLouvre 3292 "M" $=$ AHG $\mathrm{Nr} .47,5$.

23 Ibd., "T" $=$ AHG Nr.48, 21-23.

24 Hibis $32,4-5=$ AHG Nr.129, 18-21.

25 Die Aspektive, Nachwort zu: H.Schäfer, Von ägyptischer Kunst $\left({ }^{4} 1963\right)$; vgl. auch LA I,474-488. 
klaren bleibt, dass mit dem "Aspektivischen" eigentlich kein "Aspekt" verbunden ist, weil an einen Betrachter hier ubberhaupt nicht gedacht ist. Das Irrefuhrende dieser Terminologie liegt darin, dass sie den Gegensatz so ausdruckt, als handele es sich um zwei verschiedene Formen des Bezugs auf einen gedachten Betrachterstandpunkt. In Wirklichkeit schliesst die erste Form jeden Betrachterstandpunkt kategorisch aus. Sie bildet keine "Ansicht" ab, sondern veranschaulicht eine rein begriffliche Artikulation des Inhalts. Insofern traf Schäfers Ausdruck "vorstellig" durchaus das Richtige.

Die "ikonische" Darstellung des Sonnenlaufs in den traditionellen Hymnen, wie wir sie in kap. 2 analysiert haben, ist in diesem Sinne "vorstellig". Der Mensch als Bezugspunkt ist kategorisch ausgeschlossen ${ }^{26}$. Dinge werden beschrieben, die nie eines Menschen Auge geschaut hat. Im genauesten Gegensatz dazu beschränkt sich die "neue Sonnentheologie" nur auf das dem menschlichen Auge sichtbare. Die Formen, in denen sich das Wesen und Wirken der Gottheit dem menschlichen Auge darstellt, wird zur alleinigen Grundlage dessen gemacht, was man von Gott wissen und aussagen kann. Die "mythische Dimension" der Gottheit, die Dimension ihrer sprachlichen Wesensentfaltung und -Darstellung, kurz: ihr "Name", wird mit ihrer kosmischen offenbarkeit gleichgesetzt. Das menschliche Auge wird zum alleinigen Bezugspunkt der Theologie, die nur das von Gott aussagt, was dem Auge "erscheint" und sich dem deutenden "Herzen" erschliesst. Dieses Verfahren einer theologischen Ausdeutung der sichtbaren natüriichen Phänomene nenne ich die "Phänomenologie des Sonnenlaufs", im Gegensatz zu seiner "Ikonographie", deren Bilderwelt eine "vorstellige" Basis hat, und einem "Denken in Bildern" entspringt.

Was wir hier im Horizont des Themas "Ferne" als "Perspektive" beschreiben: die Bezogenheit der göttlichen Wesensdarstellung auf das menschliche Auge als Bezugspunkt, ist dieselbe Struktur, die sich in einer anderen Fragestellung als An-

26 Vgl. auch die "Verschweigung des Bezugs", die die "interpersonelle Form" des kultischen Sonnenhymnus kennzeichnet: AHG, 85ff.; LL, $359 f$. 
thropozentrik darstellt. Mit der Zerschlagung der polytheistischen Konstellationen wird der Mensch zum alleinigen Bezugspunkt des göttlichen Handelns gesetzt. Wir werden das im Einzelnen noch behandeln; im gegenwärtigen zusammenhang ist jedoch die Tatsache bedeutsam, dass die Menschheit in ihrer Rolle als Bezugspunkt des göttlichen Handelns mit Vorliebe in Wendungen wie "alle Gesichter", "alle Augen" bezeichnet wird. Durch das Auge, das "sein Dasein dem Licht zu danken hat"27, haben die Geschöpfe des Lichts am Wesen der Gottheit teil.

Sie sehen aber nur die strahlende und überwältigende Aussenseite der göttlichen Erscheinung. Die Innenseite seines Wesens bleibt ihnen verborgen. "Du bist in ihrem Angesicht, aber deinen Gang kann niemand erkennen." 28 "Der du uns erscheinst, wié kennen dein Bild nicht. Du zeigst dich in unserem Angesicht, aber wir erkennen deinen Leib ( dt ) nicht:"29 Diese vor ${ }^{30}$, in ${ }^{31}$ und nach Amarna ${ }^{32}$ vielfältig belegbare Aussage kann geradezu als Leitmotiv der neuen Sonnentheologie gelten, das als Kriterium dienen kann, einen Text dieser Richtung zuzuordnen. 33

\subsection{Ferne und Nähe}

Du hast den Himmel fern gemacht, um an ihm aufzugehen, um alles zu sehen, was du geschaffen hast, der du ein Einziger bist. 34

Du hast dich entfernt als der Ferne uber ihnen, um sie uberwachen zu kơnnen Tag fur Tag. ${ }^{35}$

27 J.W.V.Goethe, Einleitung zur Farbenlehre (Hamburger Ausgabe XIII, 323).

28 Sandman, Texts from ... Akhenaten, 93.16-17; AHG Nr.92, 26.

29 pBerlin 3050, viii, $9=$ AHG Nr.22D, 29-30.

30 Text 76 in Grab 57 (Chaemhet).

$31 \mathrm{Vgl}$. auch Sandman, 89, 14-15.

32 Texte $54,161,253,42 a$ usw.

33 S. MDIK 27.1 (1971) 8-12 mit allen mir bekannten Belegen.

34 Amarna, AHG Nr.91, 53-54; Nr.92,110-111.

35 pLouvre $3292=$ AHG $\mathrm{Nr} \cdot 47,5-6$. 
Du bist fern, aber deine Strahlen sind auf Erden, du bist in ihrem Angesicht, aber man kann deinen Gang nicht erkennen. 36

Ferner du im Lichtland, deine Strahlen beruhren die Gesichter. 37

Du bist erschienen und strahlend, du bist fern und nah (zugleich). 38

Ferner und (zugleich) Naher, den man nicht erkennen kann! 39 Deine Sonne ist allein, aber ihre strahlen sind im Gesicht, die Erde lastet, aber du dringst bis an ihr Ende (...)

Du hast dich entfernt, und du bist doch nahe, ohne dass man dich erkennen kann;

du (fahrst dahin uber) allem, was du geschaffen hast, $\mathrm{du}$ allein, und betrachtest sie, indem du allein bist. 40 Sehr, sehr Ferner, zu geheim, ihn zu erreichen, seine Strahlen aber dringen in die Erde. 41

Er entfernte sich zum Himmel und betrachtete das Geschaffene, man sieht durch sein Sehen.

Fern ist er im Lichtglanz und (zugleich) wie in diesem Lande (anwesend), seine beiden Augen dringen bis ins wustental (d.h. Totenreich). 42

Der unauflösbare Zusammenhang dieses Themas mit dem vorstehend behandelten ist evident. Es sind auch z.T. dieselben Texte, ja dieselben Textstellen, die wir hier und dort zur Veranschaulichung herangezogen haben. 43

36 Amarna, AHG $\mathrm{Nr} .92,25-26$.

37 Hibis ed. N.de G.Davies, Tf. 16 unten links (Eingang zu E).

38 AHG Nr.92, 113-114.

39 Quibell, Exc.at Saqqara $(1908-10)$, Tf. $73.3=$ pBerlin 3048 AHG Nr. $143,17$.

40 Texte $161=253$.

41 Hibis $32,4-5=$ AHG Nr.129, 20f. cf. n. 24 .

42 Hibis $32,20-21=$ AHG Nr.129, 96-99. Vgl. Sobek-Re II, $24=\mathrm{AHG} \mathrm{Nr}$. 144A, 54-55: hrjw-țw[r hrt $r$ wbn jms

r] $m 33 s_{3} \cdot \mathbf{n} \cdot \mathbf{k}$

Du hast dich entfernt [an den Himmel, um darin aufzugehen um] zu schauen, was du geschaffen hast.

Die Erganzung ist naturlich ganz hypothetisch.

$43 \mathrm{Vgl} . \mathrm{n} .21$ und $\mathrm{n} .40, \mathrm{n} .24$ und $\mathrm{n} .41, \mathrm{n} .22$ und $\mathrm{n} .35$. 
Ebenso wie "Einsamkeit" und "Ferne" beruht auch der Satz von der "Nähe" der Gottheit auf der theologischen Ausdeutung eines natürlichen Phänomens, nämlich des Sonnenlichts. Das Licht wird nun als das erkannt, was es ja auch tatsächlich ist, als strahlung der Sonne, und damit als eine Handlung, in der der Gott sich der Erde zuwendet, "kommt", wie es heisst, die "Gesichter berührt" (Beispiel 4) 44 , die Herzen belebt ${ }^{45}$, die Erde mit seiner Gegenwärtigkeit überschwemmt ${ }^{46}$, ja selbst in die Tiefe des Ozeans ${ }^{47}$ und der Unterwelt dringt, in die "Grüfte" der Toten. 48

Der sich dem Gesicht năhert, auch wenn er |fern| ist, denn jedes Gesicht ist ihm gegenuber.

Man verbringt den Tag, ihn anzuschauen und kann sich seiner nicht ersattigen. ${ }^{49}$

Jedes Auge erblickt dich sich gegenluber, wenn du als Sonne des Tages (hoch) uber der Erde stehst. ${ }^{50}$ Nahert deine Majestat sich dem Suden der Erde, dann bist du dem gegenuber, was im Norden der Erde ist; Westen und Osten, du bist in ihrem Gesicht. 51

Gerade die Ferne des Gottes, in die er sich über alle welt erhebt, macht ihn allen Augen gleichzeitig offenbar. Der unermessliche Abstand, in den Gott und Schöpfungswelt auseinandertreten, ist zugleich die notwendige Bedingung für den Bezug, der beide aufs Innigste verbindet. Die Ferne ist die Bedin-

44 Zum Motiv des "Kommens", das die "Ikonographie des Sonnenlaufs" mit der Nacht verbindet (s.dazu LL 46-48), in Bezug auf den Sonnenaufgang s. MDIK 27.1, 26 n.58. Mit dem Motiv der "Berlurung der Gesichter" vgl. AHG Nr.91, 13 und Petosiris, ed.G.Lefebvre, Inscr. No.60, 14-15: "Ferner, funkelnd in Himmel, der das Gesicht beruhrt mit Strahlen!"

45 Diese Wendung kommt wohl zuerst im Nilhymnus vor: AHG Nr.242, 92, dann in Amarna (Sandman, 11 und 13, letztere Stelle = AHG Nr.91, 31) sowie Text 60,13 ; AHG Nr.200,22; Text 189,25 .

46 Text 17,4 .

47 AHG $\mathrm{Nr} .92,58$.

48 Text 151, 36; Text 17, 15 (p). S.LL, 305 n.21.

49 Text $83,8-11$.

50 AHG Nr.92, 118-119.

$51 \mathrm{Nr} \cdot 161=253,30-32$. 
gung seiner offenbarkeit, der Strahlenglanz, der ihn verhüllt, die Bedingung seiner Parusie.

Parusie ist die leibhaftige Gegenwärtigkeit der Gottheit. Ich verbinde diesen Begriff mit dem ägyptischen wort nfrw," das wir, wie ich meine, nicht zu unrecht mit "Schönheit" übersetzen, denn es bezeichnet die Eigenschaft, der der Affekt mrwt "Liebe" korrespondiert, das, was Rudolf otto das "mysterium fascinans" des Heiligen genannt hatte. ${ }^{52}$ Die Amarnatexte verwenden die Worte nfrw "Schönheit" und mrwt "Liebe" als Synonyme von stwt "Strahlen"53. Dieser Sprachgebrauch, der für die neue Sonnen-Theologie allgemein kennzeichnend bleibt ${ }^{54}$, reflektiert die theologische Ausdeutung des Lichts als einer Form der leibhaftigen Gegenwärtigkeit Gottes, in der er seine "Schönheit" offenbart und das Gefühl der "Liebe", der hingerissenen Faszination 5 auslöst, mit der "jedes Auge" auf ihn gerichtet ist.

"Jedes Auge ruht auf Schönheit, bis du untergehst".56

"Alle Gesichter, ihre Augen sind auf dich gerichtet". 57

"Alle Arbeit geschieht, indem das Auge auf ihm ruht." 58

"Alle Augen sehen durch dich. Nichts können sie vollenden, wenn deine Majestät untergeht." 59

52 Rudolf otto, Das Heilige (29.-30.Auflage), 42, vgl. LL, $65 \mathrm{m.n.108;} \mathrm{A.}$ de Buck, Godsdiensten der Wereld II, 36; Zandee, Hymnen, 7-8. Der agyptische Begriff von gottlicher Schonheit und der davon hervorgerufenen Liebe geht fur mich am klarsten aus folgendem Abschnitt des Kairener Amunshymnus hervor (AHG Nr.87,D, 97-106):

Die Liebe zu dir ist durch die beiden Länder verbreitet

deine Strahlen sind erschienen in den Augen;

die Menschheit wird schon bei deinem Aufgang,

die Tiere ermatten, wenn du (am Mittag) strahlst;

die Liebe zu dir erfullt den sudhimmel,

die Lust an dir den Nordhimmel.

Deine Schonheit ergreift die Herzen,

die Liebe $z u$ dir lăhmt die Arme,

deine schone Gestalt erschlafft die Hände,

der Sinn verwirrt sich bei deinem Anblick.

53 LA I, 532.

54 Fur "Schønheit" vgl.z.B. $\$ 2.4$, Belege 14, 15, 16, 17, 19, 20, 22; fur Liebe 21.

55 "Trunkenheit", vgl. Text 26,5 (a).

56 AHG $\mathrm{Nr} .92,129$.

57 pLeiden J 350 II, 20; Zandee, Hymnen, 34.

58 pBerlin $3056,8,8$; LL $176 \mathrm{~m} . \mathrm{n} .44$.

59 Suti Hor AHG $\mathrm{Nr} .89,25-26$. 
"Wild und Herden wenden sich dir zu, die Pflanzen drehen sich nach deiner schönheit, es gibt kein Leben für das, was dich nicht sieht." 60

Alle Augen richten sich auf ihren schöpfer, der seinerseits seine Geschöpfe betrachtet. Allein zu diesem Zweck hat er den Himmel so fern gemacht und sich so hoch über sie erhoben. Das Licht ist nichts anderes als der Blick, den Gott selbst in der Einsamkeit seiner Himmelsferne auf die unendiche, millionenfältige Fülle seiner Geschöpfe richtet, die ihrerseits ihre Augen nicht von ihm wenden können und nur leben, solange sie ihn schauen:

Schoner, der vom Himmel herabkonmt, um zu schauen, was er geschaffen hat auf Erden. ${ }^{61}$

Im Licht kommunizieren Schöpfer und Schöpfung. Der zur Sonne gewandte Blick der Geschöpfe begegnet dem auf sie gerichteten Blick des Schöpfers, der ihre Herzen belebt und sie mit Liebe erfüllt.

\subsection{Allgegenwart des Lichts - Gotterfulltheit der Welt}

(1) Jeder Weg ist voll deines Lichts. ${ }^{62}$

(2) Jeder Weg ist voll von Liebe zu mir, nicht entsteht Mangel in diesem Lande. ${ }^{63}$

(3) Der die Millionen aufdeckt mit seinem schonen Gesicht, kein weg ist frei von inm (wenn er strahlt) auf die Erde. ${ }^{64}$

(4) Licht auf jedem Wege. ${ }^{65}$

(5) Er ist es, der die Gesichter leitet auf allen Wegen. ${ }^{66}$

60 pchester Beatty IV AHG Nr.195, 235-237 vgl. Kairo CG 42208 AHG Nr.200, 13-15:

Jedes Gesicht lebt vom Anblick deiner Schonheit, aller Same entwickelt sich, wenn du sie bestrahlst, keiner ist, der ohne dich leben kann.

61 J.Lipinska, in: ASAE 60 (1968), 167 Tf.xI fig.17.

62 pBerlin 3050, LL 206 (32) mit weiteren Belegen fur diese Formel.

63 pLeiden J $347,8,4$.

64 pLeiden J 350 II, 18; Zandee, Hymnen, $31 \mathrm{f}$.

65 Ibd., II, 19.

66 Ibd., V, $20 f$. 
(6) Bist du nicht Leiter auf allen Wegen? ${ }^{67}$

(7) Die Wege sind zu Millionen unter seiner Leitung. 68

(8) Der Millionen leitet mit seinem Strahlen. 69

(9) Kein Land entbehrt seines Anblicks,

der das Kommen und Gehen bewirkt auf allen Wegen,

der die Grenzen der Erde erreicht an einem Tage. 70

(10) Du erreichst die Grenzen der Erde mit Strahlen. 71

(11) Der die Grenzen der Erde erreicht, wenn er betrachtet die auf ihr wandeln. 72

(12) Der Vielblickende, dessen Lauf keine Grenzen hat. 73

(13) Keine Grenze gibt es fur den Umlauf seiner Lichtaugen, kein ort ist seinem Ka verborgen. 74

(14) Deine Strahlen dringen in die Grufte, kein Platz ist frei von deiner Schonheit. 75

(15) Himmel und Erde sind von deiner Schonheit durchdrungen. 76

(16) Himmel und Erde stehen unter seiner Schonheit, uberschwemmt mit Gold. ${ }^{77}$

(17) Du gibst deine Schonheit durch die Länder hin. 78

(18) Kein ort ist bar seines Lichts. 79

(19) Du hast die beiden Ufer erleuchtet mit deinen Augen, der ozean steht unter deiner Schonheit. 80

(20) Der Himmel, Erde und Berge durchdringt mit seiner schonheit. ${ }^{8}$ !

(21) Er hat seine Strahlen gegeben, sein Uräus hat den Erdkreis erleuchtet, alle Lande sind voll mit der Liebe zu ihm. 82

67 pChester Beatty IV rto 3,7 AHG 195,8.

68 Suti-Hor AHG Nr.89, $12 \mathrm{vgl}$. Text 212 (i).

69 Text 113 (q); Neschons AHG Nr.131, 57.

70 petosiris ed. Lefevbre Inscr. No.60, 9-10.

71 Text 54.

72 Suti-Hor AHG Nr.89, 53.

73 pBerlin $3049,17,6=$ AHG Nr.127B, 209-210.

74 pLouvre 3292 "H" = AHG Nr.45, 5-6.

75 pAnastasi II, 5-6 (vom KOnig).

76 Sobek-Re IV, $21-22=$ AHG $144 \mathrm{C}, 75$; Neschons, $18=$ AHG $\mathrm{Nr}, 131,47$.

77 Ritual fur Amenophis I pchester Beatty IX rto. $13=$ pBerlin 3056,7, $1-7$; LL 248 .

78 Quibell, Exc. at Saqqara $(1908-10)$, Tf.70.

79 Text 151.

80 pChester Beatty IV rto 9, 4-5 = AHG Nr.195, 187-188 vgl. 244 .

$81 \mathrm{Hibis}$ ed.N.de G.Davies Tf.9.

82 Stele Ramses IV. in Karnak ed.Helck, ZAS 82, Tf.V, 14. 
(22) Jede stadt ist erfüllt mit der Liebe zu dir, Amun, alle Lande stehen unter deiner Schönheit. 83

Diese ermüdende und dabei in keiner Weise erschöpfende Belegsammlung mag die zentrale Bedeutung veranschaulichen, die diesem Thema in der neuen Sonnentheologie zukommt. Die Lehre von der Gotterfültheit der Welt ist wiederum nichts anderes als die theologische Ausdeutung des kosmischen Phänomens der Allgegenwart des Lichts. Im Licht ist Gott selbst gegenwärtig. Die Synonymie von "Strahlen", "Schönheit" und "Liebe" tritt gerade in dieser Topik sehr deutlich heraus, vgl etwa 2 , 21-22 (Liebe) 14-17, 19-20, 22 (Schönheit). Das Licht erschliesst die welt und macht sie begehbar: das ist mit der häufigen Metapher des Wegs gemeint. 84 Das Licht schafft ordnung und Orientierung unter den Menschen:

(23) Der den Himmel hochhob für den Umlauf seiner beiden Augen, der die Erde schuf, um seinen Lichtglanz auszubreiten, um zu bewirken, dass ein Jeder seinen Nächsten erkennt. 85

(24) Wie schön bist du, wenn du aufgehst, Re! du bewirkst, dass der Räuber zurückweicht, ein Auge sieht das andere, während es niedergeschlagen ist (bei deinem Untergang). 86

(25) Wenn du dich mit dem Lichtland vereinst, dann sieht kein Auge das Andere; alles Gewürm (regt sich) auf Erden. sie schlafen blind, bis du wieder erstrahlst, und sie aufweckst, um deine Schönheit zu schauen. Wenn du erscheinst, dann blicken sie, sie erkennen durch dich, wenn du ihnen deine strahlen gibst. 87

(25a) Du bist das Licht, das für die Menschheit aufgeht, die Sonne, die die Helligkeit gibt, um erkennen und unterscheiden zu lassen Götter und Menschen, wenn du dich zeigst. Jedes Gesicht lebt vom Anblick deiner Schönheit,

83 owilson = OIFAO inv.2181 ed.Posener, in: FsRicke $(1971), 61 \mathrm{mit}$ Tf. $15 \mathrm{~B}$.

$84 \mathrm{~S}$. hierzu LL, $206 \mathrm{f}$.

85 Totb 15 B II $=$ AHG $\mathrm{Nr} .44,6-8$.

86 pchester Beatty IV rto $11,15-12,1=$ AHG Nr.195, 304-6 (dort anders). Vgl. auch Tura-Hymnus = AHG Nr.88, 42 .

87 AHG Nr.94, 13-19. 
aller Same entwickelt sich, wenn du sie bestrahlst, keiner ist, der ohne dich leben kann!

Du leitest jedermann, indem sie zu ihrer Arbeit verpflichtet sind,

du hast die Form ihres Lebens gebildet, nachdem du sichtbar wurdest. $87 a$

(26) Bei ihrem Aufgang bringt sie ihr Licht zur Welt, damit sich ein Jeder vom Anderen unterscheiden kann. ${ }^{88}$

(27) Die Morgensonne, durch die man alle Dinge erkennen kann. ${ }^{89}$

Das Licht erschafft die begehbare Welt, die distinktiven Konturen der Dinge, die geordnete wirklichkeit, in der der Mensch sich orientieren kann. Im Licht "ergreift" der Gott die welt bis an ihre äussersten Grenzen:

(28) Du hast den Himmel in Besitz genommen mit seinen beiden Horizonten

indem du erglanzt uber dem Luftraum.

Die Erde ist unter dir bis an ihr Ende,

du hast sie ergriffen. 90

Im Nutbuch und seinem demotischen Kommentar pcarlsberg I C II,14-16 wird dieser Vorgang in der nüchternen Sprache der Kosmographie folgendermassen beschrieben:

(29) So wird seine Erscheinungsform gross

dem.:seine Erscheinungsform wird gross: das ist seine Flamme

So entsteht sie in den Landen

dem.: Er lăsst sie in den Lăndern entstehen - nămlich die

87a Kairo CG 42208 AHG Nr.200.

Der wichtige Text lautet in Umschrift:

.. ntk šw wbnw.n hnmmt

$j$ tn ddw hddwt

$r$ djt sj3 tw wd ${ }^{c} w$

ntrw rmtw hft dj.k tw

nh hr nb n m33 nfrw.k

shpr prt nbt m3wj.k r.sn

n-wn ntj nh m hmt.k

s.̌m.n.k [ḥr] nb ḥnw hrr k3t.sn

jr.n.k qj n nh.sn m-ht m33.k

Vgl. auch Otto, Die biographischen Inschriften der ag. Spatzeit, $\mathrm{Nr} .6, \mathrm{~S} .139-142$.

88 Sauneron, Esna V, 151 Text Nr.331, 10.

89 pCarlsberg, VII, 1,8 ed.Iversen, 16ff. (Ebenso von Thoth I.5, I.6).

90 Text $158 \mathrm{vgl}$. auch LL $302 \mathrm{f}$. 
Flamme - in ihrem Unkreis. Man kann nicht den ort nennen,

wo er sie nicht entstehen lasst. 91

Darauf bezieht sich wohl auch das Buch von der Himmelskuh, worin es vom "Ba" des Re heisst, dass er "durch alle Lande hin" ist. 92 In den Hymnen wird auch diese Allgegenwart des Lichts auf den Menschen als Bezugspunkt bezogen:

(30) Die Leiber sind voll von deiner Schonheit,

die Augen, sie sehen durch dich,

Furcht vor dir durchdringt jedermann,

ihre Herzen sind dir zugewandt.

Schön bist du zu jeder stunde.

die Menschheit lebt von deinem Anblick.

(...) Deine susse ist in aller Herzen,

kein Leib ist deiner Schonheit bar. 93

(31) Gross an Hoheit im Himmel und auf Erden,

Jeder Leib ist erfullt mit seiner schonheit. 94

(32) Kein Leib ist hier frei von Liebe $\mathrm{zu}$ ihm. 95

(33) Die Liebe $\mathrm{zu}$ inm flutet wie der Nil

und durcharingt alle Leiber. 96

Diese Stellen gehen in der theologischen Ausdeutung der Allgegenwart des Lichts noch einen schritt weiter: der Gott erfült mit seinen strahlen nicht nur alle Lande, sondern auch "alle Leiber": durch das Auge nämlich, das sich im Schauen Gottes Schönheit "einverleibt", dringt Gottes strahlkraft bis ins Innerste der Herzen. Der sinnlichen Erfahrung der Gegenwart Gottes im Licht kann sich niemand entziehen. Die liebende Hingebung an Gottes Schönheit ergreift den ganzen Menschen $^{97}$, und ergreift alle.

$91 \mathrm{Ed}$. Lange-Neugebauer, 23.

92 Buch von der Himmelskuh BIFAO 40, 103.

93 pChester Beatty IV rto 9,4-5, AHG Nr.195, 126-131, 136-137.

94 Text 188,5 (b) mit weiteren Belegen.

95 oMichaelidis 15 vso. ed. Goedicke-Wente.

96 OIFAO 1038.

97 Der ag. Ausdruck ht bezieht sich, anders als unser "Leib", oft gerade auch auf das "geistige Innere", Gedachtnis, Bewusstsein, Innerlichkeit s. LL 196 n.22. 


\subsection{Leben (creatio continua)}

Der Zentralbegriff der Amarna-Theologie ist "Leben". Statt die Fülle der Belege hier auszubreiten, genügt es, sich in Erinnerung $z u$ rufen, dass der Begriff des "Lebens", der in dem zusatz $\mathrm{C}_{\mathrm{nh}}$ "lebend" zu dem wort jtn "Sonne" hinzutritt, den Namen des Gottes von Amarna ausmacht: erst durch diesen entscheidenden Zusatz unterscheidet sich dieser Name - (p3) jtn cnh , "du lebende Sonne" - von dem normalen wort für das Tagesgestirn, das auch in Amarna nichts anderes als "Sonne" bedeutet. 98 Der Gott von Amarna heisst "Leben", er ist die Sonne als Quelle und Bedingung allen Lebens. Er verkörpert in reinster Ausprägung den Typus eines "Lebensgottes", dessen Theologie sich aus der Frage nach dem Ursprung und der Grundlage des Lebens entfaltet, so wie der Theologie des Schöpfergottes die Frage nach dem Ursprung der welt zugrundeliegt.

Die Schu-Theologie des Mittleren Reichs, soweit sie uns aus den Sprüchen 75-80 der Sargtexte greifbar wird, hatte zwischen Kosmogonie und Biogonie, Schöpfergott und Lebensgott unterschieden. Atum gilt ihr als der Schöpfer der welt und der Lebewesen; die Aufgabe ihrer Belebung und Entfaltung aber fällt seinen beiden Kindern Schu und Tefnut zu. Schu erhält in dieser Funktion den Namen Cnh "Leben" und wird auch Nḥ̣ "Zeitfülle" genannt, Tefnut heisst $m 3^{C t}$ "Wahrheit-Gerechtigkeit-Ordnung" und dt "Dauer". Leben, Wahrheit und zeit sind die Energien, die die von Atum geschaffene Welt in Gang halten. 98 a Echnaton muss diese Theologie bekannt gewesen sein. Sie bietet das einzige Beispiel einer Triade der Struktur 1 : 2 (ein Vater : 2 Kinder, sonst immer: 2 Eltern, ein Götterkind), und während sonst der König immer in der Rolle des Götterkindes in Konstellationen des Typs 2 : 1 mit den Göttern verkehrt, treten Echnaton und Nofretete als Götterkinder-Paar

$98 \mathrm{Vgl}$. LÄ I, 526.

98a Zur Schu-Theologie des MR s. A.de Buck, Plaats en betekenis van Sjoe in de egyptische theologie (Mededeelingen der koninklijke nederlandsche akademie van wetenschappen, Afd. letterkunde, N.R. 10.9, 1947); "Primat und Transzendenz", $24 \mathrm{f}$. Unten Rap.5. 
dem einen Gott gegenüber, wobei sie die Rolle von Schu und Tefnut spielen. ${ }^{99}$ Das erklärt die auffallende Rolle der Königin als Mitglied der offiziellen "Trias von Amarna"100, erklärt aber darüberhinaus auch die verbindungen, die zwischen der Amarna-Theologie und der Schu-Theologie des Mittleren Reiches bestehen. Wir werden auf diese Zusammenhänge im Zusammenhang der Theologie des Amun-Re eingehen, der ebenfalls den Typus des Lebensgottes repräsentiert. In diesen punkten geht die Amarna-Religion über den Rahmen der "neuen Sonnentheologie" hinaus und greift andere Traditionen auf. Im gegenwärtigen Zusammenhang ist die theologische Reflexion über den Ursprung und die Grundlage des Lebens aber insoweit von Bedeutung, als auch sie sich aus der Ausdeutung der natürlichen Phänomene des Sonnenlaufs ergibt.

Die theologische Ausdeutung, die die kosmischen phänomene des Sonnenlaufs, Licht und Bewegung, im Rahmen der neuen Sonnentheologie und der Amarnareligion erfahren, erlaubt keine Unterscheidung zwischen Schöpfung und Belebung. Die formende und die beseelende, die hervorbringende und die erhaltende Energie sind ein und dieselbe kraft, die sich in Strahlung und Bewegung der Sonne manifestiert. Schöpfung steht nur als creatio continua im Blick. Der Grosse Hymnus von Amarna widmet dem Thema "Schöpfung" einen Abschnitt von 46 Versen, was nach ägyptischen verhältnissen einem regelrechten Traktat gleichkommt. Der erste Teil dieses Traktats ist einer einzigartigen Embryologie gewidmet, die an die Stelle der traditionellen Kosmogonie eine (ontogenetische) Biogonie setzt: die Lehre von der Entstehung des Lebens im Mutterleib. Der zweite Teil preist die geordnete Welt, deren Gegliedert-und Differenziertheit in völkern verschiedener Hautfarbe, Sprache 101

99 s.Mohammad Hassan Abd-ur-Rahman, "The Four-Feathered Crown of Akhenaten", in: ASAE 56, 1959, 247-249.

100 JNES 31 (1972) 152-154.

101 Die Differenzierung der Sprache ist moglicherweise ein Thema, das erst in der Amarna-Zeit aufkommt, dann aber ein verbreitetes Motiv wird, s.AHG Nr.42, 37ff; $\mathrm{Nr} .58,74 ; 129,85 f$. vgl. auch vor Amarna $\mathrm{Nr} .87 \mathrm{C}, 67 \mathrm{f}$. ("Eigenschaften"). S.CernÝ, in JEA 34, 121-122; Sauneron, in: BIFAO $60,1960,31 \mathrm{ff}$. und D.Muller, Agypten und die griechischen Isis-Aretalogien, 54-57. 
und Lebensbedingungen - vom Regen als dem Nil am Himmel ${ }^{102}$ und vom Nil aus der Unterwelt - auf die Weisheit des Schöpfers schliessen lässt, bezieht sich also ebenfalls auf den gegenwärtigen zustand. Dieser Traktat ist reine Amarna-Theologie; Ansätze und Grundgedanken werden wir aber auch in thebanischen Texten wiederfinden.

Die belebende wirkung des Sonnenlichts ist evident und wird in den Texten hundertfach ausgedrückt. Auch die Bedeutung des Sehens als Lebensregung par excellence, der Zusammenhang von Sehen und Leben, als Leben vom Anblick Gottes 103 und Aufleben der Schöpfungswelt bei Sonnenaufgang ${ }^{104}$, bedürfen keiner Dokumentation, die Seiten füllen würde. Die tiefsinnigsten und aufschlussreichsten Formulierungen knüpfen sich aber nicht an das phänomen des Lichts, sondern an Luft und zeit als die noch grundlegenderen Bedingungen der Möglichkeit von Leben:

Du hast den Himmel fern gemacht, um an ihm aufzugehen, um alles zu schauen, was du geschaffen hast, der du ein Einziger

bist,

aber Millionen von Leben sind in dir, um sie zu beleben, denn Lebensodem an den Nasen ist der Anblick deiner Strahlen. ${ }^{105}$

Die Luft, nicht das Licht, ist für den Agypter das Lebenselement kat' exochen. So wie das Licht mit "Schönheit" und "Liebe", so wird die Luft mit "Leben" gleichgesetzt. Darauf basiert auch die Rolle des Luftgottes Schu als des Lebensgottes in der oben zitierten Theologie des MR. ${ }^{106}$ Dabei hat man allerdings zwischen "Licht" und "Luft" nicht streng unterschieden. Der Gott - und der kosmologische Begriff - "Schu" beziehen sich auf die "lichte Luft", den lichterfüllten Lebens-

102 Auch dies wird zum găngigen Thema, vgl. AHG Nr.127B, 45-46; 195, 166; $144 \mathrm{C}, 39 ; 214,29-32$ und vor allem Nr.143, 164f., 100 und 46.

$103 \mathrm{Vgl}$. O., Beispiel 25a mit pChester Beatty IV AHG Nr.195, 237; Text 156, 15 (h); Amarna ed.Sandman, 23.5.

$104 \mathrm{Vgl}$. die Formel "Wenn er aufgeht, lebt die Menschheit", LL $321 \mathrm{f}$.

105 Amarna, Kleiner Hymnus AHG Nr.91, 53-56.

106 A.de Buck, a.a.o. (n.98a), 11ff. 
raum. Wie andere Völker auch hat der Agypter das Licht nicht unbedingt in Abhängigkeit von der Sonne gesehen. ${ }^{107}$ Dafür hat man allerdings gelegentlich auch der Vorstellung Ausdruck gegeben, dass nicht nur das Licht, sondern auch die Luft, als wärme = "Gluthauch", von der Sonne ausgeht. 108 Man wird annehmen dürfen, dass hierüber verschiedene einander widersprechende Vorstellungen kursierten, dass aber die neue Sonnentheologie der Einsicht in die Abhängigkeit des Lichts von der Sonne zur ausschliesslichen Geltung verhalf, eine Einsicht, deren Bedeutung für das damalige Weltbild man nicht unterschätzen darf und die in den Texten in so zahlreichen Wendungen zum Ausdruck kommt, dass die ihr beigemessene wichtigkeit ausser Zweifel steht. 109

Der "kleine" Hymnus, aus dem wir oben zitierten, deutet die Sonnenstrahlen aber nicht im Sinne des alten "Synkretismus" von Licht und Luft als kosmisches Element, sondern als beseelenden "Lebensodem". Der Gott fasst in sich "Millionen Leben"110, die in Form seiner strahlen in seine Geschöpfe eingehen. Das Leben der Geschöpfe wird als eine göttliche Emanation, und das Sonnenlicht als die Form dieser Emanation gedeutet. Die andere Stelle, wo in Amarna von den "Millionen" Emanationen des Gottes die Rede ist, stellt ausser Frage, dass Schöpfung und Erhaltung, Formung und Belebung hier vollkommen eins sind. Das Licht erfüllt nicht eine gegebene Form mit Leben, sondern bringt auch diese form selbst hervor:

Du erschaffst Millionen Verkörperungen aus dir, dem Einen:

Städte und Dörfer,

Äcker, Weg und Fluss. ${ }^{111}$

Die ganze lichterfüllte, geordnete, "begehbare" welt geht als millionenfältige Verkörperung aus dem Einen hervor, und er-

107 A.de Buck, a.a.o., $33 \mathrm{f}$.

108 CT IV 296/7; Text 52, 18-19 (e).

$109 \mathrm{Vgl}$. z.B. LL, $318 \mathrm{f}$.

110 Zum Begriff "Millionen" s.Text 149 (c).

111 Grosser Hymnus AHG Nr.92, 115-117. 
füllt sich mit den Millionen "Leben", die aus dem unendichen Vorrat der göttlichen Lebensfülle in die Geschöpfe einstrahlen.

Aber nicht nur die Sonnenstrahlung wird als ein Akt der Hervorbringung ( $m s j$, shpr ) und der Erhaltung von Leben ( $\mathbf{s}^{\mathbf{c}} \mathbf{n h}$ ) gedeutet, sondern auch die andere kosmische Manifestation des Sonnengottes: die Bewegung:

Die Erde entsteht auf deinen wink, wie du sie erschaffen hast, wenn du aufgehst, leben sie,

wenn du untergehst, sterben sie.

Du bist die Lebenszeit selbst, man lebt durch dich. ${ }^{112}$

Durch die Bewegung der Sonne - diesen Begriff drückt der Text mithilfe der Verben wbn und htp aus - entsteht die Zeit, in der alles, was lebt, sich entfaltet. Der Sonnengott scheidet durch seine Bewegung nicht nur die Zeit in Einheiten, durch die sie messbar wird"13, sondern er setzt auch die "Fristen", die der Embryo im Mutterleib, das Kücken im Ei und der Mensch auf Erden verbringt. 114

Die Zeit, die alles Leben braucht, um sich zu verwirklichen ( hpr) und der Lebensodem ( $t 3 w^{n} \mathbf{c}_{n h}$ ), der alles mit Lebenskraft beseelt, strömen von der Sonne durch ihre Strahlung und ihre Bewegung in die Schöpfungswelt ein, bringen sie fortwährend hervor und halten sie am Leben. Als die Quelle der Zeit wird der Gott Nhh "Zeitfülle" genannt 115, als Quel-

112 Ibd., 125-128.

113 Auch hier stosst man auf die Gleichsetzung von "Scheidung" und "Schopfung", wie bei dem verbreiteten Mythologumenon von der Trennung von Himmel und Erde (W.Staudacher, Die Trennung von Himmel und Erde, 1942): indem der Sonnengott das Kontinuum der Zeit "scheidet" in messbare Einheiten, bringt er die Zeit hervor. "Ich bin es, der die Jahre scheidet und die Jahreszeiten schafft": pTurin Pleyte und Rossi 133.9 $=$ pChester Beatty XI rto 3.5. G.posener macht in: RdE 28, 147f. darauf aufmerksam, dass diese pradikation bereits im pRamesseum IX 3.7 ed.Gardiner, 42 aus dem MR vorkommt, es handelt sich bei dieser Erkenntnis also nicht um eine Errungenschaft, sondern um eine Neu-Aktualisierung und verallgemeinerung der "neuen Sonnentheologie" Zum Begriff wp trw "die Zeiten scheiden" s. A.Klasens, A Magical statue Base, $96 \mathrm{zu}$ f 24 .

114 Frist im Mutterleib: AHG Nr.92, 71-74; Nr.145A, 16, B, $13 \mathrm{f}$.

115 MDIK 27.1, 27 m.n.65; Zeit und Ewigkeit, 56. 
le des Lebensodems ${ }^{\mathbf{n h}}$, "lebende (Sonne)". Schon in der Schu-Theologie des MR bezeichnen diese beiden Epitheta die Funktion des Lebensgottes, die beiden Aspekte, in denen die Wirklichkeit als das Resultat eines unablässigen Handelns verstanden wird, das ein handelnder Gott auf die welt verwendet. ${ }^{116}$ Was ist an dieser Konzeption spezifische Amarna-Theologie und was gehört in den umfassenderen Problemhorizont der "Phänomenologie des Sonnenlaufs", die die Grundlage der neuen Sonnen-Theologie bildet? Die Frage fordert zu einem Vergleich der Amarna-Konzeption mit den thebanischen Hymnen heraus. Was davon sich in ihnen wiederfindet, darf für die gemeinsame Grundlage der neuen Sonnen-Theologie in Anspruch genommen werden.

Der Hymnus der Baumeister Suti und Hor lässt genau wie später der Grosse Hymnus von Amarna auf ein Sonnenlied in Form eines Tageszeitenliedes ein zweites Lied folgen, dessen Thema die Anrufung wie eine Uberschrift zum Ausdruck bringt:

Sei gegrusst, du Sonne des Tages ${ }^{116 a}$,

Schöpfer der Menschheit, der ihr Leben schafft!

Diese Formel, die sich auch sonst in Texten belegen lässt, die der neuen Sonnen-Theologie nahestehen ${ }^{16 \mathrm{~b}}$, bringt den Begriff eines Gottes in denkbar konziser Form zum Ausdruck, der zugleich Schöpfer- und Lebensgott ist. Während aber der Amarna-Hymnus diesen Gottesbegriff in der Form eines lehrhaften Traktats anhand der theologischen Ausdeutung einer Fülle natürlicher Phänomene ausbreitet, verdichtet der Suti-HorHymnus in der Form der Eulogie ${ }^{116 \mathrm{C}}$ die Fülle der schöpferisch-belebenden Wirkungsweisen zu "Namen", mit denen der Gott gepriesen wird:

116 De Buck, a.a.0., 23; LA II, 50 III.b.2.

$116 \mathrm{a}$ Zu diesem Appellativ s. Text 114, 21 (i).

$116 \mathrm{~b}$ S. Text 232 (h).

116C S. Kapitel 6; LA II, 40-46. 
Der die Erde formte und den Boden schuf,

Chnum und Amun der Menschheit!

Der die beiden Lander ergreift vom Grossen zum Kleinen,

wohltatige Mutter der Gotter und Menschen!

Kunstler mit geduldigem Herzen,

gross an Muhewaltung bei ihrer Erschaffung ohne Zahl,

starker Hirte, der seine Herde treibt,

inre zuflucht, der ihr Leben schafft. 117

Die ganze Strophe bezieht sich auf die erd-bezogenen Wirkungsformen des Gottes und korrespondiert einer vorhergehenden Strophe, die seine himmlischen Erscheinungsformen pries. 118 Daher die Nennung der Erd-Schöpfung im ersten Vers, wo natürlich pars pro toto die ganze sichtbare wirklichkeit gemeint ist. Der zweite Vers enthält in nuce die embryologische Fragestellung des Grossen Hymnus: denn Chnum und Amun bilden nur in einem einzigen thematischen zusammenhang ein Paar, der hier unmissverständlich evoziert ist: dem königlichen Geburtsmythos. Das zeugende, formende und beseelende Prinzip, das sie dort in Bezug auf das Königskind verkörpern, wird hier dem Sonnengott in Bezug auf die Menschheit insgesamt zugeschrieben. 119 Im dritten Vers erkennen wir das oben behandelte Thema von der Allgegenwart des Lichts und Gotterfülltheit der Welt, das hier bereits in seiner persönlichen wendung erscheint: als ein "Ergreifen" all dessen, was lebt und das Licht empfängt, das von der Sonne ausstrahlt.

Chnum und Amun sind Aspekte der Vaterschaft: sie zeugen und formen das Kind, aber sie bringen es nicht zur Welt. So erklärt sich die Aussage des folgenden Verses, die ohne diesen Zusammenhang ganz ungewöhnlich wäre. Auch hier wird der Gott, wie sonst auch im Rahmen dieser Theologie, als "Mutter und Vater" gepriesen: der Vater-Aspekt kommt in Vers 2 zum Ausdruck, vgl. dazu

117 AHG Nr.89, 39-46.

$118 \mathrm{zu}$ dieser Gliederung und Deutung $\mathrm{s}$. G.Fecht, in: ZAS 94,36-42.

119 F.Daumas, Les mamnisis, 403ff., spez. 412/13. 
Chnum und Mut, der die Götter gebiert,

der jedes Auge zeugt und ihr Leben schafft 120

"Mutter und Vater": diese Metapher bringt die innige Bezogenheit von Gott und Schöpfungswelt in ihren beiden Aspekten, dem Zeugend-Hervorbringenden und dem Fürsorgend-Erhaltenden zum Ausdruck:

Mutter der Erde, Vater der Menschheit, der die Erde erleuchtet mit seiner Liebe. ${ }^{121}$

Du bist Mutter und Vater für die, die du erschaffen hast, ihre Augen, wenn du aufgehst, sehen sie durch dich. ${ }^{122}$

Du bist der Eine, der die Menschheit gebar,

Mutter und Vater für alle Augen.

Du gehst auf für sie täglich, um ihr Leben zu schaffen,

du einziger Hirte, der seine Herde schützt!

Der Millionen leitet mit seinem Licht. ${ }^{123}$

Du bist Mutter und Vater für jedes Auge,

du gehst auf für sie täglich, um ihr Leben zu schaffen, 124

Die Verbreitung dieser Formel zeigt, dass wir es mit einer Vorstellung $\mathrm{zu}$ tun haben, die der neuen Sonnen-Theologie und der Amarna-Religion gemein ist. ${ }^{125}$ wichtig ist das In-EinsSehen von Schöpfung und Erhaltung, die theologische Ausdeutung der Sonnen-Phänomene als creatio continua. Wichtig ist ferner die Anthropozentrik dieser Vorstellung, denn es wird darin ja nicht nur die sonnenstrahlung und -Bewegung als elterliche Liebe und Fürsorge ausgedeutet, sondern auch und vor

120 pBerlin $3048,3,6=$ AHG $\mathrm{Nr} .143,36-37$.

121 Louvre C 67.

122 Amarna AHG Nr.91, 21. Alternative ubersetzung: Du bist Mutter und Vater für die, deren Augen du erschaffen hast; wenn du aufgehst, sehen sie durch dich.

123 Text $113,32-35$.

124 Text 225, 23-24. Derselbe Satz auch auf der Stele BM 706, Kitchen, RI I, 330 .

125 Beachte den wichtigen Unterschied zu Text 165, 23, wo Amun genannt wird:

"Vater und Mutter (in dieser Reihenfolge!)

für den, der ihn in sein Herz gibt".

Vgl. hierzu Kap. 4 \$\$ 2 und 4. 
allem der Mensch als objekt dieser elterlichen zuwendung Gottes in den stand der Gotteskindschaft erhoben. ${ }^{126}$ Dabei steht aber der Mensch in einer Reihe mit allen Geschöpfen, "allem was Augen hat"127, wozu bei Suti-Hor auch die Götter gehören. Das zeigt, wie irrelevant die Monotheismus-Frage für das ist, worum es der neuen Sonnen-Theologie (im Gegensatz zur Amarna-Religion) geht. Die Vorstellung von der Einsamkeit und Einzigkeit Gottes, die ihn aus allen götterweltlichen Konstellationen heraus und der Welt gegenüber stellt, belässt der Welt ihre Götter und sieht sie zusammen mit den Menschen als Gottes-Kinder, denen sich der Sonnengott aus der Ferne seines einsamen Laufes als "Mutter und Vater" in liebender Fürsorge zuwendet.

Das "Künstlertum" Gottes gehört gleichfalls zu den "Leitmotiven", die der neuen Sonnen-Theologie und der Amarna-Religion gemeinsam sind. In den andern Texten kommt dieser Gedanke regelmässig in der Form des bewundernden Ausrufs zum Ausdruck, was ebenso für seinen sinngehalt von Bedeutung ist wie für die Haltung, aus der heraus sich dieser sinn erschliesst. Zwei Aspekte des göttlichen Schöpfungswerkes sind es vor allem, die dem Betrachter diesen bewundernden Ausruf entlocken: die unzählbare Fülle der Hervorbringung, und die weisheit, mit der für den Unterhalt, das Leben dieser verschiedenartigsten Geschöpfe gesorgt ist:

Was fur ein kunstler bist du in allem, was du

$$
\text { erschaffst! } 128
$$

Wieviel ist, was du erschaffst,

indem es dem Angesicht verborgen ist!

Unzählbarkeit

$(\ldots)$

Wie wirkungsvoll sind deine Pläne,

du Herr der Zeitfulle! 129

Weisheit

126 Zur Problematik der Gotteskindschaft des Menschen, die einerseits schon in der Lehre fur Merikare in aller Klarheit erfasst, andererseits aber nie ausdrucklich dargestellt wird, s. E.Otto, in: Probleme Biblischer Theologie, Fs von Rad (1971), 335-348, spez.341f.

$127 \mathrm{Vgl}$. n.122. Allgemein ist das die Bedeutung der Formel jrt nbt.

128 Text 76 .

129 Amarna, Grosser Hymnus AHG Nr.92, 76f. und 100. 
Der erste dieser bewundernden Ausrufe, der auch in den Ps 104 eingegangen ist ${ }^{130}$, bezieht sich auf die Fülle und Verschiedenheit der Geschöpfe, der zweite auf die wunderbare Einrichtung des zweifachen Nils, der die einen als Regen vom Himmel, die anderen als Strom aus der Tiefe am Leben erhält.

Was fur ein kunstler bist du in allem, was du

$$
\text { erschaffst! }
$$

Erschaffst du nicht Millionen und gebierst sie? Unzahlbarkeit

Die du im Wasser erschaffst, sie leben,

indem sie Luft atmen inmitten der Flut.

Weisheit

Die auf dem Lande, du schaffst ihren unterhalt.

Es gibt kein Aufhoren seit Anbeginn in deiner ganzen Schöpfung. $131^{\text {Ausdauer }}$

Der Suti-Hor Hymnus hebt die unzählbare Fülle hervor ( nn thw.sn ), macht aber vor allem mit der "Geduld" (w3h-jb) und der "Mühe" ( $\mathbf{C}_{3}$ wrd $)$ dieses göttlichen Künstlertums deutlich, dass es um die Ausdauer eines sich täglich wiederholenden Schaffens, um die creatio continua geht.

Mit dem Hirtenmotiv des letzten Verspaares vergleiche man schliesslich die stelle aus dem bereits zitierten Hymnus des Wesirs Paser:

Du einziger Hirte, der seine Herde schutzt, der Millionen leitet mit seinem Licht! 132

Wie das Eltern-Bild die Geschöpfe als Gotteskinder, so erklärt das Hirten-Bild sie als die Herde Gottes. Beide Metaphern der Gott-Mensch-Bezogenheit finden sich bereits in der

130 ps $104,24:$

Herr, wie sind deine Werke so gross und viel!

UnzăhlDu hast sie alle weisheitlich geordnet, barkeit und die Erde ist voll deiner Guter!

Weisheit

Zur Beziehung des 104.Psalms zum Grossen Hymnus von Amarna s. F.Crúsemann, Studien zur Formgeschichte von Hymnus und Danklied in Israel (1969), 286-288; Saeculum 23, 122 n.51 u. jetzt v.a. p. Auffret, Hymnes d'Egypte et d'Israel, OBd 34 (1981) 279-310.

131 Text 54 .

132 Text $113,33-34$ (p), (q). 
Lehre für Merikare und bestimmen das Gottesbild des Mittleren Reiches, wie es sich in den Prädikationen zwar nicht des Gottes selbst, aber seines irdischen Repräsentanten, des Königs, ausprägt. Die Metapher der "zuflucht", mit der suti-Hor das Hirtenbild ergänzt, weist besonders eindeutig auf das Königsbild des Mittleren Reiches zurück. ${ }^{133} \mathrm{Da}$ aber auch und vor allem die Amun-Re-Theologie auf diesem Gottes- und Königsbild basiert, werden wir in deren zusammenhang ausführlicher darauf einzugehen haben. ${ }^{134}$ Beide Konzeptionen haben die Anthropozentrik eines Weltbildes gemeinsam, das ausserhalb aller Konstellationen der polytheistischen Götterwelt ein höchstes Wesen verehrt. Auch das Bild Gottes als Hirten, dessen fürsorgendes Handeln dem "Kleinvieh" gilt,

das er geschaffen hat,

der Menschheit, die aus seinem Auge hervorging ${ }^{135}$

der alles Seiende schuf und was ist hervorbrachte

fur das kleinvieh, das aus seinem Auge $\mathrm{kam}^{136}$

der die Nacht wachsam verbringt, wenn alles schlaft,

um Nutzliches zu suchen fur sein Kleinvieh ${ }^{137}$

Hirte, der sein Kleinvieh schutzt ${ }^{138}$

macht den Menschen zum Bezugspunkt der Schöpfung und allen göttlichen Handelns.

Die Schöpfungstheologie der neuen Sonnen-Theologie versteht Schöpfung als creatio continua. Schöpfung und Erhaltung der Welt ereignen sich in ein und demselben Akt der "mütterlich-und-väterlichen" Zuwendung Gottes, als welcher der Sonnenlauf in der Fülle seiner-natürlichen Phänomene theologisch ausgedeutet wird.

133 J.M.A.Janssen, "De Farao als goede Herde", Mens en Dier, Amsterdam 1954, 71-79; D.Muller, in: ZAS 86 (1961) 126-144.

134 Kapitel 5, $\$ 6$, spez. 6.4.

135 Kairo JE 28569 ed.W.M.Muller, Egyptological Researches (1906) I Tf. 14-15; F.Hintze, in: ZAS 78 (1942) 55f.; Gaballa, in: JEA 63 (1977) Tf. 22 .

136 Berlin $7317=$ AHG 62,5 .

137 Kairener Amunshymnus, 7, $1=$ AHG Nr.87E, 123-124.

138 pBerlin $3053,14,7=$ Fouilles d'El-Kab I Tf. 24 . 


\subsection{Das Mysterium der Teilhabe}

Ware nicht das Auge sonnenhaft,

die Sonne könnt es nicht erblicken;

läg nicht in uns des Gottes eigne Kraft,

wie konnt uns Gottliches entzucken?

Schöner und treffender als mit dieser Goethe'schen Paraphrase einer Plotinstelle und letzlich eines platonischen Gedankens 139 könnte man nicht zum Ausdruck bringen, wodurch der Mensch nach der Vorstellung der neuen Sonnen-Theologie am Wesen der Gottheit teilhat. "Du bist die Augen selbst", heisst es im Text 151, "man sieht durch dich". So wie Ptah nach der memphitischen Lehre als Herz und zunge in jedem Leibe gegenwärtig ist ${ }^{140}$, so ist der Sonnengott in Gestalt der Augen "Fuhrer in jedem Leibe". 141 "Das Licht", so schreibt Goethe im selben zusammenhang, "ruft sich ein Organ hervor, das seinesgleichen werde und so bildet sich das Auge am Lichte fürs Licht, damit das innere Licht dem äusseren entgegentrete."142 Als Geschöpfe des Lichts werden die Lebewesen in den Texten der neuen Sonnen-Theologie als "alle Gesichter", "alle Augen" bezeichnet. Gott hat die Lebewesen zu Gefässen seines Lichts geschaffen, zu Partnern seines Blicks. Die Menschen haben nicht nur durch ihre Gott-Erschaffenheit, sondern auch durch ihr Sehvermögen an Gottes Wesen teil, durch das die belebende kraft Gottes immer wieder in sie einströmt.

In der "Ikonographie des Sonnenlaufs" wie allgemein im traditionellen polytheistischen Weltbild beruhte das "Mysterium der Teilhabe" auf dem Prinzip der Identifikation, durch das der Mensch sowohl im rituellen Kultvollzug wie nach dem Tode in götterweltliche konstellationen eintreten konnte. In

139 Johann Wolfgang von Goethe, Sämtliche Werke, Hamburger Ausgabe, Bd.13 (Hrsg,V.K.F॰v.Weizsäcker), 324 vgl. ibd., 323 und 550ff. (Kommentar mit Hinweisen auf antike Quellen, dazu: Platon, Politeia VI 508f.)

140 H.Junker, Die Gotterlehre von Memphis, APAW $1939 \mathrm{Nr} .23$ (1940), 48-54.

141 pChester Beatty IV $=$ AHG Nr.195, 250.

142 A.a.O. (n.139), 323 . 
einer Art mystischer Identifikation hat der Mensch am Leben der Gottheit teil. Dieser Begriff des Lebens wird nun in der neuen Sonnentheologie $\mathrm{zu}$ einer Handlung umgedeutet, in der Gott Subjekt und der Mensch Objekt ist. Diese Asymmetrie der Teilhabe am Leben schliesst Identifikation kategorisch aus. An die Stelle dessen tritt eine Bezogenheit von Schöpfer und Geschöpf, die enger kaum gedacht werden kann: Gotteskindschaft und Gottesebenbildlichkeit.

Das Wesen des Menschen bestimmt sich im Weltbild der neuen Sonnentheologie als eine Form der Geschöpflichkeit, die sich aus dem Begriff der creatio continua ergibt. Das bedeutet nicht ein einmal-von-Gott-Geschaffensein, sondern ein fortwährend, mit jedem Sonnenaufgang aufs neue Erschaffenwerden. Es ist das Bewusstsein dieser Geschöpflichkeit, dieses "Kreaturgefühl", das den Hymnen der neuen Sonnentheologie zugrundeliegt, das sich in ihnen äussert und das ihre innere Form bestimmt. An die stelle der "Status-Charakteristik" des Sonnengottes, die seine "Einbezogenheit" in götterweltliche Konstellationen preist ${ }^{144}$, ist das Danklied getreten, mit dem der Mensch das Handeln Gottes beantwortet, als dessen Bezugspunkt er sich sieht, mit dem das Geschöpf seinen Schöpfer preist.

Dieses neue Selbstverständnis der Hymnik kommt in jenen Versen zum Ausdruck, die von der Preisung des Sonnengottes reden. In den Sonnenliedern des alten Typs war hier von der Anbetung und dem Jubel die Rede, die dem Sonnengott von Seiten seiner vielfältigen götterweltlichen "Gemeinden" - den östlichen und westlichen "Ba's", den Mannschaften der Barke, den "Ba's" von Nechen und Buto usw. usw. - entgegengebracht werden, die Rede, in die sich der Mensch nach dem Prinzip der Identifikation mit seinem Hymnus als "einer von ihnen" einreihte. In den neuen Sonnenliedern preisen dagegen nicht mehr distinkte "Gemeinden", sondern "alle Welt", "alle Gesichter",

$143 \mathrm{Vgl}$. jedoch $\mathrm{n} .126$.

144 Zum Begriff "Einbezogenheit" s. LL 339ff.; "Status-Charaktersitik" s. AHG $3 \hat{j} \hat{\mathbf{f}}$. 
"jedes Auge" den Sonnengott, und ihr Lobpreis wird in Satztypen der zuständichkeit dargestellt, der seinen Charakter als "kreatürliche Responsion" deutlich macht. Wichtig ist aber, dass dieser Lobpreis nicht, wie im Festlied, als ein blosser Zustand des Jubels und der Festlichkeit beschrieben wird, in den Gott die welt versetzt hat, sondern dass hier Gott als Auslöser und Adressat dieses Jubels fast in jedem Vers genannt wird. Betrachten wir zunächst einige typische Darstellungen dieses Themas in Amarnahymnen:

(1) Alle Gesichter, sie leben auf bei deinem Anblick, das ganze Land ist versammelt bei deinem Erscheinen, ihre Arme sind in Lobpreis bei deinem Aufgang. ${ }^{145}$

(2) Willkommen in Frieden! ${ }^{146}$

Das ganze Land ist versammelt bei deinem Erscheinen, ihre Arme in Lobpreis bei deinem Aufgang . Sie kussen die Erde, weil du ihnen erstrahlst, sie jubeln bis zur Höhe des Himmels, Freude und Jauchzen ergreift sie, sie frohlocken beim Anblick deiner Majestät. ${ }^{147}$

(3) Ihre Arme sind in Lobpreis fur deinen Ka, du hast die Herzen belebt mit deiner schonheit. Man lebt auf, wenn du deine Strahlen gibst, jedes Land ist im Fest. ${ }^{148}$

(4) Alle Augen sehen durch dich, und freuen sich bei deinem Erstrahlen, ihre Arme in Jubel fur deinen Ka:

145 Sandman, 23 cf. 28 : Wenn du aufgehst, lebt jedes Gesicht, inre Arme geben dir Lobpreis, das ganze Land ist versammelt bei deinem Erscheinen.

$146 \mathrm{Vgl.} \mathrm{n.44.} \mathrm{In} \mathrm{der} \mathrm{traditionellen} \mathrm{Sonnenhymnik} \mathrm{ist} \mathrm{"Willkommen"} \mathrm{die} \mathrm{ty-}$ pische Anrede an den abendlich-nächtlichen Sonnengott, weil sie die Vorstellung einer leibhaftigen prasenz impliziert. Genau dies ist aber auch die Vorstellung, die die Licht-Theologie der Amarna-Religion, aber bis zu einem gewissen Umfang auch die neue Sonnen-Theologie allgemein, mit dem Sonnen-Aufgang verbindet: der Gott "kommt" in Gestalt des Lichts auf die Erde herab.

147 Sandman, 33.

148 Sandman, $13=$ AHG Nr.91, 30-33. 
du bist der Gott, der inre Leiber geschaffen hat,

sie leben auf, wenn deine Strahlen auf Erden sind. ${ }^{149}$

(5) Der am Himmel aufgeht, um die Herzen zu uberfluten, jedes Land ist im Fest bei seinem Erscheinen;

ihre Herzen sind froh in Jubel:

ihr Herr und Schøpfer ist aufgegangen uber ihnen. 150

(6) Die Menschheit jubelt vor deinem Angesicht, und gibt Lobpreis inrem Schopfer,

kusst die Erde vor dem, der sie hervorbringt. ${ }^{151}$

Der Charakter des Hymnus als eines Dankesliedes auf den Schöpfer und das Gefuhl der Dankbarkeit des Geschöpfs gegenuber dem Schöpfer kommt in den Beispielen (4)-(6) deutlich zum Ausdruck. "Sie beten dich an, wie du sie geschaffen hast" 152 . Dieses Motiv kommt auch im Kairener Amunshymnus vor, wo nach der detaillierten Schilderung der alles erschaffenden und erhaltenden Kraft Gottes, der auch hier als ein Schöpfer- und Lebensgott aufgefasst wird, der Lobgesang der Geschöpfe in direkter Rede zitiert wird:

Preis dir mit dem, was sie alle dir sagen:

"Jauchzen erschalle dir, weil du dich abgemuht hast mit uns

die Erde werde vor dir gekusst, weil du uns geschaffen hast! "153

Auch die Götter stimmen in diesen Lobgesang ein:

"Wir beten deine Macht an, wie du uns geschaffen hast, wir veranstalten dir Lobgesänge, weil du uns hervorgebracht hast, wir stimmen dir preisungen an, weil du dich abgemuht hast mit uns!" 154

Der Tura-Hymnus, der einen narrativen Schöpfungsbericht gibt, beschliesst ihn gleichfalls mit dem Danklied der Geschöpfe:

149 Sandman, 142.

150 Sandman, 91.

151 Sandman, 46.

152 Sandman, 73.

153 Kairener Amunshymnus AHG Nr.87E, 127-129. Vgl. zur Topik des Dankes der Geschbpfe fur die Schopfung LL 326-7.

154 AHG Nr.87E, 142-144. 
sie beten dich an, wie du sie geschaffen hast,

sie küssen die Erde, wie du sie geschaffen hast. 155

Besonders kennzeichnend aber für die Auffassung der Amarnareligion vom Sinn der Lobpreisung Gottes sind jene Schilderungen der morgendlichen Sonnenanbetung, in denen sie als schiere Lebensregung erscheint und die Menschen in einer Reihe mit Tieren und Pflanzen auf die lebensspendende Wirkung des Sonnenlichts reagieren:

(7) Kräuter und Bäume bewegen sich vor deinem Angesicht, die (Fische) im Wasser hüpfen bei deinem Erscheinen, 'jedes Auge' erhebt sich auf seinem Platz; sie reinigen ihre Leiber und ziehen weisse Kleider an, jedes Handwerk geht an seine Arbeit. 156

(8) Alle lebenden Pflanzen, die auf dem Erdboden wachsen, gedeihen bei deinem Aufgang, trunken von deinem Angesicht. 157 Alles wild tanzt auf seinen Füssen; die Vögel, die in den Nestern waren, fliegen auf vor Freude; ihre Flügel, die zusammengefaltet waren, spreizen sich in Lobpreis für die lebendige Sonne, ihren Schöpfer ... ${ }^{158}$

(9) Du vertreibst die Finsternis, du gibst deine Strahlen, die beiden Länder sind im Fest täglich. Was auf Füssen steht, erwacht; du hast sie aufgerichtet, sie reinigen ihre körper und ziehen weisse Leinengewänder an; ihre Arme sind in Lobpreis bei deinem Erscheinen, das ganze Land tut seine Arbeit. Alles Vieh befriedigt sich an seinen kräutern, Bäume und Pflanzen wachsen.

155 AHG $\mathrm{Nr} .88,45-46$.

156 Sandman, 76.

157 Vgl. Text 26 (a). Zum Motiv der Trunkenheit vgl, auch die Lehre des Ani, III, 7-9 Gardiner, in: JEA 45, 12ff.; LL $161 \mathrm{n.9}$.

158 Sandman, $15=$ AHG Nr.91, 57-65. 
Die Vögel fliegen auf aus ihren Nestern, ihre Flugel in Lobgebarden fur deinen Ka.

Alles wild tanzt auf seinen Fussen,

alles was aufliegt und sich niederlusst,

sie leben, wenn du fur sie aufgehst.

Die Schiffe fahren stromab

und stromauf in gleicher Weise.

Jeder Weg ist geoffnet durch dein Erscheinen.

Die Fische im Fluss

hupfen vor deinem Angesicht;

deine Strahlen sind im Innern des Ozeans. 159

Von Anbetung im eigentlichen sinne ist hier gar nicht mehr die Rede. Hier geht es nicht um einen besonderen rituellen Akt, sondern um die alltäglichen Lebensregungen der erwachenden Natur, die als ein einziger Lobgesang der 1 ichtgeschaffenen welt auf die Schöpferkraft des Lichts ausgedeutet werden: das Erwachen, Aufstehen, Waschen, Ankleiden und an die ArbeitGehen der Menschen, deren Arme sich nicht anders als die Flügel der Vögel in Lobgebärden ausbreiten ${ }^{160}$, die Lebensregungen der Tiere, das Wachsen und sich-Bewegen der Pflanzen, alles lobt den belebenden Schöpfer in der blossen Responsion auf das Sonnenlicht. In dieser extremen Form ist das reine Amarna-Religion, die ja die Möglichkeit einer persönlichen Hinwendung des Menschen zu Gott sehr stark eingeschränkt und im Grunde auf die reine Rezeptivität, das Aufnehmen seiner Strahlen, reduziert hat. 161 Ich möchte daher zum vergleich einige Schilderungen der morgendlichen Anbetung und kreatürlichen Responsion aus ramessidischen Texten danebenstellen:

159 Sandman, $94=$ AHG Nr.92, 40-58.

$160 \mathrm{Vgl}$. Zitat 9, vers 5 und vers 10 (auch Zitat 8, 7-8). S.a.n.179.

$161 \mathrm{Vgl}$. Saeculum 23, 121f. m.n.52. Die Vorstellung einer rein rezeptiven Hinwendung zum Gottlichen hat etwas Mystisches, das z.B. an G.Tersteegens Lied "Gott ist gegenwarrtig" erinnert:

Du durchdringest alles; lass dein schones Lichte,

Herr, beruhren mein Gesichte.

wie die zarten Blumen

willig sich entfalten

und der Sonne stille halten,

lass mich so, still und froh, 
(10) Deren Augenlicht getrübt war, er leuchtet für sie, um ihre Gesichter hell zu machen in einer neuen Gestalt, deren Augen glänzen, deren Ohren offen sind: jeder Leib ist bekleidet mit seinem Strahlenglanz. Der Himmel ist Gold, der Nun ist Lapislazuli, die Erde ist mit Türkis bestreut, wenn er in ihm aufgeht. Die Götter schauen, ihre Tempel stehen offen, die Menschen geraten in Staunen bei seinem Anblick. 162

Alle Bäume schwanken hin und her vor ihm, sie wenden sich nach seinem Ein-Auge hin, ihre Blätter entfaltet. Die Fische springen im Wasser, sie kommen aus ihren Gewässern heraus aus Lust an ihm. Alle wildtiere tanzen vor ihm, die Vögel schlagen mit ihren Flügeln. Sie erkennen ihn zu seiner schönen stunde, sie leben auf bei seinem Anblick täglich. 163

(11) Deine Strahlen, sie verkünden dich in den Augen der Festland- und Inselbewohner. Die Bewohner der Unterwelt umringen dich mit Preisungen, die Lebenden verneigen sich vor deinem Aufgang; das Himmelsvolk tanzt für dich vor deinem Angesicht, Volk und Vornehme beten dich an.

Wild und Herden wenden sich dir zu, alle pflanzen drehen sich nach deiner schönheit. Es gibt kein Leben für das, was dich nicht sieht. 164

deine Strahlen fassen und dich wirken lassen.

Natürlich ist bei Tersteegen das Sonnenlicht Metapher für die Gegenwärtigkeit Gottes und die "heliotrope" Lichtempfänglichkeit der Pflanzen Metapher für die rezeptive Hinwendung der wahren Frömmigkeit, während in Amarna alles ganz buchstäblich gemeint ist: Gott ist im Sonnenlicht wirklich gegenwärtig, und die Lebensregungen der Natur sind ein wirklicher Lobpreis auf den Schöpfer, in den der Mensch einstimmt. Aber in der theologischen Ausdeutung der natürlichen Phänomene geht es auch in Amarna um die Gegenwärtigkeit Gottes; daher die erstaunliche Verwandtschaft des Ausdrucks.

$162 \mathrm{Vgl.} \mathrm{Std.} \mathrm{Rit.,} \mathrm{1.Std.} \mathrm{6,} \mathrm{LL} \mathrm{151ff.;} \mathrm{Amarna.} \mathrm{Sandman} 49=$ AHG Nr.94, 17-19.

163 pLeiden J 350 II,2-10; Zandee, Hymnen, 18-25; ÄHG Nr.132.

164 pChester Beatty IV rto AHG Nr.195, 229-237. 
Diese beiden Stellen stammen aus literarischen Hymnen und verweilen auf diesem Thema ausfühlicher, als es für die im ganzen sehr viel kürzeren Gräberhymnen üblich ist. Ich zitiere nur aus dem Hymnus des Nebwenenef:

(12) Du bist es, der alles seiende gebildet hat, sie leben auf, wenn du leuchtest.

Sie wenden sich dir $z u$, wenn du fur sie erscheinst, sie sind verklärt, wenn deine Strahlen sich ausbreiten uber ihren Gliedern;

kein ort ist hier bar deines Lichts.

$(\ldots)$

Der Hauch deines Mundes kommt an jede Nase,

du bist die Augen selbst, man sieht durch dich.

Dein Lichtschein erweckt die Gesichter

und macht jedermann wach, der darniederliegt. ${ }^{165}$

Auch dieser Text deutet die Lebensregungen der erwachenden Natur als Lobpreis des Schöpfers. In die Allgegenwart des belebenden Lichts scheint auch die Unterwelt einbezogen: "verklärt", "darniederliegen" sind deutliche Anspielungen auf die Toten, von deren "Erweckung" durch das Sonnenlicht ja auch in den traditionellen Sonnenliedern die Rede ist. Der entscheidende Gedanke ist, dass sich die Anbetung des Sonnengottes in den Lebensregungen der erwachenden Natur ereignet, und dass diese morgendiche Erweckung ein Schöpfungsakt ist, dem das Aufleben der Geschöpfe als Danksagung korrespondiert. Dieser Zusammenhang kommt in dem zitat aus Text 151 in besonderer Kl arheit zum Ausdruck.

ES sind die semantischen Kategorien LEBEN und HERRSCHAFT, die in diesen Schilderungen der Anbetung als kreatürliche Re-

165 Text 151, 12-15 und 24-28. Zum Motiv der "Erweckung" s. ibd., (t). Auch hier wird, wie in dem Motiv der "Ankunft", ein ursprunglich auf die unterweltliche Erscheinungsphase des Gottes bezogener Vorstellungskomplex auf den Morgen umgedeutet. So wie die Toten bei der "Ankunft" der Sonne aus ihrem "Dornruschenschlaf" (Hornung, unterweltsbucher, 38-42) erwachen, so erwachen jetzt die Schlafenden beim Sonnenaufgang $\mathrm{zu}$ neuem Leben und ziehen nicht nur neue Kleider (Beispiel 7 und 9), sondern sogar einen neuen Menschen an (Beispiel 10, vgl. die Interpretation von J. Zandee z.St.). 
sponsion zum Ausdruck kommen. In der Abhängigkeit allen Lebens von seinem einen Ursprung manifestiert sich die Herrschaft, die der Schöpfer luber sein Geschöpf ausübt. So fährt z.B. das 9.Lied des Leidener Amunshymnus nach der zitierten Stelle (10) fort:

sie sind in seiner Hand, verschlossen mit seinem Siegel,

kein Gott kann sie offnen ausser seiner Majestät;

keiner ist, der ohne inn schaffen kann,

den Grossen Gott, das Leben der Neunheit. ${ }^{166}$

Schöpfung und Herrschaft gehören im ägyptischen Denken zusammen. ${ }^{167}$ Das Geschöpf gehört seinem Schöpfer. Diese geschöpfliche Zugehörigkeit manifestiert sich in der Abhängigkeit, die sich im Horizont einer so radikal verstandenen creatio continua, einer täglichen Neuschöpfung, bis in die Nähe einer "schlechthinnigen Abhängigkeit" steigert. 168

\section{Stilistische Aspekte: die Transformation des Tageszeiten-} liedes.

Obwohl mit den Konstellationen der polytheistischen Götterwelt auch jene Bilder hinfällig werden, in denen die traditionellen Sonnenlieder in der Form des Tageszeitenliedes die Phasen des Sonnenlaufs dargestellt hatten, halten dennoch auch die neuen Sonnenlieder an der äusseren Form des Tageszeiten1 iedes fest. Es liegt aber in der Natur der neuen "anikonischen" Darstellungsform, die sich strikt auf die sichtbaren, natürlichen Phänomene und ihre theologische Ausdeutung beschränkt, dass sich die konturen der Tageszeiten verwischen und sich bestimmte Themen nicht mit der Regelmässigkeit bestimmten Tageszeiten zuordnen lassen, wie das mit den "Ikonen" der traditionellen Sonnenlieder der Fall war. Ich möchte die neuartige Anschauung der Tageszeiten anhand des Grossen Hymnus von Amarna aufzeigen, der das klarste Beispiel eines

166 pLeiden J 350, II, 9-10, Zandee, 23-25.

$167 \mathrm{Vgl}$. Text 158 (d).

$168 \mathrm{Vg} 1$. Saeculum 23, 122. 
Tageszeitenliedes neuen Typs darstellt, und Beispiele aus anderen Sonnenlieder zum Vergleich heranziehen.

\subsection{Der Morgen}

Du erscheinst schon

im Lichtland des Himmels,

du lebende Sonne, die Leben zuweist. ${ }^{169}$

Du bist aufgegangen im Ostlichen Lichtland

und hast alle Lande erfullt mit deiner schonheit.

Die kurze strophe beschränkt sich auf das, was wir in der "Ikonographie" des Sonnenlaufs die "A"-Seite des Vorgangs genannt haben: die Handlung des Gottes. Das hat seinen Grund im zyklischen Aufbau des ganzen Liedes, das über Mittag und Nacht wieder zum Morgen zurückführt, wo dann die Schilderung der erwachenden Natur und kreatürlichen Responsion als "B"Seite in 21 Versen dargestellt wird (vgl.0., Beispiel 9). Stichworthaft und in zyklischer Anordnung stellt die strophe die semantischen Kategorien LICHT und LEBEN in den vordergrund:

schön

$\begin{array}{ll}\text { LICHT } & \text { Lichtland lebend, Leben } \\ \text { LEBEN } & \text { Lichtland }\end{array}$

Schönheit

Die Gegenwärtigkeit ("Schönheit") der göttlichen Lebensfülle im Licht ist das Thema dieser strophe, die ganz aus der alten stilform der Theophanie-Schilderung entwickelt ist:

169 Die ubliche Wiedergabe: "Der zuerst lebte", beruht auf einer Lesung Bouriants $\left(\xi_{3}\right)$, die durch die parallelstellen dieser Anrufung nicht bestätigt wird (dort vielmehr క3jw "der bestimmt, zuweist"). Da die urzeit in der Theologie von Amarna in hochst charakteristischer Weise keine Rolle spielt, ist $\lessgtr 3 j w$ auch inhaltlich die bessere Iesung. Vgl. LA I, $539 \mathrm{n} .113$. 


\begin{tabular}{|c|c|c|c|c|}
\hline \multirow{4}{*}{$\begin{array}{l}\text { intransitiver } \\
\text { Aspekt: }\end{array}$} & & (a) & Vorgang: & sdm.f 170 \\
\hline & Erscheinung & & & $\underbrace{\mathrm{CC}} \cdot k$ \\
\hline & im & & & \\
\hline & Himmel & (b) & Zustand: & PsP \\
\hline & & & & jw.k wbntj \\
\hline transitiver & $\begin{array}{l}\text { Auswirkung } \\
\text { auf die }\end{array}$ & (c) & $\begin{array}{l}\text { Handlung: } \\
\text { (=Zust and }\end{array}$ & $\begin{array}{l}\text { sdm.n.f } \\
m h \cdot n \cdot k \text { t } 3 w j\end{array}$ \\
\hline Aspekt: & Erde & & des objekts) & \\
\hline
\end{tabular}

Die Morgenstrophe des "Kleinen Hymnus" ist etwas expliziter:

(a) Du erscheinst schön,

du lebende Sonne, Herr der zeitfülle!

(b) Du bist funkelnd, schön und stark,

die Liebe $z$ dir ist gross und gewaltig;

deine Strahlen, sie berühren jedes Gesicht

(var.: sie schaffen Augen allem, was du hervorgebracht hast)

deine strahlende Haut belebt die Herzen,

(c) du hast die beiden Länder erfüllt mit Liebe zu dir. ${ }^{171}$

Auch diese längere Strophe ist aus der Theophanie-Stilform entwickelt. Der intransitive Aspekt wird hier aber erweitert:
(1) Zustand des Subjekts
PSP
thntj ${ }^{c_{n t j}}$ wsrtj
mrwt.k wrtj ${ }^{c_{3 t j}}$

(b) Zustand

$\begin{array}{ll}\text { (2) Durative } & \text { N sdm.f stwt.k tks.sn.. } 173 \\ \text { Handlung } & \text { hr }+ \text { Inf jnm.k...hr } s^{c} \text { nh... }\end{array}$

170 Emphatische Form: "Schön ist, wie du aufgehst".

171 Beachte die wiederholung des Stichworts mrwt.k in Vers 4 und 7, genau wie im Grossen Hymnus das Stichwort nfr wiederholt wird. nfrw "Schönheit" bezieht sich auf das Auge, mrwt "Liebe" auf das Herz. So ist es kein Zufall, wenn auch das Motiv des Belebens der Herzen gerade in diesem Text mehrfach vorkommt, s. AHG Nr.91, Vers 14 und vers 31, vgl, auch vers 24 .

172 Var. wbb.tj "du bist strahlend".

173 Var. stwt.k r jrt jrtj n qm3.n.k nb vgl. dazu Text 188 (c). 
Die Reihung von Eigenschaftsverben im Pseudo-Partizip (d.h. in der intransitiven Form des Resultativs, die den zustand des subjekts ausdrückt ${ }^{174}$ ) ist eine typische Form der ägyptischen Hymnik, die gerade im Unkreis der neuen Sonnentheologie eine besondere Aktualität gewinnt. Die Beispiele neuen und traditionellen Typs habe ich LL 114ff. zusammengestellt. Dabei fällt auf, dass die Beispiele des neuen Typs Eigenschaftsverben verwenden, die sich auf sichtbare Qualitäten des "Erschienenseins" beziehen wie Schönheit, Lichthaftigkeit, Grösse, Höhe, während die Beispiele des traditionellen Typs in ziemlich ausgewogenem Verhältnis sichtbare und "innere" Qualitäten wie Mächtigkeit, Verklärtheit, Beseeltheit usw. verbinden. Die Beliebtheit dieser Form in dex späten 18. Dyn. steht also im Zusammenhang mit der Ausdeutung des Lichts als der Parusie (leibhaftigen Gegenwärtigkeit = "Schönheit") des Gottes. Die gleiche Erklärung gilt auch für die auffallende Beliebtheit von Sätzen des Typs (c) in den Hymnen des neuen Typs: bringen diese Sätze, die sich formal auf den "zustand des objekts" und zwar der Erde beziehen, doch in einer denkbar knappen und klaren Form den Gedanken der "Gotterfulltheit der Welt" zum Ausdruck, als theologische Ausdeutung ihrer Erhellung.

Im Suti-Hor-Hymnus lautet die Morgenstrophe folgendermassen:

Deine Strahlen sind im Angesicht, aber man erkennt sie nicht,

Weissgold kommt deinem Glanz nicht gleich.

Du bist ein ptah, du giesst deinen Leib aus Gold,

Gebărender, der nicht geboren wird.

Einziger, der die unendliche zeitfulle durchläuft,

der auf den Wegen mit Millionen unter seiner Leitung.

Wie dein Glanz ist der Glanz des Himmels,

deine Farbe strahlt funkelnder als seine Haut. ${ }^{175}$

$174 \mathrm{Vgl} .67 \mathrm{~m} \cdot \mathrm{n} .45$.

175 Diese Strophe weicht vollkommen $a b$ von der vorlage, die sich nach saitischen Quellen rekonstruieren lasst (MDIK 27,1,6-7). Die ersten vier Verse stehen dort im Anschluss an die "Mittags-Strophe" und beziehen sich schon durch diese Anordnung nicht auf den Morgen, sondern auf den Gesamt-zyklus. Der Vorlage liegt nicht der Textplan des Tageszeitenliedes zugrunde. Die letzten vier Zeilen sind ein individueller zusatz, der sich in keiner anderen Fassung findet. 
Der Gedanke von Vers 1 kommt in anderer Formulierung in der Mittagsstrophe noch einmal vor: er gehört $\mathrm{zu}$ jenen Aspekten des Sonnenlaufs, die sich nicht auf eine seiner Phasen verteilen lassen und in denen sich, in der neuartigen Blickrichtung, in der die neue Sonnentheologie die Phänomene betrachtet, die Konturen der Tageszeiten verwischen. In der gleichen Weise ist auch im Grossen Hymnus das Motiv "b(1)" der Morgenstrophe, wie sie im Kleinen Hymnus vorliegt, in die Mittagsstrophe eingedrungen. "Weissgold" ist das Symbol der Schönheit und Lichthaftigkeit des Gottes ${ }^{176}$ und gehört thematisch mit den letzten beiden Versen zusammen. Ptah als Goldgiesser, Symbol der Selbst-Hervorbringung des Gottes - dieser und der nächste vers formulieren die schlechthinnige "Autarkie" des Gottes, der ausserhalb aller Konstellationen steht, alle Kraft und Wesensfülle in sich selbst umschliesst und unabhängig von väterlichen und mütterlichen Kräften seinen Lebenszyklus aus sich selbst heraus vollbringt. Eng damit zusammen hängt das Thema des nächsten Verspaares. Das "Durchlaufen des Nhh " bezieht sich auf die allein, als Einziger, d.h. ausserhalb der Konstellationen, unabhängig von einer "Sphäre der Seinigen" vollbrachte unendliche wiederholung der Lebenszyklen. Die Gegenüberstellung von "Einziger" und "Millionen" präfiguriert in gewissem Sinne die Stelle im Kleinen Hymnus von Amarna, wo von den "Millionen Leben in dir, dem Einzigen" die Rede ist, sowie die stelle im Grossen Hymnus, wo es heisst: "du schaffst Millionen Verkörperungen aus dir, dem Einen." 177 Das Wege-Motiv bezieht sich, wie oben gezeigt, auf den Gedanken der Allgegenwart des Lichts und der Gotterfülltheit der "begehbaren" Welt. Die Beschränkung der Darstellung auf die "A-Seite" des Vorgangs - die Handlung des Gottes ist sicher bedeutungsvoll und hängt mit dem Gedanken seiner

$176 \mathrm{Vgl}$. Daumas, in: RHR 149 (1956) 1-17; LL 129f. In einem der Hymnen auf den pfeilern des ptahmose (Leiden $K$ 11: Kitchen, RI III, 175, 2) heisst es:

p3 nbjw sw now jm.t

Der sich selbst in Gold giesst, aber nicht aus Gold ist (sondern aus einer noch viel strahlenderen unerforschlichen Substanz).

177 S. hierzu Text 149 (c); Text 253 (2); Kap.7. 
"Autarkie" zusammen, der hier im Zentrum steht. Diese Beschränkung ist aber für die "neue Sonnentheologie" nicht konstitutiv, vgl.z.B. folgendes Beispiel aus Memphis-Saqqara:

Du hast dich befestigt sehr, sehr weit,

sehr sehr fern;

du hast dich gezeigt im Himmel in deiner Einsamkeit.

Jeder Gott auf Erden,

ihre Arme sind im Lobpreis bei deinem Aufgang.

Du erglänzt, und sie sehen,

sie erheben sich, ihre Arme gebeugt in Ehrfurcht vor deinen

Machterweisen 178

Ferne und Einsamkeit des Sonnengottes - kreatürliche Responsion der Götter (die typische Formel: "ihre Arme in Lobpreis"179), deren Lebensregungen hier stellvertretend für die gesamte Schöpfung stehen.

\subsection{Der Mittag}

Du bist schon, gewaltig und funkelnd,

du bist hoch uber jedem Land.

Deine Strahlen, sie umfassen die Länder bis ans Ende deiner ganzen Schopfung,

als Re dringst du an ihre Grenzen

und unterwirfst sie deinem geliebten Sohn.

Du bist fern, aber deine Strahlen sind auf Erden,

du bist in ihrem Angesicht, aber man kann deinen Gang nicht

erkennen.

Die ersten beiden Verse, darauf habe ich bereits hingewiesen, sind aus ihrem ursprünglichen zusammenhang, der morgendlichen Theophanie, in die Mittagsstrophe hineingenommen worden, um den Begriff der Höhe und der maximalen Strahlkraft zum Ausdruck zu bringen, mit der vom Zenith seiner Bahn herab der

178 Leiden V $70=$ AHG Nr.90; Leiden $\mathrm{K} 11=$ Kitchen, RI III, 175, 2-5.

$179 \mathrm{Vgl}$. Saeculum 23, 122f. n.52. Belege LL 208 n.90. 
Gott mit seinen Strahlen die Erde "umfängt". Wie in den traditionellen Sonnenliedern auch dominiert in dieser Mittagsstrophe, in der auch hier der Gott "als Re" erscheint ( jw.k m iso $\mathrm{R}^{\mathrm{C}_{W}}$ ) das Thema HERRSCHAFT. In dem Verb ${ }^{\mathrm{C}_{f}}$ "niederbeugen" schwingt sogar etwas von dem alten Thema der Uberwindung des Feindes mit, das ja die sinn-Dimension des Politischen, in der dieses Thema hier erscheint, mit umfasste. Das abschliessende Verspaar verknüpft dann den Gedanken der Allgegenwart des Lichts mit dem Motiv der Ferne, Verborgenheit und Unerforschlichkeit des Gottes, diese typische Paradoxie von leibhaftiger Gegenwärtigkeit des Gottes im Licht bei gleichzeitiger unermesslicher Ferne, die einen der Leitgedanken der neuen Sonnen-Theologie darstellt. (vgl. 2.3)

Die zweite Strophe des Kleinen Hymnus lässt sich kaum mehr als eine "Mittags-Strophe" ausmachen:

Du erhabener Gott, der sich selbst formte,

der jedes Land erschuf und was darinnen ist hervorbrachte

an Menschen, Herden und wild

und allen Bäumen, die auf dem Erdboden wachsen -

sie leben, wenn du für sie aufgehst.

Du bist Vater und Mutter für die, die du geschaffen hast.

Ihre Augen, wenn du aufgehst, sehen durch dich.

Deine Strahlen haben das ganze Land erhellt,

jedes Her $z$ frohlockt bei deinem Anblick

du bist erschienen als ihr Herr.

Nur über den Zusammenhang von schöpfung und Herrschaft, der in dem Text ja explizit zum Ausdruck kommt, erschliesst sich die Beziehung dieser strophe zum Herrschafts-Thema, das die Vorstellung der mittäglichen Epiphanie des Gottes charakterisiert. Die Mittags-strophe des suti-Hor-Hymnus beginnt mit dem traditionellen "thematischen stichwort" d3j.k pt "du querst den Himmel", um dann in einer weise fortzufahren, die ganz offensichtlich das traditionelle Thema der "Uberwindung" aus dem Mythisch-Ikonischen (die Uberwindung des Feindes) ins Kosmische transponiert. Es handelt sich um den locus classicus für die dann weit verbreitete Ausdeutung der Sonnenbewe- 
gung als Erschaffung der Zeit: 180

Du quersi den Himmel und jedes Gesicht sieht dich (aber) dein Gang ist verborgen in ihrem Angesicht. Du zeigst dich am Morgen Tag für Tag, fest ist deine Fahrt unter deiner Majestät. Der Tag ist klein, dein Lauf ist weit, Millionen und Hunderttausende von Meilen. Ein Augenblick ist jeder Tag, den du bringst er vergeht, wenn du untergehst. Die Stunden der Nacht hast du in gleicher weise vollendet und hast sie eingeteilt; deine Arbeit kennt kein Aufhören.

Der oft kommentierte Text bedarf keiner weiteren Erläuterungen. 181 Dasselbe Thema behandelt, ebenfalls in Form einer Mittagsstrophe unter dem thematischen stichwort $\underline{\text { d}} 3 \mathrm{j}$ "überfahren", das 20. Lied des Leidener Amunshymnus:

Wie 'überfahrend' bist du, Harachte, indem du deine Aufgabe von Gestern täglich wieder vollbringst! Der die Jahre erschafft und die Monate knüpft, Tage und Nächte, die Stunden entsprechen seinem Gang. Du bist heute neuer als Gestern, beim (Verbringen) der Nacht bist du schon dem Tage bestimmt. Einzig Wachsamer, dessen Abscheu der Schlaf ist, jedermann schläft, aber seine Augen wachen. Der Millionen aufdeckt mit seinem schönen Gesicht, kein weg ist frei von ihm (wenn er strahlt) auf die Erde.

Eilenden Schritts beim Strablen verschiessen, der das Land umläuft in einem Augenblick, ohne dass inm etwas unzugänglich bliebe! Der den Himmel überquert und die Unterwelt durchläuft,

180 S. hierzu ausführlich zeit und Ewigkeit, 49-54.

181 MDIK 27.1, 8-10; Zeit und Ewigkeit, 51-54; G. Fecht, in: ZÄS 94, $25 \mathrm{ff}$. mit weiterer Lit.; Barucq-Daumas, Hymnes et Prières, Nr.68. 
Licht auf jedem Wege!

umlaufender in den Gesichtern:

Jedes Gesicht, ihre Gesichter sind auf ihn gerichtet,

von Menschen und Göttern, die sagen: "Willkommen!"182

Die den Raum erschliessende Allgegenwart des Lichts und die die zeit erschliessende Periodizität der Bewegung bilden das durchgehende Thema dieser Darstellung. Der Gedanke der Periodizität, der ja auch die traditionellen Sonnenlieder sehr beschäftigt hat ${ }^{183}$, erscheint in den Liedern des neuen Typs gern in Wendungen wie "du erscheinst an deiner stelle von gestern" (oder: "in deinem Zustand von gestern"?) 183a

Du sitzt auf dem Heck deiner Barke,

und begibst dich an deinen Platz von gestern. 184

Du gehst unter und wieder auf am Morgen,

du hast dich gezeigt an deiner stelle von gestern. 185

Die Erde wird hell zu seiner Geburt Tag für Tag,

er hat seine stelle von gestern erreicht. 186

Die Erde wird hell, wenn er sich zeigt an seiner stelle. ${ }^{187}$

Die Erde wird hell, wenn du dich zeigst an deiner stelle. ${ }^{188}$

Die Erde wird hell an seinem Lichtland von gestern. 189

Der altert und sich verjüngt am Morgen,

der Licht gibt an seiner stelle von gestern. 190

182 pLeiden J 350 II, 15-20; Zandee, Hymnen, 29-34; AHG Nr.133; MDIK 27. 1, 18f.; Zeit und Ewigkeit, $49 \mathrm{f}$.

183 S. v.a. LL, 118ff.; O., Kap.4; Derchain, "Perpetuum mobile", in: Orientalia Lovanensia Periodica 5/6 (1975/76), $153 \mathrm{ff}$.

183a Zandee, in: JEOL 16, 48; Hymnen, 4.

184 Totb 101.

185 Text 76.

186 Totb Ani $=$ AHG Nr.30, 26-27. Vgl. auch Totb Leiden T $2=$ AHG Nr.28,3.

187 Text 29, $24 \mathrm{vgl}$. Text 232, 45 (1); oCairo $25208=$ AHG Nr $193,11$.

188 Text $232,45$.

189 LL 229 "R", Vers 16, s.241 (14).

190 pChester Beatty VIII, 11 (5). 
Der den Erd |kreis umläuft| an einem einzigen Tag,

der sich zeigt an seinem Thronsitz von gestern. 191

und sehr oft:

die Erde wird hell an seiner Stelle von gestern. 192

Durch diese Periodizität wird die kontinuierliche zeit in diskontinuierliche Zeiteinheiten "geschieden" ( wpj) 193, und es ist dieses natürliche Phänomen, das theologisch ausgedeutet wird als Erschaffung der zeit im Sinne eines Akts der Belebung:

Du hast den Himmel überquert, um die zeit $\left({ }^{C_{h}}{ }^{c} w\right)$ zu erschaffen, um Menscinen und Götter am Leben zu erhalten. ${ }^{194}$

"Arbeit"195, "Aufgabe"196 und "Mühe"197 sind typische Bezeichnungen für diese Deutung der Himmel-Uberfahrt als einer Handlung Gottes, die Leben in Gestalt zeitlicher Entfaltung spendet.

\subsection{Die Nacht}

Gehst du unter im westlichen Lichtland

ist die Erde in Finsternis

in der Verfassung des Todes.

Die Schläfer in der Kammer, verhüllt sind ihre Köpfe,

kein Auge sieht das Andere.

Ihre Habe wird ihnen unter ihren Köpfen gestohlen und sie merken

$$
\text { es nicht. }
$$

Jedes Raubtier ist aus seiner Höhle gekommen,

alles Gewürm sticht.

191 Petosiris ed.Lefebvre, Le tombeau de Petosiris II, Les inscriptions, 33,10 .

192 Belege: LL 241 n.69.

$193 \mathrm{Vgl}$. n. 113.

194 AHG $\mathrm{Nr} .50,8-9$.

195 Text 54,9 (f); Suti-Hor ÄHG Nr.89, 6.

196 Zandee, Hymnen, 30; Zeit und Ewigkeit, 49f. n.2.

197 Text 76; Text 54; Neschons AHG Nr.131, 49 vgl. 19; Suti-Hor AHG Nr. $89,44 \mathrm{vgl} .6$. 
Die Finsternis ist ein Grab,

die Erde liegt in Schweigen,

ihr Schöpfer ist untergegangen in seinem Lichtland.

An die stelle der Unterweltsfahrt des Sonnengottes ist die Schilderung seiner Abwesenheit getreten, die eine Abwesenheit des Lebens bedeutet, eine kosmische "Todesbefallenheit" 198 und einen Rückfall in die "Welt vor der schöpfung", so wie jeder sonnenaufgang eine neue schöpfung darstellt.

Du gehst auf - sie leben

du gehst unter - sie sterben

Oder wie es im 104.Psalm heisst:

Verbirgst du dein Angesicht, so erschrecken sie.

Nimmst du weg (deinen) Odem, so vergehen sie und werden wieder

zu staub.

Lässest du aus deinen Odem, so werden sie geschaffen und du erneuerst die Gestalt der Erde. ${ }^{199 a}$

198 P.Seibert, Die Charakteristik, 42f.

199 H.Grapow, in: ZÄS 67 (1931) 34-38; Hornung, Der Eine und die Vielen, $169 \mathrm{f}$. Vgl. z.B. Leiden $\mathrm{K} 1$

"Der seine Stimme erhob, als die Erde mit

Schweigen überschwemmt war"

pLeiden $j 350, I V, 6$

"Er erhob seine Stimme inmitten des schweigens"

ibd. 7-8: "Er begann zu schreien, als die Erde noch in sg3 - lies: sgr "Schweigen"? - war".

Zandee, Hymnen, $70 \mathrm{f}$.

Vgl. auch AHG Nr.172, 32 und $\operatorname{RdE} 30,32$ (v) m.n.44.

199a In diesem einem Falle, der vorstellung des von Gott gleichsam in intermittierenden Intervallen ausgehenden Lebens, lässt sich so etwas wie ein "missing link" zwichen der Vorstellungswelt der "Neuen Sonnen-Theologie" und dem 104.Psalm nachweisen, das den bisherigen Kommentatoren entgangen $z u$ sein scheint. Im Brief $\mathrm{Nr} .147$ des Abimilki von Tyrus findet sich ein Gedicht, das, wie Albright, in: JEA 23, 1937, 198f. überzeugend zeigen konnte, zumindest ägyptisch inspiriert wenn nicht gar aus dem Agyptischen übersetzt ist. Darin heisst es vom Sonnengott:

Der Leben gibt durch seinen süssen odem

und (es) vermindert, wenn er verborgen ist.

Der die ganze Erde in Frieden versetzt durch seine Macht. 
Ausserhalb Amarnas kommt diese theologische Ausdeutung der Nacht als Abwesenheit Gottes und Erweis seiner Macht ex negativo m.w. nur in zwei Texten vor, im Suti-Hor-Hymnus:

Jedes Auge, sie sehen durch dich,

nichts können sie vollenden, wenn deine Majestät untergeht.

Du bist fruh auf, um aufzugehen am Morgen,

dein Licht, es öffnet dem Vieh die Augen.

Gehst du unter, dann schlafen sie in der Weise des Todes.

Stele Leiden V 70 :

Gehst du unter in deinem Lichtland, dann liegt die Erde in geballter Finsternis 200

kein Auge sieht das andere,

jedermanns Gesicht ist erblindet. 201

In Anbetracht dieser wenigen Belege wage ich nicht zu entscheiden, ob diese Deutung der Nacht ein proprium der AmarnaTheologie darstellt, der dann die Texte von Suti-Hor und Leiden $V 70$ näher stehen würden als die übrigen Sonnenlieder des neuen Typs, oder ob sie Gemeingut der neuen Sonnen-Theologie ist und nur zufällig nicht öfter begegnet. Mir ist die erste Lösung wahrscheinlicher. Gewiss liegt die Amarna-Darstellung der Nacht in der Konsequenz einer "Phänomenologie des Sonnenlaufs", die sich auf theologische Ausdeutung des Sichtbaren beschränkt. Von hiex führt kein weg zu der traditionellen Vorstellung der Unterweltsfahrt, die dem Sonnengott in das schlechthin Unsichtbare und Unerfahrbare folgt. Trotzdem hat es den Anschein, als hätte die neue Sonnentheologie an dieser Konzeption doch festgehalten oder sei zumindest nach Amarna zu ihr zurückgekehrt. 202

200 Auch dies ist eine Erscheinungsform des vorweltlichen Chaos s. Hornung, ZAS 81 (1956) $29 \mathrm{ff}$.

201 AHG $\mathrm{Nr} .90,12-15$.

202 Vgl.z.B. Text 113 - eindeutig ein Text der "neuen Sonnen-Theologie" Vers 69, sowie Text 151, der zumindest auf die Unterweltsfahrt anspielt. 
$-144-$

Zweiter Teil

A M U N - RE 
Viertes Kapitel

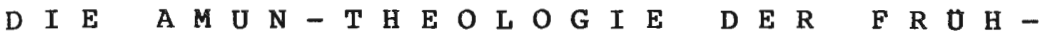 \\ Z E I T \\ Eulogien aus Gräbern von Hatschepsut bis Amenophis II
}

\title{
1 Eulogische Erweiterungen der Opferformel
}

Die Anfänge der Sonnenhymnik in thebanischen Gräbern fallen in die zeit Hatschepsuts und Thutmosis'III und stehen wohl in zusammenhang mit der Einrichtung von Sonnenheiligtümern mit regulärem Sonnenkult sowohl im Totentempel der Hatschepsut in Der-el-Bahri ${ }^{1}$ als auch im Tempelkomplex des AmunRe in Karnak. $^{2}$ In dieselbe zeit fällt auch eine sehr auffällige Erscheinung in der Geschichte der Opferformel ( hatp-djnjswt -Formel, opfergebet). ${ }^{3}$ Die opferformeln der Stelentex$t e^{4}$ - seltener: der Bandzeilen ${ }^{5}$ - werden gelegentlich eulogisch erweitert. An den Gottesnamen - Amun-Re auf den Stelen, Re-Harachte in den Deckenzeilen - werden Epitheta angehängt, die das Wesen des Gottes theologisch spezifizieren. Das geschieht ausnahmslos in einem Nominalstil der Prädikation, für den wir den Terminus "Eulogie" verwenden.

1 S. hierzu R.Stadelmannn, in: MDIK 25(1969) 166-167.

2 H.Kees, in: Or 18(1949)427-442; J.Leclant, Enquêtes sur les sacerdoces .... 47n.1 (mit Bibliographie); P.Barguet, Le temple d'Amon-Rê à Karnak (1962) 291f; B.Bruyère, in: ASAE 54(1956) 17 und 22; Abd el Qader Mohammed, in: ASAE 59(1966) 153 Tf.21; P.Anus, R.Sa'ad, in: Kêmi 19 (1969) 220m.fig.1; S.Pernigotti, in: studi Classici ed orientali 21 (1962)310-11; J.C.Goyon, in: R.Parker et al., The Edifice of Taharqa ..., $21 \mathrm{n} .3$.

$3 \mathrm{~S}$. allgemein zur Geschichte der Opferformel W.Barta, Aufbau und Bedeutung der altägyptischen Opferformel, AF 24(1968). Die hier behandelte Erscheinung ist Barta allerdings entgangen (vgl. die kurzen Bemerkungen auf S.87 und S.289).

4 Texte Nr.68,127,130,164. Allgemein zu den Stelen der theb. Gräber der 18.Dyn. S.A.Hermann, Die Stelen der thebanischen Felsgräber der 18. Dyn., AF 11(1940). Zu den "durchaus nicht vereinzelt auftretenden Einbrüchen hymnischer Anrufungen in das Totengebet" s.speziell 102-106.

5 Texte $81,92,105,108,136$.

6 Zusammenfassend: LA II $40-46$. 
Die Form der Eulogie leitet sich von dem ägyptischen Begriff des Namens her, der seinen Träger nicht nur identifiziert, sondern auch charakterisiert. 7 Die 10 Namen, mit denen der Sonnengott in der bekannten Geschichte von der "List der Isis" 8 die Göttin abspeisen und von der Frage nach seinem wirklichen Namen ablenken will, enthalten ein Kernstück der Sonnentheologie und ergänzen sich, für sich genommen, zu einer Eulogie. ${ }^{9}$ Das bekannteste Beispiel für die wesens-bestimmende Funktion des Namens stellen die fünf "Namen" des Königs dar, die zusammen seinen "Grossen Namen" bilden: sie proklamieren ein geschichtstheologisches programm ; d.h. der Name kennzeichnet eine zeitenthobene wesenheit bzw. Fähigkeit, die sich innerzeitlich in Handlungen aktualisiert. Die offiziellen Königsinschriften erweitern die königliche Namenreihe gern um weitere Prädikate zu einer Eulogie, die 30 und mehr Verse umfassen kann. ${ }^{11}$ Diese Form ist aller Wahrscheinlichkeit nach das Vorbild für die entsprechende Erweiterung des Gottesnamens in den Stelentexten der frühen 18. Dynastie.

\subsection{Typ A: Erweiterungen des Gottesnamens Amun-Re}

Diese Eulogien folgen alle demselben Textplan, benutzen dieselbe Phraseologie und teilweise sogar dieselben ausformulierten Vorbilder. Ausserdem ist diese sitte nicht auf Theben beschränkt; auch aus $\mathrm{El} \mathrm{Kab}^{12}$ und This ${ }^{13}$ sind Beispiele solcher Eulogien bezeugt. Der Stelentext des Satepihu aus This,

7 Den Zusammenhang zwischen dex ägyptischen Auffassung vom Namen und der Stilform der Eulogie habe ich in AHG, 26-33 dargelegt. Zum Namen s. ferner E.Brunner-Traut, in: LA I,281-291; P.Vernus, in: LA IV 320-326; H. Brunner, "Name und Namenlosigkeit cottes in Agypten", in: H.v.stietencron (Hrsg.), Der Name Gottes (Düsseldorf 1975) 33-49.

8 pTurin Pleyte und Rossi, 133; pChester Beatty XI rto.3. Ubersetzung von E.Brunner-Traut, in: Altägyptische Märchen ( 1976$), 115-120$.

9 Für diese Form der Eulogie als Kette von "Ich bin..."-Aussagen in einer göttlichen Selbstvorstellung hat sich in der Agyptologie der Terminus Aretalogie eingebürgert, S.LA I 425-434 mit einer Menge weiterer Beispiele.

10 So interpretiert E.Hornung, in: Saeculum 22(1971) 48-58 die königliche Namenreihe.

11 Beispiele gab ich in LA II 40-41 $\mathrm{n} \cdot 18-30$.

12 Paheri: Urk IV 111, benutzt dieselbe Vorlage wie Text 68.

13 Stele des z3-tp-jhw Urk IV 518. 
der den Namen des Onuris mit den typischen prädikaten der Amun-Re-Eulogien erweitert, steht den thebanischen Texten so nahe, dass ich ihn hier anführen möchte:

hẹtp dj njswt Jnjḥrt
nțr nțrw Opfergebet an Onuris, den göttlichsten
der Götter

njswt pt hqu 3 t3wj König des Himmels, Herrscher der beiden Länder ${ }^{a}$

nb-r-dr m st.f. nbt Allherr an allen seinen Stätten ${ }^{b}$.

ntrr ${ }^{c_{3}}$ hprw ds.f Der Grosse Gott, selbstentstanden ${ }^{c}$,

p3wtj msjw p3wtjw Urgott, der die urgötter zur welt brachte ${ }^{d}$;

shm spd prjw m Nnw Gerüstete Macht, die aus dem Urwasser kommt,

djw sšp n ḥnnmt und Licht gibt dem Himmelsvolk;

shạw j3hw.f $n$ psḍt.f dessen Strahlkraft es Licht werden lässt

für seine Neunheit,

$c_{\text {nh.sn m33.sn jm.f sie leben auf, wenn sie durch ihn sehen. }}{ }^{f}$

Dem Text liegt folgender Textplan zugrunde:

I: Herrschaft

II: Urgott

III: Erhalter: Licht

Der folgende Kurzkommentar, der die Abhängigkeit dieses Textes von demselben phraseologischen Fundus deutlich machen will, auf dem auch die thebanischen Texte basieren, wird den Parallelstellen entsprechende römische $\mathrm{Ziffern}$ beifügen als Angabe der Strophe, aus der sie stammen, wobei z.B. "I" nicht nur für "Strophe I", sondern auch für "Thema I: Herrschaft" steht, denn beides geht zusammen. Die übrigen Eulogien entfalten das Thema II meist in die Aspekte (a) Urgott, (b) Schöpfer.

a) Text 127 (TT 123) I: nswt n pt hq3 n t3

Text 92 (TT 67) nur I: nb pt nb t3

b) Text 127 I: id.; Text 164 (TT 164) als Schluss der ganzen Eulogie. Das gleiche. Epitheton auch auf der Turiner stele AHG $\mathrm{Nr} .72,4$.

c) Text 68 (TT 53) ntr ntrij hpr ds.f (am Schluss); in Text $164 \mathrm{zu}$ einer ganzen strophe (in II) entfaltet. Text 136 (TT 131) II: hpr ds.f jwtj mst.f 
d) Text 68(TT 53)II=Paheri Urk IV 111 II: p3wtj jwtj mst.f ; Text 136(131)II p3wtj t3 n zp tpj vgl.Turin stele AHG Nr. 72,2 p3wtj $n$ zp tpj; Text 164(TT 164)II p3wtj [jrjw ntt qm3w] wnnt

e) Text 68 III: tk3 $\mathbf{c}_{\mathbf{n h}}$ prjw m Nnw

jrjw sšp n hnnmmt

Paralleltext Paheri (Urk IV 111) hat djw "der gibt" statt jrjw "der schafft". Text 130 (TT 127) III:

tk3 ${ }^{c_{n h}}$ prjw m Nnw

ddw z. n jet nbt

tk3 C nh, "Lebensfeuer", ist eine Bezeichnung für die Sonne, die ausserhalb dieser Eulogien m.w. nicht vorkommt. Auch shm "Machtbild" ist eine häufige Bezeichnung der Sonne. ${ }^{14}$ In Text 164, der III zu einer langen Strophe ausbaut, wird sie shm spss $\mathbf{h}^{\mathbf{c}} \mathbf{j w} \mathrm{m}$ 3ht genannt. Der Formel unseres Textes sehr nahe steht der Anfang des Hymnus zur 7. Tagesstd., z.B. Text 41, Verse 1-2 (a).

f) Das letzte Verspaar hat in den Eulogien der opferformeln keine Entsprechung; ähnliche Aussagen finden sich aber in Hymnen der Zeit, vgl. Stellen wie

pKairo CG $58038 \mathrm{AHG} \mathrm{Nr} \cdot 87 \mathrm{C}, 80-81 \mathrm{~h}^{\mathrm{CC}} \mathbf{w}$ ntrw m nfrw.f

$$
c_{n h} \text { jbw.sn m33.sn sw }
$$

Tura-Hymnus, 6 AHG Nr.88,15 $\mathrm{C}_{\mathrm{nh}}$ psdt m33.sn sw pBerlin $3055,17,9$ AHG $\mathrm{Nr} \cdot 123,26$ C nh psdt m33.sn tw OIFAO inv. $2139 \quad[\ldots]$ n psdt

Die einzelnen Formulierungen und die darin zum Ausdruck kommenden theologischen Begriffe lassen sich zum grössten Teil auch ausserhalb dieses Textkreises und bis in die Spätzeit belegen. Aber in dieser charakteristischen zusammenstellung und thematischen Beschränkung auf die drei immer in derselben Weise angeordneten Aspekte I (Herrschaft) - II (Urgott + Schöpfer) - III (Erhalter) sind sie den fruhen thebanischen opferformel-Eulogien eigentümlich.

$14 \mathrm{Vgl}$. MDIK 27.1, $25 \mathrm{f}$. 
Auf der Basis dieser zahlreichen Korrespondenzen lässt sich der den Texten zugrundeliegende Typus in der Art einer phraseologie folgendermassen charakterisieren:

1. Das Wesen des Gottes wird dargestellt in den drei Aspekten I : Herrschaft, II: Urgott und Schöpfer, III: Erhalter bzw. Sonne.

2. Zum Aspekt "Herrschaft" gehören:

a) die Herrschaftsinsignien der åusseren Erscheinungsform

$\begin{array}{ll}\text { nb šwtj wrtj } & \text { Text 68, Paheri } \\ \text { nfr-ḥr m šwtj wrtj } & \text { Text 105 } \\ \text { nfr-ḥr m sšd šwtj } & \text { Text 164 } \\ \text { twt jrw q3 šḍ } & \text { Text 164, 105 } \\ \text { nțr c } 3 \text { ḥrj st wrt } & \text { Text 105, 100 }\end{array}$

b) Titel des Götterprimats

$\begin{array}{ll}\text { nțr nțrw } & \text { Urk IV } 518 \\ \text { jtjj nțrw nbw } & \text { Text 130; nur jtjj: Text 68, Paheri } \\ \text { hrj tp nţrw } & \text { Text } 92 \\ \text { njswt nḥ nb dt } & \text { Text 68; Paheri }\end{array}$

c) Weltherrschaft

njswt pt hq3 t3wj Urk IV 518; ähnl. Text 127

njswt t $3 w j$ Text $108 b$

hqu3 Jwnw Text 92

Nb-r-dr $\quad$ Urk IV 518; Text 164; Turin Stele AHG $\mathrm{Nr} .72$

3. Zum Aspekt Urgott/Schöpfer gehören

a) Urzeitlichkeit

p3wtj Text 68; Paheri; Urk IV 518

p3wtj t3 n zp tpj Text 164

b) Einzig(artig)keit ${ }^{16}$

jwtj snnw.f Text 68; Paheri; Text 130; 164

$w^{c}$ hr hw.f

Text 164; Text 102,2

ntr $w^{c} \quad$ Text $108 \mathrm{~b}$

$w^{c} w \quad$ Text 130

$w^{c} w j m j b 3 \underline{h}$

Text 68; Paheri

$15 \mathrm{Vgl}$. LL 172-174; $173 \mathrm{n} .20$.

16 Zum Begriff der Einzigartigkeit, der jedem ägyptischen Gott zukommt, s.Hornung, Der Eine und die Vielen, 180f. Der Begriff der Einzigkeit ist jedoch nicht, wie bei Hornung, der ihn deshalb für Agypten ablehnt und nur für die Amarna-Religion gelten lassen möchte, einem strengen Monotheismus vorbehalten, sondern kennzeichnet den Begriff eines Got- 
c) superlativische Wendungen

wr wrw Text 68; Paheri; Text 130

jtj jtjw Text 130

jtj jtjw.sn mwt mwt.sn Text $108 \mathrm{~b}$

d) Autogenese

hpr ds.f

Urk IV 518; Turin AHG Nr.72,3; Text 136

vgl. Text 164

e) Schöpfer

qm3w rmtw ntrw Text 68; Paheri; ähnl. Text 164

Text 108b: jrjw ntrw

jrjw ntt qm3w wnnt 17 Text 130,92

${ }^{\mathrm{h}}$ pt

Text $136 ;$ TT $179^{18}$

qdw jrjw jrt nbt Text 136

4. Zum Aspekt Erhalter:

a) Sonne als "lebende Flamme"

tk3 ${ }_{\text {nh }}$ prjw mnw Text 68; Paheri; Text 130, ähnl. Text

164

Sonne als "Machtbild"

shm spd/Spss Urk IV 518; Text 164; AHG 72

b) Licht für die Menschheit

jrjw š̌p/ddw ž u.ä. ${ }^{18 a}$ Urk IV 518; Text 68; Paheri; Text 130;

tes, dessen Wesen und Wirken nicht im Zusammenwirken mit anderen Göttern, in der "Konstellation der Götterwelt", sondern nur als Einzelner denkbar ist. Dieses notwendige Nur-Einer-Sein verbindet sich in Agypten mit den Begriffen des Schöpfergottes, des Lebensgottes und des Götterkönigs, und ausserhalb der Lehre von den 8 Urgöttern wohl auch mit dem Begriff eines Urgottes als Verkörperung der Präexistenz.

17 Formel; einige Belege: TT $41(7)$; pHarris I,3,3 AHG 197, 12; Text 60,17; Berlin 6764 (Ptah); pLuynes; Turin 3070; Philae 467, 3239 Leiden, Boeser, Beschr. IV,Tf.30.

18 Die kurze OF in einer Bandzeile des Grabes TT 179 habe ich in die Sammlung von STG nicht aufgenommen:

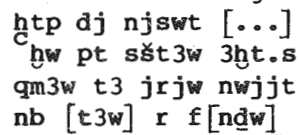

Ein Opfergebet für [Amun Re...]

der den Himmel erhob und sein Lichtland geheimmachte,

der die Erde formte und die Flut erschuf,

Herr [der Luft] an den Na[sen].

18a Dazu Stelophor BM 29944 ed. Stewart, in: JEA 53,37:

bjk 3 z3b swt

jrjw słp n hnmmt 
c) Luft

nur Text 108b; Stelophor Chicago AHG Nr.

$$
81,7-8
$$

d) ethische Instanz

Dieser Aspekt, der in den Hymnen eine so grosse Rolle spielt (s.dazu u., S.162ff.), steht in den Opferformeln mehr am Rande und scheint phraseologisch nicht so festgelegt zu sein wie die anderen Aspekte. ${ }^{18 b}$

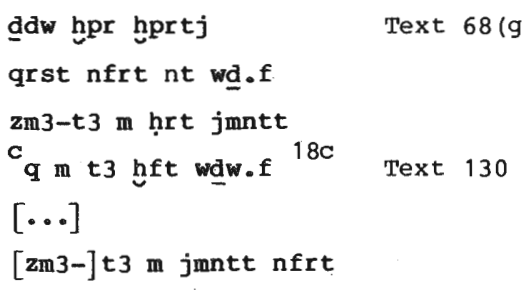

Diese Texte hängen enger untereinander zusammen, als dies bei Texten derselben Gattung lublich ist. Zu den Gemeinsamkeiten des Stils (Eulogie) und des Themas (Amun-Re) kommen noch zwei Dinge hinzu: a) der gemeinsame Textplan (vgl. dazu den Typus des Tageszeitenliedes, der - innerhalb der umfassenderen Gattung Sonnenhymnus - ebenfalls durch den gemeinsamen Textplan definiert ist) und b) der gemeinsame phraseologische Fundus (dies ist z.B. beim Tageszeitenlied nicht der Fall). Gattungen haben in der Regel ein gemeinsames Thema und eine gemeinsame Begriffswelt ${ }^{19}$, selten aber gehen diese Gemeinsamkeiten so weit, dass sie ganze "Phrasen" gemein haben wie z.B. eine derart ausgefallene und in gewisser Weise poetische Bezeichnung der Sonne wie tk3 $\mathbf{C}_{\mathbf{n h}}$ prjw $\mathbf{m}$ Nnw - "lebendige Fakkel, die aus dem Urwasser aufsteigt".

Andererseits ist dies natürlich auch kein Einzelfall, sondern das Kennzeichen all jener Textsorten, auf die sich die phraseologische Methode sinnvoll anwenden lässt: die traditio-

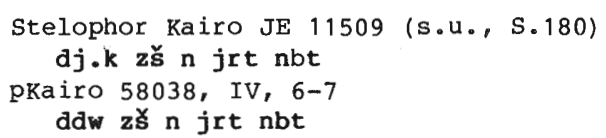

$18 \mathrm{~b}$ Text 130 liefert den einzigen Beleg fur nb $3^{C} t$ in diesen Texten. Vgl. damit die grosse Bedeutung der $m 3^{c} t$-Pradikation in den Hymnen!

$18 \mathrm{c}$ Mit diesem vers vgl. Enseignement Loyaliste ed.G.Posener, \$ 7.1 und $\mathrm{S} .32$.

$19 \mathrm{Vgl}$. GM 6(1973) $26 \mathrm{f}$. 
nellen Biographien ${ }^{20}$ - aber weniger z.B. die Biographie des Ahmose, Sohnes der Abana 21 - , die Königsinschriften 22 aber weniger z.B. die Annalen Thutmosis' III. oder die erzählenden Partien der Qadesch-Schlacht -, bestimmte Gattungen der griechisch-römischen Tempeltexte 23 und gewiss noch manche andere, bisher unerforschte Gattungen (wobei allerdings schon an unserer höchst begrenzten Untersuchung deutlich geworden sein dürfte, dass auch eine phraseologische Analyse auf mögliche "Textpläne" und andere gattungsspezifische strukturen $z u$ achten hat, die den Text als Ganzen konstituieren, aus dem die Phrase, d.h. ihr jeweiliges Vorkommen, stammt). wie es dazu kommt, dass manche Texte über die "normalen" Gemeinsamkeiten von stil, Thema und Begriffswelt hinaus auch noch über einen gemeinsamen Vorrat geprägter phrasen verfügen und wie man sich den Traditionsmodus dieser Phrasen zu erklären hat, das lässt sich wohl nur von Fall zu Fall entscheiden. Mit der "Formel" als "Gedächtnisstütze" im Sinne der "oral poetry"-Theorie ${ }^{24}$ etwa hat das hier behandelte phänomen eines phraseologischen Fundus ganz gewiss nichts zu tun.

Im Falle unserer Eulogien legt sich die Erklärung nahe, dass die Wendungen, in denen Aspekte des göttlichen wesens und wirkens erfasst werden, in geprägter Form festliegen weil sie als "Namen" oder "Titel" dieser Gottheit verstanden werden deren prägung nicht jedem freisteht. Der einzelne Textdichter oder Verfasser eines Stelentextes greift zurück auf eine traditionelle Nomenklatur, die das Werk profes-

20 J.M.A.Janssen, De traditioneele Egyptische Autobiografie vóór het Nieuwe Rijk, 2 Bde. 1946. E.Edel, Untersuchungen zur Phraseologie der äg. Inschriften des Alten Reiches, =MDIK 13(1944) 1-90.

21 Bezeichnenderweise hat E.Otto für seine Untersuchung der Spätzeitbiographien die phraseologische Methode nicht lubernommen.

22 E.Blumenthal, Untersuchungen zum Königtum des Mittleren Reiches, Bd.I: Die Phraseologie (ASAW 61.1,1970). Für die späteren Epochen stehen entsprechende Untersuchungen noch aus.

23 E.Otto, Gott und Mensch nach den Tempelinschriften der griechisch-römischen Zeit. Eine Untersuchung zur Phraseologie der Tempelinschriften (AHAW 1964).

24 A.B.Lord, Singer of Tales (1960, dt. Der Sänger erzählt 1965) s. den Forschungsbericht in G.Wienold, Formulierungsgheorie (1971) 81-94. 
sioneller, d.h. priesterlich-theologischer Arbeit ist: Arbeit an der Wesensbestimmung der Gottheit. So ist auch der phraseologische Fundus der traditionellen Biographien Ausdruck einer Arbeit an der Wesensbestimmung des Menschen (wenn wir auch in diesem Falle wesentlich weniger klar sehen, wer als Träger solcher Arbeit in Betracht kommt). Der historische Befund unserer Eulogien konfrontiert uns nun mit dem Phänomen, dass diese Arbeit nicht immer und nicht überall mit gleicher Intensität geleistet wurde. Die neue Gattung der eulogisch erweiterten Opferformel steht in engster Beziehung zu Amun-Re; für andere Götter ist sie kaum belegt. ${ }^{25}$ Ihr Aufkommen und zugleich ihre Blüte fällt in die verhältnismässig kurze zeit von Hatschepsut bis Amenophis II; spätere Eulogien, die im ganzen seltener, aber doch immer noch gelegentlich auch in opferformeln auftreten, benutzen z.T. eine neue phraseologie. zum Vergleich setze ich eine Opferformel der 19. Dyn. hierher: $25 \mathrm{a}$

htp dj njswt Jmn $R^{C} w$ Ein Opfergebet für Amun-Re

Jtmw Hrw-3htj

Atum Harachte

Hprj b3 jmntt [Hrw j3btt]

Chepre, den Ba des Westens, [Horus

des Ostens] 26

jtjj ntrw nterwt

Herrscher der Götter und Göttinnen

nb nbw njswt psdt

jtj jtjw mwt mwwt Herr der Herren, König đer Neunheit

I+II Vater der Väter, Mutter der Mutter ${ }^{27}$

hrj-tp m pt t3 d3t

Oberhaupt in Himmel, Erde und Unterwelt

25 Ein Beispiel für Osiris: Urk IV 544f.:

"Ein Opfergebet für Osiris, den Ersten der Westlichen, den Grossen Gott unter den (fünf?) Göttern,

den ersten Fürsten unter den Fursten, an der Spitze der Edlen seit der Urzeit des Landes als König, der die Menschheit bewacht, Herr der Lebenden, Oberhaupt der Toten, der den "Obersten Mund" spielt unter dem, was ist und was

25 a statue des Wesirs Paser BM 687, T.G.H.James, HT IX, Tf.10; Kitchen, RI III 18-19.

$26 \mathrm{Vgl}$. Text 113 (b).

27 Id. Text $108 \mathrm{~b}$ 
$c_{h} c$ dndw $h^{c} f^{c} \cdot k$

da.k $\mathrm{n}[\mathrm{me}] \mathrm{n} \cdot \mathrm{k}$ [t3w] grs $[\mathrm{r}] \mathrm{ht} . \mathrm{k}$ wddt.k hprwt nbwt
Die Lebenszeit ist in deiner Faust

versammelt

III du gibst davon nur ${ }^{28}$ wem du willst; Luft, Wasser, Begräbnis unterstehen dir 29

Alles, was geschieht, entspringt deinem

Befehl. 30

Textplan: Strophe 1 verknüpft Amun und Sonne in verschiedenen Namen, Strophe 2 verbindet die Aspekte Herrschaft (I) und Urgott (II), Strophe 3 ist auch hier dem Erhalter-Aspekt gewidmet.

Phraseologie: bis auf Vers 6 früher nicht nachweisbar. Am einschneidensten ist die Wandlung des Erhalter-Aspekts: an die stelle der Sonne ist der persönliche schicksalsgott, die "ethische Instanz" der Ramessidenzeit getreten.

An den Wandlungen der Phraseologie lässt sich ablesen, dass die theologische Arbeit an der Wesensbestimmung der Gottheit Amun-Re weitergeht und im Laufe der Jahrhunderte des Neuen Reichs zu immer neuen Resultaten kommt, als deren letztes und eindrucksvollstes die Gottestitulaturen der 21. Dynastie vor uns liegen. 31

\subsection{Typ B: Erweiterungen des Gottesnamens Re-Harachte}

Wir haben bereits darauf hingewiesen, dass sich mit den eulogischen Erweiterungen des Gottesnamens Amun-Re in den Opferformeln der frühen 18.Dyn. keine sonstigen Eulogien, die sich gelegentlich an Götternamen in Opferformeln anschliessen, an Länge und Differenziertheit vergleichen lassen. Das gilt auch für die eulogischen Erweiterungen des Gottesnamens Re-Harachte, die sich auf den solaren Aspekt beschränken und auf einem wesentlich beschränkteren phraseologischen Fundus beruhen. Dementsprechend sind auch die Ubereinstimmungen zwi-

28 Die "emphatische" Form dd.k hat vielleicht die Bedeutung einer solchen Einschränkung.

29 In dieser Topik s.Text $59 \mathrm{a}(\mathrm{m})$ sowie Kap.5.

$30 \mathrm{Vgl}$. Text $68(\mathrm{~g})$.

31 AHG Nr.131. 
schen den einzelnen Texten hier noch viel grösser als bei Typ A. Mit Ausnahme von Kairo CG 1079 und TT 172 stammen alle hier analysierten Belege (von denen nur wenige in die Hymnensammlung STG aufgenommen wurden und alle bis auf TT $82^{32}$ nach eigener Abschrift zitiert werden) von Deckenzeilen:

1) Typ B1 Belege: TT 59, 96A, 54, 172, 84, CGC 1079

b3 chn wbnw m nbw

shdw t3wj m $\underline{d}^{c}$ cf. Text 134 (TT131)

var. 96A: m j3mw 3ht.f : 54: m j3mw

172,84: m stwt jrtj.fj ; CGC 1079: m hodwt jrtj.fj $32 a$

hprw ds.f jwtj mst .f

nur 59, fehlt in Varr. 96A: jrjw ssp m wn hr.f. 33

tnw jrw.f $r$ ntrw

2) Typ B2 Belege: TT 96A, 99, 82, 125, 131

b3 ${ }^{\mathrm{c}}$ hh hprw ds.f

$c_{n h m ~ m}{ }^{c} t r^{c}$ nb

82: ntr ${ }^{\mathrm{C}} \mathrm{nh}$ id. in Text 114,10

131: hkn m $3^{c} t$

Das Prädikat b3 $\mathrm{c}_{\mathrm{nh}}$ wbnw m nbw "Lebender Ba, der aufgeht in Gold" ist m.W. ausserhalb dieses Texttypus nicht belegt und kann daher als Indiz gelten für die zugehörigkeit eines Textes $z u$ dieser Tradition. So wird man es als eine vereinzelte Fortfuhrung dieser Tradition ansehen, wenn noch in einer Deckenzeile des Grabes des Chaemhet (TT 57) aus der zeit Amenophis'III. der Sonnengott

b3 ${ }_{\text {nh wh wh m nbw }}$

m hrt-hrww nt $r^{c}$ w nb

genannt wird. B3 $C_{n h}$ kommt auch ausserhalb dieser Tradition vor, so $\mathrm{zu}$ Text 205 (b), 3 mit weiteren Belegen in (c). Wo mit diesem Prädikat spezifisch solare Epitheta verbunden werden, wie z.B. in einer Deckenzeile des Grabes 58:

b3 ch prjw m Nnw

sḥdw d3t m jrt.f $33 a$

32 Davies-Gardiner, The Tomb of Amenemhet, Tf.XXX, D.

$32 a$ Ahnl. Stelophor BM 26270, stewart, in: JEA 53,36.

33 zu diesem Motiv s. "Primat und Transzendenz", 10 n.14.

33a Ahnlich TT 106 (Paser), Kitchen, RI III,1. Ubrigens ist hier wie in TT 58 (nach WbZ $\langle 592\rangle$ ) sowie in den n.34 zit.stellen wie luberhaupt 
wird die fruhe Tradition wieder aufgenommen. Ausserhalb dieser Tradition stehen jedoch Fälle wie der Text des Wesirs Pa-

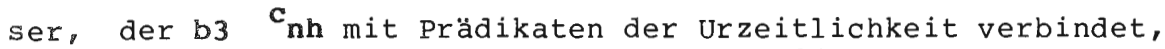
die eher in den Kontext von Typ A gehören: ${ }^{34}$

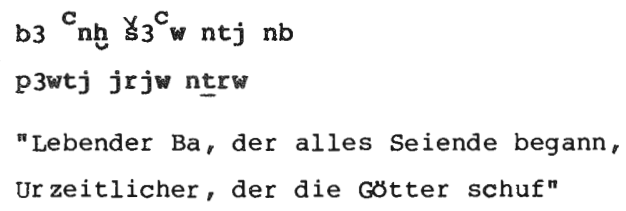

Sonst pflegen sich die Prädikate von Typ A und Typ B nicht zu uberschneiden, abgesehen von hpr ds.f, was sich in Typ B auf die tägliche spontangenese des Sonnengottes, in Typ A auf die uranfängliche Autogenese des Schöpfergottes bezieht.

Der Vergleich der beiden Typen eulogischer Erweiterungen der Opferformel, Typ A und B, ist theologisch lehrreich. Die komplexe Gestalt des Gottes Amun-Re fordert zu wesentlich umfangreicheren Wesensbestimmungen heraus als der vergleichsweise einfache Gottesbegriff des Sonnengottes, der hier nur als Sonne im Blick steht. Demgegenüber stellen die drei Aspekte, in denen Typ A das Wesen des Amun-Re zu bestimmen sucht, ganz offensichtlich so etwas wie den Versuch dar, die Wesenscharakteristiken von Amun und Re $z u$ verbinden und zu vermitteln und dadurch zu einer theologischen Ausdeutung der "synkretistischen" Formel Amun-Re zu gelangen:

Amun

Herrscher, Gotterkönig mit den Insignien des thebanischen KuItbildes

I
Amun und $\operatorname{Re}$

Urgott und Schøpfer Erhalter als Sonne

meistens in der Ramessidenzeit b3 mit dem widder geschrieben (vgl. Text $150[\mathrm{a}]$ ).

34 Sauneron, in: BIFAO 55,110. B3 $\mathrm{C}_{\mathrm{nh}}$ auch im Text 113, T. 
Dieses Problem der theologischen Vermittlung von Amun und Re bildet in der Tat das zentrale Anliegen der theologischen Arbeit, wie sie sich in den Eulogien dieses Gottes und den Wandlungen der ihnen zugrundeliegenden Phraseologie und Terminologie manifestiert.

\section{Hymnen}

Die Sonnenhymnen der Frühzeit stehen - von einer einzigen, wohl begründeten Ausnahme abgesehen: dem an unzugänglicher Stelle aufgezeichneten Text 240, der aus der Tradition der Sonnen-"Mysterien" stammt 35 - im Banne derselben Tradition, die in den Opferformeln zum Ausdruck kommt. Auch sie bevorzugen den Nominalstil der Prädikation, also die Form der Eulogie, und benutzen z.T. dieselbe Phraseologie, folgen aber einem anderen Textplan. Leider hat sich von den Hymnen dieser zeit so wenig erhalten, dass unsere verallgemeinernden Bemerkungen auf einer sehr schmalen Basis beruhen.

Die umfänglichsten Hymnen, die aus dieser zeit in Theben erhalten sind, stehen in Grab 84 des J3mw-ndh, der unter Thutmosis III. lebte und in Heliopolis tätig war. ${ }^{36}$ Der Hymnus der linken Eingangswandung, der an den morgendlichen Sonnengott gerichtet gewesen sein musste, ist verloren. Erhalten sind der Hymnus der rechten Eingangswand (an Atum) und der Hymnus auf der Stele. Der Stelenhymnus erreicht eine für diese zeit ungewöhnliche Länge von 34 Versen durch Verbindung verschiedener Texte, ein Verfahren, das wir noch an anderen zeitgenössischen Texten beobachten werden. Der erste Hymnus

35 S.Kap. 1, 41. Die eulogische Form dieses Textes ist bemerkenswert, da ja die liturgischen Sonnenlieder in der Regel im Verbalstil verfasst sind, entsprechend ihrem Bezug nicht auf ein Wesen - den Sonnengott sondern einem Vorgang - dem Sonnenlauf. Aber gerade die Hymnen aus diesem Bereich der "Mysterien", vor allem das Stundenritual, verwenden die eulogische Form sehr ausgiebig, was einerseits Zeichen hohen Alters sein kann, andererseits aber auch mit ihrem besonderen Sitz im Leben zusammenhängen wird. Vgl. die Hymnen zur 4.Std., 1-7; 5,9-14; $6,8-10,14-17,20-24 ; 7 A, 2-5,15-17 ; 9,4-7$.

$36 \mathrm{Vgl}$. W.Helck, Materialien zur Wirtschaftsgeschichte, I, 124 mit Verweis auf Urk IV 940,11 . 
umfasst 10 verse. Die erste Strophe (Verse 1-4) folgt ganz der Phraseologie der Opferformeln Typ A, Thema II (Urgott/ Schöpfer):

jng hr.k $R^{C} w$ nb nḥ̣ wcw hr hww.f hqu3 dt vgl. Urk IV,111: nswt nḥh nb dt $36 \mathrm{a}$ hprw m b3h nn snnw.f Text 164: w w hr hw.f ... snnw.f Text 130: nb hhw jwtj snnw.f; Text 68:

$c_{\text {hww pt smnw s3tw }}$ $w^{c} w$ jmj b3h

Text 136: " h hw pt shrw t3wj

Die zweite Strophe (Verse 5-10), die eine spezielle, auf den Sonnengott und seine Bewegung bezogene Thematik entwickelt, folgt einem Vorbild, das auch Text 164 benutzt hat:

ḥmw nfr prjw m Nnw

phrrw hrww n mswt.f

Text 164: phrrw grḥ mj hrww ähnl. Text

bjk špss $h^{c} j w m$ mht 165,16 .

sḩ3bw t3wj m stwt.f

164: shm కpss $\mathrm{h}^{\mathrm{C}} \mathrm{jw}$ m 3 ht sḥ3bw t3wj [m stwt.f]

phrw kmt dbnw děrt

Gmhisw bnnw pdwt 9

164: dbnw kmt, dSrt

164: Gmh [sw bnnw pdwt 9] 37

Der eulogische stil wird im Hymnus streng durchgehalten, auch dort, wo er sich auf den Sonnenlauf bezieht. Im Unterschied $\mathrm{zu}$ den stets im Verbalstil gehaltenen Sonnenliedern der in Kap. 4 und 5 behandelten Traditionen bezieht sich diese Eulogie jedoch nicht auf den Sonnenlauf in seinen einzelnen phasen, sondern auf den Sonnengott als den Vollbringer dieses Laufs insgesamt ${ }^{38}$ ( phrrw, phrw, dbnw).

Der zweite Text, dessen eigentümlicher Anruf auch auf einem Londoner Stelophor belegt ist ${ }^{39}$, nennt den Gott shdw wr "Grosser Lichtspender"40 und knüpft daran die bekannte Prädikation des Wohltäters- Erhalters

djw zs n hnmmt

vgl. Text $68=$ Paheri ${ }^{41}$, Urk IV $518^{42}$; Text $100^{43}$; Text $130^{44}$; pCairo $58038,4,7.45$

36a Vgl. Stelophor BM 2294 Stewart, in: JEA 53,37:

nb nhh ho3 dt CG 34152: njswt nhh nb dt, S.allg. MDIK 27.1,27-28.

37 Für weitere Belege s, den Komm.z.St., STG Text $102(\mathrm{~h})$.

$38 \mathrm{Vgl}$. Stundenritual, Hymnus zur 3.Tagesstunde: dbnw Kmt phrw dšrt .

39 S. Komm., (i).

40 S.Text 254,37 (K). 
Der dritte Text ist ein Schlussgebet mit Selbstvorstellung persönlicher, nicht kultischer Legitimation. ${ }^{46}$ Er benutzt ein Formular, das auch sonst, v.a. in Osiris-Hymnen dieser zeit belegt ist, vgl. z.B. TT 258 (4), Urk IV 1642f.:

Ich will dir Lob spenden, will dich erhoben,

ich will dich besänftigen in allen deinen Namen:

o Osiris Chontamenti

und ihr Götter alle des Totenreichs!

Hore auf mich, da ich zu dir rufe,

wende dein Herz zu meinem Flehen!

Es gibt keinen Gott, der sein Geschopf (sic) vergisst.

Nämlich: dein Odem des Lebens

möge eingetreten sein in meinen Leib,

dein Nordwind möge suss sein an meiner Nase.

Ich bin gekommen auf dem schönen Wege der Rechtschaffenheit

um alle meine Glieder zu bewahren.

Möge mein Ba leben, mein Ach gorttlich sein,

möge mein Name vortrefflich sein im Munde der Menschen!

In dieser Form ist das schlussgebet offenbar ein in der 18. Dyn. verbreiteter Standardtext. Der Appell um Erhörung 47 erinnert in seiner Dringlichkeit bereits an die Gebete der Persönlichen Frömmigkeit. Der Grundsatz, auf den sich dieser Appell beruft, lässt zwei Ubersetzungen zu:

41 jrjw (Paheri: djw) sక̌p n jrt nbt.

42 djw š̌p n hnmmt

43 jrjw ssp n jrt nbt $=$ Text 68 .

44 ddw zš n jrt nbt

$45=$ Text 130; vgl. auch $0 .$, 150f. 18a fur weitere Belege.

46 zur Selbstvorstellung mit kultischer Legitimation s.o., Kap.1,. Von "personlicher Legitimation" spreche ich, wenn der Anbeter in seinem Schlussgebet in eigener Sache auftritt und sich dem Gott vorstellt als "einer, der heil war auf Erden" (Kap.1,n.68), "einer, den du erhoben hast auf Erden" (AHG Nr.35,18), "einer von denen, die dich anbeten" (Text 66(q)), "ein wahrer Gerechter" (AHG 33,52: an Osiris) usw., also nicht in einer kultischen Rolle, sondern auf der Grundlage einer persónlichen Qualifikation, vgl. auch n.52.

47 Ahnlich Stele Turin Nr.153 (Thothnufe gen.Zeš); Kairo Wb Nr. $\langle 340\rangle$ und $\langle 353\rangle$. Vgl. Kopenhagen A $70=$ AHG Nr.52,12. 
(1.) Es gibt keinen Gott, der sein Geschöpf vergisst ${ }^{48}$

(2.) Es gibt keinen Gott, der den vergisst, der für ihn tätig war.

TT 258 hat den Satz offenbar im Sinne von (1) verstanden, wie die Schreibung jrt.n.f zeigt. 49 Die gewöhnliche schreibung ohne $t$ legt aber eher die Bedeutung (2) nahe. In dieser Form ist der Grundsatz - wohl ein Sprichwort - schon in der Lehre für Merikare belegt, 50 als ein Appell an den Menschen, für Gott tätig zu sein. Im Sinne von (1) kommt der Grundsatz in königlichen Texten des NR vor: kein Vater vergisst seinen Sohn. 51 Es erscheint fraglich, ob in Agypten vor der Spätzeit sich auch ein Privatmann als Geschöpf Gottes fühlen und sich Gott gegenüber auf seine Geschöpflichkeit berufen konnte. 52 Aber auch das "Handeln für Gott" ist ja zunächst ein königliches Privileg 53 und die Lehre für Merikare ist an einen König gerichtet. Doch hat sich der Privatmann, wenn er als sprecher eines Hymnus vor Gott tritt, bereits eine der königlichen Möglichkeiten, für Gott zu handeln, zu eigen gemacht, und es ist gewiss diese Handlung, auf die er sich in

48 So habe ich die Formel in MDIK 28.1, 1972, 66n.92 aufgefasst, diese Auffassung aber in LA I 1089n.13 korrigiert.

49 So nach eigener Kollation der Inschrift.

50 Merikare 130: "Gott kennt (=vergisst nicht) den, der für ihn handelt", s. $z u$ dieser und $z u$ weiteren Stellen LÄ I $1086 \mathrm{~m} . \mathrm{n} .13$.

51 Qades-Inschrift, Kitchen RI II 34,92f; Sargdeckelinschrift des Merenptah, MDIK 28, 1972,55,66 (48).

52 S.hierzu E.Otto, "Der Mensch als Geschöpf und Bild Gottes in Agypten", in: Probleme biblischer Theologie, Fs.G.V.Rad (1971) 335-348; Zeit und Ewigkeit, $62 \mathrm{~m} . \mathrm{n} .65$.

In diesem zusammenhang scheint mir die Inschrift einer wiener stele höchst bedeutungsvoll, die aus der späten 18. Dynastie stammen dürfte. Dort heisst es:

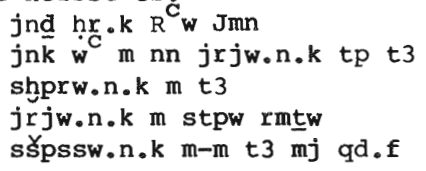

Sei gegrüsst, Amun-Re!

Ich bin einer von denen, die du geschaffen hast auf Erden,

die du hast sich entwickeln lassen in (?) der Erde,

die du zur Elite der Menschheit gemacht hast, die du ausgezeichnet hast im ganzen Lande.

(Stele Nr.75, Inv. 5815; Wreszinsky, 45ff.; RT 9,46)

$53 \mathrm{Vgl}$. Zeit und Ewigkeit, 13. 
seinem Schlusstext beruft: 54 "ich habe für dich gehandelt, indem ich dich angebetet habe; so vergiss auch du mich nicht, wenn ich dir die folgende Bitte vortrage."

J3mw-ndh übernimmt die Form der ersten strophe, wandelt aber den ersten Vierzeiler in einer weise ab, die für das Selbstverständnis seines Sonnenhymnus höchst aufschlussreich ist. Ich habe die Wendung hisj sḥtp mit "ein Besänftigungslied singen" wiedergegeben. In dem Ausdruck shtp liegt aber auch ein Bezug auf den "Untergang" ( htp ) der Sonne, ebenso wie in dw3 "anbeten" ein Bezug auf den "Morgen" ( dw3w) zum Ausdruck kommt. 55 wichtiger aber erscheint mir der zusatz "mit Weihrauch". Räucherung begleitet die "Appellationslitanei"56, die Anrufung Gottes "in allen seinen Namen".57 Auch der eulogische Hymnus kann also als eine "Räucherung für $\mathrm{Re}$ in allen seinen Namen" verstanden werden. Seine Rezitation hat man sich dann so vorzustellen, dass - wie die bei manchen Texten gelegentlich eingeschobene Rezitationsanweisung sntr hr sdt "Weihrauch auf die Flamme!" zeigt" 58 mit jedem "Namen" im erweiterten sinne eines eulogischen Prädikats ein Weihrauchkügelchen auf die Flamme geworfen wird.

Der Hymnus der rechten Eingangswandung ist vermutlich an Atum gerichtet (vgl. den Gottesnamen in Vers 9 und 21). Es wird. sich um einen alten Ritualhymnus handeln. Der eulogische Abschnitt (Vers 1-10) entwirft die Theologie des Gottes als Urgott, Schöpfer und Sonnengott ohne erkennbaren Rückgriff

54 Zur Funktion des Schlusstexts als Explikation der Handlungsintentionen des Hymnus s.LL 217-220 u.o., Kap. 1.

$55 \mathrm{Vgl}$. den Text der 18. Dyn., der später als Totb 15a ins Totenbuch eingegangen ist TT $57=$ AHG Nr.55A, 9-10; Sobekmose, Hayes, Scepter II 270/ 71: dw3.f tw m dw3jjt

shtp.f tw m mšrw

56. O.Firchow, Grundzuge der Stilistik in den altägyptischen Pyramidentexten (1953) 199f.

57 S.Schott, in: Fs Grapow (1955), 289ff.; LL,90 n.55; LA III, 1064 m.n.37.

58 Z.B. Calverley-Gardiner, The Temple of Seti I at Abydos, II Tf.5 (vgl. Tf.23): ein Morgenlied an Amun-Re (Tf.23: an Ptah) wo jedem in das Formular rs.k m htp, rs NN m htp eingefugten Namen noch ein vermerk wie sntr ! "Weihrauch!", snțr hr sdt ! "Weihrauch auf die Flamme" oder sdt sntrr ! "Flamme: Weihrauch!" angefugt ist. 
auf die in $\$ 1.1$ behandelte Phraseologie. $k 3$ ht psdt, jmj swht, nhh šss jmj Jwnw sind spezifische Atum-Attribute. 59 Man könnte sich vorstellen, dass es sich hier um einen heliopolitanischen Text handelt, von dem der Grabherr aufgrund seiner beruflichen Tätigkeit in Heliopolis Kenntnis hatte. Dem braucht nicht $z u$ widersprechen, dass Anklänge an die erste Strophe in einem thebanischen Text späterer Zeit, einer Inschrift im Tempel Sethos'I. in Gurna vorliegen; königliche Inschriften sind naturgemäss weniger ortsgebunden als private. 60

Die zweite strophe, die ebenfalls 10 Verse umfasst, ist in ihrem ersten Teil im Verbalstil formuliert. Entsprechend ist der thematische Bezug spezifiziert auf eine Phase des Sonnenlaufs: den Sonnenuntergang. Auch diese Verse wirken altertümlich, besonders 11-12, die an Pyr $728 \mathrm{c}-\mathrm{d}$ anklingen. 61

Stehen die beiden Hymnen des Grabes Nr.84 der Topik und vor allem Phraseologie der Opferformel-Eulogie fern, so gilt das Gegenteil für die anderen Hymnen dieser zeit. Die beiden Hymnen in Grab 53 sind kurz: sie umfassen nur je 6 Verse. Der linke Hymnus (Text 66) entfaltet in 4 Versen Epitheta des solaren Aspekts; der Anfang ist wahrscheinlich ohne Gottesname 62 zu ergänzen als

jnd

also eine leichte Abwandlung des in der zeitgenössischen Opferformel-Tradition - und nur in dieser - üblichen wbnw $m$ nbw wie in Text 135. Die letzten beiden Verse behandeln die Themen Urgott und Herrschaft in der Phraseologie der Opferformel-Eulogien. Text 67 verweilt in seinen letzten drei Versen etwas ausführlicher auf dem Aspekt Gottes als Wohltäters und Erhalters:

jrjw sšp n ${ }^{c}$ wt nbt

$59 \mathrm{Vgl.} \mathrm{K.Myśliwiec,} \mathrm{Studien} \mathrm{zum} \mathrm{Gott} \mathrm{Atum} \mathrm{II.} \mathrm{Name,} \mathrm{Epitheta,} \mathrm{Ikonogra-}$ phie (1979).

60 Es handelt sich um 4 Verse in einem sonst abweichenden Morgenlied; s. Text 101 , Kommentar.

61 S. zu Text 158 (f).

62 wie der Text LL III 4, vgl. zu weiteren Parallelen LL 318 n.11. 
jrjw 3 h $n$ qm3.n.f

nb smw sw3d $\underline{\text { h }} \mathrm{t}-\mathrm{n}-{ }^{\mathrm{C}} \mathrm{nh}$

Dieses Thema scheint in den Hymnen eine grössere Rolle zu spielen als in den opferformeln. Wir finden es $z \cdot B$. auch in dem kurzen Hymnus auf dem stelophor des R3jj:63

jnd $\mathrm{hr} \cdot \mathrm{k} \mathrm{nb} \mathrm{m} 3^{\mathrm{C}} \mathrm{t}$

nb rmtw jtj ntrrw

jrjw 3ht $n$ hr nb

Ahnlich Berlin 9571

jrjw 3hw n hr nb

nb ${ }^{C}$ h sw3d rhjjt

Der jedem Gesicht Wohltaten erweist,

der Herr des Lebens, der die Menschheit gedeihen lässt.

Auch der Text eines Stelophors in Chicago gehört in die gleiche Tradition: 65

jj nb.j nb nterw

Jmn nb nst t $3 w j$

Hrw-3htj ntr wr jrjw jrjjwt 66

$w^{c} w$ nn hr hw.f

nfr j3hw thn j3mw

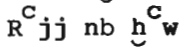

ntk js $t 3 w n$ fndw

nšp.tw $m$ dd.k
O mein Herr, du Herr der Gotter,

Amun, Herr von Karnak,

Harachte, grosser Gott, Schöpfer des

Geschaffenen,

einziger in seiner Art,

Schön an Strahlenglanz, funkelnd an Licht

Sonnenhafter, Herr der Erscheinungen;

denn du bist die Atemluft fur die Nasen,

man atmet von dem, was du gibst.

63 Der besseren Auffindbarkeit halber habe ich diesen allgemein (z.B. PM) aber irrtumlicherweise dem Inhaber von Grab 255 (Zeit:fruhestens Haremheb) zugewiesen stelophor ebenfalls dort eingeordnet; er gehort aber in die Fruhphase, mit der wir es hier zu tun haben.

64 In solchen und anderen Wendungen, die den Gott zur Maat in Beziehung setzen, erblicke ich den äg. Ausdruck für den Begriff der "ethischen Instanz". Belege aus dem Material meiner AHG habe ich dort, $543 \mathrm{zu} \mathrm{Nr}$. $69,12 \mathrm{f} .=$ Text 211,b,1-2 zusammengestellt. Vgl. noch aus dem Unkreis der fruhen thebanischen Hymnen den stelophor BM 29944 (aus Theben) Stewart, JEA 53,37: nt $w^{C} \mathrm{Ch}_{\mathrm{m}} \mathrm{m} 3^{\mathrm{C}} \mathrm{t}$ "Einziger Gott, der von der Maat lebt".

65 NHM $88906=$ AHG Nr.81.

66 Id. auf dem Stelophor Kairo JE 11509, s.u. S. 180. 
Verse 3-4 berühren sich mit der Urgott-Schöpfer-Phraseologie der OF-Eulogien ( $w^{C} w$ ḥr ḩw.f : Text 164; Text 102). Verse 5-8 entwickeln das Thema "Erhalter" in der typischen Weise der thebanischen Hymnen, wobei hier den Epitheta der Lichthaftigkeit ( nfr j3hw, thn j3mw, nb $h^{C} w$ vgl. Text 66: nb $h^{c}{ }^{c}$, š̌p ḥddwt, tḥn ḥrw ; sowie das höchst eigenartige Appellativ $\mathrm{R}^{\mathrm{C}} \mathrm{j} j$ "Re-hafter") solche der Lufthaftigkeit gegenübergestellt sind, vgl. Text 108b: nb țw sšm sw $r$ fndw. Licht und Luft sind die lebenspendenden Elemente, die vom Sonnengott ausgehen. CT IV $196 / 97$ und das Amduat belegen das Alter dieser Vorstellung. 67 Daher scheint es mir auch hier noch nicht um Amun als Luftgott zu gehen: dieser Aspekt des Gottes wird vielmehr erst später im Kontext der ramessidischen Elementenlehre realisiert (s.Kap. 5).

Besonders wichtig erscheint mir das Harfnerlied in Grab 11 mit einem Hymnus, der auch auf der statue Kairo CG 921 belegt ist, also eine verbreitete Komposition darstellt. Dieser Text geht über die bekannte Phraseologie -

Sonnenaufgang: das "Gold"-Motiv

Weltherrschaft: mit "Wasser" als drittem Bereich neben Himmel und Erde

Schöpfung: mit Betonung der Pflanzen 68

einen entscheidenden Schritt hinaus, und zwar dadurch, dass er das Thema "Wohltäter und Erhalter" ins Persönliche wendet, d.h. in einen Bezug setzt, in dem nicht mehr schlechthin "jedes Gesicht" Partner und Empfänger der göttlichen Wohltätigkeit ist, sondern ausschliesslich der Fromme: ${ }^{69}$

rdjw $t 3 w n d w 3 w$ sw

smnhw ${ }_{h}^{c}{ }^{c} w n$ jrjw hr mw.f

67 S.zu Text $54(\mathrm{e})$.

$68 \mathrm{Vgl}$. hierzu auch Urk IV, 469: nb Nprj shpr rnpjjwt "Herr des Korngottes, der die Feldgewächse hervorbringt".

69 Zum äg. Begriff der Frömmigkeit als einer Entscheidung für Gott, einer aktiven zuwendung, die sich im Handeln und Wissen ("Beherzigung") äussert, und zum "Frommen" als Partner einer reziproken Gott-Mensch-Beziehung s. meine in $\mathrm{n} .70$ zit. Arbeit. 
Der Atemluft gibt dem, der inn anbetet

und die Lebenszeit trefflich macht dessen, der 'auf seinem

Wasser handelt'

Dies ist kein Einzelfall. Die Belege, die ich anderenorts zusammengestellt habe ${ }^{70}$ sowie die von G.Posener veröffentlichten Gebetsostraka aus derselben zeit ${ }^{71}$ erlauben es, von einer ersten Phase der "Persönlichen Frömmigkeit" zu sprechen. Besonders nahe kommt Text 13 die Formulierung eines stelophors in Brooklyn ${ }^{72}$ :

$\sin c_{h} c_{w} n$ dw3w nfr [w.f]

Die schon mehrfach zum Vergleich herangezogene stele Turin = AHG Nr.72 gehört ebenfalls in diese Tradition:

htp dj njswt Jmn-R ${ }^{c} w$ nb

nst $t 3 w j$
Ein Opfergebet fur Amun-Re, Herrn von

Karnak

p3wtj n zp tpj hntj Jpt-swt Urgott des Anbeginns, Erster von Theben shm šps huprw ds.f erlauchtes Machtbild, selbstentstanden,

Nb $r$ dr m st.f nbt

dj.f ${ }^{\mathrm{c}} \mathrm{nh} \mathrm{n} \mathrm{mr} \cdot \mathrm{n} . \mathrm{f}$ Allherr an allen seinen stätten. Er gibt Leben nur 73 wem er will, ein hohes Alter dem, der inn in sein Herz

g.ibt,

t3w n r3.f $n$ ntj m hswt.f den Hauch seines Mundes dem, der in seiner Gunst steht,

n fh.n.f hr dt m33.f der hort in Ewigkeit nicht auf, ihn zu

Gott, Vater der Menschheit, 74

Amun, bleibend im Besitz aller Dinge. 75

70 "Weisheit, Loyalismus und Frommigkeit", in: E.Hornung, O.Keel (Hrsg.), Studien zu altăgyptischen Lebenslehren (1979), 12-72.

71 In: $\operatorname{RdE} 27(1975)$ 195-210.

72 T.G.H.James, Corpus of Hieroglyphic Inscriptions in the Brooklyn Museum I, Nr.176, S.75; vgl. LL, $150 \mathrm{Nr} .21|\mathrm{Br}|$.

73 Zum "emphatischen" Charakter dieser Konstruktion (?) s. "Weisheit ..." $(\mathrm{n} .70), 54 \mathrm{n} .133$.

74 Zur Prädikation Gottes als "Vater", sonst, in Bezug auf die Menschheit insgesamt, immer in der Form "Mutter und Vater" s. AHG 545 zu Text 75, 23; H.Tellenbach (Hrsg.), Das vaterbild in Mythos und Geschichte (1976) 18 n.25 sowie Kap. $3 \$ 2.5$.

75 Zu diesem alten Amun-Prádikat s.Text 134 (b). 
Die eindringlichste Formulierung für diesen Gedanken einer persönlichen Gott-Mensch-Beziehung findet aber Text 165:

jtj mwt $n$ rdjw sw m jb.f

mkhw wnjw njwt.f

Vater und Mutter für den, der ihn in sein Herz gibt,

sich abkehrend von dem, der an seiner stadt achtlos vorübergeht.

Der Stelentext des Antef ist mit 27 Versen ein langer Hymnus, besonders für diese Frühzeit, in der hymnische Inschriften meist 6-10 Verse umfassen. Genau wie Text 102 erzielt er diesen Umfang durch die Kombination dreier Hymnen üblicher Länge, die alle durch die Nennung des Namens und "er sagt:" eingeleitet werden. Dasselbe Verfahren wendet auch der zeitgenössische Stelophor Kopenhagen A 72 an, der überdies einen seiner Hymnen mit Text 175 gemein hat ${ }^{76}$ :

I Sei gegrüsst, [der sich gebiert] jede Stunde,

[der aus seiner Mutter herauskommt] täglich

und in ihr zur Ruhe geht zu seiner Stunde! 77

Du querst deine beiden Himmel in Triumph, 78

deine Mannschaft jubelnd in deinem Gefolge.

II Sei gegrïsst, Urzeitlicher der beiden Länder,

Herr der Maat ohne Gleichen,

der Eine, der seinen Er zeuger erzeugte,

der seine Mutter schuf und seine Hand hervorbrachte ${ }^{79}$

der aus dem Lichtland hervorgeht,

verklärt in Gemeinschaft seines Ka.

III Du erscheinst und erglänzt auf dem Rücken deiner Mutter

du bist erschienen als könig der Neunheit.

Nut erweist deinem Antlitz die njnj-Begrüssung,

Maat umarmt dich allezeit

in Frieden, Tag für Tag.

76 Stewart, TESH $63 \mathrm{Nr} . \mathrm{XV}$; AHG Nr.51.

77 Formel, s.zu Text 74 (a).

78 Vgl.Text 74,$6 ; 182,17$. Mit den "beiden Himmeln" des Sonnengottes ist wohl der Nord- und der Südhimmel gemeint, nicht der obere und der untere Himmel. Das Verspaar bezieht sich daher in "ikonischer" Weise auf die Mittagsphase der "Uberfahrt" (s.Kap.2\$2.2.2), nicht auf den gesamten Umlauf. 
I entspricht dem 1.Hymnus des Antef; der Text war auch sonst in Theben bekannt, vgl. zu Text 74 und $180 \mathrm{c}$ (beide Gräber, TT 57 und 192, aus der Zeit Amenophis'III.) Sein Spezifikum ist der Bezug auf den Sonnenlauf in sowohl eulogischer als auch "verbaler" Form, wobei sich die Eulogie auf den Sonnenzyklus insgesamt ( prj-htp) bezieht, der verbale Teil (Verse 4-5) aber nur auf die phase der "Uberfahrt". 80 Darin folgt der Text einer Regel, die sich oft belegen 1 ässt. 81

III $=$ Text LL III 1 , Verse 3-6.

II ist eine zwischen diese beiden traditionellen Textstücke eingeschobene Eulogie, die sich thematisch eng mit unseren Texten berührt. Auch hier geht es um Urzeitlichkeit, Einzigkeit und Autogenese, allerdings in phraseologisch anderen Ausdrucksformen. Die Themen "Herrschaft", "Schöpfung" und "wohltäter" fehlen, der solare Aspekt kommt, wiederum in anderer Phraseologie, in Vers 10-11 zum Ausdruck. Die Beziehung zur Maat, die vers 7 hervorhebt, spielt auch in Text 165 eine auffallende Rolle (Vers 1415). 82

Die starke Hervorhebung des Wohltäter-Erhalter-Aspekts im Wesensbild der Gottheit könnte ein Spezifikum der thebanischen Amun-Re-Theologie sein, wie sie sich in den Eulogien der Frühphase des NR ausprägt. Der Text des Antef (Nr.165) entwickelt in den beiden Hymnen, die er mit I verbindet, ausschliesslich diesen Wohltäter-Erhalter-Aspekt, der in dem Kopenhagener Text ganz ausgespart ist. II expliziert in den ersten drei. Versen das Beiwort $\mathrm{m}^{\mathbf{C}^{\mathbf{t}} \mathbf{j}}$, das dem $\mathrm{nb} \mathbf{m} 3^{\mathbf{c}} \mathbf{t}$ des Kopenhagener Stelophors (Vers 7) entspricht, hier wie dort in

79 zur heliopolitanischen Konzeption der "Gotteshand" s. J.Leclant, in: LA II 813-815.

80 Unter der Voraussetzung, dass meine in n.78 dargelegte Auffassung zutrifft.

$81 \mathrm{Vgl}$. LL 4-6 und passim.

82 S.n.64. 
Verbindung mit Einzigartigkeit ( jwtj snnw.f ), und interpretiert in den letzten beiden Versen die Sonnenbewegung als eine intentionale Handlung des Gottes, die auf die Erhaltung seiner Geschöpfe gerichtet ist:

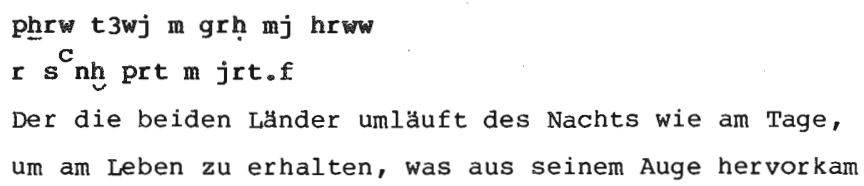

Wir haben hier in äusserster Prägnanz den Ausdruck eines anthropozentrischen Weltbildes vor uns, das den Sonnenlauf um der Menschen willen geschehen lässt, denn diese sind es, die nach einem verbreiteten biogonischen Mythos "aus dem Auge" des Schöpfergottes hervorgegangen sind. 83

Die früheste und zugleich expliziteste Darstellung dieser anthropozentrischen Ausdeutung des Sonnenlaufs findet sich in dem berühmten Schlusshymnus der Lehre für Merikare:

hnw rmtw $c_{\text {wt nt ntr }}$ Wohlversorgt sind die Menschen, das Kleinvieh Gottes

jr.n.f pt t3 n jb.sn ihretwegen erschuf er Himmel und Erde, dr.n.f snk $n$ mw er drängte die Gier des Wassers zurück $j r \cdot n . f \underline{t} 3 w n-j b{ }^{c} n h$ fndw.sn und schuf die Luft, damit ihre Nasen leben. snnw.f pw prjw In ${ }^{\mathrm{C}}$ w.f Seine Ebenbilder sind sie, aus seinem Leib hervorgegangen. wbn.f m pt $n$-jb.sn Innen zuliebe geht er an Himmel auf, jr.n.f n.sn snaw ${ }^{c}$ wt. fur sie schuf er pflanzen und Tiere, 3pdw rmw snm.st Vogel und Fische, damit sie zu essen haben. sm3.n.f hftjw.f hd.n.f Er tötete seine Feinde und ging vor gegen msw.f seine kinder, hr k3t.sn jrt sbj weil sie auf Rebellion sannen.

83 S.Kap. 5. 
jrr.f šsp $n$ jb.sn

sqdd.f $r \mathrm{~m} 33$ st

t $3 z \cdot n \cdot f$ n.f $k 3 r$ h $3 . s n$

rmj.sn jw.f hr sdim
Ihnen zuliebe lässt er es Licht werden, um sie zu sehen, fährt er (am Himmel) dahin Er errichtete sich eine Kapelle hinter ihnen, wenn sie weinen, dann hört er.

jr.n.f n.sn hq3w $m$ swht Er schuf ihnen Herrscher im Ei

tzw $r$ tzt(m) psd s3-c und Befehlshaber, um den Rücken des Schwachen

$z u$ stärken.

jr.n.f n.sn hk3w r ${ }^{c_{h}} 3 w$ Und er schuf ihnen Zauber als waffen

r hsf ${ }^{c}$ n hprjjt

um den Schlag des Schicksals abzuwehren

rsw hr.s grḥ mj hrw

wachend über sie des nachts wie am Tage.

sm3.n.f h3kw-jb $m-m$

Er erschlug die Krummerzigen unter ihnen,

mj ḥwj $\mathbf{z}$ z3.f ḥr sn.f

wie ein Mann seinen Sohn um seines Bruders

willen schlägt.

jw nțr rhw rn $n b$

Gott kennt jeden Namen.

Wie dieses Weltbild, 700 Jahre nach der vermutlichen Abfassungszeit der Lehre für Merikare (aber in genau derselben zeit, aus der die uns erhaltenen Hss. dieses Textes stammen!) in den Sonnenliedern der "neuen Sonnen-Theologie" zum Durchbruch kommt, habe ich in Kap.3 dargestellt. Dort ist die Anthropozentrik dieser Auffassung abgemildert und der Mensch in einer Reihe mit allen anderen Geschöpfen des Sonnengottes (allem was Augen hat) das Ziel der lebenspendenden und erhaltenden Mühewaltung des Sonnengottes. Auch hier ist aber oft sehr betont von der Menschheit als der "Herde" und dem "Kleinvieh" Gottes die Rede, das "aus seinem Auge hervorkam", ein Mythologem, das nicht nur auf einem Wortspiel beruht ( rmjt "Träne" - rmt "Mensch"), sondern auf eine tiefsinnige weise die zwischen dem Gott des Lichts und dem Menschen als einem "Augenwesen" waltende Beziehung zum Ausdruck bringt.

Offenbar ganz unabhängig von der "neuen Sonnen-Theologie" und früher als in den entsprechenden Sonnenliedern tritt dieses Weltbild in den thebanischen Amun-Re-Eulogien hervor, und zwar im zusammenhang der Darstellung des Wohltäter-ErhalterAspekts der Gottheit, der in diesen Texten eine so zentrale Rolle spielt, in den Hymnen mehr noch als in den Eulogien der opferformeln. 


\section{Der Papyrus Kairo 58038 (Boulaq 17) = AHG Nr.87}

In ihrer Hervorkehrung jenes Aspekts der Gottheit, die wir mit den Ausdrücken "Wohltäter", "Erhalter" und "ethische Instanz" umschreiben - in Wiedergabe ägyptischer Wendungen wie jrj 3ht "Wohltaten erweisen" $84, \mathbf{s}^{\mathbf{c}} \mathbf{n h}$ "am Leben erhalten" 85 und mit nb $3^{C_{t}}$ "Herr der Gerechtigkeit" (mit Bezug auf Versorgung der Schöpfung: "der gerechten verteilung" ${ }^{86}$ ) - stehen die thebanischen Eulogien der frühen Phase des Neuen Reichs im Banne einer Tradition theologischer Wesensbestimmung des thebanischen Gottes Amun-Re, die ihren differenziertesten Ausdruck in den Hymnen des Pap. Kairo CG 58038 (früher: Boulaq 17) gefunden hat. ${ }^{87}$ Der Text ist in einer ausgezeichneten literarischen Hs. aus der Zeit Amenophis'II. erhal$\operatorname{ten}^{88}$, daruberhinaus auf einigen ostraka der Ramessidenzeit $^{89}$ sowie in seinem ersten Teil auch auf einer votivstatuette aus Der el Bahari, die aus paläographischen Gründen nicht jünger als die 17. Dyn. sein kann und damit das nohe Alter zumindest der Abschnitte A-C des Textes unter Beweis stellt. 90 Der Anfang des Textes kommt ausserdem auf einer

84 Z.B. Text 67; Text 220,3; Berlin 9571 (0.S.163).

$85 \mathrm{zu}$ Gott als s nhw vgl. die stele eines Sängers, ed.Kuentz in: Rec. Champolțion, $601 \mathrm{f}$.

nțr ssnh hr nb

mnint ${ }_{3 t}{ }_{\text {wt }}$

šwt nšmt jrt nbt gmht

Der grosse Gott, der jedes Gesicht am Leben erhält,

Grossvieh und Kleinvieh, 'Federn' und 'Schuppen' und alles Auge, das blickt

Der programmatische Titel des pkairo 58038 I 1-2 nennt den Gott rdjw nh $\mathbf{n}$ srf nb "der Leben gibt allem Warmen".

Sehr häufig ist auch die Wendung jrj $C_{\text {nh }}$ "Leben schaffen" (z.B. parallel zu s nh pKairo 58038, VI, 4-5. 5-6; vgl. VIII,3).

86 Zum Zusammenhang mit Maat und Versorgung $\mathrm{s}$. König als Sonnenpriester, 58-65 vgl. auch LL 144f. und Otto, Gott und Mensch, $24 \mathrm{f}$.

87 AHG Nr.87; Barucq-Daumas, Hymnes et Prières, Nr.69 mit Bibliographie.

88 Zur Datierung (Amenophis II oder 17. Dyn.): G.MOller, in: ZAS 56 (1920) $34 \mathrm{ff}$.

89 OIFAO 1224, 1225, 1226. Der Freundlichkeit G.Poseners verdanke ich die Kenntnis von oChicago 16976 und oTurin 6358.

90 S. Hassan, Hymnes Religieux du Moyen Empire (1930) 157ff. Hall, HT IV Tf.50. Der nur fragmentarisch erhaltene Paralleltext BM 40959 setzt bei I.6 ein und bricht bei IV. 4 ab. 
Stele ${ }^{91}$ und in einem Totenbuch ${ }^{92}$, beide aus ramessidischer Zeit vor. Freie zitate aus diesem Text, die eher auf münliche Uberlieferung als auf eine schriftliche Vorlage schliessen lassen, finden sich in mehreren Hymnen aus Der el-Medine, vor allem Text 206 und T'ext 212.93

Der Anfang realisiert denselben Textplan, nur ausführlicher, der auch den Eulogien der Opferformeln zugrundeliegt:

\section{Herrschaft}

jnd hr.k Jmn $R^{\mathrm{C}} \mathrm{w}$

Sei gegrusst, Amun Re

nb nst t3wj hntj

Jpt-swt Herr von Theben, erster von Karnak

R3mwtf hntj sht.f

pd nmtt hntj t3-sm ${ }^{c}$

Kamutef, der seinen Gefilden vorsteht,

Weit-Schreitender, Erster von Oberägypten,

nb md3w hqu 3 pwt

wr $n$ pt smsw $n+3$

Herr der Madjoi, Herrscher von Punt,

Grosser des Himmels, Altester der Erde, ${ }^{94}$

nb ntj ma jht nbt

Herr des Seienden, bleibend im Besitz aller

Dinge. 95

\section{2. [Urgott], Einzig(artig)keit, Schöpfer}

$w^{c} h r$ hw.f m-m ntrw Einzig in seiner Art unter den Gotter, ${ }^{96}$

k3 nfr n psdt hrj tp Schöner Stier der Neuenheit, Oberhaupt

ntrw nbw aller Gotter ${ }^{97}$

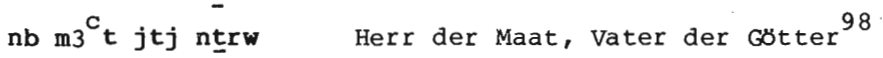

jrjw rmtw qm3w ${ }^{c}$ wt Schöpfer der Menschen und Tiere, ${ }^{99}$

91 Bankes Stela Nr.4, ed. J.Černý, Egyptian Stelae of the Bankes Collection.

92 pBM 9988, Shorter, Catalogue, 66.

93 Anklänge finden sich auch in der Stele Musée Guimet (jetzt:Louvre) C $21=$ AHG 170 .

94 Id. Tura-Hymnus AHG Nr $88,3-4$; Text $236,3-4, \operatorname{vgl}$. a.Text $75,27(j)$.

95 S.hierzu Text 134 (f).

96 Vgl. Text 102; Text 164; Stelophor Chicago AHG 87; Hornung, Der Eine und die vielen, 180 m.n.142; Otto, Gott und Mensch, 12 m.n.4-5.

97 hrj-tp nțrw :id. Text $92 d$; Berl.9571 = AHG Nr.82,2; Kairo CG 34152.

98 Ȧhnl. Text 130: nb m3 $t$ jtjj ntrw nbw. Denselben wortlaut wie der Kairener Pap. hat Text $211 \mathrm{~b}, 2$.

jtj ntrw cf Text 72.12; Text 220,2.

99 Von den Tieren, die im pxairo 58038 eine so grosse Rolle spielen, ist eigentumlicherweise in den Eulogien der Opferformeln nie, in den Hymnen nur in Text 67,5 die Rede (dort aber wohl Metapher fur die Menschheit als wt Gottes). 
nb ntj qm3w ht-n- ${ }^{C}$ nh Herr des Seienden, Schøpfer des "Lebensholzes", jrjw sma s $c^{c}$ nhw mnnt der das Futterkraut schafft ${ }^{100}$ und das vieh am Leben erhält

\section{Erhalter als Sonne}

Sham nft jr.n Pth Schönes Machtbild, das Ptah geschaffen hat, ${ }^{101}$ hwow nfr $n$ mrort Jungling, schon an Liebe, ${ }^{102}$

ddw n.f ntrw j3w dem die Gotter Lobpreis spenden;

jrjw hrjw hrjw der die Unteren und oberen erschafft ${ }^{103}$ wenn,

shd.f t3wj er die beiden Länder erleuchtet,

d3jw hrt m htpw der den Himmel quert in Frieden.

Auffallender noch als die zahlreichen Ubereinstimmungen im Einzelnen, auf die wir in den Fussnoten hingewiesen haben, ist die Tatsache, dass der Urgott-Aspekt, also die Prädikate der Urzeitlichkeit ( p3wtj, p3wtj t3wj), Uranfänglichkeit ( hpr hr h3t/jmj b3h ) und Autogenese ( hpr ds.f usw.), die in den Eulogien der Gräber eine solche Rolle spielen, im Kairener Papyrus überhaupt nicht vorkommen, und zwar weder in dem zitierten Stück, noch in allen anderen Hymnen dieser Samml.ung. Das einzige mit dem Urgott-Thema der Eulogien zusammenhängende Motiv, das im Kairener Hymnus ebenso wie in den Gräbern vorkommt, ist der Gedanke der Einzigartigkeit, Einzigkeit und Einsamkeit Gottes:

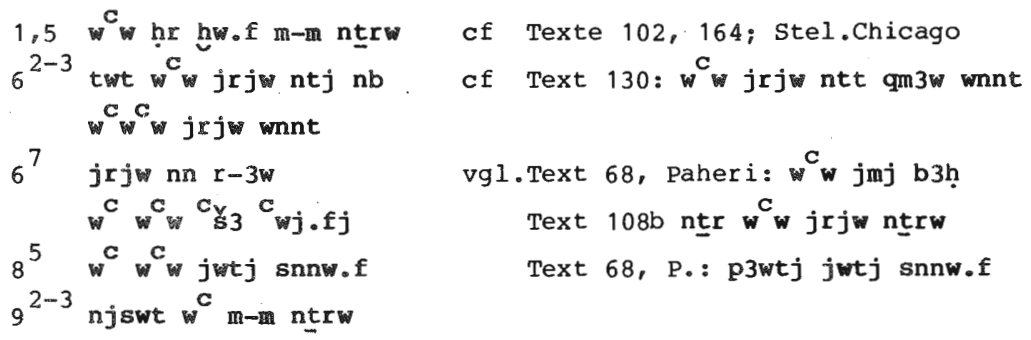

$100 \mathrm{Vgl.Text} 67: \mathrm{nb}$ siaw sw3d ht $\mathbf{n}_{\mathrm{nh}}^{\mathrm{C}_{\mathrm{h}}}$

101 Zur Prädikation der Sonne als shm, die in den Eulogien der of (Urk IV 518; Text 164; AHG Nr.72) రfter begegnet, s.MDIK 27.1,25f. Durch den Zusatz jr.n pth (vgl. Haremhab BM $551=$ AHG Nr.58.46) wird deutlich, dass bei shm wirklich an die Sonne als Gégenstand, eine Art Kultbild gedacht ist.

102 S.hierzu LL $326 f$.

103 s.Text $72(a)$. 
Der Kairener Amunshymnus setzt die Aspekte Schöpfer und Erhalter in eins und versteht unter "Schöpfung" - da er die Kategorie der Urzeit vollkommen ausblendet - die fortwährende Hervorbringung der Welt durch den "Einen Einzigen", die eine Quelle allen Lebens.

twt w $w^{C}$ jrjw ntj nb Du bist der Eine, der alles seiende geschaffen hat,

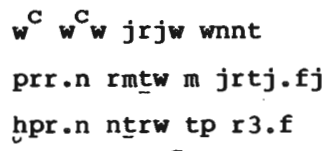

der Eine Einsame, der schuf, was ist, aus dessen Augen die Menschen hervorgingen aus dessen Ausspruch die Götter entstanden Schöpfer des Futterkrauts, das das vieh am Leben erhält und des "Lebensholzes" für die Menschheit der schafft, wovon die Fische im Fluss leben und die Vögel, die den Himmel bevölkern. Der dem, der im Ei ist, die Luft gibt der das Junge der Schlange am Leben erhält der schafft, wovon die Mücke lebt

würmer und Flöhe desgleichen, der für die Mäuse in ihren Löchern sorgt und die Käfer (?) am Leben erhält in jeglichem Holz. der Eine Einsame mit vielen Armen; der die Nacht wachend verbringt, wenn alle Welt schläft um zu suchen, was seiner Herde wohltut; Amun, bleibend im Besitz aller Dinge, Atum Harachte 
jtj jtjw ntrw nbw $c_{h}$ pt dr z $3 t w$

jrjw ntj qm3w wnnt jtjj ${ }^{c}$.w.s. hrj-tp

ntrrw Herrscher LHG, Oberhaupt der Götter!
Vater der Väter aller Götter

der den Himmel erhob und den Erdboden

niederhielt,

$(\ldots)^{105}$

Was wir in diesen versen vor uns haben, ist eine spezifische Ausprägung derselben Theologie des Lebens-Gottes, wie sie uns zuerst in den Schu-Sprüchen der Sargtexte ${ }^{106}$ entgegentritt und dann wieder in der "neuen Sonnen-Theologie", besonders in ihrer radikalen Ausprägung, der Amarna-Religion. Auch den Charakter einer "Naturlehre", der Klassifikation der Lebewesen nach ihren Lebensbedingungen, d.h. der Art und weise, in der der Lebensgott für sie gesorgt hat, hat dieser Text mit den anderen Ausprägungen der Theologie des Lebensgottes gemeinsam. 107 In der gleichsam liebevollen Durchdetaillierung der von Gott am Leben erhaltenen Geschöpfe steht dieser Abschnitt des Kairener Amunshymnus einzig da.

Zur Theologie des Lebensgottes gehört auch die Betonung der Einzigkeit. Die im pkairo 58038 dreimal belegte Formel ${ }^{\mathrm{C}}{ }^{\mathrm{C}}{ }^{\mathrm{w}}$ bedeutet wörtlich: der Eine, der allein ist. In dieser doppelten Betonung des Begriffs des Eins-Seins kommt die Vorstellung eines Gottes zum Ausdruck, der nicht wie alle anderen Götter "einbezogen" ist in die "Konstellationen" der Götterwelt ${ }^{108}$, sondern als "Einziger einsam ist" und "in der Einsamkeit seiner Einzigkeit verharrt". 109 Die Formel

105 Verse 142-144 enthalten den Dank der Götter cf.ibd.

106 S.hierzu "Primat und Transzendenz", 24f. und Kap.7.

107 S.Morenz, "Eine Naturlehre in den Sargtexten", in: WZKM 54(1957) $119 f$. A.de Buck, Plaats en betekenis van Sjoe in de Egyptische Theologie (1947) 22f. Zur Auffassung des "Nilhymnus" und des Grossen Hymnus von Amarna als "Naturlehre" s. SAK 8(1980), 1-32.

$108 \mathrm{Vgl.} \mathrm{Kap.2,} \mathrm{ferner} \mathrm{"Primat} \mathrm{und} \mathrm{Transzendenz",} \mathrm{23-25.}$

$109 \mathrm{Zu}$ Recht verweisen m.E. A.Barucq und F.Daumas in Hymnes et Prières $197(z)$ auf diese Formulierung des Jamblich (de nysteriis VIII, 2) als eine exakte Wiedergabe des äg. Begriffs $w^{\mathbf{C}} \mathbf{w}_{\mathbf{w}}$. 
gibt dem Bemluhen Ausdruck, über einen Begriff von Einzigartigkeit hinaus, wie er praktisch allen ägyptischen Göttern zukommt und sich durchaus mit der vorstellung einer Einbezogenheit in Konstellationen in Einklang bringen lässt (denn der Begriff der Einzigartigkeit setzt einen Gott ja zu den anderen Göttern in Beziehung), einen Begriff von Einzigkeit zu fassen, der den Gott zur Welt bzw. zum sein insgesamt in Beziehung setzt. Der Lebensgott ist nicht nur "einzigartig", sondern "einzig", weil nach der Auffassung dieser theologischen Tradition alles Leben aus einer einzigen quelle hervorgeht. Das hat mit Monotheismus nichts zu tun, weil ja im pKairo 58038 passim von den "Göttern" die Rede ist. Sie treten aber nicht einzeln und namentlich auf, was die vorstellung von Konstellationen implizieren würde ${ }^{110}$, sondern als Gruppe von Lebewesen, in einer Reihe mit Menschen und Tieren. Der Lebensgott ist ein "Höchstes Wesen" und als solches einzig. Dem Kairener Papyrus ist die Begrifflichkeit der "Transzendenz" noch fremd, in der eine spätere Theologie den Ort dieses Höchsten Gottes ausserhalb der Götterwelt zu denken imstande sein wird (vgl. Kap. 5). Diese frühe Stufe der Lebensgott-Theologie drückt die stellung des Höchsten Wesens noch in der Begrifflichkeit des primats aus. Darauf beziehen sich auch die nicht seltenen Prädikate der Einzigartigkeit:

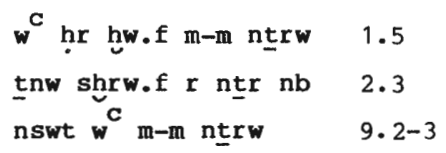

Als Herrscher der Götter d.h. in seiner spezifischen Relation zur Götterwelt ist der Gott einzigartig, als Lebensgott, der allein die ganze Fülle der Schöpfungswelt am Leben erhält, einzig. 111

Bis hierhin beruht die Theologie des Lebensgottes, wie sie im pkairo 58038 greifbar wird, vermutlich auf einer alten

110 Ausnahmen bilden nur das jr.n Pth in Vers 18 (s.n 101) und das Lied G, das in die Tradition der "Ikonographie des Sonnenlaufs" (Kap.2) gehört (auch dort wird allerdings von den beistehenden Gottern nur Thoth genannt: Vers 172).

111 Soviel zu Hornung, Der Eine und die vielen, 180f., der den Begriff der Einzigkeit nur fur den "im Anfang einzigen Schöpfergott" gelten lassen will. 
Tradition der Sonnen-Theologie, die sehr wahrscheinlich schon jener Naturlehre zugrunde liegt, deren bildlichen Ausdruck wir im Dekorationsprogramm der "Weltkammern" in den Sonnenheiligtümern der 5.Dynastie vor uns haben. Hier liegen vermutlich die gemeinsamen Quellen der sargtexte, unseres Hymnus und später der "neuen Sonnen-Theologie" und der Amarna-Religion. Im Kairener Hymnus kommt aber noch ein anderer Aspekt der Gottheit zum Ausdruck, der den sonstigen Ausprägungen einer Lebensgott-Theologie fremd ist und dessen Abwesenheit etwa in den Amarna-Hymnen ganz besonders auffällig ist: der Aspekt der "ethischen Instanz". 112 Eine reine Lebens-Theologie findet am Problem der Ethik ihre Grenze.

Abgesehen von einer Formel in $B-d d w{ }^{c}{ }_{w j . f j} n \operatorname{mrr} . f$ "der seine Arme reicht dem, den er lieb hat"113 - kommt der personale Aspekt der Gottheit als ethische Instanz im Abschnitt C zum Ausdruck, der durch den Londoner Paralleltext noch als alt ausgewiesen ist:

jnd $\mathrm{hr} \cdot \mathrm{k} \mathrm{R}^{\mathrm{C}} \mathbf{w} \mathrm{nb} \mathbf{3}^{\mathrm{C}} \mathrm{t}$ Sei gegrusst, Re, Herr der Gerechtigkeit, jmn k3r.f nb ntrw der seine Kapelle verbirgt, Herr der Gstter, Hprj hrj-jb wj3.f Chepre in seiner Barke, wd mdw hpr ntrw der befiehlt und es entstehen die Götter ${ }^{114}$ Jtmw jrjw rhjjt Atum, Schöpfer der Menschen, tnw qd.sn jrjw der ihre Wesensart unterscheidet und ihren c nh.sn Lebensunterhalt schaff, wpjw jnw.sn $w^{c} r$ snnw.f ihre Hautfarben unterscheidet, den einen vom

(n)

sdmw snmhw n ntj m Der das Flehen erhört dessen, der in Bedrängnis

btnw ist

j3m-jb hft njs n.f wohlgeneigten Herzens gegenuber dem, der zu ihm ruft;

112 Zur Abwesenheit des Aspekts der ethischen Instanz in den Amarna-Hymnen S.SAK 8(1980) 31f., Zeit und Ewigkeit, 54-61.

113 AHG 87 B, 57 .

$114 \mathrm{Vgl}$. ähnl. den Stelophor Kairo JE 11509, u.S.180: dd mdw hpr ntrrw. Verse 64-65 finden sich ubrigens auch in einer Beischrift von 'Tr 3 nach $\mathrm{WbZ}\langle 1743\rangle$. 


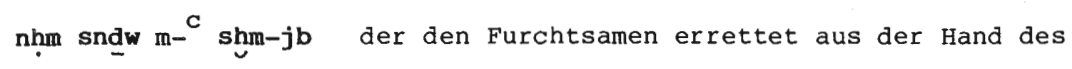

wpjw $m 3 r$ hn $^{c}$ wsr der richtet zwischen Arm und Reich.

nb sj3 hw tp r3.f Herr der Erkenntnis, auf dessen Lippen das Schopferwort ist.

jj.n H $^{\mathrm{C}} \mathrm{pj} \mathbf{n}$ mrwt.f demzuliebe die Niluberschwemmung kommt,

nb bnrt ${ }^{3}$ mrwt Herr der zuneigung, gross an Liebe,

jw.n.f $\mathbf{s}^{\mathbf{c}} \mathrm{nh}$ rhjjt wenn er kommt, lebt die Menschheit.

daw z. $n$ jrt nbt Der freien Weg gibt jedem Auge 115

jrtj m Nnw das im Nun geschaffen wurde (?);

shpr.n j3mw.f hddwt dessen Glanz es Licht werden lässt,

$\underline{h}^{\text {CC }}$ w ntrw m nfrw.f uber dessen Schơnheit die Gotter jubeln,

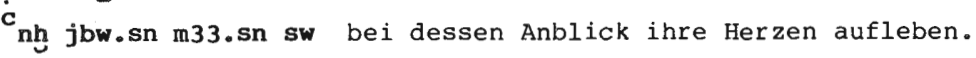

Die erste strophe ruft den Gott in den drei Namen der klassischen Drei-Gestalten-Lehre ${ }^{116}$ an, verbindet damit aber nicht, wie üblich, die Modalitäten der inner-zeitlichen Erscheinung des Sonnengottes als Morgen-, Mittag- und Abendsonne, sondern drei theologische Aspekte:

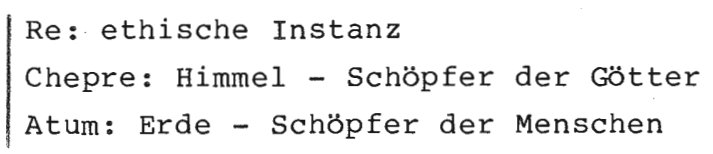

Das Epitheton jmn $\mathbf{k} 3 r$.f hat man in diesem Zusammenhang wohl im Licht der oben zit. Stelle der Lehre für Merikare zu verstehen: țzz.n.f n.f k3r ḩ3.sn, rmj.sn jw.f hr sdm "er errichtete sich eine kapelle hinter ihnen, wenn sie weinen, hört er". Die "verborgene Kapelle" ist Symbol der verborgenen Al1gegenwärtigkeit des erhörenden Herrn der Gerechtigkeit. Die zweite Strophe führt diesen Abschnitt näher aus. Das erste Verspaar bezieht sich auf das "Hören", von dem auch in der Lehre für Merikare die Rede ist, das zweite auf das "Richten", wie es ähnlich der spruch 1130 der Sargtexte zum Ausdruck bringt:

115 S.hierzu O., S. 159 m.n. 41-44.

116 S.Kap. 2; LL 339-352. 


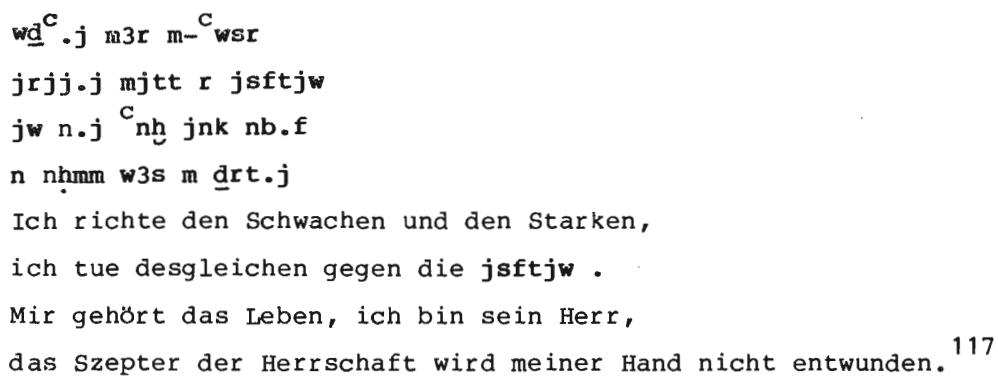

"Hören" und "Richten" sind die beiden wirkungsweisen des "Herrn der Gerechtigkeit", die man seit alters mit dem Sonnengott verbindet. Das entscheidend neue, was die Hymnen der frühen 18. Dynastie, in diesem Punkt noch über den Kairener Amunshymnus hinausgehend, diesem Bilde hinzufügen, ist der Begriff der Frömmigkeit als einer aktiven Hinwendung des Menschen $z u$ Gott - "Gottesbeherzigung" ( rdj m jb : Text 165) und "Gottesloyalität" ( jrj hr mw : Text 13) - die Gott mit seiner persönlichen Zuwendung belohnt - "Vater und Mutter" (Text 165), "Gewährung erfüllter Lebenszeit" (Text 13). Dieser Begriff von Frömmigkeit, der sich im Kairener Amunshymnus noch nicht findet, bildet die Grundlage einer neuen Gott-Mensch-Beziehung, die das Neue und Eigentümliche der thebanischen Amun-ReVerehrung darstellen dürfte.

Zum Aspekt Gottes als ethischer Instanz möchte ich noch die Gottestitulatur einer opferformel anführen, die ganz aus dem Rahmen fällt. Sie steht in einer Deckenzeile des oberen Grabes des Bürgermeisters Sennefer (TT 96A, Zeit: Amenophis II). 118

htp dj njswt ...

k3 pt shm jmj

hmw nfr jwtj sb.f

wd $^{c}$ rjjt m sb3 nfr

shdw t3wj dgg.tw.f hpr zp nfr

$117 \mathrm{Zu}$ diesem Text s. E.Otto, in: Gs.Otto (1977),1-19, spez.11.

118 Ich zitiere den unv. Text in dem derzeit unzugănglichen Grabe mit freund1. Genehmigung des Griffith Institute, Oxford, nach Davies Notebook 3/33. G.P.F.van den Boorn verdanke ich den Hinweis auf J.J.TY- 
Ein Opfergebet an (Amun-Re...)

den Stier des Himmels ${ }^{a}$, das Machtbild darin,

das gute steuerruder, das nicht fehl geht ${ }^{\mathrm{C}}$,

Richter... d

der die beiden Länder erleuchtet: immer, wenn er erblickt wird, ereignet sich Gutes ${ }^{e}$

a) k3 pt : vgl. Kairo CG 42120 (Zeit: Thutmosis III) 119 jnd $h r \cdot k R^{C} w k 3 p t$

Jmn hrj-tp ntrw

shdw stwt.f $m$ prw.f nw hrww

Sei gegrüsst, Re, Stier des Himmels,

Amun, Oberhaupt der Götter,

dessen Strahlen Licht machen bei seinen Auszügen am Tage

b) Zur shm -Prädikation der Sonne s. MDIK 27.1, $25 \mathrm{f}$.

c) S. hierzu und $\mathrm{zu}$ weiteren Stellen Text 187 (t); Corteggia$\mathrm{ni}$, in: Hommages Sauneron I (1979), 127,131(k).

d) sic: m 尔 $\mathrm{nfr}$; "als guter Stern"? Im Hinblick auf den Paralleltext bei Paheri (vgl.n.118) ist vermutlich $z u$ emendieren: $w^{C}$ rjjt $m$ pt $m t 3$

sb3 nfr shdw t $3 w j$

e) hpr zp nfr : vgl. Sinuhe B 160 und dazu W.Westendorf, in: Fs.Schott, 125-131. Die dort vorgeschlagene Bedeutung "Tod" passt freilich hier nicht (cf. auch RdE 30, 30).Eine ähnliche Aussage in Grab 11 (Urk IV 445):

... [dg3].tw.f hpr zp nfr

In der Kollokation mit dem (mir sonst in Hymnen unbekannten) Richter-Titel wd ${ }^{C}$ rjjt kann sich das prädikat hmw nfr, ganz im Sinne der späteren Topik der Persönlichen Frömmigkeit (s. dazu Text 187 [t]), nur auf die lenkende Tätigkeit Gottes im Bereich der Menschenwelt beziehen. So fügt sich auch dieser Beleg trotz seiner höchst ungewöhnlichen Formulierungen in das allgemeine Bild dieser thebanischen Amun-Re-Eulogien ein, die den Aspekt Gottes als Erhalter, Wohltäter und ethische Instanz in den Mittelpunkt stellen.

lor, F.Ll.Griffith, The Tomb of Paheri (1895) Tf.1, wo Verse 3-5 dieses Textes in einem Hymnus, nicht an Amun, sondern an eine Göttin begegnen.

119 Ed.Legrain in:ASAE IV, 182. Zu wd ${ }^{C}$ rjjt s.G.P.F.van den Boorn, in: JNES $42(1983$, im Druck). 
Zwei Kontrast-Beispiele scheinen mit geeignet, den Typus der frühen thebanischen Eulogie von verschiedenen seiten her $\mathrm{zu}$ verdeutlichen. Beides sind Hymnen auf sog. stelophoren statuetten, einer Denkmäler-Gattung, die gleichzeitig mit dieser ersten Blütezeit der Sonnenhymnik und gewiss nicht ohne Beziehung $\mathrm{zu}$ dieser aufkommt ${ }^{120}$. Das Interesse des ersten Textes liegt darin, dass er die Form der Eulogie verlässt zugunsten des Verbalstils der Sonnenlieder, thematisch aber in typischer Weise den Wohltäter-Aspekt Gottes in den Vordergrund stellt: 121

jnd hr.k jrjw jrjjwt

dd mdw hpr ntrw

wbn.k m 3ht nt pt

$h^{c} j t j$ m jrtj rhjjt

dj.k zS $n$ jrt nbt

$n c_{w t}$ nbt jmjt $t 3$

dw3.sn tw $m$ jrt.k [sn]

j3w n.k hr s [hpr.k] st

Sei gegrusst, du Schöpfer des Geschaffenen ${ }^{a}$,

der spricht und es entstehen die Grtter ${ }^{b}$ !

Du gehst auf im Lichtland des Himmels

und bist erschienen in den Augen der Menschheit. ${ }^{C}$

Du gibst freien Weg allem Auge ${ }^{d}$,

und allem Getier auf Erden.

Sie beten dich an, weil du sie geschaffen hast,

Lob dir dafur, dass du sie hervorgebracht hast!

a) Vgl. Stelophor Chicago AHG Nr.81,3; 0., S.163 m.n.66.

b) S.hierzu pkairo 58038, IV, $2(0 ., 176)$ : wd mdw hpr nţrw

c) s.hierzu LL $41 \mathrm{f}$.

d) pKairo 58038, IV,6-7: ddw ž̌ n jrt nbt

e) pKairo 58038, VII,2 - 3 und VII.7 - VIII.1, 0.S.127 Kap.3 $\$ 2.6 \mathrm{~m} \cdot \mathrm{n} \cdot 153-154$.

$120 \mathrm{zu}$ diesem Typus s.Claire Lalouette, Fidèles du Soleil (Fac. des lettres et Sciences humaines de Paris. Groupe d'études égyptologiques I.1963) sowie W.M.Stewart, in: JEA 53(1967) 34-38 mit weiterer Literatur.

121 Kairo JE 11509, nach eigener Abschrift. 
Schon dieser Kurzkommentar durfte mit seinen verweisen auf den Kairener. Amuns-Hymnus die Zugehörigkeit des Textes zur Gruppe der fruhen thebanischen Sonnenhymnen deutlich gemacht haben. Zum ersten Mal stossen wir hier ausserhalb des Kairener Hymnus auf die neuartige Motivation des Hymnus als Dank1 ied des Geschöpfs an den Schöpfer, die dann später im zusammenhang der "neuen Sonnen-Theologie" eine zentrale Rolle spielt (Kap.3\$2.6).

In genauem Gegensatz dazu steht der Text eines Stelophors im British Museum, der aus derselben zeit stammt, aber auf einer anderen Tradition fusst: ${ }^{122}$

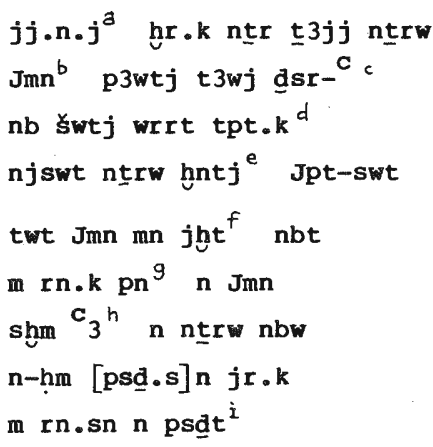

$B=p B e r l$ in $3055,6,3 f f$.

a) B: Pr- ${ }_{3}$ "Pharao". b) om. c) B ins. Jmn-R ${ }^{C}$ d) B: hr tp.k e) B hrj-jb f) B m jht nbt g) B om. h) B: shm tw $r$ i) erg. $\operatorname{nach} B$

Ich bin zu dir gekomen, du Gott, Männlichster der Götter, Amun, Urgott der beiden Länder, der den Arm erhebt, Herr der Doppelfeder und der Wrrt -Krone, die auf dir ist, König der Götter, der Karnak vorsteht.

Du bist Amun, bleibend (im Besitz) aller Dinge

in diesem deinem Namen "Amun",

du grosse Macht aller Götter,

wahrlich, sie können dir nicht den Rücken wenden

in ihrem Namen "Neunheit".

122 BM 1735 ed.I.E.S.Edwards, HT VIII,51 Tf.43; Stewart, in: BIA 5(1965) 
Das Interesse dieses Textes besteht darin, dass er, im Unterschied $z u$ den Amun-Re-Eulogien der Gräber, einen reinen AmunHymnus darstellt, der aus der Tempel-Liturgie von Karnak stammt. P3wtj t3wj $\underline{d} s{ }^{-C}$ bezeichnet als feste Verbindung eine in Karnak verehrte ithyphallische Urgott-Form des Amun als "Männlichster (=Erzeuger) der Götter".123 Ebenso spezifisch auf Kultformen des Amun bezogen sind die Epitheta der kultischen Erscheinungsform nb šwj wrrt tpt.k 124 und die Formel mn jht nbt. 125 Gegenüber diesem Text reiner Amun-Theologie, der sehr wahrscheinlich älter ist als die Gräber-Eulogien, entfalten diese eine komplexere, Amun und Re verbindende Theologie, die in dieser zeit das Neue und Zukunftsträchtige dargestellt hat.

Auf ein drittes Kontrast-Beispiel sei nur en passant verwiesen: Text 240 ( $\not H G$ Nr.25) im Grabe des Senenmut. Auch dieser Text benutzt zwar die äussere Form der Eulogie, stammt aber aus einer anderen Tradition: aus den "Mysterien" des Sonnenkults.

\section{Zusammenfassung}

Die Eulogien an Amun-Re treten in der Frühphase der thebanischen Sonnenhymnik in einer solchen Dichte auf, dass man nicht nur von Anfängen, sondern zugleich auch von einer Blüte der Amun-Re-Verehrung sprechen darf. Die grosse Verwandtschaft der Texte untereinander, ihre verwendung derselben Phraseologie und desselben Textplans, lässt darauf schliessen, dass sie den Widerhall eines theologischen Diskurses ${ }^{126}$

67: Paralleltexte: pBerlin 3055,6,3ff; Hayes, Ostraca and Name-Stones, Nr.48-49. AHG Nr.119.

$123 \mathrm{~J} . \mathrm{C}$. Goyon, in: R.Parker et al., The Edifice of Taharqa, $59 \mathrm{n} .53$.

124 S.LL 173 n.20.

125 S.Text 134 (b) .

126 Der Begriff des "Diskurses", den ich von der französischen Philosophie (M.Foucault) übernehme, scheint mir geeignet, eine Tradition sprachlicher Verständigung über und Auseinandersetzung mit einem ausgegrenzten Bereich menschlicher Praxis zu bezeichnen, für die Termini wie "Gattung" " "Textsorte" u.ä. zu kurz greifen. Eine gewisse Nähe meines Begriffs von "Diskurs" sehe ich zu dem von A.Jolles geprägten Begriff "Geistesbeschäftigung" . 
darstellen, der in der damaligen Zeit in Blüte stand und in Hymnentexten Verbreitung fand. Eine Sammlung dieser Hymnen ist uns im pKairo 58038 erhalten. Das Aufkommen eines solchen Diskurses und die Intensität und Breite (vgl. die Beispiele aus This und El-Kab) seines widerhalls im funerären Bereich passt gut zu der Politik religiöser Restauration, die man mit dem Namen der Königin Hatschepsut verbindet. ${ }^{127}$ Auch sie legt in ihren Inschriften ein religiöses Engagement an den Tag, das in mancher Hinsicht an Ramses III. erinnert. Thutmosis III. ist ihr hierin gefolgt. Zweifellos haben wir in dem emphatischen Bekenntnis $z u$ Amun-Re etwas von dem Zeitgeist jener Epoche vor uns. Allein die Existenz und Verbreitung der Eulogien, die Tatsache als solche, dass man die traditionelle opferformel im Falle Amun-Res zu einem Gotteslob erweitert, legt diesen Schluss nahe.

Wir haben hier, so scheint mir, ein literarisches Phänomen vor uns, das sich mit in gewissem sinne "propagandistischen" Erscheinungen der Literatur des Mittleren Reichs ${ }^{12} 8$ und der Amarna-zeit ${ }^{129}$ vergleichen lässt. Bei diesem propagandistischen Element denke ich weniger an die betonte Herausstellung der Herrschaft, des primats des Gottes und seiner Einzigartigkeit in der Götterwelt, denn diese henotheistische Perspektive gehört in gewissem sinne zum Gattungsstil der Eulogie. Auffallender erscheint mir vielmehr die Herausstellung der Güte Gottes als "Wohltäter", "Hirte" und "ethische Instanz", die auf dem Königsbild des Mittleren Reichs aufbaut. 130 Ebenso wie die Literatur des Mittleren Reichs der Verbreitung dieses Königsbildes dient, wollen Hymnen wie die des pKairo 58038 dieses Gottesbild im Volk verbreiten. Diese

127 S.hierzu S.Ratié, La reine Hatchepsout. Sources et problèmes (Orientalia Monspeliensia I, 1979), besonders 318-327. Das Phänomen verdient eine wesentlich ausführlichere und differenziertere würdigung.

128 S.hierzu G.Posener, Littérature et politique dans l'Egypte de la XII.e Dynastie (1956).

129 S.SAK $8(1980), 1-32$, bes.11-19.

130 E.Blumenthal, Untersuchungen zum Königtum des Mittleren Reiches, Bd.I: Die Phraseologie (ASAW 61.1,1970); Posener, a.a.O. (n.128); D. Müller, "Der gute Hirte", in: ZAS $86(1961) 126 \mathrm{ff.,} \mathrm{s.a.} \mathrm{Kap.5.}$ 
"Werbung" für den zum "Reichsgott"131 erhobenen Gott Thebens und der regierenden Dynastie hat zweifellos einen politischen Aspekt. Gerade die Gräbertexte zeigen aber, dass hinter dem literarischen Phänomen eine "Bewegung" von mehr als nur offiziellem Charakter steht. Der Inhalt dieser Texte macht es sicher, dass hier eine erste Welle "Persönlicher Frömmigkeit" vorliegt. Dieser Begriff war für den Ägypter gar nicht eindeutiger formulierbar als in der Wendung von Text 165: "Vater und Mutter für den, der ihn in sein Herz gibt". Die Entdekkung Poseners, dass eine Gruppe von Gebetsostraka der Persönlichen Frömmigkeit aus dieser Frühzeit stammt ${ }^{132}$, erhebt diese Deutung des Befundes zur Gewissheit.

Die Intention werbender Verkündigung der Grösse und Güte Gottes kommt in einer Formel sogar expressis verbis zum Ausdruck, die im Schlusstext einiger Hymnen dieser zeit vorkommt: sw3̌̌.j mrwt.k ht t3 "ich will die Liebe zu dir durch das Land hin verbreiten". ${ }^{133}$ "Eine Stelophoreninschrift aus Herakleopolis ist noch expliziter: 134

Ich will dich anbeten und die Götter hören lassen

und die Menschheit wissen lassen von deiner Schönheit

täglich für alle Tage

Solche Aussagen werfen ein Licht auf das Selbstverständnis der Gattung hymnenbeschrifteter Stelophoren und Grabeingänge als einer Institution verkündenden Gotteslobes. Wir treffen sie in späterer zeit wieder an im Rahmen einer anderen Institution, der Tempelstatue, die sich ganz ausdrücklich als Mittler zwischen Mensch und Gott versteht: 135

Ich will deine Grösse versammeln in den Gesichtern, o Herr der Götter, ich will deine Wohltaten und deine wirksamkeit der Menschheit

erzählen!

131 Zum Begriff des "Reichsgottes" als Institution s. "Primat und Transzendenz" , 17-27.

132 RdE 27 (1975) 195-210.

133 Text 67; 200 (Stelophor); Theban Necropolis Tf.XVII (Stelophor) vgl. pKairo 58038; V,6: mrwt.k ž.tj ht t3wj; TT 11 Urk IV $444 f:$ sms.j k3.k sw3s.j mrwt.k.

134 Petrie, Sedment II,49.

135 Kairo CG 42208. 
Die entsprechenden Formeln im Bereich der dritten Institution verkündenden Gotteslobes, der Persönlichen Frömmigkeit, sind wohlbekannt. ${ }^{136}$ Ich zitiere nur ein Beispiel aus dem Bereich der frühen, unseren Texten zeitgenössischen, Gebetsostra$\mathrm{ka}: 137$

Ich will von deiner Macht allen Gesichtern erzählen,

denn ich habe deine Macht (?) gesehen.

Ich will dich erhöhen, dir Lobpreis spenden ...

Dieselbe Verkündigungstopik ist auch in den Inschriften der Hatschepsut reich vertreten. 138

Die eulogische Form, deren hohes Alter durch die Hymnen des $M^{139}$ und gewisse Ansätze in den Pyramidentexten ${ }^{140}$ erwiesen ist, - sicherlich die allgemeinste und ursprünglichste Form des Gotteslobs in Agypten, der gegenüber das verbale Sonnenlied eine Besonderheit darstellt - spielt auch nach dieser ersten Periode, die von Hatschepsut bis Amenophis II. reicht, eine bedeutende Rolle in der thebanischen Sonnenhymnik. Sie kommt vor

1.) in erweiterten Opferformeln und ähnlichen "Gottestitulaturen"

2.) in Hymnen eulogischer Form ${ }^{141}$

3.) in eulogischen Abschnitten formal komplexerer Hymnen 142

Nur auf einige Beispiele von (1) sei hier abschliessend noch ein Blick geworfen.

Opferformeln, die den Gottesnamen um eulogische Prädikate erweitern, sind sehr viel häufiger, als es unsere Hymnen-Samm-

$136 \mathrm{Vgl}$. H.Brunner, in Gs Otto (1977) 119-124 sowie SAK 8(1980),6-8.

$137 \mathrm{RdE} 27,209$ : oCairo 12189.

$138 \mathrm{Vgl}$. Urk IV, 349,7;350.17;51.7;480;390. Schon Thutmosis I: Urk IV 271.

139 Selim Hassan, Hymnes religieux du Moyen Empire (1930).

$140 \mathrm{~J}$. Ste.Fare Garnot, L'hommage aux dieux sous l'Ancien Empire d' après les Textes des Pyramides (1953).

141 Z.B. Text 181, dessen "Kreuzwort"-Struktur durch die lockere Fügung appositionell aneinandergereihter nominaler syntagmen begúnstigt, wenn nicht geradezu erst ermöglicht wird.

142 Z.B. das zweite Lied des Suti-Hor-Hymnus AHG $\mathrm{Nr} \cdot 89,31-60$. 
lung (STG) erkennen lässt; wir haben nur wenige, bis zu hymnenartigen stücken ausgebaute Beispiele aufgenommen. Gottestitulaturen dieser Art kommen auch keineswegs nur in Bezug auf Amun-Re und den Sonnengott vor. ${ }^{143}$ Beispiele wie Text 184 aus der zeit Amenophis'III., Texte 23 und 258 aus der 19. und Texte 94-95 aus der 20. Dyn., die sich beliebig vermehren liessen, mögen das Fortleben der Tradition bezeugen. Sie zeigen, dass sich um die Gottesnamen feste Gottestitulaturen herausgebildet haben, die sich immer derselben Formeln bedienen. Als Beispiel sei eine nicht in unsere sammlung aufgenommene Gottestitulatur aus der Beischrift zur Festszene in Grab 65 aufgeführt: 144

dd mdw jn $J m n-R^{c} w$

nb nst t3wj hntj Jpt-swt

k3-mwt.f hrj-tp psdt

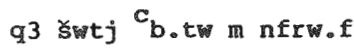

Jtmw hantj jpt.f

$c_{3} h^{c}$ w m hat-sr

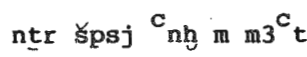

p3wtj hpr m hat

shadw t3wj In stwt.f

b3 rpsj prjw m Nnw

ntrr ${ }^{C_{3}}$ njswt ntrw

$\mathrm{Zu}$ sprechen von Amun-Re,

Herr von Theben, Erster von Karnak,

Kamutef, Oberhaupt der Neunheit,

mit hoher Doppelfeder, dessen Schönheit man sich rühmt ${ }^{145}$

Atum, der seinem Heiligtum vorsteht ${ }^{146}$,

gross an Erscheinung im Fürstenhaus. ${ }^{147}$

$143 \mathrm{Vgl.z.B}$. entsprechende Eulogien dieser zeit an Osiris: Urk IV 543f., $544 \mathrm{f}$.

144 TT $65(8)-(9)$, nach eigener Abschrift.

145 Id. Text 241,7 .

$146 \mathrm{Vgl.Text} 181$ a,3; pKairo 58038, IX,2; Barguet, Le temple d'Amon-Re à Karnak, 150,202,215.

$147 \mathrm{Vgl}$. Texte 22,60 ( hiwt B3 statt hat sr). 
Erlauchter Gott, der von der Maat lebt, Urgott, der am Anbeginn entstand: 148

der die beiden Länder erhellt mit seinen Strahlen;

erlauchter $\mathrm{Ba}$, der aus dem urwasser kommt ${ }^{149}$,

Grosser Gott, König der Gotter.

Eine besonders interessante Erscheinung stellen die eulogisch erweiterten Opferformeln des Grabes des Nebwenenef (TT 157) dar. ${ }^{150}$ Man wird dieses Phänomen nicht von der Tatsache trennen können, dass der Grabherr Hoherpriester des Amun war. Was er in seinen Opferformeln zum Ausdruck bringt, ist theologisches Wissen. 151 Die Eulogie ist die sprachliche Ausdrucksform theologischer Arbeit. Gegenstand dieser Arbeit und Thema der Eulogie ist die Wesensbestimmung der Gottheit. Das geschieht nicht ein fur allemal, sondern wird immer wieder neu in Angriff genommen. Das letzte Stuck dieser langen Reihe elaborierter Wesensbestimmungen des Amun-Re ist die Gottestitulatur in den "Dekreten" der 21. Dynastie. "152 In der Geschichte dieser Form scheint die Nachamarnazeit, d.h. die religiöse Restauration, zu deren führenden köpfen man auch den Hohepriester Nebwenenef noch rechnen muss ${ }^{153}$, eine besondere Rolle zu spielen. Durch den Schock des Umsturzes von Amarna sah sich die Amun-Re-Religion herausgefordert, das wesen des Gottes genauer $z u$ bestimmen. Die Gottestitulatur hat insofern

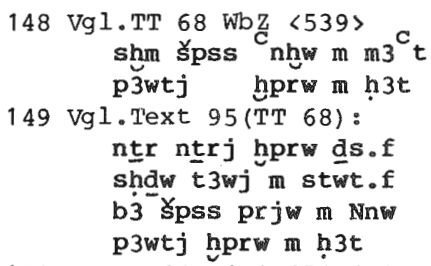

VgI. zu dieser gerade in Hohepriesterkreisen verbreiteten Topik "Weisheit, Loyalismus und Frommigkeit", 18-19.

152 AHG Nr.131 u.a., s.n.154.

153 Seine Einsetzung zum Hohepriester gehörte zu den ersten Regierungsmassnahmen Ramses'II. Der Text jetzt bei kitchen, RI III $282 \mathrm{ff}$. 
den Charakter eines "Credo" oder "Symbolon"154 als sie die Identität des Gottes genau festlegt. Der Name allein genügt nicht, weil er das umfassende Wesen der Gottheit nicht zum Ausdruck bringt. Der Name steht neben anderen Namen, die theologische Wesensaussage aber zielt auf eine alles umfassende und einschliessende Ganzheit.

Diesen Charakter eines "Symbolon" legt auch ein Typus von Gottestitulaturen an den Tag, der in den Gräbern von Der elMedine seit der Nachamarnazeit verbreitet ist: ${ }^{155}$

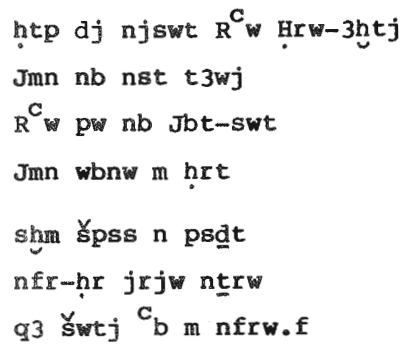

Das theologische Anliegen dieser Gottestitulaturen, das Problem der komplexen Identität von Amun und Re, manifestiert sich am klarsten in der chiastischen Verschränkung der verse 3 und $4:^{156}$

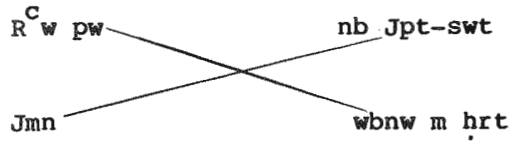

Theologische Gelehrsamkeit ist aber nur ein spezialfall des allgemeinen Ideals eines Wissens von Gott, das in der Form einer ganz untheologischen "Gottesbeherzigung" in den Inschriften des NR eine so grosse Rolle spielt. ${ }^{157}$ Allgemein lässt sich sagen, dass die Eulogie als Wesensbestimmung der Gottheit die geeignete Form ist, ein wissen von Gott darzustellen, die Form dessen, der "Gott in sein Herz gegeben hat" und im eulogischen Lob "seine Macht verkündet".

154 "Das Credo der Amun-Religion" nannte E.Meyer, in Gottesstaat, Militärherrschaft und Ständewesen (SPAW 1928) den Text AHG Nr.131.

$155 \mathrm{LL}, 330 \mathrm{f}$. n.73, vgl. Texte $241,241 \mathrm{a}, 242$.

156 Eigentlich gehören zusammen: Imn nb Ipt-swt und $R^{C}$ w whw m hrt vgl. $L L, a . a .0$.

157 S."Weisheit, Loyalismus und Frömigkeit", passim. 
Fünftes Kapitel

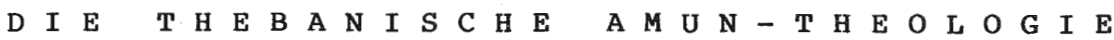

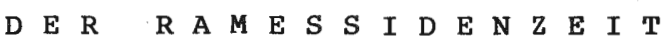

\section{Vorbemerkungen}

Die Theologie, von der in diesem Kapitel die Rede sein soll, stellt einen religiösen Entwurf dar, der an Neuartigkeit und Geschlossenheit der Amarna-Religion kaum nachsteht. Im Gegensatz $z$ dieser ist jedoch die wissenschaft seiner bisher nur in Teilaspekten ansichtig geworden, deren auffälligster vielleicht durch die unter dem stichwort der "Persönlichen Frömmigkeit" zusammengefassten phänomene repräsentiert wird. ${ }^{1}$ Das hat seinen Grund darin, dass diese neue Theologie nicht, wie die Amarna-Religion, mit Gewalt, in der Form einer "Revolution von oben", und unter militanter Ausschliessung anderer religiöser formen eingeführt wurde, sodass sich das Neue gegenuber dem Alten scharf absetzt und leicht als solches $\mathrm{zu}$ erkennen ist. Diese Theologie stellt vielmehr einen neuen Zusammenhang dar, in den das Alte gebracht wird und der erst im Laufe vieler Jahrzehnte aufgefunden und immer deutlicher zum Ausdruck gebracht wird. Wir haben es mit einem strukturwandel der alten Religion zu tun, der sich nicht nur allmählich, sondern auch unter Beibehaltung der traditionellen Ausdrucksformen vollzieht, sodass das Neue oft gar nicht am einzelnen neuartigen Ausdruck zu erkennen ist, sondern nur an der neuartigen Konfiguration traditioneller Motive. Wer nur aufs Einzelne blickt, dem wird die nachfolgende Interpretation der Befunde willkürlich erscheinen. Im Vergleich zu der Tragweite und Grundsätzlichkeit der postulierten Wandlung wird er die unterschiede auf der Oberfläche zwischen dem Alten und dem Neuen furr verhältnismässig unauffällig halten. Da-

1 So nannte J.H.Breasted die Ramessidenzeit "the age of Personal Piety" (in: Development of Religion and Thought, 1912,344ff.), erblickte also in diesem Aspekt den charakteristischsten Ausdruck der Epoche. 
her erscheint es mir unerlässlich, vorab einige derjenigen Motive und Merkmale zusammenzustellen, an denen sich mir die neue Theologie am eindeutigsten $z u$ erkennen gibt. Das sind 1. die Betonung von Einzigkeit und Verborgenheit des Gottes,

2. die Prädikation des Gottes als "Ba" in Verbindung mit dem Gedanken der Verborgenheit, 3. die Formel des "Einen, der sich zu Milionen macht" mit allen ihren Varianten, 4. die Vorstellung des der Welt als $\mathrm{Ba}$, Bild und Leib einwohnenden Gottes, der sich die Welt für diese drei Konstituenten seiner Person als Himmel, Erde und Unterwelt geschaffen hat, 5. die Lehre von den "lebenspendenden EJementen", d.h. die Vorstellung, dass Gott die Welt nicht nur durch, sondern als Licht, Luft und wasser erhält und belebt, 6 . die Idee luftartiger All-Durchdringung, wie sie sich in der Formel (Jmn) mnw $m$ jht nbt "der bleibt in allen Dingen" äussert, 7. die Rolle dieses Gottes als Zeit- und Schicksalsgott in Verbindung mit 8 . seinem personalen Aspekt einer "ethischen Instanz". Jedes einzelne dieser 8 Motive hat seine z.T. weit zurückreichende Vorgeschichte. Zum Gedanken der "Einzigkeit" Gottes vergleiche man die Bedeutung dieser Vorstellung sowohl in der "neuen Sonnentheologie" (Kap.3, $\$ 2.1$ ) als auch in der älteren Amun-ReTheologie (Kap.4), zur Ba-Prädikation die älteren Re-HarachteEulogien (Kap.4, $\$ 1.2$ ), die den Sonnengott b3 $\mathrm{C}_{\mathrm{nh}}$ "lebender $\mathrm{Ba}$ " nennen, zur "Einer-Millionen-Formel" die Vorstufen in der Amarna-Religion und sogar in den Sargtexten (STG, Text $149 \mathrm{c})^{2}$, zur Vorstellung Gottes als Ba, Bild und Leib die Konzeption der Unterweltsfahrt der Sonne als einer nächtlichen Vereinigung von $\mathrm{Ba}$ und Leichnam des Gottes (Kap.2), zur Lehre von den lebenspendenden Elementen ältere Ausprägungen des Begriffs eines "Lebens-Gottes", zur als (6.) genannten Formel deren ältere Form ohne m ( Jmn mn jht nbt, s.STG zu Text 134), zur Funktion des zeitgottes die in Kap.3, $\$ 3.2$ dargestellte Beziehung des Sonnengottes zu der von ihm "hervorgebrachten" zeit und zum Aspekt Gottes als "ethische Instanz" schliesslich unsere Analyse von Abschnitt C des pKairo 58038

2 Diesen Traditionszusammenhang hat zuerst Otto, in: FuF 35.9(1961)278f. aufgezeigt. 
(AHG Nr.87), Kap.4, $\$ 3$. Jedes einzelne dieser Motive ändert seine Bedeutung in dem neuen Zusammenhang, in den es im zuge der sich im 13.Jh.V.Chr. allmählich herauskristallisierenden Theologie des Amun-Re als eines personalen weltgottes gexät. Diesen Zusammenhang möchte ich in den folgenden Abschnitten in seinen charakteristischsten Aspekten aufzeigen.

\section{Einzigkeit und Verborgenheit}

w ${ }^{C}$ Jmn jmnw jr.sn - "Einzig ist Amun, indem er vor ihnen verborgen ist": dieser Satz aus dem "200." Lied der Leidener Amun-Hymnen, das wir unten in extenso betraciten wollen, bringt die traditionellen Themen der Einzigkeit und der Verborgenheit Gottes in einen Zusammenhang, der neuartig ist.

\subsection{Einzigkeit}

Immer wieder prädizieren die ägyptischen Quellen einem Gotte Einzigkeit. Wir sind diesem prädikat im Rahmen unserer Untersuchung in zwei verschiedenen Zusammenhängen begegnet:

1. In der "Neuen Sonnentheologie", wo die Lehre von der Einzigkeit Gottes die theologische Ausdeutung des natürlichen Phänomens der "Einsamkeit" darstellt, in der die Sonne ihre ferne und verborgene Bahn über den Himmel zieht, und

2.in der Theologie des "Lebens-Gottes", wie sie im pkairo 58038, und zwar ganz besonders im Abschnitt $E$, ausgebreitet wird, wo Amun-Re als die eine Quelle des Lebens für Götter, Menschen und Tiere gepriesen wird.

Im Kairener Papyrus geht es ebenfalls un die Sonne. Der "Lebensgott" Amun-Re wird als ein Sonnengott aufgefasst, der seine all-belebende Wirksamkeit in Gestalt der sonne entfaltet. Die NeuefSonnen-Theologie deutet den Sonnenlauf theologisch als das belebende und erhaltende Handeln des Sonnengottes an der Welt. Daraus ergeben sich zahlreiche Ubereinstimmungen zwischen den beiden konzeptionen. Trotzdem empfiehlt es sich, hier sorgfältig zu unterscheiden. Im Zusammenhang der Amun-ReTheologie richtet sich der einheitsstiftende, "zentralisierende" Blick auf die Problematik des Lebens und gibt eine Antwort auf die Erage, woher alles Leben stammt und welche Kräf- 
te bei der Entstehung, Erhaltung und Bewahrung des Lebens wirksam sind, im zusammenhang der Neuen Theologie dagegen stehen die kosmischen Vorgänge des Sonnenlaufs im Blick. Sie postuliert ihre Erkenntnis von der Einsamkeit und Einzigkeit der Sonne in polemischer Antithese zu der herkömmlichen Anschauung, nach der sich der sonnenlauf in den wechselnden Konstellationen einer um den Sonnengott gruppierten personalen "Sphäre des Seinigen" vollzieht.

In beiden theologischen zusammenhängen schliesst, wie wir gesehen haben, das postulat von der Einzigkeit Gottes die Existenz der anderen Götter nicht aus. Abqesehen von Amarna ist in den Texten durchaus immer wieder von den Göttern die Rede. Sie treten aber nicht einzeln mit ihren Eigennamen auf, sondern nur als Kollektiv. Dadurch treten sie nicht in eine Konstellation ein mit dem "Einzigen Gott", sondern werden ihm gegenübergestellt, in eine Reihe mit den anderen Lebewesen: Menschen, Tieren, ja Pflanzen. In allen zusammenhängen, in denen von der Einzigkeit Gottes die Rede ist, geht es um dieses Heraustreten eines. Gottes aus den Konstellationen und Dimensionen der Götterwelt. Dieses Phänomen hat bekanntlich immer wieder dazu verführt, die polytheistische struktur der ägyptischen Religion als eine Art Façade zu verstehen, hinter der es im Grunde immer um einen Monotheismus gegangen sei. Erik Hornung hat alle diese Versuche ebenso gründlich referiert wie widerlegt, sodass wir hier auf das einzelne nicht eingehen müssen. ${ }^{3}$ Seine Reduktion dieser Einzigkeit auf den Begriff der Einzigartigkeit, die jedem Gott als solchem zukomme und dem ägyptischen Gottesbegriff inhärent sei, geht jedoch m.E. in jenen Fällen zu weit, die wir in unserer untersuchung behandelt haben und wird auch den verwandten Erscheinungen nicht gerecht, die E.Otto 1955 in einem bahnbrechenden, die ganze festgefahrene Monotheismus-Debatte auf eine neue Ebene führenden Aufsatz unter dem vielleicht irreführenden Begriff "monotheistischer Tendenzen" zusammengefasst hatte. 4 Otto

3 Der Eine und die vielen (Darmstadt 1971) 3-17; 32-49, 180-191, 227-233. 4 In: Wdo 2(1955) 99-110. 
ging es in diesem Aufsatz durchaus nicht darum, den ägyptischen Polytheismus als blosse Façade zu desavouieren. In voller Anerkennung der Tatsache, dass sich dem Agypter die Wirklichkeit, als deren geistigen Ausdruck er die ägyptische Götterwelt versteht ${ }^{5}$, als eine Vielheit darstellt, fragt er nach denjenigen Ebenen der Wirklichkeits-Erfahrung und -Konstitution, auf denen in auffälliger Weise der Aspekt der Einheit hervortritt und der Blick des Agypters in einer unverkennbar "zentralisierenden", die Vielfalt der Erscheinungen auf Eine Gestalt hin zusammensehenden Weise auf die Wirklichkeit gerichtet ist. Er nennt vier solcher Aspekte, die er paarweise anordnet: ${ }^{6}$

der Herrschergott und der Schöpfergott

der Gott im Menschen und der Gott der Ethik.

Mit diesen Aspekten sind vier Ebenen bezeichnet, auf denen das Göttliche in einer einzigen -und nicht nur einzigartigenGestalt erfahren wird. Jede Ausprägung ägyptischer schöpfungstheologie rechnet mit einem einzigen schöpfer und die weisheit, die das Göttliche im Horizont der conditio humana behandelt, spricht nur von "Gott" ". Die Lehre vom "Gott im Menschen" scheint mir sich zum Teil mit dem Gott der Ethik zu decken, zum anderen Teil in einen ganz anderen Zusammenhang zu gehören, sodass ich sie hier ausklammern möchte. Den "Herrschergott" jedoch, den ich, anders als otto, nicht auf den König, sondern auf die Institution des im König zur Erscheinung kommenden, vom König repräsentierten und ihm als Vater übergeordneten "Reichsgottes" beziehen möchte ${ }^{8}$, wird man zu den ursprünglichen Ausdrucksformen jener Einheitserfahrung rechnen, die sich in diesem Falle auf die politische sphäre bezieht. In derselben Weise, wie in der "Einzigkeit" des Schöpfergottes die Anschauung einer kosmischen Einheit zum Ausdruck

5 A.a.O., 99 bezeichnet er die "Gestaltenfülle" der äg. Götterwelt als "Bauelemente der Theologie und des in religiösen Formen gebundenen Welterfassungswillens", das "Rohmaterial" der "Göttersysteme, die ein umfassendes Weltbild spekulierend repräsentieren".

6 A.a.O., 100 .

7 Hornung, a.a.O., 32-49; W.Barta, in: ZAS 103(1976)79-88; L\& II 771-774.

8 S. hierzu "Primat und Transzendenz", 17-27. 
kommt, die Vorstellung, dass die Welt in ihrer Vielfalt und Differeziertheit aus einem Ursprung hervorgegangen oder nach einem Plan entworfen ist, so drückt sich im Begriff der Einzigkeit des Reichs- oder Herrschergottes die Vorstellung von der Einheit der menschlichen Gesellschaft aus.

Wenn man die von Otto behandelten Befunde mit dem verbindet, was sich aus der Analyse unseres Materials ergeben hat, so erhält man folgende sechs Aspekte, in denen sich das Göttliche in besonderer Weise als Einheit darstellt:

Urgott - Schöpfergott - Lebensgott

Sonnengott - Herrschergott - Ethische Instanz

Diese Aspekte treten im zusammenhang einer konkreten Theologie nie einzeln auf (es gibt wohl keinen Gott, der nur Schöpfergott oder nur Urgott usw. wäre), aber immer in verschiedener Konfiguration und Gewichtung. Der Gott der Amarna-Religion z.B. ist weder "Urgott", noch "ethische Instanz". Die thebanische Amun-Re-Theologie der Ramessidenzeit unterscheidet sich nun dadurch von ihren Vorgängern, dass sie für ihren Gottesbegriff nicht nur alle sechs Erscheinungsformen der Einzigkeit Gottes in Anspruch nimmt, sondern diesen noch eine siebente hinzufügt: das ist die Einzigkeit des deus absconditus. Die Einzigkeit Amuns, in der, um es noch einmal zu sagen, die Existenz der anderen Götter in keiner weise geleugnet wird, beruht darauf, dass er

1. der Urgott ist, der vor aller Welt war

2. der Schöpfer, der die Welt aus dem Urzustand in den Kosmos verwandelt hat

3. der Lebensgott, der die Welt in Gestalt der drei lebenspendenden Elemente belebt, beseelt und erhält

4. der Sonnengott, der seinen Lauf allein vollbringt und mit seinem Blick die welt erleuchtet und bewacht,

5. der Herrschergott, der die Herrschaft über seine Schöpfung ausübt und von den irdischen königen repräsentiert wird ${ }^{9}$

9 Auf die Rolle Amuns als König werde ich in diesem Kapitel nicht eingehen, weil dieser Aspekt der ramessidischen Amun-Re-Theologie durch J. $\mathrm{Z}$ andee, in: Numen 3(1956) 230-234; Suppl. to Numen 31(1975) 167-168 ausführlich behandelt wurde; s.auch LA II, 774 . 
6. die ethische Instanz, die über Recht und Unrecht wacht, der "Wesir des Armen"10, der Herr über Zeit, "Gunst" 11 und Schicksal

7. der verborgene Gott, dessen Symbole, Abbilder, Namen die vielen Götter sind.

\subsection{Verborgenheit}

Die Eigenschaften des Geheimen, Abgesonderten, Unzugänglichen, Unergründlichen gehören zu einem Begriff des Heiligen, den man als eine anthropologische Universalie betrachten darf. Agypten macht da nicht nur keine Ausnahme, ihm wird sogar, und mit vollem Recht, ein "eigener sinn für das Geheimnis in der Religion" zugestanden. ${ }^{12}$ Daher beziehen sich die wörter, in denen im Agyptischen der Begriff des Verborgenen in einer besonders reichen Ausdifferenzierung zum Ausdruck kommt, ursprünglich und in erster Linie auf den Begriff des Heiligen: št3 "geheim, unzugänglich, schwierig", dsc "abgesondert"13, jmn "verborgen", spss "erlaucht, erhaben", h3p "verhüllt" u.a.m. 14 Die dem Heiligen eigene verborgenheit findet ihren Ausdruck in der Geheimhaltung und Abgeschirmtheit des Kultbildes im Allerheiligsten:

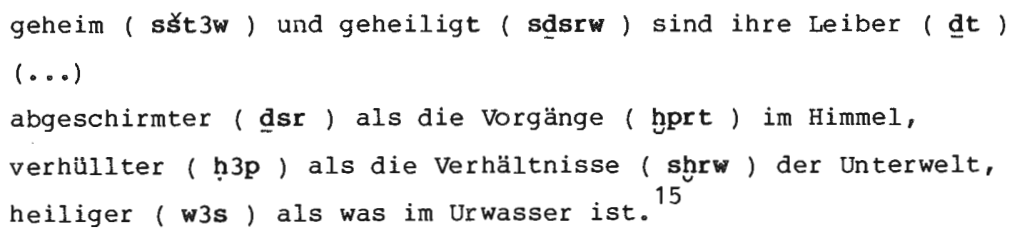

10 Posener, in: Fs Ricke (1971) 59-63.

11 Zeit und Ewigkeit, 60-64; "Weisheit, Loyalismus und Frömmigkeit", 31.

12 Leipoldt-Morenz, Heilige Schriften, 88.

13 S. hierzu Morenz, Agyptische Religion, 105f.

14 Früher hat man diese Komponente des äg. Heiligkeits-Begriffs oft verkannt und wörter wie dsr und spss gern mit Ausdrulcken entgegengesetzter Bedeutung wie "prächtig" usw. wiedergegeben. Dass auch కpss die Konnotation des Verborgenen hat, geht aus Stellen hervor wie Text 87 , 10 von Imn-rn.f: Sspss sw r rmtw ntrw 3hw mwtw "der sich šps gemacht hat gegenuber Menschen und Göttern, Verklärten und Toten."

15 Urk IV 99 cf Mariette, Abydos II 31. 
Sie findet ihren Ausdruck in der Geheimhaltung der Riten ${ }^{16}$, in den Einweihungs- und Reinigungsvorschriften der Priester $^{17}$ und in der Tempelarchitektur, deren Entwicklung bis zur Spätzeit ein gewaltiges Anwachsen der Bedeutung erkennen lässt, die diesem Aspekt des Heiligen in der ägyptischen Religionsgeschichte zukommt. In der spätzeit ist das Allerheiligste der Tempel von mehreren "Mänteln" umgeben, die es gegen die profane Aussenwelt abschirmen. ${ }^{18}$ Die Enthüllung der Kultgeheimnisse würde, nach zeitgenössischer Anschauung, eine kosmische Katastrophe auslösen. ${ }^{19}$

Mit denselben Begriffen, die die Verborgenheit des Heiligen beschreiben, wird nun auch die Verborgenheit bestimmter kosmischer Bereiche zum Ausdruck gebracht, die sich zum oberirdischen Diesseits genauso verhalten, wie das Heilige zum Profanen: Himmel und Unterwelt. Im Unterschied zu jener Verborgenheit, die allgemein im Begriff des Heiligen liegt, verbindet sich nun die spezifische Verborgenheit des Himmels und der Unterwelt in besonderer Weise mit den Gottheiten, die diese Bereiche beherrschen: mit dem Sonnengott und mit osiris. Das tiefste Geheimnis ist die mitternächtliche Vereinigung der beiden Götter, die sowohl als Vereinigung von "Ba" und Leichnam dargestellt wird - auf diesen "Leichnam" des Sonnengottes nehmen die Texte mit dem Wort sšt3w als auf den Inbegriff eines geheiligten Mysteriums Bezug - als auch als Vereinigung beider Götter $z u$ einem "Vereinigten Ba" ( b3 dmdw ). 20

Ein dritter Begriff von Verborgenheit verbindet sich mit der Gestalt des "selbst-entstandenen" Urgottes, der aufgrund seiner Autogenese keine Eltern, keine Zeugen seiner Entstehung und keine Mitwisser seines Namens hat. Die "Anonymität" dieses Gottes ist sicher der älteste und hervorstechendste

16 Vgl. P.Barguet, Le pap.Louvre 3176,24 m.A. 9; LL 19f. m.n.3 und sehr oft sonst.

$17 \mathrm{Vgl}$. die Hinweise bei Morenz, Ägyptische Religion, $106 \mathrm{ff}$.

$18 \mathrm{Vgl}$. F.Daumas, in: C.Vandersleyen, Propyläen-Kunstgeschichte 15(1975) 197.

19 Urk VI, 122ff.; ähnlich Jamblichus, De mysteriis.

$20 \mathrm{Cf}$. Hornung, Der Eine und die Vielen, 85-87. 
Zug seiner Verborgenheit ${ }^{21}$ : als

der Grosse Gott, dessen Name nicht gekannt wird

erscheint er bereits in den Pyramidentexten. ${ }^{22}$ Dieser Gottesbegriff erscheint möglicherweise von Anfang an, ganz sicher jedenfalls in den uns interessierenden Epochen des Neuen Reichs, im Zusammenhang der Theologie des Sonnengottes. Wenn in Totentexten $z \cdot B$. von Opfergaben auf dem Altar des Jmnrn.f, des "Gottes, der seinen Namen verborgen hält", die Rede ist, dann sind die opfer des sonnengottes in Heliopolis gemeint. 23 Der bekannte, in der Form eines Zauberspruchs uber1 ieferte Mythos von der List der Isis gibt dieser Vorstellung vom Sonnengott als "anonymem" Urgott jene inkonsistente und teilweise burleske Form, wie sie dem mythologischen Erzählungen der Agypter eigen ist. ${ }^{24}$ Von der Sonnentheologie ist dieser auf der Zeugenlosigkeit seines ursprungs beruhende Begriff eines anonymen Gottes dann in die Amun-Re-Theologie der Ramessidenzeit übernommen worden; einmal sicher aufgrund des sich anbietenden Wortspiels - Jmn, Jmn.rn.f - , vor allem aber sicher deswegen, weil dieser Begriff von Verborgenheit, im Unterschied zu allen anderen, per definitionem mit dem Begriff der Einzigkeit verbunden ist:

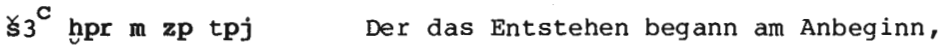

Jmn hprw m h3t nn rh Amun, der am Anfang entstand, dessen Ursprung

$$
\text { bs.f man nicht kennt }
$$

nn hpr nțr nb hr-ḥt.f vor dem kein Gott entstand,

nn kjj nțr hn ${ }^{C}$.f da.f Mit dem kein Gott zusammen war, der seine

$q \mathbf{q j} \cdot \mathbf{f}$

Gestalt sagen könnte.

$21 \mathrm{Zu}$ Imn-rn.f s. Text $87(\mathrm{k})$ und $253(\mathrm{~m})$.

22 Pyr 276c=CT VI $162 \mathrm{n}-\mathrm{p}$, vgl. ferner CT II 154d; 221e; IV 70b; II 157a (Plural). št3 rn: CT VI $389 \mathrm{i}-\mathrm{k}$.

23 Z.B. pBerlin 3050, VI, 2-3: "Gib, dass Pharao die Opfergaben empfängt im Benben-Haus auf dem Altar des Imn-rn.f ."

24 Ühersetzung und Literatur bei E.Brunner-Traut, Altägyptische Märchen $\left({ }^{4} 1976\right), 115-120$. 
nn wn mwt.f jjrjj.n.s

rn.f

nn jtj.f stj sw ddw

jnk pw

nbjw swht.f ds.f

shrm st3 mswt qm3

nfrw.f

nțr nțrj hpr ds.f

hpr.n nter nb dr

$$
s 3^{\mathrm{C}} \text {.f sw }
$$

$n n j t j \cdot k j-j r j-t w$

nn hab.n.k m ht $n$ hmt

nn ㅍnnw $r$ qd..

bw rh.tw qj.k jnw(.k)

ḩ3tjw tmhjj $r$ rh.k

wtn.tw pd.tw nnj.tw

$c_{3-t w}$ tnj-tw

drj-tw wdn-tw m drw.k

nht-tw phtj-tw
Es gibt seine Mutter nicht, die seinen

Namen schüfe, 25

nicht seinen Vater, der inn zeugte, der sagte: "das bin ich!" 26

Der selbst sein Ei formte,

Macht von geheimer Geburt, der seine Schönheit

erschuf,

Göttlichster Gott, der von selbst entstand,

jeder Gott entstand, nachdem er sich

begonnen hatte. 27

Du hast keinen vater, der dich erschuf, 28

du drangst nicht ein in den Leib eines weibes,

Ke in Chnum hat ... gebaut,

man kennt deine Gestalt und dein wesen nicht,

die Herzen sehnen $\operatorname{sich}^{29}$ danach, dich $z u$

erkennen,

man bohrt, man streckt sich, man erlahmt,

du bist $(\mathrm{zu})$ gross und erhaben,

du bist (zu) fest und zu schwer in deiner

Erstreckung

du bist (zu) stark und kraftvoll ...30

Der Begriff eines Gottes, "dessen Geburt geheim ist" 31 , "dessen Entstehungsort man nicht kennt"32, eines Gottes, der nicht nur keine Zeugen seines Entstehens hat, sondern -

25 Zur Erschaffung des Namens durch die Mutter cf. Posener, in: RdE 22 (1970) $204 f$.

26 Mit diesen worten erkennt sich der Vater im kinde wieder und erkennt das kind als das seine an, Cf. LL 99 m.n. 41 .

27 pLeiden J 350, IV, 9-11; Zandee, Hymnen, 71-75; AHG Nr.137.

28 Eine unveröffentlichte Var. dieses Textes, deren Kenntnis ich G.Posener verdanke, fügt hinzu: nn mwt.k gmj.s rn.k "du hast keine Mutter, die deinen Namen gefunden hätte", cf.n.25.

29 Cf. Ani IX, 3.

30 Černý-Gardiner, Hieratic Ostraca, Tf. 106.

31 st3 mswt, z.B. pLeiden J 350, IV, 11 Zandee, 74; pBerlin 3049, VI, 7-8 AHG Nr.127 B, 1; pGreenfield XXXI; pstrasbourg 7rto5; Neschons 4 AHG Nr.131,10; Text 42a(i); ähnl. dsr mswt, z.B. pLeiden J $344 \mathrm{~V} 50$ I. $1 \mathrm{vgl}$. dazu Haremhab BM 551= $\mathrm{AHG} \mathrm{Nr} .58,18-20$.

$32 \mathrm{Vgl}$. Text 114,11 (c). 
was das Entscheidende ist - das Geheimnis seines Wesens auch vor allen, die nach ihm entstanden, verborgen hielt:

der sich selbst geformt hat,

der sich verborgen hat vor Göttern und Menschen ${ }^{33}$

dieser Gottesbegriff wird zu einem zentralen Thema der ramessidischen Amun-Re-Theologie. Einzigkeit und Verborgenheit bedingen sich gegenseitig. Die Unerforschlichkeit dieses Gottes beruht auf der spontaneität seines Ursprungs.

Einzigkeit und Verborgenheit Gottes beziehen sich aber nicht auf die Welt vor der Schöpfung. Dort war niemand, vor dem sich Gott hätte verborgen halten können. Der Begriff der Verborgenheit meint vielmehr eine Beziehung Gottes zu der Welt, die nach und aus ihm entstanden ist. Einzig ist er als der Verborgene, den Götter und Menschen nicht ergründen können, verborgen ist er als der Einzige, der keine Zeugen seines Ursprungs hat. Im Zusammenhang der Amun-Re-Theologie erfährt die Vorstellung von der Verborgenheit und Einzigkeit des Urgottes, die sich im Rahmen der Sonnentheologie gewiss auf die welt vor der Schöpfung bezog, eine Umdeutung. Aus der temporalen Relation von Einheit und Vielheit wird eine ontologische. ${ }^{34}$ Der Eine und Verborgene steht nicht in einem zeitlichen, sondern in einem ontischen Jenseits der Welt. Dieser Begriff einer Transzendenz Gottes findet im "200." Lied der Leidener Amunshymnen seinen klarsten Ausdruck.

33 pStrasbourg 7 vs.2. Zur Autogenese des Urgottes s.a. Zandee, Hymnen, 38-39.

34 Damit soll nicht ausgeschlossen werden, dass auch die temporale Relation von Einheit und Vielheit nur eine veranschaulichende Ausdrucksform der ontologischen Beziehung ist, im Sinne einer "temporizing of essence" (K.Burke), cf. Saeculum 23, 115f. m.n.28 und 31. Doch glaube ich die historische Entwicklung jetzt klarer zu sehen als in der gen. früheren Arbeit und würde den Begriff einer 'verborgenen Einheit' in der vielheit (im Gegensatz zu: vor der vielheit) erst der ramessidischen Amun-Re-Theologie vorbehalten. 
3 Transzendenz als verborgene Einheit

3.1 Transzendenz und Verkörperung nach pLeiden $J \quad 350$ IV. 12-21.

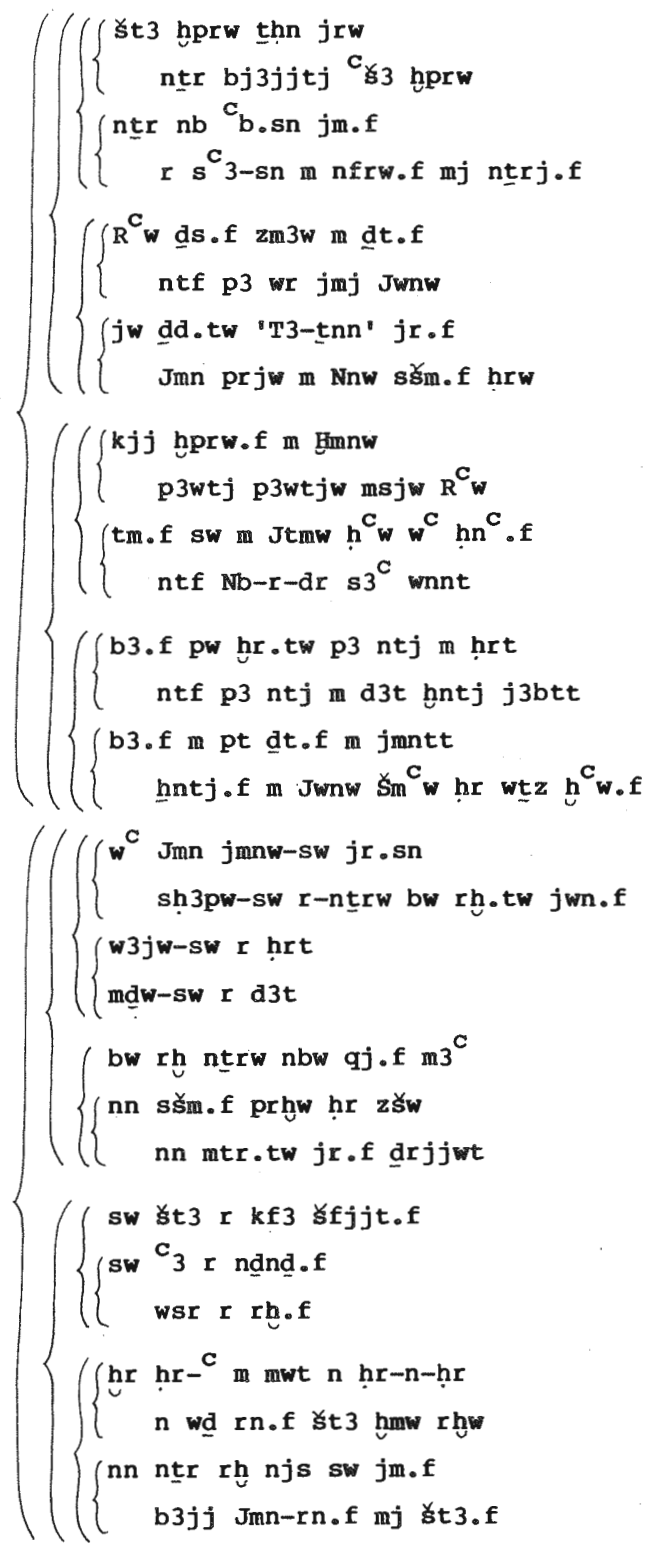


Geheim an Verwandlungen, funkelnd an Erscheinungsformen, wunderbar erscheinender Gott, reich an Gestalten!

Alle Götter rühmen sich seiner, um sich mit seiner Schönheit zu erhöhen, wie er Göttlich ist.

Re selbst ist vereinigt mit seinem Leib, er ist der Grosse in Heliopolis;

man sagt auch 'Tatenen' zu ihm, Amun, der aus dem Urwasser hervorkam, um die 'Gesichter' zu leiten.

Eine andere seiner Transformationen sind die "Acht" Urgott, Erzeuger der Urgötter, die Re gebar!

Er vollendete sich als Atum, eines Leibes mit ihm, er ist der Allherr, der das Seiende begann.

Sein Ba, sagt man, ist der, der im Himmel ist, er ist der, der in der Unterwelt ist, der im Osten gebietet.

Sein $\mathrm{Ba}$ ist im Himmel, sein Leib ist im Westen, sein Bild ist im "Südlichen Heliopolis" und trägt seine Kronen.

Einzig ist Amun, der sich vor ihnen verborgen hält, der sich vor den Göttern verhüllt, sodass man sein Wesen nicht kennt;

Er ist ferner als der Himmel, er ist tiefer als die Unterwelt,

Kein Gott kennt seine wahre Gestalt, sein Bild wird nicht entfaltet in den Schriften, man lehrt nicht liber inn etwas sicheres.

Er ist zu geheimnisvoll, um seine Hoheit zu enthüllen, er ist zu gross, um ihn zu erforschen, zu mächtig, um ihn zu erkennen.

Man fällt nieder auf der Stelle vor Schrecken, wenn man seinen geheimen Namen wissentlich oder unwissentlich ausspricht.

Es gibt keinen Gott, der ihn dabei anrufen könnte, Ba-hafter, der seinen Namen verbirgt entsprechend seiner verborgenheit. 35

35 Zandee, Hymnen, 75-86; AHG Nr. 138. 
Dieser grossartige Hymnus hat eine Form, die der inneren Form des Sonetts vergleichbar ist: seine zweiteilung in zwei ungleiche Hälften $(8+8)+(7+7)$ beruht auf einer gedanklichen Antithese, einem Aspektwechsel. Der erste Teil ist ein stück "theologia positiva" und beschreibt die innerweltliche verkörperung (hprw : Verse 1,2 und 9) des Gottes in den Göttern, dargestellt an den acht urgöttern (Verse 9-10) und den drei Göttern der "Reichstriade" Re-Atum (Verse 4-5,11-12), (Ptah)Tatenen (7) und Amun (8, auch 16), deren Beziehung zu ihm in differenzierter Begrifflichkeit ausgeführt wird: Re ist $\mathbf{z m} 3 \mathbf{w}$ m dt.f ${ }^{36}$, Atum ist $h^{c} \mathbf{w} \mathbf{w}^{\mathrm{C}} \mathbf{h n}^{\mathrm{c}} . \mathbf{f}{ }^{37}$, Tatenen und Amun "sagt man zu ihm", "er ist" ( ntf) "der Grosse in Heliopolis" und der "Allherr" - beides Bezeichnungen des Atum - die Acht Urgötter von Hermupolis sind seine "andere Gestalt" ( kjj hprw $)^{38}$, und schliesslich wird auch die Lehre von den drei Konstituenten der göttlichen Person - Ba, Leib und Bild - in diesen Zusammenhang innerweltlicher verkörperter Gegenwärtigkeit des Gottes gestellt.

Der zweite Teil ist dagegen ein stück "theologia negativa" $38 \mathrm{a}$ und liest sich wie ein widerruf all der theologischen Gelehrsamkeit, die der erste Teil aufgefahren und entfaltet hat. Dieser erste Teil handelte nicht von dem Einen, sondern von den vielen Göttern, die sein Wesen innerweltlich'reflektieren. Auch Amun als Herr von Theben gehört dazu. Der "Eine Amun" ist vor ihnen verborgen, er ist aber auch schlechthin verborgen. Uber ihn verbietet sich jede Aussage. Er ist noch

36 Die Stelle liesse zur Not auch eine andere Auffassung zu: "(Er ist) Re selbst, indem dieser mit seinem (sc.Re's) Leibe vereinigt ist", in Anspielung auf die alte heliopolitanische vorstellung von der nächtlichen vereinigung des Sonnengottes mit seinem in der Unterwelt vorhandenen Leib (Text $158(\mathrm{n})$ ), die auch im Leidener Pap.I.1 eine Rolle spielt (Zandee, 3-4 cf auch IV, 15-16 Zandee, 81; VI, 12-13 Zandee, 110).

$37 \mathrm{Vgl}$. zu dieser Formel H.Brunner, Die Geburt des Gottkonigs, 65f. sowie LL $100 \mathrm{~m} . \mathrm{n} .47$.

38 Dieser Begriff stammt aus dem Kontext der kosmogonischen "Transformationslehre", vgl. dazu u., 222-226 sowie Zeit und Ewigkeit, 21-23 m.n. 57,58 und 60; AHG S.67f; "Primat und Transzendenz", $30 \mathrm{f}$.

$38 \mathrm{a}$ So ordnet diesen Text auch E.Topitsch ein, in: Gottwerdung und Revolution (Pullach 1973), 17f. allerdings unter Absehung von der antithetischen Struktur des Gesamt-Liedes, vgl. dazu LA II 775 m.n. 185. 
jenseits von Himmel und Unterwelt, den heiligen, jenseitigen Bereichen der Welt, und selbst den Göttern verborgen, die sein ihnen unergrúndliches Wesen in dieser entrückten Sphäre reflektieren. Wieviel verborgener ist er erst den Menschen: die Schriften geben über ihn keine Auskunft, keine Lehre vermag ihn zu erfassen. Der abschliessende Vierzeiler bringt den Begriff eines deus ineffabilis in aller Klarheit zum Ausdruck und verbindet ihn mit den beiden bedeutungsvollen Epitheta "Ba-hafter" und Jmn-rn.f "Der seinen Namen verborgen hält". Darin erweist sich ihre innere Zusammengehörigkeit. Man nennt den Gott "Ba", weil man keinen Namen für ihn hat, d.h. weil sich seine verborgene, allumfassende Wesensfülle nicht begrifflich fassen lässt. "Amun" ist nur ein Deckname, mit der man sich auf den Gott in jener innerweltlichen, wenn auch jenseitigen Sphäre der Verkörperung beziehen kann, in der im Grunde jeder Göttername zugleich ein Name des Verborgenen Einen ist, "Ba" aber nennt man ihn, wenn man den Verborgenen Einen hinter den vielen Verkörperungen meint.

In dieser theologisch ausgereiftesten Darstellung ist die Beziehung des Einen zu den Vielen entzeitlicht. Hier wird der Eine nicht als der Urgott vor den Vielen gesehen, dessen Einheit in der schöpfung als vielheit aufgehoben ist, sondern als der Eine in den Vielen, eine verborgene Macht ( B3), die in den vielen Göttern Gestalt annimmt ( $\mathrm{hpr}$ ), wodurch diese erst Götter sind, und die doch alles andere als eine Art "Mana" oder gar ein abstraktes Prinzip ist, sondern ein alles Fragen und Forschen, alles wissen und Schauen übersteigendes personales Wesen.

\section{$3.2{ }^{\mathrm{N}} \mathrm{Ba} "$}

3.2.1 Einige Belege für die Kollokation von "Ba" und "Verkörperung" (hprw):

(1) jnd hr b3 dsr hprw

Gegrusst sei der Ba, heilig an Verkorperungen 39

39 ZAS $72,101 \mathrm{ff}$. Nr.24. 
(2) jnd-hr.k b3 stn hprw Sei gegrlisst, Ba, erhaben an verkörperung, jta sšp hddwt Sonne, strahlend an Licht 40

(3) b3 stn hprw jrjw wnnt Ba, erhaben an verkorperungen, der das Seiende schuf 41

Vgl. auch:

(4) $\operatorname{ar}^{c} c_{3}$ hprw Widder, gross an verkorperungen 42

In Ubereinstimmung mit der von E.Wolf-Brinkmann erschlossenen ursprlinglichen Bedeutung des Lexems b3 als "Gestaltfähigkeit" 43 bezeichnen diese Stellen einen Aspekt des komplexen Ba-Begriffs, der ihn als die eine (potentielle) Mächtigkeit von der Vielzahl (aktueller) Verkörperungen, Gestalten unterscheidet. Ba ist die Macht, die sich in Gestalten "ereignet" ( hpr ).

3.2.2 Einige Belege für die Kollokation von "Ba" und "Verborgenheit" "Heiligkeit" und "Grösse"

(5) b3 št3 mm ntrw Geheimer Ba unter den Gottern ${ }^{44}$

(6) b3 st3 jr.n.f šfjjt Geheimer Ba, dem Ehrfurcht erwiesen wird ${ }^{4}$

(7) b3 కt3 wbrw m nnw Geheimer Ba, der aus dem urwasser kommt 46

(8) b3 కts sfj hat Geheimer Ba mit widderkopfigem Antlitz 4

(9) b3 కt3 hrw wr కfjt Ba mit geheimen Gesichtern, gross an Hoheit ${ }^{47 a}$

40 pBerlin 3049, II, 2=AHG Nr.127A, 1-2.

41 Sobek-Re pstrasbourg IV 15= $\mathrm{AHG} \mathrm{Nr} .144 \mathrm{C}, 62$.

42 Sonnenlitanei $\mathrm{Nr} .26$ ed.Hornung, Das Buch der Anbetung des Re im Westen (AH 2,1975) I, 31 .

43 E.Wolf-Brinkmann, Versuch einer Deutung des Begriffes 'b3' anhand der Uberlieferung der Fruhzeit und des Alten Reichs, Diss.Basel 1966 (Freiburg 1968). Vgl. neuerdings auch W.A.Ward, The Four Egyptian Homographic Roots B3, Studia pohl, Series Maior 6,1978,67-88, dem es allerdings um die lexikographische Definition des Semems, nicht um die religionsgeschichtliche Erfassung des Begriffs geht. Seltsam ist allerdings, dass auch L.V.Zabkar in seiner Monographie uber den Begriff Ba der Bedeutung nicht ansichtig geworden ist, die er im Rahmen der ramessidischen Amun-Re-Theologie gewinnt (A Study of the Ba Concept in Ancient Egyptian Texts, $\operatorname{SAOC}(34,1968)$. Er geht auf die entsprechenden Belege uberhaupt nicht ein.

44 Hibis $32,32=$ AHG $\mathrm{Nr} .129,168$.

45 Hibis 32,2 ; pMagHarris (s.u.) $=\mathbb{A H G} \mathrm{Nr} .129,6$.

46 pLuynes; pChester Beatty VIII, 12.

47 Hibis $32,31=$ AHG $\mathrm{Nr} \cdot 129,158$.

47 a OIP XXV Tf. $23=$ AHG $\mathrm{Nr} \cdot 196,13$. 
(10) b3 špss wbnw m nnw Erlauchter $B a$, der aus dem Urwasser kommt ${ }^{48}$

(11) b3 špss hprw m h33t Erlauchter $\mathrm{Ba}$, der am Anbeginn entstand 49

(12) b3 spss prjw in nnw Erlauchter Ba, der aus dem Nun kommt, p3wtj hprw m h3t Urgott, der am Anbeginn entstand 50

(13) b3 špss jmj jtn.f Erlauchter Ba in seiner Scheibe 51

(14) b3 కpss jmj 3ht.f Erlauchter Ba in seinem Lichtauge 52

(15) b3 špss wbnw m hret Erlauchter $\mathrm{Ba}$, der am Himmel aufgeht ${ }^{53}$

(16) b3 $c_{3}$ ntrrj wbnw Grosser, gottlicher $\mathrm{Ba}$, der im Himmel m pt aufgeht ${ }^{54}$

(17) b3 wr šsp.n.f t3wj Gosser $B a$, er hat die beiden Länder erleuchtet 55

(18) b3 dsr mdt wtt ntrw Cpr sw jurw.f n rh.n.tw.f
$\mathrm{Ba}$, mit heiligen worten, der die Gotter erzeug te, der sich ausstattete mit seinen Erscheinungsformen, man kann ihn nicht erkennen 56

Dazu vergleiche man die Stellen, die Sethe, Amun $\$ 232$ zusammengestellt hat. Oberflächlich gesehen scheint es bei den meisten Stellen um die Sonne als "sichtbare Manifestation" zu gehen, die ja bereits in den frühen Eulogien oft als b3 $\mathbf{c}_{\mathbf{n h}}$ "Lebender Ba" bezeichnet wird. ${ }^{57}$ Es fällt aber auf, dass gerade der zusatz ${ }^{c}$ nh hier nicht vorkommt. Ba ist, wie Goedicke richtig bemerkt hat, ein bifocal term, ein polarer Begriff, der sowohl die verborgene Macht als auch deren sichtbare Manifestation bezeichnen kann. ${ }^{58}$ Welcher dieser polaren Aspekte gemeint ist, muss durch vereindeutigende zusätze klargestellt werden. Der zusatz $\mathbf{c}_{\mathbf{n h}}$ vereindeutigt den Ba-Begriff in Richtung auf die sichtbare Manifestation, während Zusätze wie št3, dsr, špss in die entgegengesetzte Richtung weisen.

48 E.Naville, The Temple of Deir el Bahari V, 149.

49 Neschons $2=$ AHG $\mathrm{Nr} \cdot 131,3$.

50 Text 95 cf.Kap. $4,187 \mathrm{~m} . \mathrm{n} \cdot 149$.

51 Text $242,8(\mathrm{~g})$.

52 G.Lefebvre, Le tombeau de Petosiris II, 33.3.

53 Turin 3070.

54 Sobek Re III 2.

55 BM 1224.

56 Totb $15 i$ (var).

$57 \mathrm{Vgl}$. Kap.4 $\$ 1.2$.

58 H.Goedicke, The Report about the Dispute of a Man with his Ba (1970), 25; "Primat und Transzendenz", 35. 
Ebenso bedeutet $\mathrm{Ba}$ in der Kollokation mit hprw, das sich ja seinerseits schon auf die sichtbare Manifestation einer "Ereignis gewordenen" Macht bezieht, auf die verborgene seite des Machtbegriffs. Am klarsten tritt dieser Begriff jedoch hervor, wenn man grössere Kontexte heranzieht.

\subsection{3 "Ba" und der in den Elementen verkörperte Lebensgott}

Der Hymnus Ramses'III. an Amun-Re redet den Gott nicht mit Namen an, sondern beginnt folgendermassen:

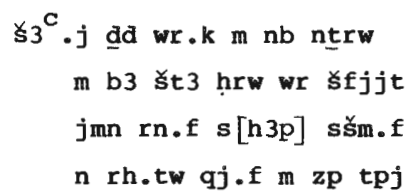

Ich will anheben, seine Grösse zu verkünden als Herr der Götter, als "Ba" mit geheimen Gesichtern, gross an Hoheit, der seinen Namen verborgen hält und sein Bild ver [hüllt] dessen Gestalt man nicht erkannte am Anbeginn. ${ }^{59}$

In den folgenden Versen, die wir unten gesondert betrachten wollen, entfaltet der Hymnus die Lehre von den lebenspendenden Elementen, in denen sich der Gott innerweltlich verkörpert. Dieser Text preist Amun als den Weltgott, dessen Körper die Welt ist. Indem er diesen Gott als "Ba" und nicht mit seinen herkömmlichen Namen anruft, bezieht er sich auf Gott als den "Ba" der Welt, das "vitale Prinzip" des Kosmos, das denselben ebenso belebt wie der menschliche Ba den Körper des. einzelnen Menschen.

Mit der im Begriff des $\mathrm{Ba}$ angelegten Möglichkeit des Aspektwechsels kann sich der Ausdruck aber auch auf die Vielzahl der kosmischen Manifestationen, und nicht auf das eine belebende Prinzip in und hinter ihnen, beziehen. So sind dann auch die "lebenspendenden Elemente" als die kosmisch erfahrbaren Wirkungsweisen des Gottes seine "Ba's", in Ubereinstimmung mit jener Lehre von den Ba's der Götter, die im Buch von der Himmelskuh dargestellt wird und derzufolge unter dem $\mathrm{Ba}$

59 OIP XXV, Tf. 23=AHG Nr.196, 12-15. 
eines Gottes ein spezifisches natürliches Phänomen zu verstehen ist, z.B. die Nacht als Ba des Kuk, der wind als Ba des Schu usw. 60 Vom Ba des Re heisst es, er sei ht t3 $r$ dr.f "über das ganze Land hin verbreitet". Das bezieht sich auf die Allgegenwärtigkeit des Lichts und ist demnach ein stück "neuer Sonnen-Theologie" (Kap.3, \$ 2.4). Ähnlich heisst es auch in der Lehre des Ani vom Sonnengott, dass "er seine Macht erweist in Millionen Gestaltungen" ( $\mathrm{sw}$ dd b3w m hhw nw hprw ). ${ }^{61}$ Auf solchen Konzeptionen der Sonnen-Theologie baut die ramessidische Amun-Re-Theologie auf, wenn sie, das Alte übersteigernd, nicht nur das Licht sondern die Gesamtheit der in der welt wirkenden belebenden Energien als Machterweise, Manifestationen, "Ba's" des Amun ansieht. So kommt es zu dem eigentümlichen Kult der zehn Ba's des Amun, den J. C.Goyon erschlossen hat. ${ }^{62}$ Ikonographisch werden diese Ba's als Fruchtbarkeitsgötter im Nil-Typus dargestellt. Die lebenspendenden Elemente, in deren Gestalt der Lebensgott seine Macht erweist, personifizieren sich in Bildern der Fülle und des Uberflusses.

"Ba" bezeichnet die Macht, von der Wirkungen ausgehen, sowie - in Ausdehnung dieses Grundbegriffs - auch die spezifische Wirkung einer spezifischen Macht, z.B. den Wind als "Ba" des Luftgottes Schu. Indem sich die ramessidische Amun-Theologie sich dieses Begriffes bedient, bezieht sie sich nicht auf eine spezifische Macht, sondern auf die Vorstellung einer "Macht schlechthin", von der alle Wirkungen ausgehen, deren erfahrbare Manifestation der Kosmos insgesamt ist. $62 \mathrm{a}$

60 Maystre, "Le Livre de la vache du ciel", BIfAo 40,102 ff., Otto, in: Saeculum 14(1963), 259-260; pTurin Pleyte und Rossi Tf.84. E.Hornung, Der ägyptische MYthos von der Himmelskuh (OBO 46, 1982), $26 f ., 47$.

61 Ani: pBoulaq 4,VII,15; A.Volten, Studien zum Weisheitsbuch des Ani, $111-112,115$; cf. Saeculum 23,125 n.63.

62 In: R. Parker et alii, The Edifice of Taharqa, 69-79.

$62 \mathrm{a} \mathrm{Vgl.} \mathrm{auch} \mathrm{die} \mathrm{Gestalt} \mathrm{des} \mathrm{"Bes} \mathrm{Pantheos",} \mathrm{dessen} 7$ köpfe die "7 Ba's des Amun-Re" darstellen, in denen sich der verborgene weltgott nicht nur innerweltlich, sondern als Welt verkörpert: "Primat und Transzendenz", $12 \mathrm{f}$. 


\subsection{4 "Ba" und der All-Eine}

Der Abschnitt "G" des mag.Pap.Harris reproduziert in Kurzfassung einen der bedeutendsten Amun-Re-Hymnen und datiert dadurch diesen Text, dessen vollständige Fassung erst im HibisTempel aus persischer zeit erhalten ist, in die 19.Dynastie. Die Kurzfassung lautet:

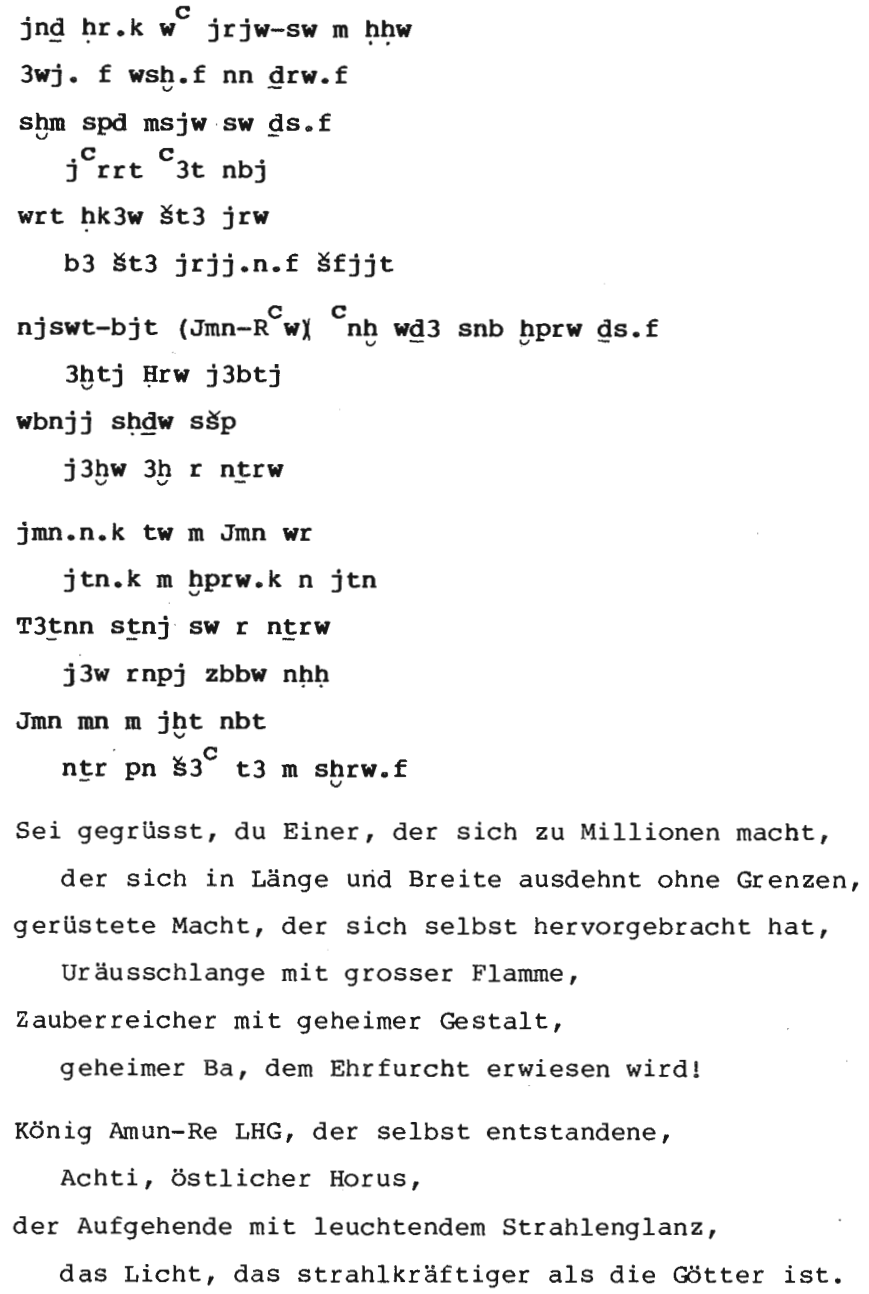


Du hast dich verborgen als Amun, der Grosse,

du hast dich entfernt in deiner Verkörperung als sonne ${ }^{63}$

Tatenen, der sich über die Götter erhebt;

der sich verjüngende Greis, der den Nḥh durchläuft,

Amun, der in allen Dingen bleibt,

dieser Gott, der die Erde begründete durch seine Pläne.

Der dreigeteilte Text $(6-4-6)$ behandelt in seiner letzten Strophe die als "Reichstriade" bekannte dreigestaltige Form des Gottes, aber nicht als Form seines innerweltlichen zur-Erscheinung-Kommens, sondern im Gegenteil als eine dreifache Form seiner Verborgenheit, die durch Wortspiele aus den drei Gottesnamen Jmn, Jtn und T3tnn erschlossen wird. Als Amun hat er sich "verborgen" ( jmn), als "Sonne" (jtn) hat er sich "entfernt" 64 und als Tatenen hat er sich "erhoben über" die Götter. Als Sonne ist er der Gott der zeit, der in periodischem Altern und sich Verjüngen die Zeitfülle durchläuft, als Amun ist er der "in allen Dingen bleibende" Lebensodem und als Tatenen ist er der schöpfer, der die welt nach seinem "Entwurf" eingerichtet hat.

Die mittlere Strophe von vier Zeilen verbindet die Aspekte "Herrschergott" und "Sonne". Der Gottesname Amun-Re erhält nicht nur den Königstitel njswt-bjt "König von ober- und unterägypten", sondern er wird sogar in Kartusche geschrieben. Solche im NR und später nicht ganz seltenen Schreibungen sind ausser für Amun-Re ${ }^{65}$ auch für Osiris 66, Ptah $^{67}$ und Re $^{68}$

63 Dies ist einer der wenigen Belege, wo die Sonne ausserhalb Amarnas als hprw des Gottes bezeichnet wird (vgl. dazu Kap.3 n.7) und bezieht sich sicher auf die "Transformationslehre", derzufolge die Sonne das letzte stadium der Schöpfung als verwandlung des Urgottes darstellt, s.n.38.

$64 \mathrm{Cf}$. Neschons=ÄHG $\mathrm{Nr} .131,86$; das Verb jtn ist in ramessidischen Hymnen auch sonst, ausserhalb des Wortspiels mit jtn "Sonne", belegt, vgl. z.B. pBerlin $3049, \mathrm{IV}, 1=\mathrm{AHG} \mathrm{Nr}$. 127A, 63-64

Inm $R^{C}$ jrjj pt $n$ b3.f shdw t3wj

jtn.f sw m hrt $n$ dt

ferner Sobek-Re III $2 \overline{2}-23$.

65 Neschons 39 .

66 Frühester Beleg: Dyn.13 (Sethe, Lesestücke, 63.22); J.Leclant, Recherches sur les monuments thébains de l'epoque dite éthiopienne, 199 n. 1; J.Bergman, Ich bin Isis, $76 \mathrm{n} .1$. 
belegt, sowie natürlich für den Gott der Amarna-Religion. 69 In Amarna bezieht sich diese königstitulatur des Gottes nicht auf die Vorstellung eines mythischen Urkönigtums ${ }^{70}$, sondern auf eine aktuelle theokratische Herrschaftskonzeption ${ }^{71}$, ebenso wie (mutatis mutandis) im thebanischen Gottesstat der 21. Dyn. ${ }^{72}$ Aber auch die übrigen Belege darf man nicht vorschnell als "mythologisch" einstufen; auch hier ist der theokratische Gedanke der in einem "Reichsgott" verkörperten, vom irdischen König nur stellvertretend ausgeübten Herrschaft gemeint. In der ramessidischen Theologie gehört die ägyptische Königsherrschaft zu den Aspekten des göttlichen wesens und darf weder auf ein mythisches Urkönigtum in der Urzeit, noch auf ein rein götterweltliches Götterkönigtum reduziert werden. Der irdische König bringt diesen Aspekt des göttlichen Wesens innerweltlich auf der Erde zur Erscheinung, die sonne aber im Himmel.

Die erste Strophe behandelt den Aspekt Gottes, der uns in diesem Zusammenhang besonders interessiert: den Aspekt der verborgenen, namenlosen Macht, für den weder der Gottesname Amun(-Re), noch die Bezeichnung ntr, die wir gewöhnlich mit "Gott" übersetzen 73 , als zureichend erscheinen. Deshalb nimmt man zuflucht zu Umschreibungen des Macht-Begriffs wie shm "Machtträger", j jert "Uräus", wr ḥk3w "Gross an Zauberkraft" und schliesslich, was man als nomen ipsum dieses Gottesbegriffs anzusehen hat, b3 št3 "verborgener Ba". Diese Strophe steht also in deutlicher Antithese zur folgenden, mittleren, die den verborgenen Gott nicht nur beim Namen

67 Bergman, a.a.o. $71 \mathrm{ff}$.

68 pKairo 58038,II,2; Himmelskuh ed.Maystre, BIFAO 40, 70 und 72; ed.Hornung, 7-8 cf. G.Fecht, in: ZaS $85,102 \mathrm{n} .1$; J.Bergman, a.a.0. 76 n. 1 . Zusammenfassend zum mythischen Urkönigtum der Götter U.Luft, Studia Aegyptiaca IV, 78-154.

69 LA I, $526 f$.

70 So G.Fecht, ZAS $85,101 \mathrm{f}$.

71 JNES 31, 151ff.

72 Der massgebliche Text flur die Auffassung dieser Zeit vom göttlichen Königtum ist das Dekret für Neschons AHG Nr.131, s.bes. Verse 95-100. Zusammenfassend vg. auch Hornung, Der Eine und die vielen, $227 f f$.

73 Zum "Gebrauch des Wortes nțr " $s$. das gleichnamige Kapitel in Hornungs Darstellung, Der Eine und die Vielen, 30-49. 
nennt, sondern diesen Namen mit königsring und Königstiteln betont herausstellt. Klarer kann man es kaum zum Ausdruck bringen, dass auch der Name nur ein Aspekt des Gottes ist, in dem er sich der Welt zuwendet, um seine Herrschaft in ihr auszuüben. Als namenloser, "geheimer" Ba ist der Gott unbegrenzt (Vers 2) und allgegenwärtig. Die Gestaltungen, in denen seine Macht sich manifestiert, sind das millionenfältige Ganze.

\subsection{Einer und Alles (Thibionsis)}

\subsubsection{Ramessidische Belege}

(1) $\mathrm{TT} 51$

Wnn-nfr p3 nb $r$ nḥh nb dit

p3 nter $w^{c}$ jrjw sw m hụw 74

(2) TT 157 Text 149

hprw w msjw sw m hḥw

(3) TT 157 Text 148

ntrr w jrjw sw m hhw

(4) TT 34 (9) Text 43 (Text des NR)

nțr w jrjw sw m ḥ̣w

(5) $\mathrm{TT} 34$ (9) Text $42 a$ (Text des NR)

Hprr hpr m ḥhw

(6) pLouvre $3292=$ AHG Nr $.47,1-2$

jnd-hr.k bsw sw m $w^{C}$

qm3.n.f hhw mj $\mathbf{c}_{\$ 3 . s n}$

(7) pLeiden J 344 vso III, $3^{75}$

$w^{c} w^{c} w$ dt.f hhw

(8) pBer1in 3049, II, $3=$ AHG Nr.127A, 5-6

jjw m ntr w $w^{76}$ [jrjw sw m] ${ }^{77}$ hhw

hpr nțr nb hrr-s3.f

(9) pNeschons, var. = AHG Nr. 131,7

nțr w jrjw sw m ḥ̣w

74 N.de Garis Davies, Two Ramesside Tombs, Tf.IX, in einer Beischrift zur Abydosfahrt.

75 J.Zandee, in: JEOL $18(1966) 255$.

$76 \mathrm{Vg} 1 . \mathrm{Nr} \cdot 20$.

77 Die Ergänzung folgt Zandee, Hymnen,76 m.n.1 und kann als gesichert gelten. 
(10) pMagHarris IV, 1-2 = Hibis 32,1

jnd-hr.k ntrr w jrjw sw m hhw

$3 w j . f$ wsh.f $\mathrm{nn}$ drw.f 78

(11) Hibis 31 B 2-3 AHG Nr. 128, 60; Taharqa Tf. $28{ }^{79}$

$w^{C} j r \cdot n \cdot f$ sw n ḥ̣w

\subsubsection{Späte Belege (in Auswahl)}

(12) Urk VIII, $1 \$ 3 b$

jjw m $w^{c}$ tnj.f sw m ḥhw

(13) Urk VIII $\$ 68 \mathrm{~b}$

$w^{C}$ jrjw ḥhw cf.ibd., \$ 138b: ḥh ḥw rn.f

(14) Medamud $\mathrm{Nr} \cdot 249,7^{80}$

ntk $\$ 3^{c}$ hpr in $w^{c}$ jrjw ḥ̣w

pr hfnw m ntrwtj.fj 81

(15) Edfou III 34

$w^{c}$ pfj jr.n.f sw $m$ ḥhw $n$ nțrw qm3w m h ${ }^{c} w . f$

(16) Edfou V, 80

sw m ntrr w qm3 ḥ̣w henw

(17) Edfou III 60, ähnl. VI $348,7 \mathrm{ff}$.

nhb wr jtj jtjw msjw sw ds.f

wbnw $m w^{c}$ shppr.n.f ḥ̣w

(18) Philae II, 49, 27-30

ntrr w jrjw hhw

$3 w . f$ wsh.f $n n$ drw.f

$\checkmark 3^{C}$ hpr nn wp hr.f

hpr nțr nb har s3 (.f)

(19) Philae II 29.8

njswt-bjt jrjw sw m hhw

jtj jtjw mwt mwwt

(20) Philae 2924 (Osiris)

jjw m $w^{c} w$ jrjw sw m ḥ̣w

78 Id. Nr.18 sowie Philae 3499 und Debod, 57.

79 Goyon, in: R.Parker et alii, The Edifice of Taharqa, 74 m.n.12.

80 Drioton, in Medamud (1925) 109.

81 Hier bezieht sich hnfnw 'Hundertausende', in Anspielung auf den Mythos von der Entstehung der Menschen aus dem Auge des Gottes, auf die Menschen, sodass mit hhw die Götter gemeint sind. 
(21) Esna $\mathrm{Nr} \cdot 387,3-4^{82}$

ntr w jrjw sw mhw nb

jrjw wnnt $m r 3^{c}$ wj.fj

p3wtj $\mathrm{s}_{3}{ }^{\mathrm{C}} \mathrm{hpr}$

tzz sp3wt m shrw.f

(22) Esna $\mathrm{Nr} \cdot 387,5-6^{83}$

w3w m hrw tkn m msdr 84

$m w^{\mathrm{C}}$ hhw nn rh.tw jnm.f

(23 usw.) lateinischer Isis-Hymnus 85

una quae es omnia

\subsubsection{Die Bedeutung der Formel}

Sämtliche NR-Belege der in letzter Zeit viel behandelten ${ }^{86}$ Formel stammen aus Theben und beziehen sich, mit Ausnahme von (1) ${ }^{87}$, auf Amun-Re. Schon dies zeigt, dass wir es mit einem Stück ramessidischer Amun-Re-Theologie zu tun haben und im Kontext dieser Theologie interpretieren mússen. Die Formel hat eine "kanonische" Form, wie sie in (1), (3), (4), (9), (10) und (21) vorliegt:

Die $\frac{\text { ntr w jrjw sw m hhw }}{\text { anderen Belege }}$ variieren diese Grundform. Die Probleme, mit denen die Interpretation dieser Formel konfrontiert ist, lassen sich wie folgt zusammenfassen:

1) $\mathbf{n t r} \mathbf{w}^{\mathbf{C}}$ : bezieht sich die Prädikation der Einzigkeit auf die Einsamkeit des Urgottes vor der Schöpfung oder auf die All-Einzigkeit Gottes in der Schöpfung?

82 Sauneron, Esna III, 368; V, 220.

83 Ders., Esna III, 368; V, 221.

84 S. dazu u. $273 f$.

85 Nach F.Junge, in: W.Westendorf (Hrsg.), Aspekte der Spätägyptischen Religion, 102. Belege entsprechender Formeln im Corpus Hermeticum habe ich in Zeit und Ewigkeit, $31 \mathrm{n} .94$ zusammengestellt, vgl. auch ibd., n. 93 sowie "primat und Transzendenz",38.

86 Sethe, Amun, $\$ 200$; Otto, in: FuF 35(1961)278; Ders., Gott und Mensch, 106; Hornung, Der Eine und die vielen, 164; J.Zandee, in: JEOL 18, $255 f$.; Saeculum 23, 125 n.62; "Primat und Transzendenz", 30 m.n.87.

87 Bei Osiris kann wohl nur an die 'Millionen' Toten gedacht sein, die als "Osirisse" zu ihm "geworden" =aus ihm "entstanden" sind ( hpr m). Der Totengott bezieht sich auf die Millionen Tote in derselben Weise, wie der Lebensgott auf die Millionen Lebewesen. 
2) jrjw sw : bezieht sich das auf die Schöpfung am Anbeginn oder auf das ständige Hervorgehen des Alls aus dem Einen?

3) hhw : sind mit "Millionen" Millionen Götter gemeint (15), oder die Gesamtheit der Lebewesen, oder ein Begriff von "All", wie er in den griechischen $(\pi \tilde{\alpha} \nu)$ und lateinischen (omnia) Formeln zum Ausdruck kommt? 88

E.Hornung hat die Formel im zeitlichen Sinne interpretiert. Er sieht in der "Einzigkeit" den zustand des Gottes vor der Schöpfung, in den Verben, die die Erschaffung $(1,3,4,8,9-11$, 13-15,18-22 vgl $2,6,16-17$ ) oder die Entstehung (5) der vielen aus dem Einen beschreiben, eine Darstellung der Ur-Schöpfung und in den "Millionen" mit (15) die polytheistische Götterwelt, die die aktuelle Wirklichkeit darstellt. ${ }^{89}$ Die Belege geben ihm weitestgehend recht: fast alle beziehen sich auf die Schöpfung, zuweilen $(8,18)$ ist die temporale Relation von Einheit und All-heit auch ausdrücklich betont durch den $\mathrm{Zu}-$ satz, dass alle Götter nach dem Einen entstanden. Es kann sich also nicht darum handeln, die Richtigkeit der Hornungschen Deutung zu bestreiten, sondern nur um die Frage, ob die Formel über ihre unbestreitbare schöpfungstheologische Bedeutung hinaus (die als solche ja in keiner Weise etwas Neues

88 Dass mit hhw wirklich "Millionen" gemeint sind und nicht, wie Sethe meinte, an die in dem Gotte Hah personifizierte "überallhin dringende Luft" (Amun $\$$ 201), bedarf wohl keiner Erörterung. Erst in ptolemäischen Texten gerät zuweilen der Gott Hah in diesen Zusammenhang (vgl. auch Drioton, in: ASAE 44(1944) 127 (c).

89 Der Eine und die Vielen, 164f. m.n.102 (Verweis auf Beleg 15). Vgl. auch S.164: "Die 'Millionen', die ungeheure und unabsehbare aber nicht unendliche Vielzahl - das ist die Realität der Schöpfungswelt, des Seienden". Ist es wirklich legitim, in Bezug auf den ägyptischen Begriff hhw von einer "nicht unendlichen Vielzahl" zu sprechen? Damit ist doch gewiss nicht präzis 1000 000, im Gegensatz zu 1000001 gemeint, sondern die unzählbare Fülle. Man darf nicht ubersehen, dass auch die Vorstellung der Unendlichkeit, wie sie im Begriff ḥw zum Ausdruck kommt, eine Kategorie des "Chaos" ist, genau wie der Begriff der "undifferenzierten Einheit". Wenn man den kosmogonischen Begriff der Differenzierung meint, spricht man nicht von dem "Einen, der zu Millionen", sondern von dem "Einen, der zu Dreien wird" (CT II 39, vgl. Otto. zu: Saeculum 14, 267 und 274f.). Vgl. auch den Text auf dem Sarg Kairo CG 6234 :

"Ich bin der Eine, der zu Zweien wurde, ich bin die Zwei, die zu Vieren wurden, ich bin die vier, die zu Acht wurden". s. dazu Maspero, in: RT 23(1901)196-197. 
darstellt in der ägyptischen Religionsgeschichte) auf einen Gottesbegriff zielt, wie ihn die lateinische Formel una quae es omnia zum Ausdruck bringt. Belege wie Nr.7 und $\mathrm{Nr} .22$ weisen eindeutig in diese Richtung. Aber auch Nr.10, der Beleg, von dem diese Untersuchung ihren Anfang nahm, lässt sich nicht auf einen rein schöpfungstheologischen Bezug reduzieren. In $\$ 3.2 .4$ haben wir uns um den Aufweis bemüht, dass es in der entsprechenden strophe dieses Hymnus um den Begriff eines Gottes geht, der als "verborgene Macht" ( b3 št3) in und hinter der millionenfältigen Vielheit steht, in die er sich entfaltet und ins "Grenzenlose" ausdehnt. 90 Diese Grenzenlosigkeit wird nicht von der Welt prädiziert, sondern von dem Gott, an den sich der Hymnus wendet. Daher ist der Gott auch die Million, zu der er sich geschaffen, in die er sich verwandelt hat: unus qui est omnia . Durch seine Verwandlung in die millionenfältige Wirklichkeit hat Gott nicht aufgehört, Einer $\mathrm{zu}$ sein. Er ist in den Vielen auf jene geheimnisvolle weise zugleich verborgen und gegenwärtig, die diese Theologie mithilfe des Ba-Begriffes $z$ fassen versucht. Ein verbreiteter Text geht sogar so weit, den Gott als den Ba der Götter und Menschen, d.h. der "Millionen" ${ }^{91}$, zu bezeichnen: 92

\section{$w^{c} w^{c} w$ qm3w wnnt}

b3 కpss nw nterw rmtw

Durch die Verbindung mit dem Ba-Begriff und die Theologie des deus absconditus wird klar, worin diese Formel über die traditionelle schöpfungstheologische Gegenüberstellung von Einheit und Vielheit hinausgeht. Antithesen, die die ramessidische "wc-ḥ̂w -Formel" zu präfigurieren scheinen, gibt es

$90 \mathrm{Vgl}$. die Stele Leiden V 70 ed.Boeser, Beschr. V 17.XIV Nr.26 = AHG Nr. 90 , wo der Sonnengott angerufen wird als

Hhw pwjj nn rh.tw drw.f

Hpre $n n$ rh.tw dt.f

Der Text stammt aus dem engsten zeitlichen Umkreis der Amarnazeit, gehört also in den zusammenhang der "Neuen Sonnentheologie". So ist vermutlich die "grenzenlose" Allgegenwart des Lichts gemeint, im Sinne von Kap.3 $\$ 2.4$.

$91 \mathrm{zu}$ dieser Bedeutung des Begriffs ḥhw s.Text 149 (c).

92 Hymnus auf den urgott im "Livre que mon nom fleurisse", pBerlin 3030 , VIII-IX; pLouvre 3336 I,1-6; pBrüssel: Speleers, in: RT 39, $28 \mathrm{ff}$. 
bereits in den älteren thebanischen Texten. So stellt z.B. der pKairo 58038 an zwei Stellen den Einen "Einsamen" Schöpfer- und Lebensgott $\left({ }_{w^{C}}{ }_{w}{ }^{C} w\right)$ der Allheit der von ihm geschaffenen und am Leben erhaltenen welt gegenüber:

\begin{tabular}{|c|c|c|}
\hline$V I, 2-3$ & $\begin{array}{l}\text { twe } w^{C} \\
{ }_{w}^{C}{ }_{w}^{C}{ }_{w}\end{array}$ & $\begin{array}{l}-j r j w n t j n b \\
-\quad j r j w \text { wnt }\end{array}$ \\
\hline $\mathrm{VI}, 7$ & $\begin{array}{r}j n d-h r \cdot k \\
{ }_{w}^{C} w^{C} w\end{array}$ & $\begin{array}{l}- \text { jrjw nn } r-3 w \\
-c_{s 3} c_{w j . f j} 93\end{array}$ \\
\hline
\end{tabular}

Im Kontext dieses Liedes wird der Begriff ntj nb/wnnt nbt dann expliziert als die Gesamtheit der Lebewesen von Göttern und Menschen bis zu Würmern, Flöhen und Mäusen. Noch näher steht unserer Formel ein in mehreren frühthebanischen Eulogien bezeugter Abschnitt: 94

$$
\begin{array}{ll}
\text { nb hhw } & \text { jwtj snnw.f } \\
w^{C} w & \text { jrjw ntt qm3 wnnt }
\end{array}
$$

Hier wird nicht nur das Begriffspaar ${ }^{C}$ - ḥhw benutzt, sondern in der Bezeichnung des Gottes als "Herr der Millionen" auch über einen rein schöpfungstheologischen Bezug hinausgegangen .

Die Antithese von $w^{\mathrm{C}}$ und hhw kommt auch in den beiden wichtigsten Hymnen der Amarna-Religion vor. Der Grosse Hymnus stellt dem Einen die millionenfältigen Gestalten der aus seinem Licht hervorgegangenen natürlichen Erscheinungswelt gegenüber: 95

93 In dieser Antithese von Einheit und Vielheit, als der Eine Gott mit den vielen Armen, hat man wohl mit Recht eine sprachliche Präfiguration des ikonographischen Typus des "Strahlenatons" erkannt, indem die Amarna-Religion ihren Gottesbegriff veranschaulicht, s. dazu Hornung, in: ZAS 97(1971) 15. Meine in: Saeculum 23,115 n.23 vorgebrachte $\mathrm{Kri}$ tik, dass es sich im pkairo 58038 nicht um den Sonnen-, sondern um den Schöpfungsgott handelt, wird im Licht einer Theologie des Lebensgottes hinfällig, die den gemeinsamen Traditionshintergrund der älteren AmunRe-Theologie, wie sie durch den Kairener Papyrus repräsentiert wird, und der Amarna-Religion dargestellt. So geht es nach meinem jetzigen Verständnis auch im pKairo 58038, VI, 7 um die Antithese von Einzigkeit (als Sonne) und vielheit innerweltlicher lebenspendender Manifestation.

94 Text 130=Text 176. Die chiastische Struktur dieses Verspaares lässt sich im folgenden Schema verdeutlichen ( $a=$ Vielheit, $b=$ Einheit):

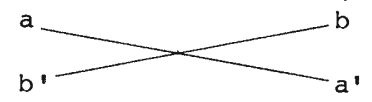

95 Sandman, Texts from ... Akhenaten, 95.12-13 vgl.zu dieser Stelle Fecht, in: ZAS 94(1967) $33 \mathrm{~m} . \mathrm{n} .7$; Text $54(\mathrm{x})$. 
jrjj.k hhw n hprw jm.k w w

njwwt dmjw

3hwt mtn jtrw

Du erschaffst Millionen Gestalten aus dir, dem Einen:

Städte und Dörfer

Acker, Weg und Fluss

Dieser Begriff einer durch das Licht begehbar, zum geordneten Kosmos gewordenen welt wird ausserhalb Amarnas wohl nie mit dem Ausdruck "Millionen" verbunden. Dem üblichen Verständnis dieses Ausdrucks sehr viel näher steht aber die Stelle im Kleinen Hymnus: 96

jrjj.k pt w3tj $x$ wbn jm.s

r m33 jrt.n.k nbt jw.k $w^{C} t j$

jw hhw $n{ }^{c}$ nh jm.k $r s^{c}$ nh sn

Du hast den Himmel fern gemacht um an ihm aufzugehen,

um alles zu schauen, was du geschaffen hast, der du ein Einziger

bist,

aber Millionen Leben sind in dir, um sie zu beleben.

An beiden stellen geht es aber nicht um die Schöpfung am Anbeginn, um die Selbst-Entfaltung eines präexistenten Einen zu der millionenfältigen wirklichkeit des gegenwärtigen $\mathrm{zu}$ stands, sondern um die gegenwärtige Beziehung von Gott und Welt, die fortwährend als millionenfältige wirklichkeit aus dem Einen hervorgeht.

Weder in der Amarna-Religion, noch in den angeführten stellen der älteren thebanischen Amun-Re-Eulogien wird diese Antithese von Einheit und Vielheit - oder beser: All-heit - mit den Begriffen des Verborgenen, Geheimnisvollen, Unergründlichen, und auch nicht mit dem Ba-Begriff verbunden. Sie wird offenbar nicht als Problem empfunden. Der thebanischen Amun-ReTheologie der Voramarnazeit scheint es gelungen zu sein, diese Antithese, die ja auch hier schon nicht rein schöpfungstheologisch, sondern als Ausdruck einer Beziehung des "Lebens-

96 Sandman, ibd., 15.1-9 s.Text 253 (s). 
gottes" zu der von ihm belebten schöpfungswelt aufgefasst wurde, mit dem Polytheismus im Sinne eines primats zu vereinbaren: als Vorrangstellung des Einen über die Vielen. Die Amarna-Religion denkt die Beziehung von Gott und Welt als das sichtbare Gegenüber von Sonne und Erde, die als belebte Schöpfungswelt täglich neu aus der Einen Quelle des Lebens hervorgeht.

Zum Problem wird die Einheit Gottes erst dort, wo sie mit der im Polytheismus realisierten Vorstellung von der Göttlichkeit der Welt in Einklang gebracht werden muss, ohne auf die Vorher-Nachher-Relation der schöpfungstheologischen Lösung reduziert werden zu können. Das ist die Situation der Ramessidenzeit. Die Einheit Gottes wird weder als Präexistenz, noch als Monotheismus realisiert, sondern als Transzendenz, als eine "verborgene" Einheit, in der alle lebendige Vielfalt auf Erden ihren Ursprung hat und deren unerforschliches Wesen nur im "farbigen Abglanz" der polytheistischen Götterwelt erfahrbar und aussagbar ist.

\section{Schöpfung}

\subsection{Schöpfungslehren als "Naturlehren"}

Eine Schöpfungslehre ist in erster Linie eine "Naturlehre", d.h. sie formuliert weniger theologisches, als kosmologisches, biologisches und anthropologisches wissen.96a Die grossen und sozusagen genuinen schöpfungslehren der ägyptischen Religionsgeschichte geben alle weniger einem Gottesbegriff als einem Weltbild Ausdruck. Die geistige Situation der Ramessidenzeit ist durch das Nebeneinander verschiedener, weniger "konkurrierender" als vielmehr gleichermassen wahrer, Weltbilder = Schöpfungslehren gekennzeichnet, deren Verhältnis zueinander man wohl am besten mit dem modernen Komplemen-

$96 a \mathrm{Vgl.} \mathrm{hierzu} \mathrm{R.Hönigswald,} \mathrm{Vom} \mathrm{erkenntnistheoretischen} \mathrm{Gehalt} \mathrm{alter}$ Schöpfungserzählungen (1957); G.v.Rad, "Hiob 38 und die altorientalische Weisheit", Suppl. to VT 3(1955)293-301; Zum Begriff der Naturlehre s. Morenz, in WZKM 54(1957), $119 \mathrm{ff}$. 
taritätsbegriff beschreibt. 97 Es kann hier nicht darum gehen, diese einzelnen Schöpfungslehren ausführlich zu referieren. 98 Andererseits müssen wir aber, um den Eklektizismus der thebanischen Texte verstehen zu können, einen kurzen Blick auf die geistige Heimat der dort zusammengebrachten Vorstellungen werfen.

\subsubsection{Heliopolis}

Die älteste ägyptische Schöpfungslehre, die alle späteren beeinflusst hat, ist die von Heliopolis. Ihr kennzeichnendes Merkmal ist die strikt "biomorphe" Anschauung der kosmogonischen Prozesse. 99 hpr "entstehen aus, werden $\mathrm{zu}$ " sowie hprw "Verkörperung, Emanation" sind die Zentralbegriffe dieser Lehre, die die Welt gleichsam als Emanation Gottes denkt. 100 Typisch für dieses Denken sind die Metaphern der "Ausscheidung": die ersten Götter werden ausgespuckt und ausgehustet, die Menschen entstehen aus den Tränen des göttlichen Auges. 101 Selbst wo das "Hervorgehen aus dem Mund" nicht mehr als Ausscheidung, sondern als ein sprechakt verstanden wird, entstehen gleichsam beiläufig und jedenfalls unabsichtlich die Namen der Götter aus den Gesprächen des Gottes mit sich selbst oder mit dem Urwasser, aus dem er hervorging. 102

$97 \mathrm{Vgl.} \mathrm{E.Hornung,} \mathrm{Der} \mathrm{Eine} \mathrm{und} \mathrm{die} \mathrm{Vielen,} \mathrm{233-240.} \mathrm{Im} \mathrm{Gegensatz} \mathrm{zu} \mathrm{Hor-}$ nung verstehe ich aber die Beziehung von Einheit und Vielheit des Göttlichen nicht als Nebeneinander von Polytheismus und "Henotheismus" im Sinne der Komplementarität, weil der Agypter sich um eine geistige vermittlung dieser pole einer dialektischen Beziehung bemüht hat, anstatt sie "nebeneinander" bestehen zu lassen. Zum Komplementaritätsbegriff s.a. U.Berner, in: GM 20(1976) 59-71.

98 S. dazu S.Sauneron, J.Yoyotte, "La naissance du monde selon l' Egypte ancienne", in: Sources Orientales I (1959),17-91; S.Morenz, Agyptische Religion (1960),167-191; S.G.F.Brandon, Creation Legends of the Ancient Near East (1963), 2.Kapitel.

99 zur Terminologie und zur Kriteriologie der Unterscheidung "bio-" und "technomorpher" Modelle der Weltschöpfung S. E.Topitsch, Gottwerdung und Revolution, 39ff.

$100 \mathrm{Vg}$. Sauneron, Yoyotte, a.a.0.,48-51 zu pBremner Rhind XXVI,21-XXVII,5 und XXVIII, 20-XXIX,6, dem locus classicus dieser Lehre, s.a. ibd.27f.

$101 \mathrm{CT}$ VII $464 / 65 \mathrm{vgl}$. u. $\$ 4.4$.

$102 \mathrm{Vgl.} \mathrm{z.B.} \mathrm{die} \mathrm{Entstehung} \mathrm{der} \mathrm{"Acht} \mathrm{Heh-Götter"} \mathrm{bei} \mathrm{Gelegenheit} \mathrm{eines}$ Gesprächs zwischen Atum und Nun CT II 5-8 Sauneron-Yoyotte a.a.0., 47 doc.7. 
Die ersten Stadien der Schöpfung entstehen unabsichtlich. Planvolles Handeln setzt erst mit der sinnvollen Einrichtung der Welt für die aus dem Urgott hervorgegangenen Geschöpfe ein. Die Schöpfung zerfällt so in zwei Phasen, die mit den Namen Atum (der Ursprung der Emanationen) und Re (der Schöpfer des Kosmos) verbunden werden. Die Hauptstücke der heliopolitanischen Naturlehre beziehen sich vermutlich auf die wirksamkeit des Re, wie das die erhaltenen Darstellungen der "Weltkammer" im Sonnenheiligtum des Niuserre nahelegen, ebenso wie die Schöpfungslehre der "Lehre für Merikare". 103 Die SchuTheologie der Sargtexte verteilt die beiden Aspekte auf Atum und Schu als Vater und Sohn: Atum als der Ursprung der hprw, Schu als der ordnende Lebensgott, der ihre Versorgung sichert. 104

\subsubsection{Memphis}

In genauer und bewusster Opposition zur heliopolitanischen Kosmogonie lässt die memphitische Schöpfungslehre die Welt aus dem planenden Entwurf eines Demiurgen hervorgehen. Ptah ist der Gott der Künstler, der Bildhauer und Handwerker. Schöpfung erscheint in dieser Konzeption als ein Akt der Scheidung: von Wasser und Land, Licht und Finsternis, Himmel und Erde. Diese Scheidung - und das ist wohl der entscheidende Gedanke - wird mit den Mitteln des Begriffs durchgeführt. Das wichtigste Organ der Schöpfung ist nicht die ausführende Hand, sondern das entwerfende "Herz" und die formulierende "zunge". Wie immer man das Alter des "Denkmals memphitischer Theologie" ansetzen mag ${ }^{105}$, der springende Punkt dieser Lehre beruht jedenfalls auf alter Tradition. Mit der Theologie von Memphis verbindet die Ramessidenzeit die Vorstellung des Urhügels, d.h. der Erschaffung des Raumes durch die Trennung von Wasser und Land, und die Vorstellung des sich als Schöp-

$103 \mathrm{zu}$ der 'Naturlehre' der 'Weltkammern' s. E.Edel, Zu den Inschriften a.d. Jahreszeitenreliefs der Weltenkammer..., NAWG 1961.8,243.

104 S. hierzu S.Morenz, in: WZKM 54(1957)119ff.; de Buck, Plaats en betekenis van Sjoe..., 21-35.

105 S.hierzu zuletzt H.A.Schlögl, Der Gott Tatenen, OBO 29,1980,110ff. 
fung durch das wort realisierenden, kunstreich ersonnenen Schöpfungsplanes. 106

\subsubsection{Amarna}

In der Amarna-Religion spielen die auf den Uranfang gerichteten Fragen keine Rolle. 107 Der spezifische Beitrag von Amarna zur Geschichte ägyptischer Schöpfungsvorstellungen liegt in der Konsequenz, mit der hier schöpfung als creatio continua gedacht und auf das gegenwärtige Gott-Welt-Verhältnis bezogen wurde. Der Grosse Hymnus, der in den Versen 59104 dieser Schöpfungslehre einen verbindlichen Ausdruck gibt, gliedert sich in zwei Teile, deren erster eine Art embryologischen Traktat darstellt, während der zweite die wohleingerichtetheit der Welt im Grossen zum Thema hat. Der embryologische Traktat stellt eine Transformation des traditionellen heliopolitanischen Themas von der Entstehung des Lebens dar, indem er es von der phylogenetischen auf die ontogenetische Ebene verlagert: aus der Erschaffung der Menschheit wird die Erschaffung des Kindes im Mutterleib. Wenn irgend, dann kann hier von einer Naturlehre gesprochen werden.

Aber auch der zweite Teil vermittelt vornehmlich kosmologische Erkenntnisse, wenn er in der Verschiedenheit der Hautfarben und Sprachen der Völker sowie der auf der Unterscheidung von Regen und Flussbewässerung beruhenden Verschiedenheit ihrer Lebensbedingungen die Wohleingerichtetheit der welt preist.

\subsubsection{Chnum}

Unter den späten Hymnen von Esna finden sich anthropologische Traktate, die Beschaffenheit und Funktion der einzelnen Körperteile minutiös und nach dem besten stand des damaligen Wissens beschreiben. 108 Chnum ist der Menschenschöpfer par

106 In der Belegsammlung zur "Schöpfung durch das Herz", u., tritt Ptah sehr auffällig hervor (Belege 5-9). Vgl. auch Morenz, Agyptische Religion, 172-174.

107 S. Saeculum 23,119f. m.n.42-43.

$108 \mathrm{~S}$. besonders Sauneron, Esna V, $95 \mathrm{ff}$. 
excellence. Die Lehre von Esna unterscheidet daher als einzige ägyptische schöpfungslehre Welt- und Menschenschöpfung und stellt Chnum die androgyne Urgottheit Neith als Weltschöpfer zur Seite. ${ }^{109}$ Mit der Schöpfungstätigkeit des Chnum, die ausschliesslich dem Menschen gilt, verbindet man die spezifisch anthropologischen Phänomene des Ka und der Individualität. Das Herz wird im Totengericht als "mein Chnum" angerufen. Der Name des Gottes erscheint oft in einer Linie mit Personifikationen des persönlichen Schicksals wie Schai, Meschenet, Renenet. 110

Man wird in dieser Ubersicht das Stichwort "Hermupolis" vermissen. Aber die üblicherweise aufgrund ihres Namens, der "die Acht" bedeutet, mit dieser stadt in Verbindung gebrachte Lehre von den Acht Urgöttern dürfte man in ramessidischer zeit kaum als einen mittelägyptischen "Import" angesehen haben. Man hat darin vielmehr den Ausdruck einer spezifisch thebanischen Lehre gesehen, der sich mit denen von Heliopolis und Memphis zu einer umfassenden Schöpfungslehre ausbauen liess.

4.2 Die Tran'formationen des Urgottes: die "Reichstriade" als kosmogonische stadien

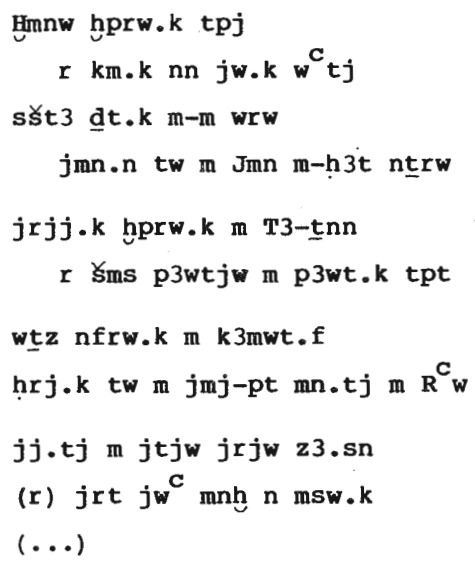

109 Sauneron-Yoyotte, a.a.0.,72.

110 MDIK 28(1972)61 m.n.39; Fecht, in: ZAS 105(1978)24. Zu Chnum als Schöpfer der individuellen Person s.a. Brunner, in LA I, $303 f$. 
Die Acht waren deine erste Gestalt,

damit du diese zur Eins vollmachtest. 111

Geheim war dein Leib unter den Uralten,

indem du dich verborgen hieltest als Amun an der Spitze der Götter.

Du nahmst deine (nächste) Gestalt an als Tatenen,

um die Urzeitlichen hervorzubringen in deiner ersten Urzeit.

Deine Schönheit erhob sich als "Stier seiner Mutter",

du entfernstest dich als der, der im Himmel ist, indem du bliebst

als Re.

Du bist wiedergekommen in den Vätern als Schöpfer ihrer Söhne,

um ein treffliches Erbe zu machen für deine Kinder.

$(\ldots)^{112}$

Der Pap. Leiden J 350, in dem man sicher die differenzierteste Darstellung der ramessidischen Amuntheologie erblicken darf, entwickelt eine Schöpfungslehre, die offensichtlich den Versuch darstellt, die heliopolitanischen und die memphitischen Traditionen in ein neues umfassendes Weltbild zu integrieren. Nach dieser Lehre verteilen sich die zentralen Gedanken der mit den drei religiösen Zentren des Landes, Theben, Memphis und Heliopolis, verbundenen schöpfungslehren auf drei aufeinanderfolgende stadien des kosmogonischen Prozesses.

Das erste Stadium, d.h. die "erste Verkörperung ( hprw )" des allumfassenden Gottes, bilden die "Acht Urgötter", die das präexistente Chaos verkörpern. Amun ist in ihnen auf eine verborgene Weise gegenwärtig: als eine Hypostase ihrer Einheit. 113 Das zweite Stadium, die "zweite Verkörperung" ist der aus dem Urwasser auftauchende "Urhügel", auf dem der bis dahin im ortlosen treibende Gott Fuss fassen und die schöpfung ins werk setzen kann. Mit diesem Stadium verbindet der Text die Hervorbringung der "Urgötter", p3wtjw, womit viel-

111 So mit Junge, "Wirklichkeit und Abbild", $105 \mathrm{~m} . \mathrm{n} .59$. In Amun werden die Acht zur Eins, vgl. ähnlich pBerlin 13603 bei Sauneron- Yoyotte, a.a.0., 58 doc. 15 .

112 pLeiden J 350 III 22-27; Zandee, Hymnen, 63-66; AHG Nr. 135 .

113 Sauneron-Yoyotte, a.a.0. $53 \mathrm{vgl}$. auch 34 . 
leicht Schu, Tefnut, Hike ("Zauber") u.a. gerne als "urgötter" auftretende Gottheiten gemeint sind. Auf die verborgene präexistenz und die erste Selbstverfestigung ${ }^{114}$ als Urhügel folgt als drittes Stadium die Entfernung. Mit der Erschaffung des Himmels und der Entfernung an ihn schafft sich der Gott eine Sphäre, in der er allein ist, getrennt von denen, die aus ihm hervorgegangen sind.

Die Götternamen, mit denen sich diese Kosmogonie verbindet, Amun, Tatenen und Re, bilden die "Reichstriade", die hier, ähnlich wie die Neunheit von Heliopolis, ein kosmogonisches Sukzessions-Schema darstellt. In dieser verbindung hat man wohl das eigentliche Anliegen des Textes zu sehen. Die Schöpfungslehren von Memphis und Heliopolis werden auf diese Weise im sinne von Stadien eines komplexen kosmogonischen prozesses in die thebanische Kosmogonie integriert. Für den ägyptischen Theologen muss das Nebeneinanderbestehen verschiedener Schöpfungslehren bei gleichzeitiger Einhelligkeit darüber, dass nur ein Gott die Welt geschaffen habe, spätestens in dem Augenblick zum problem geworden sein, wo es nicht nur um den Ausbau einer Lokaltheologie, einer Tempellehre, ging, sondern um den Entwurf eines allgemein akzeptablen Weltbilds. Den ersten Entwurf eines solchen allgemein verbindlichen weltbilds stellt die Amarna-Religion dar, die das problem der anderen Götter auf einfache und gewaltsame weise gelöst hatte. Auch die thebanische Theologie scheint mit dem Anspruch aufgetreten zu sein, ein allgemein gültiges Weltbild zu formulieren. Man erkennt das u.A. daran, dass sie sich zu ihrer verbreitung und Darstellung literarischer Mittel bedient, wie das neben dem bedeutendsten Text, dem pLeiden J 350, z.B. auch der pchester Beatty IV rto. und der pLeiden J 344 vso

$114 \mathrm{Vgl}$. CT I 316a, 318a, 336a.

Auch die Kosmogonie des pBremner-Rhind spricht von einem Akt der "Selbstverfestigung" ( $\mathrm{tz} v \mathrm{vgl}$. Wb $\mathrm{V} \mathrm{398,12-15)}$ des Urgottes: tz. n.j jm m nnw $\mathrm{m}$ nnjwt "Ich habe mich dort verfestigt im Nun und in der Trägheit". m nnw m nnjw auch Tura-Hymnus 11-12 s.u., 226. Zum Begriff der Trägheit als Eigenschaft des Chaos s.Morenz, Agyptische Religion, 175 m.n.39. Zum Text vgl. D.Lorton, in: Newsletter SSEA 7.4 (Aug. 1977) 17-23. 
(das Verso der Admonitions) bezeugen. ${ }^{115}$ Der Leidener Papyrus ist ganz auf allgemein-ägyptische Akzeptabilität hin ausgerichtet: deshalb spielt die "Reichstriade" in ihm eine so bedeutende Rolle.

Das eigentliche Anliegen dieser Schöpfungslehre ist nicht kosmologischer, sondern theologischer und religionspolitischer Natur: es geht nicht um den Entwurf einer neuen Naturlehre $115 \mathrm{a}$, sondern um eine Lösung des theologischen Problems, die verschiedenen einander im komplementären sinne ergänzenden und als unaufgebbares wissen festzuhaltenden weltbilder der einzelnen schöpfungslehren in eine umfassende Schöpfungskonzeption zu integrieren und die verschiedenen Schöpfergötter als "Transformationen" eines einzigen ebenso umfassenden Gottes zu verstehen. Obwohl diese Lehre bis in die griechisch-römische zeit nachgewirkt hat, vermisst man jeden Reflex davon in den Hymnen der Gräber. Selbst die grossen theologischen Hymnen der Ramessidenzeit (ÄHG Nr. 127-131) lassen jeden Einfluss dieser Vorstellungen vermissen, mit Ausnahme des Berliner Ptah-Hymnus pBerlin $3048=$ ÄHG Nr. 143.116 Bevor ich jedoch auf die Behandlung des schöpfungsthemas in den Gräberhymnen eingehe, sei noch ein Blick auf die einzigen beiden Hymnen geworfen, die dieses Thema nicht in der üblichen eulogischen Form, also im Nominalstil der Prädikation, behandeln, d.h. also nicht von der Schöpfung, sondern vom

115 Auch der pKairo 58038, der sog. Kairener Amunshymnus, ist eine lit. Hs. Bereits die ältere thebanische Amun-Re-Theologie lässt eine ausgeprägte Tendenz zu gesamtägyptischer Verbreitung erkennen, s.Kap.4 $\$ 4$.

115a Einzig die letzten beiden Verse des zit. Abschnitts aus pLeiden J 350 III 22-27 lassen ein "naturtheologisches" Anliegen erkennen. Hier wird die Auffassung greifbar, dass der Schöpfer, der sich als Sonne an den Himmel "entfernt" hat, zugleich "wiederkommt", um als Zeugungskraft in den Männern wirksam zu sein, ähnlich wie nach dem Denkmal memphitischer Theologie Ptah als Erkenntnis und Sprachvermögen in allen Herzen und zungen wirksam bleibt. Die "Theorie der Fortpflanzung" gehört zu den charakteristischen Themen der ramessidischen und späten Schöpfungstheologie, s.n.136.

116 S. AHG Nr.143, 70-79 mit S.590 z.St. Zu den spätzeitlichen Ausformungen s. ibd., $587 \mathrm{zu} \mathrm{Nr} .135$ und $\mathrm{Nr} .144,14-18$, mit 593 z.St., vgl.auch zeit und Ewigkeit, 21-23 m.n.58 und 60; "Primat und Transzendenz", $30-31$. 
Schöpfer reden, sondern die in erzählender Form einen Bericht der Schöpfung geben.

\subsection{Narrative thebanische Schöpfungshymnen}

\subsubsection{Der Hymnus von Tura}

Obwohl in einer Höhle in den Steinbrüchen von Tura bei Heliopolis aufgezeichnet, und zwar in einer Nische, die durch hölzerne Flügeltüren verschliessbar war ${ }^{117}$, gehört dieser Text doch nach Theben. Das geht nicht nur aus den ersten Versen in aller Deutlichkeit hervor ${ }^{118}$, sondern hat sich auch durch die glückliche Entdeckung eines paralleltexts auf Fragmenten aus dem Grabe des Gottesvaters Neferhotep (TT 50 , Zeit: Haremhab) bestätigt (Text 62d). Dadurch erklären sich die eigenartigen Umstände seiner Aufzeichnung in Tura, die aus der Amarnazeit stammen wird: als thebanischer Amun-Re-Hymnus war dieser Text in der Amarnazeit natürlich verboten und konnte nur an geheimem Orte aufgezeichnet werden, wo wahrscheinlich ein geheimer Amun-Kult stattfand.

Der Hymnus von Tura ergänzt den Kairener Amunshymnus pKairo 58038 ( HHG Nr.87) genau um den Aspekt, der dort in so auffallender Weise fehlt: um die Schöpfung. Das besondere dieser Darstellung der Schöpfung ist die narrative Form. Die einzelnen kosmogonischen Vorgänge werden in Verbalsätzen erzählt und in eine zeitlichen Abfolge gebracht:

1. Selbstverfestigung im Urwasser. Die Göttervielheit als Glieder des sich selbst formenden Gottesleibes 119

bs.n.f m hypr ds.f

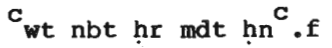
qd.n.f sw n hprt pt t3
Er kam hervor als Selbstentstandener, und alle seine Glieder redeten mit ihm. Er formte sich, als Himmel und Erde noch $\mathrm{nicht}$ entstanden waren

jw t3 m nnw r-jmjtw nnjw als die Erde im Urwasser war inmitten der "müden Flut".

117 Bakir, in: ASAE 42(1943) 83ff.

118 AHG Nr.88, 1-6. Ein Paralleltext des Anfangs ist Text 236 (TT 323), vgl. auch Text 72 (TT 55). 
2. Schöpfung der Erde (Urhügel) als Ort für die aus dem Selbstgespräch des Gottes entstandenen Götter

$\mathrm{s}_{3}{ }^{\mathrm{C}} \mathrm{n} . \mathrm{k}$ js $\mathrm{r}$ jrt $\mathbf{t} 3 \mathrm{pn}$ denn erst um zu befestigen, was aus deinem Munde hervorging (= die Götter),

$r$ smn prt $m$ r3.k hast du damit angefangen, dieses Land zu erschaffen.

3. Trennung von Himmel und Erde. Die Erde als Träger des "Bildes". 120

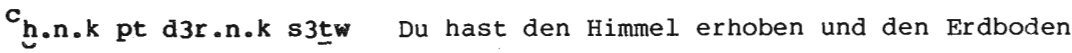
niedergestreckt

$r$ swsh $t 3$ pn $n$ tjt.k um die Erde weit zu machen für dein Bild.

4. "Erste Verkörperung" als Sonne. Schaffung des Lichts. jrjj.k hprw tpj $m R^{C} w \quad$ Du hast (d)eine erste Gestalt angenommen als Re, r shd t3wj n jrjj.k um die beiden Länder zu erleuchten fur das, was du geschaffen hast.

5. Der Schöpfungsplan ("Rückblende")

$m[k 3]^{121}$.n jb.k w ${ }^{c}$ j entsprechend dem, was dein Herz |erdacht| hat, als du allein warst.

jrjj.k st ntrw m šmsw.k du schufst es, indem die Götter in deinem Gefolge waren, dr prj.k w c $^{\mathrm{m}} \mathrm{mnw}$ nachdem du aus dem Urwasser hervorgekommen warst, in dem du allein warst.

6. Die Erschaffung der irdischen Lebewesen

jr.k rmtw ${ }^{c}$ wt mnmnt Du erschufst die Menschen, das Klein- und Grossvieh,

hprwt wnnt nbt alles Gewordene und alles Seiende.

$119 \mathrm{Zu}$ dieser Vorstellung s. LA II $775 \mathrm{~m} \cdot \mathrm{n} \cdot 190-193$.

120 Zum Bild Gottes auf Erden vgl. u., 242ff. Dort ist das Kultbild in Theben gemeint.

121 Erhalten ist nur das Det. ,davor fehlt $1 \mathrm{Q}$. Das Verb $\mathrm{k} 3 \mathrm{j}$ ist in diesem Zusammenhang gebräuchlich, s.u. $230 \mathrm{n} .131$. 
7. Dank und Lobpreis der Geschöpfe

Die folgenden 7 Verse schildern den Lobpreis und den Jubel der Geschöpfe. Danach beginnt mit erneuter Anrede der letzte Gesang des Hymnus, der offensichtlich das Thema der Erhaltung und der "Wohleingerichtetheit der Welt", in der alles, was lebt, seinen ort und sein Auskommen hat, behandelt. Leider ist er zu zerstört, um mehr als die Umrisse des Themas rekonstruieren zu können:

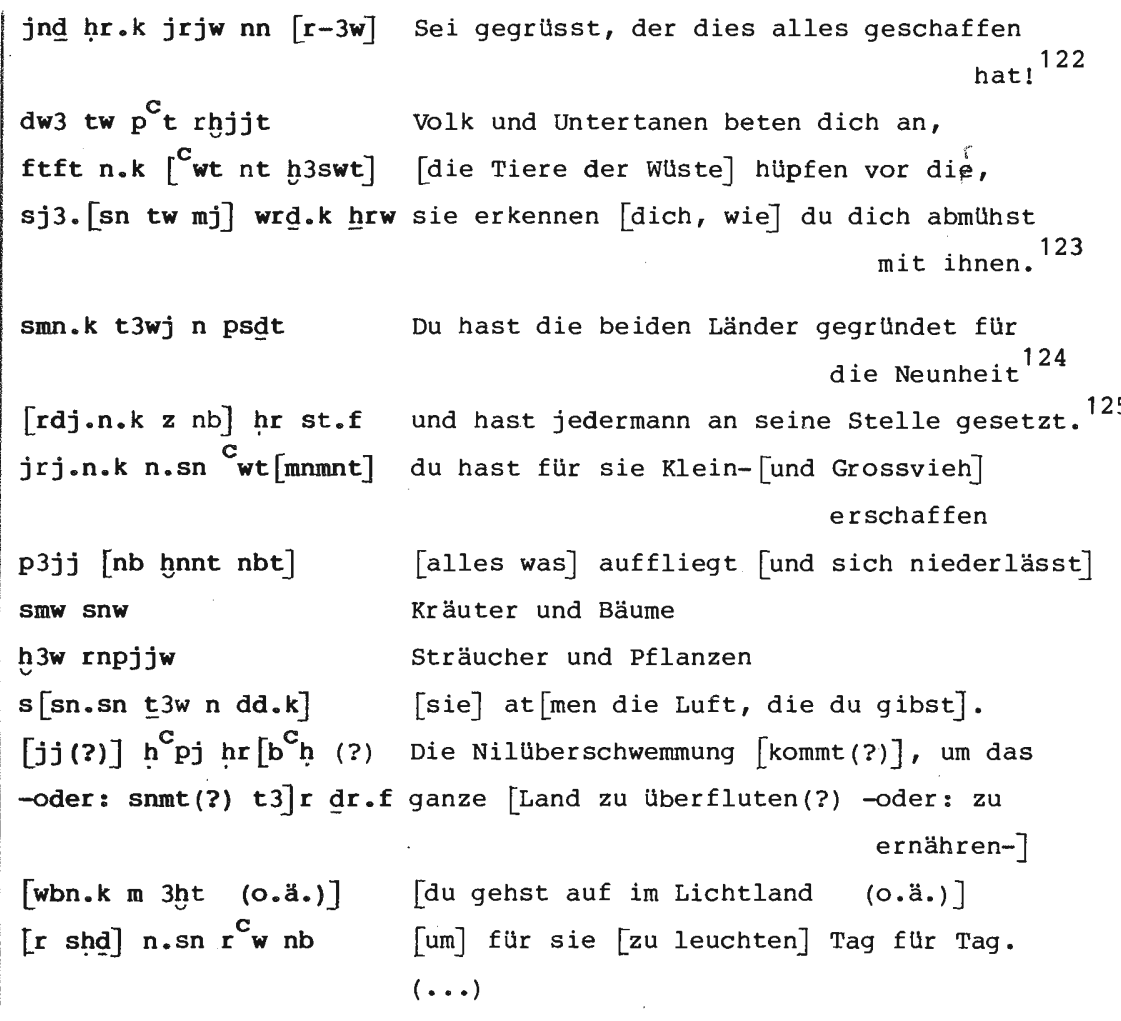

122 Id. pKairo 58038, VI,7.

123 S. hierzu Kap.3\$2.6.

124 Damit ist die Grundung des Tempels und Kulte gemeint, ein Thema, das in der Hymnik der NR ungemein verbreitet ist. Im folgenden stelle ich nur die in meiner Sammlung AHG enthaltenen Beispiele zusammen: $\mathrm{Nr} .26,39 \mathrm{f} ; \quad 38,7-9 ; 101,5-7 ; 104,19 \mathrm{f} ; 127 \mathrm{~A}, 115 ; 127 \mathrm{~B}, 139 ; 130,109 \mathrm{f}$; $144,5-15.24 \mathrm{f} ; 144 \mathrm{C}, 64 ; 192,24 ; 222,10 \mathrm{f} ., 41 \mathrm{f}$. S.S. $613 \mathrm{zu} \mathrm{Nr} .192,24$. $125 \mathrm{Vgl}$. Amarna, Grosser Hymnus AHG Nr.92,85 
Diese Darstellung der Kosmogonie weicht von der traditionellen heliopolitanischen Lehre in manchen Punkten ab. Von Schu und Tefnut ist nicht die Rede. Der Schöpfer geht keine Konstellation mit der aus ihm hervorgehenden Götterwelt ein. Er "wird" nicht "zu Dreien", sondern bleibt Einer. Die Götter sind aber das erste, was entsteht, nachdem der Gott zu sich selbst gefunden, sich zu einem körper verfestigt hat. Sie entstehen sowohl als Glieder dieses Körpers, als auch aus den Worten, die der Schöpfer mit seinen Gliedmassen wechselt.

Die Menschen entstehen nicht in der Urzeit, aus den "Tränen" des Gottes ${ }^{126}$, sondern sie werden erst geschaffen, nachdem die Welt in ihrer jetzigen Einrichtung, getrennt in Himmel und Erde, Licht und Finsternis, geschaffen ist. Diese "weise"127 Einrichtung der Welt wird vom Herzen des schöpfers erdacht, in Ubereinstimmung mit der memphitischen Lehre. Die Menschen werden zwar in einer Reihe mit den Tieren und "allem, was ist" erschaffen; im dritten Gesang wird aber deutlich, dass die Gründung der Erde um der Götter, die Erschaffung der Tiere und Pflanzen aber offensichtlich um der Menschen willen geschieht, und dass zu ihrer Erhaltung [Luft(?)], Nilüberschwemmung und [Sonnenlauf] eingerichtet werden. 128 Diese anthropozentrische Deutung der Schöpfung folgt der Lehre für Merikare. Wir dürfen nicht vergessen, dass dieser Text zwar aus wesentlich früherer zeit stammt, die Hss. aber, in denen er uns überliefert ist, dem Tura-Hymnus genau zeitgenössisch sind.

\subsubsection{Der Hymnus Hibis Tf.32 (AHG Nr. 129)}

Wie Auszüge im mag.Pap.Harris zeigen, stammt der in persischer zeit aufgezeichnete Hymnus Hibis Tf.32 aus der Ramessidenzeit. Nachdem schon die vorhergehende strophe auf einzelne

126 s. dazu unten, $235 f f$.

$127 \mathrm{Vgl}$. pLouvre $3292 \mathrm{u} . \mathrm{S} ., 240 \mathrm{~m} . \mathrm{n} .192$. Das Motiv der Weisheit schwingt auch in dem Anruf smnh-wj sj shrw.k p3 nb nhh "wie wirkungsvoll sind seine Pläne, du Herr des nhh " im Grossen Hymnus AHG Nr. 92, 100, mit, vgl. Kap.3 $\$ 2.5 \mathrm{~m} \cdot \mathrm{n} \cdot 129-130$.

128 Diese Ergänzung rechnet damit, dass die strophe bereits nach der Dreiheit der lebenspendenden Elemente Luft-Wasser-Licht aufgebaut war, $s$. dazu u., $\$ 5.2$. 
Akte der Schöpfung (die Trennung von Himmel und Erde und die Gründung des gestirnten Himmels: Verse 23-25; die Entstehung von Menschen und Göttern aus Auge und Mund: Verse 35-36) und Wesensaspekte des Schöpfers (Herr der Millionen, Urgott, Ursprung der Götter: Verse 28-31) beginnt der eigentliche Schöpfungsbericht mit vers 37. In einer Strophe von 15 versen (3751) wird mit besonderer Ausführlichkeit das Urstadium beschrieben, die selbsterschaffung des Gottes inmitten des Chaos, als "Kind der Acht"129, ohne Vater und Mutter (49), sondern selbst "Vater der Väter, Mutter der Mütter". 130 Das zweite Stadium bildet der Schöpfungsplan, die gedankliche Konzeption des Kosmos. Auch diese ungewöhnlich ausführliche Schilderung nimmt eine grosse Strophe von vielleicht 18 versen in Anspruch (leider mit erheblichen Zerstörungen; 52-69). Wiederholt ist davon die Rede, dass der Gott "Rat pflegt mit seinem Herzen" ( ndnd jb.f ), "plant" ( k3j ) 131, "ersinnt" (w3w3), "befiehlt" ( wd ).

Der dritte und längste Abschnitt dieser Schöpfungserzählung schildert in ca. 26 versen die ins-Werk-Setzung des Schöpfungsplanes $(70-95)$ :

1.) 70-71 Die Hochhebung und Befestigung des Himmels, mit der Sonne darin. 132

2.) 72 Die Ausbreitung der Erde und ihre Umschliessung ( phr ) durch den Ozean ( šn wr ).

$129 \mathrm{Vgl}$. dazu Sauneron-Yoyotte, La Naissance du monde 54-59; pBerlin $3055,20,6-7$ AHG Nr.125, 11-12 vgl. Nr .126,11; Nr.192,15-16.

$130 \mathrm{Vgl.Text}$ 108b; Paser: Kitchen RI III 18-19; pLeiden J-350 V 3-4 u.a., s. Sauneron, in: Mélanges Mariette (1962) 240-242.

131 Auch nach der Darstellung des Denkmals memphitischer Theologie sind die Schöpferworte "vom Herzen erdacht $(k 3 j)$ und von der Zunge befohlen (wd )", s. Junker, Die Gotterlehre von Memphis, Z.56, in 57 zweimal zu wiederholen.

$132 \mathrm{vgl}$. Text 59a; Text 204,5; Totb Nacht col.21: gm3w pt smnw sw m hnw.s; ähnlich Text 209; oMichailides 15 vso; Berlin $6910 \mathrm{Ag}$. Inschr. II 66-67 (von Ptah als Himmelsschopfer); pGreenfield Tf. XXXI (diese und eine Reihe paralleler Stellen: Zeit und Ewigkeit, 38 m.n.129) pGreenfield $\mathrm{XXX}, 3$ :

jrjw pt smnw sw m $c_{\text {wj.fj }}$

jr $n_{0}$ f $c_{n}$ wbn jm.s

Der den Himmel schuf und inn mit seinen Armen festsetzt

der sich einen ort schuf, um an ihm aufzugehen. 
3.) 73-74 Die "Formung" ( qd ${ }^{133}$ ) der Lebewesen: Menschen ${ }^{134}$, Gross- und Kleinvieh, Vögel, Fische, Gewürm. 135

4.) 75-78 Die Erschaffung der Fähigkeit der Fortpflanzung. 136

5.) 79-83 Die Abgrenzung der Länder und ihrer Lebensbedingungen.

6.) 84-86 Die Differenzierung der Menschen nach Hautfarben und Sprachen. 137

7.) 87-90 Die Organisation des menschlichen Körpers und seiner Teile.

8.) 91-94 Lebensbedingungen der Vögel und Fische. 138

Thema dieser strophe ist die Wohleingerichtetheit der Welt, wie sie sich aus der Wohldurchdachtheit des Schöpfunsplanes ergibt und wie sie auch der Grosse Amarna-Hymnus preist: smnh-wj sj shrw.k "wie wirkungsvoll sind deine pläne". 139 In dieser Strophe wird die kosmologische Tradition der Schópfungstheologie als Naturlehre weitergefüht.

Die folgende Strophe (96-107) berichtet in zwölf Versen, was man wohl als das vierte und letzte Stadium der schöpfung zu verstehen hat: die Entfernung des Gottes an den Himmel, um von dort die schöpfung zu betrachten. Sein Blick ist zugleich das Licht, das den Geschöpfen das Sehvermögen schenkt:

$133 \mathrm{Zu}$ qd als der spezifischen Tätigkeit des Menschenschöpfers Chnum $\mathrm{s}$. SAR 8(1980) 5f.n.19, 19 n.87.

134 Nach Vers 35 sind die Menschen bereits vor der Weltschöpfung aus den "Tränen" des Gottes entstanden. Das ist die alte heliopolitanische Lehre, an der man auch weiterhin festhalt, wo es um den ursprung des Menschengeschlechts geht (s.dazu u., 235ff.). Vielleicht ist bei dieser Protogenese des Menschengeschlechts aber noch nicht an ihre physische korperlichkeit gedacht, die erst jetzt zusammen mit den Tieren geschaffen wird.

$135 \mathrm{Zu}$ ăhnlichen Katalogen der Geschöpe s. Text 156 (n).

136 S. hierzu S.Sauneron, in: BIFAO 60,19ff.; J.Yoyotte, in: BIFAO 61, 139-146; D.Muller, Agypten und die griechischen Isisaretalogien, ASAW $53,1961,45$.

$137 \mathrm{~S}$. hierzu Sauneron, in: BIFAO $60,31 \mathrm{ff}$.

$138 \mathrm{zu}$ den Eebensmöglichkeiten der Fische, die auch im wasser atmen, vgl. Text $54,20-21(q)$.

$139 \mathrm{Vgl}$. Kap. $3 \$ 2.5 \mathrm{~m} \cdot \mathrm{n} \cdot 129-130$. 
...sw.f sw m hrt sdg3.n.f jrw

sdg 3.tw m hnw dg3.f

Er (entfernte?) sich an den Himmel, um die Geschöpfe zu betrachten;

man sieht durch seinen Blick

Vgl. damit Neschons, 33 :

dg3.tw $\mathrm{m}$ hnw $\mathrm{n} d g 3 . \mathrm{f}$

Sowie die Var. pCairo 46891 ed.Edwards, JEA 41,100:

jrjw sw $\mathrm{m} 33 \mathrm{jr}$.n.f

"Der das Licht schuf, um zu schauen, was er geschaffen hat"

Dieses Thema, das bekanntlich schon in der Lehre für Merikare ankilingt ${ }^{140}$, spielt in der "Neuen Sonnentheologie" eine grosse Rolle und wurde von uns schon in deren Zusammenhang behandelt (Kap.3 \$\$ 2.2-2.3). Dort steht es aber nicht im Kontext einer schöpfungskonzeption, sondern beschreibt als theologische Ausdeutung der kosmischen Phänomene die gegenwärtigzeitlose Verfassung der Welt. Als letzter Abschnitt der Schöpfung bekommt diese Entfernung, mit der sich der schöpfer am Ende seines wekes von seiner schöpfung distanziert, um sie als ganzes ins Auge zu fassen, noch einen anderen Sinn. In dem als "Buch von der Himmelskuh" bekannten Mythos wird die Vorstellung greifbar, dass der über seine Schöpfung herrschende Sonnengott am Anfang "über Menschen und Götter gemeinsam ( $\mathrm{m}$ jht $\left.\mathrm{w}^{\mathrm{C}_{t}}\right)^{\text {n }}$ geherrscht habe. Erst infolge der Empörung des Menschengeschlechts gegen seinen Schöpfer und Herrscher und seiner nicht vollständig durchgeführten vernichtung ist es der Schöpfergott "müde geworden, mit ihnen zusammen zu sein". So ist es zur.Hochhebung des Himmels gekommen und da-

$140 \mathrm{Vg} 1$. Text 253(u). Weitere Stellen:

BM 170 ed.Edwards, HT VIII Tf. 34:

Honw $m[p t] r$ nb

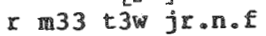

Der am [Himmel] aufgeht, Tag für Tag

um die Lånder zu schauen, die er geschaffen hat.

Edfou III 340:

ag3.kjor.n.k pr nb jm.k

k3 $h^{C C} j b \cdot k m$ jr.n.k

Du betrachtest, was du geschaffen hast, was alles aus dir

hervorging;

dann jubelt dein Herz über das, was du geschafft hast.

Die Belege in AHG sind gesammelt in $513, \mathrm{m.39} \mathrm{zu} \mathrm{S.57.}$ 
mit zur Trennung von Göttern und Menschen. 141 Der Gedanke der Distanz wird in diesem Mythos, wie es die Art mythischen Denkens ist, verzeitlicht. Die Welt, wie sie heute ist, getrennt in Diesseits und Jenseits, in eine ferne, nur abbildhaft und in Symbolen zu vergegenwärtigende Gótterwelt und in die irdischen, in stellvertretung des schöpfers vom köning verwaltete welt der Menschen, ist eine verhältnismässig junge Einrichtung, der nicht etwa das reine "Chaos" voranging, sondern ein Zustand der Gemeinschaft alier Lebewesen, der möglicherweise die Merkmale eines goldenen Zeitalters an sich trug. 142 Daher verbinden sich mit dem Thema der Erschaffung des Himmels und der Entfernung des Schöpfers an ihn Vorstellungen von besonderer Tragweite und Bedeutung, woraus sich die Häufigkeit dieses Themas in ramessidischen Hymnen erklären mag.

Die folgenden strophen des Hibis-Hymnus sehen wie eine Fortsetzung dieses Themas aus. In wirklichkeit markiert aber

141 L.Kákosy, A nap királysága. Az egyiptomi aranykormitoszok, világosság, Budapest 17(1976)229-233. Vgl. auch GM 25(1977) 34 n.61; Zur Deutung als "Urverschuldungsmythos" s.ibd.40 n.15. Allg. s.W. Staudacher, Die Trennung von Himmel und Exde. Ein vorgriechischer Schöpfungsmythos bei Hesiod und den Orphikern (Tübingen 1942). Vgl. auch H.te Velde, "The Theme of the Separation of Heaven and Earth in Egyptian Mythology", in: Stud.Aegypt. 3(1977) 161-170. Zur Deutung des Kuhbuchs als einer "Ätiologie des Unvollkommenen" s. jetzt E.Hornung, Der ägyptische Mythos von der Himmelskuh (OBO 46, 1982).

142 Aus dem Text geht nicht hervor, dass der Weltzustand vor der Erhebung des Himmels und der Entfernung des Sonnengottes besser war als der nachfolgende. Mit Otto, in: Religions en Egypte hellenistique et romaine (CESS 1967) 93-108, wird man daran festhalten, dass die vorstellungen von einem coldenen Zeitalter in ihrer ausgeprägten Form in Agypten erst spät auftreten, wenn man sie auch nicht als Reflex griechischer Einflüsse verstehen sollte. Sie entspringen vielmehr einem spezifischen zeit- und Geschichtsverständnis, das sich auch in der Ausbildung einer eschatologischen Heilserwartung ausdrückt und ebenso wie diese aus zentralen ägyptischen Vorstellungen hervorwächst (s.Königsdogma und Heilserwartung, in: D.Hellholm (Hrsge), Apokalyptik)。 Vgl. auch L.Kákosy, "Ideas about the Fallen state of the world in Egyptian Religion: Decline of the Golden Age" Acta Orientalia Hungarica XVII.2(1964)205ff。

Den Hymnen, die die Erhebung des Himmels als kosmogonische Tat preisen, liegt eine solche Wertung naturlich fern. Die Frage, um die es hier geht, ist lediglich, ob mit dieser Tat die Vorstellung einer Periodisierung der Schöpfungsgeschichte verbunden ist im Gegensatz $\overrightarrow{\mathrm{zu}}$ Stadien des kosmogonischen Prozesses. Zu diesem Problem s. SauneronYoyotte, $42 \mathrm{ff}$. 
der Ubergang in die stilform der Eulogie auch eine thematische zäsur. Im Folgenden ist von der Belebung und Erhaltung der schöpfung die Rede, die Lehre von den "lebenspendenden Elementen", auf die wir im $\$ 5$ eingehen. Es kennzeichnet die ägyptischen schöpfungsvorstellungen, dass sie die Arbeit des Schöpfungswerkes sozusagen nahtlos in die Arbeit der Erhaltung übergehen lassen. Die Schöpfung ist nur das "Erste Mal" in der ewigen wiederkehr der creatio continua. ${ }^{143}$

\subsection{Das Schöpfungsthema in den ramessidischen Gräber-Hymnen.}

Obwohl das Schöpfungsthema in den ramessidischen Sonnenhymnen eine gewaltige Rolle spielt, die geradezu als unterscheidendes Merkmal dieser gegenüber den älteren Traditionen gelten kann, so gibt es doch keinen Text, der einen narrativen Bericht der kosmogonischen Vorgänge gäbe, ja nicht einmal einen, bei dem das schöpfungsthema zentral wäre. ${ }^{144}$ Der Lobpreis des Schöpfers geht immer einher mit anderen Aspekten göttlichen wesens und wirkens, die dem Hymnus mindestens ebenso bedeutsam sind. Wenn man von blossen Epitheta wie p3wtj ( $t 3 w j)$ und hpr ds.f absieht und die Hymnen daraufhin betrachtet, wo sie im Zusammenhang des Schöpfungsthemas ins Detail gehen, dann lässt sich feststellen, dass der kosmogonische Prozess vor allem in seinen Endstadien wichtig wird. Uber den urzustand im Nun gehen die Texte zumeist in kurzen Formeln hinweg, von den "Acht". ist so gut wie nirgends die Rede ${ }^{145}$, schu und Tefnut kommen hier ebensowenig vor wie in anderen Texten der thebanischen Theologie. ${ }^{146}$ Auch hier zeigt sich wieder, dass das eigentliche Anliegen der Reflexionen über den Ursprung der welt ein theologisches ist: denn hierin erschliesst sich am klarsten die Vorstellung von der Einzigkeit Gottes. Dies, und nicht die. Schöpfung als solche, ist das

143 S. dazu Morenz, Agyptische Religion, 174ff; Sauneron-Yoyotte, $77 f$. Der Ausdruck ist erst seit der Herakleopolitenzeit belegt (Otto, a.a.0., 95).

144 Ausnahme vie1l. Text 149.

145 Einmal in zerst. Zusammenhang Text 43.

146 Text $42 a$ erwähnt das "Zwillingspaar"; cf. sonst pBerlin $3049=$ AHG Nr. 127B,208. pLeiden J $350 \mathrm{~V} \cdot 16 \mathrm{ff} .=A H G \mathrm{Nr} .141$ bezieht sich nicht auf die Kosmogonie. 
grosse Thema der zeit: kein anderer schuf vor Gott (Text 54, 14f.) 147, kein anderer schuf nach inm (Text 253,25[p]), kein anderer schuf mit ihm zusammen (Text 113,$55 ; 62 \mathrm{~d}[\mathrm{i}])^{148}$. Alles ist durch Einen Einzigen geschaffen, und dieser Eine hat Alles geschaffen (Text $151[0] ; 155[\mathrm{a}] ; 130$ [d]).149

Der andere Gedanke, der in den schöpfungstheologischen Abschnitten der Gräber-Hymnen eine zentrale Rolle spielt, bezieht sich auf den Ursprung der Menschen und Götter in Gott und den anthropozentrischen sinn der schöfung, die um dieser zuallererst aus dem urgott hervorgegangenen Wesen willen ins Werk gesetzt wurde. Das ist der Sinn der erstaunlich häufig zu belegenden Formel vom Hervorgehen der Menschen aus dem Auge, und der Götter aus dem Munde des Urgottes:

(1) prr.n rmț m jrtj。fj

hprw ntrw tp r $3 . \mathrm{f}^{150}$

(2) pr.n rmtw m jrtj.fj

ntrr jmj sptj.fj 151

(3) nb ntrw jrjw rmtw

pr.n.wr-3w m jrt.f 152

(4) nn wn $C_{\text {nh }} \mathrm{m}$ hmt.f

pron m jrt.f $r-3 w 153$

(5) bjf(?).f bw nb m jrtj.fj

hpr ntrw m r3.f 154

(6) $r \operatorname{sinnh} C_{w t} q m 3 . n . f$

rhjjt prt m jrt.f 155

$147 \mathrm{Vg} 1$, auch pBerlin 3049=AHG Nr, 127B, 120 .

$148 \mathrm{Vgl}$. zu Text $62 \mathrm{~d}(\mathrm{i})$.

$149 \mathrm{Vgl}$. auch Text $41(1)$ und $62 \mathrm{~b}(\mathrm{a})$ zur Formel jrjw 'Einziger Schöpfer', sowie Zandee, Hymnen, $70 \mathrm{zu}$ pLeiden J 350 IV, 6.

150 pKairo 58038 VI 3. prr.n kann nicht stimmen, lies entweder prrw oder pr.n.

151 Text $188(e)$.

152 Text 232(r).

153 oCairo $25208=\mathrm{AHG} \mathrm{Nr} \cdot 193,21-22$.

154 RT 13,163.16.

155 Stele Kairo JE 28569 cf. Kap.3 n.135. 
(7) hpr rmç in jrt.f

cut nbt qm3.n jb.f

ht $-n-{ }^{c}$ nh n rwdw ${ }^{c}$ wt.f 156

(8) sadw.k ntrw

(...)jj.k rmtw rmjwt jrt.k 15

(9) prj nttrw m r3.k

rmtw jut.k 158

(10) prj rontw m ntrwtj.fj

ntrw m tp-r3.f 159

(11) prj ntrw m r $3 . f$

rmtw jrt.f 160

(12) qd.f rmtw m rmjwt jrt.f

smaw.f hret ntwrw 161

(13) jr.n.f rmtw m ntrt.f

$q 3^{\mathrm{C}} \cdot \mathrm{n} . \mathrm{f}$ ntrw m r $3 . \mathrm{f}^{162}$

Vgl. dazu

(14) shpr.n.j ntrw m fdt.j

jw rntw m rmjjwt nt jrtj•j 163

(15) ntn rmjt 3ht m rn.ț n rmț 164

Das Motiv spielt noch in den Texten der griechisch-römischen Zeit eine grosse Rolle 165 und beruhrt sich auf eine m.W. noch ungeklärte weise mit der orphischen ${ }^{166}$ und auch sonst in griechischen Texten belegbaren 167 vorstellung, dass die

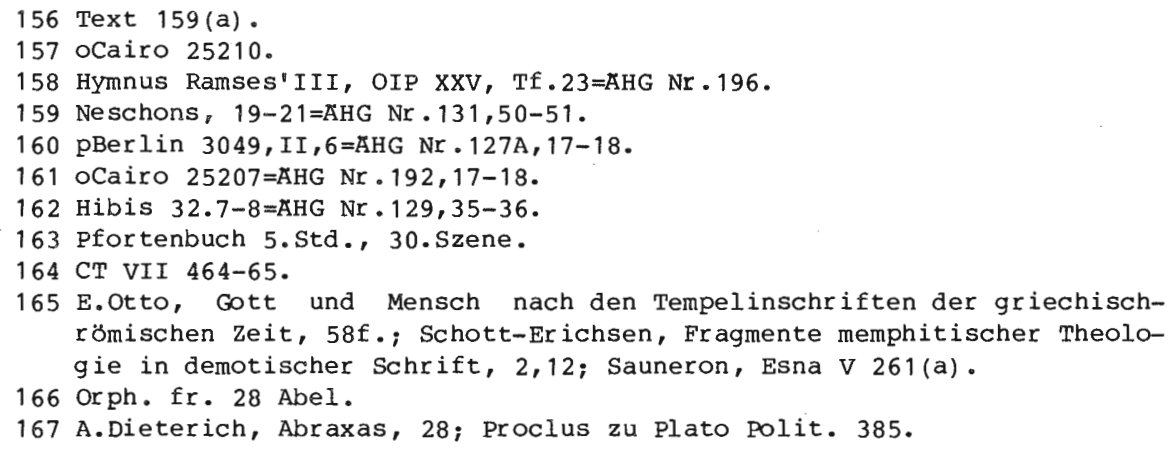
römischen Zeit, 58f.; Schott-Erichsen, Fragmente memphitischer Theologie in demotischer Schrift, 2,12; Sauneron, Esna V 261(a). 166 Orph. fr. 28 Abel.

167 A.Dieterich, Abraxas, 28; Proclus zu Plato Polit. 385. 
Götter aus dem Lachen, die Menschen aber aus den Tränen des Ur-Schöpfers entstanden.

Im Agyptischen beruht die Beziehung der Menschen zu den Tränen des Gottes bekanntlich auf dem Gleichklang der wörter "Mensch" ( rmt ) und "Träne" (rmjt.) vgl. Nr.15. In den Sargtexten $^{169}$ und im Apopisbuch ${ }^{170}$ werden auch spuren eines Mythos greifbar, die dieses Weinen des Urgottes, das zur Entstehung der Menschen fuhrte, im kosmogonischen Prozess lokalisieren. Die ersten aus dem Ur-Schöpfer hervorgegangenen Wesen, Schu und Tefnut, verflüchtigen sich in der noch raumund grenzenlosen Vorwelt. Da schickt der urgott sein "Ein-Auge" hinter ihnen her, um sie zu suchen:

\footnotetext{
"damals sandte Atum sein Ein-Auge aus, mich und meine Schwester Tefnut zu suchen" (CT II 5 b)

"Mein Auge ist es, das sie mir wieder zurlickbrachte, (sc.Schu und Tefnut), nachdem sie sich von mir entfernt hatten"

"Als ich uber sie (Schu und Tefnut) weinte, entstanden die Menschen als Trănen, die aus meinem Auge fielen.
}

Diese aus dem Urgott ausgeströmten "Menschen" sind es wohl auch, die in den Sargtexten mehrfach als seine wndwt bezeichnet werden. 172 Der Ausdruck wndwt ordnet wohl die Menschen dem Schöpfer im gleichen sinne zu, in dem sie sonst "sein Kleinvieh, seine Herde" ( cwt $_{\text {wt }}$ ) genannt werden. 173 Im Lichte dieser zusammenhänge ergibt sich die Bedeutung des Motivs,

168 So auch Esna $\mathrm{Nr} .272,2-3$ Sauneron, Esna V, 142.

169 2.B. CT II 5b; 33d; vgl. IV 174-175.

170 pBremner Rhind 29,3-4; die KF 27,1ff. ist ausfuhrlicher, cf. SauneronYoyotte, La naissance du monde, 51.

$171 \mathrm{rm} \cdot \mathrm{n} \cdot \mathbf{j} \mathrm{hr} . \mathrm{sn}$ hpr rmtw pw m rmw prjw m jrt-j (pBremner Rhind 27.2-3)

Das Weinen des urschöpfers wird auch CT IV $175 \mathrm{f}$ erwähnt, aber ohne Bezug auf die Entstehung des Menschen. Vgl. auch CT VI $344 \mathrm{f}-\mathrm{g}$ und dazu Hornung, Der Eine und die vielen, 142.

172 Z.B. CT I 376/77C. Das Wort leitet sich vermutlich wie nd.t "Hörige" von ng "eintreten fur jmd." ab und bedeutet "Klientel", s. CT I 128b; $129 \mathrm{e}, 130 \mathrm{e}, 131 \mathrm{e}$ usw., 144c, 153e, 163e, 1760; Wb I 326, 5-6. S. auch Piankoff, Les chapelles de Tout-Ankh-Amoun Tf.19. Barns, in: JEA 54 (1968) 74 .

$173 \mathrm{~s}$. dazu Kap. $3 \$ 2.5$, in fine. 
aus der sich das zähe Festhalten an ihm auch in ganz und gar unmythologischen Kontexten erklärt ${ }^{173 a}$. Die Menschen gehören nicht wie die Tiere und Pflanzen, zu der geschaffenen und wohleingerichteten Welt, sondern sie gehören wie die Götter zu jenen dem Ur-Schöpfer am Anbeginn entströmten Lebewesen, um deretwillen dann die welt geschaffen wurde. Aber es kommt noch etwas anderes hinzu. Es fällt auf, dass von den gesammelten Belegen nur 3, Nr.8, Nr.14 und 15 das Wortspiel von "Träne" und "Mensch" erwähnen, sowie dass das "Weinen" des Schöpfers und seine Gründe so unklar beleiben. Es scheint offenbar nicht daran gedacht zu sein, dass die Menschen eine besondere Beziehung zum Leiden haben (wie dann in den griechischen Quellen, wo das Weinen als Ursprung der Menschen dem Lachen als Ursprung der Götter gegenübergestellt wird ${ }^{174}$ ).Wichtig ist für den Ägypter vielmehr die Beziehung der Menschen zum Auge; ihr Charakter als "Augenwesen", wie er sich in Bezeichnungen wie jrt nbt, hr nb äussert, der in der Neuen Sonnen-Theologie eine grundlegende Rolle spielt, gehört zu den Grundbegriffen einer religiösen Anthropologie, an der man bis zuletzt festhält. 175 "Alles, was Augen hat" (womit der Ägypter aber immer nur die Menschen meint) entspringt dem "Auge" des Urgottes.

Ebenso zentral ist für den Agypter der Gedanke der Entstehung der Götter duch das wort. Belege wie Nr.14 zeigen, dass er dem MR noch fremd ist. ${ }^{176}$ Auch wenn bereits hier gelegentlich Götter aus. Wörtern entstehen, ist damit doch nicht die Vorstellung eines intentionalen Schöpfungsaktes verbunden; Wörter sind vielmehr eine Art "Ausscheidungen" wie Tränen, Schweiss, Husten, Spucken usw. ${ }^{177}$ Die Vorstellung von der schöpfung durch das Wort ist demnach wahrscheinlich nicht

173a Z.B. Hibis 32, wo es neben der "Formung" ( qd) der Menschen auftritt, s. oben, S.231 m.n.134. Eine andere Deutung, die auf der Stelle CT VI 344f-g basiert, gibt Hornung, a.a.O. (n.171).

$174 \mathrm{Vgl} \cdot \mathrm{n} \cdot 166-168$.

$175 \mathrm{Vgl}$. Otto, Gott und Mensch, 41,47-50; Brunner, in: LA I,303ff.

$176 \mathrm{Vgl}$. aber Louvre $\mathrm{C} 3,16$ bei A.Moret, Mystères egyptiens, 64. A.J. Gayet, Stèles de la XII . dynastie (1889), Tf.IV.

177 Vgl. Sauneron-Yoyotte, 39f. 
älter als die 18. Dynastie. Sie lässt die Welt nicht aus mehr oder weniger beiläufigen Ausserungen hervorgehen, sondern aus einer "im Herzen" erdachten Ordnung, die in der Form des Ausspruchs realisiert wird. Die schöpfung durch das Wort ist in erster Linie eine Schöpfung durch das "Herz", die planende Weisheit Gottes:

(1) $R^{C} w k[3 j w]$ ntt Re, der das seiende erdacht hat, nb t3-tmmw jrjw Herr der Menschheit, Schøpfer dessen, wnnt 178 was ist

(2) $m[k 3] \cdot n$ jb.k 179 als Konzeption deines Herzens

(3) qm3.n.k t3 n jb.k Du hast die Erde geschaffen nach deinem $j w . k w^{c} t j 180 \quad$ Herzen du allein.

(4) jrjw t3 m hh $n$ Der die Erde schuf als 'Erfindung' (hh: jb $181 \quad$ "suchen") (seines) Herzens

(5) von Ptah:

qm3 j3wt msjw ntrw der die Handwerke schuf und die Gotter erzeugte m jr.n jb.f $182^{-}$als Schopfung seines Herzens

(6) von Ptah:

jrjw hmw m gm.n Der die kunste schuf als Erfindung seines jb.f 183 Herzens

(7) von Ptah:

jrjw pt m qm3.n Der den Himmel machte als schøpfung seines jb.f 184 Herzens

(8) von Ptah:

dd.t $m$ jb.f $m 33$ Was in seinem Herzen erdacht wird, sieht man hpr sn 185 entstehen

178 BM 29944 ed. Stewart, JEA 53,37.

179 Tura-Hymnus, 14.

180 Amarna AHG Nr.92,79.

181 Leiden $\mathrm{K} 1$.

182 Berlin $6910 \mathrm{Ag}$. Inschr. II, 66-67.

183 TT 44 (5) (unv.).

184 pHarris, $I, 44,5=$ AHG Nr .199 .7 .

185 Kopenhagen A $719=$ AHG Nr $\cdot 223,7$. 
(9) von Ptah:

nmw t3 $\mathrm{m}$ shrw $\mathbf{n}$ Der die Erde bildete als Planung seines jb.f $186 \quad$ Herzens

(10) hpr rmtw m jrtj.fj Die Menschen entstanden aus seinen Augen. wt nbt gm3.n und jegliches Vieh, das sein Herz geschaffen jb.f 187 hat

(11) $\measuredangle 3^{C}$ [ntt] nbt $m$ Der alles Seiende begonnen hat als Schöpfung qm3.n jb.f 188 seines Herzens

(12) jrjw pt t3 m Der Himmel und Erde erschuf mit seinem

$$
\text { jb.f } 189 \text { Herzen }
$$

(13) sqn.n.f t3 shpr Er festigte die Erde und liess den Urhügel hr tp $\langle\mathbf{r} 3 . f\rangle^{190}$ nach dem Ratschluss seines Herzens

m shrw..m jb.f 191

(14) m33 jr.k r hm.n Schau doch auf das, was dein Herz geformt

$$
\text { jb.k hat }
$$

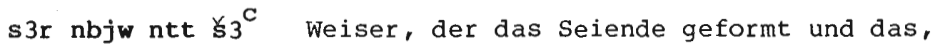

$$
\text { wnnt } 192 \text { was ist begonnen hat. }
$$

(15) ntr pn $53^{C} w$ t3 Dieser Gott, der das Land schuf nach seinen

$$
\text { m shrw.f } 193 \quad \text { Plänen }
$$

Das Thema spielt auch in spätzeittexten eine Rolle 194 sowie natürlich im Denkmal memphitischer Theologie, auf das wir hier nicht einzugehen haben. 195

Im Übergang von der 18. zur 19. Dynastie wird der Gedanke der Schöpfung durch das Wort von der Erschaffung der Götter-

\footnotetext{
186 pBerlin 3048, III, $1=$ A HG $\mathrm{Nr} \cdot 143,22$.

187 Text 159.

188 pBerlin $3049, \mathrm{XI}, 3-4=\mathrm{AHG} \mathrm{Nr} .127 \mathrm{~B}, 80$.

189 Neschons, 9-10=ÄHG $\mathrm{Nr} \cdot 131,26$.

190 Das Det. des Mannes mit der Hand am Mund nach hr tp legt die Annahme nahe, dass hier ein Wort fur "Ausspruch" gemeint ist.

191 Sobek Re IV 9-10=AHG Nr.144C, 38.

192 pLouvre 3292=AHG $\mathrm{Nr} .45,11-12$.

193 Hibis $33,4-5=$ AHG $\mathrm{Nr} \cdot 130,22$.

194 Z.B. Sauneron, Esna V, $361 \mathrm{Nr} .260 .10 ; 220 \mathrm{Nr} .387 .3$; Otto, Gott und Mensch, 58.

195 H.Junker, Die Götterlehre von Memphis, 56f. s. Morenz, Agyptische Religion, 172-174.
} 
welt, auf die er bis dahin beschränkt war, auf die Erschaffung des gesamten Kosmos, "alles Seienden" ausgedehnt. ${ }^{196}$ Die Vorstellung von der schöpfung durch das wort nach dem im Herzen erdachten Plan betont den ordnungsaspekt der Schöpfungswelt, ihren rationalen charakter. Was im Herzen des Gottes erdacht wurde und aus seinem Munde hervorgeht, sind nicht die Dinge selbst, sondern "die Namen aller Dinge", 197 die sich der Agypter in der Art eines onomastikons hierarchisch geordnet dachte. Ein Onomastikon zählt nicht Individuen auf, sondern Klassen ${ }^{198}$, und kann daher als ein erschöpfendes Inventar des Kosmos und ein Abbild seines Aufbaus verstanden werden. Die Lehre von der Schöpfung durch das wort hat die Wohleingerichtetheit der Welt, ihre Fülle und Ordnung, im Blick, und führt sie zurück auf die Weisheit des Schöpfers, die geistige Konzeption im Herzen. Das ist ein Aspekt der Welt, wie er vor allem in der Amarna-Religion (und von da über den 104.Psalm und die weisheit auch in der hebräischen ${ }^{199}$, im Vordergrund steht.

Eine Eigentümlichkeit der Ramessidenzeit aber und in gewissem Sinne auch eine Antithese zum Weltbid der Amarna-Religion scheint eine schöpfungslehre darzustellen, derzufolge der Schöpfer eine "dreistöckige" welt für die dreigestaltige Form seiner innerweltlichen Verkörperung eingerichtet hat: den Himmel in seiner unerreichbaren Höhe und Ferne für seinen "Ba", die Erde in ihrer unabsehbaren Weite und Breite für sein "Bild" und die Unterwelt in ihrer unergründichen Tiefe und Verborgenheit für seinen "Leichnam".

Im Weltbild von Amarna spielt die Unterwelt bekanntlich keine Rolle. 200 Hier gliedert sich die welt in sehr scharfer und

196 S. ausführlich Text $149(L)$.

197 Denkmal memphit. Theol., $55=$ m3t $\mathbf{r n} \mathbf{n}$ jht nbt ; ähnl. pBerlin 3055 XVI $3 f .=$ AHG Nr.122,7.

198 Das gilt auch für Grössen wie 'Himmel', 'Sonne', 'Mond', 'König' u.a. die man als einelementige Klassen $z$ verstehen hat.

199 S. n.96a.

200 Obwohl nicht ausdrücklich hervorgehoben, ergibt sich das doch in aller Klarheit aus der wohldokumentierten Ubersicht, die L.Zabkar, A Study of the Ba Concept in Ancient Egyptian Texts, 156-159, uber die den $\mathrm{Ba}$ betreffenden Anschauungen der Amarna-zeit vom Leben nach dem Tode gibt. Ebenso deutlich tritt diese Reduktion des Weltbildes auf 
rationalistisch anmutender Weise in Himmel und Erde, oben und unten als die sphären von Gott und Schöpfung. Gott hat den Himmel "für sich" geschaffen, als den Ort, von wo aus er die Schöpfung "betrachtet" und durch die lebenspendenden Strahlen dieses Blickes jeden Morgen aufs neue ins Leben ruft. Das Weltbild der traditionellen Sonnenreligion war wesentlich komplexer: durch die Einbeziehung der Unterwelt in die sphäre des Sonnengottes, die Vorstellung seiner Nachtfahrt, die ihn mit den Toten, den Gottheiten der Erdtiefe und schliesslich mit seinem "Leichnam" in Verbindung bringt, gliedert sich die Welt hier in ein oberirdisches Diesseits und in ein Jenseits, das eine himmlische und eine unterweltliche sphäre hat.

Das Weltbild der ramessidischen Amun-Theologie ergibt sich aus dem neuartigen Begriff eines allgegenwärtigen Gottes, der die Welt nicht wie der Sonnengott der Amarnareligion und der Neuen Sonnentheologie von aussen mit seinem Licht, sondern von innen mit seiner "Macht" erfüllt. Aus diesem Gottesbegriff ergibt sich jene kosmogonische Konzeption, die sich die Begrifflichkeit der traditionellen Sonnentheologie, die Vorstellung von "Ba" und "Leichnam" des Gottes, zu eigen macht, um durch Hinzunahme der dritten Komponente, des "Bildes", etwas ganz und gar Neues auszudrücken. Indem der Weltschöpfer, wie es heisst, den Himmel emporgehoben hat, um seinen $\mathrm{Ba}$ zu erhöhen ${ }^{201}$, die Erde weit machte für sein Bild

Himmel und Erde aus der Ersetzung des Themas der Unterweltfahrt durch die Schilderung der Nacht in den hymnischen Darstellungen des Sonnenlaufs hervor, s.Kap.3\$3.3. Wenn, wie Niklas Luhmann postuliert, die "Fortschrittlichkeit" eines systems im Prozess der gesellschaftlichen Evolution sich nach dem Grade seiner Komplexität bestimmt, dann stellt das Weltbild der Amarna-Religion, das an Komplexität weit hinter dem traditionellen Weltbild der ägyptischen Religion zurücksteht, einen Rückschritt dar. Es verdankt seine Durchsetzung ja auch einem revolutionären, nicht einem evolutionären prozess. Sein Scheitern mag sich systemtheoretisch damit erklären, dass es aufgrund seiner geringen Komplexität unzeitgemäss, d.h. der Aufgabe einer sinnstiftenden Wirklichkeitskonstitution nicht gewachsen war.

$201 \mathrm{Vgl}$. Text 141,23(q): "Du hast den Himmel geschaffen für deinen Ba, als du allein warst; Text 255,8(g): "Der den Himmel schuf, um seinen $\mathrm{Ba}$ zu erhöhen". Weitere Stellen s. AHG S.562 zu Nr 100,23. 
und die Unterwelt tief für seinen Leichnam ${ }^{202}$, wird darin die Idee einer ko-extension von Gott und Welt zum Ausdruck gebracht. Gott erschafft die Welt im Prozess seiner eigenen Gestaltwerdung und Ausdehnung. Das ist nicht allein eine "Entfernung", wie in der Tradition der Neuen Sonnen-Theologie, sondern eine Ausdehnung in alle Richtungen zugleich. Gott erfült die welt von innen heraus bis an ihre Grenzen und, nach dem "200." Lied der Leidener Amunshymnen, noch darüber hinaus $(\mathrm{s} .0 ., \$ 3.1)$.

Wie immer, wo sich eine neue Konzeption traditioneller Begrifflichkeit bedient, ist es eine delikate Aufgabe, sie in den Formulierungen der Texte aufzuspüren. Ganz klar kommt sie in Text 17 zum Ausdruck:

pt hr b3.k hir stzz 3hwok

d3t $\underline{h r} \underline{h} 3 t . k$ ḥr sḥ $3 p d t . k$

t3 pn $\underline{\text { hr }}$ hnntj.k

Der Himmel trägt deinen Ba und erhöht deinen Lichtglanz,

Die Unterwelt trägt deinen Leichnam und verhüllt deinen dt -Leib

Dieses Land trägt dein Bild

202 In der binären Form, die nur Himmel und Unterwelt - auch: Himmel und Erde - gegenüberstellt, findet sich das Motiv auch im Kontext der Sonnentheologie, vgl. z.B.

1) pTurin Pleyte und Rossi: Tf. 146,8:

jrjw $t 3 r \operatorname{sh} 3 p d t . f$

h pt $\mathrm{n}$ b3.f

2) Text 256, id. TT 178 (8: an Osiris; auch Text 256 ist wohl an Osi$r$ is gerichtet)

jrjw n.f (=dem geschaffen wurde) pt $r$ sq3 b3.f

d3t $r$ sh3p dt.f (TT 178: smdw d3t $n$ h3t.f )

3) Text 113,56f.

[sšt3.n.k d3t] r sḥ̂p sšm.k

h.k pt $r$ s3h $[\mathrm{b} 3 . \mathrm{k}]$

4) Edfou III 186

${ }_{h}$ pt $n$ b3.f wbn.f jm.s

d3t st3tj hạp dt.f

5) Quibell, Exc.at Saqqara IV (1908-10), Tf.73.3 cf. n.223:

h pt m stzw [sw $n] 3 h t . f$

dt.f $\operatorname{mnh}[t j \mathrm{j} d 3 t]$

6) Totb 15B II, Berlin 7317=AHG Nr. 44 und 62; hier, im Sinne der Neuen Sonnentheologie, als Himmel und Erde:

hw pt $r$ hpt jrtj.fj

jrjw t3 r swsh j3hw.

Vgl. auch Zandee, Hymnen, 3-4. 
Von hier ausgehend möchte man sie auch überall dort ansetzen, wo neben Himmel/Ba und Unterwelt/Leichnam auch vom Bild auf der Erde die Rede ist, z.B.

(1) pLeiden J 350 IV 15-16 s.0., \$ 3.1

(2) ibd., VI. 12-13 203

d3t st $3 t$ ḥr $\operatorname{sḥ} 3 p$ nb.s

db $3 t j j m j$ h $3 w . s$

b3.f jmj pt

hwt.f w3st $n$ hnntj.f

... n s $s^{c} h . f n t j m ~ d 3 t$

Die geheime Unterwelt verhüllt ihren Herrn

Der-im-Sarge ist bei ihr.

Seine Ba ist der, der im-Himmel-ist,

Sein Tempel ist Theben für sein Bild

Die Totenstadt gehört seiner Mumie, die in der Unterwelt ist.

(3) pBerlin 3050 VIII, $1-3^{204}$

Du hast den Himmel emporgehoben, um deinen Ba zu erhöhen,

du hast die unterwelt verhuillt für deine Falkenbilder!

Du hast den Himmel erhoben, so weit deine Arme reichen,

du hast die Erde ausgebreitet mit deinem Lauf!

Der Himmel jauchzt dir zu, weil dein Ba so gewaltig ist,

die Erde zittert vor dir, weil dein Bild so heilig ist!

(4) pBerlin 3049

AHG 127A 63-64 Der den Himmel schuf für seinen Ba

um die beiden Länder zu erleuchten

66-67 Der die unterwelt verhült, um sein "Geheimnis" 205

$\mathrm{zu}$ verbergen

84-85 Der die Krone trägt in Theben

in jenem seinem Kultbild, das grösser ist als die

Götter.

203 Zandee, Hymnen, 110-111.

204 AHG Nr.22D,2-11. Vgl. hierzu LL 305.

205 Zur Bezeichnung des Leichnams des Sonnengottes als "sein Geheimnis" s. LL, 84-86. 
Ed fou III 196

Sein $\mathrm{Ba}$ ist im Lichtland,

sein $d t$-Leib ist in der Unterwelt,

sein erlauchtes Bild $\left({ }^{\mathbf{c}} \mathbf{h m}\right)$ ist auf dem Grossen Thron.

(6) Theb.Tempel gr.Zeit Urk VIII $\$ 12 b^{206}$

Der den Himmel aufhängte, befestigt auf seinem Grunde, um sein Lichtland geheim zu machen fur seinen $\mathrm{Ba}$;

Der dieses Land machte und schuf, was auf ihm ist,

fur sein erhabenes Bild;

der die Unterwelt machte, finster und unendlich (kk.tj hhtj) 207

um seinen dt -Leib darin geheim zu machen;

der ein Tor machte vom einen zum anderen aus dem Wunsche,

herumzugehen und $z u$ schauen, was er geschaffen hat.

(7) Graffito des Osorkon, Daressy, RT 18(1896)182.

Der den Himmel hochhebt indem er | in ihm| erscheint

er dauert unter seiner Sonne

wie die Unterwelt unter seinem dt -Leib,

um sein Geheimnis zu verhullen.

Der Grosse, der am Anbeginn endstand,

die beiden Länder tragen sein Bild (lies: hnntj.f)

Ein Teil der Belege bezieht sich nicht auf die Schöpfung, sondern beschreibt eine gegenwärtig-zeitlose Verfassung der welt (Nr.1, 2, 5). Das scheint der sinn dieses Topos zu sein, auch dort, wo er als kosmogonisches Bild formuliert ist. Ebenso wie die im folgenden Abschnitt $z$ u behandelnde Topik der lebenspendenden Elemente geht dieser Topos in die vorstellung eines Weltgottes über. Indem der Gott die Welt als Ba, Bild und Leib als den drei Aspekten seiner person bewohnt und erfüllt, personifiziert er den Kosmos:

$206 \mathrm{Vgl}$. Sethe, Amun $\$ 150$, "Primat und Transzendenz", 12.

$207 \mathrm{Vgl}$. Text $156(\mathrm{~d})$. 
Sein Leib ist der wind,

der Himmel ruht auf seinem Haupt

das Urwasser trägt sein "Geheimnis",

sein Priester ist der 'Falke auf der Palastfaçade'(=der König) 208

Deine Füsse sind auf der Erde,

dein Haupt ist im Himmel.

Du richtest dich auf mit der Kraft deiner Arme,

dein Gewicht aber ruht auf dem Geheimen.

Der Himmel ist über dir, die Unterwelt unter dir,

Geb ist wirkungsvoll, dich zu verbergen,

sie kennen nicht, was aus deinem Leibe entsteht.

Deine Kraft hebt Wasser zum Himmel,

der Hauch deines Mundes sind die wolken,

der Atem deiner Nase sind die Winde (usw.) 209

Du bist der Himmel, du bist die Erde, du bist die Unterwelt

du bist das Wasser, du bist die Luft zwischen ihnen. 210

Deine beiden Augen sind Sonne und Mond,

dein Kopf ist der Himmel,

deine Füsse sind die Unterwelt. 211

\section{Leben}

\subsection{Der Begriff des Lebensgottes}

In derselben Weise, wie man mit Bezug auf die ägyptische Religion von dem Begriff des "Schöpfergottes" sprechen kann, der im Zusammenhang der einzelnen Schöpfungslehren einmal mit diesem, ein andermal mit einem anderen Gottesnamen, immer jedoch mit der Vorstellung eines Einzigen Schöpfers verbunden wird, in derselben Weise tritt in der Uberlieferung, wo es um die Frage der Belebung und Erhaltung der Schöpfung geht, der Begriff eines Lebensgottes hervor. Auch wenn es in der Regel der schöpfer selbst ist, der sich um die Erhaltung seiner

208 Hibis $33=$ AHH $\mathrm{Nr} .130,25-28$.

209 pBerlin $3048=$ AHG $\mathrm{Nr} .143,90-102$.

$210 \mathrm{Hibis} 33=\mathrm{AHG} \mathrm{Nr} .130,205 \mathrm{f}$.

211 Text $88,12-15$. 
Schöpfung kümmert - die Schu-Theologie des MR, auf die wir gleich eingehen wollen, bildet da m.W. die einzige Ausnahme unterscheiden die Texte doch sehr genau zwischen (1.) dem Ursprung des Werdens am Anbeginn, (2.) der Einrichtung des Kosmos und (3.) seiner fortwährenden Belebung, Beseelung und Bewegung. Diesen drei Kategorien entsprechen die Begriffe des Urgottes, Schöpfergottes und Lebensgottes, die wir darum ebenfalls auseinanderhalten müssen, auch wenn es dann in einem zweiten Schritt der theologischen Reflexion um ihre ausdrückliche Gleichsetzung geht.

Der Begriff des Lebensgottes tritt uns vermutlich bereits im $\mathrm{AR}$ als Bedeutung des Gottesnamens "nhw "der Lebende" entgegen.212 Auf sicherem Boden stehen wir aber erst bei der Theologie des Luftgottes Schu, die in den sprüchen 75-80 der Sargtexte in leichter Umformung für die Zwecke der "Totenliteratur" zur Darstellung kommt und die aus dem Anfang des Mittleren Reiches stammt. 213 schu erscheint hier als Gott sowohl des Luftraums zwischen Himmel und Erde, als auch des Lebensodems "in den Nasen" der einzelnen Lebewesen. 214 Seine Aufgabe ist es, die Geschöpfe zu beleben und mit den ihnen zukommenden Lebensbedingungen $z u$ versorgen und am Leben $\mathrm{zu}$ erhalten, und zwar im Auftrag seines Vater Atum, des Schöpfergottes. 215 Hier wird also zwischen Schöpfergott und Lebensgott unterschieden, wenn auch die Verbindung von vater und Sohn in Wendungen bis an die Grenze einer wesenseinheit herangeführt wird, die an die christologischen Formeln der frühen Kirchen erinnern. 216 Als Lebensgott wird Schu $\mathrm{C}_{\mathrm{nh}}$ "Leben" 217 und nḥh "Zeitfülle"218 genannt. Denn wie sich das

212 H.Junker, Der Lebendige als Gottesbeiname im Alten Reich, Anz.AW Wien, $1954 \mathrm{Nr} .12$.

213 S. hierzu A. de Buck, Plaats en betekenis van Sjoe in de egyptische theologie (Mededelingen der Koninklijke nederlandse Akademie van Wetenschappen, afd.letterkunde, N.R.10.9, 1947), 16ff., spez. 21-25; $\mathrm{Z}$ andee, Hymnen, $131 \mathrm{f}$.

214 CT II 42-43, de Buck, a.a.0. $21 f$.

215 CT II 43, de Buck, 22. Vgl. auch "Primat und Transzendenz", 25.

216 De Buck, a.a.O., $32 f$.

217 Zahlreiche Belege bei de Buck, a.a.0., 22-23.

218 De Buck, 23. 
einzelne Leben in der "Zeitspanne" ( $\left.{ }^{c_{h}}{ }^{c} w\right)$ entfaltet, die ihm aus dem unerschöpflichen Vorrat der Zeit ( nḥ̣ ) zugemessen ist ${ }^{219}$, so entfaltet sich das schlechthinnige Leben des Lebensgottes, aus dem alles einzelne Leben hervorgeht, in der schlechthinnigen zeitfülle, aus der die einzelnen Jahre und "Lebenszeiten" hervorgehen: 220

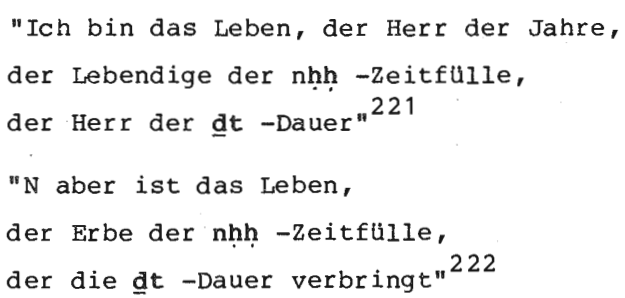

Im NR tritt uns der Begriff des Lebensgottes in verschiedenen zusammenhängen entgegen, die wir bereits behandelt haben: in der frühen thebanischen Theologie des Amun-Re, wie sie v.a. im pKairo 58038 dargestellt wird (Kap.4, \$3) und ganz besonders ausgeprägt in der Neuen Sonnentheologie 223 , vor allem in der Amarna-Religion, wo ebenfalls die Begriffe ${ }^{c} n$ und nḥ in der Bestimmung des Gottesbegriffs eine zentrale Rolle spielen (Kap.3, $\$ 2.5$ ). Die ramessidische Amun-Theologie baut auf diesen Traditionen auf. Sie gelangt zu dem Begriff eines Lebensgottes, der nicht wie Aton und der noch rein solar ver-

$219 \mathrm{zu} \mathrm{C}_{\mathrm{h}} \mathrm{C}_{\mathrm{w}}$ und nhh s. Zeit und Ewigkeit, 11-18,54-57.

$220 \mathrm{Vgl}$. hierzu LL 87-88; Zeit und Ewigkeit, 36-41.

221 CT II 39.

222 CT VI $389 \mathrm{~g}$.

223 Ein wichtiger Text für die Lebensgottvorstellung im Bereich der Neuen Sonnen-Theologie ausserhalb Amarnas ist der Text, Quibell, Exc.at Saqqara IV(1908-10) Tf.73,3, der sich mit Hilfe des pBerlin 3048 (ÄHG $143,10 \mathrm{f}$.$) ergänzen lässt:$

Strahlender, Leben der Götter (cf. pleiden J 350 II 10)

Leuchtender, der im Lichtband aufgeht (...)

Lebendiger, wenn er die Finsternis auftut.

Vgl. auch pBerlin 3049, IX,3:

p3 nhjj nter jwtj sk m-m skjjw

rnpjj $n r^{c} n b$ nn jnw drw.f

Du Lebendiger, Gott, $\overline{d e r}$ nicht vergeht inmitten der Vergänglichen, der sich Tag für Tag verjüngt ohne seine Grenzen je zu erreichen. Zur solaren Lebensgott-Konzeption und ihrer Beziehung zur Zeitfulle s. LL 87-88. 
standene Lebensgott-Aspekt der frühen Amun-Re-Theologie der Welt "von aussen" durch seine "Strahlenhände" Leben zuführt 224 , sondern der die Welt sowohl als Makrokosmos von innen heraus belebt wie er mikrokosmisch als Lebenskraft in jedem einzelnen Lebewesen wirkt. Dieser Begriff wird in der alten, durch Einfügung der Präposition $m$ im neuen Sinne umgedeuteten Formel $\mathrm{Jmn} m n \mathrm{~m}$ jht nbt "Amun der bleibt in allen Dingen" 225 zum Ausdruck gebracht. Das ist der "pneumatische" Aspekt der Luft als Lebensodem, der jetzt begrifflich klar von dem kosmischen Aspekt geschieden wird ${ }^{226}$, auch wenn Amun beide verkörpert, genau wie Schu in den Sargtexten. Amun ist der "Lebensodem im Inneren aller Dinge"227, eine "aligegenwärtige verborgene Lebensmacht". ${ }^{228} \mathrm{Als}$ Inbegriff des kosmischen Lebens verkörpert auch er, wie vor ihm Schu, die kosmische "Zeitfülle", in der sich dieses Leben vollzieht und die dann immer mehr als der Lebensvollzug des Weltgottes selbst aufgefasst wird, der durch seine Lebensbewegung die zeit hervorbringt; die zeit als kosmogonische Energie, die alles hervorbringt, was sich als seiendes in ihr entfaltet, 229 ist eine Wirkungsweise des Lebensgottes, da die Begriffe "Zeit" und "Leben" im Agyptischen nicht zu trennen sind. 230 wie schu im MR heisst Amun geradezu "das Leben"231, wobei allerdings im Hinblick auf manche schreibungen mit -jj 232 oder $-w 233$ eine Ubersetzung wie "der Lebende" präziser

$224 \mathrm{Vgl}$. n.93. S. a. Saeculum 23,117-118.

225 S. dazu Text 134 (b); Sethe, Amun $\$ \$ 219-230$.

$226 \mathrm{Vgl}$. \$ 5.2.1, Beispiel (14), wo sich in (3) der Name Jmn mn $\mathrm{m}$ jht nbt auf den "pneumatischen" Aspekt der Luft, B3 $\mathrm{n}$ కw auf ihren kosmischen Aspekt bezieht.

$227 \mathrm{Vgl}$. Sethe, Amun $\$ 193$; Esna Nr.249.4, Sauneron, Esna V,89.

228 Zandee, Hymnen, $132 \mathrm{mit}$ Bezug auf die Schu-Theologie der Sargtexte.

229 Zeit und Ewigkeit, 36-41.

$230 \mathrm{Vgl}$. LL 87-88; zahlreiche entsprechende Belege in Zeit und Ewigkeit, $30-41$ und $49-63$.

231 nh mit Gottesdeterminativ: Berlin 818; FIFAO 20,119f. Der el Medine Nr.280; OCairo 12225 ed.Posener, RdE 27,206; Urk VIII $\$ 65 \mathrm{c}$; Hibis 31

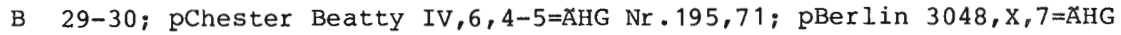
Nr.143,248; s. auch Sethe, Amun $\$ \$ 205-6$; Otto, Gott und Mensch, 110-111.

232 Z.B. pBerlin 3049, IX,3; Hibis Tf.32,9; Mariette, Monuments divers Tf. 46; Urk VIII \$ 139d; Barguet, Le temple d'Amon-Rê, 303.

233 so die AR-Form, s. Junker, a.a.o. 
sein dürfte; am sinn ändert sich dadurch nichts. ${ }^{234}$ Wie schon im MR konzentriert sich in der Vorstellung vom "Lebensodem" ( $t 3 w n \mathrm{C}_{\mathrm{nh}}$ ) der Inbegriff sowohl der Wirkungsweise des Lebensgottes wie der Form, in der jedes Lebewesen an seinem Wirken teilhat. So wird Amun als Lebensgott zum Gott des Lebensodems und als solcher z.B. in der Szene VIII des spätzeitlichen Geburtsmysteriums angerufen. 235 Ebenso wie im MR wird dieser Lebensodem des Einzelnen zum kosmischen Element der Luft in Beziehung gesetzt, sodass Amun auch als Luftgott erscheint. Die Luft ist nichts anderes als sein eigener Lebensodem, ebenso wie die Zeitfülle die zeitliche Form seines eigenen Lebensvollzugs darstellt. ${ }^{236}$ Man darf aber sein Wesen nicht, wie es sethe wollte, auf einen reinen Luftgott reduzieren. Vielmehr ist überall dort, wo das kosmische wirken Amuns in Gestalt der Luft genannt wird, im gleichen Zusammenhang auch von Wasser und Licht die Rede. Es sind die drei Elemente, die zusammen seine Erscheinungsform als Lebensgott bilden.

\subsection{Die Topik der lebenspendenden Elemente und die Entstehung der ramessidischen Weltgott-Idee.}

\subsubsection{Beispiele}

(1) Text 206

Wasser

Der den Nil herauffuhrt, damit sie zu essen haben, der jedem Auge Gutes zufluhrt;

wenn er aufgeht, lebt die Menschheit,

Licht ihre Herzen leben, wenn sie ihn sehen.

234 Durch den Kontext wird an den Stellen deutlich gemacht, dass der Begriff des 'Lebens', auch in der Partizipform "der Lebendige", transitiv gemeint ist, als belebende Energie. Sethe und otto ubbersetzen "das Leben", Barguet "Celui qui est la vie". Zu Osiris als nh(jj) s. Derchain, Le pap.Salt 825 (72); Junker-Winter, Philä II 203.29.

235 Daumas, Les Mamisis des temples égyptiens (1958), $428 \mathrm{ff}$.

236 Zum Zusammenhang von "Luft" und "Zeit" $\mathrm{s}$. Zeit und Ewigkeit, $40 \mathrm{n}$. $137,63 \mathrm{~m} \cdot \mathrm{n} \cdot 74$.

237 S. hierzu: "Primat und Transzendenz". Die späten Quellen, von denen ich in diesem Aufsatz ausgegangen bin, sowie die religionsgeschichtlichen Parallelen werden hier nicht nochmals angefuhrt, s. dazu 7-13. 
Luft

Der dem, der im Ei ist, Luft gibt,

der Fische und vögel erhält.

Der für die Mäuse sorgt in ihren Höhlen,

und für Würmer und Flöhe gleichermassen. 238

(2) Text $17=$ Text 186

Du hast deine Gestalt angenommen als Lufthauch,

Luft um inn an die Nase zu geben.

Man lebt, wenn du es willst.

Du bist der Schöpfer, der gebiert die geboren werden

mit deinem Mund, deinen Augen, deinen Armen.

Der Nil wallt auf in seiner Höhle,

Wasser

er wartet, um aus dir hervorzugehen.

König der Zeitfülle als Oberhaupt der Götter,

sie sehen und leben durch dich.

Der Himmel trägt deinen $\mathrm{Ba}$ und erhebt deinen Lichtglanz

Licht

die Unterwelt enthält deinen Leichnam und birgt deinen Leib

dieses Land trägt dein Bild,

man jauchzt und rühmt mit deinem Namen.

Das Wasser ist unter dir luberschwemmt mit Gold,

der Himmel ist Fayence um deinetwillen.

(3) pLeiden J 350 V 19ff. 239

Sein Ba ist Schu,

sein Herz ist Tefnut;

er ist Harachte der im Himmel ist.

Sein rechtes Auge ist der Tag,

Licht sein linkes Auge ist die Nacht,

er ist es, der die "Gesichter" auf allen Wegen fuhrt. 240

238 S. Text $206(\mathrm{~h})$ für die Beziehungen dieses Texts zum pKairo 58038 sowie im Text 212 und einer Stele in Stockholm (AHG Nr.163).

239 AHG $\mathrm{Nr} .141$. Zandee, Hymnen, 98-107.

240 Ahnlich alterniert auch das unmittelbar identifizierende ntf "er ist" mit anderen Formen der Beziehung des Gottes zu anderen Göttern in IV, 12-21 s. oben $\$ 3.1$. Zum Motiv der "Wege" s. Kap.3 $\$ 2.4$. 


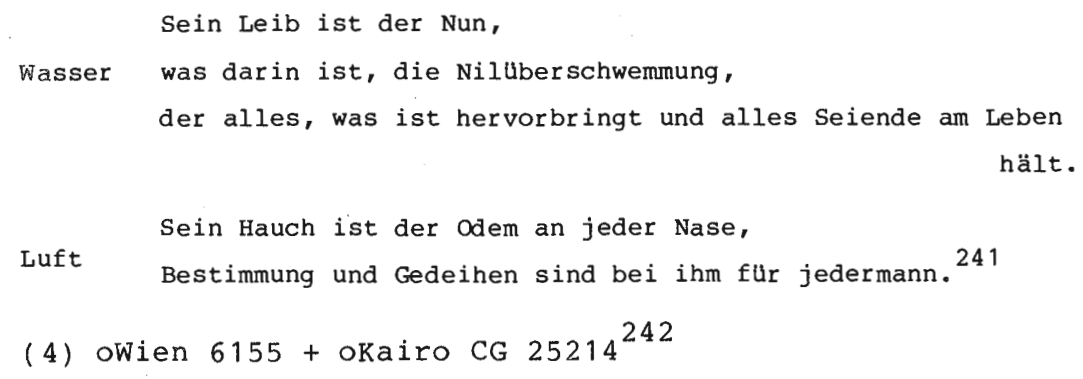

Licht

Du hast dich geschaffen als Sonne( $క w$ ) des Tages ${ }^{243}$,

und als Mond der Nacht,
Wasser indem du (zugleich) der Nil bist ${ }^{244}$, der die Menschheit

am Leben hält

Luft und die Luft, die die Kehlen atmen lässt.

(5) Text 156

Leben

Dir gehört das Leben, kein anderer wird sein,

der Leben gibt jedem Gesicht. (...)

Licht

Du bist das Licht, das das Böse vertreibt,

kein Auge lebt, das dich nicht sieht.

Luft

Du bist die Luft, die die Kehle atmen lässt,

kein Raubtier lebt, das deiner entbehrt.

Wasser

Du bist der Nil, der die Menschheit am Leben erhält,

kein Gesicht lebt, wenn du nicht in ihm bist.

(6) Der Hymnus Ramses'III. 245

Deine Haut ist das Licht,

Licht dein Hauch ist das 'Lebensfeuer', (c nht ${ }^{246}$ )

alle kostbaren Edelsteine sind an deinem Leibe vereinigt.

241 Der typische Zusammenhang von "Luft" und "Schicksal", s. LL 216 m.n.137; Zeit und Ewigkeit, $63 f$.

242 Ed.G.Vittmann, in; WZKM 72(1980) 1-6.

$243 \mathrm{w}$, in Opp. zu j $\mathrm{C}_{\mathrm{h}}$, also nicht 'Licht', sondern 'Sonne'. Für కw als neuäg. Aquivalent für jnt s. S.Schott, Die Deutung der Geheimnisse, 79, wo im "Ritual für die Abwehr des Bösen" 95, 20/21 mäg. jtn näg. p3 šcw n dw3 wiedergegeben wird.

244 jw.k m $\mathbf{H}^{\mathrm{C}} \mathrm{pj}$, nicht: ntk !

245 OIP XXV, Tf. 23; AHG Nr. 196.

$246 \mathrm{Vgl}$. Urk VIII 1g, Sethe, Amun $\$ 202$. 
Deine Glieder sind der Lufthauch an jede Nase,

Luft man atmet dich ein, um zu leben.

Dein Geschmack ist der Nil,

Wasser man salbt sich mit dem Glanz deines Lichtauges.

(...)

Man kommt und geht auf deinem Antlitz

Erde in deiner Erscheinungsform als Erdgott.

(7) Neschons AHG Nr.131

Strahlende Fackel mit grossem Licht,

man sieht vermoge ( $\mathrm{m}-\underline{h n w}$ ) seines Blickes. 247

Man verbringt den Tag, ihn anzuschauen, und wird seiner nicht

Luft wenn es tagt, beten zu ihm alle Gesichter. 248

satt,

Funkelnd an Erscheinungen inmitten der Neunheit,

seine Gestalt eignet jedem Gott. 249

Wasser Es kommt der Nil, es weht stromauf der Nordwind

und Luft im Innern dieses geheimnisvollen ( št3 ) Gottes. 249a

(8) Graffito des Osorkon 250

Aufgehender in der Zeitfulle ( nḥ. ),

Untergehender in der Fortdauer ( $\mathrm{d} t$ ) 251

Licht der an die Grenzen der Ewigkeit dringt (mz hntj ...)

Der die Geburt wiederholt beim Leuchten in der Nacht

in seiner wirksamen ( $\mathrm{mnh}$ ) Gestalt als Mond.

Der als Nil kommt, um die beiden Länder zu uberschwemmen,

Wasser der jeden Mund am Leben hält mit seinen Ausflussen;

die Luft ist er, die aus dem Luftraum niederschwebt,

Luft um jede Kehle atmen zu lassen

247 Id. Hibis 32, s.o.

$248=$ Text $83,11-12$.

249 Fur solche Aussagen s. die Zusammenstellung "Primat und Transzendenz", 37.

$249 \mathrm{a} \mathrm{Vgl}$. Hibis $32=\mathrm{AHG} \mathrm{Nr} \cdot 129,144-45$.

250 Ed. Daressy, in: RT $18(1896) 182$.

251 Zur typischen Korrelation von Nḥ mit dem Sonnenaufgang und dt mit dem Sonnenuntergang $\mathrm{s}$. Zeit und Ewigkeit, $44 \mathrm{n} .155$. 
(9) Die Stele der Verbannten 252

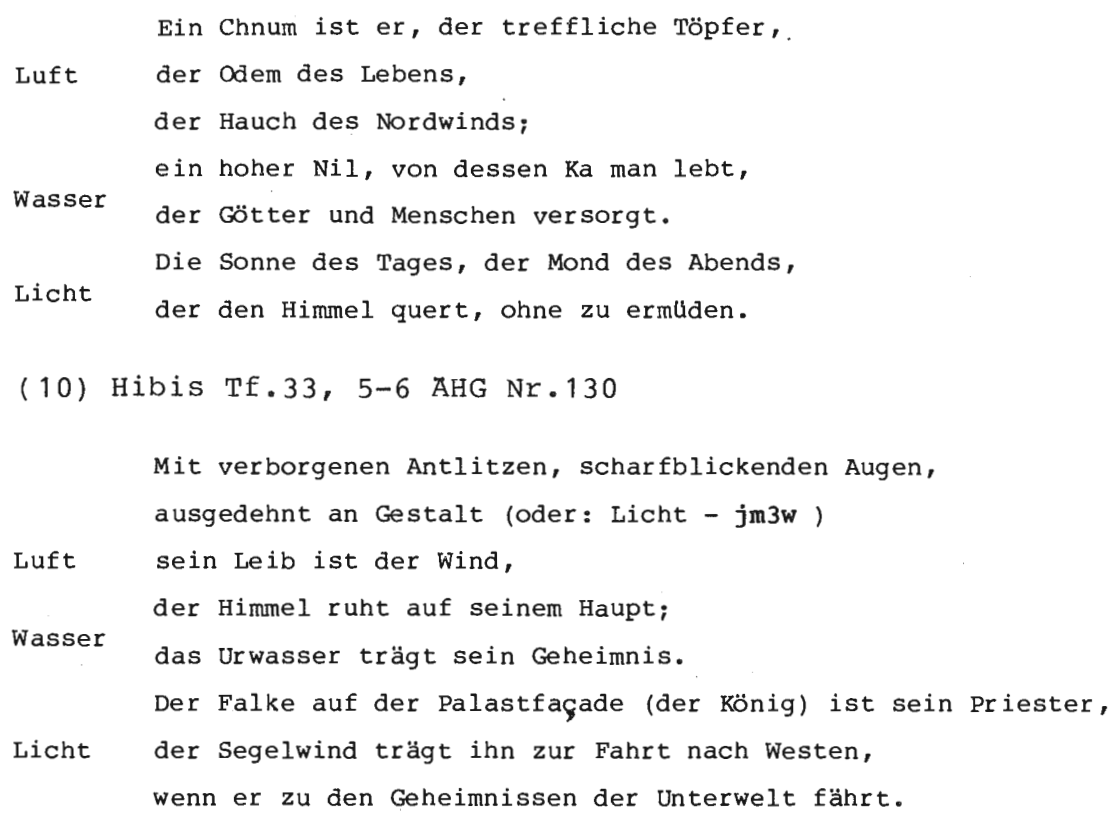

(11) Esna Nr.387.4-5 253

Der jedermann die Wege beschreiten und stromauf, stromab

Licht fahren lässt beim Schauen seiner beiden Augen

$$
\text { ( ntrwtjfj })^{254}
$$

Der Nil ( Nnw) kommt hervor, der Nordwind weht stromauf

Wasser auf Geheiss dieses erhabenen Gottes.

und tuft Er kommt als Uberschwemmung nach seinem Belieben

um die beiden Länder zu erfüllen mit seinen Gütern.

Leben Das Leben, das alle Dinge lebendig macht ( jrj ${ }^{c_{n h}} j_{\text {hbt }}$ nbt )

Wasser und Luft sind in seiner Hand,

er gibt davon, wem er will.

252 Ed. v. Beckerath, in: $\operatorname{RdE} 20$ (1968) 7-36.

253 Sauneron, Esna III 368,V 220-21.

254 Ein schöner Beleg für das "Weg-Motiv" als Ausdruck der vom Licht erschlossene, "begehbar" gemachten Welt, s. dazu Kap.3 $\$ 2.4$. 
(12) pBerlin $3049=$ AHG Nr.127A, 99-110

Deine Sonne leuchtet,

jedes Gesicht sieht, seit dein rechtes Auge erschien am

Licht

Anbeginn .

Dein linkes Auge, es vertreibt die Finsternis,

der Himmel frohlockt, wenn es seine Geburt wiederholt,

sein Licht in der Nacht kommt dem Tage gleich,

kein Aufhören ( sk) deines Aufgehens gibt es in Ewigkeit.

Der Nil, er strömt mit deinem Tau ( j3dt ),

er verjungt sich in deinem Leib.

Wasser

Alles, was er zeugt, gehort dir, denn du hast es geschaffen

Jedes Gesicht lebt von seiner Nahrung, die du ihnen gibst.

Ausdauernder, der nicht mude wird, am Leben zu erhalten, was

du geschaffen hast!

Luft

Die Nasenlöcher atmen die Luft, die du gibst,

der Himmel kommt mit seinem Nordwind

als dem Hauch auf deinem Munde.

(13) pBerlin $3048=$ AHG Nr.143, 100-125 (Auszüge)

Deine Kraft hebt das Wasser zum Himmel,

der Hauch deines Mundes sind die Wolken,

Luft

der Atem deiner Nase sind [die Winde];

Regen

dein Speichel ist auf den Bergen,

der mit Wasser umkleidet die Blătter der Băume

Wasser

auf allen whstenbergen;

Ozean

Umkreisender, der die beiden Himmelsufer umläuft. Ozean bis zum Ende der Nut!

$(\ldots)$

Keiner ist, der ohne dich leben könnte:

denn aus deiner Nase geht die Luft hervor

und aus deinem Munde die Flut.

Leben

Das "Lebensholz" wächst auf dir,

du begrlunst die Erde, sodass die Gotter Uberfluss haben,

die Menschen und das vieh. 
Durch dein Licht sehen sie:

Wenn du untergehst, entsteht Finsternis.

Deine beiden Lichtaugen schaffen Licht (...)

Dein rechtes Auge ist die Sonne,

dein linkes Auge ist der Mond,

dein Geleit sind die unermüdlichen (Sterne).

(14) Hibis 31 : die 10 Namen des Amun. 255

(1) Ihn, den die in den Gauen schauen, ${ }^{256}$ das Licht

der beiden Länder

Sonne der Stier der Nilüberschwemmung, der ewig lebt

in seinem Namen: Re, Tag für Tag.

Licht

(2) Lebendig an Geburten, der seinem linken Auge

Mond

gebietet

den alle welt liebt in seinem Namen: Voller

( $\mathrm{mnh}$ ) Mond

(3) Gott der jb - und h3tj-Herzen, der die Luft

aushustet

Luft

und die Kehle atmen lässt in seinem Namen:

Amun, bleibend in allen Dingen,

Ba des schu für alle Götter.

(4) Der Körper (=die Verkörperung?) des Lebens, der

das "Lebensholz" erschafft,

Wasser

der Korngott, der die beiden Länder überflutet, ohne den nichts lebt in Agypten in seinem

Namen "Grosser Nil". 257

255 S. dazu J.C.Goyon, in: R.Parker et alii, The Edifice of Taharqa 6979. Für einen Teil dieses Hymnus existiert eine Parallele auf einem demotischen Ostracon ed. M.Smith, in: Enchoria VII,1977, 155-149.

256 So nach Goyon, a.a.o.

257 Die folgenden 6 Namen sind nach einem anderen Schema gebildet, der sie deutlich als einer anderen Ebene zugehörig kennzeichnet:

(5) Rs-wdi3

"Der heil erwacht"

nțr jrjw š̌p

(=Osiris)

(6) K3-njswt $c_{n h}$

Gott, der das Licht schafft

"Lebender Königs-Ka"

ntr hnmmt

(=Horus)

(7) b3 b3w

"widder der Widder"

(cf. LL 78-87)

(8) Hrw3htj

Harachte

Gott der Menschheit

ntr $\mathbf{C}_{\text {wt mnmnt }}$

Gott des Klein- und Grossviehs

nter sdrw

Gott der schlangen 
Der folgende Hymnus, Verse $58 \mathrm{ff}$. , behandelt die Ba's in extenso. In Hibis sind aber nux die ersten drei Gesänge, die sich auf die ersten drei Ba's beziehen, aufgezeichnet:

58- 85: Amun = Atum-Chepre-Re, Urgott, Schöpfer, Sonnengott.

86-102: Amun = Atum, Osiris, Thoth: der Mond

103-133: Amun = Schu: Wind und Lebensodem.

Der vierte Gesang hätte dann Amun als Nun behandelt, ein Aspekt des Gottes, der gerade in äthiopischer zeit besonders hervortritt. 258

(15) Hibis $32=$ AHG Nr.129, 107-151

Im Anschluss an die in vier grossen Gesängen dargestellten vier Stadien des kosmogonischen Prozesses:

I 37- 51 Selbstenstehung als Urgott

II 52- 69 Konzeption der Schöpfung "im Herzen"

III 70- 95 Ausfuhrung des Schöpfungsplanes

IV 96-107 Entfernung als Sonne

widmen sich die folgenden Strophen dem Thema der Erhaltung der schöpfung:

V 108-129 Der Sonnenlauf

VI 130-151 Die lebenspendenden Elemente

Er hat den Himmel geschaffen unter seiner Aufsicht und befährt ihn, um die Erde zu erleuchten fur seine kinder Er fährt nord- und sudwärts und betrachtet, was er geschaffen

hat

seine Augen bestrahlen die beiden Länder:

Sein linkes Auge ist in der Nacht, wenn er der Mond ist,

um die Tageszeiten, Monate und Jahre zu scheiden;

seine Sonne ist am Tag, sein Mond ist in der Nacht,

Licht er bleibt nicht aus in Ewigkeit;

er dauert in Millionen und Abermillionen,

sein königtum erstreckt sich an die Enden der zeit.

(9) b3 jmjw mw

"Ba der Wassertiere"

(10) Nhbk3w Nèhebkau

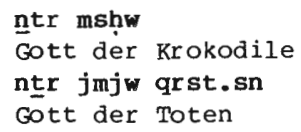

258 S. dazu J.Leclant, Recherches sur les monuments thébains de la XXV.e dynastie, dite éthiopienne, Bd'E 36(1965) 240-41. 
Der Nilbringer, er hat die Quellocher aufgetan, er hat das Wasser stromen lassen aus seiner Höle,

Wasser es schwillt an und sinkt nach seinem Belieben. Ein Ausspeiender ist er, der wieder einschlurft nach seinem wunsch.

Der Sudwind fährt nordwärts, der Nordwind nach suden, Luft Westwind und ostwind sind in seinen Nasenlochern. Die sturme haben ihre Tage, die Sterne ihren Dienst nach dem Gebot dieses erlauchten Gottes...

\subsubsection{Ursprung und Entwicklung}

Die Vorstellung einer Dreiheit lebenspendender Elemente tritt uns zuerst in der loyalistischen Tradition des MR entgegen 259 , wo die Rolle des Königs als eines allumfassenden Versorgers dargestellt wird entweder in der Form einer verfügung über die Elemente wie im Sinuhe 260 :

Die Sonne geht auf dir zuliebe,

das Wasser im Fluss - nur wenn du es willst, wird es getrunken,

die Luft im Himmel - nur wenn du es willst, wird sie geatmet.

oder in der Form metaphorischer Identifikation wie im Enseignement Loyaliste ${ }^{261}$ :

Re ist er, durch dessen Strahlen man sieht,

einer, der die beiden Länder mehr erleuchtet als die Sonne.

Ein Begrunender ist er, mehr als eine hohe Niluberschwemmung,

er hat die beiden Lănder erfullt mit dem "Lebensholz".

Wenn er sich erzurnt, erstarren die Nasen,

besänftigt er sich, atmet man Luft.

An diese Tradition knüpft der stark ausgeprägte Loyalismus der Amarna-Religion an ${ }^{262}$, der den könig preist als

259 S. dazu SAK $8(1980), 16-19$.

260 B 232-234.

261 G. Posener, L'Enseignement loyaliste $(1976), 21 \mathrm{f}$, , 68f.(\$ 3 ).

262 S. ausfuhrlicher SAK $8(1980), 1-32$. 


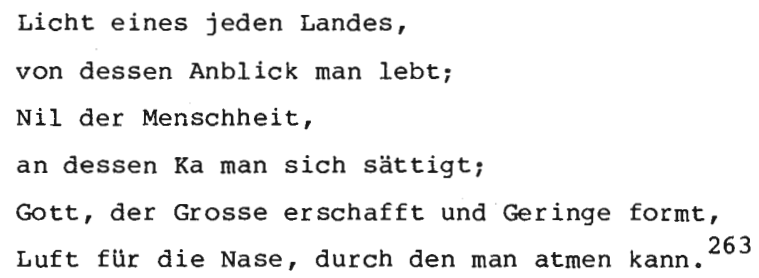

In dieser Topik erscheint der König als ein Lebensgott auf der sozialen Ebene. Seine alles versorgende, alles belebende, schicksalsbestimmende Wirksamkeit wird in einer kosmischen Metaphorik dargestellt, die ihre Allumfassendheit zum Ausdruck bringen soll, dabei aber doch immer im sozialen Bezug gemeint ist. Der König ist nicht Licht, Luft und Nil schlechthin, sondern "für" die Menschheit oder auch, noch kennzeichnender, für den Loyalen. ${ }^{264}$ Genau diese Einschränkung wird hinfällig, wo diese Topik nun im theologischen Bereich zur Darstellung des innerweltlichen wirkens der Gottheit als des allumfassenden Lebensgottes herangezogen wird. Mit Bezug auf den Gott sind Licht, Luft und Nil nicht Metaphern, sondern buchstäblich gemeint als kosmische Energien, in denen sich seine alles belebende Wirksamkeit manifestiert. War schu als Gott der Luft und des Lebensodems der Lebensgott, und erfüllten Amun-Re und Aton als Sonne diese Funktion, so bringt die ramessidische Lebensgott-Theologie diese Tradition in eine umfassende Synthese ein, indem sie die Gesamtheit der "Elemente", Licht, Luft und Wasser, als kosmische Wirkungsweisen des Lebensgottes erklärt, der also Lichtgott, Luftgott und Nilgott in Einem ist.

Diese Konzeption entwickelt sich im Laufe der 19. Dynastie von der "theistischen" Vorstellung einer Verfügung Gottes über die Elemente zur "pantheistischen" Vorstellung einer Verkörperung Gottes in den Elementen, d.h. zur Idee eines Weltgottes, dessen Augen das Licht, dessen Atem die Luft und des-

263 Inschrift im $\mathrm{Grab}$ des Panehsi=AHG Nr.234. Der Text findet sich fast wörtlich ebenso auch, auf Chons bezogen, auf einem ramessidischen würfelhocker an dem Muttempel (CG 917), s. SAK 8(1980), 1ff.

264 SAK $8(1980), 18 \mathrm{n} .83$. 
sen Schweiss das Wasser sind. Beispiel 1 (Text 206 aus Grab 215: Zeit Sethos I) steht am Anfang dieser Entwickung. Dieser Text entnimmt sein Material fast vollständig dem pKairo 58038 und ordnet es nur um nach dem neuen, vermutlich durch die Amarna-Religion ins allgemeine Bewusstsein gehobenen DreierSchema der Elemente. Beispiel 2, ein Text, der in den Gräbern 194 und 23 (Zeit: Ramses II und Merenptah) aufgezeichnet ist, wird aus der vorgeschrittenen 19. Dyn. stammen. Auch er benutzt eine ältere Vorlage, der das Elementenmodell noch fremd ist:

Text 253 Du hast deine Gestalt angenommen als Lufthauch um ihn an die Nasen zu geben -

man lebt, wenn du es willst.

Du bist es, der die kinder der kinder erschafft

mit deinem Mund, deinen Augen, deinen Händen.

In der Vorlage knüpfen sich daran weitere Prädikate des schöpfergottes. Das Wirken Gottes als belebender Lufthauch wird hier mit seinem Schöpfertum ebenso verbunden wie z.B. in einem Hymnus des Berliner Amunrituals ${ }^{265}$ :

Du bist es, der Luft gibt an jede Nase

um zu beleben, was du geschaffen hast mit deinen Händen,

$\mathrm{du}$ bist dieser Gott, der du schaffst mit deinen Händen,

du allein, kein anderer ist mit dir.

Der Suti-Hor-Hymnus fasst diesen Doppelaspekt Gottes als Lebensodem und schöpfer in die knappe Formel: ${ }^{266}$

Chnum und Amun der Menschheit

Der Grosse Amarna-Hymnus widmet ihm, ebenfalls im Hinblick auf die Manifestation Gottes im Lebensodem, seinen embryologischen Exkurs. Wir befinden uns hier und in Text 253 eindeutig auf dem Boden der Neuen Sonnen-Theologie. ${ }^{267}$ Beispiel (2) fährt jedoch anders fort. Er verknüpft mit der Luft-Gestalt des Gottes die Erwähnung des Nils und geht dann, im Zusammen-

265 pBerlin 3055= «HG $\mathrm{Nr} \cdot 125,21-24$.

266 AHG Nr.89,40.

267 S.O., Kap.3\$2.5. 
hang mit der Erwähnung der Sonne als $\mathrm{Ba}$, zu der Lehre von der dreifachen Verkörperung Gottes als $\mathrm{Ba}, \mathrm{Bild}$ und Leib in den drei kosmischen Bereichen Himmel, Erde und unterwelt über:

$\begin{array}{llll}\text { Luft ( hprw ) } & & 27-32 \\ \text { Nil } & \text { ( pr hntj ) } & 33-34 \\ \text { Sonne } & & \text { b3 } & 37 \\ & & \text { h3 } 3 t & 38 \\ & & \text { hnntj } & 39\end{array}$

Luft und Nil werden zum Gott in eine Beziehung gesetzt, die über die blosse Verfügung deutlich hinausgeht. Er "verwandelt sich in" Luft, und der Nil "geht aus ihm hervor". Das Licht, die Sonne, wird als Ba des Gottes bestimmt, ein Begriff, der seinerseits Glied eines ternären Systems ist, ebenso wie das Licht. Durch die Verschränkung ${ }^{268}$ tritt der innere Zusammenhang der beiden triadisch organisierten Konzeptionen deutlich hervor: beide beziehen sich auf den Zusammenhang von Gott und Welt. Als Lebensgott und Schöpfer der Lebewesen belebt Gott die welt in Gestalt der drei lebenspendenden Elemente, als Welt-Schöpfer erfüllt Gott die Welt, die er sich zum Raum seiner dreigestaltigen Verkörperung erschuf:

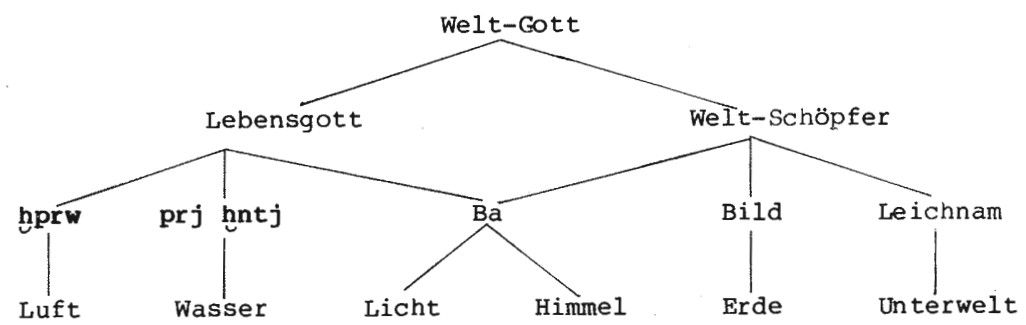

Dieses Schema macht zugleich deutlich, wie weit man noch von der klaren Lösung eines Welt-Gott-Begriffs im eigentlichen Sinne entfernt ist, der dann von der 20. Dyn. an (Beispiel 4-6

268 Dieselbe Verschränkung findet sich auch in pLeiden J 350 III 1-2: "Die Sonnenscheibe des Himmels strahlt vor dir ( $\mathbf{n}$ hr.k ) der Nil entströmt seinem Quelloch wegen deiner Urgöttlichkeit. Die Erde ist gegründet fur dein Bild, dir allein gehört, was Geb wachsen lässt." 
stammen aus der 20.Dynastie) die verbindliche "Formulierung dieser Konzeption darstellt: 269

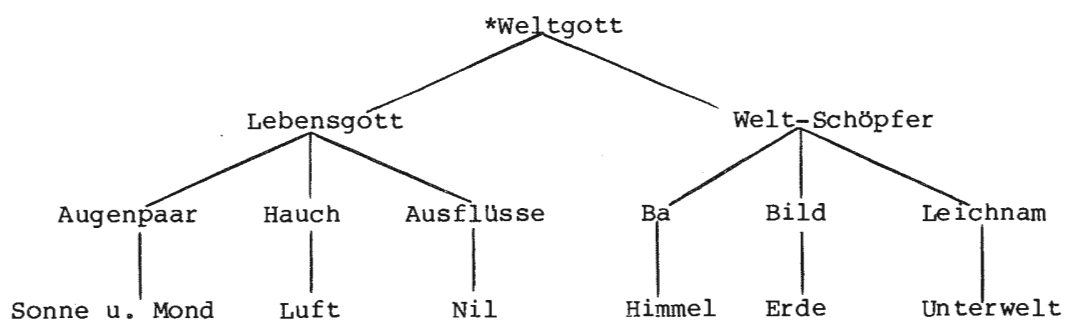

Auf die zahlreichen Belege dieses Gottesbegriffs in den Tempelinschriften der griechisch-römischen zeit brauchen wie hier nicht einzugehen ${ }^{270}$; nur einen typischen Text möchte ich herausgreifen, weil er in der Verbindung dieses Begriffs eines Lebensgottes mit den Aspekten des Schöpfers und Urgottes, und in der Unterordnung dieser drei Aspekte des Weltgottes unter den lubergreifenden, umfassenden Begriff des "Verborgenen Ba" so etwas wie die Quintessenz der Thebanischen Theologie zum Ausdruck bringt: 271

Es währt der Erhabene Ba als König der Götter

im verbringen der Zeitfulle, wahrend inm die Dauer vor Augen steht. 272

Er ist der Erhabene $\mathrm{Ba}$, der im Anbeginn entstand,

Der Schöpfer des Himmels, der Erde und der Unterwelt.

Der das Leben schafft: nämlich wind, Licht

Wasser ( qbht ) und 'Lebensfeuer', von deren Wirken alles lebt.

Der Text macht zugleich noch einmal deutlich, dass es bei dieser Topik zentral um den Gedanken der Belebung der welt geht. Daraus erklärt sich die Dreizahl der Elemente. Wo demgegenüber die Frage nach den Elementen im Mittelpunkt steht, die

269 Dieses Schema mag das Gesagte veranschaulichen, entspricht aber nicht, wie das vorige, einem konkreten ägyptischen Text. Das soll durch den vorgesetzten Asterisk angedeutet werden.

270 S. dazu "Primat und Transzendenz", 5-13.

271 Urk VIII $\$ 1 \mathrm{~g}$.

$272 \mathrm{Vgl}$. zu derartigen Aussagen, die immer das Wort dt (nicht nḥ̣ ) $\mathrm{zu}$ verwenden scheinen, zeit und Ewigkeit, 68-69. 
die welt konstituieren, tritt zu dieser Dreizahl als viertes die Erde hinzu. Diese Frage wird in der Theologie Amun-Re's als eines Weltgottes ebenfalls zum Thema. Zu ihrer Klärung bedient man sich wiederum des Ba-Begriffs. Im Sonnenheiligtum von Medinet Habu wird Amun-Re als "Ba mit vier Köpfen auf einem Hals"273 dargestellt, in dem 4 Ba's "vereinigt" sind: 274

$\begin{array}{ll}\text { Der Ba des Osiris: } & \text { das Wasser } \\ \text { Der Ba des Geb: } & \text { die Erde } \\ \text { Der Ba des Schu: } & \text { die Luft } \\ \text { Der Ba des Chepre: } & \text { das Licht }\end{array}$

Bei dieser auch sonst im NR und in der spätzeit verbreiteten Elementenlehre, die die 4 Elemente als $4 \mathrm{Ba}^{\prime} \mathrm{s}$ darstellt die sich in (oder $z u$ ) einem $B a$ vereinigen ${ }^{275}$, geht es um die vier kosmischen Bereiche, die zusammen den Kosmos bilden (und die zugleich den vier "Generationen" der heliopolitanischen Neunheit entsprenden) 276 , während es in der Topik der "lebenspendenden Elemente" eher um Energien geht, die den Kosmos beleben. In der spätramessidischen Weltgott-Theologie vermischen sich diese beiden Aspekte, sodass auch hier gelegentlich die Erde hinzutritt. 277

273 S. dazu Text $156(t)$.

274 Medinet Habu VI 420 B.2.

275 Zuerst im Totb des Ani in einer Vignette zu Totb 17(Urk V,50). In saitischer zeit gilt der Widder von Mendes als Vereinigung der $4 \mathrm{Ba}^{\prime} \mathrm{s}=$ Elemente, s. Wild, in: BIFAO 60 (1960) $57 \mathrm{n.3}$, vgl. ferner LL, 80; Sauneron, Esna IV, Nr.405,1-2; 431,2; 437,6; 441,2; Sander-Hansen, Die religiösen Texte auf dem Sarg der Anchnesneferibre, 128; Urk VI, 75,18; Goyon, in: Parker, Goyon, Leclant, The Edifice of Taharqa, 79 $\mathrm{n} .80$.

$\mathrm{Zu}$ Osiris als Wasser vgl. die alte Vorstellung des Nils als Ausfluss des Osiris: Pyr 848a ff; CT IV 130; Urk IV 1779; Mariette, Abydos II 54/55=AHG Nr.220,23-25; OCairo 25209; Caminos, MDIK 16, 21.8-9,22 und ofter; Bonnet, RARG 571; Frankfurt, Kingship and the Gods, 190ff; Junker, Das Götterdekret uber das Abaton, $37 f f$.

276 Wenn man für Chepre Atum einsetzt. Vgl. zur Elementen-Vierheit auch Assmann, Das Grab des Basa (AV 6, 1973), 72-73.

$277 \mathrm{Vgl}$. Beispieltext 6 (AHG Nr.196). 


\section{Der Gott des Einzelnen: Gott als "ethische Instanz"}

Wenn man der Bedeutung, die diesem Aspekt Gottes im Ganzen des ramessidischen Gottesbegriffs zukommt, gerecht werden wollte, müsste man ihm einen Abschnitt widmen, der alle fünf vorhergehenden aufwiegt. Denn dieser Aspekt tritt nicht als letzter neben fünf oder sechs andere, sondern bildet sozusagen die andere seite eines zweigesichtigen Gottes, der zugleich Weltgott und Nothelfer ist ${ }^{278}$ : kosmisch und persönlich, all-erschaffendes und all-belebendes Prinzip und Gott des Einzelnen. Diese zweiseitigkeit, die zusammenfassung aller in der welt wirkenden göttlichen Kräfte in den beiden Brennpunkten des kosmischen und des persönlichen Gottes und ihre Verbindung $\mathrm{zu}$ der dualen Einheit eines umfassenden Gottesbegriff stellt zugleich die eigenste Leistung der ramessidischen Theologie dar, die sie gegenüber allem Früheren abhebt. In gewissem Sinne beerbt sie aber darin die Amarna-Religion: denn hier war bereits, allerdings mit einem ganz anderen, ungemein selektiven Zugriff auf die Wirklichkeit, dieselbe "Fokussierung" aller göttlichen Kräfte vorgenommen, aber nicht zu einer "dualen Einheit" zusammengefasst, sondern auf Gott und König verteilt worden. 279 Dieser Schritt, der sich in seiner Gewaltsamkeit und zuviel Sinnhaftes ausschliessenden Selektivität als nicht haltbar erwies ${ }^{280}$, musste zweifellos vorhergehen, um die Integrationsleistung der ramessidischen Theologie historisch zu ermöglichen.

\subsection{Leben}

\$ 5 hat auschliesslich den kosmischen Aspekt des "Lebensgottes" behandelt. Als solcher steht Amun-Re in einer Tradition anderer Lebensgötter, die entweder als Luft (und Licht ${ }^{281}$ )

$278 \mathrm{Vgl.die}$ entsprechenden Bemerkungen F.Junges, in:W.Westendor $f$ (Hrsg.), Aspekte der spätäg. Religion, 95ff. zu Isis als "Kosmosgottin und Nothelferin" .

$279 \mathrm{Vgl}$. Zeit und Ewigkeit, 54-61 sowie SAK 8(1980)1-32. Bei dieser "Verteilung" darf aber nicht an eine "Gewaltenteilung" gedacht werden, vgl. hierzu Abschnitt 6.4 .

$280 \mathrm{VgI}$. n. 200. 
oder als Licht (und Luft ${ }^{282}$ ) in der Funktion einer all-belebenden Kraft aufgetreten waren, und die Amun-Re dadurch überbietet, dass er alles in Einem ist: Licht, Luft und Wasser. Er überbietet sie aber auch dadurch, dass er noch in einem ganz anderen Sinne "das Leben" ist:

(1) oBoston MFA 11.1498, Hymnus des Wesirs Hori an AmunRe: 283

$\begin{array}{ll}\text { twt p3 }{ }_{\text {nh }}^{c} & \text { du bist das Leben, } \\ \text { n3 hsw } r \text { ht.k } & \text { die Segensgluter unterstehen dir } \\ \text { wsrw }{ }_{h}^{c} \text { w } & \text { Reichtum und Lebenszeit, } \\ \text { jm3h zm3-t3 } & \text { Ehrwlirdigkeit und Begräbnis }\end{array}$

(2) Inschrift des Hohenpriesters Roma-Raii in Karnak: 284

$c_{\mathrm{nh}} \mathrm{m}-\mathrm{c} \cdot \mathrm{k}$

snb hr.k

Š3jj Rnnt

dmdw $m h^{h}{ }^{c} \cdot k$
Das Leben ist in deiner Hand, Gesundheit ist bei dir, Bestimmung und Erfullung sind vereint in deinem Griff.

(3) Denkstein Ramses III. in Karnak: 285

$$
\stackrel{t}{\mathrm{C}} \mathrm{nh} \mathrm{mw}_{\mathbf{n g}} \mathbf{c} \cdot k
$$$$
\text { wdi3 snb } \underline{h r} \cdot k
$$

Luft, Wasser

und Leben sind in deinem Griff,

Heil und Gesundheit sind bei dir.

Das früheste Beispiel dieser in ramessidischen Hymnen ungemein verbreiteten Topik des "personalen Lebensgottes" findet sich in einem thebanischen Grab: in Grab 49 aus der zeit des Eje (Text 59a): 286

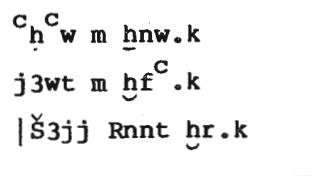

\author{
Die Lebenszeit ist in dir \\ das Alter ist in deinem Griff, \\ Bestimmung und Erfullung sind bei dir;
}

$281 \mathrm{Zu}$ Schu als Lichtgott s. de Buck, Plaats en betekenis..., 33-35.

$282 \mathrm{Zu}$ Re als spender der Luft s. Text 52(e); LL 215f.(43)-(44).

283 Ed. J.Černý, in: JEA 44(1958) 23 Tf.X.

$284 \mathrm{Ed}$. G.Lefebvre, Les inscriptions des grands-prêtres...., 32 .

$285 \mathrm{Ed}$. Kitchen, Ramesside Inscr. V,239 vgl. RdE 30(1978)42f.

286 Ẹrgänzt nach Bankes Coll. Stela 8, Kitchen, RI I,396. Weitere varr. s.(m) zu Text 59a. 
w3d-wj ntj m hawt.k wohl dem, der in deiner Gunst steht!

n ph.n.] sw dw nb Ihn kann kein Ubel erreichen.

Mit seiner abschliessenden Seligpreisung ${ }^{287}$ stellt der Text klar, um was für einen Begriff von Belebung es hier geht, wenn davon. die Rede ist, dass die Lebensgüter "in Gottes Hand" sind: nicht um das Leben als eine kosmische allgegenwärtige Kraft, die "in allen Dingen bleibend" wirkt, sondern um ein Gelingen der persönlichen Existenz, das nur dem zuteil wird, der "in Gottes Gunst" steht.

"In der Hand", "im Griff" heisst soviel wie: in freier Verfügung. Hier geht es um einen Segen, den Gott nicht wie Licht, Nil und Luft unterschiedlos in die welt verströmt und an dem jedermann gleichermassen Anteil hat, sondern den er nur dem gibt, der "auf Gottes Wasser handelt" und Gottes Grösse "beherzigt".288 Der Mensch ist auf diesen "Segen" ( hawt ) 289 ebenso, aber in einem anderen Sinne, angewiesen wie auf den "Lebensodem" als den Inbegriff der kosmischen all-wirkenden Lebensenergie, die ihn geschaffen hat und erhält. Was ihm dieser Segen vermittelt, lässt sich abstrakt und zusammenfassend vielleicht als das Prinzip des Bestandes bezeichnen, wie es sich im Diesseits vor allem als "langes Leben" ( ${ }_{h} c_{w} q^{3}$ ), erfüllt mit Gedeihen, Glück, Gesundheit, erweist, wie es aber dann besonders im Bestehen der Todesschwelle in Erscheinung tritt, die Fortdauer im Jenseits, die gemeint ist, wenn von "Ehrwürdigkeit" ( jm3h 290) und "schönem Begräbnis" ( qrst nfrt 291, die Rede ist. Dies ist nichts anderes als das al-

287 Zur Formgeschichte der "begründeten Seligpreisung", einer Schöpfung der Amarnazeit, s. "Weisheit, Loyalismus und Frömmigkeit", $29 f$ f.

288 jrj hr mw "auf jmds. Wasser handeln" und rdj m jb "sich ins Herz geben" sind die häufigsten Umschreibungen des äg. Frömmigkeitsbegriffs, s. dazu "Weisheit..." (passim).

289 Zum Begriff hawt s. Zeit und Ewigkeit,60-64; H.Tellenbach (Hrsg.), Das Vaterbild im Mythos und Geschichte (1976),26-28; "Weisheit..." $30 f ., 39 f ., 47$.

290 Der Ausdruck jm3h bezeichnet den Status des wohlversorgten Grabherrn, den man bereits zu Lebzeiten erreicht und der dann uber den Tod hinaus fortbesteht, vgl. "Weisheit...", $39 \mathrm{m.n} .100$.

291 Besonders klar kommt diese Wertung des "schönen Begräbnisses" im pChester Beatty IV rto 8,6-7 zum Ausdruck: 
te Prinzip der Maat 292 , worunter man bis zur Amarnazeit die Ordnung der von Gott am Anfang der Dinge wohleingerichteten Welt verstand, das Prinzip der gerechten Verteilung der gottgeschaffenen Lebensgüter. Die Befolgung der Maat, der gerechten Ordnung, ist dem Menschen aufgetragen; er übt Gerechtigkeit für den Schöpfer, der "von ihr lebt". 293 wie eng die Begriffe "Maat" und "Leben" zusammengehören, zeigt bereits die Schu-Theologie der Sargtexte: dort wirkt neben schu als "Leben" seine Schwester Tefnut als "Maat".294 Ăhnlich bedeutsam ist der Maat-Begriff in der Amarna-Religion. Hier verkörpert der Gott Aton den kosmischen, der König den personalen Aspekt des Lebensgottes, die "ethische Instanz", die "von der Maat lebt".295 Schon hier gewinnt man den Eindruck, dass sich die "Gerechtigkeit" des Einzelnen weniger in der Befolgung einer unveränderbar vorgegebenen ordnung erweist, als in der Befolgung der königlichen Lehre und des königlichen Willens: gerecht ist, wer dem könig folgt. ${ }^{296}$ Genau dies kennzeichnet den ramessidischen Begriff eines personalen Lebensgottes, der nicht nur die Lebensgüter, die Segnungen des "Bestandes", "in der Hand" hat, sondern der auch nach seinem eigenen willen darüber verfügt. Der Erfolg ist nicht mehr die durch das Prinzip Maat garantierte notwendige Konsequenz der

jw twn.f m qrst nfrt

n jb htp hr m $3^{\mathrm{C}} \mathrm{t}$

"Sein Lohn ist ein schönes Begräbnis

für ein Herz, das mit der Maat zufrieden ist".

(Vgl. zum Kontext $\$ 6.2$, wo das ganze lied zitiert wird.) so bittet der Sänger im gleichen Text, 7,4 den Gott:

mtn.k m qrst nfrt

n hsjj rdjw has n.k

prjof tp t 3 m b3 nfr r m33 nb ntrw

"Dein Lohn werde in einem schönen Begräbnis zuteil

dem Sänger, der dafür sorgt, dass dir gesungen wird,

auf dass er wieder herauskomme in die Oberwelt als

vollkommener $\mathrm{Ba}$, um den Herrn der Götter zu schauen".

Noch in griech. Texten begegnet dieser Begriff als summum bonum, vgl.

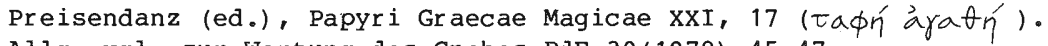

Allg. vgl. zur Wertung des Grabes RdE 30(1978) 45-47.

292 Zu Maat als "Prinzip des Bestandes" S. SAK 8(1980) 22f n. 110.

$293 \mathrm{Zu}$ dieser Konzeption s. König als Sonnenpriester, 63f.; Hornung, Der Eine und die vielen, 209-212.

294 S. hierzu A.de Buck, Plaats en betekenis van Sjoe...21f.m.n.133-136.

295 R.Anthes, die Maat des Echnaton von Amarna, JAOS Suppl.1952.

$296 \mathrm{Vgl}$. SAK $8(1980), 23 \mathrm{~m} \cdot \mathrm{n} \cdot 111$. 
guten Tat, sondern steht allein bei Gott und entspringt seinem freien willen. 297

Diesen oft behandelten Zusammenhängen brauchen wir hier nicht im Einzelnen nachzugehen. ${ }^{298}$ wichtig ist im gegenwärtigen Zusammenhang nur die Vorstellung der Personalität Gottes, die Vorstellung eines göttlichen Willens, die sich in der Ramessidenzeit mit dem Begriff des Lebensgottes verbindet, und der der Begriff der Persönlichen Frömmigkeit als der entsprechenden Haltung des Menschen genau korrespondiert.

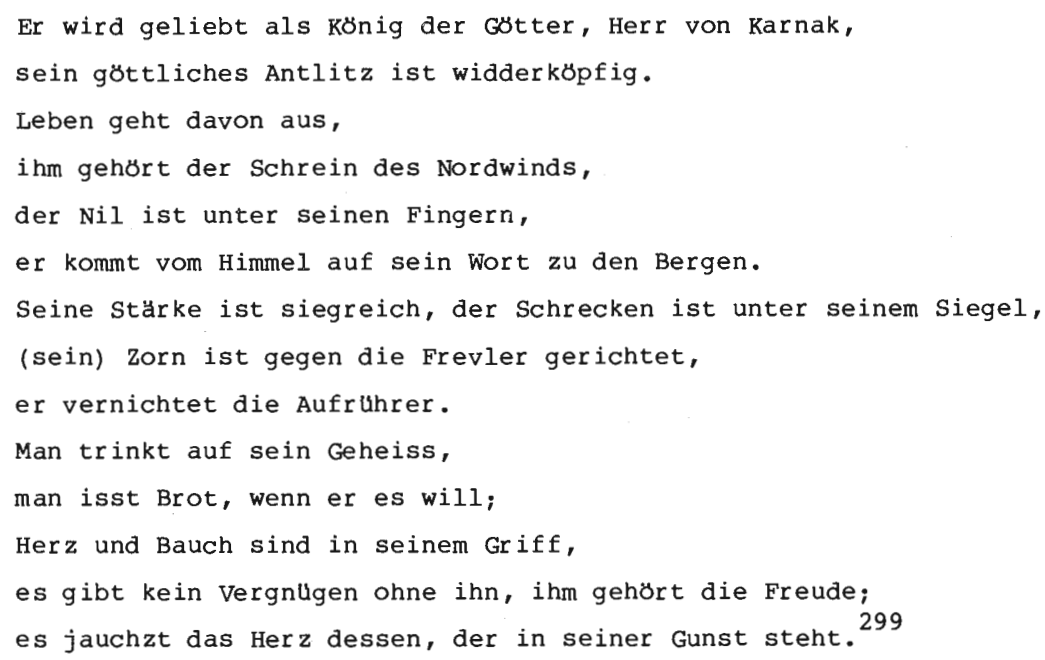

Im ptah-Hymnus des pHarris sind die beiden Aspekte des Lebensgottes, der kosmische und der personale, unter den Oberbegriff des "Herrn der Zeit" gestellt:

Herrscher der Zeitfulle, Herr der Dauer,

Herr des Lebens, der die Kehle atmen lăsst,

297 S. den bahnbrechenden Aufsatz von H.Brunner, "Der freie wille Gottes in der äg. Weisheit", in: Sagesses du proche orient ancien (CESS 1963) 103-117.

$298 \mathrm{Vgl}$. Uber die in n.297 zit. Arbeit hinaus noch S.Morenz, Die Heraufkunft des transzendenten Gottes in Agypten, SSAW 109.2(1964); E.Otto, Die biographischen Inschriften der ăgyptischen Spätzeit (PA 2, 1954) $22 \mathrm{ff}$; "Weisheit...", 12-15.

299 pChester Beatty IV rto $8,9-9,1=$ AHG Nr.195, 161-174. 


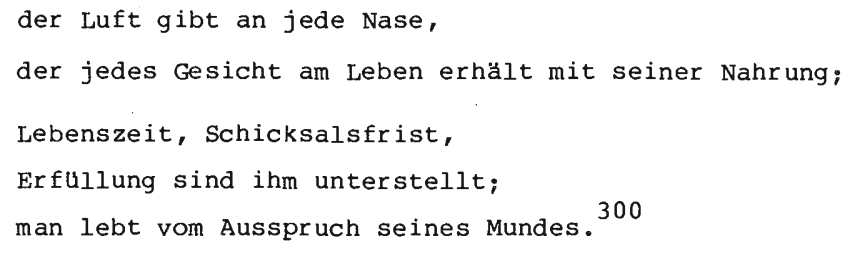

Dass der Agypter zwischen "Zeit" und "Leben" nicht scharf unterscheidet, haben wir bereits hervorgehoben. ${ }^{301}$ Die kosmische zeit, nhh und dt , ist nichts anderes als der Lebensvollzug des Gottes selbst, an dem jedes einzelne Lebewesen ebenso Anteil hat wie an der Luft, die Gottes eigener Atem und zugleich der Lebensodem an jeder Nase ist. Wenn Gott aber nicht als eine kosmische Energie, sondern als Person gedacht wird, dessen planendem Willen und "Ausspruch" die Zeit und das, was in ihr ist, Schicksal und Geschichte also, entspringen, dann wird die traditionelle orientierung des Agypters zur Vergangenheit und zu der am Anfang der Dinge ein für allemal gesetzten gerechten Ordnung hinfällig. Der Blick wendet sich um und richtet sich nun auf eine zukunft, die grundsätzlich offen ist, die in Gottes Hand liegt und seinem freien planenden Willen entspringt: ${ }^{302}$

Nhh rn.k "Zeitfulle" ist dein Name

dt sšm.k "Dauer" ist dein Bild,

k3.k hprw nbw Dein Ka ist alles, was geschieht. ${ }^{303}$

6.2 Retter und Nothelfer 304

jw ḥr nb hr 'n.k-jmjj'

qn hsj m jst w $t$

wsrw mj šw $3 w$ m $r 3-w c$

jht nbt m mjtt

300 pHarris $\mathrm{I}, 44=$ AHG $\mathrm{Nr} \cdot 199,13-19$.

$301 \$ 5.1 \mathrm{~m} \cdot \mathrm{n} \cdot 217-222,220-230$.

302 Fur eine ausfuhrliche Behandlung dieser wende, allerdings ausschliesslich im Rahmen einer Theologie der Zeit, s. Zeit und Ewigkeit, 61-69; vgl. auch unten, 283-86.

303 Text $17(=\mathrm{Nr} \cdot 186) \quad 43-45(\mathrm{Y})$.

304 S. hierzu H.Brunner, in: MDIK 16(1958)5ff; E.Otto, in: Tradition und Glaube (Fs K.G.Kuhn) 9-22. 
bnr.k m jb.sn $r-3 w$

nn ht šwtj m nfrw.k

jn-jw hु3rt hr 'h3jj.n jm.k'?

kttw hrr 'jtj.n mwt.n'? $304 a$

wsrw hr ${ }^{C_{b}}$ m nfrw.k

jw hr n šw hwr.k

nttw hr phr hr.k 305

hrjw h3jjt hrr ${ }^{C_{\zeta}} \mathbf{n} \cdot k$

wnn $r n \cdot k r m k j-h^{c} w n w^{c} n b$

wd3 snb n ntj hr mw

nhm m- hntj 306

sh3 nfr m $3 t$ hw-n-hr

nhm m-r 3 n šmw $308^{\circ}$

jw hr nb ${ }^{c} n w n-h r_{\bullet} k$ r spr.sn hr.k

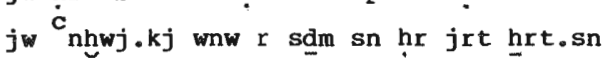

p3jj.n ptḥ mrjw ḥmw.f

mjnw mrjw jdrt.f

jw twn.f m qrst nfrt 309

n jb htpw hr m3 ${ }^{\mathrm{C}} \mathrm{t}$ (pChester Beatty IV rto. 7.11-8.7)

304a Dieser "Chor der Bedurftigkeit" ist ein beliebtes literarisches Thema der Zeit, vgl. Cerný-Gardiner, Hieratic Ostraca, Tf.5, 1.

305 ntj "in Fesseln schlagen", Ggs. wh" "losen", vgl. pTurin pleyte und Rossi $73+18,1$ (JEA 41 Tf.IX,42, 15f) wnw ntjw ntfw wh $w$ "wer in Fesseln war, wurde losgebunden und befreit"; pChester Beatty IX vso 2,7

$=$ AHG Nr . 189, 26-28:

Du suisser Hauch für den Mann, der in Banden liegt;

er sagt: 'komm zu mir, Amun!'-

es wird Tag, und du. erlöst ( $\mathbf{w h}^{\mathbf{c}}$ ) ihn.

Ahnlich p'Turin Pleyte und Rossi 26,3.2:

Du gibst Luft dem, der gebunden ist. Israelstele, ed. Kitchen, RI, IV, 13,12:

Er gibt Luft den Untertanen, die gebunden waren.

Vgl. ebenfalls mit Bezug auf den König, AHG Nr.241,9-10. S. ferner Text 187 (s) mit weiteren Verweisen.

Ahnlich pLeiden J 350 III 18-19=AHG Nr.194,13-14; Zandee, Hymnen,59.

Vgl. pLeiden J 350 III 20: 3h-r $3 \mathrm{~m}$ 3t hr-n-hr AHG Nr.174,17f :

"Wortmächtig im Augenblick der Panik

ein susser Lufthauch flur den, der ihn anruft"

$\mathrm{Z}$ andee, Hymnen, 60 .

308 Um "Errettung aus dem Munde der Menschen" flehen sehr viele Gebete der persönlichen Frömmigkeit: Cerný-Gardiner, Hieratic Ostraca, 89 vso=AHG $\mathrm{Nr} .190,38-39 ; 8,1$; Statuette Leiden D 19: Boeser, Beschr.XII Tf.V(22); RT III,104; Bruyère, Mert Seger fig.36. Cf. Bankes Coll. Stela Nr.6=AHG $\mathrm{Nr} \cdot 160$. Im Titel der Lehre des Amenemope $(\mathrm{I}, 11)$ wird solches auch als Ziel weisheitlicher Unterweisung genannt: "um ihn 


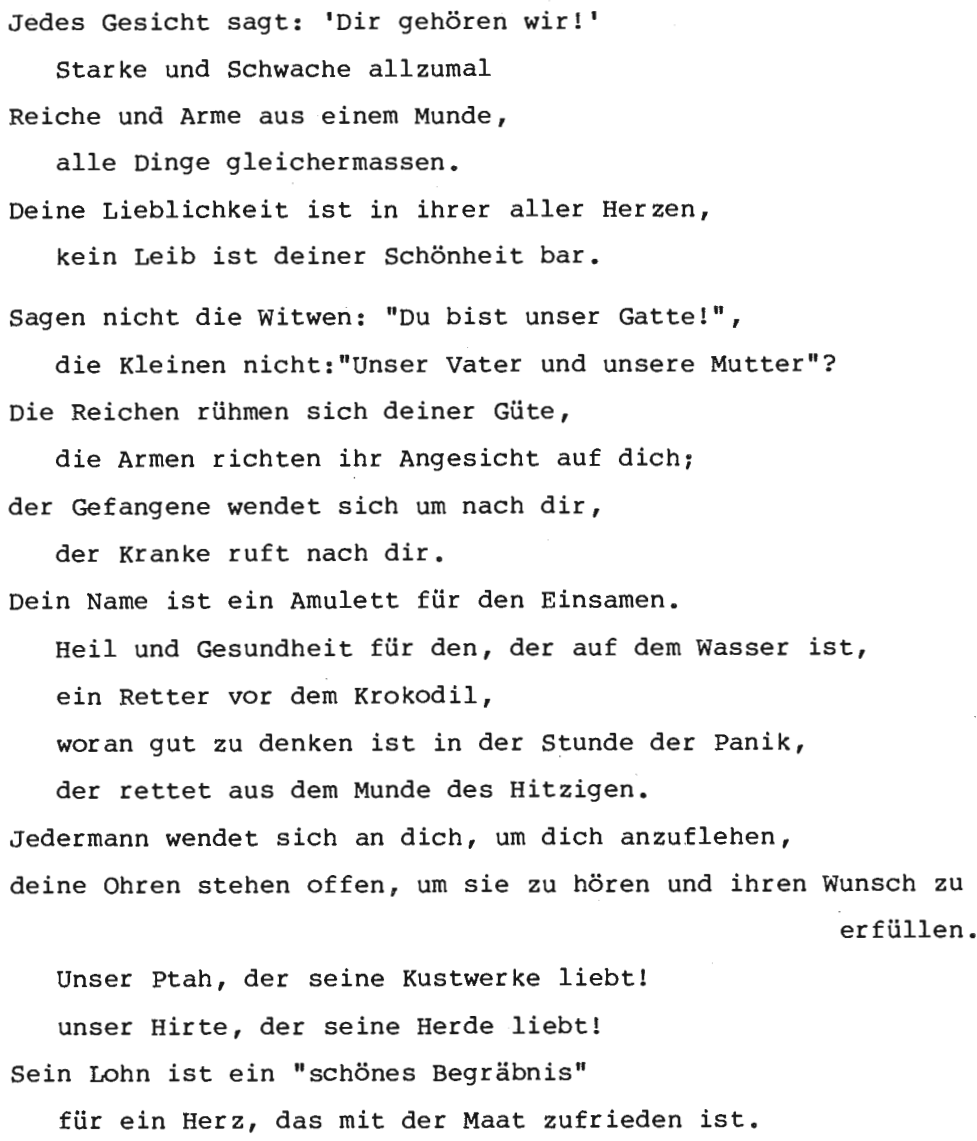

Dieses Lied,das als eine repräsentative Behandlung des Themas für eine Fülle anderer Texte stehen kann 310 , behandelt die existenzielle Grundangewiesenheit des Menschen auf Gott. Das Bewusstsein einer solchen Grundangewiesenheit gehört sicher seit dem AR zu den Grundlagen des ägyptischen Weltbildes; ${ }^{311}$ aber es gewinnt doch eine ganz andere Aktualität und Schärfe im Horizont eines zukunftsoffenen zeitverständnisses, das den

zu erretten aus dem Munde der Leute".

$309 \mathrm{Vgl}$. n.291.

310 In AHG Nr.147-200 wurde eine vollständige Sammlung der längeren Texte angestrebt. Besonders nahe steht dem Lied des pChester Beatty IV das "70." Lied der Leidener Amunshymnen ÄHG Nr.174.

$311 \mathrm{Vgl.bes.A.de} \mathrm{Buck,} \mathrm{"Het} \mathrm{religieus} \mathrm{karakter} \mathrm{der} \mathrm{oudste} \mathrm{egyptische} \mathrm{Wijs-}$ heid", in: NThT $21(1932) 322 \mathrm{ff}$. 
Menschen an eine zukunft ausgeliefert sieht, die ganz und gar in Gottes Hand liegt. ${ }^{312}$ Von daher ergibt sich dieser Begriff einer absoluten Angewiesenheit auf Gott, ohne den das in die Verborgenheit der zukunft hin ausgerichtete Leben nicht zu bestehen ist.

Die Neue Sonnen-Theologie war solchen Anschauungen bereits bis in die Formulierung hinein schon sehr nahe gekommen, vgl. den Satz

nn ht šwtj m nfrw.k Kein Leib ist deiner Schönheit bar

mit Text 151,15

nn bw క̌w m hạdwt.k Kein ort ist deines Lichtes bar. Auch der im pchester Beatty vorhergehende Satz (Vers 126)

jw hwt mhtj m nfrw.k Die Leiber sind erfüllt mit deiner Schönheit wendet den in den Texten der Neuen Sonnen-Theologie so oft begegnenden Satz, dass der Sonnengott mit seinem Aufgang "die beiden Länder mit seiner schönheit erfüllt"313 ins Innere und vom Schauen des äusseren Lichts zu einer Erleuchtung und Durchdringung des ganzen inneren Menschen von Gottes Grösse. 314 Nicht nur die Augen, sondern auch die Herzen der Menschen wenden sich zu Gott. So fährt pchester Beatty fort:

jrtj gmh.sn jm.k

jw snd.k $n$ hr nb

jb.sn phrw hr.k
Die Augen, sie blicken auf dich

Furcht vor dir erfüllt jedermann

ihre Herzen sind dir zugewandt. ${ }^{315}$

Die Vorstellung von der Allgegenwart des Lichts, wie sie im Rahmen der Neuen Sonnentheologie ausgebildet wurde, wird hier in Bezug auf den Menschen verinnerlicht und von dem Phänomen

312 Der locus classicus dieser Auffassung ist das 18. Kap. der Lehre des Amenemope (XIX.11ff.) s. I.Grumach, Untersuchungen zur Lebenslehre des Amenemope 124-128, vgl. auch ibd.VI, 18-VII, 10 Grumach, 49-55; zeit und Ewigkeit, $66 \mathrm{f}$. mit weiterer Lit. in n.90.

$313 \mathrm{Vgl}$. Kap. $3 \$ 2.4$.

$314 \mathrm{zu}$ ht "Leib" als Bezeichnung des "inneren Menschen" s.LL, 196 n. 22. Vgl. auch die Belege bei Text 188 (b). Das Wort kommt im pchester Beatty IV noch an zwei anderen stellen vor, die ebenfalls eine verinnerlichte Auffassung von der Allgegenwart des Lichts zum Ausdruck bringen:

Vers 4 "Dein Auge ist in jedem Leib"

Vers 250 "Führer bist du in jedem Leibe".

315 VII,9-10 Verse 127-129. 
der "Lichtabhängigkeit" all dessen, "was Augen hat"316 ausgeweitet zur umfassenden und existenziellen Gottangewiesenheit des Menschen.

Dieselbe Umdeutung exfährt die Vorstellung von der Aligegenwart des Lichts auch in Bezug auf den Gottesbegriff, auch hier in nur leichter Abwandlung vorgeprägter Formulierungen. Die neue Sonnen-Theologie erschliesst aus dem Phänomen des Lichts, in dem der unerreichbare ferne Sonnengott den irdischen Lebewesen spurbar nahe kommt, den Gedanken der gleichzeitigen Ferne und Nähe Gottes:

w3jw tknw nn rh.tw.f Der Ferne und nahe, der nicht erkannt werden kann. 317

Vgl.damit nun folgende Stelle aus einem Text der Thebanischen Amun-Theologie:

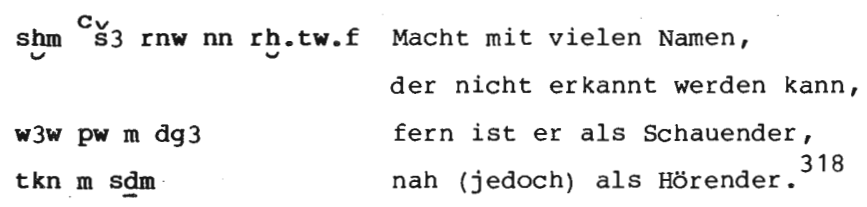

Der Begriff der "Nähe" Gottes erschliesst sich nun nicht aus der sinnlichen Erfahrung des Lichts, sondern aus der übersinnlichen Vorstellung einer göttlichen Allwissenheit und Allgegenwart, in der Gott dem Herzen, das sich "ihm zuwendet" unmittelbar nahe ist. Wenn der "schauende Gott" noch mit der Sonne identifiziert werden konnte, im Begriff des "Hörenden Gottes" wird die kosmische "Phänomenologie" der Neuen SonnenTheologie transzendiert in Richtung auf den Begriff eines personalen Gottes, der nicht wie das Sonnenlicht allen gleicher-

$316 \mathrm{Vgl}$. $\$ 4.4 \mathrm{mit} \mathrm{n} .175 ;$ Kap. $3 \$ 2.5 \mathrm{mit} \mathrm{n} .127$, auch $\$ 2.6$.

317 Hymnus (Fragment) ed. Quibell, Exc. at Saqq. IV $(1908-10)$ Tf.73.3= pBerlin 3048 II $8-9=$ AHG Nr.143,17 vgl. Kap.3 $\$ 2.3$.

318 pBerlin 3049,VIII.4 = AHG Nr.127B, 34-35. In der Spătzeit wird diese Formel passiv ungedeutet: Gott wird (als sonne) in der Ferne geschaut, aber (als wind) nah gehört:

w3w $\mathrm{m} \mathrm{hrw}$ fern in den Gesichtern

tkn m madrw nah in den ohren

Edfou I 40; Urk VIII 15h; Esna Nr.387.5-6, Sauneron, Esna III, 368;

Esna V 220-21; Sethe, Amun $\$ \$ 204,207 f$. 
massen nahe ist, sondern jeweils dem, der zu ihm ruft; der nicht, wie das Sonnenlicht, "einfach da" ist, sondern der "gefunden" werden muss. 319

Der Gott des Einzelnen

... hat Augen wie Ohren

ein Gesicht auf allen Seiten für den, den er liebt,

Der die Gebete dessen erhört, der zu inm ruft,

der von ferne kommt ${ }^{320}$ zu dem, der ihn anruft,

in einem Augenblick. 321

Er blickt auf die Menschen, keiner ist, den er nicht kennt,

und er hört auf Millionen von ihnen. ${ }^{322}$

Du bist es, der hört mit seinen onren,

du blickst auf Millionen in den Ländern. ${ }^{323}$

Mit vielen Augen und grossen Ohren 324 ,

der Millionen leitet mit seinem Leuchten. ${ }^{325}$

Der Herr des Lebens, der gibt, wem er will,

der Erdkreis steht unter seiner Aufsicht. ${ }^{326}$

\subsection{Richter 327}

In der Allgegenwart und der Allwissenheit äussert sich nicht nur die Gnade Gottes, die dem Bedrängten nahe ist und

319 Mit dem Ausdruck gmj "gefunden werden" bezeichnet man in den Texten der persönlichen Frömmigkeit die erfahrene Offenbarung der Gottheit, s. AHG $597 \mathrm{zu} \mathrm{Nr} \cdot 148,39 f$.

320 Id. Berlin 20377=AHG Nr.148B,24; Graffito in TT 139=AHG $\mathrm{Nr} \cdot 147,32$.

321 pLeiden J 350 III 16-17=AHG Nr.194; Zandee, Hymnen, $57 \mathrm{f}$.

322 Stele der Verbannten, AHG, S.71.

323 Totb des Hunefer, AHG Nr.42A,40f.

$324 \mathrm{Vgl}$. p.mag.Harris VII,6: "Der 77 Augen und 77 Ohren hat"; Hibis 32,31 cf. Urk VI,75:

"Der geheime Ba mit widderförmigen Antlitzen,

mit vier Gesichtern auf einem Hals,

mit 777 Ohren,

mit Millionen und Abermillionen Augen".

325 Ahnl. Edfou II 69 , III 67:

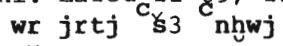

šrm hḥw m psd.f

S. auch Otto, Gott und Mensch, 30 und 113.

326 Neschons $22-24=$ AHG $\mathrm{Nr} \cdot 131,56-59$.

$327 \mathrm{Vgl}$. hierzu G.Posener, "Amon juge de pauvre", in: Fs Ricke (1971), $59 f f$. 
den Bittenden erhört, sondern auch die Gerechtigkeit Gottes, die gegen das Böse vorgeht. Diese beiden Aspekte des Retters und des Richters, der Gnade und der Gerechtigkeit, lassen sich kaum trennen, da die Gerichtssituation unter den verschiedenen Notlagen, aus denen heraus Gott um Beistand angerufen wird und in denen er als Retter in Erscheinung tritt, eine ausgezeichnete Rolle zu spielen scheint. Das Böse manifestiert sich in der menschlichen sphäre vornehmlich als Unrecht und der Notschrei des Bedrängten ergeht vor allem um Gerechtigkeit. Gott rettet, indem er das Böse bestraft:

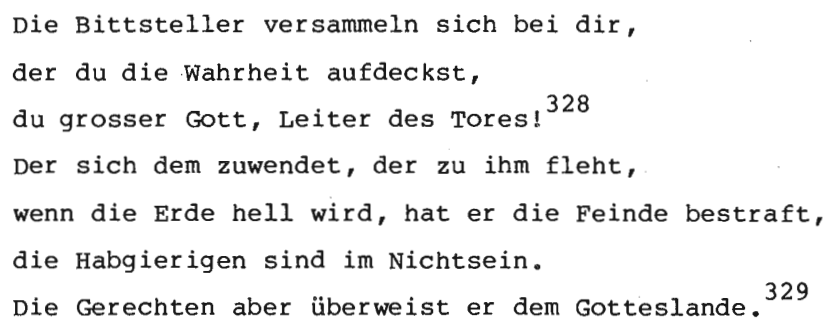

So preist ihn auch Text 212. Hier steht nicht nur die menschliche Gerichtssituation im Blick, wo Gott um Beistand für den Armen angefleht wird, der sich bestechlichen Richtern ausgeliefert sieht, sondern das von Gott selbst veranstaltete Gericht, das über Recht und Unrecht entscheidet. In diesem Gericht geht es um das Schicksal nach dem Tode. Nur wer hier besteht, wird "dem Westen zugewiesen" 330 und erhält ein "schönes Begräbnis". ${ }^{331}$ So stossen wir auch hier wieder auf Amun, den "Herrn des Begräbnisses" 332 , der auch die Vorstellungen vom Totengericht auf sich vereinigt. In der Tat ist ja der Begriff Gottes als "ethische Instanz" für den Ägypter auch kaum von der Idee des Totengerichts zu trennen; in diesem Punkt

328 Dies bezieht sich auf die Institution der Rechtsprechung am Tor, s.LL $82(6)$.

329 pChester Beatty IV rto 11,4-5=ÄHG Nr.195, 261-267.

330 S. RaE $30,46 f$.

$331 \mathrm{Vgl}$. n.291.

332 "Amun, Herr des Begräbnisses, der ein (hohes) Alter gibt" heisst Amun bereits in einer Inschrift des Grabes TT 57 aus der Zeit Amenophis' III (Mém.Miss.I 129). 
sind die Wirkungssphären von Re und Osiris schon früh ineinander úbergegangen. Wer vor Gottes Gerechtigkeit nicht besteht, fällt dem Tod anheim. Der Tod, nicht der physische Tod, der nach ägyptischer Anschauung für den Gerechten die Chance eines Ubergangs darstellt in ein Leben auf anderer Seins-Ebene, sondern das absolute Ende, das Nicht-Sein ( tm-wnn), ist die Waffe, die Gott gegen das Böse bereithält. In seiner Hand ist nicht nur das Leben, sondern auch der Tod ${ }^{33}$. Darin zeigt sich am klarsten, wie weit und in welcher Richtung er über den traditionellen ägyptischen Begriff eines Lebensgottes hinausgeht:

Die Luft ist in seiner Nase, der wind in seinem Inneren

Leben und Tod sind inm anheimgestellt;

er ist es, der die verstopfte Kehle atmen lässt

und die Kehle eng werden lässt nach seinem Belieben.

Es gibt kein Leben ohne ihn,

wir sind alle aus seinem Auge hervorgegangen. 334

Im Zusammenhang des Themas "Gott als Richter" geht es um das Problem des Bösen. Die Amarna-Religion hatte es vollkommen ausgeklammert, und bis zu einem gewissen Grade gilt das auch für die Neue Sonnen-Theologie insgesamt. ${ }^{335}$ Jedenfalls wird das "Ikon" des Sonnenfeindes, worin die traditionelle Sonnenreligion in der ihr eigenen Form eines bildhaft veranschaulichenden und vielfältige Sinn-Dimensionen in-Eins sehenden Denkens diesen Komplex gefasst hatte, wie alle anderen "Ikone" auch vermieden. 336 Demgegenüber stellt aber bereits der pKairo 58038 den personalen Aspekt Gottes als "Gott des Einzelnen" und "ethische Instanz" in genau den beiden Aspekten des erhörenden Retters und des gerechten Richters dar, die auch den ramessidischen Hymnen die wichtigsten sind. 337 Diese Strophe zeichnet aber den personalen Aspekt Gottes noch

$333 \mathrm{Vgl.} \mathrm{hierzu} \mathrm{E.Otto,} \mathrm{"Zur} \mathrm{Geschichte} \mathrm{einer} \mathrm{religiosen} \mathrm{Formel",} \mathrm{in:} \mathrm{ZaS}$ $87(1962) 150-154$.

334 oCairo $25208=$ AHG $\mathrm{Nr} \cdot 193,17-22$.

$335 \mathrm{Vgl}$. hochstens Text $151(\mathrm{~m})$.

$336 \mathrm{~S}$. Kap. $2 \S 2.2 .2 ; \operatorname{Kap} .3 \$ 3.2$.

337 S. Kap.4 $\$ 3$. 
ganz in dem für diese Frühphase der Amun-Re-Theologie typischen milden Licht des gütigen wohltäters, dem das Problem des Bösen zumindest nicht aktuell ist.

Demgegenüber tritt in dem Bilde, das sich die Ramessidenzeit von der Personalität Gottes macht, das Problem des Bösen in aller Schärfe hervor. Der Text, der ihm den breitesten Raum widmet, ist Text 156 im Grab des Dritten Amunspriester Tjanefer (Zeit Ramses III). Der ramessidische Amun-Re ist ein Gott, der sich gegen das Böse erzürnt und mit unwiderstehlicher Gewalt dagegen vorgeht.

Wer vermag deinem zorn zu widerstehen, wer das Rasen

$$
\text { deiner Gewalt abzuwenden? } 338
$$

Dieser Gott, der Leben und Tod in Händen hält, hat ein Doppelgesicht, das gleichermassen lebenspendend wie todbringend, erhaltend wie vernichtend wirkt:

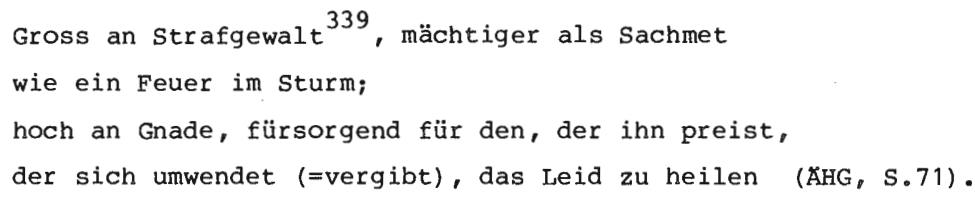

Dieses Gottesbild hat eine Vorgeschichte, auf die abschliessend wenigstens in wenigen worten noch eingegangen werden muss.

\section{4 "Gewaltenteilung" und "Repräsentanz"}

Dem Kenner wird nicht entgangen sein, in welch grosser Nähe viele der in diesem Abschnitt behandelten Formulierungen und Vorstellungen zur Königstheologie des MR stehen. Das gilt für das zuletzt behandelte "Doppelgesicht der Macht", die Verfüqung über Leben und Tod, die sich in einem Königshymnus etwa so liest:

338 Hymnus der Verbannten-stele, AHG S.71.

$339 \mathrm{zu}$ b3w in der Bedeutung "Zorn" s.Posener, RdE 27,201 n.9; E. Wente, Late Ramesside Letters, $46(\mathrm{~g})$; Gardiner, JEA 48,62 n.3. 
Bastet ist er, die die beiden Länder schützt;

wer ihn anbetet, wird von seinem Arm beschirmt werden.

Sachmet ist er gegen den, der seine weisung übertritt;

wer sich seine Ungnade zuzieht, muss zum Nomaden werden 340

Leben ist er für den, der ihm Loblieder spendet,

aber seine Feinde werden (zu Nichtseienden?) 341

Die Form, in der die ramessidischen Hymnen das Thema Gottes als "ethischer Instanz" behandeln, konfrontiert uns mit einer Phraseologie, die uns aus Königstexten, ja bis zu einem gewissen Grade sogar Privatinschriften der 1.zz. und des MR vertraut ist. Das gilt z.B. für die Topik des "Hirten" 342 und des "Patrons"343, des "Gatten der Witwe" und "Vatersund-Mutter der Waisen", des Erretters des Armen oder Schwachen vor dem Reichen oder Starken, des Fährmanns, der den Mittellosen übersetzt, des steverruders 344 , der "Zuflucht" (jbw), des unbestechlichen Richters usw. usw. ${ }^{345}$ Nur der Nothelfer im eigentlichen Sinne scheint Gottes ureigenste Domäne zu sein: nur er hört auf den weinenden und kommt von ferne zu dem, der zu ihm ruft. ${ }^{346}$ Alle anderen Aspekte seiner Personalität teilt er, so scheint es, mit dem König und sogar zu einem guten Grade auch mit dem Privatmann. Im Hinblick auf die geschichtliche Entwicklung sieht es sogar so aus, als habe Gott den Gaufürsten und den König in diesen Wirkungsweisen "beerbt", als sei er in Bereiche "eingedrungen", die vorher als königliche bzw. allgemein menschliche Domäne angesehen wurden.

Eine solche Interpretation trifft wohl nicht ganz daneben. Die Lehre für Merikare, die die Wohleingerichtetheit der

340 Enseignement Loyaliste ed. Posener, 5.11-14.

341 Ibd. . 4.7-8.

342 S.dazu D.Müller, "Der Gute Hirte", ZÄS 86(1961)126-144. S.hierzu und zum Folgenden die grundlegende Arbeit von E.Blumenthal, Untersuchungen zum Königtum des Mittleren Reichs I (1970).

343 Zum Begriff des "Patrons" vgl.H.Tellenbach (Hrsg.), Das Vaterbild..., $16-20$.

$344 \mathrm{Vgl}$. Text $187(\mathrm{t}) ; \mathrm{Kap} .4 \mathrm{~m} \cdot \mathrm{n} .118$.

345 Zur Funktion der Bildrede in der Persönlichen Frömmigkeit s.LA I, 430 n.8.

$346 \mathrm{Vgl}$. "Weisheit, Loyalismus und Frömnigkeit", $48 \mathrm{ff}$. 
Welt preist und die sowohl die schöpfung als auch den Sonnenlauf um der Menschen willen geschehen lässt, weiss zwar einerseits von dem "Hörenden Gott", der in seiner "verborgenen Kapelle"347 dem Weinenden nahe ist, aber es heisst dann auch: 348

\section{Er schuf ihnen Herrscher 'im Ei'}

und Machthaber, um den Rücken des Schwachen zu stärken.

Das heisst doch soviel als dass Gott die gerechte verteilung der von ihm geschaffenen Lebensgüter und die Durchsetzung der gerechten Weltordnung in der menschlich-sozialen sphäre an den König und seine Beamte gleichsam delegiert habe. Genau dieselbe Auffassung kommt auch in dem kulttheologischen Traktat über den "König als Sonnenpriester" zum Ausdruck und gehört gewiss zu den Grundlagen der ägyptischen Königstheologie. 349 Die Aufgabe des Königs ist die Versorgung der Menschen mit Gerechtigkeit und der Götter mit Opfer, die Verwirklichung der Maat und die Vernichtung der Isfet. In eine ähnliche Richtung weist auch die selbstrechtfertigung Gottes im Sargtextspruch 1130. Dort wird ausdrücklich betont, dass der Schöpfer die Lebensgüter für alle Menschen gleich geschaffen habe

aber ihre Herzen haben das, was ich angeordnet habe, verletzt. 350

Das Böse ist in der schöpfung nicht angelegt: es entspringt dem sich aus dieser Ordnung lösenden Willen ("Herzen") des Menschen. Das könnte darauf hinweisen, dass der Gott, der an dem Bösen keine Mitverantwortung trägt, auch seine Bekämpfung den Menschen überlässt, die es in die Welt gebracht haben; genau dies scheint ihm ja der berühmte "Vorwurf an Gott" in den Admonitions zum Vorwurf $\mathrm{zu}$ machen. ${ }^{351}$ Aber in dem sargtext heisst es dann weiter: 352

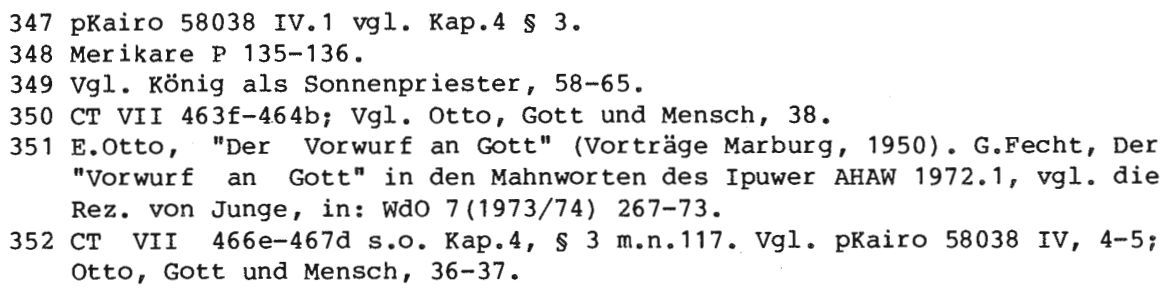
"Vorwurf an Gott" in den Mahnworten des Ipuwer AHAW 1972.1, vgl. die Rez. von Junge, in: Wdo $7(1973 / 74)$ 267-73.

352 CT VII 466e-467d s.o. Kap.4, \$ 3 m.n.117. Vgl. pKairo 58038 IV, 4-5; Otto, Gott und Mensch, 36-37. 
Ich richte den Schwachen und den Starken, ich gehe ebenso vor gegen die, die unrecht tun.

Mir gehört das Leben, ich bin sein Herr,

niemand kann das Szepter der Herrschaft meiner Hand entwinden.

Hier ist in aller Klarheit vom Richtertum Gottes die Rede. Gott hat das unrechttun verboten ${ }^{353}$ und lässt es nicht geschehen. Jeder hat sich vor ihm zu verantworten.

Wir durfen uns das verhältnis von Gott und irdischen Machthabern nicht im Sinne einer "Gewaltenteilung" denken, so als spreche der König auf Erden, Gott aber im Jenseits Recht, sondern vielmehr im Sinne der Repräsentanz: der König bringt in seiner irdischen Rechtsprechung das Richtertum Gottes zur Erscheinung. Die vermutung liegt nahe, dass dieselbe struktur, der Repräsentanz auch überall dort vorliegt, wo von der gerechten und wohltätigen Ausübung von Macht die Rede ist. Der Mensch, der so handelt, als Gatte der witwe, Zuflucht des Bedrängten, Fährmann des Schifflosen, handelt als Ebenbild Gottes. $353 \mathrm{a}$ Im Licht der Idee von der Gottebenbildlichkeit des Menschen bekommt diese gesamte phraseologie, lange bevor sie in den Hymnen auftaucht, bereits theologische Bedeutung. Sie verweist auf menschliche Formen der Maat-Verwirklichung, die abbildhaft an der Güte und Gerechtigkeit eines Gottes teilhaben, der seine Schöpfung als Richter und Hirte, als Ernährer und Beistand erhält und verwaltet.

353 Das ist gemeint, wenn es im Ag heisst: "Ich habe nicht befohlen, dass sie Unrecht tun"; "verbieten" wird als "nicht befehlen, dass" ausgedruckt, genau wie "verhindern" durch "nicht veranlassen, dass". Daher hat das unrechttun der Menschen den Charakter der Ubertretung eines ausdrlicklichen verbots und nicht nur, wie diese stelle oft interpretiert wird, den eines Handelns ausserhalb von Gottes veranlassung und Verantwortung. Das "Unrecht" scheint nach dem Sinnzusammenhang der Stelle in der Zerstorung der gottgeschaffenen Gleichheit aller Menschen, also in der Unterdrlickung des Schwachen (Armen) durch den Starken (Reichen) zu bestehen. Damit vergleiche man die paradigmatische Bedeutung der 'Habgier' in der Weisheitsliteratur von Ptahhotep bis Amenemope.

$353 a$ E.Hornung, "Der Mensch als Bild Gottes in Agypten", in: 0.Loretz, Die Gottebenbildlichkeit des Menschen (1970), 151; vgl.auch Brunner, LA I, 306 m.n.29; E.Otto, "Der Mensch als Geschöpf und. Bild Gottes in Agypten", Fs.G.V.Rad (1971) 335-348. 
Oft kommt diese Gottebenbildlichkeit Maat-verwirklichenden Handelns in den Texten auch explizit zum Ausdruck, z.B. wenn einer von sich sagt

w3h jb hr sdmt mảw Geduldigen Herzens beim Anhören der Aussage

$m j$ nter $m$ wnwt.f wie der Gott in seiner Stunde. ${ }^{354}$

Hier liegt auch die.Erklärung für die oft als befremdich empfundene sitte, sich mit Götternamen als Inbegriffen bestimmter Eigenschaften oder Handlungsweisen $\mathrm{zu}$ schmücken, $354 \mathrm{a}$ $z . B$. wenn sich ein Mentuhotep nicht nur "Sohn des (Korngottes) Nepre, Gatte der (Webgöttin) Taiit" nennt, sondern geradezu

Mesechnet und Chnum, der Menschen exschafft. 355

Ein Rudj-ahau nennt sich "Thoth im Gericht". ${ }^{356}$ Anchtifi von Mocalla bezeichnet sich als

$$
\begin{aligned}
& \text { Apis, Herr der Rinder, } \\
& \text { Sechat-Hor, Herrin der Ziegen } \\
& \text { Nepre, Herr des korns } \\
& \text { Taiit, Herrin der Gewänder. }
\end{aligned}
$$

In diesen Bezügen reflektiert das Menschenbild der 1.2z. und des MR denselben Gottesbegriff, der in der Lehre für Merikare, dem Sargtext Spruch 1130 und (vermutlich) den Admonitions im Blick steht. Der Unterschied zwischen göttlichem und menschlichem Handeln liegt darin, dass die Götter diese Eigenschaften immer und in Bezug auf die welt insgesamt verkörpern, die Menschen jedoch nur in ihrer räumlich, sozial und zeitlich begrenzten sphäre.

354 J.M.A.Janssen, De traditioneele egyptische autobiografie vóór het Nieuwe Rijk (1946) I, 12 Nr.17; Kairo CG 20539; Urk IV 49; TT 27 Treppe, rechts: OA 12(1973)32. Zur Göttlichkeit des zuhörens vgl. auch Anii $x, 8 f$.

354 a Vgl. hierzu E.Blumenthal, Untersuchungen zum königtum des Mittleren Reichs I, 105; Otto, Fs.v.Rad, 344; LA I, 21; G.Posener, L'Enseignement loyaliste (1976), $20 \mathrm{f}$.

355 Stele London 14333 ed.Goedicke, JEA 48(1962) $25 \mathrm{ff}$. s.a. Schenkel, JEA $50(1964) 6 f f$.

356 Faulkner, JEA 37,49.

357 Vaudier, Mo'alla, $242 \mathrm{ff} .$, s.auch Posener, Littérature et politique, 77. 
Die Unterscheidung von "Gewaltenteilung" und "Repräsentanz" erlaubt es nun auch, die Beziehung von Gott und König in der Amarna-Religion etwas differenzierter zu erfassen, jener beiden Brennpunkte, in denen hier alle Erscheinungsformen des Göttlichen zusammengefasst werden. Auch hier wird man sich davor hüten mússen, diese zweiheit von Gott und König, kosmischem Lebensgott und personalem Gott des Einzelnen, im Sinne einer Gewaltenteilung aufzufassen. Zumindest würde dies dem Selbstverständnis dieser Religion zuwiderlaufen. Auch hier macht der König dem Gott seinen Rang nicht streitig, wenn er als "Schicksal und Lebenspender" auftritt" ${ }^{358}$, sondern setzt nur das göttliche Wirken in die Menschenwelt hinein fort. Das Problem, dass gerade im thematischen Bereich des Schicksals und der "ethischen Instanz" Gott und König hier identische Prädikate tragen, findet in der struktur der Repräsentanz, der Gottebenbildlichkeit des Königs, seine Lösung. In Amarna bekommen diese Vorstellungen nur deshalb eine soviel schärfere Kontur, weil die Zwischenwelt der vielen Götter ausgeschaltet ist, die in der behandelten Topik wie Ressortgötter auftreten; Thoth, Chnum, Bastet, Sachmet, Schai, Mesechnet, Renenet, Nepre, Taiit, Sechat-Hor, Apis usw. So bleiben allein Gott und König übrig. Damit wird es auch dem Einzelnen unmöglich, in seinem Handeln göttliche Eigenschaften zu verwirklichen. 359

358 Entsprechende Prădikate kommen in den Amarnatexten mit Bezug auf den Gott und auf den Konig vor, vgl. Zeit und Ewigkeit, 58 n.47.

359 Die Repräsentanz des "Sonnen-" und "Reichs-"Gottes (wie dieser etwas ungluckliche Begriff gemeint ist, habe ich in: "Primat und Transzendenz", 18-26, zu zeigen versucht) ist naturlich seit je dem könig vorbehalten; der Einzelne vermag nur einzelne Aspekte des Göttlichen abzubilden, wie sie sich in den Gestalten der polytheistischen Götterwelt verkörpern. Eine interessante Frage, auf die hier aber nur am Rande verwiesen werden kann, ist, ob man das verhältnis der Götter zueinander nicht ebenfalls eher im Sinne der "Repräsentanz" als der "Gewaltenteilung" verstehen musse. Das Richtertum des Thoth ist ein klares Beispiel: hierin repräsentiert er den Sonnengott, dem er ebensowenig den Rang streitig macht wie auf Erden der. Wesir dem Konig. Entsprechendes scheint aber viel allgemeiner zu gelten und wirft ein Licht auf das problem des agyptischen "Synkretismus" wie auf den ramessidischen "Pantheismus", der die Gottervielheit insgesamt als Repräsentation des Einen erklärt. Die Struktur des griech. Polytheismus ist - jedenfalls in der archaischen Form - dem gegenuber eher die der "Gewaltenteilung", wie H.Blumenberg, Arbeit am Mythos (1979) gezeigt hat. 
Nach Amarna wird die gesamte Topik der "ethischen Instanz" - der gute Hirte, die Zuflucht des Bedrängten, der Fährmann und Pilot, der Wesir des Armen usw. - auf die Gottheit bezogen. Gott wird nun in genau jenen Aspekten seines Wesens gepriesen, die nach herkömmlicher Anschauung im Bereich der menschlichen Gesellschaft "abzubilden" dem Menschen selbst nicht nur möglich, sondern geradezu aufgetragen war. Der geistige Wandel, der sich in diesen gattungsgeschichtlichen Verlagerungen ausdrückt, ist so zu verstehen, dass die Gottheit nun unmittelbar - und nicht mehr im sinne der Repräsentanz in von ihr selbst geschaffenen Institutionen und eingesetzten Instanzen - in Erscheinung tritt. Sie setzt ihr Wesen selbst in Handlung um, verfügt selbst über die von ihr geschaffene Fülle und Ordnung. Diese Vorstellung einer unmittelbaren, frei entscheidenden Verfügung wird mit den Wendungen zum Ausdruck gebracht, die vom "in der Hand" "im Griff" sein jener Prinzipien reden, die sich nicht nur auf die Erschaffung, sondern vor allem auf die Verteilung der Lebensgüter beziehen.

Dieser geistige Wandel ist kein Phänomen der Amun-Theologie, ja nicht einmal der Religion insgesamt; er umfasst die gesamte ägyptische Wirklichkeit und schlägt in alle Ebenen der Lebenswelt durch, wie man z.B. an der Abwandlung der Brief-Formel sehen kann, mit der man über sein Befinden Auskunft gibt: 360

"Heute geht es mir gut", sagt man in der 19.Dyn.,

"meinen zustand von morgen kenne ich nicht."

In der 20. Dyn. heisst das:

"Heute geht es mir gut; das Morgen liegt in Gottes Hand."

Auch das, was wir oben als die Ersetzung des Prinzips Maat durch die Gunst - den "Segen" ( ḩswt ) - Gottes bezeichnet haben, entspricht genau dem, was man in jüngerer zeit von verschiedenen Seiten als Unterschied zwischen der jüngeren (Amenemope und spätere) und der älteren weisheitsliteratur heraus-

360 Nachweise gab ich in: Zeit und Ewigkeit, 66 m.n.87-88. 
gearbeitet hat ${ }^{361}$ und was sich in folgendem Modell darstellen lässt: 362

åltere Konzeption

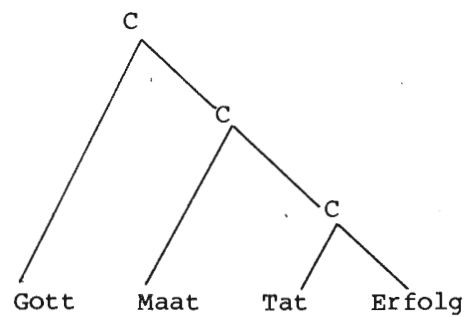

jüngere Konzeption

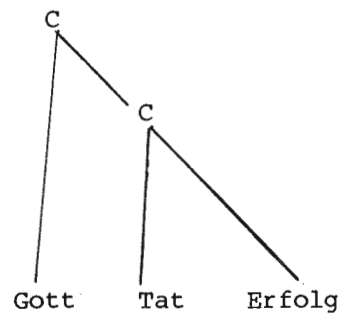

In der "jüngeren Konzeption" ist die Maat aus ihrer vermittelnden Position verschwunden und unmittelbar in Gottes Willen aufgegangen. Der Mensch "repräsentiert" nun nicht mehr die Gottheit in seiner Verwirklichung der Maat, im Sinne eines sich-Einfügens in eine göttlich fundierte ordnung, sondern er befolgt Gottes willen, gehorcht seinen Geboten, "beherzigt" seine Grösse und "handelt auf seinem Wasser". In diesem Zusammenhang stellt sich die Frage, wie denn die Gottheit dem Menschen ihren Willen offenbare, und der Hinweis auf das gleichzeitig in grossem Umfang auftretende orakelwesen und gelegentliche Fälle von Traumoffenbarung liegt auf der Hand. 363 Ich meine aber, dass man das problem wesentlich radikaler sehen muss: es erscheint mir durchaus fraglich, ob der Ägypter überhaupt.von der Wissbarkeit des göttlichen Willens ausging. Ich muss die Frage hier auf sich beruhen las-

361 E.Otto, Die biographischen Inschriften der ägyptischen Spätzeit, PÄ 2 1954, 22ff. Brunner, in: Sagesses du proche orient Ancien (CESS, 1963),103-117; I.Grumach, Untersuchungen zur Lebenslehre des Amenemope (MÄs 23,1972 ) u.A.

362 "Weisheit, Loyalismus und Frömnigkeit", 14. "C" bezeichnet die Kausalfunktion, die die Ursache-Wirkung-Relation der von ihr dominierten Begriffe anzeigt: Gott bewirkt die Ordnung "Maat", die ihrerseits bewirkt, dass die gute Tat zum Erfolg führt (ältere Konzeption), bzw: Gott bewirkt den Erfolg (jüngere Konzeption, das Thema vom Amenemope Kap. 18).

$363 \mathrm{zu}$ dieser problematik s. bes. Morenz, Ägyptische Religion, $63 f f$. 
sen, glaube aber, dass manche Phänomene des ramessidischen Lebensgefühls sich mit diesem Austritt aus der Geborgenheit im Prinzip Maat erklären lassen.

Den genannten Wandel, der einem Epochenwechsel gleichkommt, in all seinen Aspekten nachzugehen, ist hier nicht der Ort. Nur auf zwei punkte sei abschliessend aufmerksam gemacht:

1.) Erst im Rahmen der "jüngeren Konzeption" bekommt das Unrecht ( jsft) den Charakter der "Sünde", d.h. eines Vergehens gegen Gott. Der Mensch, der gegen die Gebote der Maat verstösst, scheitert. Wer aber gegen den Willen Gottes verstösst, versündigt sich, d.h. er stört eine unmittelbare Beziehung, in der er immer schon zu Gott steht. Da er es mit einem vergebenden Gott zu tun hat, kann er diese störung durch eine Tat aktiver Wiedergutmachung heilen. Das ist der Hintergrund jener sakralrechtlichen Institutionen, denen wir die inschriftlichen Zeugnisse der "Persönlichen Frömmigkeit" verdanken.

2.) Die ältere Konzeption negiert die Geschichte. Sie sieht den Sinn menschlichen Handelns in der Verwirklichung einer ewigen ordnung. "Die Maat ist gross und dauert; sie wurde nicht gestört seit der Zeit ihres Schöpfers." 364 Die fortschreitende zeit wird aufgehoben durch fortwährende Rückbindung an den Ursprung. Die jüngere Konzeption erschliesst einen ganz neuen Begriff von der Geschichtlichkeit der menschlichen Existenz und von der Vergänglichkeit des Daseins. 365 In der vergehenden zeit realisiert sich der wille Gottes. Im Glück der Schlachten entscheidet sich seine Gunst. Wenn er sich von Ägypten abwendet, fällt es in die Hand innerer oder äusserer Feinde, wenn er sich ihm wieder zuwendet, blühen Macht, Wohlstand, Gerechtigkeit. 366 Die Geschichtstheologie

364 Ptahhotep 88-89 nach pLondon2. pprisse liest statt jrjw-sj "wsjr" "Osiris", s. dazu Westendorf, MIO 2(1954)165ff; U.Luft, Studia Aegyptiaca IV, $158 \mathrm{f}$.

$365 \mathrm{Vgl}$. das Thema der "Vergänglichkeitsklage" in Harfnerliedern, Osirishymnen, Totenklagen usw., vgl.Gs Otto (1977),68ff; Zeit und Ewigkeit, 15-18 und bes. 67 .

366 Die ältere Konzeption rechnet zwar mit der störbarkeit, aber auch mit der Wiederherstellbarkeit der ordnung=Maat; beides liegt in der Hand 
der Ramessidenzeit steht im Banne desselben Gottesbegriffs, wie ihn die Hymnen als Herrn des Schicksals besingen. So stehen auch die folgenden, einem in den Gräbern aufgezeichneten Hymnus fast gleichlautenden, Sätze in einer historischen Inschrift Ramses'II:

Die Zeitfülle ist sein Name,

die ewige Dauer ist sein Bild, seinem willen entspringt die Wirklichkeit. ${ }^{367}$

des Menschen bzw. des Königs. Wenn die ordnung gestört wird, wenden sich die Götter von Agypten ab (Neferti, Tutanchamun). Die jüngere Geschichtstheologie sieht das umgekehrt: wenn sich die Götter - bzw. "Gott" (Re-Amun-Re) - von Agypten abwenden, schwindet daraus die ordnung. Vgl. dazu Morenz, Die Heraufkunft des transzendenten Gottes in Agypten, 43-46, sowie meinen Beitrag: Königsdogma und Heilserwartung", in D.Hellholm (Hrsg.), Apokalyptik im Mittelmeerraum und im alten orient.

367 Kitchen, Ram.Inschr. II , 346.8. 
Th.G.Allen "Some Egyptian Sun Hymns", in: JNES 8 (1949) 349-356.

- The Egyptian Book of the Dead. Documents in the oriental Institut Museum at the University of Chicago (1960).

H.Altenmüller "'Messersee', 'gewundener Wasserlauf' und 'Flammensee'. Eine Untersuchung zur Lesung und Gleichsetzung der drei Bereiche, in: ZAS 92 (1966) 86-95.

R.Anthes "Sonnenboote in den Pyramidentexten", in: ZAS 82 (1957) 77-89.

J.Assmann Liturgische Lieder an den Sonnengott. Untersuchungen zur ägyptischen Hymnik I, MÄS 19 (1969).

- Der König als Sonnenpriester. Ein kosmographischer Begleittext zur kultischen Sonnenhymnik in thebanischen Tempeln und Gräbern, ADAIK 7 , 1970 .

- "Zwei Sonnenhymnen der späten XVIII.Dyn. in thebanischen Gräbern der Saitenzeit", in: MDIK 27.1 (1971) 1-33.

- "Die 'Häresie' des Echnaton. Aspekte der Amarna-Religion", in: Saecu$\operatorname{lum} 23$ (1972) 109-126.

- "Eulogie, Königs-", in: LÄ II (1975) 40-46.

- Zeit und Ewigkeit im alten Ägypten. Ein Beitrag zur Geschichte der Ewigkeit, AHAW 1975.

- Agyptische Hymnen und Gebete, (1975).

- "Das Bild des Vaters im alten Ägypten", in: H.Tellenbach (Hg.), Das Vaterbild in Mythos und Geschichte (1976) 12-49.

- "Gott", in: LÄ II (1976) 756-786.

- "Fest des Augenblicks, Verheissung der Dauer. Die Kontroverse der ägyptischen Harfnerlieder", in: Fs E.Otto, 55-84.

- "Weisheit, Loyalismus und Frömmigkeit", in: E.Hornung, O.Keel (Hg.), Studien zu altägyptischen Lebenslehren, ОВО 28 (1979) 11-72.

- "Primat und Transzendenz. Struktur und Genese der ägyptischen Vorstellung eines 'Höchsten Wesens'", in: W.Westendorf (Hg.), Aspekte der spätägyptischen Religion (GOF IV.9, 1979) 7-40.

- "Die 'Loyalistische Lehre' des Echnaton", in: SAK 8 (1980) 1-32.

- "Die Zeugung des Sohnes. Spiel, Bild, Erzählung und das Problem des ägyptischen Mythos", in: Id., w.Burkert, F.Stolz, Funktionen und Leistungen des Mythos. Drei altorientalische Beispiele (ОВО 48, 1982) $13-61$. 
- "Königsdogma und Heilserwartung. Politische und kultische Chaosbeschreibungen in ägyptischen Texten", in: D.Hellholm (Hg.), Apocalypticism in the Mediterranean World and the Near East (im Druck).

- Sonnenhymnen in thebanischen Gräbern (im Druck).

P.Auffret Hymnes d'Egypte et d'Israel (OBO 34, 1981).

P.Barguet Le temple d'Amon-Re à Karnak. Essai d'exegèse (1962).

A.Barucq L'expression de la louange divine et de la prière dans la bible et en Egypte, BE 33 (1962).

A.Barucq, F.Daumas Hymnes et prières de l'Egypte ancienne (1980).

J.v.Beckerath "Die 'Stele der Verbannten' im Museum des Louvre", in: RdE 20 (1968) 7-36.

J.Bergman Ich bin Isis. Studien zum memphitischen Hintergrund der griechischen Isisaretalogien (1968).

U.Berner "Uberlegungen zur Ubertragbarkeit des Komplementaritätsbegriffes auf ägyptische Gottesvorstellungen, in: GM 20 (1976) 59-71.

H.Blumenberg Arbeit am Mythos (1979).

E.Blumenthal Untersuchungen zum königtum des Mittleren Reichs I. Die Phraseologie, ASAW 61.1 (1970).

P.du Bourguet "Esquisse de théologie égyptienne des temps pharaoniques", in: Humanisme et foi chrétienne, Mélanges scientifiques du centenaire de l'institut catholique de Paris, publ.par Ch.Kannengiesser et Y.Marchasson (1976) 437-449.

J.H.Breasted Development of Religion and Thought in Ancient Egypt (1912, repr. 1972).

H.Brunner "Eine Dankstele an Upuaut", in: MDIK 16 (1958) 5-19.

- "Die religiöse Wertung der Armut im alten Agypten", in: Saeculum 12 (1961) 319-344.

- "Echnaton und sein Versuch einer religiösen Reform", in: Universitas 17 (1962) 149-162.

- "Der freie Wille Gottes in der ägyptischen Weisheit", in: Sagesses du Proche Orient ancien CESS (1963), 103-117.

- Die Geburt des Gottkönigs, ÄA 10 (1964).

- Die südlichen Räume des Tempels von Luxor, AV 18 (1977).

- "Persönliche Frömmigkeit", in: LÄ IV (1982) 951-963.

E.Brunner-Traut Gelebte Mythen. Beiträge zum altägyptischen Mythos (1981).

A.de Buck De zegepraal van het licht (1930).

- The Egyptian Coffin Texts, 7 Bde. (1935-61). 
- Plaats en betekenis van Sjoe in de egyptische theologie, Mededeelingen en verhandelingen der koninklijke akademie van wetenschappen, afd. letterkunde, N.R. 10.9 (1947).

W.Burkert structure and History in Greek Mythology and Ritual (1979).

J.Černý Egyptian Stelae in the Bankes Collection (1958).

N.de Garis Davies The MMA Expedition: the Temple of Hibis III, the Decoration (1950).

Ph.Derchain "Perpetuum mobile", in: Orientalia Lovanensia Periodica $6 / 7$ (1975/76) 153-161.

- Le papyrus Salt 825 (BM 10051). Rituel pour la conservation de la vie en Egypte (1965).

E.Dondelinger Die Treibtafel des Herodot am Bug des ägyptischen Nilschiffes (1976).

Edfou M.de Chalvet, marquis de Rochemonteix, E.Chassinat, Le Temple d' Edfou, 14 Bde, (1892-1934).

G.Fecht "zur Frühform der Amarna-Theologie. Neubearbeitung der Stele der Architekten Suti und Hor", in: ZÄS 94 (1967) 25-50.

E.Feucht-Putz Die königlichen Pektorale. Motive, Sinngehalt und zweck (1967).

R.B.Finnestad "Ptah, creator of the gods. Reconsideration of the Ptah Section of the Denkmal", in: Numen 23 (1976) 81-113.

O.Firchow "Königsschiff und Sonnenbarke", in: WZKM 54 (1957) 43-42.

H.Frankfort Kingship and the Gods. A Study of Ancient Near Eastern Religion as the Integration of Society and Nature (1947).

J.Ste.Fare Garnot L'hommage aux dieux sous l'ancien empire d'après les textes des pyramides (1953).

S.Hassan Hymnes religieux du Moyen Empire (1930).

E.Hornung "Chaotische Bereiche in der geordneten 'Welt'", in: zAs 81 (1956) 28-32.

- Das Amduat. Die Schrift des verborgenen Raumes 3 Bde, AA 8 und 13, 1963 und 1967.

- "Der Mensch als Bild Gottes in Agypten", in: O.Loretz, Die Gottebenbildlichkeit des Menschen (1967) 123-156.

- Der Eine und die Vielen. Altägyptische Gottesvorstellungen (1971).

- Das Grab des Haremhab im Tal der Könige (1971).

- Altägyptische Unterweltsbücher (1972).

- Das Buch der Anbetung des Re im Westen (1975). 
- "Monotheismus im pharaonischen Ägypten", in: O.Keel (Hg.), Monotheismus im Alten Israel und seiner Umwelt, Bibl.Beitr. 14 (1980) 83-97.

- "Die Tragweite der Bilder", in: Eranos Jb. 1979 (1981) 183-237.

- Der ägyptische Mythos von der Himmelskuh. Eine Ätiologie des Unvol1kommenen, OBO 46 (1982).

T.G.H.James Corpus of Hieroglyphic Inscriptions in the Brooklyn Museum (1974).

F.Junge "Wirklichkeit und Abbild. Zum innerägyptischen Synkretismus und zur Weltsicht der Hymnen des Neuen Reichs", in: G.Wiessner (Hg.), Synkretismusforschung. Theorie und Praxis, GOF 1 (1978) 87-108.

- "Isis und die ägyptischen Mysterien", in: W.Westendorf (Hg.), Aspekte der spätägyptischen Religion, GOF IV.9 (1979) 93-115.

H.Junker Die Götterlehre von Memphis, APAW $1939 \mathrm{Nr} .23$ (1940).

L.Kakosy Selected Papers, StudAeg VII (1981).

J.Karkowski "Studies on the Decoration of the Eastern wall of the vestibule of Re-Horakhty in Hatshepsut's Temple at Deir el-Bahari", in: Etudes et Travaux IX (1976) 68-78.

- "Deir el Bahari 1974-75", in: Et.et Trav. XI (1979) 217-220.

O.Keel (Hg.) Monotheismus im Alten Testament und seiner Umwelt, Bibl. Beitr. $14(1980)$.

K.A.Kitchen Ramesside Inscriptions, Historical and Biographical, 7 Bde, $1968 \mathrm{ff}$.

A.Klasens A Magical Statue Base (Socle Behague) in the Museum of Antiquities at Leiden, OMRO 33 (1952).

W.B.Kristensen The Meaning of Religion (1960).

C.Lalouette Fidèles du soleil, Faculté des lettres et sciences humaines de Paris, groupe d'études égyptologiques I (1963).

J.Leclant Recherches sur les monuments thébains de la XxV.dynastie dite "éthiopienne", BE 36 (1965).

G.Lefebvre Le tombeau de Petosiris II, Les textes (1923).

U. Luft Beiträge zur Historisierung der Götterwelt und der Mythenschreibung, Stud.Aeg.IV (1978).

Medinet Habu VI Medinet Habu VI, The Temple proper II, OIP 841963.

E.Meyer Gottesstaat, Militärherrschaft und Ständewesen in Ågypten, SPAW 1928.

S.Morenz Agyptische Religion (1960).

- "Eine Naturlehre in den Sargtexten", in: WZKM 54 (1957) 119-129. 
- Die Heraufkunft des transzendenten Gottes in Agypten, SSAW 109.2 (1964)。

- Gott und Mensch im Alten Ägypten (1965).

D.Müller Agypten und die griechischen Isisaretalogien, ASAW 53.1 (1961).

K.Mý́liwiec Studien zum Gott Atum II: Name, Epitheta, Ikonographie, НАВ 8 (1979) .

Marquis of Northampton et alii Theban Necropolis, Report on some Excavations (1908).

E.Otto "Die Lehre von den beiden Ländern in der ägyptischen Religionsgeschichte", in: Stud.Aeg.I (1938) $10 \mathrm{ff.}$

- Die biographischen Inschriften der ägyptischen Spätzeit, PA 2 (1954).

- "Monotheistische Tendenzen in der ägyptischen Religion", in: Wdo 2 (1955) 99-110.

- Das ägyptische Mundöffnungsritual, 2 Bde. ÅA 3 (1960).

- "Zum Gottesbegriff der ägyptischen Spätzeit", in: FuF 35.9 (1961) $277-280$.

- "Zur Geschichte einer religiösen Formel", in: ZÄs 87 (1962) 150- 154.

- "Altägyptischer Polytheismus. Eine Beschreibung", in: Saeculum 14 (1963) 249-285.

- Gott und Mensch nach den Tempelinschriften der griechisch-römischen Zeit. Eine Untersuchung zur Phraseologie der Tempelinschriften, AHAW (1964).

- Wesen und wandel der ägyptischen Kultur (1969).

- "Der Mensch als Geschöpf und Bild Gottes in Agypten", in: Fs. von Rad (1971) 335-348.

- "Gott als Retter in Agypten", in: Tradition und Glaube, Fs. K.G. Kuhn (1971) 9-22.

R.A.Parker et alii The Edifice of Taharqa by the Sacred Lake at Karnak (1979).

A.Piankoff Le livre du jour et de la nuit, BE 13 (1942).

G.Posener Littérature et politique dans l'Egypte de la XII.e dynastie (1956).

- "Amon, juge du pauvre", in: Fs. Ricke (1971) 59-63.

- L'enseignement loyaliste. Sagesse egyptienne du Moyen Empire (1976).

J.E.Quibell Excavations at Saqqara IV (1908-10) .

A.Roccati "I libro dei morti di Sesonq", in: OrAnt 15 (1976) 233-250.

A.Rupp Vergehen und Bleiben. Religionsgeschichtliche Studien zum Personverständnis in Agypten und im Alten Testament (1976). 
M.Sandman Texts from the time of Akhenaten, BiblAeg VIII (1938).

S.Sauneron Esna $V$. Les fêtes religieuses d'Esna aux derniers siècles du paganisme (1962).

S.Sauneron, J.Yoyotte "La naissance du monde selon l'Egypte ancienne", in: Sources Orientales I (1959) 17-91.

H.Schäfer Ågptische und heutige Kunst und Weltgebäude der alten Agypter (1928).

- "Altägyptische Bilder der auf- und untergehenden Sonne", in: ZÄS 71 (1935) 15-38.

H.A.Schlögl Der Sonnengott auf der Blüte, AH 2 (1977).

- Der Gott Tatenen, OBO 29 (1980).

S.Schott Mythe und Mythenbildung im Alten Ägypten, UGA A 15 (1945).

- "Altägyptische Vorstellungen vom Weltende", in: Analecta Biblica 12 (1959) 319-330.

K.C.Seele The Tomb of Tjanefer at Thebes (1959).

P.Seibert Die Charakteristik. Untersuchung zu einer ägyptischen Sprechsitte und ihren Ausprägungen in der Folklore und Iiteratur, ẢA 17 (1967).

K.Sethe Amun und die acht Urgötter von Hermopolis, APAW 1929.

A.W.Shorter Catalogue of Egyptian Religious Papyri in the British Museum. Copies of the Book Pr(t)-m-hrw I (1935).

H.M.Stewart "Some Pre-'Amārnah Sun Hymns", in: JEA 46 (1960) 83-90.

- "Egyptian Funerary Statuettes and the Solar Cult", in: Bull.Inst. Arch. 4 (1964) 165-170.

- "Traditional Egyptian Sum Hymns of the New Kingdom", Bull.Inst.Arch. 6 (1967) 29-74.

- "Stelophorous Statuettes in the British Museum", in: JEA 53 (1967) 34-38.

E.Thomas "Solar Barks from Prow to Prow", in: JEA 42 (1956) 65-79.

P.Vernus "Le dieu persommel dans 1'Egypte pharaonique", in: Centre interdisciplinaire d'Etude de l'évolution des idées, des sciences et techniques, Colloques de la soc. Ernest Renan (1977) 143-157.

G.Vittmann "Die Hymne des Ostrakons wien 6155 + Kairo CG 25214", in: WZKM 72 (1980) $1-6$.

W.Westendorf Altägyptische Darstellungen des Sonnenlaufs auf der abschüssigen Himmelsbahn, MÄS 10 (1966).

- "Ursprung und Wesen der Maat", in: Fs Walter Will (1966) 201-225. 
L.V.Zabkar A Study of the Ba Concept in Ancient Egyptian Texts, SAOC 34 (1968).

- "A Hymn to Osiris Pantokrator at Philae", in: ZÄS 108 (1981) 141-171.

J.Zandee De hymnen aan Amon van Papyrus Leiden J 350, OMRO 28 (1947).

- "Prayers to the Sun Got from Theban Tombs", in: JEOL 16 (1959/60) $48-71$.

- "Hymnical Sayings addressed to the Sun God By the High Priest of Amun Nebwenenef, from his Tomb in Thebes", in: JEOL 18 (1964) 253-165.

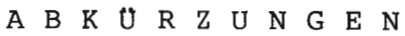

Abkürzungen folgen der Konvention des Lexikons der Ägyptologie (LÄ); darüberhinaus werden verwendet

AHG Assmann, Ägyptische Hymnen und Gebete

LL Id., Liturgische Lieder an den Sonnengott

STG Id., Sonnenhymnen in thebanischen Gräbern

Text+Nr. bezieht sich auf die Edition STG. Für die Gräber vgl. den Stellenindex. 
R E G I S T E R I: $S$ a $c h$ e $n$

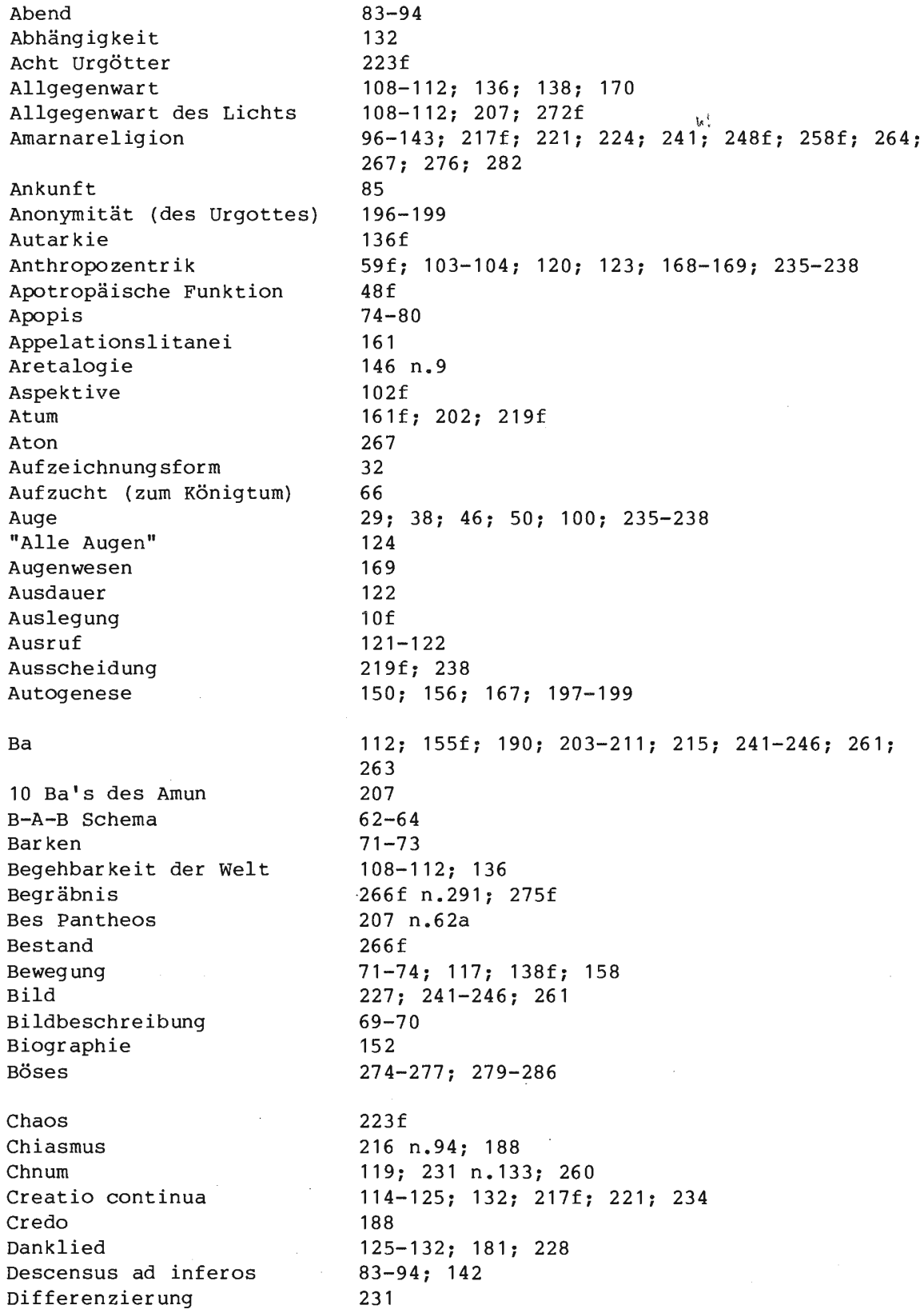




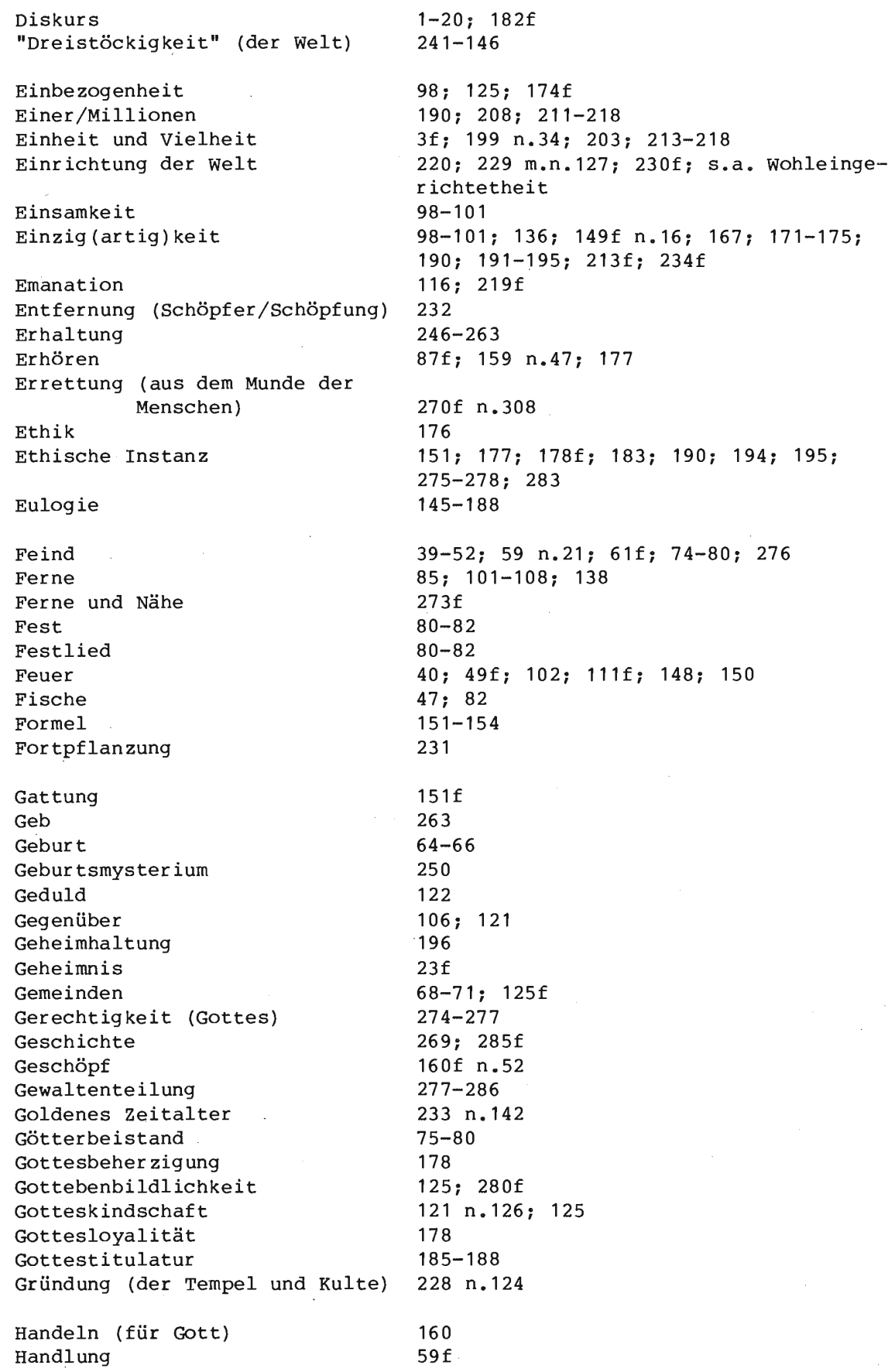




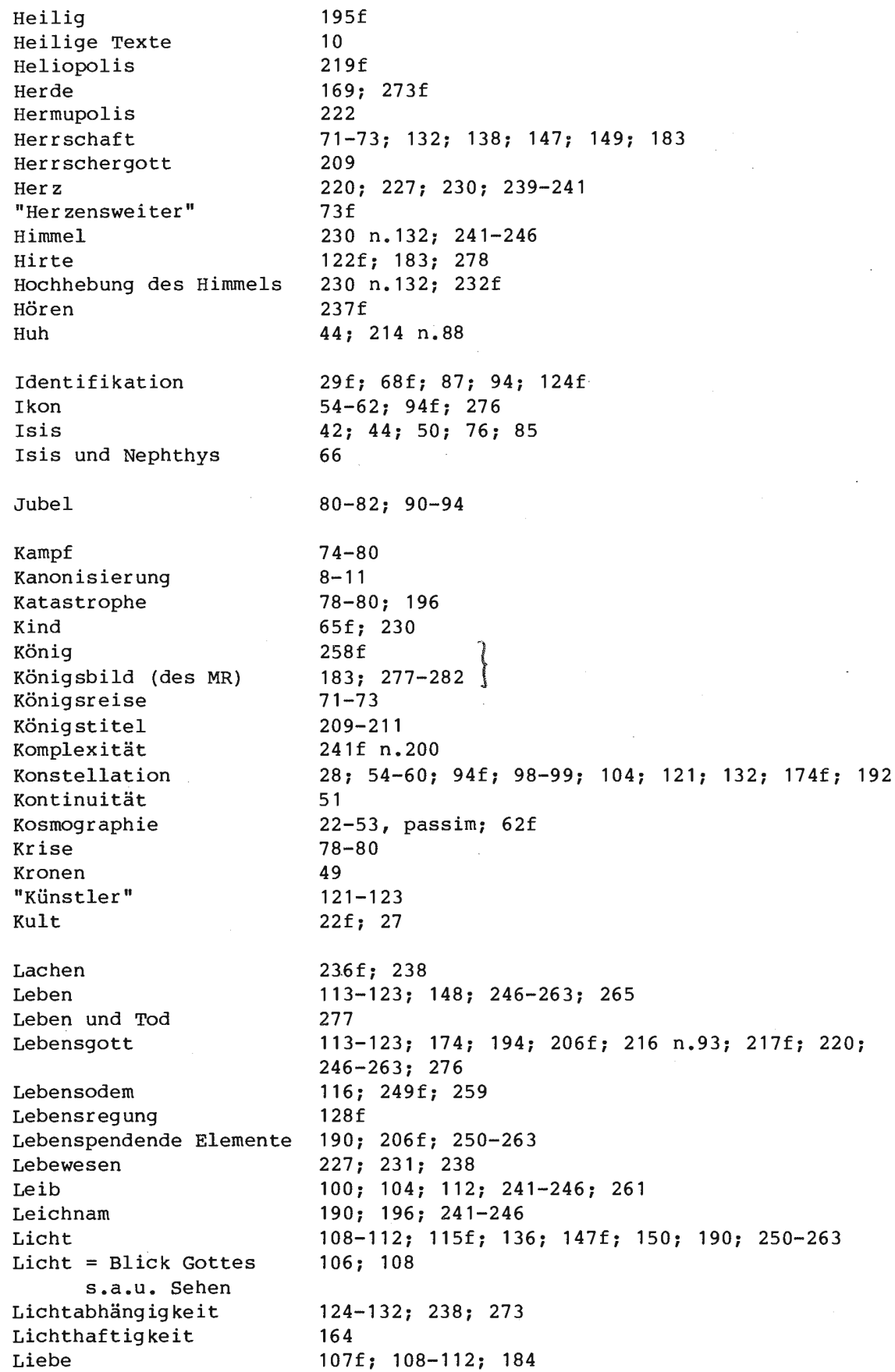




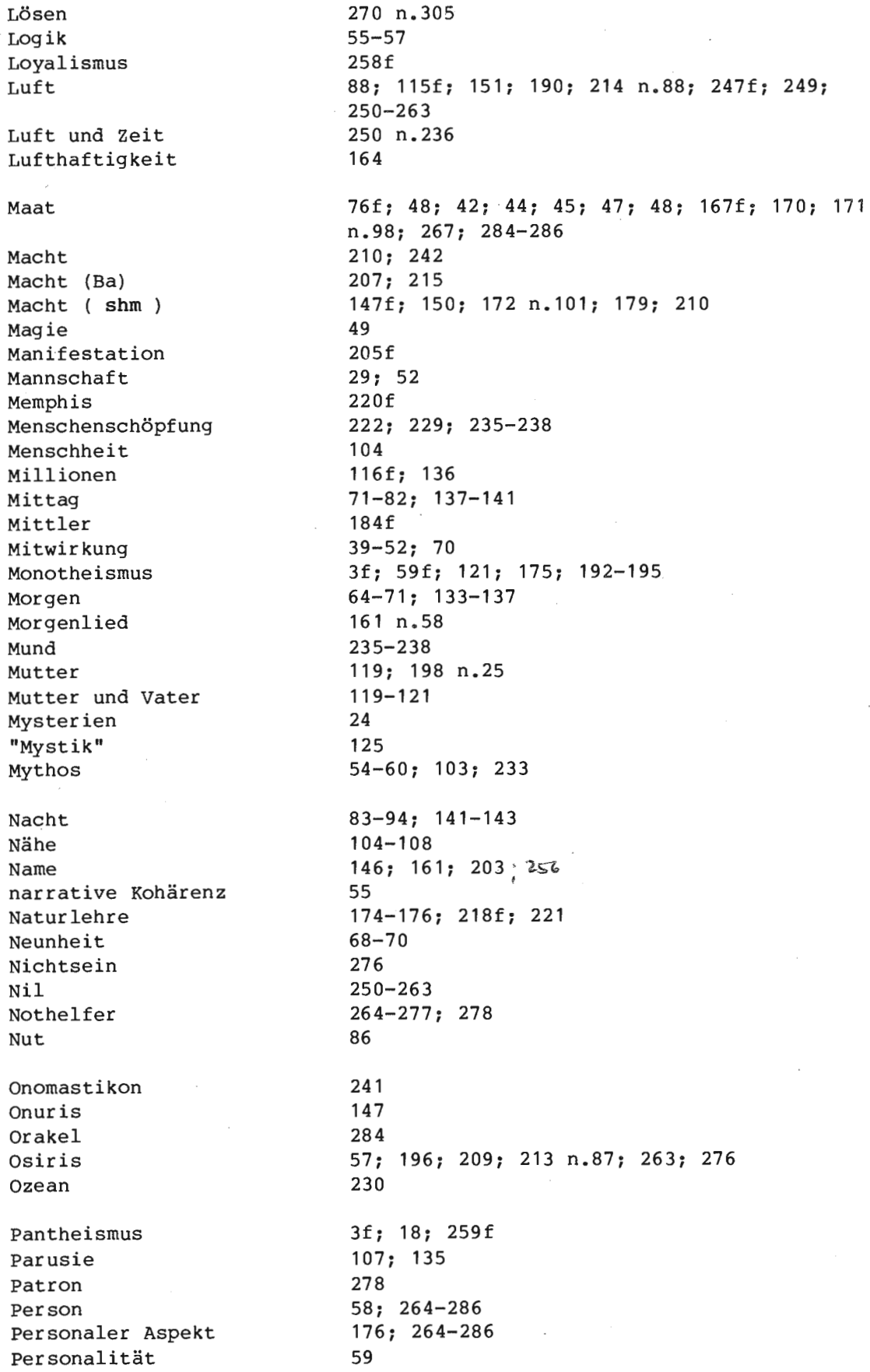




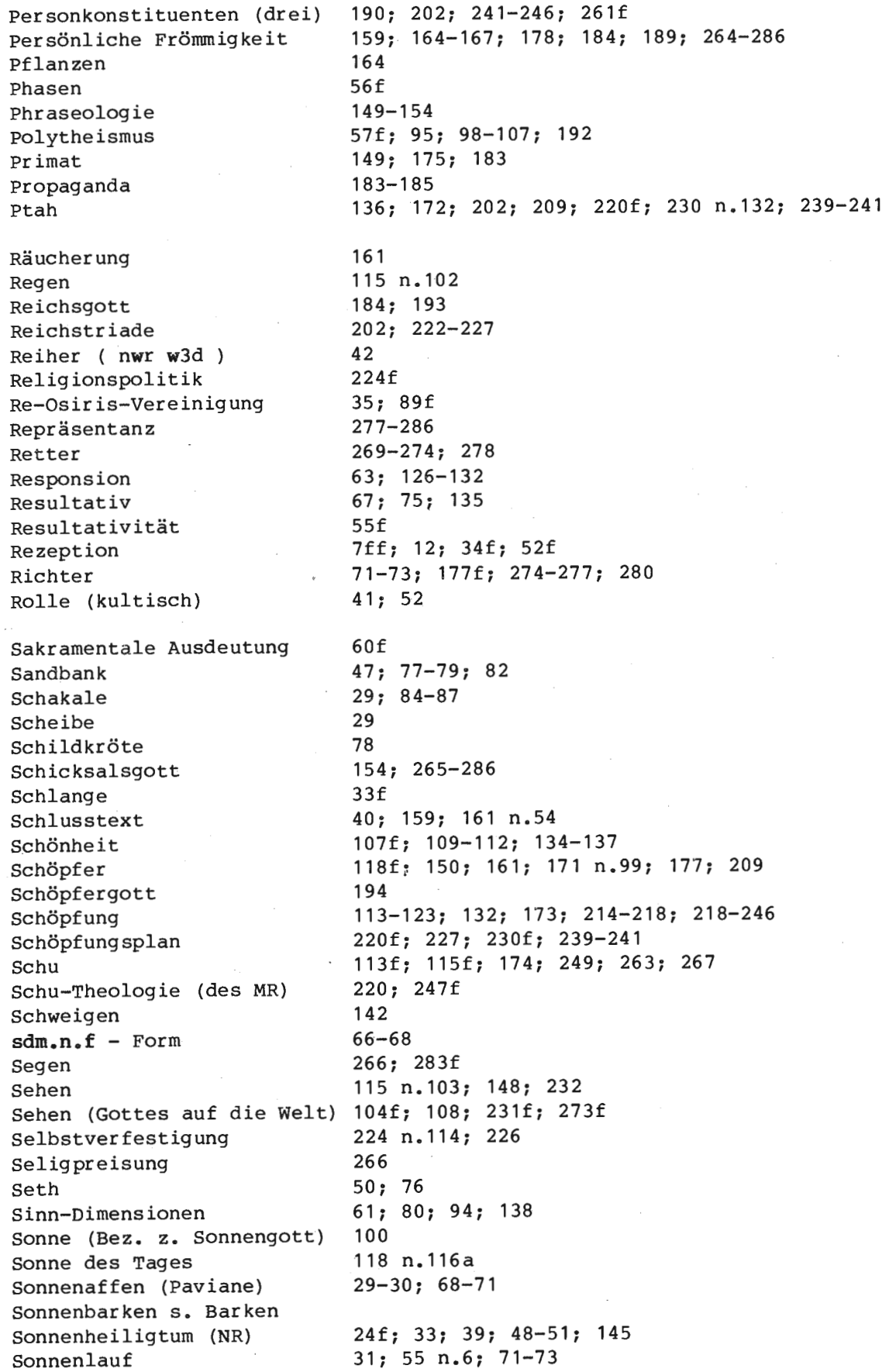


Sonnenuntergang

Sonnenzyklus s. zyklus

Sphäre des Seinigen

Spontangenese

Sprache

Sprechakt

Standardtexte

Statuscharakteristik

"Steuer ruder"

Stelophor

Stier

stillstand $\left(\mathbf{c}_{\mathbf{h}} \mathbf{c}_{\mathbf{w}}\right)$

Strahlenaton

stundenritual

Sünde

Sukzession

"Sympathie"

Tageszeitenlied

Tatenen

Tefnut

Teilhabe

Tempelarchitektur

Tempelstatue

Textplan

Theismus

Theokratie

Theologie

Theologische Ausdeutung

Theologia negativa

Theologia positiva

Theophanie

Thoth

Thought-couplet

Tod

Totenfürsorge

Totengericht

Tränen

Transformationen (des Urgottes)

Transitivität

Transzenden $z$

Trennung von Göttern und Menschen

Trennung von Himmel und Erde

Trias von Amarna

Triumphzug

Uberfahrt

Uberlieferung, produktive

Uberlieferung, reproduktive

Uberwindung

Umarmung (Mutter)

Umarmung (Vater)

Unterwelt

Unterweltsbücher

Uräen

Urgott

\section{$84 f$}

$28 f$

156

27 ; $219 f$

$40 \mathrm{f}$

$14 ; 22 \mathrm{f}$

$101 ; 125$

$179 ; 278$

8 n. 13; 180 n. 120

179

78

$216 \mathrm{n} .93$

$33 \mathrm{f}$

285

224

$78-80$

$60-94 ; 118 ; 132-143$

209; 224

$113 \mathrm{f} ; 267$

$51 \mathrm{f} ; 94 ; 124-132$

196

164

$146-154 ; 171$

259

210

152f; 154; 156f; 174-176; 187; 189;

$194 ; 224 \mathrm{f}$

96-143, passim

$202 \mathrm{f}$

202

$67 f$

$51 ; 76 ; 85$

$66 \mathrm{f}$

$83-94 ; 142$

84-89

275-277

229 ; 235-238

202 n. $38 ; 222-227$

66-68

$175 ; 203$

$233 \mathrm{n} .141 \mathrm{f}$

117 n. 113; 220; 227; 233 n. 141

$113 \mathrm{f}$

$74-80$

$71-74 ; 167$

$7-14 ; 15$

$7-14$

$61 \mathrm{f} ; 74-80 ; 138 f$

$84 ; 88 \mathrm{f}$

90

241-246

$11-14 ; 19$

$33 ; 38 ; 49$

$148 f ; 158 ; 161 ; 167 ; 172 ; 182 ; 194$;

$213 ; 223 f$ 


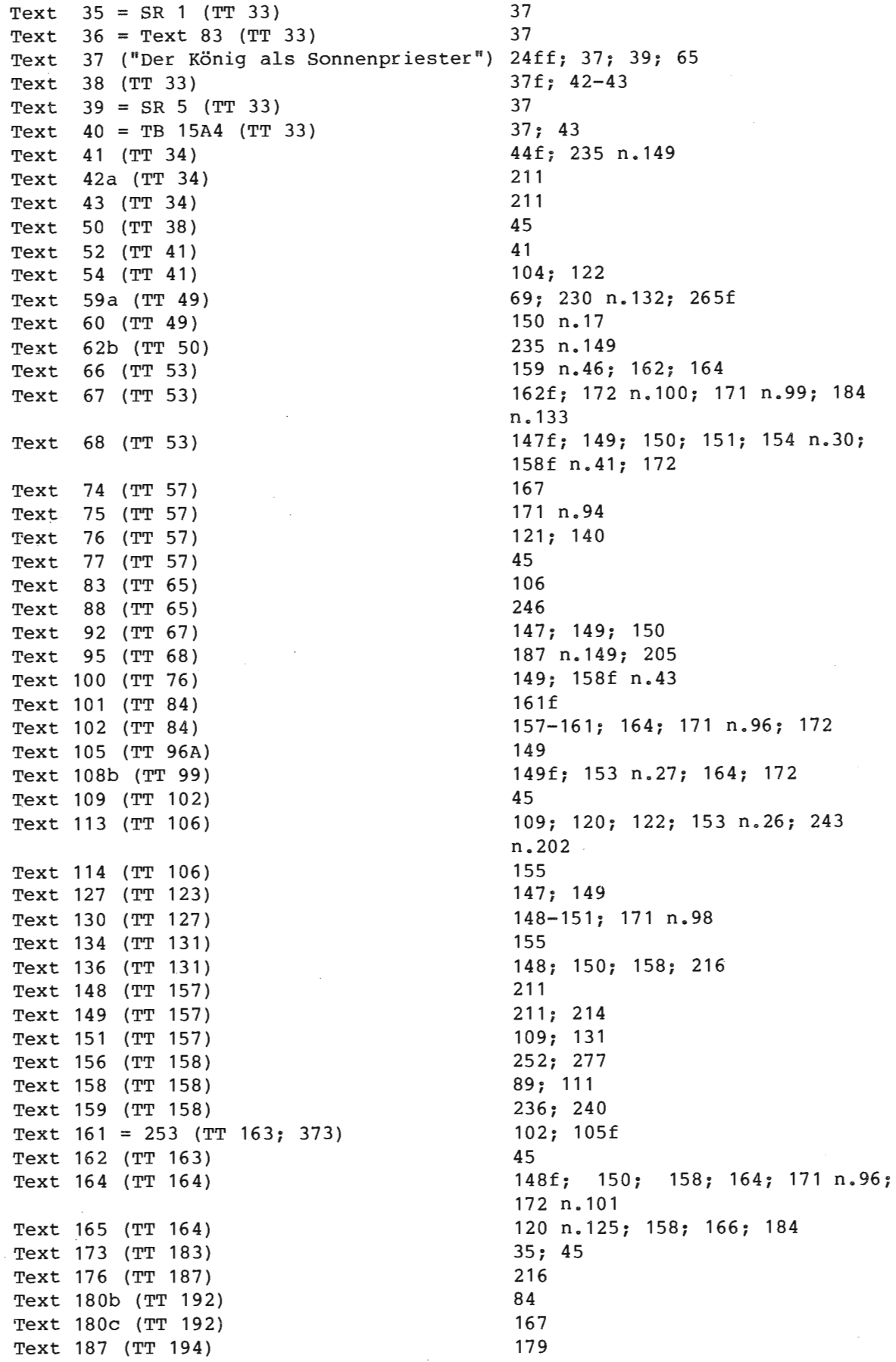




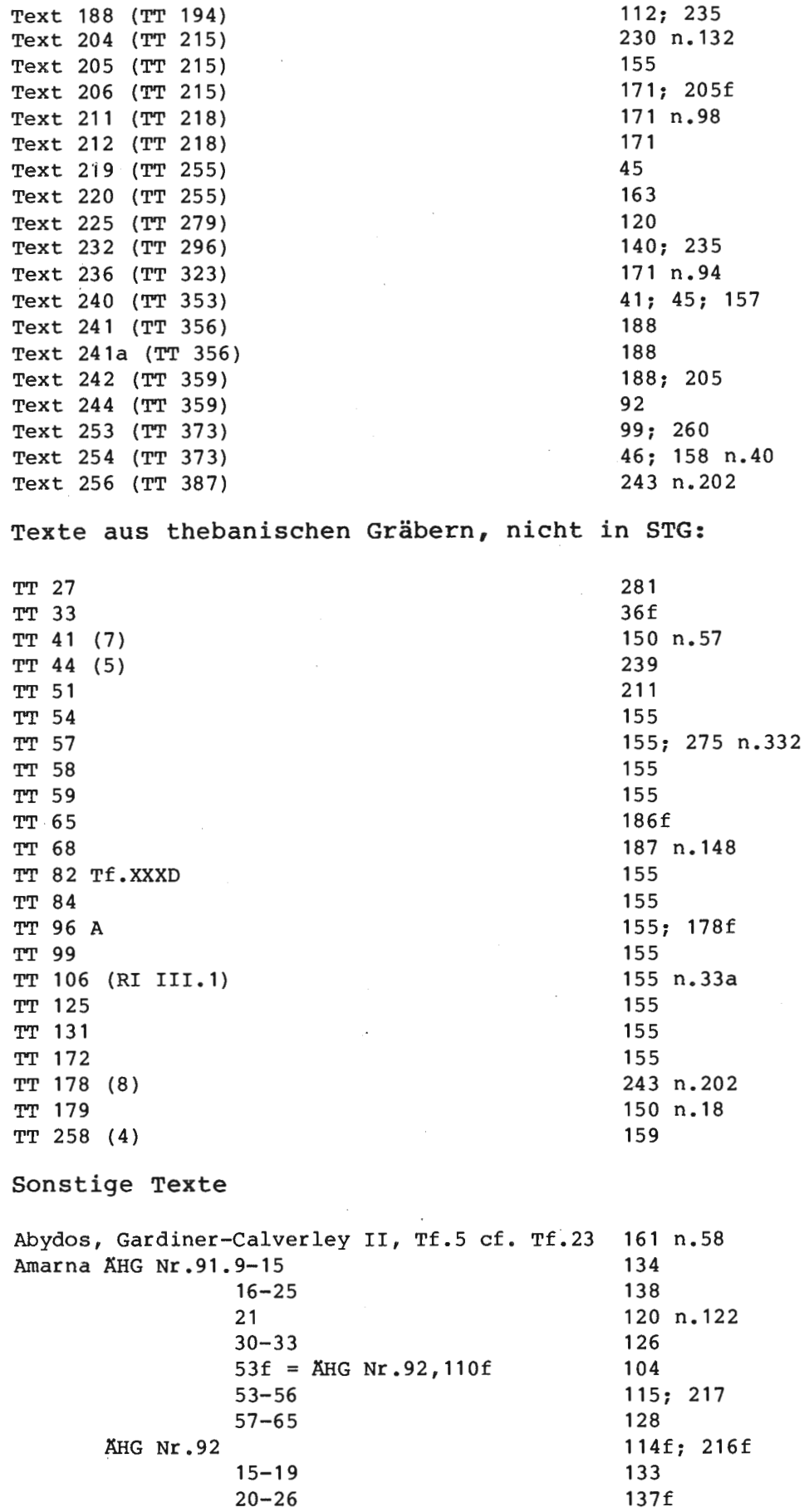

Sonstige Texte

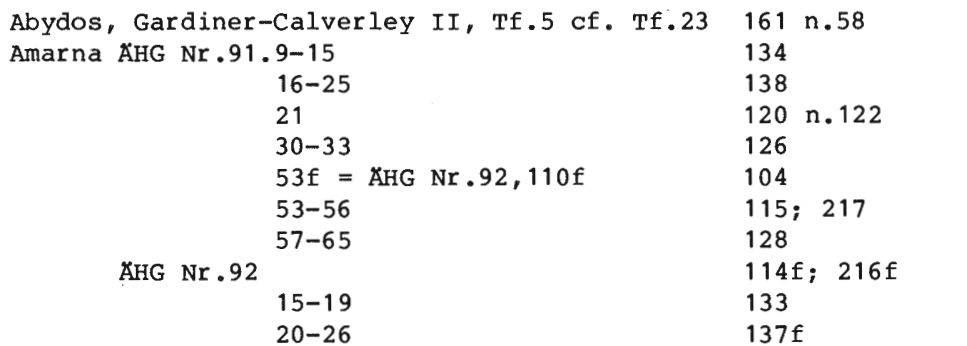


$\begin{array}{lll}\text { AHH Nr .92 25-26 } & 105\end{array}$

$26 \quad 104$

$27-37 \quad 141 \mathrm{f}$

40-58 $128 \mathrm{f}$

$79 \quad 239$

$76 f, 100 \quad 121$

113-114 105

115-117 116

118-119 106

125-128 117

126-127 142

$129 \quad 107$

AHG Nr.94,13-19 110

AHG Nr.234 259

Amarna, ed.Sandmann, $23 \quad 126$

Amarna, ed.Sandmann, $28 \quad 126 \mathrm{n} .145$

Amarna, ed.Sandmann, $33 \quad 126$

Amarna, ed.Sandmann, $46 \quad 127$

Amarna, ed.Sandmann, 73 127

Amarna, ed.Sandmann, $76 \quad 128$

Amarna, ed.Sandmann, $91 \quad 127$

Amarna, ed.Sandmann, $142.126 \mathrm{f}$

Amduat I, 1-2 $31 \mathrm{f}$

Amduat I, 20 91

Amduat I, 57

Amenemope pBM $10474, \mathrm{x}, 19 \mathrm{f}$

89 n. 140

48

$222 \mathrm{n} .312$

207

Ani VII, 15

Berlin 6764

Berlin $6910 \mathrm{Ag}$. Inschr. II, 66-67

$150 \mathrm{n} \cdot 17$

$230 \mathrm{n} .132 ; 239$

$63 \mathrm{f}$

$123 ; 243$ n. 202

Berlin 7317 (ÄHG Nr.62)

163

274

$232 \mathrm{n} .140$

$153 f$

101

205

$181 \mathrm{f}$

$158 \mathrm{n} .36 \mathrm{a}$

$239 ; 150 \mathrm{n} \cdot 18 \mathrm{a}$

BM 29944

Bologna 1891 (AHG Nr.59)

cf.Kairo JE 13698; pLeiden J 344 vso I.9-10

Brooklyn '37.263E

68

$165 \mathrm{n} .72$

Buch von der Himmelskuh

$207 ; 232 f$

Chicago Field Museum of Nat.Hist. 88906

(AHG Nr.81)

$\begin{array}{lll}\text { CT } & 184-185 \\ \text { II } & 5 \mathrm{~b} \\ \text { II } & 39 \\ \text { II } & 42 \mathrm{f} \\ \text { IV } & \\ \text { IV } & 64 \mathrm{c} \\ \text { IV } & 196 / 97 \\ \text { IV } & 198 \mathrm{ff} \\ \text { VI } & 395 \\ \text { VI } & 389 \mathrm{~g}\end{array}$

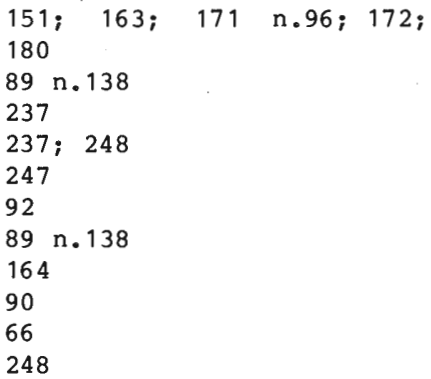




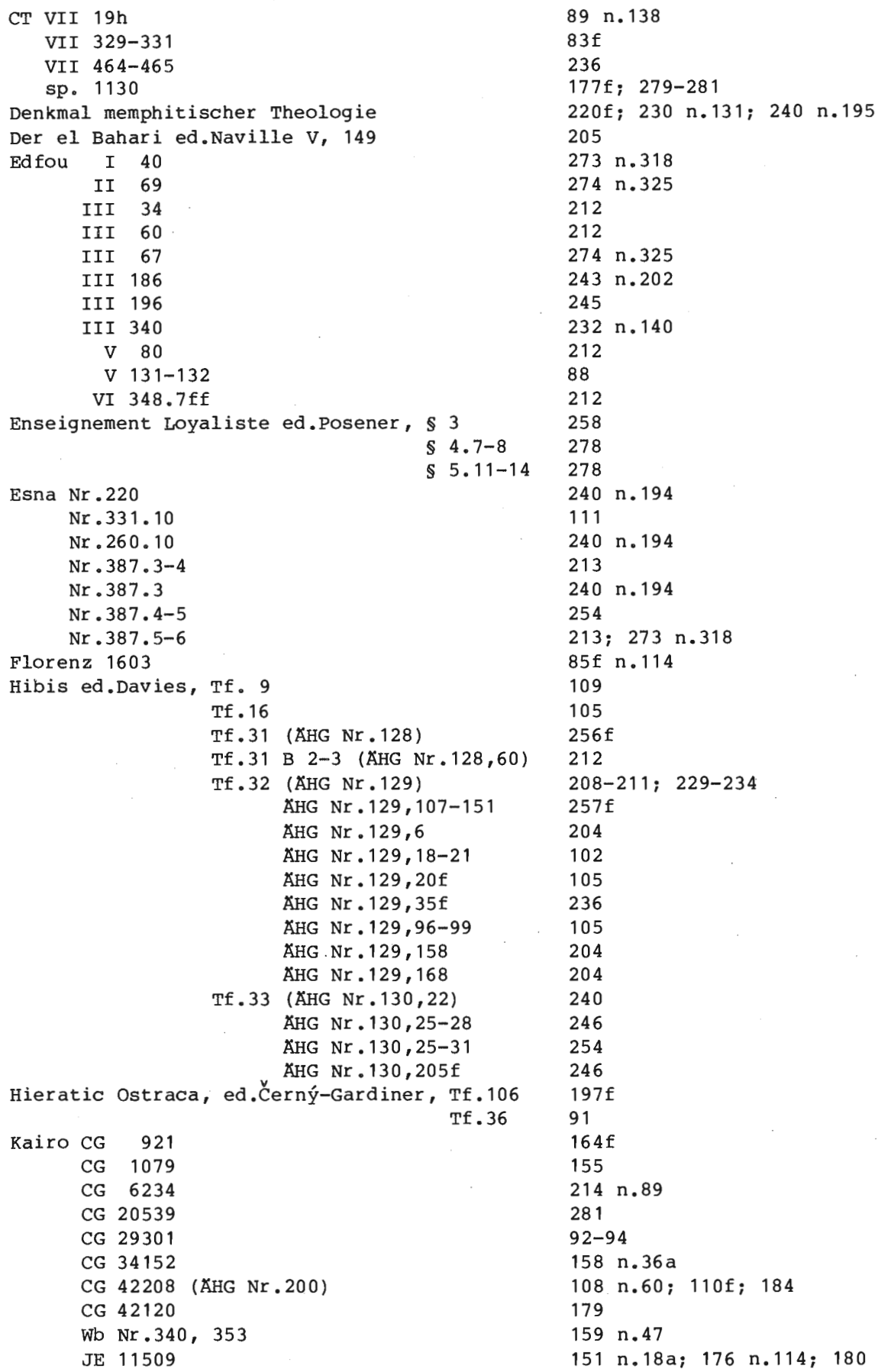




$$
\begin{aligned}
& \text { JE } 28569 \\
& \text { JE } \frac{12 / 6}{24 / 6}
\end{aligned}
$$

Kopenhagen A 70 ( AHG Nr.52)
A 72
A 719 (ÄHG Nr.223)

Kuhbuch s. Buch von der Himmelskuh

$$
\text { K } 11 \text { (RI III, 175.2) }
$$

V 70 (AHG Nr.90)=Leiden K 12 bzw. K 11 Boeser, Beschr. IV Tf.30

Livre du jour ed.Piankoff, BE 13, 14

$18 \mathrm{f}$

London UC 14333

Louvre $\mathrm{C} \quad 3$

Louvre C 21 (AHG Nr.170)

Louvre C 67

Louvre C 218 (AHG Nr.219)

Medamud $\mathrm{Nr} .249 .7$

Medinet Habu VI 420 B

$$
421 \mathrm{~B}
$$$$
422 \text { A, 36-56 }
$$$$
=\mathrm{pBM} 10541,51-58
$$

Taharqa Tf. 20, 18-22

422-423

Merikare

Merikare

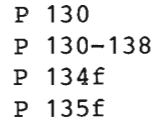

$123 ; 235$

72 n. 60

$46 ; 159$ n. 47

166-168

239

239

$136 \mathrm{n} .176$

$101 ; 137 ; 143$

$150 \mathrm{n} .17$

$51 ; 52$

77

281

$238 \mathrm{n} .176$

$171 \mathrm{n} .93$

120

57

212

263

50

$28 f$

39

123

160 n.50

$168 \mathrm{f}$

177

279

281

$46 \mathrm{f}$

$75 \mathrm{f}$

253

205

211

240

236

274

232

$209 \mathrm{n} .64$

232

204 ; 231 ; $252 \mathrm{f}$

206

265

112

148

185

87

102

236

235

236

112 ; $230 \mathrm{n} .132$

$88 ; 252$

110

109 


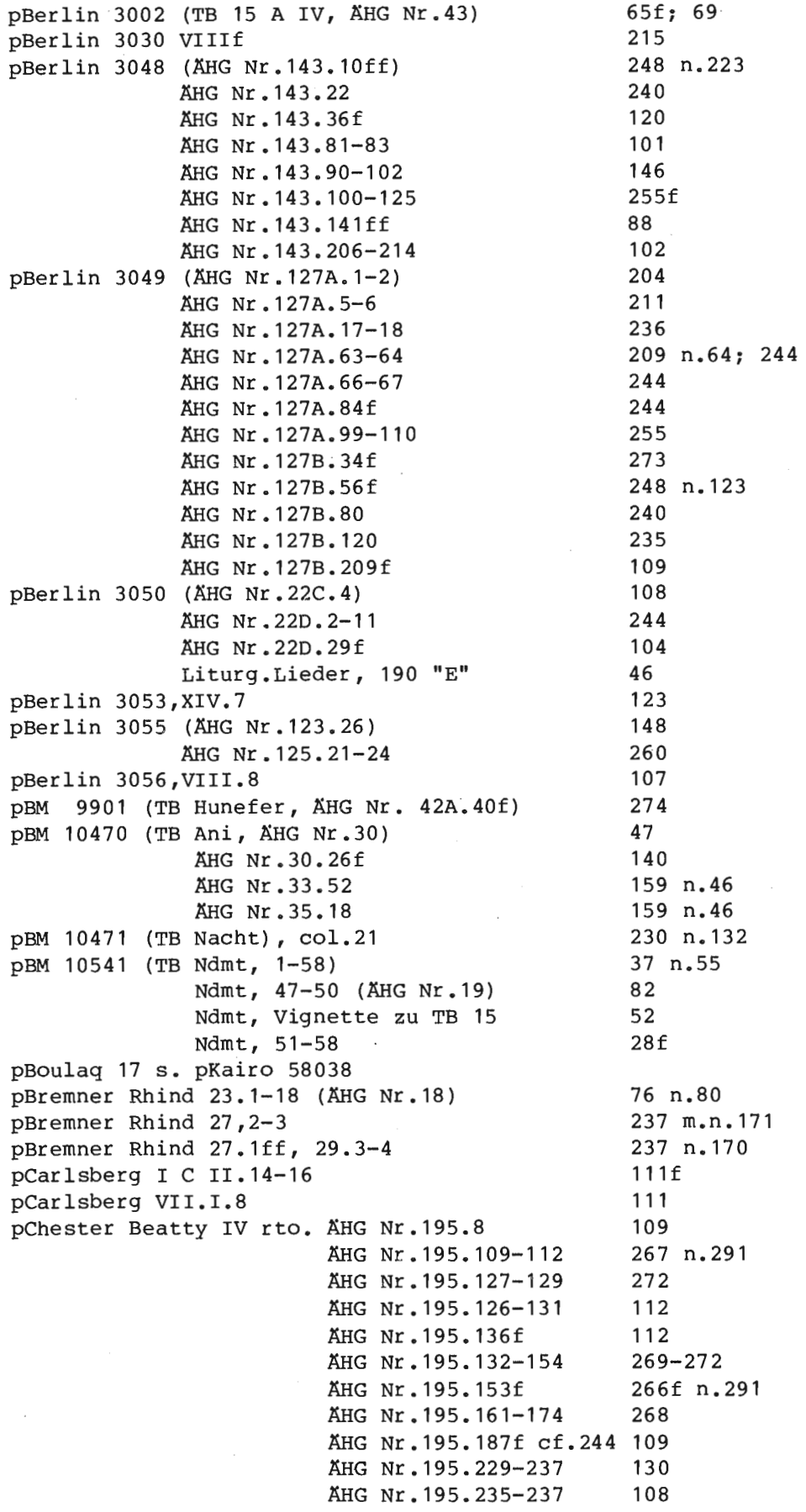




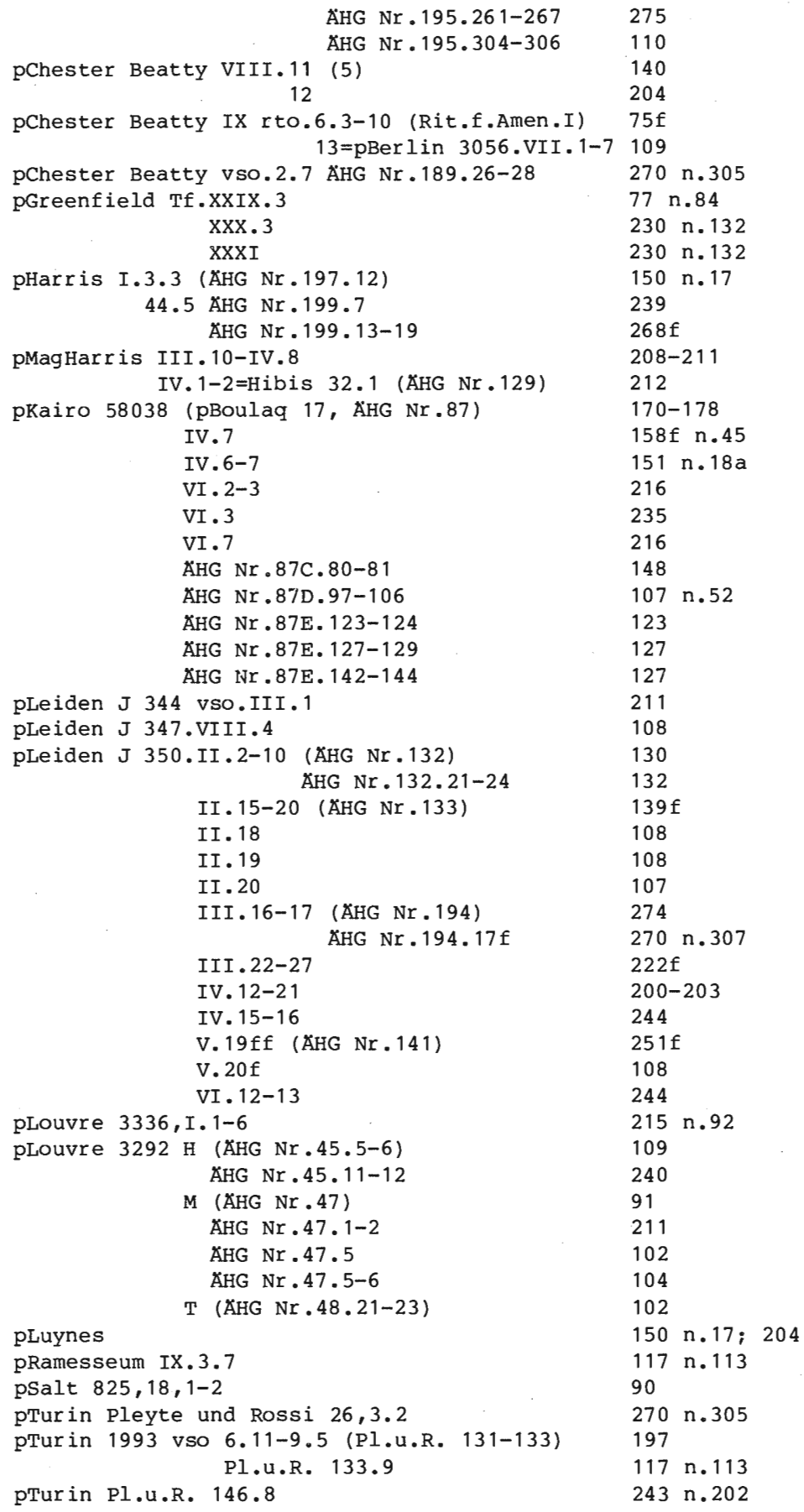




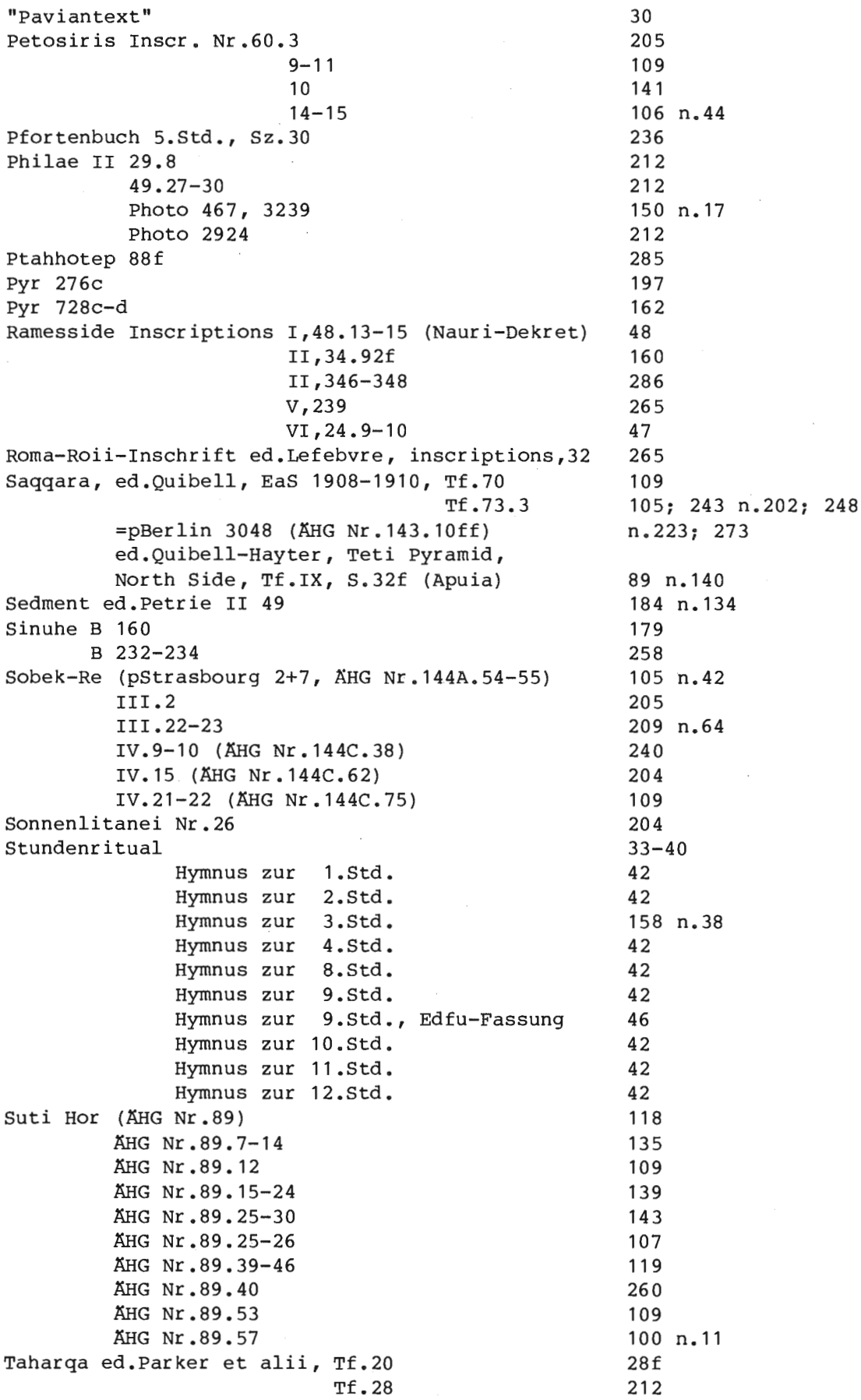


Tanis ed.Montet, Necr.Roy. II, Tf.41 (AHG Nr.50) 141

Theban Necropolis, ed.Northampton et alii, Tf.VII 66

Tf.XVII $184 \mathrm{n} .133$

Totenbuch, Kap. 15

15A2 (pLeiden T2 LL III4

$9 \mathrm{f} ; 36 \mathrm{f}$

15A4 s.pBerlin 3002

15B2 ( AHG $\mathrm{Nr} .44 .23$ )

69

AHG $\mathrm{Nr} .44 .28-30$

87

ÄHG $\mathrm{Nr} .44$

15B3 (LL 12)

$15 i$

100

101

Turahymnus (ÄHG Nr.88)

AHG $\mathrm{Nr}$. 88 . 3-4

AHG Nr.88.15

XHG $\mathrm{Nr} .88 .36$

AHG $\mathrm{Nr} .88 .45 \mathrm{f}$

88

$92 ; 110 ; 243$ n.202

91

205

$29 ; 69$

140

226-229

$171 \mathrm{n} .94$

148

239

128

$148-150 ; 165$

Turin Stele (AHG Nr.72)

$159 \mathrm{n.} 47$

Tur in Nr.153

Turin 3070

Urk IV 49

$150 \mathrm{n} .17 ; 205$

281

195

$111=$ Text 68

$146 \mathrm{n.12} ; 149 \mathrm{f} ; 158 \mathrm{f}$

$\mathrm{n} .41$

444f. (TT11)

469

518

$n \cdot 133 ; 179$

$164 \mathrm{n} .68$

146f; $149 \mathrm{f}$; $158 \mathrm{f} \mathrm{n.42;}$

172 n. 101

$544 \mathrm{f}$

153

$1642 \mathrm{f}$

159

1673

VI 75

97

$122 \mathrm{ff}$

VIII $\$ \quad 1 \mathrm{~g}$

\$ $3 \mathrm{~b}$

\$ $12 \mathrm{~b}$

70

274 n. 324

47

$79 ; 196$

262

212

245

273 n. 318

$\$ 15 \mathrm{~h}$

212

\$ $138 \mathrm{~b}$

212

$254 ; 274 ; 277$

Verbanntenstele (RdE 20,7ff ÄHG S.71)

Zeitschriften:

ASAE 60,167 Tf.XI fig.17

108

BIFAO 55.110 (Paser)

156

MDIK 28,55,66(48) (Merenptah Sarg)

$160 \mathrm{n} .51$

Rec.Champollion $601 \mathrm{ff}$

170 n. 85

235

RT $13,163.16$

245

RT 18,182

$253 \mathrm{f}$

RT 18,186

JEA $23,198 \mathrm{f}$

JEA 37,49

142 n.199a

ZAS $72,101 \mathrm{ff} \mathrm{Nr.24}$

281

ZÅs 82 , Tf.V. 14

203

109 


\section{ORBIS BIBLICUS ET ORIENTALIS}

Bd. 1 OTTO RICKENBACHER: Weisheitsperikopen bei Ben Sira. X-214-15* Seiten. 1973. Vergriffen.

Bd. 2 FRANZ SCHNIDER: Jesus der Prophet. 298 Seiten. 1973. Vergriffen.

Bd. 3 PAUL ZINGG: Das Wachsen der Kirche. Beiträge zur Frage der lukanischen Redaktion und Theologie. 345 Seiten. 1974. Vergriffen.

Bd. 4 KARL JAROŠ: Die Stellung des Elobisten zur kanaanäischen Religion. 294 Seiten, 12 Abbildungen. 1982. 2. verbesserte und überarbeitete Auflage.

Bd. 5 OTHMAR KEEL: Wirkmächtige Siegeszeichen im Alten Testament. Ikonographische Studien zu Jos 8, 18-26; Ex 17, 8-13; 2 Kön 13, 14-19 und 1 Kön 22, 11. 232 Seiten, 78 Abbildungen. 1974. Vergriffen.

Bd. 6 VITUS HUONDER: Israel Sohn Gottes. Zur Deutung eines alttestamentlichen Themas in der jüdischen Exegese des Mittelalters. 231 Seiten. 1975.

Bd. 7 RAINER SCHMITT: Exodus und Passa. Ibr Zusammenhang im Alten Testament. 124 Seiten. 1982. 2. neubearbeitete Auflage.

Bd. 8 ADRIAN SCHENKER: Hexaplarische Psalmenbruchstücke. Die hexaplarischen Psalmenfragmente der Handschriften Vaticarıus graecus 752 und Canonicianus graecus 62. Einleitung, Ausgabe, Erläuterung. XXVIII - 446 Seiten. 1975.

Bd. 9 BEAT ZUBER: Vier Studien zu den Ursprüngen Israels. Die Sinaifrage und Probleme der Volks- und Traditionsbildung. 152 Seiten. 1976. Vergriffen.

Bd. 10 EDUARDO ARENS: The $H \Lambda \Theta O N$-Sayings in the Synoptic Tradition. A Historico-critical Investigation. 370 Seiten. 1976.

Bd. 11 KARL JAROŠ: Sichem. Eine archäologische und religionsgeschichtliche Studie, mit besonderer Berücksichtigung von Jos 24. 280 Seiten, 193 Abbildungen. 1976.

Bd. 11a KARL JARǑ́ / BRIGITTE DECKERT: Studien zur Sichem-Area. 81 Seiten, 23 Abbildungen. 1977.

Bd. 12 WALTER BUHLMANN: Vom rechten Reden und Schweigen. Studien zu Proverbien 10-31. 371 Seiten. 1976.

Bd. 13 IVO MEYER: Jeremia und die falschen Propheten. 155 Seiten. 1977.

Bd. 14 OTHMAR KEEL: Vögel als Boten. Studien zu Ps 68, 12-14, Gen 8, 6-12, Koh 10, 20 und dem Aussenden von Botenvögeln in Agypten. - Mit einem Beitrag von Urs Winter zu Ps 56, 1 und zur Ikonographie der Göttin mit der Taube. 164 Seiten, 44 Abbildungen. 1977.

Bd.15 MARIE-LOUISE GUBLER: Die frübesten Deutungen des Todes Jesu. Eine motivgeschichtliche Darstellung aufgrund der neueren exegetischen Forschung. XVI - 424 Seiten. 1977. Vergriffen.

Bd. 16 JEAN ZUMSTEIN: La condition du croyant dans l'Evangile selon Matthieu. 467 pages. 1977.

Bd. 17 FRANZ SCHNIDER: Die verlorenen Söbne. Strukturanalytische und historisch-kritische Untersuchungen zu Lk 15. 105 Seiten. 1977.

Bd. 18 HEINRICH VALENTIN: Aaron. Eine Studie zur vor-priesterschriftlichen Aaron-Überlieferung. VIII - 441 Seiten. 1978. 
Bd. 19 MASSÉO CALOZ: Etude sur la LXX origénienne du Psautier. Les relations entre les leçons des Psaumes du Manuscrit Coislin 44, les Fragments des Hexaples et le texte du Psautier Gallican. 480 pages. 1978.

Bd. 20 RAPHAEL GIVEON: The Impact of Egypt on Canaan. Iconographical and Related Studies. 156 Seiten, 73 Abbildungen. 1978.

Bd. 21 DOMINIQUE BARTHÉLEMY: Etudes d'bistoire du texte de l'Ancien Testament. XXV - 419 pages. 1978.

Bd. 22/1 CESLAS SPICQ: Notes de Lexicographie néo-testamentaire. Tome I: p. 1-524. 1978. Epuisé.

Bd. 22/2 CESLAS SPICQ: Notes de Lexicographie néo-testamentaire. Tome II: p. 525980. 1978. Epuisé.

Bd. 22/3 CESLAS SPICQ: Notes de Lexicographie néo-testamentaire. Supplément. 698 pages. 1982.

Bd. 23 BRIAN M. NOLAN: The royal Son of God. The Christology of Matthew 1-2 in the Setting of the Gospel. 282 Seiten. 1979.

Bd. 24 KLAUS KIESOV: Exodustexte im Jesajabuch. Literarkritische und motivgeschichtliche Analysen. 221 Seiten. 1979.

Bd. 25/1 MICHAEL LATTKE: Die Oden Salomos in ibrer Bedeutung für Neues Testament und Gnosis. Band I. Ausführliche Handschriftenbeschreibung. Edition mit deutscher Parallel-Übersetzung. Hermeneutischer Anhang zur gnostischen Interpretation der Oden Salomos in der Pistis Sophia. XI - 237 Seiten. 1979.

Bd.25/1a MICHAEL LATTKE: Die Oden Salomos in ibrer Bedeutung für Neues Testament und Gnosis. Band Ia. Der syrische Text der Edition in Estrangela Faksimile des griechischen Papyrus Bodmer XI. 68 Seiten. 1980.

Bd. 25/2 MICHAEL LAT'TKE: Die Oden Salomos in ibrer Bedeutung für Neues Testament und Gnosis. Band II. Vollständige Wortkonkordanz zur handschriftlichen, griechischen, koptischen, lateinischen und syrischen Uberlieferung der Oden Salomos. Mit einem Faksimile des Kodex N. XVI - 201 Seiten. 1979.

Bd. 26 MAX KUCHLER: Frühjüdische Weisheitstraditionen. Zum Fortgang weisheitlichen Denkens im Bereich des frühjüdischen Jahweglaubens. 703 Seiten. 1979.

Bd. 27 JOSEF M. OESCH: Petucha und Setuma. Untersuchungen zu einer überlieferten Gliederung im hebräischen Text des Alten Testaments. XX - $394-37 *$ Seiten. 1979.

Bd. 28 ERIK HORNUNG / OTHMAR KEEL (Herausgeber): Studien zu altägyptischen Lebenslebren. 394 Seiten. 1979.

Bd. 29 HERMANN ALEXANDER SCHLOGL: Der Gott Tatenen. Nach Texten und Bildern des Neuen Reiches. 216 Seiten, 14 Abbildungen. 1980.

Bd. 30 JOHANN JAKOB STAMM: Beiträge zur Hebräischen und Altorientalischen Namenkunde. XVI - 264 Seiten. 1980.

Bd. 31 HELMUT UTZSCHNEIDER: Hosea - Prophet vor dem Ende. Zum Verhältnis von Geschichte und Institution in der alttestamentlichen Prophetie. 260 Seiten. 1980.

Bd. 32 PETER WEIMAR: Die Berufung des Mose. Literaturwissenschaftliche Analyse von Exodus 2,23-5,5. 402 Seiten. 1980.

Bd. 33 OTHMAR KEEL: Das Böcklein in der Milch seiner Mutter und Verwandtes. Im Lichte eines altorientalischen Bildmotivs. 163 Seiten, 141 Abbildungen. 1980.

Bd. 34 PIERRE AUFFRET: Hymnes d'Egypte et d'lsraël. Etudes de structures littéraires. 316 pages, 1 illustration. 1981. 
Bd. 35 ARIE VAN DER KOOIJ: Die alten Textzeugen des Jesajabuches. Ein Beitrag zur Textgeschichte des Alten Testaments. 388 Seiten. 1981.

Bd. 36 CARMEL McCARTHY: The Tiqqune Sopherim and Other Theological Corrections in the Masoretic Text of the Old Testament. 280 Seiten. 1981.

Bd. 37 BARBARA L. BEGELSBACHER-FISCHER: Untersuchungen zur Götterwelt des Alten Reiches im Spiegel der Privatgräber der IV. und V. Dynastie. 336 Seiten. 1981.

Bd. 38 MÉLANGES DOMINIQUE BARTHÉLEMY. Etudes bibliques offertes à l'occasion de son 60e anniversaire. Edités par Pierre Casetti, Othmar Keel et Adrian Schenker. 724 pages. 31 illustrations. 1981.

Bd. 39 ANDRÉ LEMAIRE: Les écoles et la formation de la Bible dans l'ancien Israël. 142 pages. 14 illustrations. 1981.

Bd. 40 JOSEPH HENNINGER: Arabica Sacra. Aufsätze zur Religionsgeschichte Arabiens und seiner Randgebiete. Contributions à l'histoire religieuse de l'A rabie et de ses régions limitrophes. 347 Seiten. 1981.

Bd. 41 DANIEL VON ALLMEN: La famille de Dieu. La symbolique familiale dans le paulinisme. LXVII - 330 pages, 27 planches. 1981.

Bd. 42 ADRIAN SCHENKER: Der Mächtige im Schmelzofen des Mitleids. Eine Interpretation von 2 Sam 24. 92 Seiten. 1982.

Bd. 43 PAUL DESELAERS: Das Buch Tobit. Studien zu seiner Entstehung, Komposition und Theologie. 532 Seiten + Übersetzung 16 Seiten. 1982.

Bd. 44 PIERRE CASETTI: Gibt es ein Leben vor dem Tod? Eine Auslegung von Psalm 49. 315 Seiten. 1982.

Bd. 45 FRANK-LOTHAR HOSSFELD: Der Dekalog. Seine späten Fassungen, die originale Komposition und seine Vorstufen. 308 Seiten. 1982.

Bd. 46 ERIK HORNUNG: Der ägyptische Mythos von der Himmelskuh. Eine Ätiologie des Unvollkommenen. Unter Mitarbeit von Andreas Brodbeck, Hermann Schlögl und Elisabeth Staehelin und mit einem Beitrag von Gerhard Fecht. XII - 129 Seiten, 10 Abbildungen. 1982.

Bd. 47 PIERRE CHERIX: Le Concept de Notre Grande Puissance (CG VI, 4). Texte, remarques philologiques, traduction et notes. XIV - 95 pages. 1982.

Bd. 48 JAN ASSMANN / WALTER BURKERT / FRITZ STOLZ: Funktionen und Leistungen des Mythos. Drei altorientalische Beispiele. 118 Seiten. 17 Abbildungen. 1982.

Bd. 49 PIERRE AUFFRET: La sagesse a bâti sa maison. Etudes de structures littéraires dans l'Ancien Testament et spécialement dans les psaumes. 580 pages. 1982.

Bd. 50/1 DOMINIQUE BARTHÉLEMY: Critique textuelle de l'Ancien Testament. 1. Josué, Juges, Ruth, Samuel, Rois, Chroniques, Esdras, Néhémie, Esther. Rapport final du Comité pour l'analyse textuelle de l'Ancien Testament hébreu institué par l'Alliance Biblique Universelle, établi en coopération avec Alexander R. Hulst †, Norbert Lohfink, William D. McHardy, H. Peter Rüger, coéditeur, James A. Sanders, coéditeur. 812 Seiten. 1982.

Bd. 51 JAN ASSMANN: Re und Amun. Die Krise des polytheistischen Weltbilds im Ägypten der 18.-20. Dynastie. XII - 309 Seiten. 1983. 